Maria Fernanda Aguiar Calió

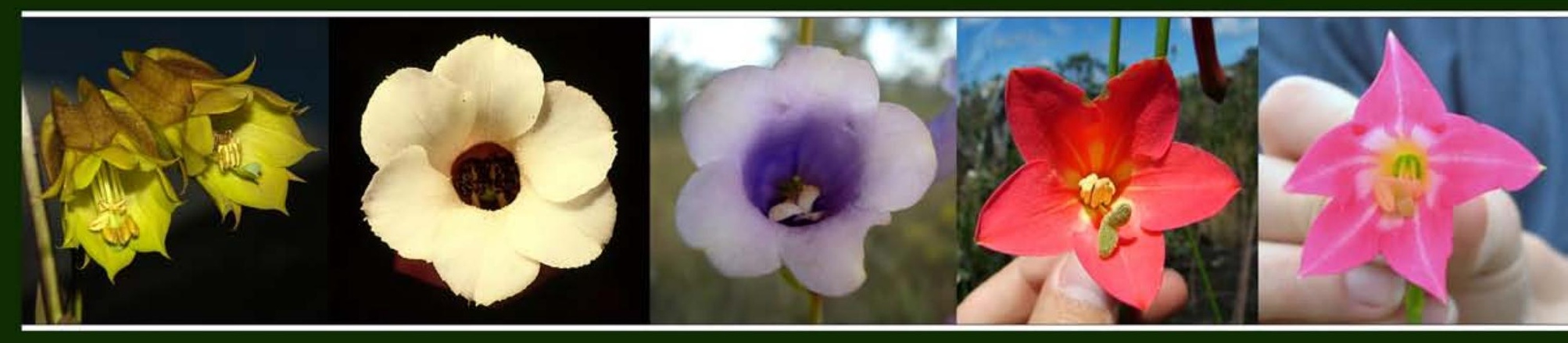

\title{
Sistemática de Helieae Gilg (Gentianaceae)
}

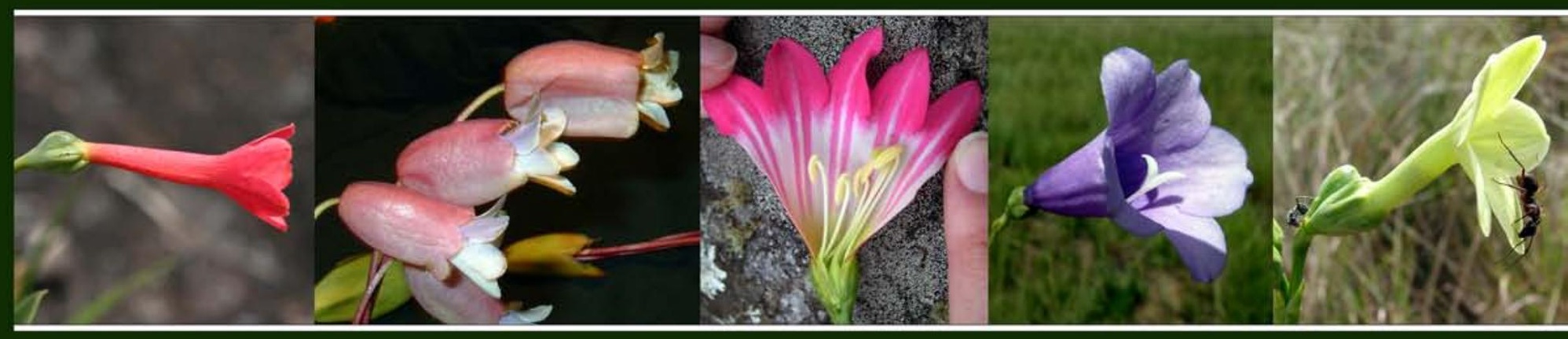

\section{São PaUlo 2009}




\section{Maria Fernanda Aguiar Calió}

\section{Sistemática de Helieae Gilg \\ (Gentianaceae)}

SÃo PAULO

2009 


\section{Maria Fernanda Aguiar Calió}

\section{Sistemática de Helieae Gilg \\ (GentianAceae)}

Tese apresentada ao Instituto de Biociências da Universidade de São Paulo, para a obtenção de Título de Doutor em Ciências, na Área de Botânica.

Orientador: Prof. Dr. José Rubens Pirani

\section{SÃo PAULO}




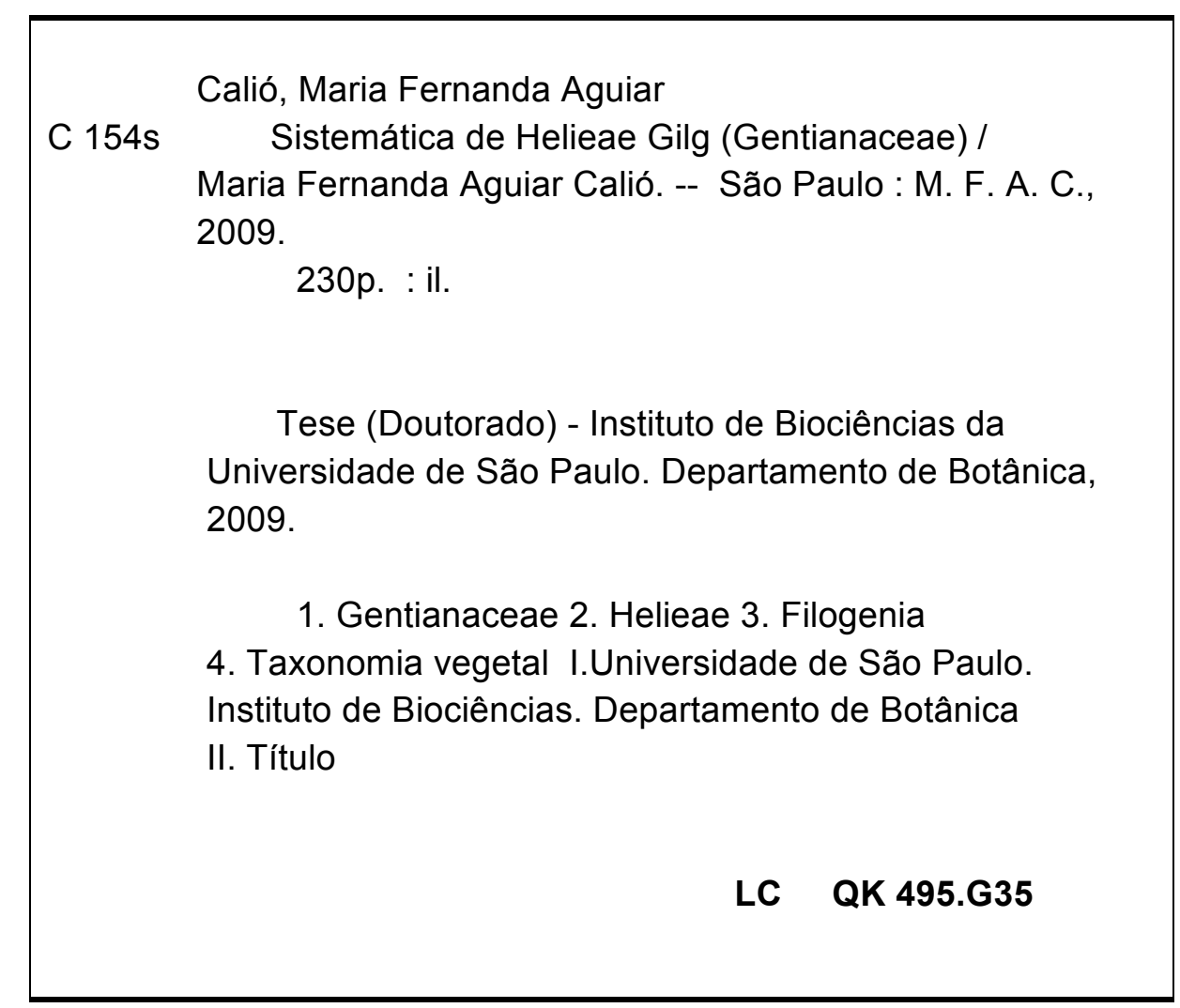

\section{Comissão Julgadora:}

Prof(a). Dr(a).

Prof(a). Dr(a).
Prof(a). Dr(a).

Prof(a). Dr(a).

Prof. Dr. José Rubens Pirani

Orientador 
À minha família. 
"Não tem mais jeito, João Grilo morreu. Acabou-se o Grilo mais inteligente do mundo. Cumpriu sua sentença e encontrou-se com o único mal irremediável, aquilo que é a marca de nosso estranho destino sobre a terra, aquele fato sem explicação que iguala tudo o que é vivo num só rebanho de condenados, porque tudo o que é vivo morre. Que posso fazer agora?"

"Valha-me Nossa Senhora, / Mãe de Deus de Nazaré! A vaca mansa dá leite, / a braba dá quando quer. A mansa dá sossegada, / a braba levanta o pé. Já fui barco, fui navio, / mas hoje sou escaler. Já fui menino, fui homem, / só me falta ser mulher. Valha-me Nossa Senhora, / Mãe de Deus de Nazaré."

"Levante, Chicó. Não está vendo que sou eu? Estou vivo, rapaz!" 


\section{AGRADECIMENTOS}

Gostaria de expressar meus agradecimentos a todos que contribuíram para a concretização deste trabalho.

Ao Prof. Dr. José Rubens Pirani, pela dedicação e seriedade com que me orientou na realização deste trabalho e todos aqueles que o precederam. Sua ampla experiência em morfologia e sistemática vegetal contribuiu não somente para o engrandecimento desta Tese, mas também para minha formação acadêmica.

À Fundação de Amparo à Pesquisa do Estado de São Paulo (FAPESP - processo 03/109183), pela concessão de bolsa de Doutorado Direto e de auxílio financeiro (Reserva Técnica), indispensável para custeio das despesas relacionadas à pesquisa.

A International Association for Plant Taxonomy (IAPT), pela concessão de auxílio financeiro (IAPT Research Grants Program in Plant Systematics 2006).

A National Science Foundation (NSF - processo 0317612), pela concessão de auxílio financeiro ao projeto "Phylogeny and biogeography of the neotropical tribe Helieae - Gentianaceae", coordenado pela Dra. Lena Struwe (Rutgers, the State University of New Jersey, E.U.A.), que custeou parte da pesquisa desta Tese desenvolvida nos E.U.A.

A Rutgers State University of New Jersey, pelo auxílio financeiro concedido para realização de dois estágios de um mês no laboratório da Dra. Lena Struwe.

À Pró-Reitoria de Pós-Graduação da Universidade de São Paulo, pelo auxílio financeiro concedido para participação no "XVII International Congress of Botany", realizado em Viena, Áustria.

Ao Departamento de Botânica e ao Programa de Pós-Graduação em Botânica do IBUSP, pelo excelente curso de pós-graduação.

À Profa. Dra. Lena Struwe (Rutgers, the State University of New Jersey), pelo incentivo à pesquisa em Gentianaceae e por ter compartilhado seus conhecimentos acerca da sistemática da família, disponibilizando literatura de difícil acesso, bem como materiais de herbários estrangeiros. Além disso, a angariação de fundos para pesquisa por parte da Dra. Struwe custeou diversas atividades de pesquisa relacionadas a esta Tese.

À Dra. Katherine B. Lepis (Rutgers, the State University of New Jersey), por ter compartilhado parte dos dados moleculares obtidos durante seu Doutorado, o que permitiu ampliar o escopo deste trabalho e, dessa forma, engrandecê-lo.

À Profa. Dra. Lúcia Garcez Lohmann, por todos os ensinamentos que generosamente transmitiu aos alunos do Laboratório de Sistemática Vegetal desde seu ingresso no IBUSP. Seus conhecimentos sobre sistemática molecular foram imprescindíveis para superar dificuldades encontradas no desenvolvimento deste trabalho. Na fase final do projeto, parte dos procedimentos experimentais foi realizada no recém-criado "Laboratório de Sistemática Molecular", pelo qual é responsável. Além disso, parte das análises filogenéticas foi efetuada em computador adquirido no âmbito de um de seus projetos de pesquisa.

Ao Dr. Richard C. Winkworth (University of the South Pacific, Fiji), pelo auxílio nas análises filogenéticas do primeiro capítulo desta Tese, bem como por todos os ensinamentos sobre 
sistemática molecular repassados aos alunos do Laboratório de Sistemática Vegetal durante cursos ministrados em 2006 e 2007. Sua experiência na área foi também imprescindível para solucionar problemas metodológicos envolvidos na obtenção dos dados moleculares.

Ao Prof. Dr. Renato de Mello-Silva (IBUSP), pelo auxílio na resolução de importantes questões nomenclaturais da tribo Helieae. Além disso, grande parte das análises filogenéticas apresentadas nesta Tese foi efetuada em computador adquirido no âmbito de um de seus projetos de pesquisa.

À Profa. Dra. Mariana Cabral de Oliveira, por ter permitido a utilização da infra-estrutura do Laboratório de Algas Marinhas "Édison José de Paula" (IBUSP) para realização de praticamente toda a seção de biologia molecular desta Tese. Seus conhecimentos sobre técnicas moleculares foram igualmente valiosos para superar as dificuldades encontradas nessa fase do projeto.

Aos alunos do Laboratório de Algas Marinhas do IBUSP "Édison José de Paula", pela assistência nos procedimentos de extração e amplificação de DNA.

Aos técnicos do Centro de Estudos do Genoma Humano do IBUSP, onde o seqüenciamento de DNA foi realizado.

Aos seguintes colegas pesquisadores, pelo auxílio nas coletas, obtenção de espécimes e/ou fotografias, imprescindíveis para o desenvolvimento do projeto: Benoît Francis Patrice Loeuille, Cláudio Nicoletti de Fraga, Denise Sasaki, Euder Glendes Martins, Fabiana Fatima Begale, George John Shepherd, Herbert Serafim de Freitas, Inês Cordeiro, José Rubens Pirani, Juliana Hanna Leite El Ottra, Juliana Lovo, Katherine Lepis, Leandro Cézanne de Souza Assis, Lia Monguilhott Bezerra, Lívia Echternacht Andrade, Lívia Godinho Temponi, Marcelo Trovó Lopes de Oliveira, Maria Ana Farinaccio, Matheus Fortes Santos, Maura Albergaria Pena, Maurício Takashi Coutinho Watanabe, Rafaela Campostrini Forzza, Renato de Mello-Silva, Richard Charles Winkworth, Ruy José Válka Alves.

Aos curadores dos herbários cujo acervo fora analisado neste trabalho, pelo auxílio na localização dos materiais e pelas valiosas digitalizações de exsicatas.

À M. Sc. Renata Souza de Oliveira, pela confecção dos mapas de distribuição geográfica que compõem esta Tese.

À Fabiana Fatima Begale, pela solicitude e assistência na localização de materiais de herbário, fundamentais para o desenvolvimento do projeto.

À Dra. Juliana Lovo, pelo companheirismo e constante apoio durante o desenvolvimento desta Tese.

Aos docentes, técnicos e alunos do Laboratório de Sistemática Vegetal do IBUSP, pelo agradável convívio durante a realização deste trabalho.

À minha família, pela compreensão, confiança e apoio desde que ingressei no Doutorado.

Ao meu querido marido, José Eduardo A. R. Marian, pelo envolvimento em todas as fases deste trabalho (do projeto inicial à Tese) e por todo o amor e carinho que me fazem uma pessoa mais feliz. 


\section{ÍNDICE}

Introdução Geral

Capítulo 1 - Filogenia baseada em morfologia e revisão de Prepusa e Senaea (Gentianaceae: Helieae) - plantas raras e endêmicas do leste do Brasil .17

Capítulo 2 - Padrões evolutivos em Helieae (Gentianaceae): evidências morfológicas e de seqüências de DNA plastidiais e nucleares

Capítulo 3 - Estudo filogenético de Helieae (Gentianaceae) com ênfase nos limites genéricos de Calolisianthus Gilg, Chelonanthus Gilg e Helia Mart., baseado em dados moleculares e morfológicos

Capítulo 4 - Nova lectotipificação de Calolisianthus Gilg (Helieae, Gentianaceae). .89

Capítulo 5- Revisão de Calolisianthus Gilg (Helieae, Gentianaceae), um gênero endêmico dos campos rupestres e cerrados no Brasil

Capítulo 6- Novas combinações no gênero Chelonanthus Gilg (Helieae, Gentianaceae)

Capítulo 7 - Nova lectotipificação de Helia Mart. e revisão de Helia sensu stricto (Helieae, Gentianaceae)

Considerações Finais

Resumo

Abstract

Anexo 1-Morphology-based phylogeny and revision of Prepusa and Senaea (Gentianaceae: Helieae) - rare endemics from eastern Brazil

Anexo 2 - Evolutionary patterns in neotropical Helieae (Gentianaceae): evidence from morphology, chloroplast and nuclear DNA sequences 


\section{LISTA DE TABELAS, FIgURAS E APÊNDICES}

\section{Capítulo 1}

Figura 1. Senaea janeirensis. A, flores. Prepusa viridiflora. B, inflorescência; C, flores, visão frontal. Fotos:

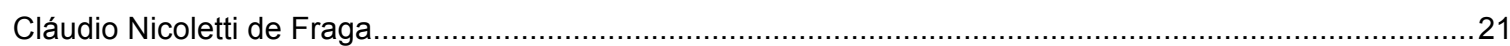

Figura 2. Prepusa montana. A, hábito; B, tronco; C, flores. Fotos: Maria Fernanda Calió …….......................22

Figura 3. Prepusa connata. A, planta inteira; B, inflorescência; C, flor, visão frontal. Prepusa hookeriana. D, hábito; E, flor, visão frontal. Fotos: A-C, Ruy Válka Alves; D-E, George John Shepherd .23

\section{CAPítulo 3}

Tabela 1. Táxons e códigos de acesso ao GenBank para espécies utilizadas nesse estudo. Informações sobre "vouchers" fornecidas apenas para espécimes seqüenciados nesse estudo (indicados por "X"). ${ }^{*}=$ amostras trabalhadas no Laboratório de Algas Marinhas "Édison José de Paula" (IBUSP). Nomes "informais" apresentados com aspas. Ref. 1: Presente estudo; Ref. 2: Thiv et al. (1999); Ref. 3: Mansion e Struwe (2004); Ref. 4: Struwe et al. (2009); Ref. 5: Frasier et al. (2008); Ref. 6: Chassot et al. (2001); Ref. 7: Yuan e Kupfer (1995); Ref. 8: Hagen e Kadereit (2001); Ref. 9: Chen et al. (2005); Ref. 10: Yuan et al. (2003); Ref. 11: Gould e Struwe (2004)...

Tabela 2. Nome das matrizes e respectivos conjuntos de dados e de táxons; tipo de sistema de busca empregado nas análises; número de árvores retidas e utilizadas para construção da árvore de consenso estrito na análise de parcimônia

Tabela 3. Características das matrizes individuais e combinadas: número de táxons, caracteres totais, inde/s, caracteres constantes e variáveis, e caracteres informativos para parcimônia. Estatísticas das árvores resultantes: comprimento das árvores, $\mathrm{Cl}, \mathrm{RI}, \mathrm{HI}$, número de nós com valores de probabilidade posterior de análise Bayesiana maiores que 0.85 (topologia da parcimônia / topologia da Bayesiana)............................59

Figura 1. Consenso estrito da análise de parcimônia da matriz "Combinada Total Grande com indels", i.e., incluindo dados moleculares e morfológicos, e todos os táxons. Porcentagens de bootstrap e probabilidades posteriores de análise Bayesiana estão representadas sobre os ramos. Nomes informais entre aspas. Asterisco indica táxons incluídos nas análises apenas com dados morfológicos.

Figura 2. Consenso estrito da análise de parcimônia da matriz "Combinada Total Média com indels", i.e., incluindo dados morfológicos e moleculares, e apenas táxons com dados para ao menos uma das partições moleculares. Porcentagens de bootstrap e probabilidades posteriores de análise Bayesiana estão representadas sobre os ramos. Nomes informais entre aspas

Figura 3. Consenso estrito da análise de parcimônia da matriz "Combinada Total Pequena com indels", i.e., incluindo dados morfológicos e moleculares, e apenas táxons com dados para as três partições. Porcentagens de bootstrap e probabilidades posteriores de análise Bayesiana estão representadas sobre os ramos. Nomes informais entre aspas

Figura 4. Seis caracteres morfológicos mapeados sobre a filogenia de Helieae obtida com a análise de parcimônia da matriz "Combinada Total Grande com indels" (táxons dos grupos-externos foram removidos). Lista de caracteres morfológicos e matriz com codificações são encontradas nos Apêndices A e B. (a) Agregação dos grãos de pólen (car. 88), (b) Alças na exina (car. 91), (c) Indumento na margem dos lobos do cálice (car. 39), (d) Filetes em seção transversal (car. 69), (e) Região escurecida no ápice dos lobos da corola (car. 57), (f) cor principal da corola (car. 44).

Figura 5. Seis caracteres morfológicos mapeados sobre a filogenia de Helieae obtida com a análise de parcimônia da matriz "Combinada Total Grande com indels" (táxons dos grupos-externos foram removidos). Lista de caracteres morfológicos e matriz com codificações são encontradas nos Apêndices A e B. (a) Estruturas interestipulares (car. 20), (b) Forma do ápice do botão floral (car. 55), (c) Posição das anteras na antese (car. 70), (d) Espessura da exina na região equatorial (car. 91), (e) Hábito (car. 1), (f) Corola no fruto (car. 53). 
Figura 6. Mapeamento das áreas geográficas onde ocorrem as espécies amostradas de Helieae, codificadas de acordo as Províncias Biogeográficas sensu Cabrera e Willink (1980). Árvore modificada com base na topologia obtida com a análise de parcimônia da matriz "Combinada Total Grande com indels" (táxons dos grupos-externos foram removidos). Nomes informais entre aspas

Apêndice A. Caracteres morfológicos e respectivos estados utilizados nesse estudo. Detalhes sobre os caracteres em Struwe et al. (2009)......

Apêndice B. Matriz de dados morfológicos empregada nas análises filogenéticas. Táxons com nomes informais estão indicados entre aspas. Na matriz, táxons polimórficos foram representados com letras: $\mathrm{a}=$ $0 / 1 ; b=1 / 2 ; c=0 / 2 ; d=0 / 1 / 2 ; ?=$ dados ausentes.

Apêndice C. Inserções e deleções (indels) de ITS recodificados usando o método de "simple indel coding". Para cada indel, os estados 0 e 1 indicam, respectivamente, a ausência e presença do indel...... 75

Apêndice D. Inserções e deleções (indels) de 5S-NTS recodificados usando o método de "simple indel coding". Para cada indel, os estados 0 e 1 indicam, respectivamente, a ausência e presença do indel.......75 Apêndice $E$

Figura E1. Consenso estrito da análise de parcimônia da matriz "Combinada Total Grande sem indels", i.e., incluindo dados moleculares e morfológicos, e todos os táxons. Porcentagens de bootstrap e probabilidades posteriores de análise Bayesiana estão representadas sobre os ramos. Nomes informais entre aspas. Asterisco indica táxons incluídos nas análises apenas com dados morfológicos ..... .. 76

Figura E2. Consenso estrito da análise de parcimônia da matriz "Combinada Total Média sem indels", i.e., incluindo dados morfológicos e moleculares, e apenas táxons com dados para ao menos uma das partições moleculares. Porcentagens de bootstrap e probabilidades posteriores de análise Bayesiana estão representadas sobre os ramos. Nomes informais entre aspas......

.77

Figura E3. Consenso estrito da análise de parcimônia da matriz "Combinada Total Pequena sem indels", i.e., incluindo dados morfológicos e moleculares, e apenas táxons com dados para as três partições. Porcentagens de bootstrap e probabilidades posteriores de análise Bayesiana estão representadas sobre os ramos. Nomes informais entre aspas.

78

Figura E4. Consenso estrito da análise de parcimônia da matriz "Morfologia" (inclui todos os táxons). Porcentagens de bootstrap e probabilidades posteriores de análise Bayesiana estão representadas sobre os ramos. Nomes informais entre aspas.

Figura E5. Consenso estrito da análise de parcimônia da matriz "ITS com indels" (inclui apenas táxons com dados de ITS). Porcentagens de bootstrap e probabilidades posteriores de análise Bayesiana estão representadas sobre os ramos. Nomes informais entre aspas

Figura E6. Consenso estrito da análise de parcimônia da matriz "ITS sem indels" (inclui apenas táxons com dados de ITS). Porcentagens de bootstrap e probabilidades posteriores de análise Bayesiana estão representadas sobre os ramos. Nomes informais entre aspas

Figura E7. Consenso estrito da análise de parcimônia da matriz "5S-NTS com indels" (inclui apenas táxons com dados de 5S-NTS). Porcentagens de bootstrap e probabilidades posteriores de análise Bayesiana estão representadas sobre os ramos. Nomes informais entre aspas

Figura E8. Consenso estrito da análise de parcimônia da matriz "5S-NTS sem indels" (inclui apenas táxons com dados de 5S-NTS). Porcentagens de bootstrap e probabilidades posteriores de análise Bayesiana estão representadas sobre os ramos. Nomes informais entre aspas.

Figura E9. Consenso estrito da análise de parcimônia da matriz "Combinada Molecular Média com indels", i.e., incluindo apenas dados moleculares, e somente táxons com dados para ao menos uma das partições moleculares. Porcentagens de bootstrap e probabilidades posteriores de análise Bayesiana estão representadas sobre os ramos. Nomes informais entre aspas......

Figura E10. Consenso estrito da análise de parcimônia da matriz "Combinada Molecular Média sem indels", i.e., incluindo apenas dados moleculares, e somente táxons com dados para ao menos uma das 
partições moleculares. Porcentagens de bootstrap e probabilidades posteriores de análise Bayesiana estão representadas sobre os ramos. Nomes informais entre aspas......

Figura E11. Consenso estrito da análise de parcimônia da matriz "Combinada Molecular Pequena com indels", i.e., incluindo apenas dados moleculares, e somente táxons com dados para as duas partições moleculares. Porcentagens de bootstrap e probabilidades posteriores de análise Bayesiana estão representadas sobre os ramos. Nomes informais entre aspas .86

Figura E12. Consenso estrito da análise de parcimônia da matriz "Combinada Molecular Pequena sem indels", i.e., incluindo apenas dados moleculares, e somente táxons com dados para as duas partições moleculares. Porcentagens de bootstrap e probabilidades posteriores de análise Bayesiana estão representadas sobre os ramos. Nomes informais entre aspas

\section{Capítulo 5}

Figura 1. Calolisianthus bellissimus. A, hábito, com representação esquemática da seção transversal do caule; $\mathrm{B}$, detalhe do nó; $\mathrm{C}$, face abaxial da folha; $\mathrm{D}$, botão floral; $\mathrm{E}$, flor isolada, visão lateral; $\mathrm{F}$, cálice rebatido, evidenciando coléteres na região interior; $\mathrm{G}$, detalhe do ápice e margem do lobo do cálice; $\mathrm{H}$, corola rebatida, evidenciando inserção e tamanho desigual dos estames; I, detalhe do ápice e margem do lobo da corola; J, estames (faces abaxial e adaxial), com representação esquemática da seção transversal do filete; K, gineceu, com representação esquemática da seção transversal do estilete; L, detalhe do estigma; M, fruto com cálice e corola persistentes. Todos desenhados a partir de Calió \& al. 87 (SPF) ....121

Figura 2. Calolisianthus pedunculatus. A, hábito, com representação esquemática da seção transversal do caule; $B$, detalhe do nó; $C-E$, variação foliar, face abaxial; F, flor, visão lateral; G, cálice rebatido, evidenciando coléteres na região interior; $\mathrm{H}$, detalhe do ápice e margem do lobo do cálice; I, corola rebatida, evidenciando inserção e tamanho desigual dos estames; J, detalhe do ápice e margem do lobo da corola; K, estames (visão abaxial e adaxial); L, gineceu; M, detalhe do estigma. Todos desenhados a partir de Calió \& al. 173 (SPF), exceto (C) de Giulietti et al. CFCR 1319 (SPF) e (E) de Lovo \& al. 145 (SPF) ...122

Figura 3. Calolisianthus pendulus. A, hábito, com representação esquemática da seção transversal do caule; $B$, detalhe do nó; $C$, face abaxial da folha; $D$, flor, visão lateral; $E$, cálice rebatido, evidenciando coléteres na região interior; $F$, detalhe do ápice e margem do lobo do cálice; $G$, corola rebatida, evidenciando inserção e tamanho desigual dos estames; $\mathrm{H}$, detalhe do ápice e margem do lobo da corola; I, estames (visão abaxial e adaxial); J, gineceu; K, detalhe do estigma. Todos desenhados a partir de Calió \& al. 86 (SPF) 123

Figura 4. Calolisianthus speciosus. A, hábito, com representação esquemática da seção transversal do caule; $\mathrm{B}$, detalhe do nó; $\mathrm{C}$, face abaxial da folha; $\mathrm{D}$, detalhe dos nectários extra-florais na face abaxial da folha; E-F, variação floral, visão lateral; G, cálice rebatido, evidenciando coléteres na região interior; $H$, detalhe do ápice e margem do lobo do cálice; I, corola rebatida, evidenciando inserção e tamanho desigual dos estames; J, detalhe do ápice e margem do lobo da corola; K, estames (visão abaxial e adaxial); L, gineceu; M, detalhe do estigma. Todos desenhados a partir de Watanabe \& al. 116 (SPF), exceto (A-D) de Calió \& al. 105 (SPF) e (F) de Calió \& al. 109 (SPF) 124

Figura 5. Calolisianthus bellissimus. A, hábito; $\mathrm{B}$, flor, visão frontal; $\mathrm{C}$, flor com corola rebatida. Calolisianthus pendulus. D, hábito; E, flor, visão frontal. Fotos: B-C, Lívia Temponi; demais, Maria Fernanda Calió 125

Figura 6. Calolisianthus pedunculatus. A, hábito; B-C, variação floral, visão lateral; D-G, variação floral, visão frontal. Fotos: A, Katherine Lepis; B, Richard Winkworth; C, Lívia Echternacht; D, Juliana Lovo; E, Marcelo Trovó; F-G, Maria Fernanda Calió 126

Figura 7. Calolisianthus speciosus. $A$, hábito; $B$, inflorescência; $C-D$, variação floral, visão frontal. Fotos: $A$, Lia Bezerra; B-C, Benoît Loeuille; D, Marcelo Trovó . 127

Figura 8. Distribuição geográfica. A, Calolisianthus bellissimus; $\mathrm{B}$, Calolisianthus pedunculatus .................128

Figura 9. Distribuição geográfica. A, Calolisianthus pendulus; B, Calolisianthus speciosus 129 
Apêndice A. Lista de exsicatas, indicando coletor e número, número da espécie no tratamento taxonômico e herbários. Negrito = espécimes-tipo; scan = imagem digitalizada da exsicata. Calolisianthus bellissimus = 1; Calolisianthus pedunculatus $=2$; Calolisianthus pendulus $=3 ;$ Calolisianthus speciosus $=4$. 131

\section{CAPÍtulo 6}

Figura 1. Chelonanthus abditus. A, hábito, com representação esquemática da seção transversal do caule; $B$, detalhe do nó; $C$, face abaxial da folha; $D$, flor, visão lateral; $E$, cálice rebatido; $F$, detalhe do ápice e margem do lobo do cálice; $G$, corola rebatida, evidenciando inserção e tamanho desigual dos estames; $H$, detalhe do ápice e margem do lobo da corola; I, estames (faces abaxial e adaxial); J, gineceu; K, detalhe do estigma. Todos desenhados a partir de Heringer \& al. 3340 (UEC)

Figura 2. Chelonanthus amplissimus. A, hábito, com representação esquemática da seção transversal do caule; B, detalhe do nó; C, face abaxial da folha; D, botão floral; E, flor, visão lateral; F, cálice rebatido; G, detalhe do ápice e margem do lobo do cálice; $\mathrm{H}$, corola rebatida, evidenciando inserção e tamanho desigual dos estames; I, detalhe do ápice e margem do lobo da corola; J, estames (faces abaxial e adaxial); K, gineceu; L, detalhe do estigma. Todos desenhados a partir de Calió \& Sasaki 66 (SPF)..... 150

Figura 3. Chelonanthus abditus. A, ramo com folhas; B, flor, visão lateral; C, flor, visão frontal. Chelonanthus amplissimus. D. hábito; E, flor, visão frontal. Fotos: A-C, Marcelo Trovó; D-E, Denise Sasaki ..................151

Figura 4. Distribuição geográfica. A, Chelonanthus abditus; B, Chelonanthus amplissimus .........................152

Apêndice A. Lista de exsicatas, indicando coletor e número, número da espécie no tratamento taxonômico e herbários. Negrito = espécimes-tipo; scan = imagem digitalizada da exsicata. Chelonanthus abditus = 1; Chelonanthus amplissimus $=2$. 153

\section{CAPítulo 7}

Figura 1. Helia brevifolia. A, hábito, com representação esquemática da seção transversal do caule; $\mathrm{B}$, detalhe do nó; $C$, face abaxial da folha; $D$, botão floral; $E$, flor, visão lateral; F, cálice rebatido; $G$, detalhe do ápice e margem do lobo do cálice; $\mathrm{H}$, corola rebatida, evidenciando inserção e tamanho desigual dos estames; I, detalhe do ápice e margem do lobo da corola; J, estames (faces abaxial e adaxial); K, gineceu; L, detalhe do estigma. Todos desenhados a partir de Trovó \& al. 316 (SPF), exceto (A) e (D) de Calió \& al. 169 (SPF).

Figura 2. Helia oblongifolia. A, hábito, com representação esquemática da seção transversal do caule; B, detalhe do nó; $C$, face abaxial da folha; $D$, inflorescência; $E$, flor, visão lateral; F, cálice rebatido; $G$, detalhe do ápice e margem do lobo do cálice; $\mathrm{H}$, corola rebatida, evidenciando inserção e tamanho desigual dos estames; I, detalhe do ápice e margem do lobo da corola; J, estames (faces abaxial e adaxial); K, gineceu; L, detalhe do estigma. Todos desenhados a partir de Calió \& al. 205 (SPF). 170

Figura 3. Helia brevifolia. A, hábito; B, folhas dispostas em roseta; C, inflorescência jovem; D, flor, visão lateral; E-F, flor, visão frontal. Fotos: Marcelo Trovó

Figura 4. Helia oblongifolia. A, hábito; B, inflorescência jovem; C, inflorescência madura; D, flor, visão lateral; E, flor, visão frontal. Fotos: Maria Fernanda Calió.

Figura 5. Distribuição geográfica. A, Helia brevifolia; B, Helia oblongifolia. 173

Apêndice A. Lista de exsicatas, indicando coletor e número, número da espécie no tratamento taxonômico e herbários. Negrito = espécimes-tipo; scan = imagem digitalizada da exsicata. Helia brevifolia $=1 ;$ Helia oblongifolia $=2$. 
- InTRodução Geral 


\section{INTRODUÇÃO GERAL}

\section{Gentianaceae}

Gentianaceae Juss. é uma família de Angiospermae que se distribui praticamente por todas as regiões terrestres do globo (exceto Antártica), ocupando uma grande variedade de habitats e apresentando uma grande diversidade morfológica (Albert \& Struwe 2002). Os membros da família variam amplamente quanto ao hábito, podendo ser árvores (e.g. Anthocleita R.Br., Potalia Aubl.), arbustos (e.g. Prepusa Mart., Symbolanthus G. Don), trepadeiras (e.g. Lagenanthus Gilg, Purdieanthus Gilg) ou, mais freqüentemente, ervas. A maioria é autotrófica, embora existam representantes saprofíticos (como Cotylanthera Blume, Voyria Aubl.). A venação das folhas é, em geral, acródroma, mas há espécies em que a venação é pinada e geralmente broquidódroma (e.g. Macrocarpaea Gilg, Tachia Aubl.). As flores apresentam-se normalmente agrupadas em inflorescências, entretanto há casos em que são solitárias (e.g. Saccifolium Maguire \& Pires, Voyria). As flores são freqüentemente tetrâmeras ou pentâmeras, ocorrendo também flores trímeras (Pycnosphaera Gilg), hexâmeras (e.g. Prepusa, Senaea Taub.) e 8-16-meras (e.g. Anthocleista, Potalia). Usualmente a corola é actinomorfa, embora haja espécies com corolas zigomorfas (e.g. Chelonanthus Gilg, Symbolanthus). A coloração do cálice pode variar entre verde, alva, amarela, laranja ou vinho, e a da corola entre azul, roxa, rosa, vermelha, amarela, alva ou verde. $O$ fruto é freqüentemente seco e de paredes finas, mas pode ser também fibroso ou coriáceo, como em Symbolanthus, ou carnoso, como em Chironia L. e Potalia (Struwe et al. 2002; Gentian Research Network 2009).

Apesar dessa grande variação morfológica, a família é caracterizada pela seguinte associação de características: folhas opostas; ausência de látex e estípulas; presença de coléteres; corola gamopétala com prefloração contorcida (ou sem prefloração valvar ou imbricada); filetes adnatos à corola; ovário súpero (ou ausência de ovário ínfero), bicarpelar, com glândulas ou disco nectaríferos na base e com placentação parietal; e ausência de estigma subdividido (Calió 2009; Judd et al. 2002; Simpson 2006; Stevens 2008; Struwe et al. 2002). Dentre todas essas características, a única considerada exclusiva de Gentianaceae, considerando apenas Gentianales, é a placentação do tipo parietal (Albert \& Struwe 2002). As demais, apesar de permitirem o fácil reconhecimento de Gentianaceae, são, na verdade, sinapomorfias de níveis hierárquicos mais abrangentes, ou representam a ausência de uma determinada autapomorfia que caracteriza famílias proximamente relacionadas (presença de estado plesiomórfico). Por exemplo, folhas opostas, coléteres e corola com prefloração contorcida são sinapomorfias da ordem em que se insere a família 
(Gentianales). Presença de látex, estigma subdividido, ovário ínfero e prefloração imbricada ou valvar são, respectivamente, atributos diagnósticos de Apocynaceae, Gelsemiaceae, Rubiaceae e Loganiaceae, pertencentes à ordem Gentianales; como visto acima, a ausência desses atributos é utilizada para caracterizar Gentianaceae. A presença de disco nectarífero, outra característica utilizada no reconhecimento das gencianáceas, é compartilhada com as demais famílias de Gentianales, bem como com Lamiales e Solanales. Estames epipétalos e ovário bicarpelar, por sua vez, são sinapomorfias das Euasterídeas (APG 1998, 2003). Por fim, a presença de corola gamopétala é comum a todas as Asterídeas (Albert \& Struwe 2002).

Quimicamente, a situação é semelhante, pois, apesar da grande variedade de compostos secundários típicos de Gentianaceae (Jensen \& Schripsema 2002), a família é caracterizada tanto pela ausência de alcalóides, cuja presença é sinapomorfia de Gentianales, como pela presença de seco-iridóides e xantonas, atributos compartilhados com Loganiaceae, Apocynaceae e Gelsemiaceae (Albert \& Struwe 2002).

Embora haja dificuldade em se delimitar o bauplan da família (Albert \& Struwe 2002), Gentianaceae, descrita por Jussieu (1789), foi universalmente aceita em classificações subseqüentes e, atualmente, aparece muito bem sustentada em todos os trabalhos de filogenia molecular (APG 1998, 2003; Backlund et al. 2000; Bremer \& Struwe 1992; De Laet \& Smets 1996; Struwe et al. 1994, 1998). A circunscrição do grupo não mudou muito desde sua descrição, exceto pela exclusão de Menyanthoideae Gilg (Wagenitz 1964), inclusão de Potalieae (antigamente parte de Loganiaceae; Leewenberg \& Leenhouts 1980) e inclusão de Saccifoliaceae (antigamente uma família monotípica; Maguire \& Pires 1978; Struwe et al. 1998, 1999; Thiv et al. 1999). Em sua circunscrição mais atual, Gentianaceae é formada por cerca de 1690 espécies agrupadas em 87 gêneros (Albert \& Struwe 2002).

Gentianaceae apresenta grande importância econômica, visto que muitas espécies da família são cultivadas para uso em ornamentação (como Eustoma Salisb., Exacum L., Gentiana L. e Sabatia Adans.), bem como para extração de substâncias de valor medicinal (e.g. Centaurium Hill., Chironia, Gentiana e Swertia L.) e flavorizantes (Heywood 1978; Jensen \& Schripsema 2002; Judd et al. 2002).

\section{As tribos: classificação e caracterização}

Em 1895, Gilg segregou muitas das espécies conhecidas até então em gêneros palinologicamente distintos, agrupando-os em tribos de acordo com suas semelhanças polínicas. Apesar das classificações anteriores terem se baseado em caracteres florais (Grisebach 1839; Bentham 1876), os quais seriam de mais fácil acesso aos taxonomistas, 
foi o sistema de Gilg o adotado nos trabalhos posteriores, de enfoque principalmente florístico (e.g. Maguire 1981, Maguire \& Boom 1989).

Mais recentemente, o uso de seqüências de DNA plastidial, especificamente $t r n L$ intron e matK, contribuiu com o aumento do conhecimento acerca das relações filogenéticas dentre as Gentianaceae (Struwe et al. 1998, 2002; Thiv et al. 1999). Os resultados desses estudos sustentaram somente parte das tribos propostas por Gilg, levando Struwe et al. (2002) a apresentarem uma nova classificação no nível genérico e de tribos, que, apesar de se basear apenas em dados moleculares, apresenta grande congruência com dados de morfologia externa (Mészáros et al. 2002), palinológicos (Nilsson 2002) e químicos (Jensen \& Schripsema 2002). Foram reconhecidas 6 tribos monofiléticas - Saccifolieae, Exaceae, Chironieae, Gentianeae, Potalieae e Helieae - além de um gênero com posicionamento incerto, Voyria (Struwe et al. 2002). Essa é a classificação que vem sendo aceita pelos pesquisadores de Gentianaceae e a que foi adotada na presente Tese.

Saccifolieae é formada por cinco gêneros (três monoespecíficos) e cerca de 20 espécies, todas neotropicais, mas com ocorrência mais concentrada no escudo das Guianas (Struwe et al. 2002). Algumas das espécies têm distribuição muito restrita, como Saccifolium bandeirae Maguire \& Pires, que ocorre no Pico da Neblina, na fronteira entre Venezuela e Brasil (Struwe et al. 1998), e Hockinia montana Gardner, que ocorre na Serra dos Órgãos (RJ, Brasil; Gardner 1843). Também faz parte dessa tribo o gênero Curtia Cham. \& Schltdl., que tem distribuição bastante ampla, mas com maior diversidade no Brasil (Crespo \& Marcondes-Ferreira 2009).

Segundo Struwe et al. (2002), os gêneros de Exaceae apresentam distribuição paleotropical, ocorrendo também em regiões temperadas da África. A tribo compreende seis gêneros e cerca de 144-184 espécies, sendo a maior parte pertencente aos gêneros Sebaea Sol. ex R.Br. e Exacum (60-100 e 65 espécies, respectivamente). Exaceae não possui gêneros de ocorrência natural no Brasil.

Chironieae é formada por cerca de 23 gêneros e 160 espécies. Na análise molecular de Struwe et al. (2002), essa tribo apresentou-se subdividida em 3 clados que receberam o status de subtribos: Canscorinae, Chironiinae e Coutoubeinae. Canscorinae tem distribuição paleotropical. Chironiinae é encontrada em regiões temperadas e contém Zygostigma australe (Cham. \& Schltdl.) Griseb., que ocorre no Brasil, Argentina e Uruguai. Coutoubeinae tem distribuição neotropical e inclui os gêneros Coutoubea Aubl. (cinco espécies; Guimarães \& Klein 1985), Deianira Cham. \& Schltdl. (sete espécies; Guimarães 1977), Schultesia Mart. (18 espécies; Guimarães 2004) e Symphyllophyton Gilg (com uma só espécie, endêmica do Sudeste do Brasil), todos com ocorrências no Brasil. Também fazem parte da tribo Chironieae os gêneros Eustoma, com espécies cultivadas para ornamentação, e Centaurium, com espécies introduzidas na América do Sul (Melderis 1972). 
De acordo com Struwe et al. (2002), Gentianeae é uma tribo formada por mais de 900 espécies agrupadas em 17 gêneros (três monoespecíficos). A maioria das espécies dessa tribo ocorre em habitats alpinos e temperados do Hemisfério Norte, sendo que apenas 3 gêneros têm distribuição mais ampla, atingindo regiões temperadas do Hemisfério Sul (Gentiana, Gentianella Moench e Halenia Borkh.). Gentianeae não possui gêneros de ocorrência natural no Brasil.

Potalieae contém 13 gêneros (seis monoespecíficos) e cerca de 154 espécies, distribuídas ao redor do Equador (Struwe et al. 2002). Apenas dois gêneros ocorrem no Brasil: Neurotheca Salisb. ex Benth. \& Hook.f. (três espécies; Struwe et al. 2002) e Potalia (nove espécies; Struwe \& Albert 2004). Fazem parte ainda dessa tribo os gêneros Enicostema Bl. (Struwe et al. 2002) e Lisianthius P. Browne (Weaver 1972), os quais também ocorrem nos neotrópicos.

Helieae, a tribo tratada nesta Tese de Doutorado, é abordada mais detalhadamente na seqüência.

\section{Helieae: caracterização morfológica e histórico nomenclatural}

Helieae é formada por cerca de 23 gêneros e mais de 200 espécies (Struwe et al. 2002). É uma tribo exclusivamente neotropical, sendo que a maioria de suas espécies apresenta distribuição restrita, por exemplo, a áreas de campos rupestres e campos de altitude do Sudeste do Brasil (Calolisianthus Gilg, Helia Mart., Prepusa e Senaea), a vales e cordilheiras andinos (Lagenanthus) e a savanas arenosas do escudo das Guianas (Aripuana Struwe, Maas \& V.A. Albert, Celiantha Maguire, Chorisepalum Gleason \& Wodehouse, Neblinantha Maguire) (Struwe et al. 2002). Dentre as espécies de distribuição restrita, várias são consideradas raras (alguns exemplos são apresentados em Calió \& Guimarães 2009). Poucas são as espécies com distribuição mais ampla, como Chelonanthus alatus (Aubl.) Pulle e Tetrapollinia caerulescens (Aubl.) Maguire \& B.M. Boom. A quantidade de espécies por gênero varia de modo bastante peculiar, sendo que aproximadamente $63,5 \%$ do total de espécies está concentrada nos gêneros Macrocarpaea e Symbolanthus, com mais de 100 e cerca de 30 espécies, respectivamente, enquanto que 15 gêneros (cerca de 65,2\% do total de gêneros) possuem apenas de uma a três espécies cada (cálculos baseados nas estimativas de números de espécies apresentados em Calió 2009).

Quanto à morfologia, as plantas dessa tribo exibem grande variação em caracteres reprodutivos e vegetativos, mas podem ser caracterizadas, de modo geral, pelo cálice com estruturas glandulares na região dorsal ou áreas glandulares nos lobos; filetes desiguais em seu comprimento; anteras com apêndices apicais estéreis e recurvadas depois da antese; 
estilete achatado, enrolando-se quando seco; e estigma bilamelado (Struwe et al. 2002). Vale ressaltar ainda que as flores são em geral entomófilas (Irlbachia Mart.), ou polinizadas por morcegos e beija-flores (Chelonanthus, Macrocarpaea e Symbolanthus) e possivelmente por mariposas em Aripuana (Struwe et al. 1997, 2002).

$\mathrm{Na}$ circunscrição atualmente aceita, Helieae é monofilética, mas a delimitação dos gêneros e espécies e suas relações são pouco conhecidas (Struwe et al. 2002). Além disso, muitos nomes de espécies estão incorretamente aplicados e o status de uma série de outros nomes não é conhecido (Struwe et al. 2002). Isso se deve, em parte, ao fato de que as delimitações no nível genérico e específico têm sido tradicionalmente difíceis de se estabelecer em Helieae, um grupo de taxonomia complicada e controversa (Weaver 1972, Struwe \& Albert 1998a).

Em 1756, Patrick Browne descreveu o gênero Lisianthius com duas espécies da Jamaica. Em 1763, Adanson, em seu tratamento, citou Browne como autor do nome, mas mudou a grafia para Lysianthius. Em 1767, Linnaeus mencionou Browne como autor do gênero, mas alterou novamente a grafia para Lisianthus; além disso, em 1774, atribuiu binômios às espécies de Browne (Lisianthus longifolius e Lisianthus cordifolius).

Em 1775, Aublet, no seu tratamento sobre plantas da Guiana Francesa, apresentou o gênero Lisyanthus com quatro espécies: L. purpurascens, L. alatus, L. grandiflorus e $L$. caerulescens. Aublet apresentou detalhada descrição morfológica para o gênero, grafando o nome diferentemente das maneiras previamente apresentadas e sem referir Browne como autor do nome.

Em 1827, Martius descreveu uma série de novas espécies em Lisianthus e dois novos gêneros: Irlbachia, contendo uma espécie, e Helia, com duas espécies. É interessante ressaltar que, embora tivesse utilizado a grafia de Linnaeus em Lisianthus, Martius atribuiu a autoria do nome a Browne, Aublet e Ruiz \& Pavon, os quais também haviam descrito espécies nesse gênero.

Em 1839, Grisebach transferiu as espécies de Browne para um novo gênero por ele criado, Leianthus (uma mudança claramente ilegítima segundo o International Code of Botanical Nomenclature, ICBN 2006), utilizando o nome Lisyanthus Aubl. para as outras espécies descritas até aquele momento. Grisebach (1839) apresentou o gênero Lisyanthus subdividido em 5 seções: Macrocarpaea, Choriophyllum, Chelonanthus, Helia e Calolisyanthus (Irlbachia Mart. foi reconhecido como um gênero à parte). Em 1845, Grisebach não fez alterações quanto ao posicionamento dos gêneros tratados nas seções (apenas incluiu espécies), entretanto, alterou a grafia do gênero para Lisianthus, mantendo Aublet como autor, e alterou a grafia da seção Calolisyanthus para Calolisianthus.

Em 1891, Kuntze reconheceu que era preciso escolher outro nome para as plantas nomeadas por Aublet como Lisyanthus, pois: 1) essas espécies precisavam ser realocadas 
para um novo gênero, pois não estavam relacionadas ao Lisianthius de Browne; 2) Aublet não havia descrito um novo gênero com o nome "Lisyanthus", mas apenas adicionado espécies a um gênero já existente; e 3) o nome Lisyanthus (com a grafia de Aublet) não poderia ser utilizado para nomear esse grupo de plantas, pois este seria um homônimo em relação ao nome Lisianthius de Browne. Com base nessa constatação de que, além de uma grande confusão quanto à ortografia e ao uso dos nomes, havia um grave problema quanto à delimitação e compreensão da identidade dos gêneros nesse grupo, Kuntze tentou solucionar essas questões da seguinte maneira: 1) transferiu todas as espécies que ele considerava como pertencentes ao "Lisyanthus" de Aublet para Helia Mart.; e 2) apresentou Lisianthus de Linnaeus e Leianthus de Grisebach como sinônimos de Lisianthius de Browne. Com exceção do nome Lisianthius e suas variantes, havia outros nomes genéricos disponíveis para esse grupo de plantas; os dois mais antigos eram Helia e Irlbachia, ambos descritos por Martius em 1827, na mesma obra. Kuntze escolheu o nome Helia por este gênero possuir maior número de espécies.

Apesar do cuidadoso tratamento de Kuntze (1891), as circunscrições por ele propostas não chegaram a ser adotadas. É importante ressaltar ainda que Struwe \& Albert (1998a, 1999) e Zijlstra et al. (1999) apresentaram discussões acerca da possibilidade de Aublet ter intencionalmente descrito um novo gênero sob a grafia Lisyanthus. As evidências apresentadas por Zijlstra et al. (1999) parecem mais consistentes e, por isso, Lisyanthus (grafia de Aublet) será aqui considerado como uma variante ortográfica de Lisianthius $P$. Browne.

Em 1895, Gilg atribuiu status genérico às seções de Grisebach, restabelecendo Helia como gênero, bem como criando os gêneros Calolisianthus (com essa grafia), Chelonanthus e Macrocarpaea. Além disso, Gilg (1895), baseando sua classificação em caracteres polínicos, reconheceu tribos e subtribos criadas por outros autores e criou tribos novas, como Helieae, na qual posicionou os gêneros portadores de tétrades polínicas (e.g. Calolisianthus, Helia, Prepusa e Senaea).

Estudos polínicos realizados por Nilsson $(1968,1970)$ deram sustentação às estreitas circunscrições genéricas propostas por Gilg (1895), além de sugerirem uma série de mudanças taxonômicas no sentido de reduzir ainda mais a circunscrição de determinados gêneros. Tais mudanças foram realizadas por Maguire (1981) e Maguire \& Boom (1989), que descreveram alguns novos gêneros, como Rogersonanthus Maguire \& B.M. Boom e Tetrapollinia.

Weaver (1972) publicou uma revisão taxonômica de Lisianthius P. Browne. O autor constatou que uma série de atributos morfológicos distinguia Lisianthius dos demais gêneros do denominado "complexo Lisianthoide", com os quais Lisianthius havia sido confundido conceitual ou ortograficamente até então. Além das diferenças morfológicas, o gênero 
distribui-se exclusivamente no Caribe e América Central, região onde ocorrem poucas espécies do "complexo Lisianthoide". Esse trabalho contribuiu, portanto, para o esclarecimento acerca da identidade de Lisianthius, encerrando a discussão sobre o relacionamento entre esse e os demais gêneros desse complexo.

$\mathrm{Na}$ década de 1980, Maas e seus colaboradores desenvolveram uma série de estudos taxonômicos com as espécies desse "complexo Lisianthoide", excluindo Lisianthius (Cobb \& Maas 1983; Maas et al. 1983). Com base nos resultados desses trabalhos, Maas (1985) combinou os gêneros Adenolisianthus Gilg, Brachycodon Progel, Calolisianthus, Chelonanthus, Helia e Pagaea Griseb. em Irlbachia.

Análises filogenéticas realizadas a partir da década de 90 (vide Struwe \& Albert 1998a para uma visão geral sobre o assunto) indicaram que, para que Irlbachia sensu Maas pudesse ser considerado um gênero monofilético, seria necessária a inclusão dos gêneros Macrocarpaea, Symbolanthus e Tachia. Além disso, se uma circunscrição mais ampla fosse aceita para esse grupo de plantas, o nome correto a ser utilizado, segundo o ICBN (2006, Art 11.5), seria Helia, devido ao fato de Kuntze (1891) ter dado prioridade ao nome Helia na sinonimização por ele proposta. Com base nisso, a sinonimização de Helia sob Irlbachia feita por Maas (1985) é ilegítima. Esse equívoco de Maas não foi percebido logo, e o nome Irlbachia foi amplamente empregado em trabalhos florísticos (Cordeiro 1987, 2003, 2005; Costa 1999; Harvey 1995; Pringle 1995) e na identificação de materiais de herbário (Struwe \& Albert 1998a).

Uma das maneiras de impedir a continuidade do uso incorreto do nome Irlbachia é optando por circunscrever estreitamente os gêneros, ao invés de adotar um nome genérico para designar todo esse grupo de plantas. Além disso, a aceitação de gêneros mais estreitos facilita a categorização de toda a diversidade dessas plantas. Com base nisso, a presente Tese não emprega o nome Irlbachia sensu Maas, seguindo Struwe et al. (2002) na apresentação de gêneros mais estreitamente circunscritos.

\section{Motivações para estudo do grupo e estabelecimento do projeto de pesquisa}

Apesar de Struwe et al. (2002) terem contribuído para a delimitação das tribos de Gentianaceae, as hipóteses de relações filogenéticas dentro de Helieae não se sustentaram apenas com os dados de $t r n L$ intron e matK. O uso de seqüências da região do ITS do DNA nuclear ribossomal havia sido bastante elucidativo no estudo das relações filogenéticas em outras tribos (Chassot et al. 2001; Struwe et al. 1998; Thiv et al. 1999, 2000; Yuan et al. 1996), e seqüências de 5S-NTS, também do DNA nuclear ribossomal, pareciam ser informativas o suficiente para auxiliar na compreensão das relações em Helieae (Struwe \& 
Gould 2004). Além disso, acreditava-se que a grande diversidade morfológica do grupo poderia prover muitos caracteres para a realização de análises filogenéticas.

Embora o esforço para conhecimento e compreensão das gencianáceas tenha aumentado, Helieae é relativamente pouco conhecida se comparada às demais tribos da família (Struwe et al. 2002). Revisões taxonômicas preliminares de Helieae resultaram na descoberta de novos gêneros (e.g. Maguire 1985) e no reconhecimento de uma série de espécies (e.g. Struwe \& Albert 1998b). Isso indica que a tribo foi ainda pouco estudada e provavelmente contém uma diversidade bem maior do que a conhecida entre os gêneros, muitos dos quais nunca foram revisados.

Em julho de 2003, iniciou-se um grande projeto de pesquisa sobre filogenia e biogeografia de Helieae ("Phylogeny and biogeography of the neotropical tribe Helieae Gentianaceae"), financiado pela National Science Foundation (NSF, processo 0317612). O projeto visava analisar a diversidade de Helieae, um grupo de plantas neotropicais taxonomicamente complexo, por meio da integração de trabalhos de revisão taxonômica dos gêneros, bem como providenciar hipóteses filogenéticas e biogeográficas bem sustentadas para o grupo. Tal projeto foi proposto pela Dra. Lena Struwe (Rutgers, the State University of New Jersey, E.U.A.).

Entre os gêneros de Helieae que não haviam sido alvo de revisões, havia quatro de distribuição praticamente endêmica ao Brasil: Calolisianthus, Helia, Prepusa e Senaea. Com a necessidade de um pesquisador disposto a concentrar esforços no estudo desses gêneros endêmicos e tão pouco conhecidos, fui convidada a desenvolver um projeto de Doutorado sob orientação do Dr. Pirani.

Além da possibilidade de integrar laboratórios nacional e estrangeiro, fazer parte desse grande projeto de pesquisa contribuiria diretamente com uma das linhas de pesquisa já desenvolvida no Laboratório de Sistemática Vegetal do Instituto de Biociências da Universidade de São Paulo: o estudo da vegetação de áreas de alta altitude no Brasil. Outros fatores que motivaram o estudo desses gêneros foram: a) a possibilidade de conhecer a morfologia de um novo grupo de plantas (pois meus estudos durante a Iniciação Científica haviam se concentrado em outra família da ordem Gentianales, Rubiaceae); b) a possibilidade de trabalhar com técnicas laboratoriais e métodos de análises que desconhecia; c) a interessante distribuição geográfica do grupo, restrita a áreas de alta altitude brasileiras, com curiosos exemplos de disjunções e endemismos; e d) a necessidade de um mapeamento detalhado da ocorrência das espécies, uma vez que algumas delas pareciam ser raras (a julgar pelo pequeno número de espécimes em acervos de herbários), fato que poderia ser indicativo de que as mesmas encontravam-se ameaçadas. 


\section{Objetivos}

Nesse contexto, esta Tese de Doutorado tem os seguintes objetivos:

- obter filogenias de Helieae baseadas em dados morfológicos e moleculares, para avaliar as circunscrições genéricas e elucidar as relações de parentesco entre os gêneros;

- estudar a morfologia e taxonomia das espécies de Calolisianthus, Helia, Prepusa e Senaea, gêneros ou endêmicos ou centrados no Brasil;

- documentar e estudar a distribuição geográfica das espécies;

- estudar as relações filogenéticas entre as espécies de cada gênero.

\section{Organização da tese}

Além desta "Introdução Geral" e das "Considerações Finais", a Tese está organizada em 7 capítulos. Os capítulos 1 e 2 são resumos de artigos já publicados, que, por estarem redigidos em inglês, somente puderam ser incluídos como anexos. Os capítulos 3,4 e 5 estão estruturados como artigos científicos, cada um estando de acordo com a formatação exigida pelos respectivos periódicos aos quais serão submetidos. Obras de referência, como Brummit \& Powell (1992) ou Stafleu \& Cowan (1976-1988), foram seguidas na elaboração desta Tese, mas não são citadas nas referências bibliográficas de cada capítulo devido às normas de cada periódico científico. Os capítulos 6 e 7 apresentam resultados que, para serem publicados, dependerão da junção com resultados obtidos por outra pesquisadora, Dra. Katherine B. Lepis (Rutgers University, NJ, EUA), que estudou o gênero Chelonanthus. Tal gênero mostrou-se parafilético nas análises filogenéticas: algumas espécies emergem juntamente com Helia e serão combinadas nesse gênero, e a espécie-tipo, Ch. purpurascens, emerge juntamente com duas espécies de Calolisianthus. Serão elaborados dois artigos, um de revisão de Chelonanthus (incluindo os dados do capítulo 6) e um de revisão de Helia (incluindo os dados apresentados no capítulo 7), ambos em colaboração com Katherine B. Lepis, Lena Struwe e José Rubens Pirani. Seguindo a formatação exigida pelos periódicos científicos, as respectivas tabelas, figuras e apêndices são apresentados ao final de cada capítulo desta Tese. Com relação às figuras, as ilustrações a nanquim referentes ao primeiro capítulo foram elaboradas por Bobbi Angel, e as demais por Klei Souza. Além disso, é importante ressaltar que as espécies, as combinações e os nomes novos apresentados nos capítulos 4, 5, 6 e 7 não estão sendo efetivamente publicados na presente Tese.

O capítulo 1 é um resumo expandido do artigo "Morphology-based phylogeny and revision of Prepusa and Senaea (Gentianaceae: Helieae) - rare endemics from eastern 
Brazil", publicado em 2008 no periódico internacional Kew Bulletin (Calió et al. 2008); o artigo, em sua versão original em inglês, compõe o Anexo 1. Esse trabalho apresenta filogenia baseada em caracteres morfológicos, detalhadas descrições morfológicas, chaves de identificação e ilustrações das espécies, além de discussões sobre a distribuição geográfica e sobre o estado de conservação dessas plantas.

O capítulo 2 é um resumo expandido do artigo "Evolutionary patterns in Neotropical Helieae (Gentianaceae): evidence from morphology, chloroplast and nuclear DNA sequences"; publicado em 2009 no periódico internacional Taxon (Struwe et al. 2009); o artigo, em sua versão original em inglês, compõe o Anexo 2. Esse trabalho apresenta análises filogenéticas realizadas no nível da tribo com base em dados morfológicos e moleculares (trnL intron e matK de cloroplasto, e ITS nuclear ribossomal), aponta problemas quanto à circunscrição de alguns gêneros, discute o uso de alguns atributos morfológicos tradicionalmente utilizados na classificação da tribo e, por fim, analisa a evolução de alguns caracteres morfológicos.

O capítulo 3 apresenta filogenias de Helieae resultantes da análise de dados morfológicos e moleculares (ITS e 5S-NTS, ambos nucleares ribossomais), enfatizando a circunscrição genérica de Calolisianthus, Chelonanthus e Helia. Esse capítulo comporá um manuscrito a ser submetido ao periódico internacional Molecular Phylogenetics and Evolution e, por essa razão, já se apresenta formatado segundo as normas dessa revista científica. Esse artigo será publicado em colaboração com José Rubens Pirani, Katherine B. Lepis e Lena Struwe.

O capítulo 4 apresenta a proposta de uma nova lectotipificação para o gênero Calolisianthus e será submetido ao periódico internacional Taxon, apresentando formatação segundo as normas dessa revista científica. Esse artigo será publicado em conjunto com José Rubens Pirani.

O capítulo 5 apresenta o estudo taxonômico de Calolisianthus, com detalhadas descrições morfológicas, chaves de identificação, ilustrações das espécies e mapas de distribuição geográfica. Assim como o capítulo 4, será submetido à Taxon e terá José Rubens Pirani como co-autor.

O capítulo 6 apresenta descrições morfológicas, ilustrações e mapas de distribuição de duas espécies anteriormente pertencentes a Calolisianthus, mas que serão combinadas em Chelonanthus.

O capítulo 7 apresenta uma nova lectotipificação do gênero Helia, bem como as descrições morfológicas, ilustrações e mapas de distribuição geográfica das espécies de Helia sensu stricto. 


\section{Referências Bibliográficas}

Adanson, M. 1763. Familles de plantes, vol. 2. Vincent, Paris.

Albert, V.A. \& Struwe, L. 2002. Gentianaceae in context. In: Struwe, L. Albert, V.A. (eds.), Gentianaceae - Systematics and Natural History. Cambridge University Press, Cambridge, pp. 1-20.

Aublet, M.F. 1775. Histoire des plantes de la Guiane Françoise. Vol.1. P.-F. Didot, London Paris.

APG. 1998. An ordinal classification for the families of flowering plants. Ann Missouri Bot. Gard. 85: 531-553.

APG II. 2003. An update of the Angiosperm Phylogeny Group classification for the orders and families of flowering plants: APG II. Bot. J. Linn. Soc. 141: 399-436.

Backlund, M., Oxelman, B. \& Bremer, B. 2000. Phylogenetic relationships with the Gentianales based on $n d h F$ and $r b c \mathrm{~L}$ sequences, with particular reference to the Loganiaceae. Amer. J. Bot. 87: 1029-1043.

Bentham, G. 1876. Gentianaceae. In: Bentham, G. \& Hooker, J. (eds.), Genera plantarum, vol. 2. parte 2. L. Reeve \& Co., Williams \& Norgate, London, pp. 799-820.

Bremer, B. \& Struwe, L. 1992. Phylogeny of the Rubiaceae and the Loganiaceae: congruence or conflict between morphological and molecular data. Am. J. Bot. 79(10): 1171-1184.

Browne, P. 1756. The civil and natural history of Jamaica in three parts, ed. 1. T. Osborne \& J. Shipton, London.

Brummitt, R.K. \& Powell, C.E. 1992. Authors of plant names. Royal Botanic Gardens, Kew.

Calió, M.F. 2009. Gentianaceae. In: Neotropikey. Version 1, March 2009. Royal Botanic Gardens, Kew. http://www.kew.org/science/tropamerica/neotropikey/families/Gentianaceae.htm, acessado em 5/agosto/2009.

Calió, M.F. \& Guimarães, E.F. 2009. Gentianaceae. In: Giulietti, A.M., Rapini, A., Andrade, M.J.G., de Queiroz, L.P. \& Cardoso Silva, J.M. (org.), Plantas raras do Brasil. Belo Horizonte - MG: Conservação Internacional, Universidade Estadual de Feira de Santana, pp. 185-186.

Calió, M.F., Pirani, J.R. \& Struwe, L. 2008. Morphology-based phylogeny and revision of Prepusa and Senaea (Gentianaceae: Helieae) - rare endemics from eastern Brazil. Kew Bull. 63: 169-191.

Chassot, P., Nenomissa, S., Yuan, Y.-M. \& Küpfer, P. 2001. High paraphyly of Swertia L. (Gentianaceae) in the Gentianella-lineage as revealed by nuclear and chloroplast DNA sequence variation. Plant Syst. Evol. 229: 1-21.

Cobb, L. \& Maas, P.J.M. 1983. Seed coat morphology in Irlbachia (Gentianaceae). Proc. 
Kon. Ned. Akad. Wetensch., ser C., 86: 127-136.

Cordeiro, I. 1987. Flora da Serra do Cipó, Minas Gerais: Gentianaceae. Bol. Bot. Univ. de São Paulo 9: 227-242.

Cordeiro, I. 2003. Flora de Grão-Mogol, Minas Gerais: Gentianaceae. Bol. Bot. Univ. de São Paulo 22 (2): 137-140.

Cordeiro, I. 2005. Gentianaceae. In: Wanderley, M.G.L., Shepherd, G.J., Melhem, T.S., Giulietti, A.M. (eds.), Flora Fanerogâmica do Estado de São Paulo, Vol. 4. São Paulo, pp. 211-222.

Costa, M.A.S. 1999. Gentianacae. In: Ribeiro, J.E.L.S. et al. (eds.), Flora da Reserva Ducke: guia de identificação das plantas vasculares de uma floresta de terra-firme na Amazônia Central. Manaus, INPA, pp. 566-567.

Crespo, S.R. de M. \& Marcondes-Ferreira, W. 2009. Revisão taxonômica do gênero Curtia (Gentianaceae). Rodriguésia 60(2): 423-444.

De Laet, J. \& Smets, E. 1996. A commentary on the circunscription and evolution of the order Gentianales, with special emphasis on the position of Rubiaceae. Opera Bot. Belg. 7: 11-18.

Gardner, G. 1843. Descriptions of four new genera of plants from the Organ Mountains. Lond. J. Bot. 2: 9-15.

Gentian Research Network. http://gentian.rutgers.edu/. Acessado em 5 agosto 2009.

Gilg, E.F. 1895. Gentianaceae. In: A. Engler \& K. Prantl (eds.), Die Natürlichen Pflanzefamilien. Vol 4 (2). Verlag von Wilhelm Engelmann, Leipzig, pp. 50-108.

Grisebach, A.H.R. 1839 [1838]. Genera et Species Gentianearum. Stuttgart.

Grisebach, A.H.R. 1845. Gentianaceae. In: De Candolle, A. (ed.), Prodromus systematis naturalis regni vegetabilis. Fortin, Masson, et Sociorum, Paris, pp. 39-141.

Guimarães, E.F. 1977. Revisão taxonômica do gênero Deianira Chamisso et Schlechtendal (Gentianaceae). Arq. Jard. Bot. Rio de Janeiro 21: 46-123.

Guimarães, E.F. 2004. Novos sinônimos para as espécies de Schultesia Mart. e Xestea Griseb (Gentianaceae). Rodriguésia 55 (85): 67-72.

Guimarães, E.F. \& Klein, V.L.G. 1985. Revisão taxonômica do gênero Coutoubea Aublet (Gentianaceae). Rodriguésia 37: 21-45.

Harvey, Y.B. 1995. Gentianaceae. In: Stannard, B.L. (ed.), Flora of the Pico das Almas, Chapada Diamantina-Bahia, Brazil. Royal Botanic Gardens, Kew, pp. 321-327.

Heywood, V.H. 1978. Flowering plants of the world. Oxford University Press. New York.

ICBN, 2006. McNeill, J., Barrie, F.R., Burdet, H.M., Demoulin, V., Hawksworth, D.L., Marhold, K. Nicolson, D.H., Prado, J., Silva, P.C., Skog, J.E., Wiersema, J.H. \& Turland, N.J. (eds.), International Code of Botanical Nomenclature (Vienna Code) adopted by the Intrenational Botanical Congress Vienna, Austria, July 2005, A.R.G. Gantner Verlag, 
Ruggel Liechtenstein.

Jensen, S.R. \& Schripsema, J. 2002. Chemotaxonomy and pharmacology of Gentianaceae. In: Struwe, L. \& Albert, V.A. (eds.), Gentianaceae: Systematics and Natural History. Cambridge University Press, pp. 573-631.

Judd, W.S., Campbell, C.S., Kellog, E.A., Stevens, P.F. 2002. Plant systematics: a phylogenetic approach. Sinauer Associates, Sunderland, Massachusetts. $2^{\mathrm{a}}$ edição.

Jussieu, A.L. 1789. Genera plantarum, secundum ordines naturales disposita, juxta methodum in Horto regio parisiensi exaratam, anno M.DCC.LXXIV. Herissant, Paris.

Kuntze, C.E.O. 1891. Revisio generum plantarum, vol. 2. Arthur Felix, Leipzig.

Leewenberg, A.J.M. \& Leenhouts, P.W. 1980. Taxonomy. In: Leewenberg, A.J.M. (ed.), Engler and Prantl's Die natürlichen Pflanzenfamilien, Angiospermae: Ordnung Gentianales, Fam. Loganiaceae. Vol. 28b (1). Duncker and Humblot, Berlin, pp. 8-96.

Linnaeus, C. 1767. Mantissa plantarum. Impensis Direct. Laurentii Salvii, Stockholm.

Linnaeus, C. 1774. Systema vegetabilium, secundum classes, ordines, genera, species, cum characteribus et differentiis. J.C. Dieterich, Gottingae et Gothae. $13^{\circ}$ ed.

Maas, P.J.M. 1985. Nomenclatural notes on neotropical Lisyantheae (Gentianaceae). Proc. Kon. Ned. Akad. Wetensch., Ser. C. 88: 405-412.

Maas, P.J.M., Nilsson, S., Hollants, A.M.C., Welle, B.J.H., Persoon, H. \& Heusden, E.C.H. 1983. Systematic studies in neotropical Gentianacae - the Lisianthius complex. Acta bot. Neerl. 32: 371-374.

Maguire, B. 1981. Gentianacaea. In: Maguire, B. et al. (eds.), The Botany of the Guayana Highland Part XIII. Mem. New York Bot. Gard. 51: 2-56.

Maguire, B. 1985. Gentianaceae - part 2. Phytologia 57: 311-312.

Maguire, B. \& Boom, B.M. 1989. Gentianaceae (part 3). In: Maguire, B. et al. (eds.), The Botany of the Guayana Highland Part XI. Mem. New York Bot. Gard. 32: 330-388.

Maguire, B. \& Pires, J.M. 1978. Saccifoliaceae - a new monotipic family of the Gentianales. In: Maguire B. et al. (eds.), The Botany of the Guayana Highland - Part X. Mem. New York Bot. Gard. 29: 230-245.

Martius, C.F.P., von. 1827. Nova genera et species plantarum quas in itinere per Brasiliam, vol. 2. V. Wolf, München.

Melderis, A. 1972. Taxonomic studies on the european species of the genus Centaurium Hill. Bot. J. Linn. Soc. 65(2): 224-250.

Mészáros, S., Laet, J. De, Goethals, V., Smets, E. \& Nilsson, S. 2002. Cladistics of Gentianaceae: a morphological approach. In: Struwe, L. \& Albert, V.A. (eds.), Gentianaceae: Systematics and Natural History. Cambridge University Press, Cambridge, pp. 310-376. 
Nilsson, S. 1968. Pollen morphology in the genus Macrocarpaea (Gentianaceae) and its taxonomical significance. Svensk Bot. Tidskr. 62: 338-364.

Nilsson, S. 1970. Pollen morphological contributions to the taxonomy of Lisianthus L. s.lat. (Gentianaceae). Svensk Bot. Tidskr. 64: 1-43.

Nilsson, S. 2002. A review of palinology. In: Struwe, L. \& Albert, V.A. (eds.), Gentianaceae: Systematics and Natural History. Cambridge University Press, Cambridge, pp. 377-572.

NSF (National Science Foundation).

http://www.nsf.gov/awardsearch/showAward.do?AwardNumber=0317612

Pringle, J.S. 1995. Family 159A. Gentianaceae. In: Harling, G. \& Andersson, L. (eds.), Flora of Ecuador, vol. 53. Department of Systematic Botany, Gothenburg University, Göteborg, pp. 1-131.

Simpson, M.G. 2006. Plant systematics. Elsevier Academic Press. Amsterdam, Boston.

Stafleu, F.A. \& Cowan, R.S. 1976-1988. Taxonomic Literature: A selective guide to botanical publications and collections, with dates, commentaries and types. 2nd much enlarged ed. v. 1-7, suppl. 1-6.

Stevens, P.F. 2008 onwards. Angiosperm Phylogeny Website. Version 9, June 2008. [and more or less continuously updated since]. http://www.mobot.org/MOBOT/research/APweb/. Acessado em 4 agosto 2009.

Struwe, L. \& Albert, V.A. 1998a. Lisianthius P.Br., its probable homonym Lisyanthus Aubl. (Gentianaceae) and the priority of Helia Mart. over Irlbachia Mart. as its substitute. Harvard Pap. Bot. 3: 67-71.

Struwe, L. \& Albert, V.A. 1998b. Six new species of Gentianaceae from the Guayana Shield. Harvard Pap. Bot. 3: 181-197.

Struwe, L. \& Albert, V.A. 1999. Nomenclatural issues in Helieae-Gentianaceae: a response to Zijlstra et al. Harvard Pap. Bot. 4 (1): 293.

Struwe, L. \& Albert, V.A. 2004. A monograph of Neotropical Potalia Aublet (Gentianaceae: Potalieae). Syst. Bot. 29 (3): 670-701.

Struwe, L., Albert, V.A. \& Bremer, B. 1994. Cladistics of the family level classification of the Gentianales. Cladistics 10: 175-206.

Struwe, L., Albert, V.A., Calió, M.F., Frasier, C., Lepis, K.B., Mathews, K.G., Grant, J.R., 2009. Evolutionary patterns in Neotropical Helieae (Gentianaceae): evidence from morphology, chloroplast and nuclear DNA sequences. Taxon 58(2): 479-499.

Struwe, L. \& Gould, K.R. 2004. Redefinition of Symbolanthus to include Wurdackanthus (Gentianaceae-Helieae). Novon 14: 354-359.

Struwe, L., Kadereit, J., Klackenberg, J., Nilsson, S., Thiv, M., von Hagen, K.B. \& Albert, V.A. 2002. Systematics, character evolution and biogeography of Gentianaceae, including a 
new tribal and subtribal classification. In: Struwe, L. \& Albert, V.A. (eds.), Gentianaceae Systematics and Natural History. Cambridge University Press, Cambridge, pp. 21-309.

Struwe, L., Maas, P.J.M. \& Albert, V.A. 1997. Aripuana cullmaniorum, a new genus and species of Gentianaceae from white-sands of southeastern Amazonas, Brazil. Harvard Pap. Bot. 2: 235-253.

Struwe, L., Maas, J.P., Pihlar, O. \& Albert, V.A. 1999. Gentianaceae. In: Berry, P.E., Yatskievych, K. \& Holst, B.K. (eds.) Flora of the Venezuelan Guayana. Vol. 5 Missouri Botanical Garden, St. Louis, pp. 474-542.

Struwe, L., Thiv, M., Kadereit, J.W., Pepper, A.S.-R., Motley, T.J., White, P.J., Rova, J.H.E., Potgieter, K. \& Albert, V.A. 1998. Saccifolium (Saccifoliaceae), an endemic of Sierra de la Neblina on the Brazilian-Venezuelan frontier, is related to a temperate-alpine lineage of Gentianaceae. Harvard Pap. Bot. 3: 199-214.

Thiv, M., Struwe, L., Albert, V.A. \& Kadereit, J.W. 1999. The phylogenetic relationships of Saccifolium bandeirae Maguire \& Pires (Gentianaceae) reconsidered. Harvard Pap. Bot. 4: 519-526.

Thiv, M., Struwe, L. \& Kadereit, J.W. 2000. The phylogenetic relationships and evolution of the Canarian laurel forest endemic Ixanthus viscosus (Aiton) Griseb. (Gentianaceae): evidence from matK and ITS sequences, and floral morphology and anatomy. Plant Syst. Evol. 218: 299-317.

Wagenitz, G. 1964. Gentianales. In: Melchior, H.A. Engler's Syllabus der Pflanzenfamilien, vol. 2, ed. 12. Gebr. Börntraeger, Berlin, pp. 405-424.

Weaver, R.E. 1972. A revision of the neotropical genus Lisianthius (Gentianaceae). J. Arnold Arb. 53: 76-100, 234-272, 273-311.

Yuan, Y.-M., Küpfer, P. \& Doyle, J.J. 1996. Infrageneric phylogeny of the genus Gentiana (Gentianaceae) inferred from nucleotide sequences of the internal transcribed spacers (ITS) of nuclear ribosomal DNA. Amer. J. Bot. 83(5): 641-652.

Zijlstra, G., Maas, P.J.M., Gandhi, K. 1999. On the nonexistence of Lisyanthus Aublet. Harvard Pap. Bot. 4(1): 289-292. 


\section{- Capítulo $1-$}

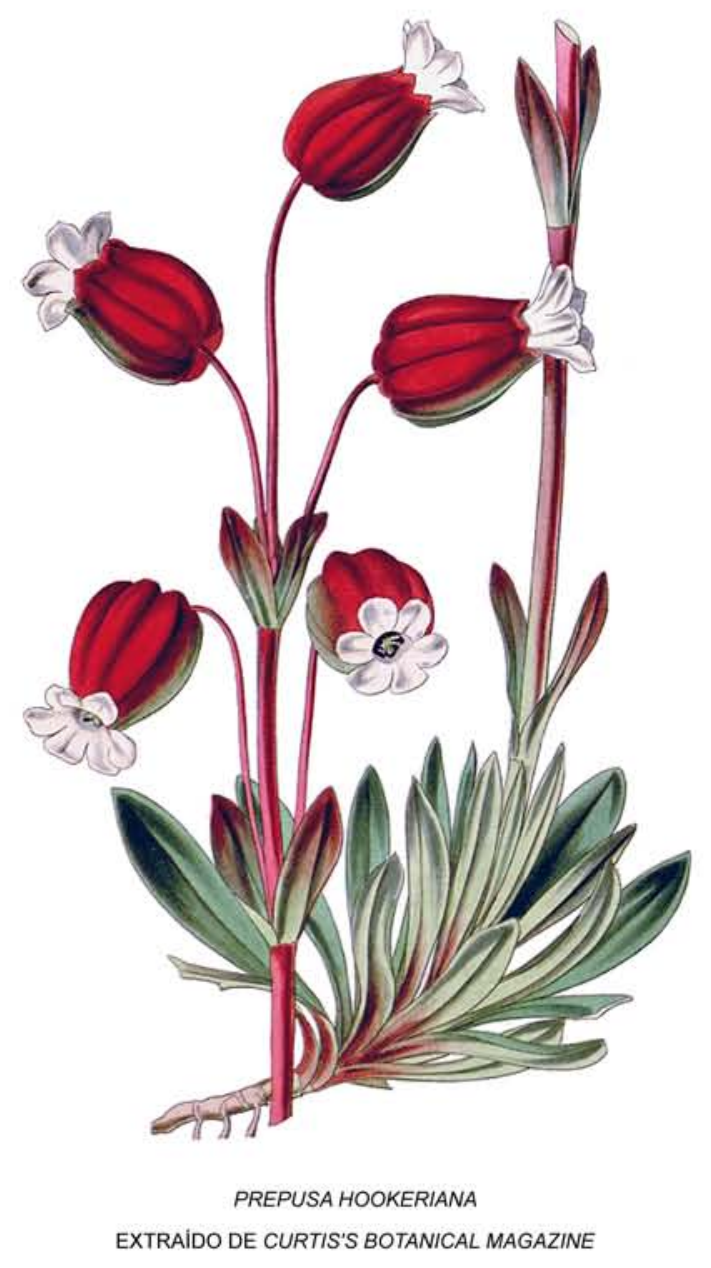

Filogenia baseada em MORFologia E REVISÃo de Prepusa e Senaea (Gentianaceae: Helieae) PLANTAS RARAS E ENDÊMICAS DO LESTE DO BRASIL 


\section{CAPÍTULO 1}

Filogenia baseada em morfologia e revisão de Prepusa e Senaea (Gentianaceae:

Helieae) - plantas raras e endêmicas do leste do Brasil ${ }^{1}$

Os gêneros Prepusa Mart. e Senaea Taub. (Gentianaceae) compreendem ervas, arbustos ou pequenas árvores restritas a habitats montanhosos dos estados da Bahia, Espírito Santo, Minas Gerais e Rio de Janeiro. Devido ao compartilhamento de alguns atributos morfológicos, ambos os gêneros foram tentativamente posicionados em Helieae, embora esta hipótese carecesse de embasamento filogenético. Além das descrições originais, até recentemente esses gêneros haviam sido tratados apenas em trabalhos de cunho florístico. Entretanto, a publicação de um artigo de filogenia e revisão de ambos os gêneros (Calió et al. 2008, Anexo 1) disponibilizou novas e atualizadas informações acerca dos mesmos. A seguir, o conteúdo do artigo, que é parte integrante desta Tese, é apresentado de forma resumida.

Com base principalmente em exemplares de coleções de herbários, a morfologia externa das espécies de Prepusa e Senaea foi investigada com o objetivo de levantar caracteres para análise filogenética, bem como para elaboração de descrições morfológicas detalhadas. Os dados obtidos foram analisados sob óptica dos princípios bayesianos (buscas com modelo "standard" realizadas no MrBayes) e da parcimônia (buscas de branch and bound realizadas no PAUP*), com avaliação da sustentação das relações por meio das probabilidades posteriores, bootstrap e índice de decaimento.

Os resultados das análises filogenéticas apresentaram um quadro consistente das relações de Prepusa e Senaea. Os gêneros são monofiléticos e irmãos entre si, essa relação sendo sustentada pelas flores 6-meras, cálice membranáceo e estiletes cilíndricos. No clado das espécies de Prepusa, $P$. montana Mart. é a primeira a ramificar, seguida de $P$. viridiflora Brade; P. alata Porto \& Brade é irmã do par P. connata Gardner e $P$. hookeriana Gardner. As duas espécies de Senaea são irmãs entre si. A filogenia representando essas relações de parentesco e as discussões acerca da evolução do grupo encontram-se no Anexo 1.

Morfologicamente, Prepusa e Senaea diferem-se principalmente pelo tamanho relativo do cálice: em Prepusa, esta estrutura é grande, de tamanho maior ou equivalente à

\footnotetext{
${ }^{1}$ Artigo publicado no Kew Bulletin; versão original em inglês no Anexo 1.
} 
metade do comprimento da corola; Senaea apresenta cálice pequeno, muito mais curto que a corola. Além disso, Senaea apresenta corola lilás a azulada (Fig. 1A) com lobos da corola quase tão longos quanto o tubo, enquanto Prepusa apresenta corola variando entre esverdeada a amarelada ou alva (Figs. 1C, 2C, 3C e 3E), com lobos da corola muito mais curtos que o tubo. As duas espécies de Senaea diferenciam-se entre si principalmente pela presença de papilas no pedicelo e cálice em S. coerulea Taub., e ausência das mesmas em S. janeirensis Brade. Prepusa montana é a única espécie do gênero que atinge o porte de arvoreta (Figs. 2A e 2B); diferencia-se das demais também pelo cálice e corola de cor amarelo-esverdeada a creme. Prepusa viridiflora distingue-se das demais pelo cálice alado de coloração verde-amarronzada, com lobos triangulares (Figs. 1B e 1C). Prepusa alata, $P$. connata e $P$. hookeriana possuem cálice de coloração avermelhada, rosada ou vinácea (Figs. 3A, 3B e 3D), sendo que apenas o cálice de $P$. alata é alado. Prepusa connata diferencia-se das demais pelas brácteas conatas em $2 / 5$ a $4 / 5$ de seu comprimento, enquanto $P$. hookeriana apresenta brácteas conatas em até, no máximo, 1/5 de seu comprimento. As descrições morfológicas detalhadas, chaves de identificação e ilustrações das espécies estão apresentadas no Anexo 1.

Quanto à distribuição geográfica, Prepusa montana ocorre em campos rupestres e cerrados da Chapada Diamantina, na Bahia. Prepusa viridiflora ocorre nos campos de altitude do Espírito Santo, nos municípios de Castelo e Domingos Martins. Prepusa connata e $P$. hookeriana ocorrem nos campos de altitude da Serra dos Órgãos, no Rio de Janeiro, sendo a distribuição de $P$. hookeriana um pouco mais ampla, por ocorrer também na região do Itatiaia. Prepusa alata ocorre apenas na região de Santa Maria Madalena (Pedra do Desengano), onde também ocorre Senaea janeirensis. E, por fim, S. coerulea foi coletada em localidades esparsas na Cadeia do Espinhaço, em Minas Gerais. Sugere-se que esse padrão de distribuição em mosaico deva ter se originado a partir de eventos de vicariância seguidos de especiação alopátrica. Os mapas representando a distribuição de cada espécie, bem como discussões sobre a biogeografia desses gêneros, constam no Anexo 1.

É importante ressaltar que todas essas espécies apresentam distribuição bastante restrita, muitas vezes ocorrendo apenas em um pico de montanhas. Populações de Prepusa alata, $P$. connata, $P$. hookeriana, $P$. viridiflora e Senaea janeirensis são conhecidas apenas de áreas de proteção ambiental. Prepusa montana ocorre em áreas de proteção e também fora dessas áreas, enquanto $S$. coerulea foi reportada apenas para áreas não-protegidas. As espécies de Prepusa e Senaea foram classificadas, de acordo com os critérios propostos pela "International Union for Conservation of Nature" (IUCN), como: (1) Vulnerável (VU, $P$. montana); (2) Em perigo (EN, $P$. hookeriana e $P$. viridiflora); e (3) Em perigo crítico (CR, $P$. alata, P. connata, S. coerulea e S. janeirensis). S. coerulae pode, inclusive, estar extinta, pois não é encontrada desde 1982, apesar das freqüentes coletas realizadas nas regiões 
onde essa espécie fora reportada. Mais detalhes quanto à distribuição geográfica e categorização segundo os critérios da IUCN são apresentadas no Anexo 1.

Alguns meses após a publicação do artigo de Calió et al. (2008), Cláudio Nicoletti de Fraga, pesquisador do Instituto de Pesquisa Jardim Botânico do Rio de Janeiro e doutorando pela Universidade Federal de Minas Gerais, coletou espécimes de Senaea no Espírito Santo, nas mesmas localidades onde ocorre $P$. viridiflora. Ainda não foi possível estudar o material herborizado, mas a análise de fotografias sugere se tratar de $S$. janeirensis. Se essa identificação for confirmada, essa espécie não poderá mais ser classificada como "em perigo crítico", devendo ser categorizada como "em perigo" segundo os critérios da IUCN.

\section{Referência bibliográfica}

Calió, M.F., Pirani, J.R. \& Struwe, L. 2008. Morphology-based phylogeny and revision of Prepusa and Senaea (Gentianaceae: Heliae) - rare endemics from eastern Brazil. Kew Bull. 63: 169-191. Anexo 1. 


\section{- Capítulo 2}

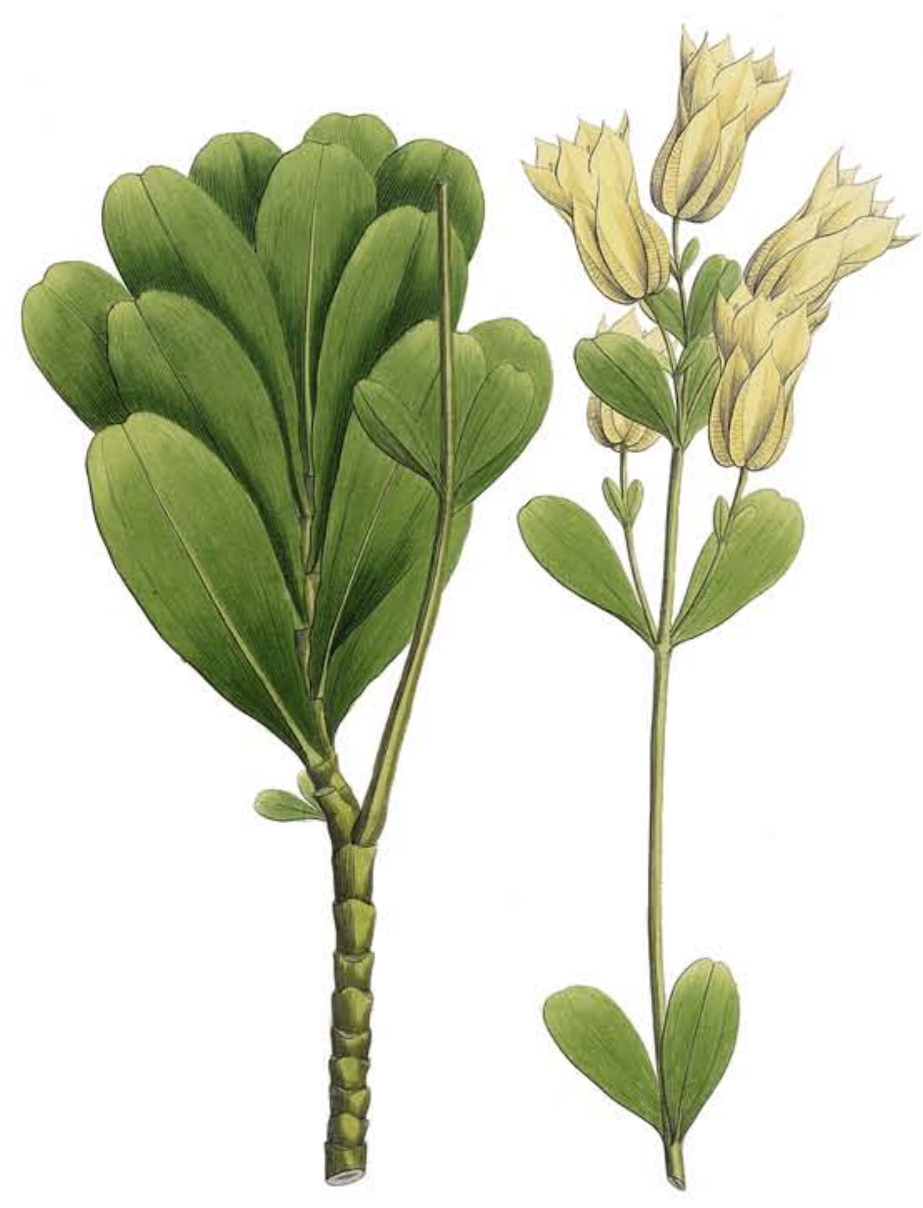

PREPUSA MONTANA

EXTRAIDO DE NOVA GENERA ET SPECIES PLANTARUM

Padrões evolutivos em Helieae (Gentianaceae): EVIDÊNCIAS MORFOLÓGICAS E DE SEQÜÊNCIAS DE DNA PLASTIDIAIS E NUCLEARES 


\section{CAPÍTULO 2}

\section{Padrões evolutivos em Helieae (Gentianaceae): evidências morfológicas e de seqüências de DNA plastidiais e nucleares ${ }^{1}$}

Embora a reconstrução das relações filogenéticas de Gentianaceae tenha sido tema de pesquisas desde a década de 90 , somente houve avanço substancial na área em 2002, com a publicação do trabalho de Struwe e colaboradores. Com o aumento da amostragem de táxons e a inclusão de maiores conjuntos de dados, Struwe et al. (2002) obtiveram filogenias com maior resolução, nas quais se basearam para elaborar uma nova classificação da família no nível de tribos. A base de dados utilizada, entretanto, não foi suficiente para resolver e sustentar as relações filogenéticas entre os grupos menos inclusivos. Fazia-se necessária, portanto, a exploração de novos conjuntos de dados que fossem mais informativos no nível genérico.

O estabelecimento de um grande projeto de cooperação internacional em 2003, com o objetivo de estudar as relações filogenéticas entre os gêneros de Helieae (vide Introdução desta Tese para histórico detalhado), resultou na obtenção de grande quantidade de dados moleculares e morfológicos. Os resultados da exploração inicial desses dados foram publicados recentemente no periódico internacional Taxon (Struwe et al. 2009, Anexo 2). Este último artigo, elaborado em colaboração com pesquisadores de outras instituições de pesquisa, faz parte da presente Tese de Doutorado e, portanto, é apresentado de forma resumida na seqüência, bem como integralmente no Anexo 2.

Struwe et al. (2009) amostraram 59 espécies representativas de praticamente todos os gêneros de Helieae. Foram incluídos 23 táxons de outras tribos de Gentianaceae para garantir enraizamento apropriado nas análises filogenéticas, pois as relações entre as tribos eram, em sua maioria, desconhecidas. Dados morfológicos foram obtidos principalmente a partir da análise de materiais de herbários e da compilação de dados provenientes de literatura, totalizando 127 caracteres. Aqueles relacionados ao hábito das plantas, merisma das flores e agregação de pólen foram mapeados nas filogenias obtidas para se investigar sua evolução em Helieae.

Seqüências de DNA plastidial, especificamente matK e trnL intron, provenientes de estudos anteriores, bem como seqüências novas da região ITS do DNA nuclear ribossomal,

\footnotetext{
${ }^{1}$ Artigo publicado na Taxon; versão original em inglês no Anexo 2.
} 
compuseram as matrizes de dados moleculares. Também foram utilizadas matrizes binárias (ausência / presença) com dados de recodificação dos eventos de inserção-deleção (indels) de trnL intron e ITS. As matrizes foram combinadas de modos diferentes, incluindo ou não táxons com determinado conjunto de dados. A congruência entre as partições de dados foi avaliada por meio do teste ILD (Incongruence Length Difference). Análises de parcimônia foram realizadas com o programa NONA por meio do Winclada. A estratégia de busca envolveu uma primeira busca padrão, seguida de busca com método de ratchet. Os resultados foram compilados em árvores de consenso estrito, com medição de sustentação dos nós por meio de análises de Jackknife. Detalhes acerca da metodologia empregada apresentam-se descritos no Anexo 2.

Apesar do teste ILD ter indicado grande heterogeneidade entre os diferentes conjuntos de dados, a inspeção visual indicou congruência entre as topologias, o que justificou a análise combinada entre as diferentes partições. Detalhamentos sobre resultados da análise individual de cada partição de dados estão relatados no Anexo 2.

O consenso estrito da matriz combinada "pequena" (i.e., incluindo apenas táxons para os quais se possuía ao menos um conjunto de dados moleculares) foi o mais resolvido e com valores de Jackknife mais altos. Em resumo, Helieae foi recuperada como monofilética, tendo Gentianeae como tribo-irmã. Prepusa montana emergiu na base da tribo como grupo-irmão das demais espécies de Helieae, que apresentaram-se agrupadas em dois grandes clados: um deles formado por representantes dos gêneros Chorisepalum, Macrocarpaea e Tachia ("subclado Macrocarpaea"); o outro compreendendo representantes de Adenolisianthus, Aripuana, Calolisianthus, Chelonanthus, Helia, Irlbachia, Lehmaniella, Neblinantha, Purdieanthus, Symbolanthus e Tetrapollinia ("subclado Symbolanthus"). Além da quase completa resolução das relações internas de Helieae, diversos gêneros foram recobrados como monofiléticos, com exceção de Chelonanthus e Irlbachia, que emergiram como polifiléticos.

Embora tenha levado à redução dos valores de Jackknife, a adição de táxons para os quais se possuía apenas dados morfológicos (análise combinada "grande") não alterou grande parte dos agrupamentos da análise combinada "pequena". Essa congruência entre as análises reforçou a robustez das hipóteses propostas para a evolução de Helieae, bem como permitiu avaliar e discutir questões acerca da filogenia da tribo, com praticamente todos seus gêneros representados na análise combinada "grande". Informações adicionais sobre os agrupamentos resultantes de cada análise combinada e sobre o mapeamento dos caracteres morfológicos, estão descritas no Anexo 2.

Apesar da baixa resolução em diversos nós dos cladogramas, foi possível constatar que uma série de atributos morfológicos (da morfologia externa, polínicos e de sementes) sustentam agrupamentos importantes. Helieae, por exemplo, é definida pelas seguintes 
sinapomorfias: sépalas com margem hialina; estilete achatado, retorcido e persistente nos frutos; fruto pêndulo; pólen liberado em tétrades; e sementes angulosas, com testa apresentando espessamentos em bandas. Futuras análises que venham a incluir novos conjuntos de dados poderão, possivelmente, revelar outros caracteres promissores.

O estudo do hábito das plantas e do merisma das flores revelou que os estados "hábito lenhoso" e "flores polímeras" evoluíram diversas vezes independentemente em Gentianaceae. Com a análise da evolução do hábito lenhoso, evidenciou-se a importância da inclusão, em estudos futuros, de dados referentes ao ciclo de vida das plantas (anual vs. perene). A investigação da correlação entre ambos os atributos poderá auxiliar no entendimento dos eventos de origem e diversificação do hábito lenhoso em Gentianaceae, os quais podem estar associados ao padrão de especiação de algumas linhagens da família.

Discussões acerca das filogenias obtidas, bem como das análises de evolução de caracteres, encontram-se detalhadas no Anexo 2.

\section{Referências bibliográficas}

Struwe, L., Albert, V.A., Calió, M.F., Frasier, C., Lepis, K.B., Mathews, K.G., Grant, J.R., 2009. Evolutionary patterns in Neotropical Helieae (Gentianaceae): evidence from morphology, chloroplast and nuclear DNA sequences. Taxon 58(2): 479-499. Anexo 2.

Struwe, L., Kadereit, J., Klackenberg, J., Nilsson, S., Thiv, M., von Hagen, K.B. \& Albert, V.A. 2002. Systematics, character evolution, and biogeography of Gentianaceae, including a new tribal and subtribal classification. In: Struwe, L. \& Albert, V.A. (eds.) Gentianaceae Systematics and Natural History. Cambridge University Press, Cambridge, pp. 21-309. 


\section{- Capítulo 3}

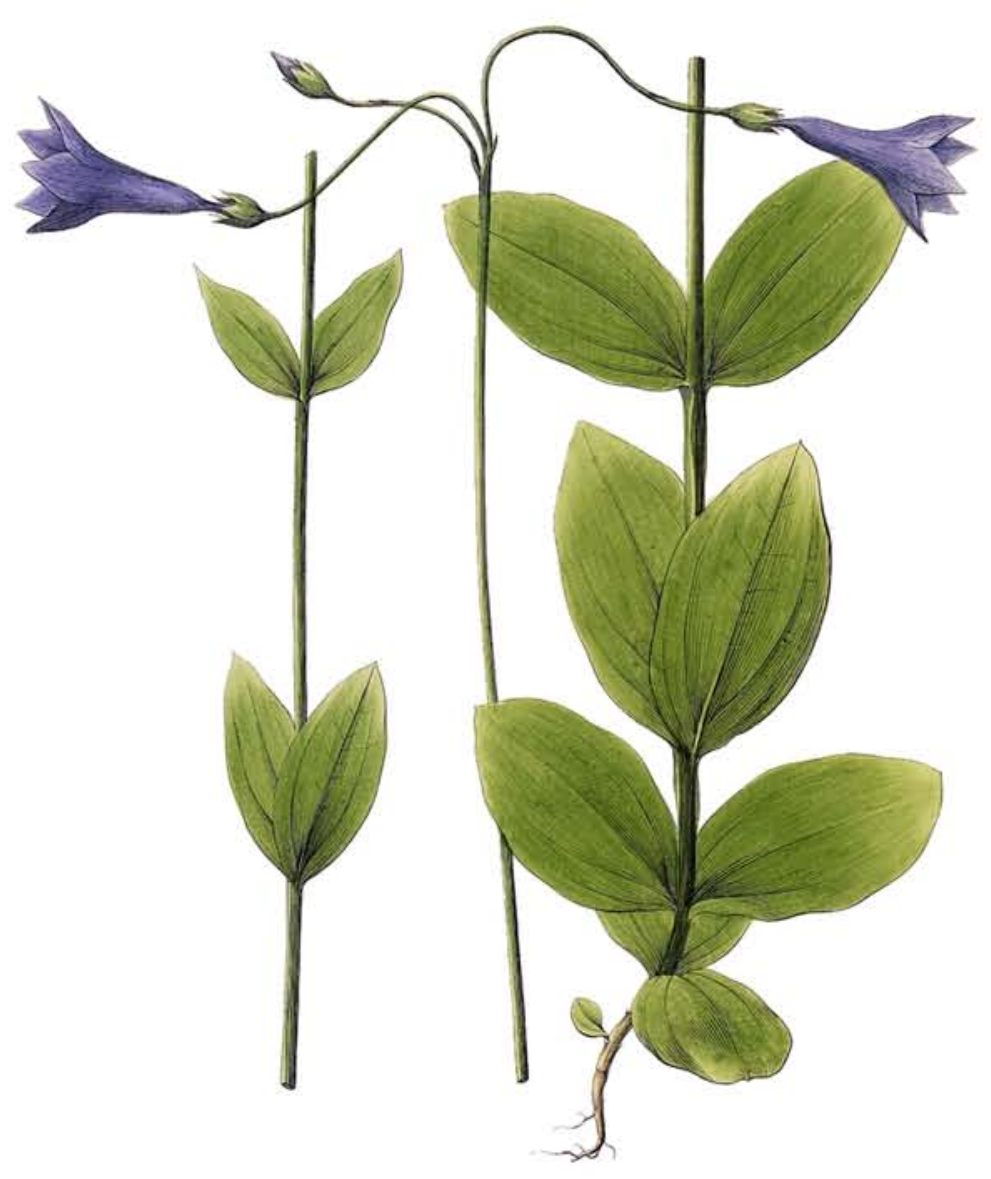

LISIANTHUS PENDULUS

EXTRAIDO DE NOVA GENERA ET SPECIES PLANTARUM

Estudo filogenético de Helieae (Gentianaceae) com Ênfase nos limites genéricos de Calolisianthus Gilg, Chelonanthus Gilg e Helia Mart., BASEADO EM DADOS MOLECULARES E MORFOLÓGICOS 


\title{
CAPÍTULO 3
}

\section{Estudo filogenético de Helieae (Gentianaceae) com ênfase nos limites genéricos de Calolisianthus Gilg, Chelonanthus Gilg e Helia Mart., baseado em dados moleculares e morfológicos ${ }^{1}$}

\begin{abstract}
Phylogenetic relationships in Helieae (Gentianaceae) were investigated. DNA sequences from two nuclear regions (ITS and 5S-NTS) and morphological data were analyzed separately and in combination using parsimony and Bayesian inference. A total of 86 specimens representing 17 and 51 Helieae genera and species, respectively, were included in the phylogenetic analyses; 47 specimens are sequenced for both regions, and eight have only morphological data. The complete data set produced topologies largely congruent with the ones obtained from two subsets, one without missing data, and another including taxa without data for one molecular partition. The use of new information led to a consistent result in the relative position of some clades and allowed defining new generic circumscriptions for Calolisianthus, Chelonanthus, Helia, and, to a lesser extent, Symbolanthus.
\end{abstract}

Keywords 5S-NTS, generic circumscription, Gentianaceae, Helieae, ITS, morphology, phylogeny, total evidence

\section{Resumo}

As relações filogenéticas de Helieae (Gentianaceae) foram investigadas. Seqüências de DNA de duas regiões nucleares (ITS e 5S-NTS) e dados morfológicos foram analisados separadamente e em conjunto por meio de análises de parcimônia e Bayesiana. Foram incluídos 86 espécimes representantes de 17 gêneros e 51 espécies de Helieae. Desse total, 47 espécimes possuem seqüências das duas regiões e oito possuem apenas dados morfológicos. O conjunto de dados completo gerou topologias largamente congruentes com aquelas obtidas com a análise de dois subconjuntos, um sem "dados ausentes" e outro incluindo táxons sem dados para uma das partições moleculares. A inclusão de maior número de táxons e de um novo conjunto de dados gerou um resultado consistente quanto

\footnotetext{
${ }^{1} \mathrm{~A}$ ser submetido à revista internacional Molecular Phylogenetics and Evolution.
} 
ao posicionamento relativo de alguns clados, permitindo a definição de novas circunscrições genéricas para Calolisianthus, Chelonanthus, Helia e, em menor grau, para Symbolanthus.

Palavras-chave 5S-NTS, circunscrição genérica, evidência total, Filogenia, Gentianaceae, Helieae, ITS, morfologia

\section{Introdução}

Gentianaceae Juss. é uma família de Angiospermae que se distribui praticamente por todas as regiões terrestres do globo (exceto Antártica), ocupando uma grande variedade de habitats e apresentando uma ampla diversidade morfológica (Albert e Struwe 2002).

O uso de seqüências de DNA plastidial, especificamente trnL intron e matK, contribuiu com o aumento do conhecimento acerca das relações filogenéticas dentre as Gentianaceae (Struwe et al., 1998, 2002; Thiv et al., 1999). Os resultados desses estudos levaram Struwe et al. (2002) a apresentarem uma nova classificação no nível genérico e de tribos, que, apesar de se basear apenas em dados moleculares, apresenta grande congruência com dados de morfologia externa (Mészáros et al., 2002), palinológicos (Nilsson, 2002) e químicos (Jensen e Schripsema, 2002). Foram reconhecidas 6 tribos monofiléticas - Saccifolieae, Exaceae, Chironieae, Gentianeae, Potalieae e Helieae - além de um gênero com posicionamento incerto, Voyria (Struwe et al., 2002). Dessas, apenas Saccifolieae e Helieae são endêmicas da região neotropical, sendo Helieae maior em número de gêneros e espécies.

Helieae, apesar de ser uma tribo que apresenta grande diversidade morfológica, pode ser caracterizada pelo cálice com estruturas glandulares na região dorsal ou com áreas glandulares nos lobos, filetes de comprimentos desiguais, anteras recurvadas depois da antese e com apêndices apicais estéreis, estigma bilamelado, e estilete achatado que se enrola quando seco (Struwe et al., 2002).

O primeiro estudo com o objetivo de elucidar as relações filogenéticas em Helieae foi realizado por Struwe et al. (2009). Baseando-se em dados moleculares e morfológicos, as análises sustentaram a monofilia da tribo, bem como de algumas subdivisões internas. Foi constatada a necessidade de rever a classificação dos gêneros Chelonanthus Gilg e Irlbachia Mart., pois ambos emergiram como não monofiléticos. Mais especificamente, a espécie-tipo de Chelonanthus, Ch. purpurascens, emergiu separadamente das demais espécies (denominadas informalmente de "Chelonanthus de flores verdes"), e I. pratensis emergiu no mesmo clado de Ch. purpurascens, mas separadamente das demais Irlbachia. 
Apesar desse estudo ter sido bastante elucidativo, ainda são necessários novos trabalhos para resolver as relações filogenéticas internas da tribo.

Dentro desse contexto, o presente estudo visa (1) esclarecer as relações intergenéricas em Helieae, usando novas seqüências de DNA nuclear; (2) estudar o efeito da maior amostragem de táxons e da adição de um novo conjunto de dados na filogenia da tribo; (3) embasar conclusões filogenéticas com toda a informação disponível, incluindo caracteres morfológicos, por meio de análise de evidência total; (4) fornecer embasamento para novas circunscrições genéricas; (5) evidenciar possíveis sinapomorfias morfológicas para caracterizar clados em particular; (6) sugerir um cenário biogeográfico da história da tribo.

\section{Materiais e métodos}

\subsection{Amostragem de táxons}

Foram analisados 17 dos 23 gêneros de Helieae, totalizando 51 espécies da tribo, além de 20 gêneros de Chironieae, Gentianaea e Potalieae juntas, totalizando 73 espécies de Gentianaceae. Devido às incertezas quanto às relações entre Helieae, Gentianeae e Potalieae (Struwe et al., 2002), seguiu-se a proposta de ampla seleção de táxons como grupo-externo apresentada por Struwe et al. (2009). Das 51 espécies do grupo-interno, representadas por 86 espécimes, 8 foram incluídas somente com dados morfológicos nas análises: Chelonanthus sp. ined. 1, Lagenanthus princeps (Lindl.) Gilg, Lehmanniella splendens (Hook.) Ewan, Neblinantha neblinae Maguire, N. parvifolia Maguire, Rogersonanthus arboreus (Britton) Maguire et B.M. Boom, Symbolanthus argyreus (Maguire) Struwe et K.R. Gould, S. elisabethae (M.R. Schomb.) Gilg. As demais possuem seqüências de ao menos um dos conjuntos de dados moleculares (Tabela 1).

Foram estudadas as regiões ITS (internal transcribed spacer) e 5S-NTS (non trancribed spacer do gene $5 S$ ) do DNA nuclear ribossomal. No total, 47 seqüências de ITS e 44 de 5S-NTS foram obtidas para o presente estudo (em outro momento, serão submetidas ao Genbank), representando principalmente gêneros que haviam sido pouco estudados até então (Tabela 1). Dependendo da disponibilidade de material, mais de um espécime de cada espécie foi analisado, utilizando-se amostras provenientes de material desidratado em sílica-gel ou de material de herbário (Tabela 1). Além disso, foram utilizadas 51 seqüências de ITS e três de 5S-NTS obtidas diretamente do Genbank (Tabela 1). 


\subsection{Dados morfológicos}

A matriz morfológica utilizada nesse estudo é basicamente a mesma apresentada por Struwe et al. (2009), com algumas alterações, i.e. adição ou remoção de caracteres, codificação de todos os caracteres referentes às espécies que ainda não haviam sido amostradas, e modificações na codificação de alguns caracteres, devido ao aumento do conhecimento sobre a morfologia do grupo (Apêndices A e B). Os critérios para seleção dos caracteres, delimitação dos estados e tratamento dos dados estão descritos em Struwe et al. (2009).

Os novos dados morfológicos foram obtidos a partir da análise de material preservado em álcool (durante expedições de coleta) ou de material herborizado, proveniente dos seguintes herbários: AAU, ALCB, BHCB, BR, CHRB, CEN, CEPEC, CESJ, CGMS, COL, CTES, CVRD, ESA, ESAL, F, G, GUA, HB, HRB, HUCS (não indexado), HUEFS, HUFU, HXBH, IAC, IAN, IBGE, INPA, IPA, K, LIL, LP, MBM, MBML, MG, MO, NY, PMSP, R, RB, RBR, RUSU, S, SJRP, SP, SPF, SPFR, SPSF, U, UB, UEC, UFG, UPCB, UPS, US, VIC, W. Além disso, foram consultados os trabalhos de Bouman et al. (2002), Struwe et al. (2002) e Nilsson et al. (2002) para complementação dos dados sobre sementes e pólen.

\subsection{Dados moleculares}

As extrações de DNA genômico foram feitas a partir de material de herbário ou de folhas desidratadas em sílica-gel (Tabela 1), com emprego do DNeasy plant mini kit (Qiagen), seguindo o protocolo do fabricante com algumas modificações. Aproximadamente $1 \mathrm{~cm}^{2}$ de folha seca foi triturada com pistilo em um tubo tipo Eppendorf com nitrogênio líquido, ou pulverizada em máquina FastPrep (Bio 101) por 15 seg à velocidade 5 . Ao tubo com fragmentos de folha, foi adicionado $400 \mu \mathrm{l}$ de tampão AP1 e $30 \mu \mathrm{l}$ de $\beta$-mercaptoetanol (ao invés de $4 \mu \mathrm{l}$ de solução estoque de RNase A); em seguida, o tubo foi incubado em banho a $65^{\circ} \mathrm{C}$ durante $10 \mathrm{~min}$, com agitação periódica. Subseqüentemente, foi feita a adição de $130 \mu \mathrm{l}$ de tampão AP2 e incubação em gelo por 5 min. Posteriormente, a amostra foi centrifugada a $13000 \mathrm{rpm}$ durante $5 \mathrm{~min}$. Desse ponto em diante, seguiu-se exatamente o protocolo fornecido pelo fabricante.

As reações de amplificação foram feitas em máquinas DNA Engine with Dual Alpha Unit PTC 200 (Bio Rad) ou GeneAmp® PCR System 9700 (Applied Biosystems). Na amplificação, foram utilizados dNTPs da marca IDT, os demais reagentes sendo da marca Promega. O DNA foi diluído (1:100) no caso de amostras estocadas em sílica-gel, ou utilizado sem diluição no caso de amostras de herbário. Sempre que possível, a região foi 
amplificada duas vezes para cada espécime (em dois tubos separados) e, em seguida, os dois produtos finais foram combinados e homogeneizados.

A região do ITS (ITS1-5.8S-ITS2) foi amplificada utilizando-se os iniciadores desenhados por Nickrent et al. (1994). Algumas amostras somente puderam ser amplificadas com o uso dos iniciadores internos desenhados por White et al. (1990), de modo que o ITS1 e o ITS2 foram amplificados separadamente. A região foi amplificada em reações de $50 \mu$ l contendo: $10 \mu \mathrm{l}$ tampão $5 \mathrm{x}, 1.5 \mu \mathrm{l} 25 \mathrm{mM} \mathrm{MgCl}_{2}, 1 \mu \mathrm{l}$ dNTPs a $10 \mu \mathrm{M}, 2 \mu \mathrm{l}$ BSA, $2 \mu \mathrm{l}$ de cada iniciador $(10 \mu \mathrm{M}), 0.4 \mu \mathrm{l}$ de Taq polimerase e $1 \mu \mathrm{l}$ de DNA. As condições utilizadas para amplificação foram: 1 min a $97^{\circ} \mathrm{C}$, seguido de 35 ciclos de 1 min a $94^{\circ} \mathrm{C}, 1$ $\min$ a $50^{\circ} \mathrm{C}, 2 \min$ a $72^{\circ} \mathrm{C}$, e extensão final por $4 \min$ a $72^{\circ} \mathrm{C}$.

A região do 5S-NTS foi amplificada com os iniciadores desenhados por Cox et al. (1992). A região foi amplificada em reações de $50 \mu \mathrm{l}$ contendo: $10 \mu \mathrm{l}$ tampão $5 \mathrm{x}, 3.5 \mu \mathrm{l} 25$ $\mathrm{mM} \mathrm{MgCl} 2,1 \mu \mathrm{l}$ dNTPs a $10 \mu \mathrm{M}, 2 \mu \mathrm{l}$ BSA, $2 \mu \mathrm{l}$ de cada iniciador $(10 \mu \mathrm{M}), 0.2 \mu \mathrm{l}$ de Taq polimerase e $1 \mu \mathrm{l}$ de DNA. As condições utilizadas para amplificação foram: 2 min a $95^{\circ} \mathrm{C}$, 35 ciclos de 1 min a $94^{\circ} \mathrm{C}, 30-60$ seg a $55-60^{\circ} \mathrm{C}, 30-60$ seg a $72^{\circ} \mathrm{C}$, e extensão final por 4 $\min$ a $72^{\circ} \mathrm{C}$.

Para avaliar a qualidade das regiões-alvo amplificadas, os produtos de PCR foram aplicados em gel de agarose a 1\% (GIBCO) contendo brometo de etídio ou Gel red ${ }^{T M}$ Nucleic Acid Gel Stain (Biotium) e visualizados sob luz UV. No caso da amplificação do ITS, para algumas amostras de herbário foi necessário fazer uma segunda PCR usando-se as mesmas quantidades de reagentes e 1-3 $\mu \mathrm{L}$ do produto da primeira PCR como molde, obtendo-se, dessa forma, um produto em concentração adequada para seqüenciamento. No caso do 5S-NTS, os produtos foram aplicados em gel de agarose Low melting a $1.2 \%$ (GIBCO) para separar as bandas múltiplas resultantes e extrair a banda-alvo (detectada por comparação do tamanho das bandas com o ladder, Invitrogen). O processo de extração de DNA do gel foi realizado com o Illustra GFX ${ }^{T M}$ DNA and gel band purification kit (GE Healthcare), seguindo-se o protocolo do fabricante. Um microlitro do DNA da banda extraída foi utilizado como molde em uma segunda PCR, realizada sob as mesmas condições da primeira.

Os produtos de amplificações bem sucedidas (i.e., com apenas uma banda forte) foram purificados com o Illustra GFX ${ }^{T M} D N A$ and gel band purification kit (GE Healthcare). Um homogeneizado contendo o produto de PCR e $200 \mu \mathrm{l}$ de Capture Buffer foi transferido para um tubo de $1.5 \mathrm{ml}$. Em seguida, mais $300 \mu \mathrm{l}$ de Capture Buffer foram adicionados a esse homogeneizado e, posteriormente, o volume total foi transferido para a coluna com filtro acoplada ao tubo coletor (fornecidos no kit). Desse passo em diante, foi seguido exatamente o protocolo apresentado nas instruções do fabricante. A etapa de eluição foi 
feita com 40 ou $50 \mu$ de água ultrapura, de acordo com a concentração aparente da amostra (visualizada no transiluminador).

As amostras purificadas foram aplicadas em gel de agarose a $4 \%$ juntamente com Low mass DNA ladder (Invitrogen) para quantificação aproximada da concentração. Em seguida, os produtos foram enviados ao Centro de Estudos do Genoma Humano (Instituto de Biociências, Universidade de São Paulo), para realização das reações de seqüenciamento (com os mesmos iniciadores e mesmas condições das reações de amplificação) e seqüenciamento das amostras. O seqüenciamento foi feito em sistema MegaBACE 1000 (GE Healthcare), utilizando DYEnamic ET Dye Terminator Kit (com Thermo Sequenase ${ }^{T M}$ /I DNA Polimerase), e as seqüências foram analisadas pelo software Sequence Analyser utilizando o Base Caller Cimarron 3.12.

As condições acima descritas aplicam-se somente às amostras trabalhadas no Laboratório de Algas Marinhas "Édison José de Paula" (Instituto de Biociências, Universidade de São Paulo) - as mesmas são indicadas por um asterisco na Tabela 1. As demais amostras foram amplificadas, purificadas e seqüenciadas em condições ligeiramente diferentes no "Plant Systematics Laboratory" (Rutgers University, NJ, EUA), por K. B. Lepis.

Apenas seqüências de boa qualidade, com picos únicos e distintos, foram utilizadas. As seqüências foram montadas e editadas com o Sequencher $4.8^{\mathrm{TM}}$ (Gene Codes Corp., Ann Arbor, Michigan, USA). As bases foram individualmente checadas, procurando-se concordância entre as fitas complementares. O alinhamento foi feito com o ClustalX 1.81 (Thompson et al., 1997), seguido de ajustes manuais feitos no MacClade 4.08 para OS $X$ (Maddison e Maddison, 2005), usando o critério de similaridade (Simmons, 2004). A codificação de eventos de inserção/deleção (inde/s) não autapomórficos foi realizada manualmente seguindo o método de simple indel coding (Simmons e Ochoterena, 2000), sendo adicionados como caracteres binários nas matrizes de dados (Apêndices $C$ e $D$ ). Todas as matrizes, alinhamentos e árvores serão disponibilizadas no TREEBASE (www.treebase.com).

\subsection{Análises de dados}

As partições de dados, i.e., Morfologia, ITS, indels do ITS, 5S-NTS e indels do 5SNTS, foram analisadas individualmente ou combinadas, com variações nos táxons utilizados em cada análise para testar se a ausência de dados em algumas partições afetaria a topologia das análises combinadas (ver Tabela 2 para nomes das matrizes e respectivos conjuntos de dados e táxons). Em suma, além das matrizes das partições individuais, foram montadas matrizes contendo apenas dados moleculares combinados ("Combinadas Moleculares"), bem como matrizes combinando todos os dados moleculares e morfológicos 
("Combinadas Totais"). Quanto ao número de táxons, há as matrizes "Pequenas", incluindo apenas táxons que contêm dados de todos os conjuntos, as "Médias", incluindo táxons que contêm dados de ao menos uma das partições moleculares, e as "Grandes" com todos os terminais, incluindo aqueles para os quais não se obtiveram dados moleculares. Optou-se por avaliar a congruência entre as partições por meio de comparações "nó-a-nó" para detectar clados conflitantes e com altos valores de sustentação.

Análises de máxima parcimônia foram conduzidas utilizando PAUP* 4.0b10 (Swofford, 2000), com todos os caracteres tratados como não-ordenados e com o mesmo peso. As análises das matrizes "5S-NTS", "Combinada Molecular Pequena" e "Combinada Total Pequena" foram conduzidas com o sistema de busca denominado "A" (Tabela 3), com os seguintes parâmetros: busca heurística com 1000 réplicas de random taxon addition sequence, 10 árvores retidas a cada passo, e com TBR branch swapping, com ramos colapsados quando o comprimento mínimo era igual a zero. As matrizes "Morfologia", "ITS" e as combinadas "Molecular Média", "Total Média" e "Total Grande" foram analisadas com o sistema de busca denominado "B" (Tabela 3), composto de duas etapas com os seguintes parâmetros: i) busca heurística com 1000 réplicas de random taxon addition sequence, 10 árvores retidas a cada passo, com TBR branch swapping nas melhores árvores, com ramos colapsados quando o comprimento mínimo era igual a zero, e não mais do que 10 árvores salvas por réplica; ii) as melhores árvores encontradas em (i) foram usadas como árvores iniciais em uma segunda busca heurística usando TBR branch swapping, com ramos colapsados quando o comprimento mínimo era igual a zero, salvando múltiplas árvores (função MULTREES acionada), até atingir o limite de 200 mil árvores salvas. O sistema "B" foi empregado com o objetivo de explorar um maior número de ilhas do espaço amostral. Os níveis relativos de homoplasia em todas as partições foram acessados a partir dos índices de consistência $(\mathrm{Cl})$, de retenção $(\mathrm{RI})$ e de homoplasia $(\mathrm{HI})$, como implementados no PAUP* $4.0 b 10$ (Swofford, 2000).

A sustentação dos ramos foi obtida por meio de bootstrap (Felsenstein, 1985), seguindo o seguinte protocolo: busca heurística, 1000 réplicas de bootstrap, 1 random addition sequence replicates, com 1 árvore retida a cada passo, TBR branch swapping, salvando múltiplas árvores (função MULTREES acionada), até atingir o limite de 5 mil árvores salvas.

As inferências Bayesianas foram realizadas com o programa MrBayes versão 3.1.2 (Huelsenbeck e Ronquist, 2001; Ronquist e Huelsenbeck, 2003). O melhor modelo de substituição de nucleotídeos foi inferido com MrModeltest versão 2.2 (Nylander, 2004) e selecionado segundo o critério AIC ("SYM + I +G" para ITS e "HKY + G" para 5S-NTS). Os dados morfológicos e indels foram incluídos nas reconstruções filogenéticas e analisados com o modelo standart discrete (Lewis, 2001). 
Cada análise foi feita com duas buscas paralelas, cada uma com 4 cadeias de Markov, utilizando os parâmetros padrão. Cada busca foi iniciada com uma árvore aleatória e rodada por 5 milhões de gerações, amostrando árvores da distribuição posterior a cada 100 gerações (para um total de 50.000 amostras). 25\% das árvores foram descartadas como burnin, as restantes sendo utilizadas para computar o consenso de maioria $(50 \%)$ e calcular as probabilidades posteriores dos clados. Não foram efetuadas análises Bayesianas a partir das matrizes "Combinadas Moleculares".

\subsection{Estudo das sinapomorfias morfológicas}

Dados morfológicos (Apêndices A e B) foram mapeados sobre a topologia da análise "Combinada Total Grande" seguindo o critério da parcimônia, como implementado no programa MacClade 4.08 para OS X (Maddison e Maddison, 2005), com o intuito de evidenciar possíveis sinapomorfias morfológicas.

\subsection{Estudo biogeográfico}

As áreas geográficas das espécies amostradas de Helieae e a topologia resultante da análise da matriz "Combinada Total Grande" foram utilizadas para reconstruir um cenário de sua história de distribuição espacial. Alguns ramos de Helieae foram retirados manualmente, de modo que cada espécie estivesse representada por apenas um ou dois ramos. Além disso, foram removidos os ramos correspondentes às outras tribos.

As áreas foram codificadas de acordo com a ocorrência das espécies dentro das províncias biogeográficas propostas por Cabrera e Willink (1980), com uma modificação: a província Guiana foi considerada como parte da província Amazônica. No caso das espécies que ocorrem em mais de uma província biogeográfica, a codificação considerou apenas a província em que a distribuição é mais expressiva, ou seja, a região para a qual há maior registro de coletas. Apenas para três espécies não foi possível fazer essa escolha, devido à distribuição igualmente expressiva em mais de uma província: Chelonanthus matogrossensis ocorre nas províncias biogeográficas Amazônica e dos Andes, enquanto $C$. purpurascens e Tetrapollinia caerulescens ocorrem nas províncias Amazônica e do Cerrado. As áreas foram tratadas como estados de um caráter não-ordenado, sendo otimizadas sobre a topologia empregando o critério da parcimônia, como implementado no programa MacClade 4.08 para OS X (Maddison e Maddison, 2005). 


\section{Resultados}

\subsection{Alinhamentos e análises filogenéticas}

Não houve necessidade de excluir partes das seqüências de DNA, pois o alinhamento não apresentou áreas com ambigüidades.

Nas análises de parcimônia das matrizes em que se empregou o sistema de busca "B", não houve redução no comprimento das árvores obtidas após a segunda etapa. O comprimento das matrizes, estatísticas sobre as árvores e valores de $\mathrm{Cl}, \mathrm{RI}$ e $\mathrm{HI}$ para as análises individuais e combinadas estão sumarizadas na Tabela 3.

A partição "Morfologia" apresentou maior proporção relativa de caracteres informativos (98\%), entretanto produziu as árvores de parcimônia e Bayesiana com menor resolução, bem como apresentou os menores valores de $\mathrm{Cl}$ e RI e maior valor de HI. Outras partições que apresentaram valores altos de proporção relativa de caracteres informativos foram "5S-NTS com indels" e "5S-NTS sem indels" (77 e 75\%, respectivamente).

\subsubsection{Congruência entre partições}

A comparação das topologias obtidas nas análises das partições individuais não evidenciou nenhuma relação incongruente e com altos valores de sustentação. Devido ao nível geral de congruência entre as diferentes partições, as mesmas foram combinadas. Apesar da análise individual da matriz "Morfologia" ter resultado em uma árvore de consenso estrito com pouca resolução (Apêndice E, Fig. E4), observou-se que a junção dos dados morfológicos aos moleculares (análises "Combinadas Totais", Figs 1 a 3; Apêndice E, Figs. E1 a E3) aumentou a resolução de alguns clados, tendo pouco efeito sobre os valores de $\mathrm{Cl}, \mathrm{RI}$ e $\mathrm{HI}$. As árvores obtidas com as análises de cada matriz diferem principalmente no grau de resolução, este sendo mais baixo nas árvores resultantes das análises de partições individuais, e mais alto na análise da matriz "Combinada Total Média" (Fig. 2; Apêndice E, Fig. E2). O elevado número de clados bem sustentados nas análises de dados combinados, em relação às análises das partições individuais, sugere que os diferentes conjuntos de dados são amplamente congruentes. Por essa razão, consideramos as árvores obtidas com as análises das matrizes "Combinadas Totais" (Figs. 1, 2 e 3) as melhores aproximações das relações filogenéticas de Helieae, e, portanto, as discussões são baseadas nessas topologias (as demais são apresentadas no Apêndice E, Figs. E1 a E12). 


\subsubsection{Matriz de indels}

A adição da matriz com os indels codificados não alterou significativamente as topologias obtidas, bem como pouco alterou os valores de $\mathrm{Cl}$, RI e $\mathrm{HI}$ (Tabela 3). Comparando-se as topologias obtidas a partir das matrizes "5S-NTS com indels" e "5S-NTS sem indels" (Apêndice E, Figs. E7 e E8), evidenciou-se que a adição dos indels à matriz gerou o colapso de três ramos pertencentes aos "Chelonanthus de flores verdes", bem como alterou o posicionamento de um espécime de Ch. purpurascens. Entretanto, na análise sem os indels codificados, esses agrupamentos apresentaram baixos valores de sustentação ou até mesmo nenhuma sustentação. A comparação entre as topologias obtidas com as análises das matrizes "ITS com indels" e "ITS sem indels" (Apêndice E, Figs. E5 e E6) evidenciou que a combinação dos mesmos com a matriz ITS, além de agrupar dois espécimes de Calolisianthus speciosus, levou ao colapso de parte dos ramos de Gentianeae; tais ramos, porém, não receberam valores de sustentação na análise sem indels.

Além dessas diferenças já apontadas para as matrizes individuais, as matrizes combinadas apresentaram, em alguns casos, outras pequenas alterações. Comparando-se as topologias obtidas com a análise "Total Média com indels" e "Total Média sem indels" (Fig. 2; Apêndice E, Fig. E2), evidenciou-se que a adição dos indels agrupou todas as espécies amostradas de Potalieae em um clado monofilético, tendo o mesmo efeito sobre os espécimes de Ch. purpurascens. Já a comparação entre as topologias obtidas com a análise "Total Grande com indels" e "Total Grande sem indels" (Fig. 1; Apêndice E, Fig. E1) evidenciou que a adição dos indels, apesar de recuperar Potalieae como monofilético, não agrupa os espécimes de Ch. purpurascens. Além disso, essa adição de indels agrupa Chorisepalum psychotrioides com as espécies de Tachia.

Apesar dessas pequenas diferenças, as topologias resultantes das análises das matrizes combinadas contendo os indels codificados foram escolhidas para embasar a discussão final, pois apresentaram maior número de caracteres informativos na análise de parcimônia e valores de $\mathrm{Cl}, \mathrm{RI}$ e $\mathrm{HI}$ semelhantes, bem como maior número de nós com PP maior do que 0.85 , se comparadas às topologias das respectivas matrizes sem os indels codificados (Tabela 3). As árvores resultantes das demais análises são apresentadas no Apêndice E (Figs. E1 a E12).

\subsubsection{Comparações entre topologias das análises de parcimônia e Bayesiana}

As topologias resultantes das análises Bayesianas (não apresentadas) e de parcimônia são idênticas nos casos das partições moleculares individuais, enquanto que 
aquelas resultantes das análises da matriz "Morfologia" e das "Combinadas Totais" são amplamente coincidentes, mas apresentam posicionamento diferente de alguns táxons. Tanto a análise de parcimônia quanto a análise Bayesiana da matriz "Morfologia" resultaram em topologias pouco resolvidas e com valores de sustentação baixos ou ausentes. $\mathrm{Na}$ análise Bayesiana, "Ca. acutangulus", Ca. amplissimus, Ch. purpurascens e todas as espécies de Irlbachia emergem em um clado (0.87 PP, probabilidade posterior), enquanto na análise de parcimônia tais espécies não se agrupam (Apêndice E, Fig. E4). Além disso, na análise de parcimônia, algumas espécies de Calolisianthus emergem em um clado com baixo valor de sustentação, enquanto que na Bayesiana tais espécies emergem em uma grande politomia.

Em relação às matrizes "Combinadas Totais", a maior parte das diferenças observadas entre as topologias obtidas nas análises de parcimônia e Bayesiana não altera a composição dos grandes clados resultantes e, de modo geral, correspondem a agrupamentos que em uma ou outra análise não receberam valores de sustentação significativos ou que emergiram totalmente sem resolução. A diferença entre as topologias resultantes das análises da matriz "Combinada Total Pequena" está no posicionamento de Ch. grandiflorus, que, na análise Bayesiana, agrupou-se com as espécies de Helia, Ch. acutangulus e Ch. matogrossensis (1.00 e $0.99 \mathrm{PP}$, com e sem indels, respectivamente), enquanto que na análise de parcimônia esse táxon agrupa-se com outras espécies de "Chelonanthus de flores verdes", ainda no clado H (Fig. 3; Apêndice E, Fig. E3). Nas análises das matrizes "Combinada Total Média" e "Combinada Total Grande", o resultado é semelhante, mas Adenolisianthus arboreus acompanha Ch. grandiflorus nos agrupamentos da análise Bayesiana ("Total Grande": 0.74 e 0.76 PP, com indels e sem indels, respectivamente; "Total Média": 1.00 e 1.00 PP, com indels e sem indels, respectivamente). Já na análise de parcimônia dessas mesmas matrizes, Ch. grandiflorus emerge em uma politomia dentro do clado H (Figs. 1 e 2; Apêndice E, Figs. E1 e E2).

Além dessas diferenças, a análise Bayesiana da matriz "Combinada Total Grande" apresentou Ch. purpurascens como monofilético (0.73 e 0.59 PP nas análises com e sem indels, respectivamente) e I. pratensis como espécie-irmã do clado F (0.97 PP nas análises com e sem indels). Tais resultados das análises Bayesianas não contradizem aqueles obtidos a partir das análises de parcimônia, pois nestas últimas os agrupamentos em questão não receberam sustentação por meio de bootstrap (Fig. 1; Apêndice E, Fig. E1). A maior diferença encontrada entre essas topologias, entretanto, está no posicionamento das duas espécies de Neblinantha, as quais, nas análises de parcimônia, emergem no clado E, enquanto na Bayesiana emergem no clado J (0.72 e 0.73 PP, nas análises com e sem indels, respectivamente). Dessa forma, os clados E, G, I e J não são exatamente iguais nas topologias das análises Bayesiana e de parcimônia, devido ao diferente posicionamento de 
Neblinantha. É importante ressaltar que nenhum desses clados teve sustentação por meio de bootstrap na análise de parcimônia da matriz "Combinada Total Grande" (Fig. 1; Apêndice E, Fig. E1); esse fato se deve, provavelmente, ao posicionamento das espécies de Neblinantha, uma vez que na análise da matriz "Combinada Total Média" (Fig. 2; Apêndice E, Fig. E2), que não inclui tais táxons, os mesmos clados receberam altos valores de sustentação.

Excetuando-se o posicionamento de Neblinantha, os consensos estritos de parcimônia e os consensos de maioria das análises Bayesianas apresentaram topologias quase idênticas. Por essa razão, neste trabalho são apresentadas apenas as topologias das análises de parcimônia, às quais foram adicionados os valores de bootstrap e de probabilidades posteriores da análise Bayesiana (Figs. 1 a 3; Apêndice E, Figs. E1 a E12).

\subsubsection{Principais resultados filogenéticos}

A topologia resultante da análise da matriz "Combinada Total Grande com indels" (Fig. 1) é aqui utilizada para a descrição dos principais clados resultantes, entretanto é possível notar que os mesmos clados (indicados por letras e números ou nomes) estão presentes nas topologias obtidas com as matrizes "Combinada Total Média com indels" (Fig. 2) e "Combinada Total Pequena com indels" (Fig. 3). Os principais resultados são:

(1) Potalieae, Gentianeae e Helieae emergem como 3 grupos monofiléticos, sustentados, respectivamente, por: 61 de porcentagem de bootstrap (PB) e 0.99 PP; 78 PB e 1.00 PP; 91 PB e 1.00 PP.

(2) Prepusa montana emerge como grupo-irmão das demais Helieae (clado A; 90 PB, 1.00 $\mathrm{PP})$.

(3) Macrocarpaea (clado Mac; 100 PB, 1.00 PP), Tachia (clado Tac; 100 PB, 1.00 PP) e Chorisepalum emergem juntas (clado B; 60 PB, 0.94 PP), sendo Chorisepalum mais proximamente relacionado a Tachia (0.82 PP).

(4) esse clado formado por Macrocarpaea, Tachia e Chorisepalum é irmão do clado C (73 PB, 0.98 PP), que é composto por dois ramos: um contendo três espécies de Irlbachia (clado Irl; 98 PB, 1.00 PP) e outro com todas as demais espécies (clado D; 63 PB, 0.98 PP).

(5) o clado D, por sua vez, é formado por dois clados, o clado E e o clado G, ambos sem valores de sustentação na análise "Combinada Total Grande" (mas muito bem sustentados nas demais análises).

(6) o clado $E$ é formado por espécies de diversos gêneros, cujo relacionamento é difícil de ser discutido devido à falta de sustentação de alguns ramos. Entretanto, dentro desse clado, as espécies Calolisianthus amplissimus, "Ca. acutangulus" (ambas formando o 
clado Cal1; 100 PB, 1.00 PP) e Ch. purpurascens agrupam-se consistentemente (clado F; 93 PB, 1.00 PP).

(7) os clados $\mathrm{H}$ e I compõem o clado $\mathrm{G}$, sendo que apenas o clado $\mathrm{H}$ possui sustentação na análise "Combinada Total Grande" (62 PB, 0.99 PP). Esse clado é formado pelas duas espécies de Helia (Clado Hel, 100 PB, 1.00 PP), por Adenolisianthus arboreus e por todas as espécies de "Chelonanthus de flores verdes"; entretanto, as relações entre todas essas espécies não se apresentam resolvidas.

(8) O clado I é formado pelos clados J e K, sendo que J não possui sustentação na análise "Combinada Total Grande" (embora seja muito bem sustentado na "Combinada Total Média"), sendo formado por espécies descritas em dois gêneros, Symbolanthus (clado Sym) e Rogersonanthus (clado Rog, 82 PB, 1.00 PP).

(9) O Clado K (78 PB, 0.99 PP) contém espécies de dois gêneros, todos os terminais de Tetrapollinia (clado Tet; 100 PB, 1.00 PP) e alguns pertencentes a Calolisianthus (clado Cal2; 100 PB, 1.00 PP).

\subsection{Estudo das sinapomorfias morfológicas}

O mapeamento dos caracteres morfológicos evidenciou alto grau de homoplasia; entretanto, em alguns casos, certos atributos configuram-se como sinapomorfias de determinados clados (Figs. 4 e 5). Uma discussão completa sobre tais caracteres é apresentada na seção 4.2 .

\subsection{Estudo biogeográfico}

As espécies de Helieae utilizadas nesse estudo ocorrem em cinco províncias biogeográficas segundo o sistema de Cabrera e Willink (1980): Amazônica (concentrando maior número de linhagens), do Cerrado, dos Andes, Atlântica e do Caribe. A reconstrução da província ocupada pelo ancestral do clado A (todas as espécies exceto o clado de Prepusa) indicou a província Amazônica como provável área de distribuição ancestral (Fig. $6)$. 


\section{Discussão}

\subsection{Rumo a uma filogenia mais resolvida utilizando dados combinados}

Um dos objetivos do presente estudo foi ampliar o número de espécies do clado "Symbolanthus" sensu Struwe et al. (2009) com dados moleculares amostrados, principalmente da região ITS, a qual havia se mostrado bastante informativa. A comparação entre a topologia resultante da análise individual da matriz "ITS" (Apêndice E, Figs. E5) e a topologia apresentada por Struwe et al. (2009), com o mesmo conjunto de dados, mas menor número de táxons estudados, evidenciou que apenas a maior amostragem de espécies com dados de ITS não levou ao aumento da resolução da topologia. Com base apenas nos dados de ITS, o presente estudo obteve exatamente os mesmos clados obtidos anteriormente por Struwe et al. (2009), apresentando praticamente o mesmo grau de informação entre os mesmos. Isso indica que o emprego do ITS para resolver as relações em Helieae é limitado, pois, apesar de fornecer sustentação para grandes clados, não permite a resolução de grupos menos inclusivos.

De fato, foi claramente a combinação dos dados de ITS com dados de 5S-NTS, uma região notória por sua rápida taxa de evolução (Sastri et al., 1992), que resultou em maior resolução entre os clados menos inclusivos, anteriormente pouco resolvidos. É importante ressaltar que ambos os conjuntos de dados mostraram-se bastante congruentes e complementares, pois individualmente reconstruíram os mesmos clados principais e, quando combinados, resultaram em uma árvore mais resolvida.

Por outro lado, a combinação dos dados moleculares com os dados morfológicos merece ênfase especial. A comparação entre as topologias obtidas com as análises das matrizes "Combinada Molecular Média" (Apêndice E, Fig. E9) e "Combinada Total Média" (Fig. 2), ou seja, análises com exatamente o mesmo conjunto de táxons, mostra que a adição da morfologia não alterou a composição dos grandes clados obtidos a partir da análise de dados moleculares, e aumentou a resolução dentro dos clados menos resolvidos (e.g., clados G e E, Fig. 1).

Entretanto, a inclusão de táxons apenas com dados morfológicos (matriz "Combinada Total Grande", Fig. 1) pode ocasionar problemas. O primeiro, e mais óbvio, é a grande quantidade de "dados ausentes" - um problema não intrínseco ao conjunto de dados morfológicos per se - que claramente resulta em redução geral dos valores de sustentação e diminuição da resolução de alguns clados (na maior parte das vezes, clados que não apresentaram valores altos de sustentação na análise "Combinada Total Média", Fig. 2). Apesar disso, os "dados ausentes" não necessariamente impedem o posicionamento 
desses táxons com seus congêneres (e.g., Symbolanthus argyreus e S. elisabethae, que agruparam-se com as demais espécies de Symbolanthus).

O segundo problema causado pela inserção de táxons apenas com dados morfológicos é o possível posicionamento incorreto dos mesmos. Um exemplo dessa asserção é o posicionamento de Calolisianthus amplissimus. No estudo de Struwe et al. (2009), essa espécie, incluída na análise apenas com dados morfológicos, emergiu juntamente com as demais espécies de Calolisianthus, formando um grupo monofilético. No presente estudo, Ca. amplissimus, incluído na análise também com dados moleculares, emergiu em outro clado, configurando-se como uma espécie filogeneticamente distante das demais espécies do gênero. Provavelmente, esse problema é causado pelo grande compartilhamento de atributos morfológicos dentre as espécies de Helieae como um todo, fato responsável por grande parte dos problemas taxonômicos que historicamente envolveram os táxons da tribo (para uma revisão sobre o assunto, vide Struwe e Albert, 1998; Zijlstra et al., 1999). Por fim, esse compartilhamento generalizado de atributos morfológicos reflete-se na qualidade dos caracteres utilizados na matriz, a grande maioria homoplástica.

O terceiro e último problema foi detectado apenas por meio da comparação entre as topologias resultantes das análises de parcimônia e Bayesiana da matriz "Combinada Total Grande", e deve ser resultante não somente do uso de táxons apenas com dados morfológicos, mas também dos métodos empregados para reconstrução filogenética. Ambas as formas de análise resultaram em topologias bastante congruentes, inclusive similares quanto ao posicionamento de seis táxons dos quais se possuía apenas dados morfológicos. Entretanto, as duas espécies de Neblinantha, cujo posicionamento também dependia apenas de dados morfológicos, emergiram em clados distintos em cada análise. É difícil entender por que razão somente esses táxons apresentaram posicionamento tão distinto, mas o resultado indica que pelo menos um dos métodos empregados falha na reconstrução filogenética, talvez devido à utilização de menor quantidade de dados (no caso, apenas dados morfológicos) ou à qualidade dos dados morfológicos (neste caso, muito homoplásticos).

Apesar dos problemas observados, acredita-se que o emprego dos dados morfológicos é essencial no estudo das relações filogenéticas de Helieae, mesmo que talvez ainda estejam na forma de uma matriz incompleta, pois tais dados são, em grande parte, responsáveis pelo direcionamento de pesquisas futuras e são as evidências fenotípicas visíveis dos padrões evolutivos que tentamos desvendar. 


\subsection{Circunscrições genéricas}

Struwe et al. (2009) apontaram a necessidade de redefinir os gêneros de Helieae. O presente trabalho, além de fornecer maior embasamento para as circunscrições sugeridas naquele trabalho, traz evidências para outras redelimitações, em alguns casos bastante distintas das circunscrições tradicionais.

\subsubsection{Calolisianthus}

$\mathrm{Na}$ filogenia apresentada por Struwe et al. (2009), Calolisianthus foi apresentado como um gênero monofilético. Entretanto, o presente trabalho refutou a monofilia desse gênero em sua circunscrição tradicional, pois as espécies que o compõem emergem em dois clados não proximamente relacionados, ambos com altos valores de sustentação (Fig. 1, clados Cal1 e Cal2). Tradicionalmente, essas espécies foram tratadas em conjunto devido às suas similaridades morfológicas e distribuição geográfica coincidente (e.g., Gilg, 1895), mas, à luz desses novos resultados, atentou-se para características que sustentam essa separação.

O clado Cal1, formado por Ca. amplissimus e "Ca. acutangulus", agrupou-se com Ch. purpurascens formando o clado $\mathrm{F}$, que é caracterizado pela presença de pólen liberado em políades (car. 88, Fig. 4a) e presença de alças na exina (car. 91, Fig. 4b). É importante ressaltar que ambas as características são compartilhadas por outros grupos: o pólen também é liberado em políades nas espécies do clado Irl e em I. pratensis, e alças na exina também são encontradas em I. pratensis e nas espécies de Neblinantha. Isso indica que tais características são provavelmente sinapomorfias de um nível mais abrangente. Por exemplo, no caso do car. 91, as alças da exina seriam sinapomorfia do clado $E$, com reversão no clado-irmão de Neblinantha. No caso do car. 88, devido à reconstrução equívoca, o nível ao qual se aplica à sinapomorfia é incerto. Do modo como se apresenta, o pólen liberado em políades pode ser interpretado como: a) uma novidade evolutiva que surgiu no ancestral do clado $\mathrm{C}$, com posteriores reversões no clado-irmão do clado $\mathrm{F}$ e no clado G; ou b) uma característica que surgiu independentemente nos ancestrais dos clados Irl e do clado E, seguida de reversão no clado-irmão do clado F. Apesar desse compartilhamento com outros grupos, tais características sustentam o não relacionamento entre os clados Cal1 e Cal2 (que compreende as demais espécies de Calolisianthus). Outras características presentes nas espécies do clado $\mathrm{F}$ e ausentes no clado Cal2 são as margens ciliadas ou papilosas dos lobos do cálice e da corola (cars. 39 - Fig. 4c - e 58) e os filetes achatados (car. 69, Fig. 4d), em oposição às margens sem cílios ou papilas e aos 
filetes cilíndricos presentes em todas as espécies do clado Cal2. Tais caracteres, por sua vez, também são homoplásticos, mas permitem a caracterização de clados em particular.

O clado Cal2, que compreende Calolisianthus pedunculatus, Ca. pendulus, Ca. speciosus e Ca. sp. ined., apesar de emergir com alta sustentação, não apresenta nenhum atributo morfológico que seja exclusivo, sendo caracterizado apenas por sinapomorfias homoplásticas. Por exemplo, considerando apenas o clado I, no qual estão inseridos os clados Cal2, Tet, Sym e Rog, lobos da corola com ápice escurecido (car. 57, Fig. 4e) é sinapomorfia de Cal2; entretanto, considerando-se a tribo toda, "região escurecida no ápice do lobo da corola" configura-se como um caráter homoplástico, devido ao compartilhamento dos lobos escurecidos com outros clados, i.e, clados H e Cal1, e com Purdieanthus.

Em termos taxonômicos, essa divisão das espécies tradicionalmente tratadas como Calolisianthus em dois clados distintos e não aparentados implica a necessidade de rever a circunscrição do gênero. Ca. amplissimus é a espécie-tipo do gênero, e, por essa razão, o nome Calolisianthus deveria permanecer ligado a tal espécie. Sendo assim, as espécies do clado Cal2 necessitariam de um novo nome, o que poderia ser conseguido por meio da descrição de um novo gênero ou por transferência para gêneros filogeneticamente aparentados. Entretanto, essa espécie-tipo é um lectótipo (designado por Pringle, 1995), e suas características morfológicas, principalmente polínicas, contradizem o protólogo do gênero. Segundo o Código Internacional de Nomenclatura Botânica (ICBN, 2006), essa é uma das razões para se rejeitar uma lectotipificação. Dentro desse panorama taxonômico e filogenético, proporemos uma nova lectotipificação com uma das espécies do clado Cal2, mantendo o nome genérico ligado às espécies desse clado (Calió e Pirani, em prep.; Capítulo 4). Isso evitará a descrição de um novo gênero ou a proliferação de novas combinações em uma tribo reconhecida por sua complicada história nomenclatural.

\subsubsection{Chelonanthus}

Com a nova lectotipificação de Calolisianthus, Ca. amplissimus e "Ca. acutangulus" precisam ser transferidos para outro gênero. O posicionamento de ambas as espécies juntamente com Chelonanthus purpurascens, a espécie-tipo de Chelonanthus, formando o clado $\mathrm{F}$, fornece embasamento para transferência de tais espécies para Chelonanthus (vide capítulo 6 desta Tese). Vale ressaltar que o clado $F$ é fortemente sustentado e bem caracterizado morfologicamente, principalmente por caracteres polínicos (ver seção 4.2.1 para maior detalhamento). Além dos caracteres descritos na seção anterior, a cor lilás da corola, presente tanto em táxons de Cal1 como em Cal2, é um atributo que deve ser enfatizado. Observações realizadas nas populações naturais mostraram que a cor lilás que Ca. amplissimus, "Ca. acutangulus" e Ch. purpurascens exibem difere levemente da cor lilás 
presente em Ca. speciosus. Essa diferença pode ser uma evidência de que os pigmentos responsáveis pela coloração da corola em tais táxons sejam, de fato, distintos e não deveriam ser categorizados em conjunto. Entretanto, para a elaboração do caráter "cor de flor" (car. 44) apenas o padrão geral de coloração da corola foi levado em consideração, sem atenção às nuances particulares existentes. O mapeamento da cor de flor evidencia o surgimento independente do estado "azul, roxo, lilás" em diversos grupos (Fig. 4f). Dentro desse panorama, a investigação detalhada da química dos pigmentos florais poderia trazer informações para codificação apropriada dos estados desse caráter. Se fosse constatado que a diferença observada realmente corresponde à uma composição química distinta, a cor lilás, tal como exibida por $\mathrm{Ca}$. amplissimus, "Ca. acutangulus" e Ch. purpurascens, poderia se configurar como uma robusta sinapomorfia do clado $\mathrm{F}$.

\subsubsection{Helia s.str. e Helia s.l.}

Ambas as espécies tradicionalmente tratadas como Helia $(H$. brevifolia e $H$. oblongifolia) emergiram em um clado com altos valores de sustentação (clado Hel = Helia s.str.). A presença de ócrea, a corola não inflada e os estiletes eretos (cars. 20 - Fig. 5a 45 e 61, respectivamente) são consistentes sinapomorfias morfológicas do clado, embora sejam compartilhadas pontualmente com outros clados mais distantes.

Esse pequeno clado emerge dentro de um grupo maior, juntamente com Adenolisianthus e todas as espécies de "Chelonanthus de flores verdes" (clado $\mathrm{H}$ ). Todas as espécies desse clado maior compartilham diversos atributos morfológicos, como ápice dos lobos da corola escurecido, botão floral com ápice arredondado, anteras eretas e exina espessada no equador (cars. 57, 55, 70 e 92, respectivamente; Figs. 4e, 5b-d). Tais atributos poderiam se configurar como sinapomorfias de um só gênero que incluísse todas as espécies desse clado, assim como foi sugerido por Struwe et al. (2009), embora sejam homoplásticos. O nome genérico mais antigo disponível para nomear esse clado é Helia, descrito por Martius (1827). Vale ressaltar que a espécie tipo de Chelonanthus, Ch. purpurascens, emerge em outro clado (clado F), separadamente das espécies de "Chelonanthus de flores verdes", o que faz com que essas espécies de fato necessitem de um novo nome genérico. Além disso, Adenolisianthus é um gênero monoespecífico e poderia ser adequadamente incluído em um gênero mais amplo, sem envolver grandes complicações nomenclaturais.

Com base nisso, futuramente apresentaremos um estudo de revisão de Helia s.l., incluindo as duas espécies de Helia s.str., Adenolisianthus e as nove espécies de "Chelonanthus de flores verdes" (correspondente ao clado H). Dados parciais obtidos com o 
estudo das espécies de Helia s.str. e questões quanto à tipificação do nome do gênero são apresentados no capítulo 7 desta Tese.

\subsubsection{Symbolanthus}

O presente estudo evidenciou a proximidade filogenética de Rogersonanthus com as espécies de Symbolanthus, formando o clado J. Esse resultado foi surpreendente, pois, no estudo de Struwe et al. (2009), Rogersonanthus emergiu juntamente com os "Chelonanthus de flores verdes". Essa divergência entre os resultados obtidos naquele e no presente estudo se deve, provavelmente, à inclusão de dados moleculares de uma espécie de Rogersonanthus, que anteriormente fora incluída nas análises apenas com dados morfológicos.

O clado $\mathrm{J}$ é sustentado por duas sinapomorfias morfológicas: o hábito lenhoso e a presença de lacunas estaminais (cars. 1 - Fig. 5e - e 63, respectivamente). Além dessas, pode ser caracterizado também pela corola decídua no fruto (car. 53, Fig. 5f), apesar desse ser um caráter bastante homoplástico. Com base nesse compartilhamento de atributos, as três espécies de Rogersonanthus serão futuramente sinonimizadas sob Symbolanthus.

\subsection{Estudo biogeográfico}

O emprego de "províncias biogeográficas" para reconstrução de áreas ancestrais impõe alguns limites para inferências precisas, permitindo apenas uma abordagem generalizada quanto à região florística ocupada pela linhagem ancestral. Entretanto, essa abordagem generalizada pode ser bastante conveniente, especialmente em grupos nos quais as relações filogenéticas ainda não estão claramente estabelecidas, e para os quais o emprego de uma codificação mais refinada (i.e., com áreas mais restritamente delimitadas) certamente resultaria na impossibilidade da reconstrução da área ancestral.

Embora não tenha sido possível a reconstrução da área ancestral no nó basal da tribo, é possível extrapolar que a tribo inteira, incluindo o clado de Prepusa, teve origem na província Amazônica, apesar de Prepusa ocorrer atualmente na província biogeográfica do Cerrado. A ausência de gêneros de Gentianeae, tribo-irmã de Helieae, na província do Cerrado corrobora essa hipótese. Os resultados obtidos no presente estudo sugerem que, a partir da província Amazônica, a tribo experimentou maior diversificação por meio da colonização de outras províncias neotropicais; tal padrão é observado em diversas outras famílias de Angiospermas (para exemplos das conexões entre regiões da província Amazônica e regiões das demais províncias biogeográficas, vide Fiaschi e Pirani, no prelo). 
Apesar das limitações que nossos resultados nos impõem, julgamos que inferências preliminares quanto ao cenário geral de história biogeográfica do grupo sejam oportunas, principalmente por permitir o direcionamento de pesquisas futuras, especialmente quanto ao estudo de atributos morfológicos e eco-fisiológicos que possam estar relacionados à ocupação das diferentes áreas. Por exemplo, com base em estudo filogenético das espécies de Potalia (Potalieae, Gentianaceae), Frasier et al. (2008) evidenciaram um padrão de especialização edáfica: espécies mais basais na filogenia ocorrem em áreas com solos arenosos e pobres em nutrientes, enquanto as demais espécies ocorrem em solos lateríticos; tal padrão sugere que "áreas de areias brancas" amazônicas sejam ancestrais e que a partir delas tenha havido diversificação e ocupação de outras áreas.

\section{Conclusões}

O presente estudo filogenético contribuiu significativamente para a elucidação quanto ao posicionamento de diversos táxons de Helieae e, com base nesses resultados, a circunscrição de alguns gêneros foi reavaliada. Embora a quantidade de espécies utilizadas na reconstrução filogenética de Helieae venha aumentando gradualmente nos últimos anos (Struwe et al., 2002; Struwe et al., 2009), a amostragem de táxons ainda é insuficiente e representa um grande obstáculo para o entendimento da evolução da tribo. Por exemplo, os dois gêneros com maior número de espécies, Symbolanthus e Macrocarpaea (com aproximadamente 30 e 100 espécies) estão representados nas análises por apenas seis e cinco espécies, respectivamente. Além disso, a inclusão de dados moleculares, além dos dados morfológicos, parece ser indispensável para o posicionamento de muitos táxons, em especial dos diversos gêneros que possuem apenas de 1 a 3 espécies. Somente com uma filogenia bem resolvida, incluindo maior número de táxons, será possível fazer inferências mais robustas quanto à evolução da tribo.

A importância relativa de dados morfológicos e moleculares na reconstrução de filogenias é questão bastante controversa, com forte tendência à maior valorização dos dados de seqüência de DNA (e.g., Scotland et al., 2003), existindo, entretanto, um clamor crescente pela maior inclusão de dados não-moleculares (e.g., Lee, 2004; Wiens, 2004). Estudos realizados em Helieae demonstraram que caracteres moleculares reconstroem hipóteses mais robustas (Struwe et al., 2002, 2009; o presente estudo), ao passo que reconstruções filogenéticas baseadas apenas em dados morfológicos freqüentemente resultam em topologias pouco resolvidas e com baixos valores de sustentação (e.g., Mészáros et al., 2002). Além disso, o mapeamento de atributos morfológicos, especialmente daqueles utilizados para caracterização e delimitação genérica, evidencia o alto grau de 
homoplasia desse tipo de dado (Struwe et al., 2009; o presente estudo). Certamente, esse elevado compartilhamento de atributos morfológicos contribuiu para a complicada história taxonômica da tribo, que tradicionalmente apresentou problemas quanto à circunscrição dos gêneros.

Entretanto, com base nos resultados obtidos no presente estudo, mostrou-se que, apesar de homoplásticos, muitos atributos morfológicos configuram-se como sinapomorfias de clados em particular, dependendo do nível de generalidade da abordagem. Além disso, como no caso dos diferentes tons de lilases das corolas (ver seção 4.2.2), o próprio emprego dos caracteres para obter filogenias permite o teste de homologia do caráter (i.e., iluminação recíproca; Daly et al., 2001). É interessante ressaltar ainda que caracteres que anteriormente configuravam-se como homoplásticos tornaram-se sinapomórficos com a inclusão de novos conjuntos de dados, devido ao agrupamento das espécies caracterizadas por um determinado estado do caráter em questão; esse fato sugere que, em alguns casos, a presença de determinado atributo em clados não relacionados pode ser indicativo de falta de resolução da filogenia e, dessa forma, pode ser um bom direcionador de pesquisas futuras. Sendo assim, foi possível reavaliar a importância do emprego de caracteres morfológicos, que se mostraram essenciais no processo de reconstrução filogenética da tribo. Estudos futuros devem não apenas prosseguir com a inclusão de dados morfológicos utilizados anteriormente, mas também buscar novas fontes de evidências.

\section{Referências}

Albert, V.A., Struwe, L., 2002. Gentianaceae in context. In: Struwe, L., Albert, V.A. (Eds.), Gentianaceae - Systematics and Natural History. Cambridge University Press, Cambridge, pp. 1-20.

Bouman, F., Cobb, L., Devente, N., Goethals, V., Maas, P.J.M., Smets, E., 2002. The seeds of Gentianaceae. In: Struwe, L. and Albert, V.A. (Eds.), Gentianaceae - Systematics and Natural History. Cambridge University Press, Cambridge, pp. 498-572.

Cabrera, A.L., Willink, A., 1980. Biogeografia de America Latina. Secretaria General de la Organización de los Estados Americanos, Washington, D.C.

Calió, M. F., Pirani, J.R., em prep. Nova lectotipificação de Calolisianthus Gilg.

Chassot, P., Nemomissa, S., Yuan, Y.-M., Küpfer, P., 2001. High paraphyly of Swertia L. (Gentianaceae) in the Gentianella-lineage as revealed by nuclear and chloroplast DNA sequence variation. Plant Syst. Evol. 229, 1-21.

Cox, A.V., Bennet, M.D., Dyer, T.A., 1992. Use of the polymerase chain reaction to detect spacer size heterogeneity in plant 5S-rRNA gene clusters and to locate such clusters in 
wheat (Triticum aestivum L.). Theor. Appl. Genet. 83, 684-690.

Chen, S., Xia, T., Wang, Y., Liu, J., Chen, S., 2005. Molecular systematics and biogeography of Crawfurdia, Metagentiana and Tripterospermum (Gentianaceae) based on nuclear ribosomal and plastid DNA sequences. Ann. Bot. 96, 413-424.

Daly, D.C., Cameron, K.M., Stevenson, D.W., 2001. Plant systematics in the Age of Genomics. Plant Physiol. 127, 1328-1333.

Felsenstein, J., 1985. Confidence-limits on phylogenies - an approach using the bootstrap. Evolution 39, 753-779.

Fiaschi, P., Pirani, J.R., no prelo. Review of plant biogeographic studies in Brazil. J. Syst. Evol.

Frasier, C.L., Albert, V.A., Struwe, L., 2008. Amazonian lowland, white sand areas as ancestral regions for South American biodiversity: biogeographic and phylogenetic patterns in Potalia (Angiosperamae: Gentianaceae). Org. Div. Evol. 8, 44-57.

Gilg, E.F., 1895. Gentianaceae. In: Engler, A., Prantl, K. (Eds.), Die Natürlichen Pflanzefamilien. Vol 4 (2). Verlag von Wilhelm Engelmann, Leipzig, pp. 50-108.

Gould, K.R., Struwe, L., 2004. Phylogeny and evolution of Symbolanthus and Wurdackanthus (Gentianaceae - Helieae) in the Guayana Highlands and Andes, based on ribosomal 5S-NTS sequences. Ann. MO. Bot Garden 91, 438-446.

Hagen, K.B. von, Kadereit, J.W., 2001. The phylogeny of Gentianella (Gentianaceae) and its colonization of the southern hemisphere as revealed by nuclear and chloroplast DNA sequence variation. Org. Div. Evol. 1, 61-79.

Huelsenbeck, J.P., Ronquist, F., 2001. MRBAYES: Bayesian inference of phylogenetic trees. Bioinformatics 17, 754-755.

Jensen, S.R., Schripsema, J., 2002. Chemotaxonomy and pharmacology of Gentianaceae. In: Struwe, L., Albert, V.A. (Eds.), Gentianaceae: Systematics and Natural History. Cambridge University Press, Cambridge, pp. 573-631.

ICBN, 2006. McNeill, J., Barrie, F.R., Burdet, H.M., Demoulin, V., Hawksworth, D.L., Marhold, K., Nicolson, D.H., Prado, J., Silva, P.C., Skog, J.E., Wiersema, J.H. \& Turland, N.J. (Eds.), International Code of Botanical Nomenclature (Vienna Code) adopted by the Intrenational Botanical Congress Vienna, Austria, July 2005, A.R.G. Gantner Verlag, Ruggel Liechtenstein.

Lee, M.S.Y., 2004. Molecular and morphological datasets have similar numbers of relevant phylogenetic characters. Taxon 53, 1019-1022.

Lewis, P.O., 2001. A likelihood approach to estimating phylogeny from discrete morphological character data. Syst. Biol. 50, 913-925.

Maddison, D.R., Maddison, W.P., 2005. MacClade4 (Versão 4.08): analysis of phylogeny 
and character evolution. Sinauer, Sunderland, Massachusetts, USA.

Mansion, G., Struwe, L., 2004. Generic delimitation and phylogenetic relationships within the subtribe Chironiinae (Chironieae: Gentianaceae), with special reference to Centaurium: evidence from nrDNA and cpDNA sequences. Mol. Phylogenet. Evol. 32, 951-977.

Martius, C.F.P. von., 1827. Nova genera et species plantarum quas in itinere per Brasiliam, vol. 2. V. Wolf, München.

Mészáros, S., Laet, J. De, Goethals, V., Smets, E., Nilsson, S., 2002. Cladistics of Gentianaceae: a morphological approach. In: Struwe, L., Albert, V.A. (Eds.), Gentianaceae: Systematics and Natural History. Cambridge University Press, Cambridge, pp. 310-376.

Nickrent, D.L., Schuette, K.P., Starr, E.D., 1994. A molecular phylogeny of Arceuthobium (Viscaceae) based on nuclear ribossomal DNA internal transcribed spacer sequences. Am. J. Bot. 81, 1149-1160.

Nilsson, S., 2002. Gentianaceae - a review of palynology. In: Struwe, L., Albert, V. A. (Eds.), Gentianaceae - Systematics and natural history. Cambridge University Press, Cambridge, pp. 377-497.

Nylander, J.A.A., 2004. MrModeltest versão 2.2. Program distributed by the author. Evolutionary Biology Centre, Uppsala University. Disponível em: http://www.abc.se/ nylander/

Pringle, J.S., 1995. Family 159A. Gentianaceae. In: Harling, G., Andersson, L. (Eds.), Flora of Ecuador, vol. 53. Department of Systematic Botany, Gothenburg University, Göteborg, pp. 1-131.

Ronquist, F., Huelsenbeck, J.P., 2003. MrBayes 3: Bayesian phylogenetic inference under mixed model. Bioinformatics 19, 1572-1574.

Sastri, D.C., Hilu, K., Appels, R., Lagudah, E.S., Playford, J., 1992. An overview of evolution in plant 5S DNA. Plant Syst. Evol. 183, 169-181.

Scotland, R.W., Olmstead, R.G., Bennet, J.R., 2003. Phylogeny reconstruction: the role of morphology. Syst. Biol. 52, 539-548.

Simmons, M.P., 2004. Independence of alignment and tree search. Mol. Phylogenet. Evol. 31, 874-879.

Simmons, M.P., Ochoterena, H., 2000. Gaps as characters in sequence-based phylogenetic analyses. Syst. Biol. 49, 369-381.

Struwe, L., Albert, V.A., 1998. Lisianthius P.Br., its probable homonym Lisyanthus Aubl. (Gentianaceae) and the priority of Helia Mart. over Irlbachia Mart. as its substitute. Harvard Pap. Bot. 3, 67-71. 
Struwe, L., Albert, V.A., Calió, M.F., Frasier, C., Lepis, K.B., Mathews, K.G., Grant, J.R., 2009. Evolutionary patterns in Neotropical Helieae (Gentianaceae): evidence from morphology, chloroplast and nuclear DNA sequences. Taxon 58, 479-499.

Struwe, L., Kadereit, J., Klackenberg, J., Nilsson, S., Thiv, M., von Hagen, K.B., Albert, V.A., 2002. Systematics, character evolution, and biogeography of Gentianaceae, including a new tribal and subtribal classification. In: Struwe. L., Albert, V.A. (Eds.), Gentianaceae Systematics and Natural History. Cambridge University Press, Cambridge, pp. 21-309.

Struwe, L., Thiv, M., Kadereit, J.W., Pepper, A.S.-R., Motley, T.J., White, P.J., Rova, J.H.E., Potgieter, K., Albert, V.A., 1998. Saccifolium (Saccifoliaceae), an endemic of Sierra de la Neblina on the Brazilian-Venezuelan frontier, is related to a temperate-alpine lineage of Gentianaceae. Harvard Pap. Bot. 3, 199-214.

Swofford, D.L., 2000. PAUP*: Phylogenetic Analysis Using parcimony * and Other Methods. Version 4.0b10. Sinauer, Sunderland, USA.

Thiv, M., Struwe, L., Kadereit, J.W., 1999. The phylogenetic relationships and evolution of the Canarian laurel forest endemic Ixanthus viscosus (Aiton) Griseb. (Gentianaceae): evidence from matK and ITS sequences, and floral morphology and anatomy. Plant Syst. Evol. 218, 299-317.

Thompson, J.D., Gibson, T.J., Plewniak, F., Jeanmougin, F., Higgins, D.G., 1997. The Clustal $X$ windows interface: flexible strategies for multiple sequence alignment aided by quality analysis tools. Nucleic Acids Res. 25, 4876-4882.

White, T.J., Bruns, T., Lee, S., Taylor, J., 1990. Amplification and direct sequencing of fungal ribosomal RNA genes for phylogenetics. In: Innis, M.A., Gelfund, D.H., Sninsky, J.J., White, T.J. (Eds.), PCR protocols: a guide to methods and amplifications, Academic Press, San Diego, California, USA, pp. 315-322.

Wiens, J.J., 2004. The role of morphological data in phylogeny reconstruction. Syst. Biol. 53, 653-661.

Yuan, Y.-M., Kupfer, P., 1995. Molecular phylogenetics of the subtribe Gentianinae (Gentianaceae) inferred from the sequences of internal transcribed spacers (ITS) of nuclear ribossomal DNA. Plant Syst. Evol. 196, 207-226.

Yuan, Y.-M., Wohlhauser, S. Möller, M., Chassot, P., Mansion, G., Grant, J., Küpfer, P., Klackenberg, J., 2003. Monophyly and relationships of the tribe Exaceae (Gentianaceae) inferred from nuclear ribossomal and chloroplast DNA sequences. Mol. Phylogenet. Evol. $28,500-517$.

Zijlstra, G., Maas, P.J.M., Gandhi, K., 1999. On the nonexistence of Lisyanthus Aublet. Harvard Pap. Bot. 4, 289-292. 


\section{Tabela 1}

Táxons e códigos de acesso ao GenBank para espécies utilizadas nesse estudo. Informações sobre "vouchers" fornecidas apenas para espécimes seqüenciados nesse estudo (indicados por "X"). * = amostras trabalhadas no Laboratório de Algas Marinhas "Édison José de Paula" (IBUSP). Nomes "informais" apresentados com aspas. Ref. 1: Presente estudo; Ref. 2: Thiv et al. (1999); Ref. 3: Mansion e Struwe (2004); Ref. 4: Struwe et al. (2009); Ref. 5: Frasier et al. (2008); Ref. 6: Chassot et al. (2001); Ref. 7: Yuan e Kupfer (1995); Ref. 8: Hagen e Kadereit (2001); Ref. 9: Chen et al. (2005); Ref. 10: Yuan et al. (2003); Ref. 11: Gould e Struwe (2004).

\begin{tabular}{|c|c|c|c|c|}
\hline Taxon & Tribo "Voucher" & Localidade & ITS & 5S-NTS \\
\hline Centaurium maritimum (L.) Fritsch & Chironeae & & $\begin{array}{l}\text { AJ011466, AJ011476 } \\
\text { Ref. } 2\end{array}$ & \\
\hline Chironia linoides L. & Chironeae & & $\begin{array}{l}\text { AY251692, AY251722 } \\
\text { Ref. } 3\end{array}$ & \\
\hline Coutoubea spicata Aubl. & Chironeae & & $\begin{array}{l}\text { EU709780 } \\
\text { Ref. } 4\end{array}$ & \\
\hline Ixanthus viscosus (Aiton) Griseb. & Chironeae & & $\begin{array}{l}\text { AJ011471, AJ011481 } \\
\text { Ref. } 3\end{array}$ & \\
\hline Orphium frutescens (L.) E. Mey. & Chironeae & & $\begin{array}{l}\text { AJ011465, AJ011475 } \\
\text { Ref. } 3\end{array}$ & \\
\hline Sabatia angularis (L.) Pursh & Chironeae & & $\begin{array}{l}\text { AJ011467, AJ011477 } \\
\text { Ref. } 3\end{array}$ & \\
\hline Anthocleista amplexicaulis Baker & Potalieae & & $\begin{array}{l}\text { DQ449914 } \\
\text { Ref. } 5\end{array}$ & \\
\hline Enicostema verticillatum (L.) Engl. & Potalieae & & $\begin{array}{l}\text { EU709781 } \\
\text { Ref. } 4\end{array}$ & \\
\hline Fagraea berteroana A. Gray ex Benth. & Potalieae & & $\begin{array}{l}\text { DQ449918 } \\
\text { Ref. } 5\end{array}$ & \\
\hline Fagraea fragrans Roxb. & Potalieae & & $\begin{array}{l}\text { AY251689, AY251719 } \\
\text { Ref. } 3\end{array}$ & \\
\hline Lisianthius jefensis A. Robyns \& T.S. Elias & Potalieae & & $\begin{array}{l}\text { EU709782 } \\
\text { Ref. } 4\end{array}$ & \\
\hline Lisianthius seemannii (Griseb.) Kuntze & Potalieae & & $\begin{array}{l}\text { EU709783 } \\
\text { Ref. } 4\end{array}$ & \\
\hline Potalia amara Aubl. & Potalieae & & $\begin{array}{l}\text { DQ449919 } \\
\text { Ref. } 5\end{array}$ & \\
\hline Bartonia virginica (L.) Britton, Sterns, \& Poggenb. & Gentianeae & & $\begin{array}{l}\text { AJ318533, AJ410312 } \\
\text { Ref. } 6\end{array}$ & \\
\hline Crawfurdia thibetica Franch. & Gentianeae & & $\begin{array}{l}\text { Z48145, Z48123 } \\
\text { Ref. } 7\end{array}$ & \\
\hline Gentiana lutea L. & Gentianeae & & $\begin{array}{l}\text { Z48122, Z48119 } \\
\text { Ref. } 7\end{array}$ & \\
\hline Gentianella amarella (L.) Börner & Gentianeae & & $\begin{array}{l}\text { AJ580573 } \\
\text { Ref. } 4\end{array}$ & \\
\hline Gentianopsis crinita (Froel.) Ma & Gentianeae & & $\begin{array}{l}\text { AJ294631, AJ294691 } \\
\text { Ref. } 8\end{array}$ & \\
\hline
\end{tabular}


Halenia palmeri A. Gray

Obolaria virginica L.

Swertia perennis $L$

Tripterospermum volubile (D. Don) Hara

Adenolisianthus arboreus Gilg

Aripuana cullmaniorum Struwe, Maas \& V.A. Albert

"Calolisianthus acutangulus" (Mart.) Gilg

"Calolisianthus acutangulus" (Mart.) Gilg

Calolisianthus amplissimus (Mart.) Gilg

Calolisianthus amplissimus (Mart.) Gilg

Calolisianthus amplissimus (Mart.) Gilg

Calolisianthus pedunculathus (Cham. \& Schltdl.) Gilg

Calolisianthus pedunculathus (Cham. \& SchltdI.) Gilg Calolisianthus pedunculathus (Cham. \& Schltdl.) Gilg Calolisianthus pedunculathus (Cham. \& Schltdl.) Gilg Calolisianthus pedunculathus (Cham. \& Schltdl.) Gilg Calolisianthus pedunculathus (Cham. \& Schltdl.) Gilg Calolisianthus pedunculathus (Cham. \& Schltdl.) Gilg Calolisianthus pendulus (Mart.) Gilg

Calolisianthus pendulus (Mart.) Gilg

Calolisianthus speciosus (Cham. \& Schltdl.) Gilg

Calolisianthus speciosus (Cham. \& Schltdl.) Gilg

Calolisianthus speciosus (Cham. \& Schltdl.) Gilg

Calolisianthus speciosus (Cham. \& Schltdl.) Gilg

Gentianeae

Gentianeae

Gentianeae

Gentianeae

Helieae

Helieae

Helieae

Helieae

Helieae

Helieae

Helieae

Helieae

Helieae

Helieae

Helieae

Helieae

Helieae

Helieae

Helieae

Helieae

Helieae

Helieae

Helieae

Helieae

Helieae
(1)

AJ29632 AJ294692

Ref. 8

AJ318549, AJ41032

Ref. 6

AJ580550

Ref. 4

AY858667

Ref. 9

EU709784

Ref. 4

EU709785

Ref.

Barbosa e Araújo 231 (SPF)

Brasil, Goiás,

Pereira-Silva et al. 7097 (SPF)

Brasil, Minas Gerais

Calió e Sasaki 66 (SPF)

Pereira-Silva et al. 7411 (SPF)

Brasil, São Paulo

Brasil, Goiás

Romero et al. 926 (SPF)

Brasil, Minas Gerais

Ref.

Ref. 1

Ref. 1

$\mathrm{X}^{*}$

Ref. 1

$X^{*}$

Ref. 1

Ref. 1

EU709786

Ref. 4

Calió et al. 15 (SPF)

Farinaccio et al. 621 (SPF)

Brasil, Minas Gerais

Brasil, Paraná

Loeuille et al. 339 (SPF)

Brasil, Bahia

Lovo et al. 145 (SPF)

Mello-Silva e Forzza 2797 (SPF)

Pirani et al. 5393 (SPF)

Trovó e Watanabe 361 (SPF)

Calió et al. 86 (SPF)

Mello-Silva e Ferreira 2848 (SPF)

Calió et al. 51 (SPF)

Calió et al. 106 (SPF)

Calió et al. 125 (SPF)

Trovó et al. 415 (SPF)

Ref. 1

Ref. 1

$X^{*}$

Ref. 1

$X^{*}$

Ref. 1
$X^{*}$

Ref. 1

Brasil, Bahia

Brasil, Minas Gerais

$X^{*}$

Ref. 1

Brasil, Minas Gerais

Ref. 1

Brasil, Minas Gerais

$X^{*}$

Ref. 1

Brasil, Minas Gerais

Brasil, Goiás

Brasil, Minas Gerais

Brasil, Bahia

Brasil, Minas Gerais 
Calolisianthus speciosus Gilg

Calolisianthus sp. ined.

Calolisianthus sp. ined.

Chelonanthus acutangulus (Ruiz et Pav.) Gilg

Chelonanthus acutangulus (Ruiz et Pav.) Gilg

Chelonanthus alatus (Aubl.) Pulle

Chelonanthus alatus (Aubl.) Pulle

Chelonanthus albus (Spruce ex Progel) V.M. Badillo

Chelonanthus angustifolius (Kunth) Gilg

Chelonanthus angustifolius (Kunth) Gilg

Chelonanthus grandiflorus (Aubl.) Chodat et Hassl.

Chelonanthus grandiflorus (Aubl.) Chodat et Hassl

Chelonanthus grandiflorus (Aubl.) Chodat et Hassl.

\section{Helieae}

Chelonanthus matogrossensis (J.M.G. Pers. et Maas) Struwe et V.A. Albert

Chelonanthus purpurascens (Aubl.) Struwe, S. Nilsson et V.A. Albert

Chelonanthus purpurascens (Aubl.) Struwe, S. Nilsson et V.A. Albert

Chelonanthus purpurascens (Aubl.) Struwe, S. Nilsson et V.A. Albert

Chelonanthus purpurascens (Aubl.) Struwe, S. Nilsson et V.A. Albert

Chelonanthus viridiflorus (Mart.) Gilg

Chelonanthus viridiflorus (Mart.) Gilg

Chelonanthus viridiflorus (Mart.) Gilg

Chelonanthus viridiflorus (Mart.) Gilg

Chelonanthus sp. ined. 2

Chorisepalum psychotrioides Ewan

Helia brevifolia Cham.
Helieae

Helieae

Helieae

Helieae

Helieae

Helieae

Helieae

Helieae

Helieae

Helieae

Helieae

Helieae

\section{Calió et al. 87 (SPF)}

Bezerra et al. 46 (SPF)

Gomez et al. 837 (MO)

Hawkes et al. 5048 (MO)

Maas $9316(U)$

Berry 5541 (NY)

Poole 2049 (NY)

Molina $18 S 364$ (US)

Alencar 621 (US)

Kelloff et al. 598 (US)

Mori et al. 25561 (NY)

Solomon 7880 (NY)

Helieae

Helieae

Helieae

Helieae

Helieae

Helieae

Helieae

Helieae

Helieae

Helieae

Helieae
Calió et al. 119 (SPF)

Maas 7456 (US)

Calió et al. 84 (CHRB)

Calió et al. 157

Chatrou 321 (U)

Vargas 454 (NY)

Calió et al. 168 (SPF)
Harley 15889 (US)
Brasil, Minas Gerais

Brasil, Minas Gerais

Colômbia, Antioquia

Bolívia

Guiana Francesa

Venezuela, Bolívar

Brasil, Amazonas

Brasil, Amazonas

Colômbia, Santande

Guiana

Guiana Francesa

Bolívia

Brasil, Bahia

Guiana

Brasil, Bahia

Brasil, Minas Gerais

Brasil, Minas Gerais

Bolívia

Costa Rica

Brasil, São Paul
EU709787

Ref. 4

Ref. 1

$\mathrm{X}^{*}$

Ref. 1

Ref. 1

X (ITS 1)

Ref. 1

Ref.

EU709790

Ref. 4

EU709789

Ref. 4

$\mathrm{X}$

Ref. 1

X (ITS 2)

Ref. 1

$X$

Ref. 1
EU709788

Ref. 4

$X$

Ref. 1

X (ITS 2)

Ref. 1

$X^{*}$.

Ref. 1

EU709791
Ref. 4

Ref. 4
$X$

Ref. 1

Ref.

$\mathrm{X}$ (ITS 2)

Ref. 1

$X^{*}$

Ref. 1

Ref. 1

EU709792

Ref. 4

$X$
Ref. 1

Ref. 1
EU709793

Ref. 4

$\mathrm{X}^{*}$
Ref.
Ref.

$\mathrm{X}^{*}$

Ref.

Ref.

Ref. 1

$X$

Ref.

$X$

Ref.

$X$

Ref. 1

$X$

Ref.

Ref.

$X$

Ref. 1

X

Ref.

Ref. 1

$x$

Ref. 1

$X$

Ref. 1

$X$

Ref 1

$X$

Ref.

$X$

Ref.

$\mathrm{X}^{*}$

Ref. 1 


\begin{tabular}{|c|c|c|c|c|c|}
\hline Helia brevifolia Cham. & Helieae & Serafim et al. 27 (SPF) & Brasil, São Paulo & $\begin{array}{l}\mathrm{X}^{*} \\
\text { Ref. } 1\end{array}$ & $\begin{array}{l}\mathrm{X}^{*} \\
\text { Ref. } 1\end{array}$ \\
\hline Helia brevifolia Cham. & Helieae & Trovó et al. 316 (SPF) & Brasil, São Paulo & $\begin{array}{l}X^{*} \\
\text { Ref. } 1\end{array}$ & $\begin{array}{l}X^{*} \\
\text { Ref. } 1\end{array}$ \\
\hline Helia oblongifolia Mart. & Helieae & Calió et al. 205 (SPF) & Brasil, Minas Gerais & $\begin{array}{l}\mathrm{X}^{*} \\
\text { Ref. } 1\end{array}$ & $\begin{array}{l}\mathrm{X}^{*} \\
\text { Ref. } 1\end{array}$ \\
\hline Helia oblongifolia Mart. & Helieae & Irwin et al. 21805 (NY) & Brasil, Minas Gerais & $\begin{array}{l}\mathrm{X} \\
\text { Ref. } 1\end{array}$ & $\begin{array}{l}X \\
\text { Ref. } 1\end{array}$ \\
\hline Helia oblongifolia Mart. & Helieae & Harley et al. 25924 (NY) & Brasil, Bahia & $\begin{array}{l}X^{*} \\
\text { Ref. } 1\end{array}$ & $\begin{array}{l}X \\
\text { Ref. } 1\end{array}$ \\
\hline Helia oblongifolia Mart. & Helieae & & & $\begin{array}{l}\text { EU709794 } \\
\text { Ref. } 4\end{array}$ & \\
\hline Irlbachia nemorosa (Willd. ex Roem. \& Schult.) Merr. & Helieae & & & $\begin{array}{l}\text { EU709795 } \\
\text { Ref. } 4\end{array}$ & \\
\hline Irlbachia poeppigii (Griseb.) L. Cobb \& Maas & Helieae & & & $\begin{array}{l}\text { EU709796 } \\
\text { Ref. } 4\end{array}$ & \\
\hline Irlbachia pratensis (Kunth) L. Cobb \& Maas & Helieae & Berry 7579 (NY) & & $\begin{array}{l}\text { EU709797 } \\
\text { Ref. } 4\end{array}$ & $\begin{array}{l}\text { X } \\
\text { Ref. } 1\end{array}$ \\
\hline Irlbachia pumila (Benth.) Maguire & Helieae & & & $\begin{array}{l}\text { EU709798 } \\
\text { Ref. } 4\end{array}$ & \\
\hline Macrocarpaea angelliae J.R. Grant \& Struwe & Helieae & & & $\begin{array}{l}\text { AY397760, AY397761 } \\
\text { Ref. } 3\end{array}$ & \\
\hline Macrocarpaea apparata J.R. Grant \& Struwe & Helieae & & & $\begin{array}{l}\text { DQ401413 } \\
\text { Ref. } 4\end{array}$ & \\
\hline Macrocarpaea domingensis Urb. \& Ekman & Helieae & & & $\begin{array}{l}\text { EU709799 } \\
\text { Ref. } 4\end{array}$ & \\
\hline Macrocarpaea gattaca J.R. Grant & Helieae & & & $\begin{array}{l}\text { DQ401414 } \\
\text { Ref. } 4\end{array}$ & \\
\hline Macrocarpaea macrophylla Gilg & Helieae & & & $\begin{array}{l}\text { AJ489915 } \\
\text { Ref. } 10\end{array}$ & \\
\hline Macrocarpaea rubra Malme & Helieae & Calió et al. 169 & Brasil, São Paulo & $\begin{array}{l}\mathrm{X}^{*} \\
\text { Ref. } 1\end{array}$ & \\
\hline Prepusa montana Mart. & Helieae & Calió et al. 116 & Brasil, Bahia & $\begin{array}{l}\mathrm{X}^{*} \\
\text { Ref. } 1\end{array}$ & \\
\hline Prepusa montana Mart. & Helieae & & & $\begin{array}{l}\text { EU709805 } \\
\text { Ref. } 4\end{array}$ & \\
\hline Purdieanthus pulcher (Hook.) Gilg & Helieae & & & $\begin{array}{l}\text { EU709800 } \\
\text { Ref. } 4\end{array}$ & \\
\hline Rogersonanthus quelchii (N.E.Br.) Maguire \& B.M. Boom & Helieae & Fiaschi e Plunkett 3192 (SPF) & Venezuela, Bolívar & $\begin{array}{l}\mathrm{X}^{*} \\
\text { Ref. } 1\end{array}$ & \\
\hline Symbolanthus australis Struwe & Helieae & Dorr et al. $6691(\mathrm{NY})$ & & $\begin{array}{l}\text { EU709801 } \\
\text { Ref. } 4\end{array}$ & $\begin{array}{l}X \\
\text { Ref. } 1\end{array}$ \\
\hline Symbolanthus frigidus (Sw.) Struwe \& K. Gould & Helieae & & & $\begin{array}{l}\text { EU709802 } \\
\text { Ref. } 4\end{array}$ & $\begin{array}{l}\text { AY143370 } \\
\text { Ref. } 11\end{array}$ \\
\hline Symbolanthus nerioides (Griseb.) Ewan & Helieae & Sobel e Strudwick 2164 (NY) & Venezuela, Mérida & $\begin{array}{l}\mathrm{X} \\
\text { Ref. } 1\end{array}$ & $\begin{array}{l}\text { AY143377 } \\
\text { Ref. } 11\end{array}$ \\
\hline Symbolanthus pulcherrimus Gilg & Helieae & & & $\begin{array}{l}\text { EU709803 } \\
\text { Ref. } 4\end{array}$ & $\begin{array}{l}\text { AY143379 } \\
\text { Ref. } 11\end{array}$ \\
\hline Tachia grandiflora Maguire \& Weaver & Helieae & & & $\begin{array}{l}\text { DQ401415 } \\
\text { Ref. } 4\end{array}$ & \\
\hline
\end{tabular}


Tachia guianensis Aubl.

Tachia loretensis Maguire \& Weaver

Tachia occidentalis Maguire \& Weave

Tachia parviflora Maguire \& Weaver

Tetrapollinia caerulescens (Aubl.) Maguire \& B.M. Boom

Tetrapollinia caerulescens (Aubl.) Maguire \& B.M. Boom

Tetrapollinia caerulescens (Aubl.) Maguire \& B.M. Boom

\section{Helieae}

Helieae

Helieae

Helieae

Helieae

Helieae

Helieae
DQ401419

Ref. 4

DQ401421

Ref. 4

DQ401423

Ref. 4

DQ401424

Ref. 4

$\mathrm{X}^{*}$

Ref. 1

Ref 1

EU709804

Ref. 4
$X$ 


\section{Tabela 2}

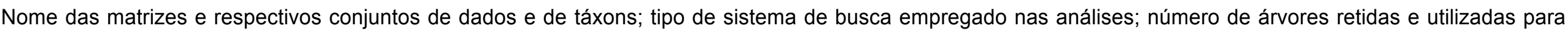
construção da árvore de consenso estrito na análise de parcimônia.

\begin{tabular}{|c|c|c|c|c|c|}
\hline Nome da matriz & Conjunto de dados & Conjunto de táxons & $\begin{array}{l}\text { Sistema } \\
\text { de busca }\end{array}$ & $\begin{array}{l}\text { Árvores } \\
\text { retidas }\end{array}$ & $\begin{array}{l}\text { Árvores } \\
\text { usadas }\end{array}$ \\
\hline Morfologia & Morfologia & Todos & $\mathrm{B}$ & 910 & 200000 \\
\hline ITS sem indels & ITS (sem indels) & Com ITS & B & 9350 & 200000 \\
\hline ITS com indels & ITS (com indels) & Com ITS & $\mathrm{B}$ & 8000 & 200000 \\
\hline 5S-NTS sem indels & 5S-NTS (sem indels) & Com 5S-NTS & A & 1194 & 1194 \\
\hline 5S-NTS com indel & 5S-NTS (com indel) & Com 5S-NTS & A & 4759 & 4759 \\
\hline Combinada molecular pequena sem indels & ITS + 5S-NTS (sem indels) & Com dados para ambos os conjuntos moleculares & A & 1897 & 1897 \\
\hline Combinada molecular pequena com indels & ITS + 5S-NTS (com indels) & Com dados para ambos os conjuntos moleculares & A & 548 & 548 \\
\hline Combinada molecular média sem indels & ITS + 5S-NTS (sem indels) & Com dados para ao menos um conjunto molecular & $\mathrm{B}$ & 9400 & 200000 \\
\hline Combinada molecular média com indels & ITS + 5S-NTS (com indels) & Com dados para ao menos um conjunto molecular & $\mathrm{B}$ & 8110 & 200000 \\
\hline Combinada total pequena sem indels & ITS + 5S-NTS + morfologia (sem indels) & Com dados para ambos os conjuntos moleculares & A & 385 & 385 \\
\hline Combinada total pequena com indels & ITS + 5S-NTS + morfologia (com indels) & Com dados para ambos os conjuntos moleculares & A & 216 & 216 \\
\hline Combinada total média sem indels & ITS + 5S-NTS + morfologia (sem indels) & Com dados para ao menos um conjunto molecular & $\mathrm{B}$ & 7670 & 200000 \\
\hline Combinada total média com indels & ITS + 5S-NTS + morfologia (com indels) & Com dados para ao menos um conjunto molecular & $\mathrm{B}$ & 7020 & 200000 \\
\hline Combinada total grande sem indels & ITS + 5S-NTS + morfologia (sem indels) & Todos & $\mathrm{B}$ & 7000 & 200000 \\
\hline Combinada total grande com indels & ITS + 5S-NTS + morfologia (com indels) & Todos & B & 5730 & 200000 \\
\hline
\end{tabular}




\section{Tabela 3}

Características das matrizes individuais e combinadas: número de táxons, caracteres totais, indels, caracteres constantes e variáveis, e caracteres informativos para parcimônia. Estatísticas das árvores resultantes: comprimento das árvores, $\mathrm{Cl}, \mathrm{RI}, \mathrm{HI}$, número de nós com valores de probabilidade posterior de análise Bayesiana maiores que 0.85 (topologia da parcimônia / topologia da Bayesiana).

\begin{tabular}{|c|c|c|c|c|c|c|c|c|c|c|c|}
\hline Conjuntos de dados & Táxons & $\begin{array}{l}\text { Caracteres } \\
\text { totais }\end{array}$ & Indels & $\begin{array}{l}\text { Caracteres } \\
\text { constantes }\end{array}$ & $\begin{array}{l}\text { Caracteres } \\
\text { variáveis }\end{array}$ & $\begin{array}{l}\text { Caracteres } \\
\text { informativos }\end{array}$ & $\begin{array}{l}\text { Comprimento } \\
\text { da árvore }\end{array}$ & $\mathrm{Cl}$ & $\mathbf{R I}$ & $\mathrm{HI}$ & $\begin{array}{l}\text { Nós } \\
(P P \geq 0.85)\end{array}$ \\
\hline Morfologia & 108 & 126 & 0 & $0(0 \%)$ & $126(100 \%)$ & $123(98 \%)$ & 619 & 0.271 & 0.756 & 0.729 & $28 / 31$ \\
\hline ITS sem indels & 100 & 676 & 0 & $264(39 \%)$ & $412(61 \%)$ & $326(48 \%)$ & 1624 & 0.444 & 0.769 & 0.556 & $54 / 56$ \\
\hline ITS com indels & 100 & 731 & 55 & $264(36 \%)$ & $467(64 \%)$ & $381(52 \%)$ & 1730 & 0.449 & 0.773 & 0.551 & $54 / 58$ \\
\hline 5S-NTS sem indels & 47 & 327 & 0 & $56(17 \%)$ & $271(83 \%)$ & $245(75 \%)$ & 792 & 0.622 & 0.864 & 0.378 & $28 / 28$ \\
\hline 5S-NTS com indels & 47 & 354 & 27 & $56(16 \%)$ & $298(84 \%)$ & $272(77 \%)$ & 849 & 0.612 & 0.864 & 0.388 & $27 / 27$ \\
\hline Combinada Molecular Pequena sem indels & 47 & 1003 & 0 & $555(55 \%)$ & $448(45 \%)$ & $372(37 \%)$ & 1084 & 0.649 & 0.872 & 0.351 & - \\
\hline Combinada Molecular Pequena com indels & 47 & 1085 & 82 & $596(55 \%)$ & $489(45 \%)$ & $411(38 \%)$ & 1158 & 0.642 & 0.872 & 0.358 & - \\
\hline Combinada Molecular Média sem indels & 100 & 1003 & 0 & $320(32 \%)$ & $683(68 \%)$ & $571(57 \%)$ & 2432 & 0.499 & 0.801 & 0.501 & - \\
\hline Combinada Molecular Média com indels & 100 & 1085 & 82 & $320(29 \%)$ & $765(71 \%)$ & $653(60 \%)$ & 2594 & 0.500 & 0.804 & 0.500 & - \\
\hline Combinada Total Pequena sem inde/s & 47 & 1129 & 0 & $626(55 \%)$ & $503(45 \%)$ & $421(37 \%)$ & 1194 & 0.637 & 0.868 & 0.553 & $32 / 34$ \\
\hline Combinada Total Pequena com inde/s & 47 & 1211 & 82 & $667(55 \%)$ & $544(45 \%)$ & $460(38 \%)$ & 1268 & 0.632 & 0.869 & 0.368 & $33 / 35$ \\
\hline Combinada Total Média sem indels & 100 & 1129 & 0 & $320(28 \%)$ & $809(72 \%)$ & $692(61 \%)$ & 3079 & 0.449 & 0.783 & 0.551 & $65 / 72$ \\
\hline Combinada Total Média com indels & 100 & 1211 & 82 & $320(26 \%)$ & $891(74 \%)$ & $774(64 \%)$ & 3238 & 0.452 & 0.787 & 0.548 & $69 / 74$ \\
\hline Combinada Total Grande sem indels & 108 & 1129 & 0 & $320(28 \%)$ & $809(72 \%)$ & $694(61 \%)$ & 3119 & 0.443 & 0.782 & 0.557 & $63 / 71$ \\
\hline Combinada Total Grande com indels & 108 & 1211 & 82 & $320(26 \%)$ & $891(74 \%)$ & $776(64 \%)$ & 3279 & 0.446 & 0.786 & 0.554 & $65 / 72$ \\
\hline
\end{tabular}




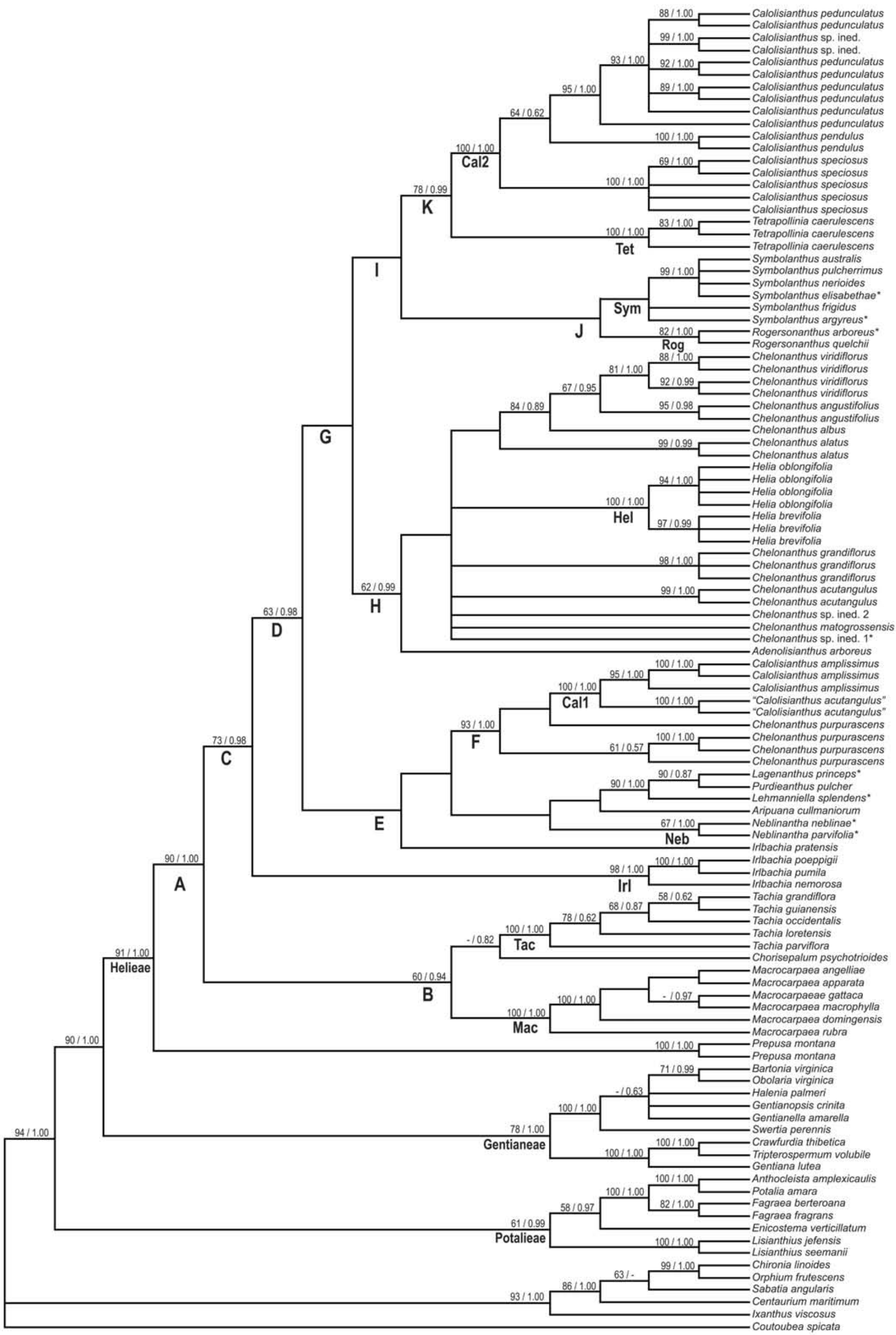

Fig. 1. Consenso estrito da análise de parcimônia da matriz "Combinada Total Grande com indels", i.e., incluindo dados moleculares e morfológicos, e todos os táxons. Porcentagens de bootstrap e probabilidades posteriores de análise Bayesiana estão representadas sobre os ramos. Nomes informais entre aspas. Asterisco indica táxons incluídos nas análises apenas com dados morfológicos. 


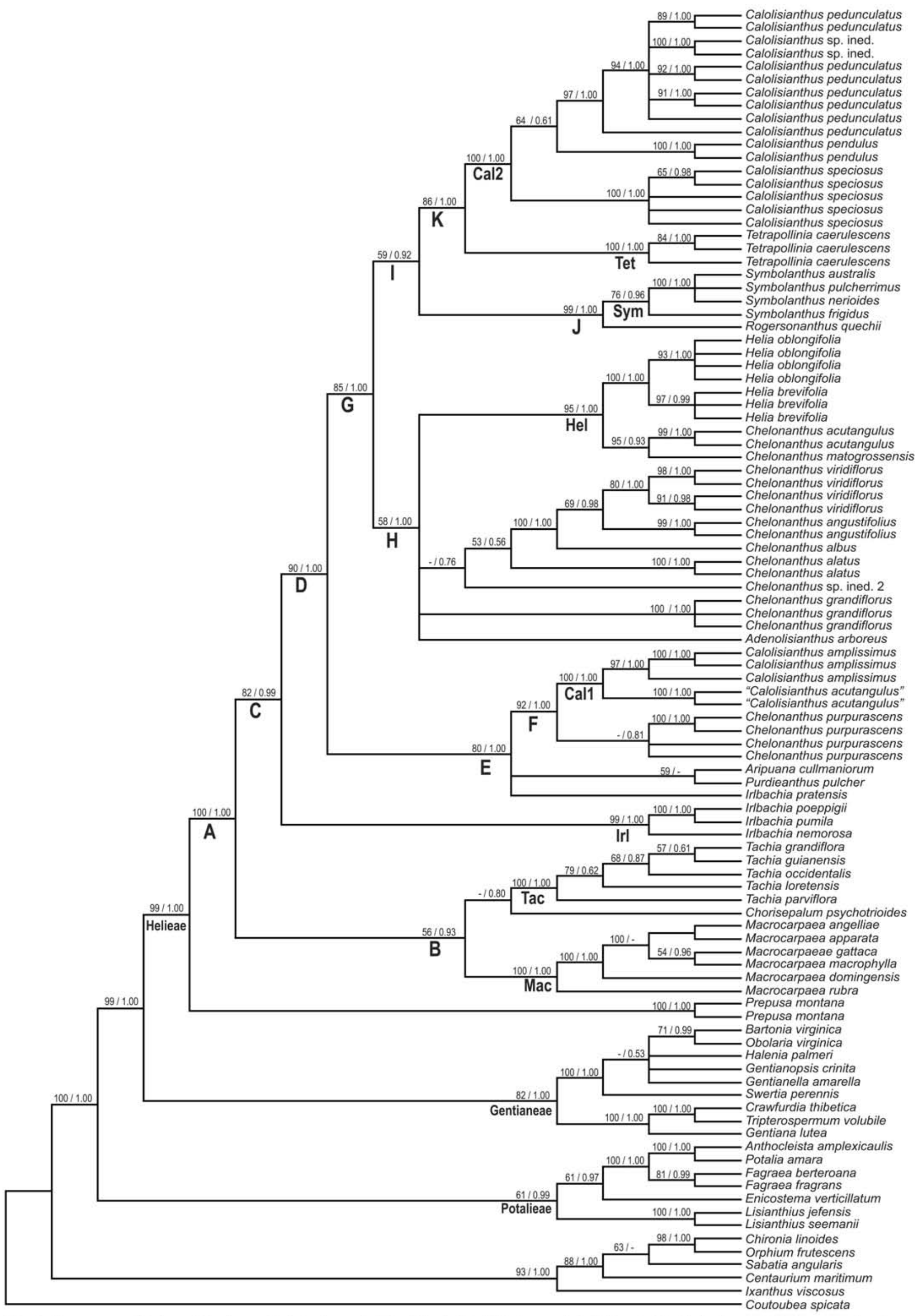

Fig. 2. Consenso estrito da análise de parcimônia da matriz "Combinada Total Média com indels", i.e., incluindo dados morfológicos e moleculares, e apenas táxons com dados para ao menos uma das partições moleculares. Porcentagens de bootstrap e probabilidades posteriores de análise Bayesiana estão representadas sobre os ramos. Nomes informais entre aspas. 


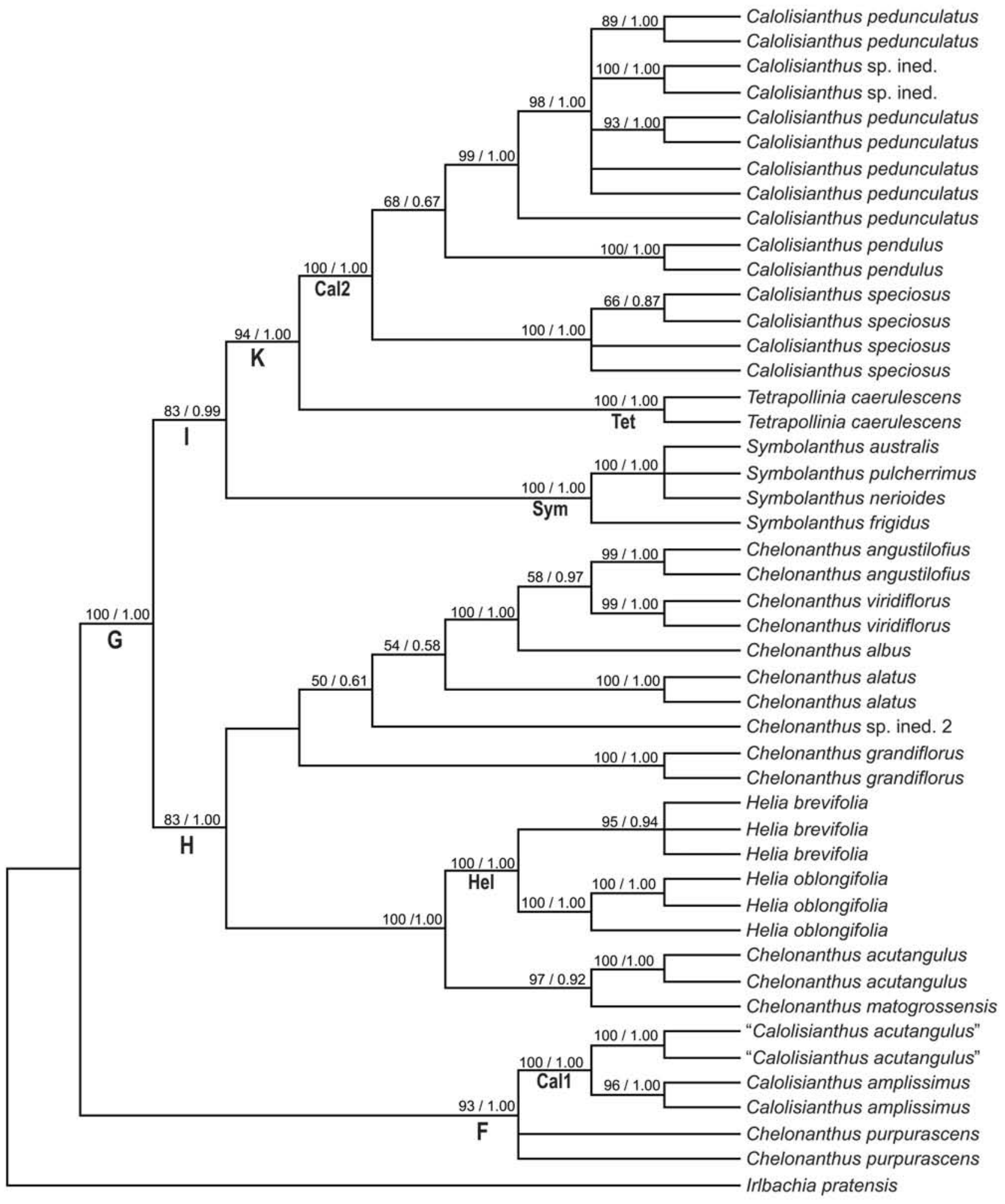

Fig. 3. Consenso estrito da análise de parcimônia da matriz "Combinada Total Pequena com indels", i.e., incluindo dados morfológicos e moleculares, e apenas táxons com dados para as três partições. Porcentagens de bootstrap e probabilidades posteriores de análise Bayesiana estão representadas sobre os ramos. Nomes informais entre aspas. 

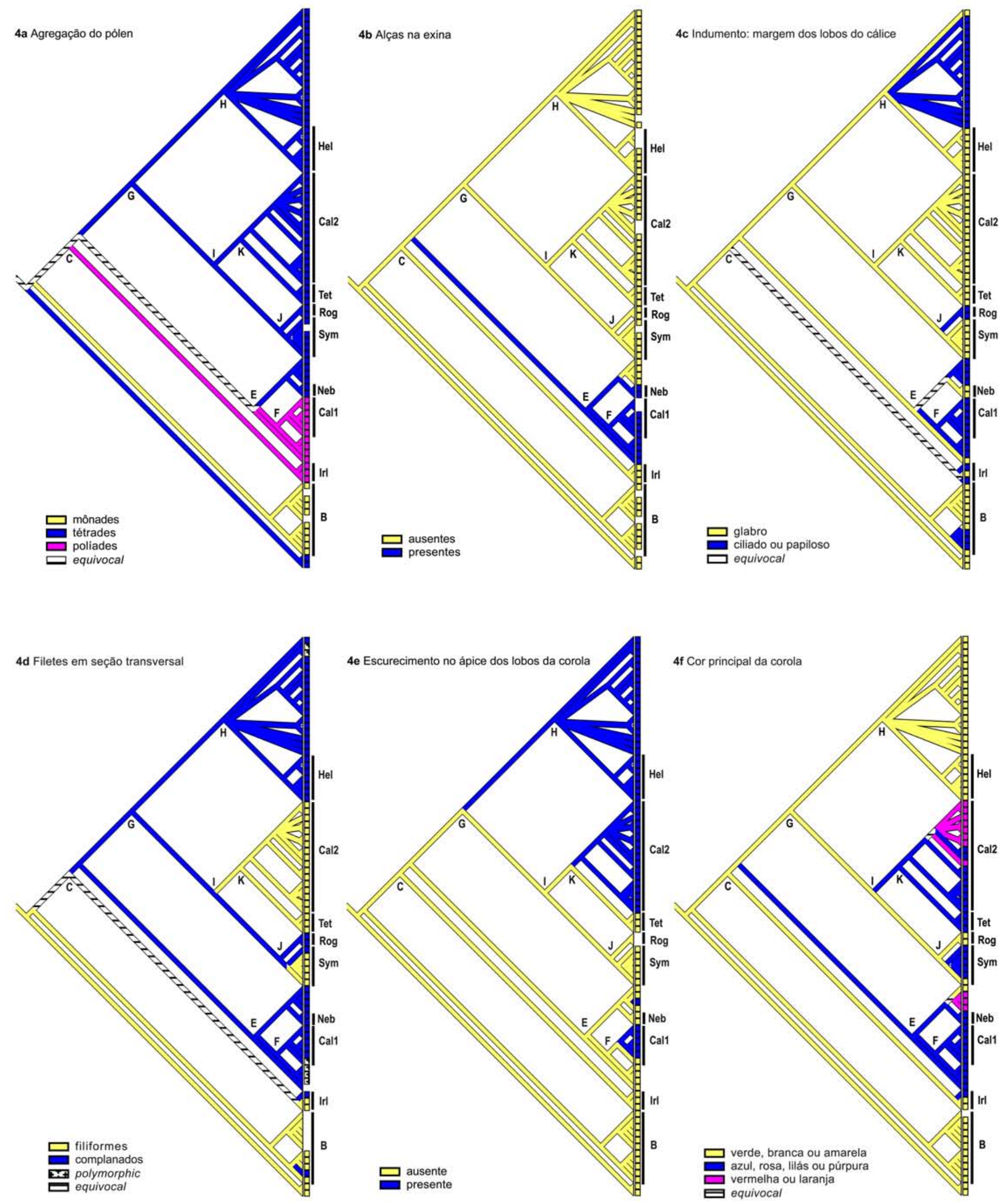

Fig. 4. Seis caracteres morfológicos mapeados sobre a filogenia de Helieae obtida com a análise de parcimônia da matriz "Combinada Total Grande com indels" (táxons dos grupos-externos foram removidos). Lista de caracteres morfológicos e matriz com codificações são encontradas nos Apêndices A e B. (a) Agregação dos grãos de pólen (car. 88), (b) Alças na exina (car. 91), (c) Indumento na margem dos lobos do cálice (car. 39), (d) Filetes em seção transversal (car. 69), (e) Região escurecida no ápice dos lobos da corola (car. 57), (f) cor principal da corola (car. 44). 

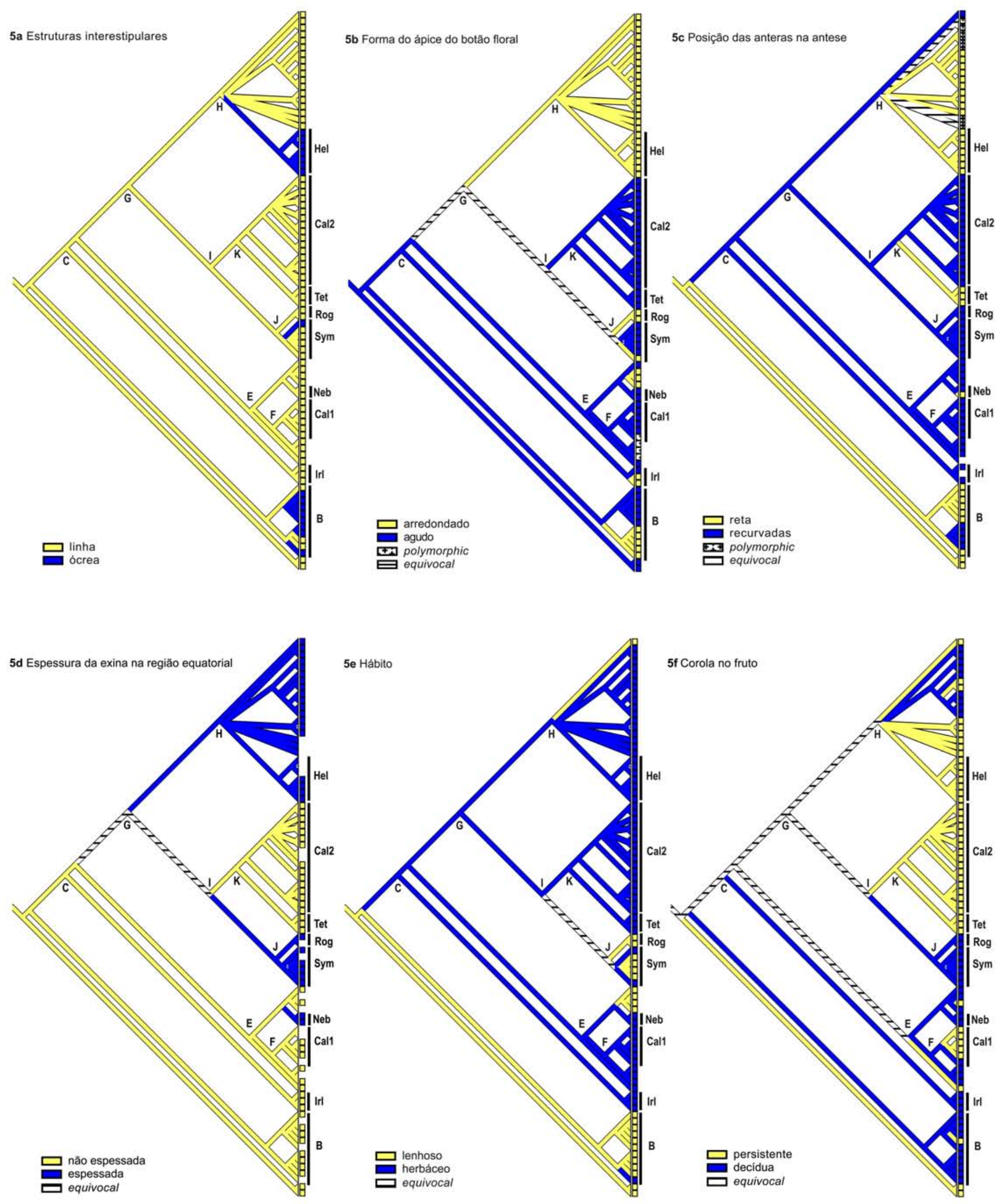

Fig. 5. Seis caracteres morfológicos mapeados sobre a filogenia de Helieae obtida com a análise de parcimônia da matriz "Combinada Total Grande com indels" (táxons dos grupos-externos foram removidos). Lista de caracteres morfológicos e matriz com codificações são encontradas nos Apêndices A e B. (a) Estruturas interestipulares (car. 20), (b) Forma do ápice do botão floral (car. 55), (c) Posição das anteras na antese (car. 70), (d) Espessura da exina na região equatorial (car. 91), (e) Hábito (car. 1), (f) Corola no fruto (car. 53). 


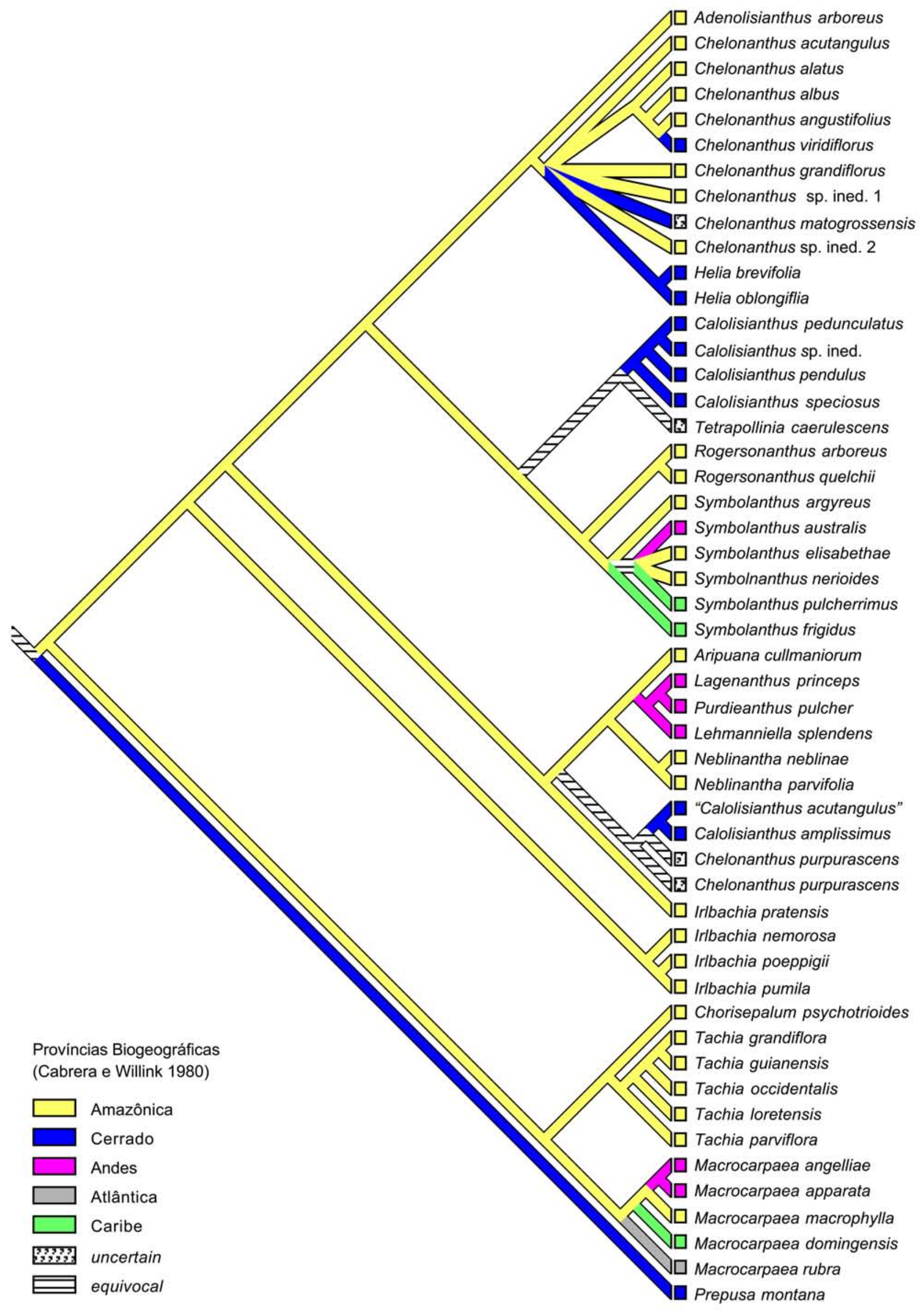

Fig. 6. Mapeamento das áreas geográficas onde ocorrem as espécies amostradas de Helieae, codificadas de acordo as Províncias Biogeográficas sensu Cabrera e Willink (1980). Árvore modificada com base na topologia obtida com a análise de parcimônia da matriz "Combinada Total Grande com indels" (táxons dos grupos-externos foram removidos). Nomes informais entre aspas. 


\section{Apêndice A}

Caracteres morfológicos e respectivos estados utilizados nesse estudo. Detalhes sobre os caracteres em Struwe et al. (2009).

1. Hábito: lenhoso (0); herbáceo (às vezes lenhoso na base) (1). Ervas subarbustivas foram codificadas como herbáceas, e o hábito lenhoso foi restringido a plantas com crescimento secundário presente também nos ramos.

2. Saprófitas: não (0); $\operatorname{sim}(1)$.

3. Caule: ereto (0); volúvel (1).

4. Cor do caule: verde-amarronzada (0); branca, amarela ou laranja (1); vermelha ou purpúrea (2).

5. Resina nos nós: ausente (0); presente (1).

6. Posição das folhas na base: igualmente distribuídas (0); agrupadas em roseta basal (1).

7. Posição das folhas no ápice dos ramos: igualmente distribuídas (0); agrupadas no ápice (1).

8. Ramos jovens: glabros (0); pilosos, pubescentes (1); híspidos (2); papilosos (3).

9. Indumento papiloso nas partes vegetativas: ausente (0); presente (1).

10. Indumento híspido nas partes vegetativas: ausente (0); presente (1).

11. Margem da folha: inteira (0); crenulada (1); denteada (2).

12. Indumento na face abaxial das folhas: ausente (0); presente (1).

13. Pequenos tricomas na margem das folhas: ausentes (0); presentes (1).

14. Margem da folha: com a mesma textura e cor do restante do limbo (0); delgada, sem cor e membranácea (hialina)(1).

15. Margem da folha: não espessada (0); espessada (1).

16. Margem da folha: plana (0); revoluta (1).

17. Pecíolo: presente, distinto (0); ausente ou indistinto (folhas sésseis) (1). Em folhas com base atenuada, esse caráter pode ser difícil de codificar. Por essa razão, baseamos a codificação no fato da lâmina alcançar ou não a base da folha (i.e. folhas com pecíolos alados seriam codificadas como "pecíolo ausente" se a ala alcançasse a base da folha).

18. Invaginação da nervura central: ausente (0); presente (1).

19. Base da folha: livre (0); conata (1).

20. Estruturas interestipulares: linha (0); ócrea (1). A diferença entre linha e ócrea é que a primeira é apenas uma área com uma cicatriz, enquanto a segunda é um tecido que envolve parcialmente o caule.

21. Número de pares de nervuras secundárias: 0 (0); 1-2 (1); 3 ou mais (2).

22. Curso do par basal de nervuras secundárias: reto (0); curvado em direção ao ápice (1). 
23. Nervuras secundárias na face abaxial: não proeminentes (0); proeminentes (1).

24. Posição da inflorescência: terminal (0); axilar (1).

25. Tipo de inflorescência: cimosa (com flor apical) (0); racemosa (sem flor apical, inclui tirso) (1).

26. Número de flores: 2 ou mais por inflorescência (0); solitárias (1).

27. Indumento nos ramos da inflorescência: glabro (0); piloso (1); híspido ou papiloso (2); tuberculado (3).

28. Fusão basal dos ramos da inflorescência: não fundido (0); fundido (1).

29. Bractéolas: presentes (0); ausentes (1).

30. Forma e estrutura das bractéolas: triangular, escamiforme (0); foliácea (1). Bractéolas referem-se às estruturas abaixo de cada flor.

31. Orientação da flor na antese: ereta a horizontal (0); nutante (pedicelo curvado 180 graus) (1).

32. Merisma do cálice: 5 (0); 4 (1); 2 (2); 6-7 (3).

33. Cor do cálice: verde (0); branca, amarela, laranja (1); vermelha, purpúrea, azul (2).

34. Posição das sépalas: em 1 verticilo (0); em 2 verticilos (decussado) (1).

35. Espessamento na região dorsal dos lobos do cálice: ausente (0); presente (1).

36. Apêndices na região dorsal dos lobos do cálice: ausentes (0); carenados (1); alados, 1 ala (2); alados, 2 alas (3).

37. Área glandular na região dorsal dos lobos do cálice: ausente (0); presente (1).

38. Margem dos lobos do cálice: cartácea (0); membranácea, hialina (1).

39. Indumento na margem dos lobos do cálice: glabro (0); ciliado ou papiloso (1).

40. Indumento na face dorsal dos lobos do cálice: glabro (0); piloso (1).

41. Cálice no fruto: persistente (0); decíduo (1).

42. Textura do cálice: membranáceo, papiráceo (0); coriáceo, lenhoso (1).

43. Merisma da corola: 5 (0); 4 (1); 6-7 (2); 8 ou mais (3).

44. Cor principal da corola: verde, branca ou amarela (0); azul, rosa, lilás ou púrpura (1); vermelha ou laranja (2).

45. Forma do tubo da corola acima do ponto de inserção dos estames: não inflada (0); inflada (1).

46. Constrição da corola na fauce: ausente (0); presente (corola com forma de balão) (1).

47. Forma do tubo da corola na região abaxial: simétrica, sem giba (0); assimétrica, com giba (1).

48. Indumento no exterior da corola: glabro (0); papiloso (1).

49. Plicas na corola: ausentes (0); presentes (1).

50. Indumento no interior da corola: ausente (0); presente (1).

51. Glândulas no interior da corola: ausentes (0); presentes (1). 
52. Textura da corola: não carnosa, delgada (0); carnosa ou coriácea, espessa (1).

53. Corola no fruto: persistente (0); decídua (1).

54. Apêndices apicais nos lobos da corola: ausentes (0); presentes (1).

55. Forma do ápice do botão floral: arredondado (0); agudo (1).

56. Estivação da corola: contorta (0); valvar-contorta (1); imbricada (2).

57. Região escurecida no ápice do lobo da corola: ausente (0); presente (1).

58. Indumento na margem do lobo da corola: glabro (0); fimbriado (1); ciliado ou papiloso (2).

59. Inserção dos estames no tubo da corola: distante dos lobos (0); entre os lobos (1); muito próximo dos lobos (2).

60. Comprimento dos filetes: isodínamos (0); heterodínamos (1).

61. Simetria do androceu: estames dispostos radialmente em relação à fauce $(0)$; estames agrupados na porção basal da fauce (1).

62. Base dos filetes: livre (0); inserido sobre uma base carnosa, sem anel (1); inserido em anel carnoso ou com apêndices estaminais basais (2).

63. Lacunas estaminais: ausentes (0); presentes (1).

64. Corona: ausente (0); presente (1).

65. Base dos filetes: não alada (0); alada (1).

66. Interior do tubo da corola abaixo da região de inserção dos estames: não alado (0); alado ou costado (1).

67. Inserção do filete em relação à corola: não curvado, paralelo ao tubo (0); curvado em 90 graus, perpendicular ao tubo (1).

68. Angulação dos filetes próximo às anteras: não curvados (0); curvados 180-360 graus (1).

69. Filetes em seção transversal: filiformes (0); complanados (1).

70. Posição das anteras na antese: retas (0); recurvadas (1); espiraladas ao longo do comprimento (2); dobradas para trás, versáteis (3).

71. Apículo estéril no ápice da antera: ausente (0); presente (1).

72. Disco ou tecido nectarífero na base do ovário: ausente (0); presente (1).

73. Posição do ovário: séssil (0); estipitado (1).

74. Persistência do estilete no fruto: persistente (0); decíduo (às vezes a base persiste) (1).

75. Forma do estilete: delgado e longo (0); largo e curto (1).

76. Seção transversal do estilete quando seco: filiforme (0); achatado e espiralado ao longo do seu comprimento (2).

77. Posição do estilete: reto (0); curvado em direção ao ápice (1).

78. Forma do estigma: bilamelado (0); obcônico-simples (1); capitado-peltado (2).

79. Forma do lobo do estigma: arredondado a elíptico (0); linear (1).

80. Posição dos frutos: ereta a horizontal (0); pêndula (1). 
81. Tipo de deiscência do fruto: indeiscente (0); bivalvar, apical (1); 4-valvar (2); bivalvar, medial (3).

82. Valvas do fruto: persistentes (0); decíduas, sem deixar os traços vasculares secos (1); decíduas, com traços vasculares secos (2).

83. Textura do epicarpo fresco: delgado (0); carnoso (1); coriáceo (2).

84. Mesocarpo: sem separação (0); separando-se em uma parte externa delgada e uma parte interna fibrosa (1).

85. Cor do fruto maduro e fresco: castanha a bege (0); verde a amarela (1); vermelha a purpúrea (2).

86. Placenta em frutos maduros: inconspícua (0); cartácea, delgada (1); lenhosa, espessa (2); carnosa (3).

87. Forma da placenta: simples (0); peltada (1); intrusiva (2).

88. Agregação dos grãos de pólen quando liberados: mônades (0); tétrades (1); políades (2).

89. Abertura do pólen: colporado (0); porado (1).

90. Espículas na columela e muro: ausentes (0); presentes (1).

91. Alças na columela e muro: ausentes (0); presentes (1).

92. Espessura da exina na região equatorial: não espessada (0); espessada (1).

93. Espessura da exina na região polar: não espessada (0); espessada (1).

94. Processos especiais na região polar: nenhum (0); glóbulos (1); espícula (2).

95. Margem dos poros: lamelar espessada (0); lamelar não espessada (1); protuberante (2); intrusiva (3).

96. Perfuração nas paredes internas em tétrades e políades: ausente (0); presente (1).

97. Lúmen: liso (0); granuloso (1).

98. Teto: ausente (0); presente, inteiro (1); presente, perfurado (2).

99. Macro-glóbulos na columela e muro: ausentes (0); presentes (1).

100. Micro-glóbulos na columela e muro: ausentes (0); presentes (1).

101. Processos alongados na columela e muro: ausentes (0); presentes (1).

102. Processos curtos na columela e muro: ausentes (0); presentes (1).

103. Espessamento do muro: uniforme (0); desigual (1).

104. Muro: liso (0); granular (1); carenado (2); não fundido (3).

105. Tamanho das aberturas no retículo: iguais (0); maiores na região polar (1); maiores na região equatorial (2).

106. Padrão do teto/columela: reticulado (0); escabro a verrucoso (1); estriado (2).

107. Retículo: finamente reticulado, estriado (0); grosseiramente reticulado (1); irregularmente reticulado (2).

108. Forma da semente: angular, poliédrica (0); globosa, subglobosa, elíptica (1); comprimida (2). 
109. Costelas na superfície da semente: ausentes (0); presentes (1).

110. Ala nas sementes: ausente (0); uma ala presente, contornando todos os lados da semente (1); várias alas presentes, parcialmente contornando um ou mais (mas não todos) os lados da semente (2).

111. Hilo: indistinto (0); distinto (1).

112. Forma das células da testa: poligonais (0); alongadas (1).

113. Forma da parede externa da testa: côncava (0); convexa (1).

114. Espessamentos em faixas na parede externa da testa: ausentes (0); presentes (1).

115. Forma das paredes anticlinais da testa: retas (a levemente curvadas) (0); curvadas a em forma de S (1); ondulada a em zigue-zague (2).

116. Espessura geral da testa nas paredes anticlinais: delgada (0); espessa (1).

117. Forma dos limites das paredes anticlinais da testa: reta (0); convexa (1); côncava (2).

118. Espessamentos em faixas nas paredes anticlinais da testa: ausentes (0); presentes (1).

119. Papilas ou grânulos na parede anticlinal da testa: ausentes (0); presentes (1).

120. Poros na parede anticlinal da testa: ausentes (0); presentes (1).

121. Retículo na parede anticlinal da testa: ausente (0); presente (1).

122. Espessamentos na parede interna da testa: ausentes (0); presentes (1).

123. Estrutura da parede interna da testa: lisa (0); com poros (1).

124. Papilas ou grânulos na parede interna da testa: ausentes (0); presentes (1).

125. Retículo na parede interna da testa: ausente (0); presente (1).

126. Grânulos na cutícula: ausentes (0); presentes (1). 


\section{Apêndice B}

Matriz de dados morfológicos empregada nas análises filogenéticas. Táxons com nomes informais estão indicados entre aspas. Na matriz, táxons polimórficos foram representados com letras: $a=0 / 1 ; b=1 / 2 ; c=0 / 2 ; d=0 / 1 / 2 ; ?=$ dados ausentes.

\begin{tabular}{|c|c|c|c|c|c|c|c|c|c|c|c|c|c|}
\hline \multirow[t]{2}{*}{ Táxon } & \multicolumn{13}{|c|}{ Número do caráter } \\
\hline & $\begin{array}{l}0000000000 \\
0000000001 \\
1234567890 \\
\end{array}$ & $\begin{array}{l}0000000000 \\
1111111112 \\
1234567890 \\
\end{array}$ & $\begin{array}{l}0000000000 \\
2222222223 \\
1234567890\end{array}$ & $\begin{array}{l}0000000000 \\
3333333334 \\
1234567890 \\
\end{array}$ & $\begin{array}{l}0000000000 \\
4444444445 \\
1234567890\end{array}$ & $\begin{array}{l}0000000000 \\
5555555556 \\
1234567890 \\
\end{array}$ & $\begin{array}{l}0000000000 \\
6666666667 \\
1234567890\end{array}$ & $\begin{array}{l}0000000000 \\
7777777778 \\
1234567890 \\
\end{array}$ & $\begin{array}{l}0000000000 \\
8888888889 \\
1234567890 \\
\end{array}$ & $\begin{array}{l}0000000001 \\
9999999990 \\
1234567890 \\
\end{array}$ & $\begin{array}{l}11111 \\
00001 \\
67890\end{array}$ & $\begin{array}{l}1111111111 \\
1111111112 \\
1234567890\end{array}$ & $\begin{array}{l}111111 \\
222222 \\
123456 \\
\end{array}$ \\
\hline Centaurium mariti & 1000010000 & 0000001000 & $? ? 00000001$ & $? 00$ & 0000000000 & 0000000020 & 00001 & 0000000000 & 1000002000 & $0000 ? ? ? 200$ & $00 ? ? ? 2 ? 100$ & $0000 ? 0 ? 001$ & 101110 \\
\hline Chironia linoides & 1000000101 & 0110001000 & 1100001001 & 0000000011 & 0001000000 & $00 ? 0000020$ & 1000000001 & $010 ? 00110 ?$ & ??00???000 & $0000 ? ? ? 200$ & 0002020100 & $00000 ? 1000$ & 100101 \\
\hline Coutoubea spicata & 1000000000 & 0000000000 & b100100000 & 0100010100 & 0010000000 & 0000100020 & 0000111000 & 0000001000 & 1000002110 & $0010 ? ? 1000$ & 0000101100 & $00001 ? 000 ?$ & $? 01011$ \\
\hline Ixanthus viscosus & 1000000000 & 0000001010 & 1100000001 & $0 \mathrm{a} 00000010$ & $10 \mathrm{a} 0000000$ & 0010100020 & 1000101001 & $00010 ? 1200$ & 1000022000 & $0000 ? ? ? 200$ & $000 ? 020100$ & $00000 ? 000 ?$ & $? 0 ? ? 10$ \\
\hline Orphium frutescens & 0000000100 & 0110001000 & $? ? 00001001$ & 0000000011 & 0001000000 & 0010000020 & 1012 & 0001001200 & 1000022000 & $0000 ? ? ? 200$ & & 0000 & \\
\hline Anthocleista amplexicaulis & 0000101000 & 0000001000 & 2000000000 & 0101100000 & 0131000000 & 0110100000 & 0100100010 & 1101000200 & 0010132010 & $00002 ? ? 200$ & $00 ? ? ? 1 ? 200$ & 1000a1?0?? & ?????0 \\
\hline Enicostema verticillatum & 1000000210 & 0101 & 000 & 0000 & 000 & 0010 & 0200 & 1001000200 & 000 & ??0?? & ???? & $00 ?$ & 011 \\
\hline Fagraea berteroana & 0000101000 & 0000010000 & 2000000000 & 0000100000 & 0100000000 & 0110000000 & 0200000010 & 0101001000 & $00102320 \mathrm{a} 0$ & $00000 ? ? 000$ & 0002000100 & $110001 ? 0 ? 1$ & ?????0 \\
\hline Fagraea fragrans & 0000101000 & 0000010001 & 2001000000 & 0000000000 & 0100000000 & 0010000200 & 0000001010 & 0001000100 & $001023 ? 000$ & $00000 ? ? 000$ & 00020c00?0 & $110001 ? 0 ? 1$ & ?????0 \\
\hline Lisianthius jefensis & 00000 & 0000010000 & 1101000000 & 1000 & 0001110000 & 0000 & 0000 & 100 & 1000022000 & 0000 & 100 & 010 & 000100 \\
\hline Lisianthius se & 1000000000 & 0000001000 & b110000001 & 1000010000 & 0000000000 & 0001 & 000 & 200 & 3000 & 000 & & 000 & \\
\hline Potalia amara & 0001101000 & 0000001001 & 2000000000 & 0111100100 & 0130000000 & 0110000000 & 0100000010 & 1101000200 & 0010131010 & $00002 ? ? 100$ & $000 ? ? 1 ? 200$ & $10000 ? ? 0 ? ?$ & ?????0 \\
\hline Crawfurdia thib & 0010 & 100 & 000 & 100 & & & & & & & & & \\
\hline Gentiana lutea & 1000000000 & 0000001010 & $110100000 ?$ & 0000000100 & $0000 ? 00000$ & 0000100010 & 0000110010 & 0110 & 1000000000 & $? ? 000$ & $00 ? ? 020201$ & 1100 & 000010 \\
\hline Gentianella amarella & 1002000000 & 0010001010 & 1100000001 & 0020000010 & 0001000000 & 1000100000 & 0000110013 & 0010100000 & 1000000000 & $0000 ? ? ? 000$ & 0000020100 & 0000 & 00000a \\
\hline Gentianopsis crinita & 1002000000 & 0010001000 & 1100000001 & 01200 & 00001 & 1000100100 & 0000 & 000 & 1000 & 0000 & 200 & ? ?? & ???110 \\
\hline palmeri & 1000000000 & 0010001010 & 1100000001 & 0100000010 & 0010000000 & 1000100000 & 0000 & 0000 & 1000 & 0000 & 000 & 000 & $00 c$ \\
\hline Obolaria virginica & 1102000000 & 0000001010 & 2001000001 & 0200000000 & 0011000000 & 1000120010 & 0000100010 & 0100100000 & 3000000000 & $0000 ? ? ? 000$ & 0000000100 & $0000 ? ? ? 000$ & 000000 \\
\hline Swertia perennis & 1002000000 & $00000010 \mathrm{a} 0$ & 1100000001 & 0020000000 & 0001000000 & 1000100010 & 0000100013 & 0010100200 & 1000010000 & $0000 ? ? ? 000$ & $00 ? ? 0 ? ? \mathrm{~d} 00$ & 0?00?????? & ?????? \\
\hline Tripterospermum volubile & 1010000000 & 1000000000 & 1101010000 & 1000020100 & 0000100010 & 0010100001 & $00001 ? 0010$ & $01111 ? 1011$ & $000023 ? 000$ & $0000 ? ? ? 200$ & 0002020201 & 0000a????? & ?????0 \\
\hline Adenolisianthus arboreus & 0000001000 & 0001001000 & 1100000000 & 0000101100 & 0100100000 & 0100001201 & 1010100011 & 1100011001 & $30000221 \mathrm{a} 0$ & $0110 ? ? 0000$ & 0010b02010 & 0?012????? & ?????0 \\
\hline Aripuana cullmaniorum & 0000000000 & 0001010000 & 2000000000 & 0000101110 & 0100000000 & 0010110010 & 0100000011 & 1100010000 & 1000022100 & $0000 ? ? 0000$ & 0000001010 & $0011010 ? 0 ?$ & $? ? 10 ? 0$ \\
\hline "Calolisianthus acutangulus" & 1000000000 & 0001001000 & $11100 \mathrm{a} 0000$ & 0000101110 & 0101100000 & 0100101201 & 1000000111 & 1100011001 & $30000222 ? ?$ & ?????????? & ???????0?0 & ?????????? & ?????? \\
\hline Calolisianthus amplissimus & 1000000000 & 0001001000 & b1100a0000 & 0000101110 & 0101100000 & 0100101201 & 1000000111 & 1100011001 & 3000022200 & 1010110000 & $00001020 ? 0$ & ?????????? & ?????0 \\
\hline Calolisianthus pedunculatus & 1000000000 & $000100 a 000$ & b1100a0000 & 0000101100 & 0102100000 & 0100101001 & 1000000101 & 1100011001 & 3000022100 & $0010 ? 10000$ & 0000102010 & 0011?????? & ?????0 \\
\hline Calolisianthus pendulus & 1000000000 & $000100 a 000$ & $11100 \mathrm{a} 0000$ & 0000101100 & 0101100000 & 0100101001 & 1000000101 & 1100011001 & 3000022100 & $0010 ? 10000$ & 0000102010 & 0?11?????? & ?????0 \\
\hline Calolisianthus speciosus & 1000000000 & 0001001000 & b1100a0000 & 0000101100 & 0101100000 & 0100101001 & 1000000101 & 1100011001 & 3000022100 & $0010 ? 10000$ & 0000102010 & $0011 ? ? 2 ? ? ?$ & ?????0 \\
\hline
\end{tabular}



\begin{tabular}{llllllllllllll}
0 & \\
1234567890 & 1234567890 & 1234567890 & 1234567890 & 1234567890 & 1234567890 & 1234567890 & 1234567890 & 1234567890 & 1234567890 & 1234567890 & 1234567890 & 123456 \\
\hline
\end{tabular}

Calolisianthus sp. ined. Chelonanthus acutangulus Chelonanthus alatus Chelonanthus albus Chelolanthus angustifolius Chelonanthus grandiflorus Chelonanthul matogrossensis Chelonanthus purpurascens Chelonanthus viridiflorus Chelonanthus sp. ined. 1 Chelonanthus sp. ined. 2 Chorisepalum psychotrioides Helia brevifolia Helia oblongifolia Irlbachia nemorosa

๗े Irlbachia poeppigil Irlbachia pratensis Irlbachia pumila Lagenanthus princeps Lehmanniella splendens Macrocarpaea angelliae Macrocarpaea apparata Macrocarpaea domingensis Macrocarpaea gattaca Macrocarpaea macrophylla Macrocarpaea rubra Neblinantha neblinae Neblinantha parvifolia Prepusa montana

Purdieanthus pulcher Rogersonanthus arboreus Rogesonanthus quelchii Symbolanthus argyreus Symbolanthus australis $1000000000000100100011100 a 0000 \quad 00001011000101100000010010100110000001011100011001$ 30000221?? ????????? ???????0?0 ????????? ?????? $1000000000 \quad 00010010 a 0$ b110000000 0000101110 010010a000 0110001201 10a00001aa 11000110013000022100 0100?1?000 1110b?2010 0000?????? ?????? 1000000000 00010010a0 b110000000 0000101110 010010a000 0010001201 1000000a1a 110a011001 3000022100 0100?1?000 00101?2010 0001?????? ?????? 1000000000 000100a000 b110000000 0000101110 0100?00000 0010001201 100000011a 110a011001 3000022100 0100?1?000 11102?2010 00a1?????? ?????? $1000000000 \quad 000100 a 0001110000000$ 0000101110 0100?0a000 0000001201 1000000a10 110a011000 3000022100 0100?1?0aa 00?02?2010 00a1?????? ?????? 1000000000 000100a0a0 b110000000 0000101110 010010a000 0100001201 10a0000110 1100011001 3000022100 0100?1?000 00100?2010 0001?????? ?????? $100000000000010010 a 01110000000000010111001001000000000001201$ 100000001a 110a011001 300002210? ?????1???? ??????2010 0001?????? ?????? 1000000000 000100a000 1110000000 a000101110 0101100000 0a10a00201 10000001a1 110a011001 3000022210 1010?1?000 00100?2010 00a1?????? ?????0 100000000000010010001110000000000010111001001010000010001201 10000000010 110a011000 3000022100 0110?1?0aa 0010??2010 00a1?????? ?????0 $1000000000 \quad 00010010 a 01110000000000012111001001000000000001201$ 1001000a10 1101011001 30000221?0 0??0???000 00102?2010 0001?????? ?????? $100000000000010010 \mathrm{a} 01110000000000010111001001000000000001201$ 100000001a 110a010000 3000022100 0??0?1?000 00100?2010 00a1?????? ?????? 00001000000000100000 211a20001? 010110??00 112??00000 0011100000 0000?0?0?0 ??0101000? 2201022000 0000??1000 0000001211 0011?????? ?1?01? 10000100000001001011 b1a0000000 $000010110001000000000100001 \mathrm{c01}$ 00a0000110 1100011001 30000221?? ????????? ???????010 00110?2?0? ?00000 $1000000000 \quad 0001001011 \quad 11 \mathrm{a} 00000000000101100 \quad 0100000000 \quad 0100001 \mathrm{c} 01 \quad 00 \mathrm{a} 00001101100011001 \quad 30000221 \mathrm{a} 0 \quad 0100 ? ? 0200 \quad 0010202010 \quad 00110 ? 2 ? 0 ? \quad ? 00000$ $1000000000 \quad 00000000001100000000 \quad 0000101110 \quad 0001000000 \quad 0010100201 \quad 10 ? 0100111110001100130000122 ? 1 \quad 0012 ? ? ? 000 \quad 0100100010 \quad 00112 ? ? ? 0 ? \quad ? 01100$ $10000000002000001000110000000100001011000000000000 \quad 0010000000 \quad 10 ? 010000 ? 0100011001 \quad 30000122 ? 10012 ? ? 1000 \quad 0100100100 \quad 00112 ? 0 ? 0 ? \quad ? 010 ? 0$ $1000010000 \quad 0000011000 \quad 0 ? ? 00000000000111100 \quad 0101000000 \quad 0000100 ? 01$ 10?0?00??? $100001100130000 ? 22 ? 1$ 1012?11000 01001000?0 00012???0? ?00100 $10000000000000001000 \quad 0 ? ? 0000000 \quad 0000101110 \quad 0000000000 \quad 0010000200 \quad 10 ? 0100001010011100 ? \quad 30000122110012 ? ? ? 000 \quad 0100100100 \quad 00112 ? ? ? 0 ? \quad ? 010 ? 0$ $00000003001001000000110 a ? 10000 \quad 1000111110 \quad 01021101010010000001 \quad 1000100111 \quad 1 ? 01011001 \quad 300002 ? 110 \quad 0 ? 00310000 \quad 0000202010 \quad 0 ? 111 ? ? ? 0 ? \quad ? 00 ? 00$ $0000000000 \quad 0001000000 \quad 11000 ? 0000 \quad 1000101110 \quad 0102110100 \quad 00100002010010100111 \quad 1 ? 0001 ? 0 ? 1 \quad 3000022110 \quad 0 ? 00310000 \quad 0000001010 \quad 00111 ? 000 ? \quad ? 00100$ 000000000001000100012110000001000010110011001000000110000001100000110111010110003201022000 00001?1000 0000001??? ?????????? ?????? 000000010101000001012100001001 a000101111 $1100100000 \quad 011000000110000011010101011000 \quad 32010220000000 ? ?, 1000$ 0000001012 00110?0??? ?????0 $00000000000000010100210000000100001011101100100000 \quad 0110000001 \quad 10001011111100011000 \quad 32010220100000 ? ? 0000 \quad 000000021200100 ? ? 0 ? ?$ ?????0 $0000000101010000 a 100 \quad 21000011010000101000 \quad 1100100000 \quad 0110000001 \quad 1000001000010001100$ a 3201022000 0000???1000 0000001010 0011?????? ?????0 $0000000101010100010021100021010000101011 \quad 11001000000110000001 \quad 1000001 ? 01010101100032010220000000 ? ? 1000 \quad 0000001010001101 ? ? 0 ?$ ?????0 10000000000000000001211000000100001011001100010000 0110000c01 0000001000 0100011000 32010220?? ?????????? ????????? ????????? ?????? $1000000000000 ? 0010001100 ? 10001100010 ? 1000001 ? 000000010100201$ ?0?0100111 00000??0?1 ?000022110 1100??0000 0000101010 00110?2??? ?????0 1002000000 000?011000 1100?10001 002011?100 0001?00000 0010100001 ?0?0100010 10010??0?0 ?000022110 1100??0000 0000101??? ?????????? ?????? $00000010000001011000 \quad 11 \mathrm{a} 0000001 \quad 0310020000 \quad 0020100000 \quad 000010000 \mathrm{a} \quad 10000001001100011001 \quad 10000221 \mathrm{a} 0 \quad 0000000011 \quad 01 ? ? 01 ? 010 \quad 0000 \mathrm{a} ? 1000 \quad 000010$ $0000000310010000000011000020001020101110 \quad 0102110100 \quad 000000120110001000111101010001300002211000003 ? 00010000202010$ 0?111????? ?00?00 00000000000000010000 ??00000000 $00001011100100101000 \quad 011000 ? 201 \quad 10101001111100011001 \quad 30000221 \mathrm{a} 0$ 0110???010 0010102010 0011010??? ?????0 $0000000000000001100011100030000000101110010010 ? 000 \quad 011000 ? 201101010011111000110013000022100$ 0??????010 0010102010 0011010??? ?????0 10000000000001011001110000000000001011000101100000001010000110101001111101011001 10000221a0 0100???000 00??202??? ?????????? ?????? $0000000000000000000011000 a 0000$ 0000101100 0101100000011010000110110001011101011001 1020022??? ?????????? ????????10 0????????? ?????? 


\begin{tabular}{|c|c|c|c|c|c|c|c|c|c|c|c|c|c|}
\hline \multirow[t]{3}{*}{ Táxon } & \multicolumn{13}{|c|}{ Número do caráter } \\
\hline & $\begin{array}{l}0000000000 \\
0000000001\end{array}$ & $\begin{array}{l}0000000000 \\
1111111112\end{array}$ & $\begin{array}{l}0000000000 \\
2222222223\end{array}$ & $\begin{array}{l}0000000000 \\
3333333334\end{array}$ & $\begin{array}{l}0000 \\
4445\end{array}$ & $\begin{array}{l}0000000000 \\
5555555556\end{array}$ & $\begin{array}{l}0000000000 \\
6666666667\end{array}$ & $\begin{array}{l}0000000000 \\
7777777778\end{array}$ & & $\begin{array}{l}0000 \\
9999\end{array}$ & & & $\begin{array}{l}111111 \\
222222\end{array}$ \\
\hline & & 1234567890 & 1234567890 & & 1234567890 & & & & & 1234567890 & & & 123456 \\
\hline Symbolanthus elisabethae & 0000000000 & 0000000000 & b100010000 & 0000101100 & 0101100000 & 0110100001 & 1011000101 & 1101011001 & 1020022100 & $0100 ? ? ? 000$ & $00 ? ? 202010$ & 0011a?2??? & ??1??0 \\
\hline Symbolanthus frigidus & 1000000000 & 0001000000 & 2100000000 & 0000101100 & 0100100000 & 0110000001 & 1010100101 & 1101011001 & $30000221 \mathrm{a} 0$ & $0100 ? ? 1000$ & $00 ? ? 202010$ & $0011 ? ? 2 ? ? ?$ & ?????0 \\
\hline Symbolanthus nerioides & 0000000000 & 0000000000 & 1100000000 & 0000101100 & 0101100000 & 0110100001 & 1011000101 & 1101011001 & 1020022100 & 0100???000 & $00 ? ? ? 02010$ & 00???????? & ?????? \\
\hline Symbolanthus pulcherrimus & 0000000000 & 0000000000 & $2100 ? 10000$ & 0000101100 & 0101100000 & 0110100001 & 1011000101 & 1101011001 & 1020022100 & $01000 ? ? 000$ & 0000202010 & $0011 a ? 2 ? ? ?$ & ??1?00 \\
\hline Tachia grandiflora & 0000100000 & 0000000001 & 200121??1? & 0000111100 & $1100 ? 00000$ & 0110100001 & $100000 ? 1 ? 0$ & $?$ ?101011000 & 1100022??? & ?????????? & ?????????? & ?????????? & ?????? \\
\hline Tachia loretensis & 0000100000 & 0000000001 & 200121??1? & 0010111100 & 0100100000 & 0100100001 & $100000 ? 1 ? 0$ & $? 101011000$ & 1100022000 & $0000 ? ? ? 000$ & $000 ? 0 \mathrm{c} 0 ? ? ?$ & ?????????? & ?????? \\
\hline Tachia occidentalis & 0000100000 & 0000000001 & 20012a??1? & 0010111100 & 1100000000 & 0110100001 & $10000011 ? 0$ & 0101011000 & 1100022000 & $0000 ? ? ? 101$ & $0 ? ? 0 ? ? 0 ? ? ?$ & ?????????? & ?????? \\
\hline Tachia parviflora & 0000100000 & 0000000001 & 11012a??1? & 0000101100 & $1100 ? 00000$ & 0110100001 & $100000 ? 1 ? 0$ & 0101011000 & 1100022??? & ?????????? & ?????????? & ?????????? & ?????? \\
\hline Tetrapollinia caerulescens & 1000000000 & 0001001000 & $0 ? ? 0000000$ & 0000101100 & 0101100000 & 0000100001 & $10 ? 0000000$ & $100001000 a$ & 1000022111 & $0000 ? ? 1000$ & 1000000000 & $00002 ? 0000$ & 001100 \\
\hline
\end{tabular}




\section{Apêndice C}

Inserções e deleções (indels) de ITS recodificados usando o método de "simple indel coding". Para cada indel, os estados 0 e 1 indicam, respectivamente, a ausência e presença do indel.

\begin{tabular}{|c|c|}
\hline Indels & Posição no alinhamento \\
\hline 1 & 5 \\
\hline 2 & 26 \\
\hline 3 & 38 \\
\hline 4 & 40 \\
\hline 5 & $41-42$ \\
\hline 6 & 58 \\
\hline 7 & 65 \\
\hline 8 & 70 \\
\hline 9 & 90 \\
\hline 10 & 91 \\
\hline 11 & 108 \\
\hline 12 & $109-110$ \\
\hline 13 & 111 \\
\hline 14 & 112 \\
\hline 15 & 113 \\
\hline 16 & 136 \\
\hline 17 & 137 \\
\hline 18 & 138 \\
\hline 19 & 146 \\
\hline 20 & 147 \\
\hline 21 & 149 \\
\hline 22 & 158 \\
\hline 23 & $170-172$ \\
\hline 24 & 175 \\
\hline 25 & 184 \\
\hline 26 & 198 \\
\hline 27 & 209 \\
\hline 28 & $219-220$ \\
\hline 29 & 229 \\
\hline 30 & 239 \\
\hline 31 & 254 \\
\hline 32 & 255 \\
\hline 33 & 435 \\
\hline 34 & 436 \\
\hline 35 & 437 \\
\hline 36 & 442 \\
\hline 37 & $443-449$ \\
\hline 38 & 455 \\
\hline 39 & 456 \\
\hline 40 & 465 \\
\hline 41 & 471 \\
\hline 42 & 470 e $472-473$ \\
\hline 43 & 478 \\
\hline 44 & $479-482$ \\
\hline 45 & 484 \\
\hline 46 & 485 \\
\hline 47 & 486 \\
\hline 48 & 489 \\
\hline 49 & 514 \\
\hline 50 & 601 \\
\hline 51 & 608 \\
\hline 52 & 627 \\
\hline 53 & 634 \\
\hline 54 & 639 \\
\hline 55 & 648 \\
\hline
\end{tabular}

\section{Apêndice D}

Inserções e deleções (indels) de 5S-NTS recodificados usando o método de "simple indel coding". Para cada indel, os estados 0 e 1 indicam, respectivamente, a ausência e presença do indel.

\begin{tabular}{cl}
\hline Indels & Posição no alinhamento \\
\hline 1 & 2 \\
2 & 3 \\
3 & 4 \\
4 & 5 \\
5 & $6-7$ e10-16 \\
6 & $8-9$ \\
7 & 19 \\
8 & $115-120,123-144,146-178$ e $180-189$ \\
9 & 121 \\
10 & 122 \\
11 & 179 \\
12 & 190 \\
13 & 191 \\
14 & 192 \\
15 & 204 \\
16 & $216-224$ \\
17 & $225-231$ e $234-237$ \\
18 & 232 \\
19 & 233 \\
20 & $238-243$ e $246-249$ \\
21 & 244 \\
22 & 245 e $250-256$ \\
23 & 257 \\
24 & $262-265$ e $268-272$ \\
25 & 266 \\
26 & 267 \\
27 & 305 \\
\hline &
\end{tabular}




\section{Apêndice $E$}

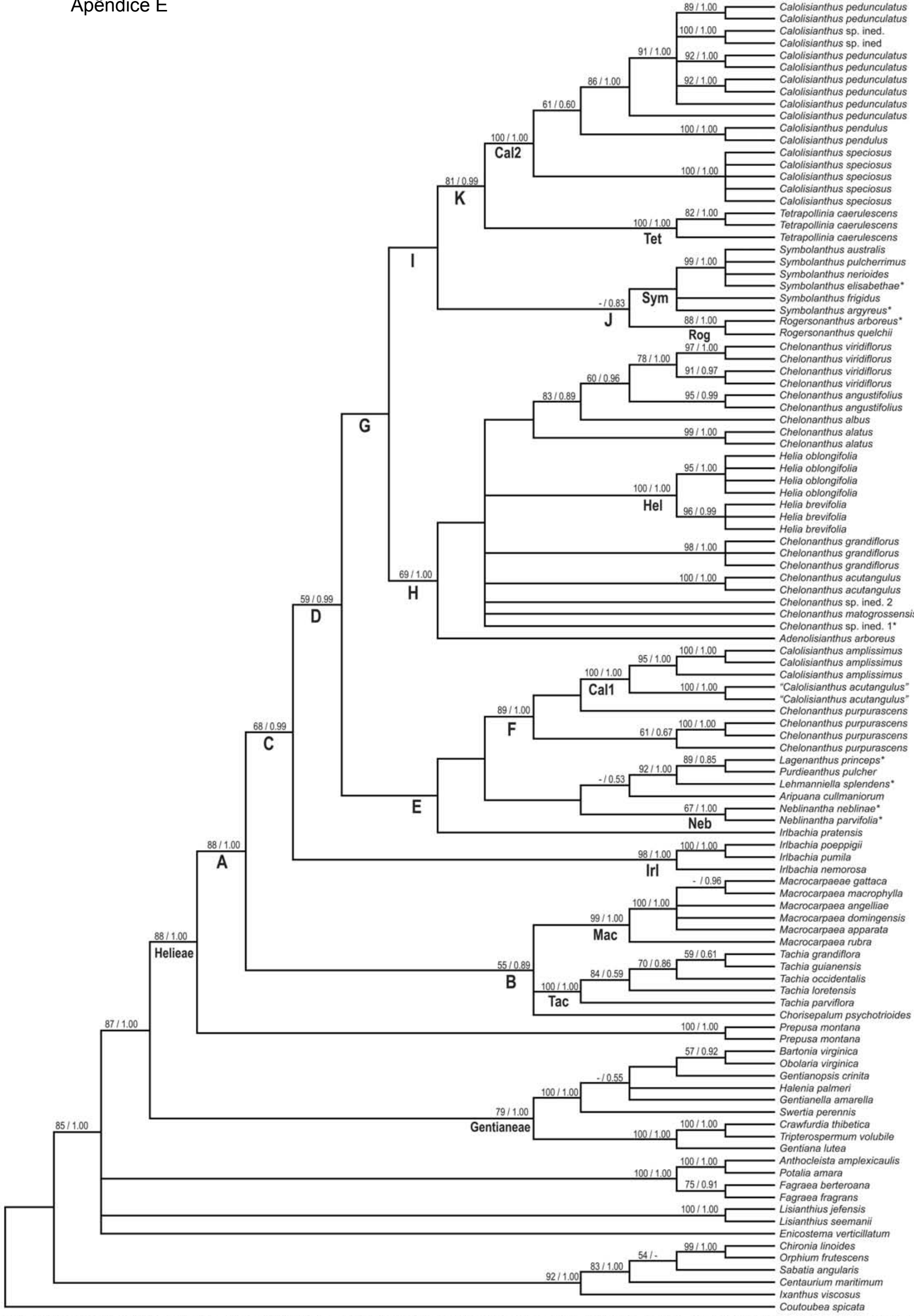

Fig. E1. Consenso estrito da análise de parcimônia da matriz "Combinada Total Grande sem indels", i.e., incluindo dados moleculares e morfológicos, e todos os táxons. Porcentagens de bootstrap e probabilidades posteriores de análise Bayesiana estão representadas sobre os ramos. Nomes informais entre aspas. Asterisco indica táxons incluídos nas análises apenas com dados morfológicos. 


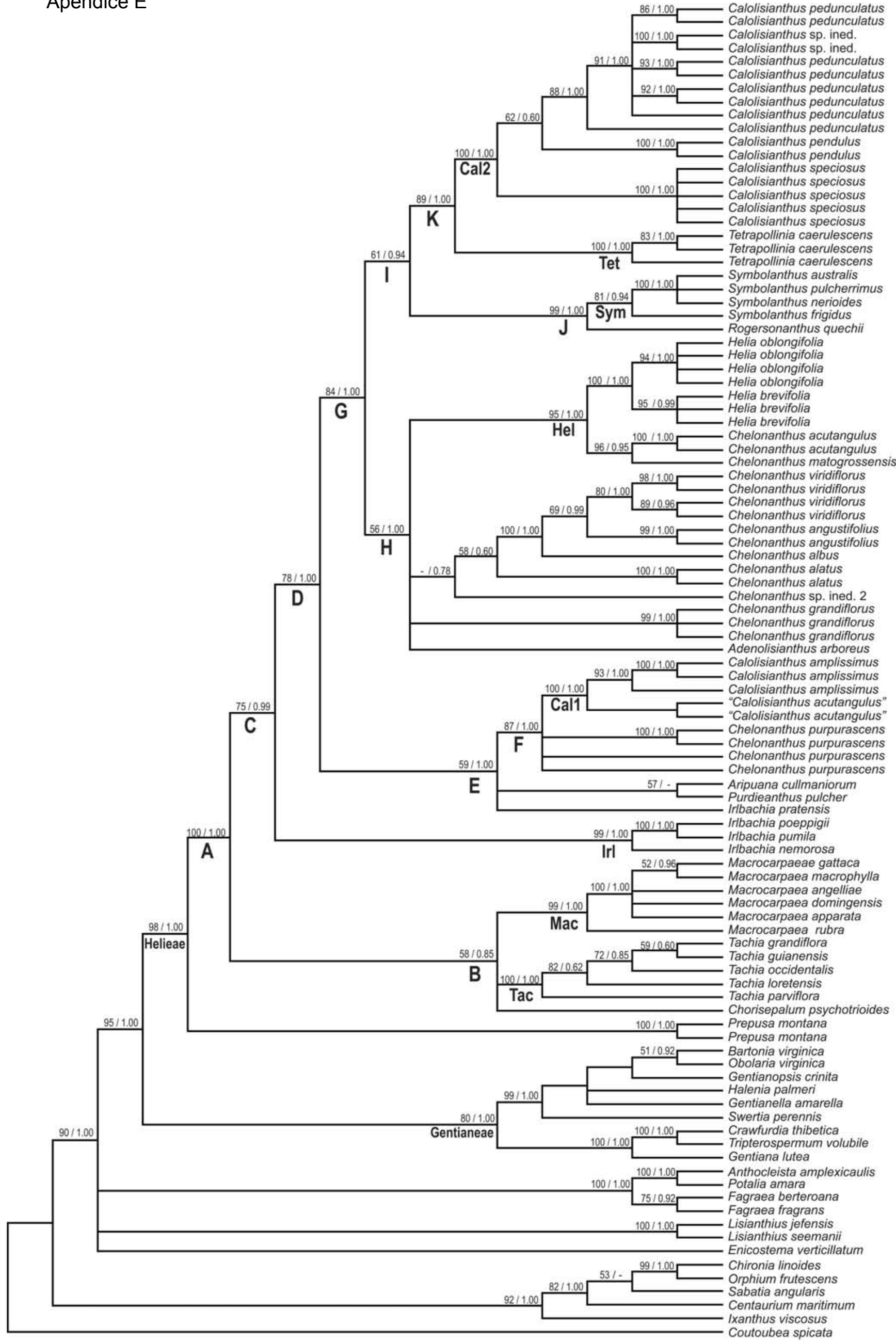

Fig. E2. Consenso estrito da análise de parcimônia da matriz "Combinada Total Média sem indels", i.e., incluindo dados morfológicos e moleculares, e apenas táxons com dados para ao menos uma das partições moleculares. Porcentagens de bootstrap e probabilidades posteriores de análise Bayesiana estão representadas sobre os ramos. Nomes informais entre aspas. 


\section{Apêndice $E$}

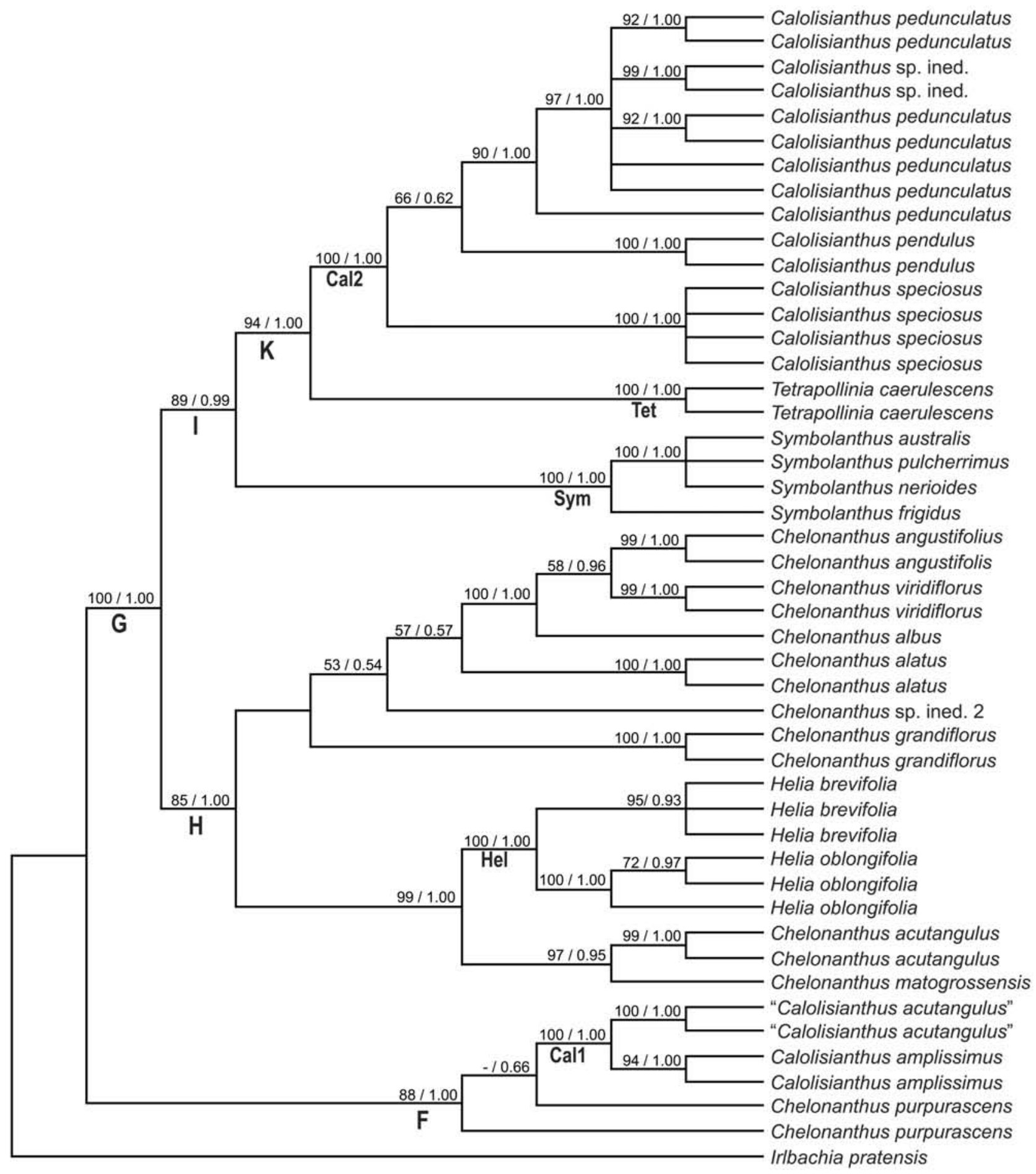

Fig. E3. Consenso estrito da análise de parcimônia da matriz "Combinada Total Pequena sem indels", i.e., incluindo dados morfológicos e moleculares, e apenas táxons com dados para as três partições. Porcentagens de bootstrap e probabilidades posteriores de análise Bayesiana estão representadas sobre os ramos. Nomes informais entre aspas. 
Apêndice $E$

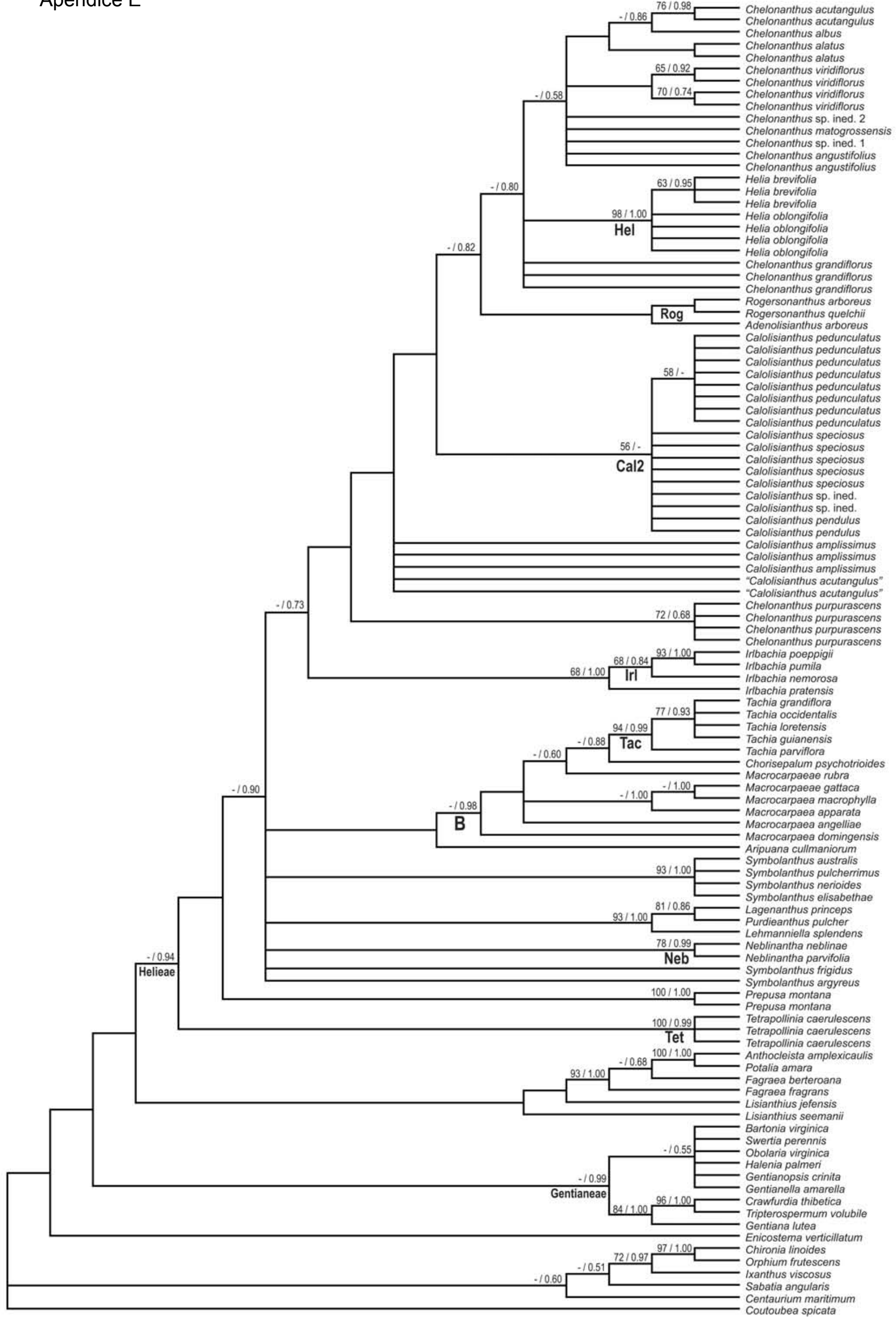

Fig. E4. Consenso estrito da análise de parcimônia da matriz "Morfologia" (inclui todos os táxons). Porcentagens de bootstrap e probabilidades posteriores de análise Bayesiana estão representadas sobre os ramos. Nomes informais entre aspas. 


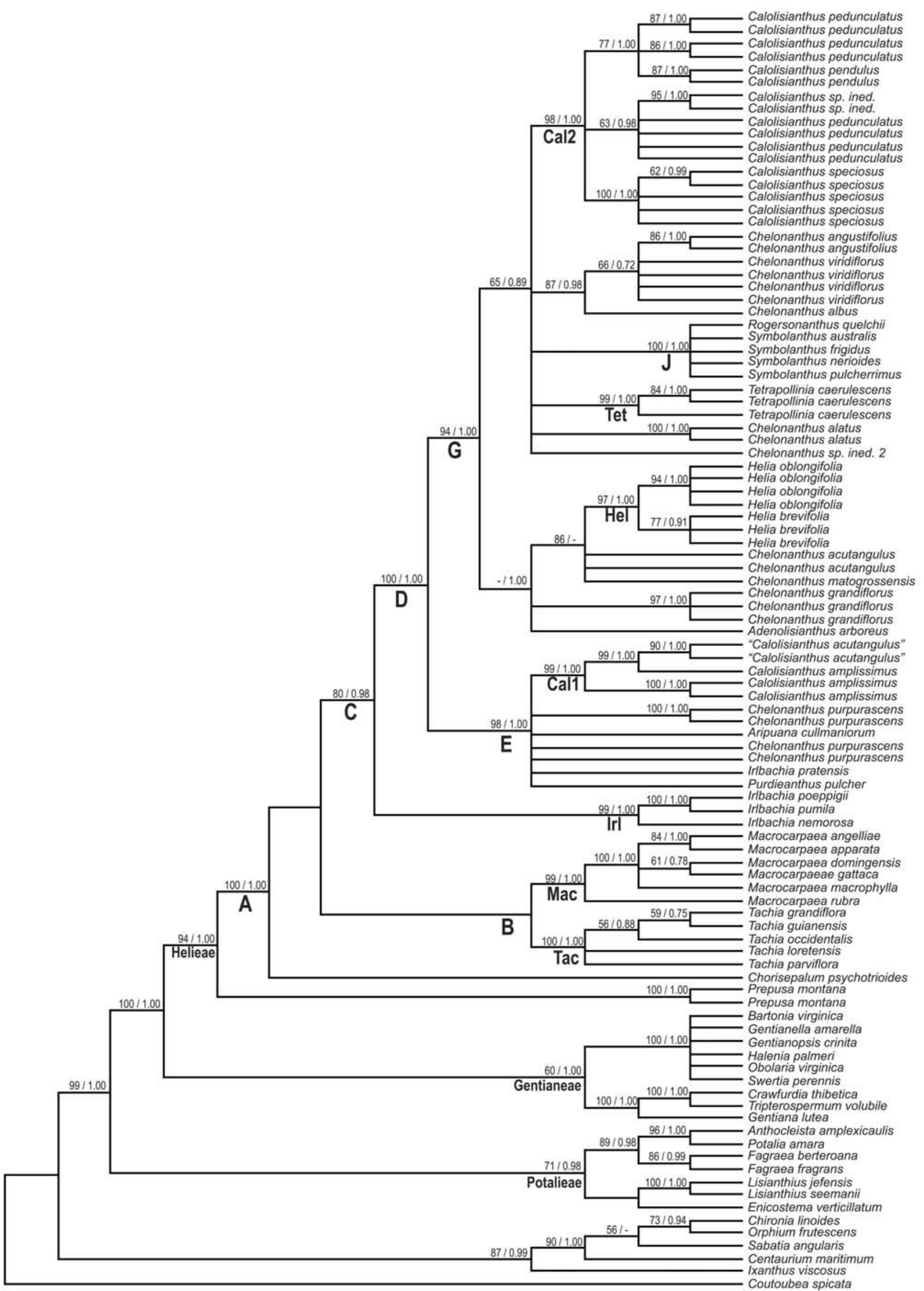

Fig. E5. Consenso estrito da análise de parcimônia da matriz "ITS com indels" (inclui apenas táxons com dados de ITS). Porcentagens de bootstrap e probabilidades posteriores de análise Bayesiana estão representadas sobre os ramos. Nomes informais entre aspas. 


\section{Apêndice $E$}

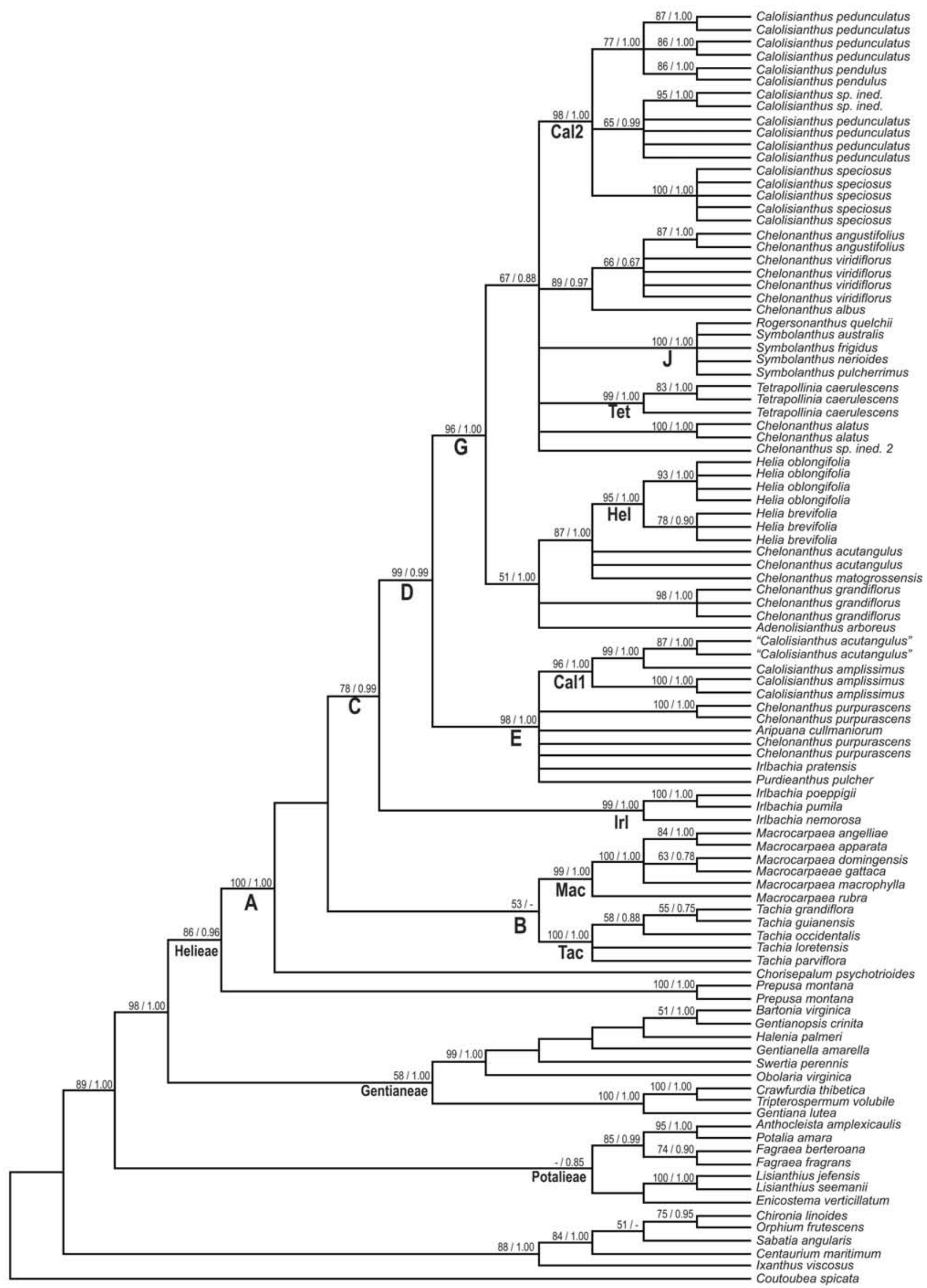

Fig. E6. Consenso estrito da análise de parcimônia da matriz "ITS sem indels" (inclui apenas táxons com dados de ITS). Porcentagens de bootstrap e probabilidades posteriores de análise Bayesiana estão representadas sobre os ramos. Nomes informais entre aspas. 


\section{Apêndice $E$}

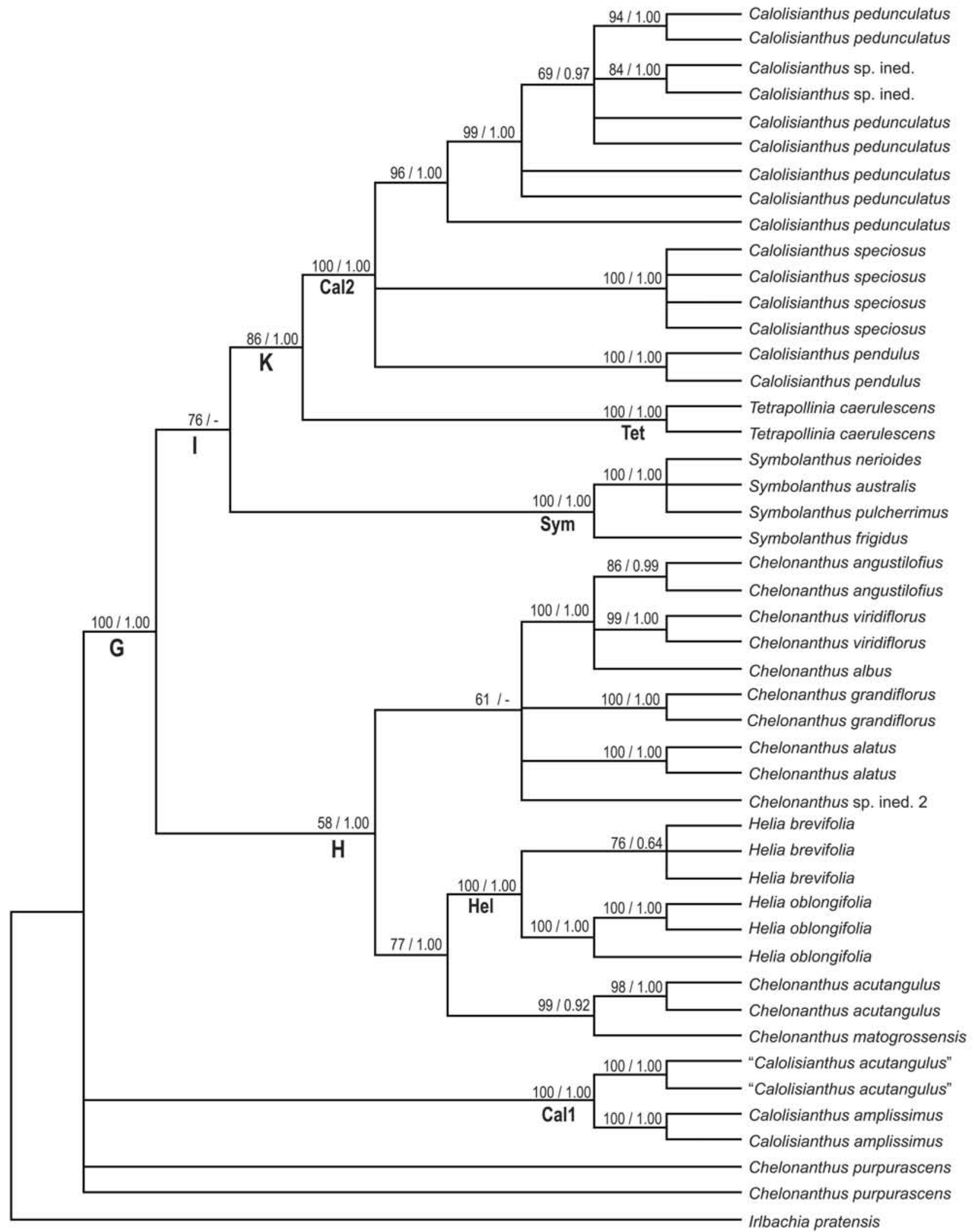

Fig. E7. Consenso estrito da análise de parcimônia da matriz "5S-NTS com indels" (inclui apenas táxons com dados de 5S-NTS). Porcentagens de bootstrap e probabilidades posteriores de análise Bayesiana estão representadas sobre os ramos. Nomes informais entre aspas. 


\section{Apêndice $E$}

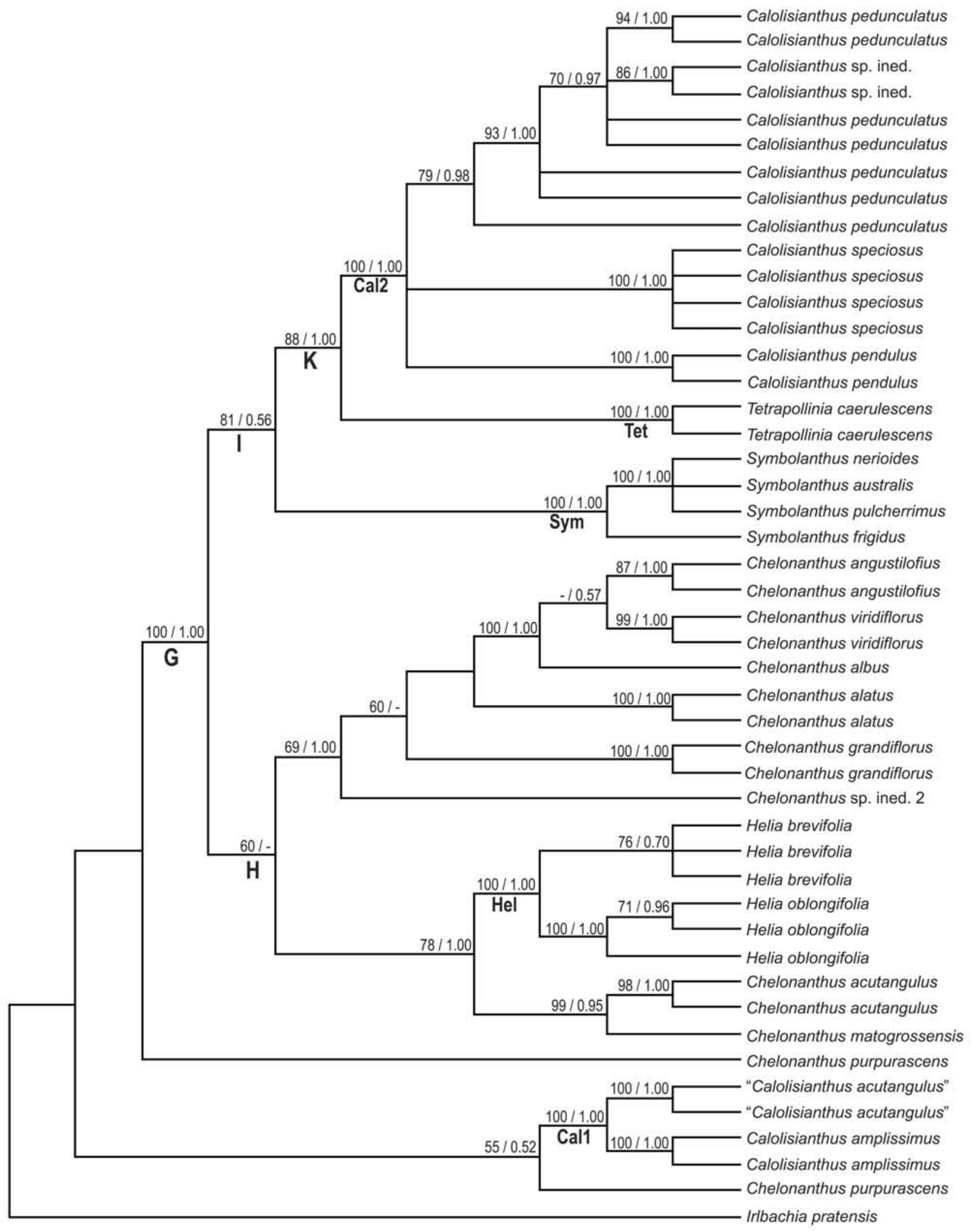

Fig. E8. Consenso estrito da análise de parcimônia da matriz "5S-NTS sem indels" (inclui apenas táxons com dados de 5S-NTS). Porcentagens de bootstrap e probabilidades posteriores de análise Bayesiana estão representadas sobre os ramos. Nomes informais entre aspas. 


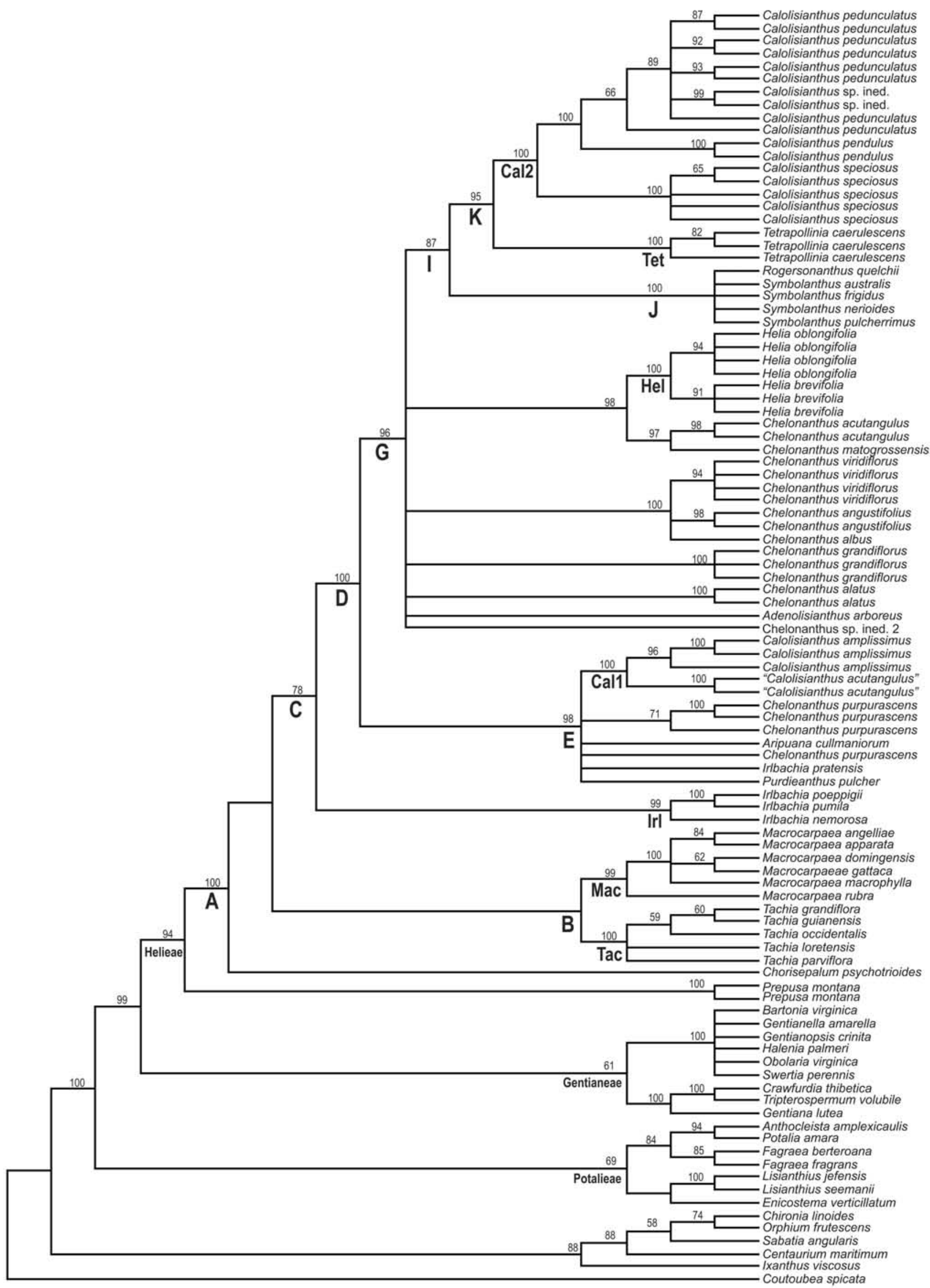

Fig. E9. Consenso estrito da análise de parcimônia da matriz "Combinada Molecular Média com indels", i.e., incluindo apenas dados moleculares, e somente táxons com dados para ao menos uma das partições moleculares. Porcentagens de bootstrap e probabilidades posteriores de análise Bayesiana estão representadas sobre os ramos. Nomes informais entre aspas. 


\section{Apêndice $E$}

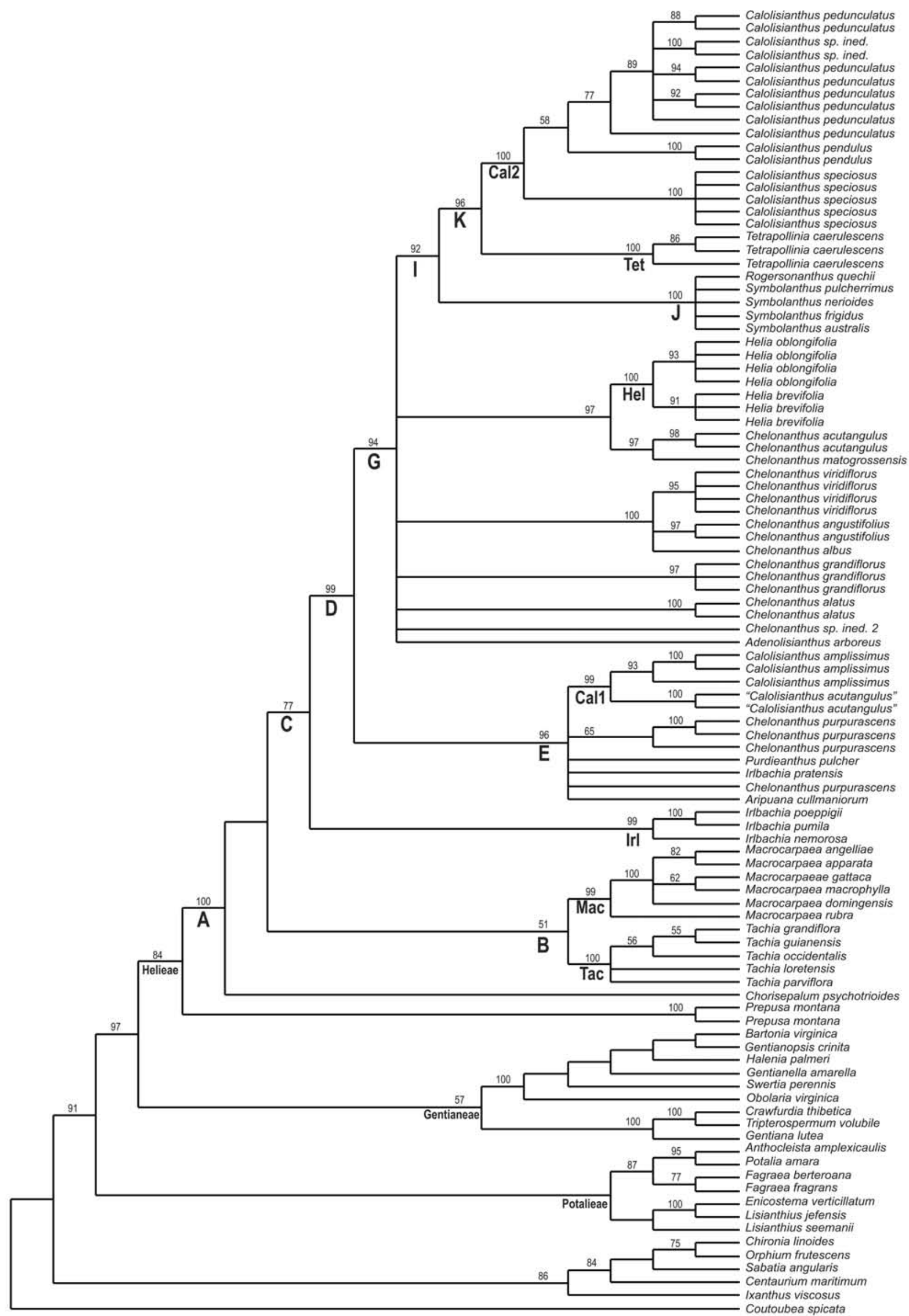

Fig. E10. Consenso estrito da análise de parcimônia da matriz "Combinada Molecular Média sem indels", i.e., incluindo apenas dados moleculares, e somente táxons com dados para ao menos uma das partições moleculares. Porcentagens de bootstrap e probabilidades posteriores de análise Bayesiana estão representadas sobre os ramos. Nomes informais entre aspas. 


\section{Apêndice $E$}

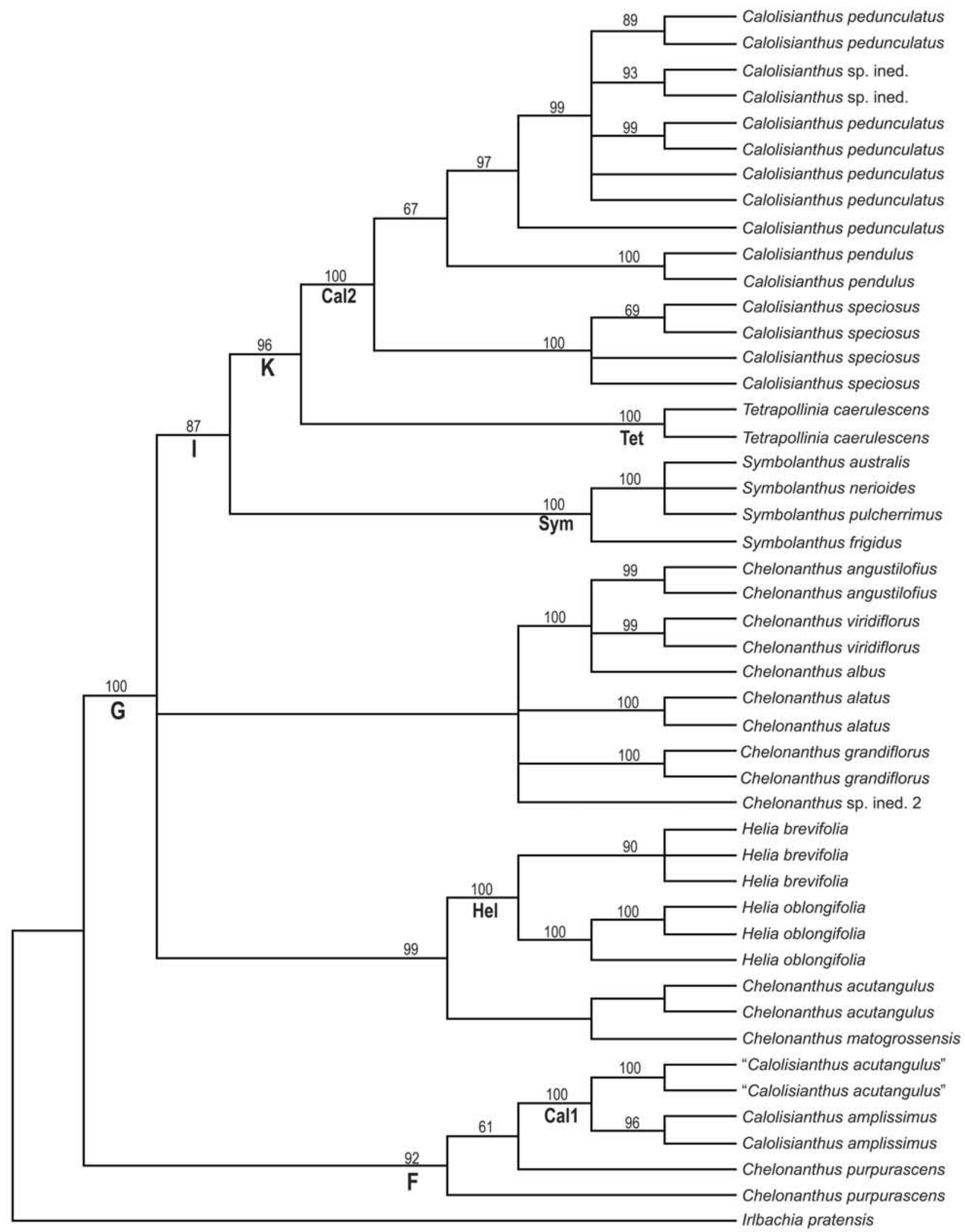

Fig. E11. Consenso estrito da análise de parcimônia da matriz "Combinada Molecular Pequena com indels", i.e., incluindo apenas dados moleculares, e somente táxons com dados para as duas partições moleculares. Porcentagens de bootstrap e probabilidades posteriores de análise Bayesiana estão representadas sobre os ramos. Nomes informais entre aspas. 


\section{Apêndice $E$}

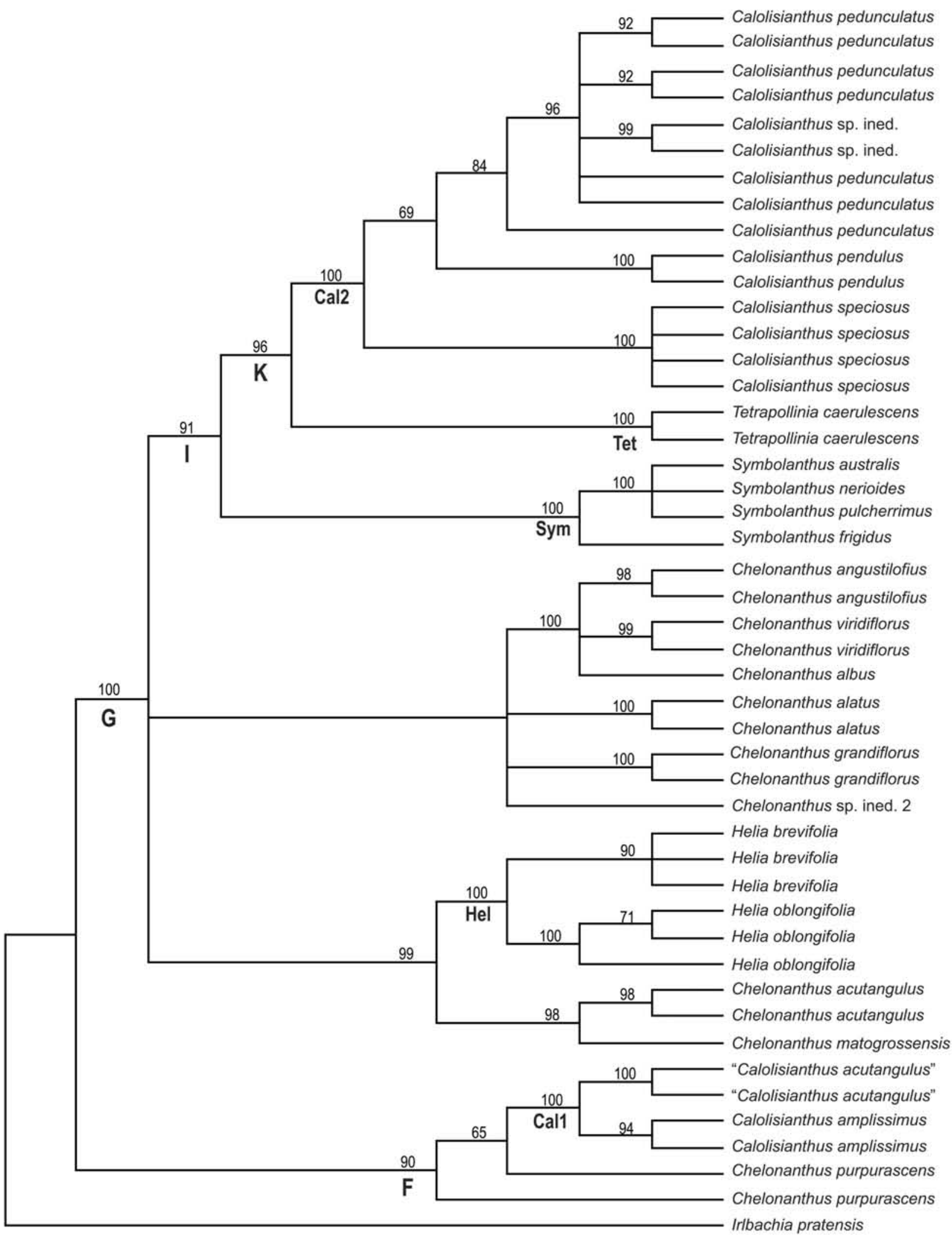

Fig. E12. Consenso estrito da análise de parcimônia da matriz "Combinada Molecular Pequena sem indels", i.e., incluindo apenas dados moleculares, e somente táxons com dados para as duas partições moleculares. Porcentagens de bootstrap e probabilidades posteriores de análise Bayesiana estão representadas sobre os ramos. Nomes informais entre aspas. 


\section{- Capítulo 4}

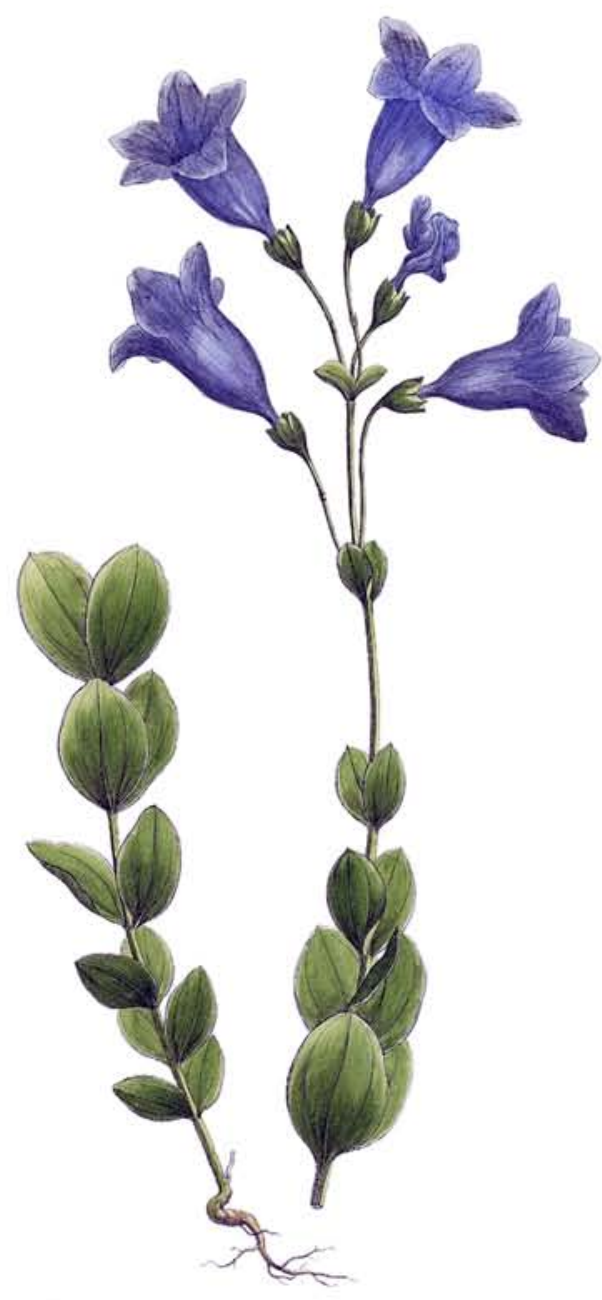

LISIANTHUS INFLATUS

EXTRAIDO DE NOVA GENERA ET SPECIES PLANTARUM

Nova lectotipificação de Calolisianthus Gilg

(Helieae, Gentianaceae) 


\title{
CAPÍTULO 4
}

\section{Nova lectotipificação de Calolisianthus Gilg (Helieae, Gentianaceae) ${ }^{1}$}

\begin{abstract}
The existing lectotypification of Calolisianthus Gilg is questioned. It is proposed that this lectotype is rejected and superseded by the designation of a new lectotype, based on a) conflict with the protologue; b) necessity of avoiding describing a new genus or synonymizing Calolisianthus species under other generic names; and c) maintenance of the name associated to a traditional generic concept.
\end{abstract}

Key words Calolisianthus, Gentianaceae, Helieae, new lectotypification, nomenclature

\section{Resumo}

A lectotipificação de Calolisianthus Gilg é questionada. Propõe-se que esse lectótipo seja rejeitado e substituído pela designação de um novo lectótipo, com base nos seguintes argumentos: a) conflito com o protólogo; b) necessidade de evitar a descrição de um novo gênero ou sinonimizações das espécies de Calolisianthus sob outros nomes genéricos; c) manutenção do uso do nome associado a um conceito genérico tradicional.

Palavras-chave Calolisianthus, Gentianaceae, Helieae, nomenclatura, nova lectotipificação

O gênero Calolisianthus foi estabelecido por Gilg (1895) com base em Lisianthus sect. Calolisianthus Griseb. (1839). Segundo a descrição apresentada por Gilg, uma das principais características que diferencia Calolisianthus dos demais gêneros proximamente relacionados é o pólen liberado em tétrades e apresentando "exina uniformemente macrorreticulada e espessada". Esta condição diferencia-se, por exemplo, da "exina microrreticulada, parecendo perfurada" em Helia Mart., "exina microrreticulada e com numerosos espinhos alongados e pontiagudos" em Irlbachia Mart., e da "exina espessada e macrorreticulada nas laterais e microrreticulada na região superior" em Symbolanthus (Gilg, 1895). O gênero Calolisianthus foi originalmente circunscrito com 6 espécies brasileiras $-C$. amplissimus (Mart.) Gilg., C. speciosus (Cham. \& Schltdl.) Gilg, C. pendulus (Mart.) Gilg, C. pulcherrimus (Mart.) Gilg, C. pedunculatus (Cham. \& Schltdl.) Gilg., C. acutangulus (Mart.) Gilg. - e uma espécie das Antilhas, C. frigidus (Sw.) Gilg, que atualmente é tratada como

\footnotetext{
${ }^{1}$ A ser submetido ao periódico internacional Taxon.
} 
uma espécie de Symbolanthus (Struwe \& Gould, 2004). Apesar da instabilidade quanto às delimitações dos gêneros de Helieae, tribo à qual pertence Calolisianthus, circunscrições mais estreitas vêm sendo favorecidas pelos pesquisadores dessa tribo (e.g. Struwe \& al., 1997; Struwe \& al., 2002).

Pringle (1995), em seu tratamento sobre as Gentianaceae do Equador, adotou a ampla circunscrição genérica proposta por Maas (1985), que sinonimizou uma série de gêneros em Irlbachia Mart., inclusive Calolisianthus (vide Struwe \& Albert, 1998 para discussões sobre a ilegitimidade dessa proposta). Apesar de Calolisianthus não ocorrer no Equador e, conseqüentemente, não ter sido alvo de seu estudo, ao elaborar o cabeçalho do gênero Irlbachia, Pringle formalizou a tipificação de Calolisianthus, com a escolha da espécie C. amplissimus (Mart.) Gilg como lectótipo.

Estudos sobre a morfologia polínica de gêneros de Gentianaceae mostraram que $C$. amplissimus possui pólen liberado em políades e com exina macrorreticulada portando muro elevado e com alças (Nilsson, 2002). Durante a elaboração da revisão taxonômica de Calolisianthus (Calió \& Pirani, em prep., Cap. 5), evidenciou-se que a escolha por $C$. amplissimus como lectótipo contrariava diretamente o protólogo do gênero, principalmente devido à distinta morfologia polínica. Há também outras características que diferenciam $C$. amplissimus das demais espécies de Calolisianthus: a presença de grandes alas no caule ( $\times$ pequena alas ou costelas), folhas membranáceas ( $\times$ folhas coriáceas), hábito herbáceo sem lenhosidade na base ( $x$ hábito subarbustivo a herbáceo com lenhosidade na base) e ocorrência em locais mais úmidos e sombreados (x locais mais secos e expostos diretamente ao sol). Todas essas características já indicavam a necessidade de tratar $C$. amplissimus, além de C. acutangulus (Mart.) Gilg, separadamente das demais. Além disso, estudos filogenéticos com dados morfológicos e moleculares refutaram a monofilia de Calolisianthus em sua circunscrição tradicional: C. amplissimus e C. acutangulus agruparam-se com a espécie-tipo de outro gênero (Chelonanthus purpurascens) enquanto que as demais espécies emergiram como uma linhagem independente em outro clado, e proximamente relacionadas aos gêneros Symbolanthus e Tetrapollinia (Calió \& al., em prep., Cap. 3). A relação entre Ch. purpurascens, $\mathrm{Ca}$. amplissimus e $\mathrm{Ca}$. acutangulus é fortemente sustentada, sendo que os grãos de pólen liberados em políades e a exina com alças configuram-se como sinapomorfias morfológicas que caracterizam o clado formado por essas espécies (Calió \& al., em prep., Cap. 3).

Vale ressaltar ainda que a conseqüência da manutenção da lectotipificação proposta por Pringle (1995) seria a necessidade de associar as demais espécies de Calolisianthus a outro nome genérico, utilizando um já existente (Symbolanthus ou Tetrapollinia, devido ao relacionamento filogenético próximo) ou criando um nome novo. De fato, essas espécies exibem atributos morfológicos que as distinguem de Symbolanthus e Tetrapollinia, e que, 
em um contexto filogenético, configuram-se como possíveis sinapomorfias que justificam a atribuição de status genérico às mesmas. Entretanto, considerando-se que essas espécies de Calolisianthus pertencem à Helieae - tribo conhecida por seus complicados problemas nomenclaturais (Struwe \& Albert, 1998; Weaver, 1972; Zijlstra \& al., 1999) causados principalmente pelas grandes variações quanto às delimitações de seus gêneros (e.g. Grisebach, 1839, 1845; Kuntze, 1891; Gilg, 1895; Maas, 1985) -, transferi-las para outros gêneros ou até mesmo criar um novo nome genérico é absolutamente desvantajoso e contrário aos interesses de maior estabilidade nomenclatural.

Por fim, devido às características morfológicas e ecológicas explicitadas acima, o uso do conceito genérico Calolisianthus não está associado a $C$. amplissimus (e $C$. acutangulus), mas sim às demais espécies do gênero.

Desta forma, argumenta-se em favor de uma nova lectotipificação de Calolisianthus, com base em três argumentos: a) há discordância entre o protólogo do gênero e a espécie escolhida por Pringle (1995) como lectótipo (art. 10.5b, CINB); b) evitar a descrição de um novo gênero ou transferências para outros gêneros para acomodar os binômios de Calolisianthus, em uma tribo já notória pela proliferação e confusão nomenclatural; e c) manutenção do uso do nome Calolisianthus associado a um conceito genérico tradicional e bem difundido, que envolve atributos morfológicos e ecológicos característicos.

Escolhemos C. speciosus para a nova lectotipificação do gênero Calolisianthus, pois, além de não contradizer o protólogo e corresponder ao conceito do gênero, historicamente essa espécie não teve problemas associados ao uso de seu nome, além de ser facilmente identificável.

Calolisianthus Gilg in Engler \& Prantl Nat. Pflanzenfam. 4(2): 99.1895 - Tipo: Calolisianthus speciosus (Cham. \& Schltdl.) Gilg (novo lectótipo, aqui designado).

\section{Referências bibliográficas}

Calió, M.F. \& Pirani, J.R., em prep. Revisão de Calolisianthus Gilg (Helieae, Gentianaceae), um gênero endêmico dos campos rupestres e cerrados no Brasil. A ser submetido a Taxon.

Calió, M.F., Pirani, J.R. Struwe, L. \& Lepis, K.B., em prep. Estudo filogenético de Helieae (Gentianaceae) com ênfase nos limites genéricos de Calolisianthus Gilg, Chelonanthus Gilg e Helia Mart., baseado em dados moleculares e morfológicos. A ser submetido a Molecular Phylogenetics and Evolution. 
ICBN, 2006. McNeill, J., Barrie, F.R., Burdet, H.M., Demoulin, V., Hawksworth, D.L., Marhold, K. Nicolson, D.H., Prado, J., Silva, P.C., Skog, J.E., Wiersema, J.H. \& Turland, N.J. (eds.), International Code of Botanical Nomenclature (Vienna Code) adopted by the Intrenational Botanical Congress Vienna, Austria, July 2005, A.R.G. Gantner Verlag, Ruggel Liechtenstein.

Gilg, E. 1895. Gentianaceae. Pp. 50-108 in: Engler, H.G.A. \& Prantl, K.A.E. (eds.), Die natürlichen Pflanzenfamilien, vol. 4(2). Verlag von Wilhem Engelmann, Leipzig.

Grisebach, A.H.R. 1839 [1838]. Genera et species plantarum. J.G. Cotta, Stuttgart and Tübingen.

Grisebach, A.H.R. 1845. Gentianaceae. Pp. 39-141 in: Candolle, A. de (ed.), Prodromus systematis naturalis regni vegetabilis, vol. 9. Fortin, Masson, et Sociorum, Paris.

Kuntze, C.E.O. 1891. Revisio generum plantarum, vol. 2. Arthur Felix, Leipzig.

Maas, P.J.M. 1985. Nomenclatural notes on neotropical Lisyantheae (Gentianaceae). Proc. Kon. Ned. Akad. Wetensch. C 88: 405-412.

Nilsson, S. 2002. Gentianaceae - a review of palynology. Pp. 377-497 in: Struwe, L. \& Albert, V.A. (eds.), Gentianaceae - systematics and natural history. Cambridge University Press, Cambridge.

Pringle, J.S. 1995. Family 159A. Gentianaceae. Pp. 1-131 in: Harling, G.\& Andersson, L. (eds.), Flora of Ecuador, vol. 53. Department of Systematic Botany, Gothenburg University, Göteborg.

Struwe, L. \& Albert, V.A. 1998. Lisianthius P.Br., its probable homonym Lisyanthus Aubl. (Gentianaceae) and the priority of Helia Mart. over Irlbachia Mart. as its substitute. Harvard Pap. Bot. 3(1): 67-71.

Struwe, L. \& Gould, K. 2004. Redefinition of Symbolanthus to include Wurdackanthus (Gentianaceae - Helieae). Novon 14: 354-359.

Struwe, L., Kadereit, J., Klackenberg, J., Nilsson, S., Thiv, M., von Hagen, K.B. \& Albert, V.A. 2002. Systematics, character evolution and biogeography of Gentianaceae, including a new tribal and subtribal classification. Pp. 21-309 in: Struwe, L. \& Albert, V.A. (eds.), Gentianaceae - Systematics and Natural History. Cambridge University Press, Cambridge.

Struwe, L., Maas, P.J.M. \& Albert, V.A. 1997. Aripuana cullmaniorum, a new genus and species of Gentianaceae from white-sands of southeastern Amazonas, Brazil. Harvard Pap. Bot. 2(2): 235-253.

Weaver, R.E., Jr. 1972. A revision of the neotropical genus Lisianthius (Gentianaceae). J. Arnold Arb. 53: 76-100, 234-272, 273-311.

Zijlstra, G., Maas, P.J.M., Gandhi, K. 1999. On the nonexistence of Lisyanthus Aublet. Harvard Pap. Bot. 4(1): 289-292. 


\section{- Capítulo 5}

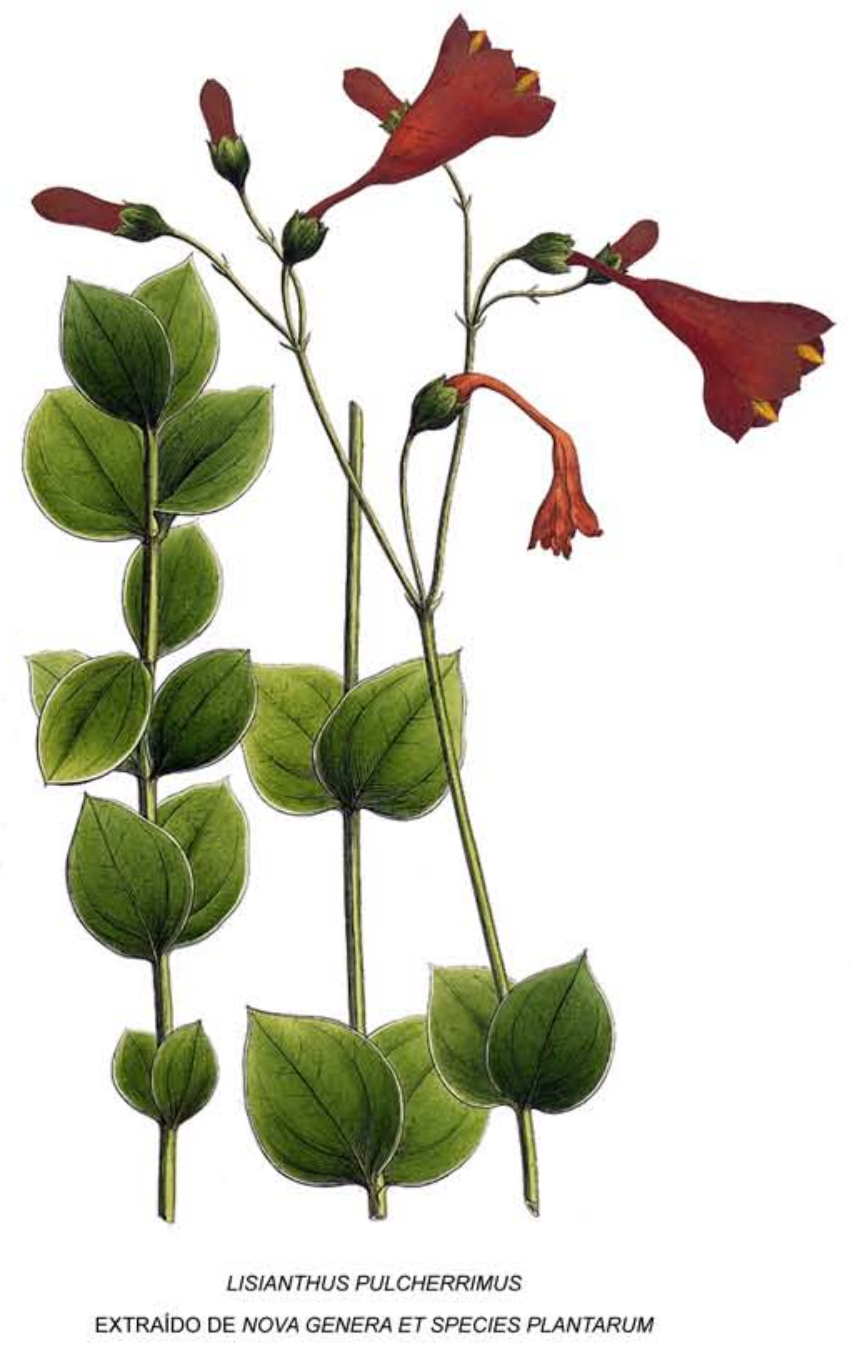

Revisão de Calolisianthus Gilg (Helieae, Gentianaceae), um Gênero endêmico dos campos RUPESTRES E CERRADOS NO BRASIL 


\title{
CAPÍTULO 5
}

\section{Revisão de Calolisianthus Gilg (Helieae, Gentianaceae), um gênero endêmico dos campos rupestres e cerrados no Brasil ${ }^{1}$}

\begin{abstract}
The genus Calolisianthus Gilg (Helieae, Gentianaceae) formerly encompassed 6-10 species, but as a result of molecular and morphological studies, 4 species are now recognized. These are endemic to campos rupestres and cerrados in Brazil. The genus is characterized by herbaceous to subshrubby habit, by pink, red, purple-blue or lilac flowers, and by shedding pollen in reticulate tetrads with islands of coarse reticulum. Taxonomic key, morphological descriptions, illustrations, distribution maps, and comments about conservation status are provided.
\end{abstract}

Key words Calolisianthus, distribution, morphology, nomenclature, revision, typification

\section{Resumo}

O gênero Calolisianthus Gilg (Helieae, Gentianaceae) constituía-se de 6-10 espécies, mas como resultado de estudos moleculares e morfológicos, 4 espécies são agora reconhecidas. Estas são endêmicas dos campos rupestres e cerrados do Brasil. O gênero é caracterizado pelo hábito herbáceo a subarbustivo, pelas flores de cor rosa, vermelha, roxo-azulada ou lilás e por tétrades polínicas com exina reticulada, apresentando ilhas de retículo mais espessado. São apresentados chave de identificação, descrições morfológicas, ilustrações, mapas de distribuição e comentários sobre o status de conservação de cada espécie.

Palavras-chave Calolisianthus, distribuição, morfologia, nomenclatura, revisão, tipificações

\section{Introdução}

Gentianaceae é uma família de Angiospermas com cerca de 87 gêneros e 1690 espécies (Struwe \& al., 2002). São reconhecidas 6 tribos monofiléticas (Struwe \& al., 2002), sendo que Helieae é uma das mais diversas quanto à sua morfologia e uma das maiores em número de gêneros (Struwe \& al., 2009), representando mais de $50 \%$ do total de gêneros presentes na região Neotropical (Calió, 2009). Essa tribo tem uma história nomenclatural

\footnotetext{
${ }^{1}$ A ser submetido ao periódico internacional Taxon.
} 
complexa (Struwe \& Albert, 1998; Zijlstra \& al., 1999), com grandes alterações quanto à circunscrição de seus gêneros, ora bastante abrangentes (Lisyanthus/Lisianthus em Grisebach, 1839, 1845; Helia em Kuntze, 1891; Irlbachia em Maas, 1985), ora mais estreitos (Gilg, 1895; Maguire, 1981, 1985; Maguire \& Boom, 1989; Struwe \& al., 1997). Estudos filogenéticos evidenciaram a possibilidade de categorizar a diversidade morfológica, geográfica e ecológica da tribo por meio da aceitação de gêneros estreitamente circunscritos, sendo assim reconhecidos vinte e três gêneros (Struwe \& al., 2002, 2009).

Calolisianthus Gilg é um desses gêneros e, em sua circunscrição tradicional, compreendia 6-10 espécies de ervas e subarbustos distribuídos em áreas de cerrado e campos rupestres, na região centro-leste do Brasil, com ocorrências esparsas no leste da Bolívia. Calolisianthus nunca foi alvo de revisão, mas foi abordado em diversos trabalhos de cunho florístico, tanto sobre regiões bastante restritas, como Serra do Cipó e Grão-Mogol em Minas Gerais (Cordeiro 1987, 2004), Mucugê e Pico das Almas na Bahia (Harley \& Simmons, 1986; Harvey, 1995) e Parque do Ipiranga no município de São Paulo (Cordeiro, 1983), quanto sobre áreas mais amplas, como as listas e floras dos estados de São Paulo (Angely, 1971; Cordeiro, 2005), Santa Catarina (Fabris \& Klein, 1971) e Paraná (Angely, 1965). O tratamento mais completo foi o de Progel (1865), que envolveu todas as Gentianaceae do território brasileiro.

Recentemente, resultados de análises filogenéticas baseadas em dados morfológicos e moleculares refutaram o monofiletismo de Calolisianthus em sua circunscrição até então aceita (Calió \& al., em prep., Cap. 3). Resumidamente, a espécie que havia sido designada como lectótipo do gênero (Pringle, 1995) agrupou-se com a espécie-tipo de outro gênero (Chelonanthus purpurascens), enquanto que as demais espécies emergiram como uma linhagem independente em outro clado, e proximamente relacionadas aos gêneros Symbolanthus e Tetrapollinia. Havia quatro diferentes maneiras de lidar com esse resultado: a) criar um novo gênero para acomodar essas espécies que emergiram no clado com Symbolanthus e Tetrapollinia; b) sinonimizar essas espécies em Tetrapollinia; c) sinonimizar essas espécies e Tetrapollinia em Symbolanthus; ou d) escolher um novo lectótipo para o gênero dentre essas espécies, e, dessa forma, manter o nome Calolisianthus vinculado às mesmas. A nova lectotipificação foi o caminho escolhido, não apenas por ser a opção mais concordante com os interesses de estabilidade nomenclatural mas também pela constatação de que o lectótipo escolhido por Pringle (1995) para Calolisianthus está em conflito com o protólogo (Calió \& Pirani, em prep., Cap. 4).

O objetivo deste capítulo é, com base nessa nova lectotipificacão, apresentar a revisão do gênero Calolisianthus em sua nova circunscrição, incluindo descrições morfológicas, ilustrações, mapas de distribuição geográfica e informações sobre status de conservação e fenologia. 


\section{Materiais e Métodos}

O estudo morfológico baseou-se na análise de material vivo durante as expedições de coleta e de material dos seguintes herbários (exsicatas ou fotos): ALCB, BHCB, CHRB*, CEN, CEPEC, CESJ*, CTES, E, ESA*, F, G, GUA, HAL, HB*, HRB, HUCS (não indexado), HUEFS, HUFU, HXBH, IAC, IBGE, IPA, K, L, LIL, LP, M, MBM*, NY*, P, PMSP*, R*, RB*, RBR, RUSU, SJRP, SP*, SPF*, SPFR, SPSF*, U, UB, UEC*, UFG, UPCB*, US*, VIC, W* (* indica herbários visitados). Materiais-tipo dos herbários $E, F$ (B phototypes), HAL, K, M, P foram analisados apenas por meio de fotos. Uma listagem de todos os materiais examinados encontra-se no Apêndice A.

A observação detalhada do material foi feita sob microscópio estereoscópico SZ Olympus. Somente estruturas completamente desenvolvidas foram medidas e, para tanto, foram utilizados o retículo milimétrico do microscópio para estruturas diminutas e paquímetro para estruturas maiores que $1 \mathrm{~cm}$. Flores foram re-hidratadas com gotas de glicerina por cerca de 40 segundos em forno de microondas, anteriormente às medições. As formas de estruturas foram descritas segundo Radford \& al. (1974), os padrões de venação, segundo Hickey (1979) e tipologia de inflorescências, segundo Weberling (1989). Dados sobre o status de conservação são fornecidos com base nos critérios da IUCN (2001).

Devido a dificuldades em se descrever certas estruturas e para garantir compreensão da descrição morfológica, foi proposta uma padronização da terminologia utilizada. O par de profilos (estruturas foliares foliáceas ou escamiformes mais próximas da base do cálice) é denominado como "bractéolas". A estrutura caulinar compreendida entre a base do cálice e a "bractéola" é denominada "pedicelo". As estruturas foliares subtendendo várias flores agrupadas ou, no caso das flores solitárias, abaixo do par de "bractéolas" (em direção à base) são denominadas "brácteas", sendo estas estruturas foliáceas ou escamiformes.

As coordenadas para elaboração de mapas de distribuição geográfica foram obtidas a partir de medições locais (informadas nas etiquetas das exsicatas) ou por meio de georreferenciamento posterior, que tomou por base o município em que foi coletado o material. Os mapas foram elaborados com o programa ArcGIS 9.2 (ESRI, 2006).

\section{Resultados e Discussão}

Morfologia. - O estudo detalhado de espécimes de Calolisianthus permitiu o aumento do conhecimento acerca da morfologia do gênero; atributos característicos do gênero e de cada espécie apresentam-se ilustrados nas figuras de 1 a 7 . As espécies do 
gênero Calolisianthus caracterizam-se por serem ervas com base lenhosa a subarbustos, inteiramente glabros. A porção aérea da planta (ou em alguns casos aparentemente toda ela) morre após a floração e frutificação, sendo que o estudo de indivíduos no campo mostrou a presença de um rizoma simpodial, do qual brota um ramo com folhas, flores ou frutos, e um ou mais restos de ramos antigos, provavelmente remanescentes de outros ramos que um dia também floresceram, frutificaram e morreram (assim como o padrão descrito por Bell, 1991). Com base nisso, é muito provável que essas plantas sejam perenes, porém com ramos monocárpicos anuais. A porção aérea do caule é sempre verde e cilíndrica, embora pareça quadrangular ao toque. Isso se deve à presença de quatro costelas ou pequenas alas que se prolongam a partir da linha estipular até o nó imediatamente inferior (e.g. Fig. 2A).

As folhas dispõem-se ao longo do caule de modo bastante característico, apresentando-se mais agrupadas na porção basal do caule e mais distanciadas entre si em direção ao ápice (Fig. 4A). Além disso, variam em tamanho, sendo muito pequenas na base (freqüentemente difíceis de serem observadas), aumentando e depois reduzindo gradualmente seu tamanho em direção ao ápice, de modo que as folhas na porção mediana do caule são maiores do que as da base e do ápice da planta. As folhas são opostas e unidas por uma linha estipular típica de Gentianales. São sempre verdes e lustrosas ao menos na face adaxial, levemente discolores, de textura carnosa e com margem hialina. Em muitos casos, a nervura central na face abaxial é bem proeminente e prolonga-se um pouco além da base da folha, formando uma pequena quilha ou ala. Apresentam a base curtopeciolada ou, mais freqüentemente, séssil, com forma atenuada, arredondada ou cordiforme, enquanto o ápice varia entre arredondado a acuminado, podendo ou não ser mucronado (Figs. 2C-E). Na face abaxial, próximo à base, há nectários extra-florais, sempre conspícuos em C. speciosus (Fig. 4C), e pouco conspícuos (aparecendo como pequenas manchas de difícil delimitação) ou inconspícuos nas demais espécies. Estudos anatômicos detectaram a presença de tecido nectarífero em plantas cujo nectário não era conspícuo (Delgado, 2008). Formigas são usualmente observadas sobre essa área na base das folhas.

Nas plantas desse gênero, assim como em muitas outras Gentianaceae, a distinção entre porção vegetativa e porção reprodutiva é bastante complicada, de modo que não é possível estabelecer o limite basal da inflorescência. Freqüentemente, a porção caulinar que subtende as flores não apresenta costelas ou alas e sempre apresenta-se encimada por um par de estruturas foliáceas ou escamiformes (e.g. Figs. 5A e 5D; ver seção "Materiais e Métodos" para explicação da terminologia aplicada às mesmas). As flores são solitárias ou agrupadas em cimeiras dicasiais, freqüentemente paucifloras (Figs. 5D e 7B).

Os botões florais, sempre agudos no ápice (Fig. 1D), são eretos quando nascem, mas, com o desenvolvimento da flor, vão paulatinamente atingindo uma posição quase 
horizontal; em alguns casos, a flores maduras são pendentes. Tais diferenças quanto ao posicionamento dos botões e flores devem-se à angulação do pedicelo. O cálice, bastante característico de Helieae, é verde, coriáceo e apresenta usualmente cinco lobos com margens hialinas e uma região nectarífera na porção dorsal, sobre a qual freqüentemente são observadas formigas. Em materiais frescos, essa região apresenta-se como uma faixa brilhante, normalmente com coloração verde mais clara do que o resto do cálice (Fig. 6B); em materiais de herbário, essa região apresenta-se escurecida. Interiormente, o cálice apresenta uma série de coléteres, i.e. estruturas glandulares comuns a Gentianales (Fig. 2G). A corola pode ser campanulada, infundibuliforme ou hipocrateriforme (Figs. 7B, 5A, 6C, respectivamente) e apresenta coloração lilás a alva, roxo-azulada, vermelha ou rosa, sendo que guias de nectários podem ou não estar presentes. A corola é usualmente subcarnosa, mas a porção mais basal, que fica recoberta pelo cálice, é mais frágil e tem a forma levemente ovóide, pois envolve perfeitamente o ovário. Logo acima dessa porção recoberta pelo cálice, há uma região espessada, que internamente corresponde ao ponto de inserção dos estames. Essa região espessada pode ou não ser a porção mais estreita de toda a corola. No caso das corolas campanuladas e infundibuliformes, acima desse ponto, a corola alarga-se abruptamente. Os lobos da corola são usualmente cinco e variam quanto ao seu formato, dispondo-se horizontal ou perpendicularmente em relação ao tubo (Fig. 6B-C). A corola é actinomorfa. mas as estruturas reprodutivas apresentam-se agrupadas na porção inferior da corola (Fig. 5B).

O androceu heterodínamo é formado por cinco estames (usualmente), com filetes longos e delgados, cuja coloração varia entre verde, alva a amarelada ou rosada (Fig. 5C). As anteras são introrsas, recurvam-se após a antese, apresentam coloração variando entre alva a amarela, rosa ou verde, são dorsifixas, sagitadas na base e possuem um apêndice estéril no ápice (e.g. Fig. 2K). O pólen é liberado em tétrades e apresenta exina reticulada com ilhas de retículo mais espessado (Nilsson, 2002). O gineceu é formado por um ovário verde, súpero, bicarpelar, bilocular, com placentação parietal. $\mathrm{Na}$ base do ovário, há um tecido de textura diferenciada, que provavelmente é um disco nectarífero (e.g. Fig. 1K). A porção apical do ovário transforma-se gradualmente em um estilete cilíndrico, longo e delgado, que apresenta coloração variando de verde a amarela, alva ou lilás, encimado por dois lobos estigmáticos, carnosos e internamente papilosos, cuja coloração varia como a do estilete (Fig. 6E). Na fase final da vida da flor, provavelmente após a fecundação, o estilete apresenta-se comprimido e espiralado em seu comprimento. Estilete, corola e cálice são persistentes no fruto (Fig. 5A), que é uma cápsula acastanhada, com muitas sementes.

As sementes das espécies de Calolisianthus caracterizam-se por sua forma angulosa, retangular a cúbica, laterais levemente côncavas; a testa apresenta células convexas, com espessamentos em faixas ou reticulados (Bouman \& al., 2002). Não foram 
realizados estudos quanto à dispersão das sementes; entretanto, acredita-se que, apesar do tamanho diminuto, as sementes não sejam adaptadas à dispersão à longa distância.

Estudos sobre polinização com espécies desse gênero concluíram que a autopolinização espontânea é muito freqüente, devendo ser esse o principal mecanismo para produção de sementes (Freitas \& Sazima, 2009). Acredita-se que essa deva ser a principal estratégia de sobrevivência dessas espécies, pois habitualmente essas plantas não são encontradas formando populações. Grande parte do material de herbário observado apresenta etiquetas com os dizeres "rara", "escassa" ou "apenas um indivíduo"; além disso, poucas foram as vezes em que se observaram, em campo, populações extensas ou com muitos indivíduos.

Além do padrão único de ornamentação dos grãos de pólen, as espécies de Calolisianthus não apresentam sinapomorfias exclusivas que o caracterizem. Entretanto, poucos são os gêneros e espécies de Helieae que apresentam distribuição geográfica semelhante ou igual a das espécies de Calolisianthus, o que permite fácil identificação das plantas encontradas no Brasil. Somente seis gêneros da tribo, além de Calolisianthus, ocorrem no leste brasileiro: Chelonanthus, Helia, Macrocarpaea, Prepusa, Senaea e Tetrapollinia. Tetrapollinia é o gênero-irmão de Calolisianthus (vide capítulo 3 da presente Tese) e, apesar de apresentar flores lilases a alvas como algumas espécies de Calolisianthus, diferencia-se deste último pelo porte herbáceo, diminuto e delicado, sem lenhosidade na base; além disso, a única espécie de Tetrapollinia ocorre em áreas brejosas, onde não se encontra Calolisianthus. Também ocorrem em áreas brejosas as espécies de Helia, cujas corolas hipocrateriformes e de tubo muito estreito apresentam coloração creme a amarelo-esverdeadas. Quatro espécies de "Chelonanthus de flores verdes" (Ch. candidus, Ch. grandiflorus, Ch. matogrossensis e Ch. viridiflorus), além de ocorrerem em áreas brejosas, podem ser encontradas em áreas mais campestres, como as espécies de Calolisianthus; entretanto, diferem destas últimas pelo porte herbáceo sem crescimento secundário, e pela cor alva ou creme a esverdeada da corola e das folhas membranáceas. Além disso, tanto as espécies de Helia quanto essas quatro espécies de Chelonanthus apresentam botões florais com ápice arredondado. Chelonanthus purpurascens, assim como Calolisianthus, ocorre em áreas campestres e apresenta botões florais com ápice agudo e corola lilás; entretanto, a presença de folhas membranáceas em $C$. purpurascens, bem como sua ocorrência, em geral, em solos mais úmidos e próximos a cursos de água, permite a diferenciação em relação a Calolisianthus, posição sustentada por estudos filogenéticos (Calió \& al., em prep., Cap. 3). As espécies de Macrocarpaea ocorrem apenas em vegetações florestais e apresentam folhas pecioladas. Por fim, Prepusa e Senaea diferem de Calolisianthus por possuírem flores hexâmeras, com cálice membranáceo e inflado. Além dessas, convém mencionar duas espécies que foram tradicionalmente tratadas 
como Calolisianthus, mas que estão sendo excluídas desse gênero com base nos estudos filogenéticos: C. amplissimus e C. acutangulus (vide seção "Tratamento taxonômico"). Essas espécies apresentam corola lilás como $C$. speciosus, mas diferenciam-se desta última principalmente pela ausência de crescimento secundário, pelo caule alado, pela ausência de nectários extra-florais na base das folhas e pelos grãos de pólen liberados em políades.

Distribuição geográfica. - Infelizmente, apesar de se ter alcançado um mapeamento virtualmente completo da distribuição dessas espécies, não é possível apresentar uma abordagem histórica quanto à ocupação das diferentes regiões, devido, principalmente, ao desconhecimento acerca das relações filogenéticas entre essas espécies. Entretanto, o relato sobre os padrões de distribuição encontrados corrobora e complementa relatos de padrões já observados e descritos para outros grupos de plantas (e.g. Giulietti \& Pirani, 1988; Harley, 1988; Fiaschi \& Pirani, no prelo).

Calolisianthus compreende 4 espécies, todas endêmicas do Brasil. Ocorrem principalmente em áreas de altas altitudes, de Santa Catarina ao Tocantins, com maior expressão nas serras mineiras, baianas e goianas, que correspondem largamente à "Província biogeográfica do Cerrado" sensu Cabrera \& Willink (1980). Apesar da sobreposição das áreas de ocorrência, cada espécie apresenta um padrão de distribuição diferente. C. bellissimus, uma espécie nova, é a que tem endemismo mais restrito, sendo encontrada apenas na região do Ibitipoca e arredores (Fig. 8A; ver seção Tratamento Taxonômico para descrição da espécie). C. pendulus ocorre desde o Paraná até a porção sul (Minas Gerais) da Cadeia do Espinhaço (Fig. 9A). C. pedunculatus ocorre nas mesmas regiões que $C$. pendulus, mas estende-se à porção baiana da Cadeia do Espinhaço e às serras goianas (Fig. 8B). Essas três espécies são encontradas apenas em campos rupestres e, devido à disposição "insular" ou "em mosaico" dessa vegetação (Giulietti \& Pirani, 1988) ou "em arquipélago" (Prance, 1994), apresentam distribuição disjunta entre os diferentes conjuntos de serras. Por outro lado, C. speciosus, além de ocorrer em campos rupestres, é encontrada também em cerrados e, provavelmente por essa razão, apresenta distribuição praticamente contínua, ocupando uma faixa desde a porção mais meridional das serras mineiras até as serras goianas (Fig. 9B).

Conservação. - Apenas Calolisianthus bellissimus pode ser categorizada como espécie ameaçada segundo os critérios da IUCN (2001). Entretanto, é importante ressaltar que as espécies de Calolisianthus muito raramente são encontradas em locais perturbados, e que já foram, inclusive, extintas em algumas localidades. Por exemplo, as coletas mais recentes de $C$. pendulus e $C$. pedunculatus no município de São Paulo datam da década de 70 e, atualmente, tais localidades estão completamente urbanizadas. Isso indica que, 
apesar de não terem sido categorizadas diretamente como ameaçadas, as outras três espécies também possuem status de conservação preocupante, principalmente devido ao fato de ocorrerem em habitats ameaçados por atividades antrópicas e pouco protegidos por unidades de conservação (Klink \& Machado, 2005). Estimativas sobre desmatamento dos cerrados (que também incluem as áreas campestres) prevêem perda total dessa vegetação em cerca de 20 anos, o que caracteriza esse bioma como gravemente ameaçado (Machado \& al., 2004) e, indiretamente, classifica como ameaçadas as espécies endêmicas dessa formação vegetal. Particularmente, os campos rupestres, formação vegetal em que as quatro espécies são encontradas prioritária ou exclusivamente, destacam-se pelo grande número de espécies ameaçadas; dessa forma, áreas que apresentam essa formação vegetal também se caracterizam como áreas prioritárias para conservação e para desenvolvimento de estudos científicos (e.g. Costa \& al., 1998).

\section{Tratamento taxonômico}

Calolisianthus Gilg in Engler \& Prantl Nat. Pflanzenfam. 4(2): 99. 1895 - Tipo: Calolisianthus speciosus (Cham. \& Schltdl.) Gilg²

Ervas com base lenhosa a subarbustos, glabros. Caule cilíndrico, 4-costado, raramente 4alado. Folhas opostas, mais agrupadas na base do caule e tornando-se mais esparsas em direção ao ápice, verdes, glabras, carnosas, sésseis ou curto-pecioladas, margem inteira, plana, hialina; venação acródroma, nervuras primárias e secundárias conspícuas; nectários extra-florais na base da face abaxial, conspícous ou pouco evidentes. Inflorescência terminal, cimeira dicasial ou flores solitárias; brácteas e bractéolas escamiformes ou foliares, com margem hialina; bractéolas 1 par por flor ou ausentes nas flores terminais da inflorescência. Flores diclamídeas, heteroclamídeas, 5-meras, raramente 4-meras ou 6meras, actinomorfas, pediceladas. Cálice verde, urceolado, coriáceo, glabro; lobos levemente desiguais, com área glandular na região dorsal; prefloração imbricada; coléteres no interior do cálice. Corola rosa, vermelha, roxa a azulada ou lilás a alva, infundibuliforme, hipocrateriforme ou campanulada, geralmente com uma constrição na altura de inserção dos estames, alargando-se acima desse ponto, carnosa, glabra; prefloração contorcida. Estames 5 , heterodínamos, inclusos, epipétalos, inseridos entre 1/10 e 1/3 da porção inferior do tubo da corola; filetes filiformes; anteras dorsifixas, sagitadas na base, agudas no ápice, com

\footnotetext{
${ }^{2}$ Lectótipo apresentado com base na proposta de nova lectotipificação do gênero (Calió \& Pirani, em prep., Cap. 4.
} 
apêndice estéril, recurvadas na antese; pólen liberado em tétrades. Ovário súpero, verde, estilete longo e delgado, achatado quando seco; estigma bilamelado, lobos estreitamente elípticos/oblongos a elípticos/oblongos; placentação parietal; óvulos numerosos. Fruto cápsula, unilocular, 2-valvar, sementes numerosas; cálice, corola e estilete persistentes.

Etimologia. - "Calo" é um prefixo de origem grega que significa "bonito". Sendo assim, Calolisianthus significa "Lisianthus bonito" (para discussões sobre a origem etimológica do nome Lisianthus, ver Struwe \& Albert, 1998; e Zijlstra \& al., 1999). Em 1839, ao cunhar a palavra Calolisianthus, Grisebach não explicitou a razão para escolha do nome, mas apresentou na descrição a frase "floribus pulchre coloratis" (flores belamente coloridas). Em 1845, em um novo tratamento, Grisebach descreveu as mesmas plantas com a frase "floribus ... speciosis coeruleis v. coccineis" (flores chamativas azuis ou vermelhas). Dessa forma, supõe-se que o prefixo "calo" refira-se mesmo à beleza das flores.

\section{Chave para as espécies}

1. Folha com nectários extra-florais conspícuos na base abaxial da lâmina, ápice geralmente arredondado (raramente agudo); ápice dos lobos do cálice arredondado; corola campanulada, lobos da corola com margem erosa e ápice arredondado 4. C. speciosus

1'. Folha com nectários extra-florais inconspícuos ou pouco conspícuos na base abaxial da lâmina, ápice geralmente agudo a acuminado (raramente arredondado); ápice dos lobos do cálice geralmente agudo a acuminado (raramente arredondado); corola infundibuliforme ou hipocrateriforme, lobos da corola com margem inteira a levemente sinuada e ápice agudo a acuminado.

2. Costelas caulinares pouco evidentes, confundindo-se com estrias verticais resultantes da desidratação, ou, quando evidentes, não alcançam o nó inferior; folhas sempre sésseis; corola rosa 1. C. bellissimus

2'. Costelas ou alas caulinares bastante evidentes e sempre alcançando o nó inferior; folhas sésseis ou curto-pecioladas; corola vermelha, roxa ou azulada.

3. Base da folha atenuada, arredondada ou cordada; corola vermelha, tubo (22-)30$70 \mathrm{~mm}$ compr.; filetes $10-45 \mathrm{~mm}$ compr., anteras creme a amarelas 2. C. pedunculatus 
3'. Base da folha atenuada; corola roxa ou azulada, tubo 15.7-25(-36) $\mathrm{mm}$ compr.; filetes $4.3-12.5 \mathrm{~mm}$ compr., anteras alvas a róseas ou esverdeadas ..... 3. C. pendulus

1. Calolisianthus bellissimus Calió \& Pirani, sp. ined. - Tipo: "Brasil, Minas Gerais, Mun. Lima Duarte, Parque Estadual do Ibitipoca, beira da trilha do Morro do Cruzeiro", 20 Jan 2005, M.F. Calió, L.M. Bezerra, L.G. Temponi, L.C.S. Assis, R.F. Monteiro \& R.C. Forzza 87 - Holótipo: SPF!

Ervas lenhosas na base a subarbustos (mais freqüente), $40-70 \mathrm{~cm}$ alt. Caule $4-5.3 \mathrm{~mm}$ diâm. na base da planta, $1.3-5 \mathrm{~mm}$ diâm. abaixo das flores, internós 8-20 mm compr. na base, 11-130 mm compr. abaixo das flores; costelas $0.1-0.2 \mathrm{~mm}$ larg. Folhas sésseis, nectários extra-florais inconspícuos; lâmina estreitamente elíptica a elíptica, 33-73 × 8-24 $\mathrm{mm}$, base atenuada a longamente atenuada, ápice agudo a acuminado; 1-2 pares de nervuras secundárias, nervuras terciárias inconspícuas. Flores 1-10; brácteas foliáceas ou escamiformes, estreitamente elípticas a elípticas, lanceoladas a largamente ovadas, 4.2-51 $\times 1.2-18.5 \mathrm{~mm}$, base truncada ou atenuada a longamente atenuada, margem inteira, erosa ou levemente sinuada, ápice acuminado; bractéolas foliáceas ou escamiformes, estreitamente elípticas a elípticas, 4.5-25 × 1-10 mm, base truncada, margem inteira, erosa ou esparsamente denticulada, ápice agudo a acuminado; pedicelo 18-58 × 1-3 mm. Cálice 12.3-17 × 6-8.5 mm; tubo 2.5-7 mm compr.; lobos 5, estreitamente elípticos a elípticos, oblongos, ovados ou obovados, 7.5-12 × 3.8-6 mm, margem erosa, ápice agudo. Corola rosa, com guias de nectários alvescentes, ápice dos lobos alvescente a esverdeado, infundibuliforme, $50-59 \mathrm{~mm}$ compr., 3.1-4.8 vezes maior que o cálice; tubo $34-41 \mathrm{~mm}$ compr., 3.5-4.5 mm larg. na base, 3-5.8 mm larg. abaixo da inserção dos estames, 10-12 $\mathrm{mm}$ larg. no ápice; lobos 5, elípticos a largamente elípticos ou ovados a largamente ovados, 13-20.1 × 9-13 mm, margem plana, inteira a levemente sinuada, ápice agudo, raramente apiculado, apículo 0.8-1 mm compr. Estames 5; filetes verdes na base tornando-se alvos em direção ao ápice, 19-24 mm compr.; anteras alvas a creme, estreitamente oblongas, 5.6-6.7 × 1-1.5 mm, apêndice estéril 0.4-1 mm compr. Ovário estreito-ovóide a ovóide, 8$12 \times 4.5-6 \mathrm{~mm}$; estilete verde na base tornando-se alvo em direção ao ápice, 20-22 × 0.5$1.2 \mathrm{~mm}$; lobos do estigma amarelados a esverdeados, estreitamente elípticos a elípticos, 4$6 \times 1.3-2.5 \mathrm{~mm}$. Fruto estreito-ovóide a ovóide , 21-24 × 7-10 mm. (Fig. 1, Fig. 5A-C).

Etimologia. - A escolha do epíteto específico baseou-se na bela aparência das flores, muito vistosas e chamativas. 
Distribuição, habitat e conservação. - A espécie é encontrada em camposrupestres, entre 1400 e 1600 m de altitude, principalmente na região do Parque Estadual do Ibitipoca e com uma ocorrência em São Tomé das Letras, em Minas Gerais (Fig. 8A). Devido à sua distribuição muito restrita, essa espécie é categorizada como "em perigo crítico" segundo os critérios da IUCN (2001).

Morfologia e fenologia. - Os espécimes de herbário analisados estavam todos identificados como Calolisianthus pedunculatus ou C. pulcherrimus. Entretanto, ao se observar em maior detalhe as características de tais materiais, bem como exemplares frescos, constatou-se a necessidade de tratá-los como uma espécie à parte. Difere das demais espécies desse gênero pela coloração rósea da corola com guias de nectários alvos, pelas costelas caulinares pouco evidentes e pela ramificação do caule na base da planta. É encontrada com flores e frutos praticamente o ano todo.

Parátipos. - BRASIL, MINAS GERAIS: Lima Duarte, arredores do P.F.E. de Ibitipoca, trilha que sai da portaria do Parque para o lado esquerdo, 9.ii.2001, Forzza \& al. 1809 (SP!); Parque Estadual do Ibitipoca, Caminho Lagoa Seca, 13.i.1988, Andrade \& al. 1107 (BHCB!); Lagoa Seca, 23.iii.1988, Andrade \& al. 1141 (BHCB!); no caminho para o Morro do Cruzeiro, 30.xi.2004, Bezerra \& al. 46 (SPF!); aceiro, na trilha para Cachoeirinha, 23.ii.1992, Eiterer \& Freiras 87 (CESJ, MBM!); Lago das Miragens, 30.xi.1991, Lisboa s.n. (ESA!); próximo à gruta dos viajantes, 2.xi.1991, Oliveira \& Forzza 44 (SP!); xii.2000, Salimena s.n. (CESJ!); beira da trilha do Pião, 20.i.2005, Calió \& al. 88 (SPF!); 14.vii.2005, Trovó \& al. 182 (SPF!); Pico do Peão, 28.ix.1970, Braga s.n. (RB!); 16.vii.1977, Brüger s.n. (CESJ, RB!); 26.ii.1977, Coons \& al. 77-319 (VIC!); 13.v.1970, Sucre \& Krieger 6785 (BR, CEN!, CEPEC, F, G, K, LIL, MBM!, MG, MO, RB!, U!, UEC!); Extremidade Norte, 24.iii.2002, Valente \& Araújo 171 (CESJ, SP!); 29.ix.1970, Braga \& al. 1896 (RB!); Perto da Gruta dos Viajantes, 12.iii.1994, Forzza s.n. (SPF!); v.1970, Krieger s.n. (CESJ!); 12.v.1970, Krieger s.n. (CESJ, ESA!, RB!); 16.vii.1977, Márcio s.n. (BHCB!); 30.ix.1970, Marinho s.n. (CESJ, MBM!, RB!); Próximo à mata dos ratos da Dodora, 18.xii.1986, Souza \& al. s.n. (BHCB!, SPF!); 13.vii.1977, Valle \& al. s.n. (VIC!); 24.iii.1995, Tombolato s.n. (IAC!). São Tomé das Letras, 24.iii.1995, Tombolato s.n. (IAC!).

2. Calolisianthus pedunculatus (Cham. \& Schltdl.) Gilg in Engler \& Prantl Nat. Pflanzenfam. 4(2): 99. 1895 = Lisianthus pedunculatus Cham. \& Schltdl., Linnaea 1: 199. 1826 = Lisianthus elegans Mart. var. simplex Mart., Nov. Gen. sp. pl. 2(2): $98.1827 \equiv$ Lisianthus elegans Mart. var. pedunculatus (Cham. \& Schltdl.) Griseb., Gen. et Sp. Gent., 187. 1839, nom. superfl. \& illeg. = Helia elegans (Mart.) Kuntze, Revis. gen. pl. 2: 428. 1891 $\equiv$ Irlbachia pedunculata (Cham. \& Schltdl.) Maas, Proc. Kon. Ned. Akad. Wetensch. C. 88(4): 410. 1985 - Tipo: "Brasilia, [Minas Gerais], Serra de Carassa", 2 Abril 1819, Sellow 1628 Holótipo: B [destruído, foto F!]; lectótipo (aqui designado): K [imagem digitalizada da exsicata!]; HAL [imagem digitalizada da exsicata!], L!, W! 
= Lisianthus elegans Mart. var. robusta Mart., Nov. Gen. sp. pl. 2(2): 98; tab. 177. 1827Tipo: "Brasil, Minas Gerais, M. Itambé, territ. Adamanti.", Maio, Martius s.n. - Lectótipo (aqui designado): $M$ [foto SPF!]; $M(\times 2)$ [fotos SPF!].

$=$ Lisianthus pulcherimus Mart., Nov. Gen. sp. pl. 2(2): 97; tab. 176. 1827, syn. nov. (non L. pulcherrimus Donn.Sm. in Pittier Prim. fl. costaric. 2: 166. 1898) $\equiv$ Helia pulcherrima (Mart.) Kuntze, Revis. gen. pl. 2: 428. 1891 = Calolisianthus pulcherrimus (Cham. \& Schltdl.) Gilg in Engler \& Prantl Nat. Pflanzenfam. 4(2): 99. 1895 =Irlbachia pulcherrima (Mart.) Maas, Proc. Kon. Ned. Akad. Wetensch. C. 88(4): 410. 1985 - Tipo: "Brasil, Minas Gerais, Morro de V. Ricca", Martius 1006 - Holótipo: M [foto SPF!].

= Lisianthus tenuifolius Spreng., Syst. veg. 4(2): 339. $1827 \equiv$ Helia tenuifolia (Spreng.) Kuntze, Revis. gen. pl. 2: 428. 1891 = Lisianthus angustifolius Mart., Nov. Gen. sp. pl. 2(2): 99; tab. 178. 1827, nom. illeg. (non L. angustifolius Kunth in Bonpland \& Humboldt Nov. gen. sp. 3: 181.1819 [1818]) - Tipo: "Brasil, Minas Gerais, Serro Frio", s.d., Martius 1385 Holótipo: M [foto SPF!].

$=$ Calolisianthus pedunculatus (Cham. \& Schltdl.) Gilg var. damazianus Beauverd, Bull. Herb. Boissier ser. 2, 7: 146. 1907, syn. nov. - Tipo: "Brésil, Ouro Preto", Outubro 1904, Damazio 1480 - Holótipo G [imagem da planta escaneada!].

= Calolisianthus kermesinus Gilg in schedulae.

Ervas lenhosas na base a subarbustos, $20-100 \mathrm{~cm}$ alt. Caule 1.5-6.5 mm diâm. na base da planta, 1.3-5 mm diâm. abaixo das flores, internós 10-55 mm compr. na base, 40-180 mm compr. abaixo das flores; costelas $0.1-1 \mathrm{~mm}$ larg. Folhas sésseis ou curto-pecioladas, pecíolo 0.5-3 $\mathrm{mm}$ compr., nectários extra-florais inconspícuos (raramente pouco conspícuos); lâmina linear a orbicular, lanceolada a ovada ou obovada, 10-65 × 1-47 mm, base atenuada, arredondada ou cordada, ápice agudo a acuminado ou arredondado, raramente mucronado, múcron $0.2-0.3 \mathrm{~mm}$ compr.; 1-4 pares de nervuras secundárias, nervuras terciárias conspícuas ou não, reticuladas. Flores 1-10; brácteas foliáceas ou escamiformes, ovadas a largamente ovadas ou triangulares a largamente deltóides, 2.1-15 $\times 1-14 \mathrm{~mm}$, base truncada, atenuada a longamente atenuada ou cordada, margem inteira, ápice agudo a acuminado; bractéolas foliáceas ou escamiformes, estreitamente triangulares a deltóides, 2-7.5 × 1.2-2.4 mm, base truncada ou atenuada, margem inteira, raramente erosa, ápice agudo a acuminado; pedicelo $10-80 \times 0.8-1.8 \mathrm{~mm}$. Cálice 8-15 × 5-8 mm; 
tubo 2-5 mm compr.; lobos 5, elípticos, oblongos, lanceolados a largamente ovados ou obovados, 5-9 × 2-6 mm, margem inteira, erosa ou levemente denticulada, ápice agudo a acuminado, raramente arredondado. Corola vermelha, com ou sem guias de nectários vináceos ou alvescentes a amarelados, às vezes com a base do tubo amarelada a esverdeada, ápice dos lobos amarelado a esverdeado, infundibuliforme ou hipocrateriforme, 33-76 mm compr., 3.5-5.8 vezes maior que o cálice; tubo (22-)30-70 mm compr., 2.3-4.5 $\mathrm{mm}$ larg. na base, $1.9-7 \mathrm{~mm}$ larg. abaixo da inserção dos estames, 4.5-23 mm larg. no ápice; lobos (4-)5, elípticos a largamente elípticos, ovados a largamente ovados ou triangulares a deltóides, 7-19.3 × 3.5-16 mm, margem plana, inteira a levemente sinuada, ápice agudo a acuminado, raramente apiculado, apículo 0.2-0.7 mm compr. Estames (4-)5; filetes amarelos a creme-esverdeados, 10-45 mm compr.; anteras creme a amarelas, estreitamente elípticas, estreitamente oblongas ou lanceoladas, 2.3-6 × 0.9-1.5 mm, apêndice estéril 0.25-0.6 mm compr. Ovário verde, estreita a largamente ovóide, 5.6-6.9 × 2.8-5 mm; estilete amarelado a esverdeado, $12-46 \times 0.2-1 \mathrm{~mm}$; lobos do estigma amarelados a esverdeados, estreitamente elípticos a elípticos ou estreitamente oblongos, 3$6.5 \times 0.6-2 \mathrm{~mm}$. Fruto estreito-ovóide a ovóide, 14-24 × 6-11 mm (Fig. 2, Fig. 6).

Etimologia e nomes populares. - Apesar de Chamisso e Schlechtendal (1826) não terem explicitado as razões para escolha do epíteto específico, presume-se que "pedunculatus" refira-se à longa e bastante distinta estrutura caulinar que sustenta as flores. Popularmente conhecida como genciana-da-terra (referido para L. elegans; Pio-Correa, 1926) e genciana-trombeta-vermelha (Fabris \& Klein, 1971).

Taxonomia. - Dois fatores contribuíram para a sinonimizar, sob C. pedunculatus, as diferentes espécies antigamente reconhecidas, ambas apoiadas por vultosas amostras: a existência de espécimes com atributos morfológicos intermediários entre os extremos que as caracterizavam, e a fraca correlação entre as formas e a distribuição geográfica. A escolha do material do $\mathrm{K}$ como tipo nomenclatural de $L$. pedunculatus baseou-se no melhor estado de preservação desse exemplar. No protólogo de L. elegans, Martius (1827) não citou separadamente os materiais que correspondiam a cada variedade, entretanto, com base na descrição apresentada, é possível identificá-los. A escolha do material para lectotipificação deste nome baseou-se na flor em melhor estado de preservação e na semelhança com a ilustração apresentada juntamente com o protólogo. Os demais materiais correspondentes à variedade robusta apresentam etiquetas com informações diferentes das do material escolhido como lectótipo, citando apenas "Minas Gerais" ou "Brasil, Minas Gerais, V.R." como localidade de coleta; entretanto, ambas são, concordantes com o 
protólogo. O nome Lisianthus angustifolius Mart. é ilegítimo, pois se trata de um homônimo posterior do nome $L$. angustifolius Kunth, publicado muitos anos antes, para designar uma espécie atualmente denominada Chelonanthus angustifolius (Kunth) Gilg.

Distribuição, habitat e conservação. - C. pedunculatus é encontrado em camposrupestres, principalmente na Cadeia do Espinhaço (porções baiana e mineira), estendendose pela Serra da Mantiqueira e Serra do Mar (porções leste de São Paulo, Paraná e Santa Catarina). Ocorre também na região da Chapada dos Veadeiros (=Serra Geral do Paraná) e Serra Geral de Goiás, no Estado de Goiás, e na região da Serra da Ponte Alta, na porção mais ocidental de Minas Gerais (Fig. 8B). A altitude em que é encontrada varia entre 700 e $1850 \mathrm{~m}$, sendo freqüentemente encontrada acima de $1000 \mathrm{~m}$. Essa espécie não se enquadra em categorias ameaçadas segundo os critérios da IUCN (2001).

Morfologia e fenologia. - Pela circunscrição proposta pelo presente trabalho, essa espécie apresenta grande variedade morfológica de porte, forma das folhas e tamanho das flores. Entretanto, todas as plantas apresentam corola infundibuliforme de coloração vermelha. Floresce e frutifica praticamente o ano todo.

Material selecionado. - Aproximadamente 480 coleções analisadas (relação completa no Apêndice A). BRASIL, BAHIA: Abaíra, Catolés, Campo do Ouro Fino, 1315'29.4"S 41054'9.9"W, 18.ix.2007, Loeuille \& al. 339 (SPF!); Barra da Estiva, Morro do Ouro, 19.vii.1981, Giulietti \& al. CFCR 1309 (SPF!, U!); Lençóis/Palmeiras, Path to Fumaça fall, v.1992, Alves \& Becker 4165 (RB!); Mucugê, Serra do Sincorá, NW face of Serra de Ouro, to the East of the Barra da Estiva, Ituaçu road, about $9 \mathrm{~km} \mathrm{~S}$ of

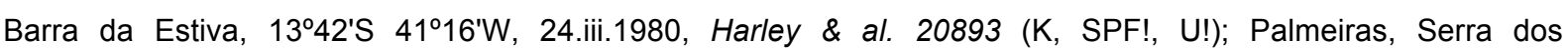
Lençóis/Morro do Pai Inácio, ca. $14,5 \mathrm{~km} \mathrm{NW}$ of Lençóis just $\mathrm{N}$ of the main Seabra-ltaberaba road, $12^{\circ} 27^{\prime} \mathrm{S}$

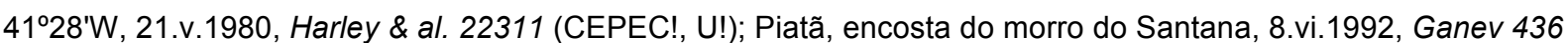
(HUEFS!, K, NY!, SPF!); Rio de Contas, caminho para o Pico das Almas, indo para Queiroz, 13031'13"S 41056'07"W, 2.iv.2004, Pirani \& al. 5393 (SPF!). GOIÁs: Alto Paraíso de Goiás, Parque Nacional da Chapada dos Veadeiros, próximo à sede do IBDF, próximo ao riacho José Jacó, 9.ii.1987, Romaniuc Neto \& al. 634 (NY!, SP!); São Domingos, Serra Geral de Goiás, Rod GO-110, 18 km L de São Domingos., 15.v.2000, Hatschbach \& al. 71159 (MBM!); São João d'Aliança, Serra Geral do Paraná, $4 \mathrm{~km}$ by road E of São João da Aliança, 24.iii.1973, Anderson \& al. 7880 (NY, UB!). MINAS GERAIS: Augusto de Lima, Serra do Cabral, ca. 12 km da cidade em direção à Fazenda Serra do Cabral, 1800'40"S 4419'41"W, 20.iii.1994, Sakuragui \& al. CFCR 15269 (CHRB!, ESA!, SPF!); Belo Horizonte, Pico da Serra do Curral, 23.iii.1929, Ducke s.n. (RB!); Botumirim, Serra da Canastra, Caminho de Botumirim para Barra do Veado, 23.vii.1985, Martinelli 11283 (RB!); Brumadinho, Serra da Calçada (trecho da Serra da Moeda), Retiro das Pedras, à direita da estrada que vai da BR 040 ao Retiro,

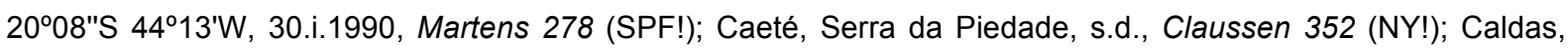
14.i.1919, Hoehne s.n. (SP, SPF!); Catas Altas, Serra do Caraça, Caminho para Capelinha e Gruta Lourdes, 200.5'39"S 4328'42"W, 28.i.2004, Calió \& al. 65 (SPF!); Conceição do Mato Dentro, Parque Nacional da Serra do Cipó, Km 131, 12.iv.1994, Castro s.n. (HUFU, SPF!); Congonhas do Norte, Serra Talhada (setor nordeste da 
Serra do Cipó), 6,8 km da estrada Congonhas do Norte - Gouveia, entrada a 3,7 km NW de Congonhas do Norte, estrada pelo alto da serra em local denominado localmente Retiro dos Pereiras, nascentes do Rio Preto,

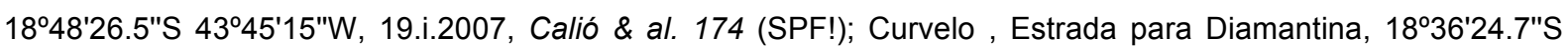
4353'52.9"W, 19.iii.2005, Trovó \& Ribeiro 133 (SPF!); Datas, Morro do Coco, $1 \mathrm{~km}$ do entroncamento para Diamantina., 24.iii.1986, Mello-Silva \& al. CFCR 9755 (CHRB!, SPF!); Diamantina , Estrada Diamantina Conselheiro Mata, aproximadamente $2 \mathrm{~km}$ da estrada Diamantina Gouveia (BR 259). Lado esquerdo da estrada., 18¹5'59.3"S 4342'02"W, 17.vii.2006, Lovo \& al. 145 (SPF!); Formoso, Parque Nacional Grande Sertão Veredas, Cabeceira do Rio Preto, 15¹2'07"S 4550'50"W, 29.v.1999, Oliveira \& al. 1081 (IBGE, RB!, U!); Gouveia, Barro Preto, Torre Telemig, 29.xi.1985, Hatschbach \& Silva 50305 (MBM!); Grão-Mogol, próximo da saída na estrada para Francisco Sá, 7.i.1996, Mello-Silva \& al. CRCR 9016 (SP, SPF!); Itabirito, Pico do Itabirito, Serra dos Inconfidentes, 29.iii.1994, Teixeira s.n. (U!); Itacambira, Estrada Itacambira - Juramento, ca. 9 km de Itacambira, 1702'45.1"S 4320'58"W, 22.ii.2002, Souza \& al. 28165 (ESA!, SPF!); Itumirim, Serra da Bocaina, 29.vi.1987, Shepherd \& al. 19008 (UEC!); Itutinga, Estrada entre Lavras e São João del Rey, 7.iii.1995, Souza \& al. 7804 (ESA!, HUFU!, SPF!); Jaboticatubas, Serra do Cipó, Km 126 ao longo da rodovia Lagoa Santa - Conceição do Mato Dentro - Diamantina, 5.iii.1972, Joly \& al. 1048 (SP!, UEC!); Jequitinhonha, ca. 47 km ao sul de Pedra Azul, na estrada para Jequitinhonha, $16^{\circ} 22^{\prime} \mathrm{S} 41^{\circ} 03^{\prime} \mathrm{W}, 20 . x .1988$, Harley \& al. 25263 (F, MBM, SP, SPF!, U!); Joaquim Felício, Serra do Cabral, estrada pela Serra do Cabral, 17.iv.1981, Rossi \& al. CFCR 1178 (SPF!, U!); Lavras, Poço bonito, 14.v.1988, Almeida s.n. (SPSF!); Moeda, Serra da Moeda, 19.vi.1986, Grandi \& al. s.n. (BHCB!); Morro do Pilar , a 22 km do Morro do Pilar, 31.vii.1979, Shepherd 10212 (UEC!); Nova Lima, Lagoa Grande, 10.iv.1945, Williams \& Assis 6552 (US!); Ouro Branco, Serra do Ouro Branco, 9.iii.2005, Temponi \& al. 418 (SPF!); Ouro Preto, Parque Estadual do Itacolomi, entrada da Mata do Cibrão, 13.iii.2007, Araújo \& Coser s.n. (VIC!); Poços de Caldas, Campo do Saco, 2150'20"S 46³3'53"W, 13.i.1981, Gouvea \& al. 720 (UEC!); Rio Vermelho, Morro do Ambrósio, Pedra Menina, 31.iii.1985, Giulietti \& al. CFCR 7708 (SP!); Sabará, Gaya, 23.iii.1933, Mello-Barreto 2795 (BHCB!); Santa Bárbara, Serra do Caraça, Cascatinha, SW de Catas Altas, 2005'S 4327'W, 14.v.1990, Arbo \& al. 4046 (K!); Santa Luzia, Serra do Cipó, Km 132, 2.ix.1933, Mello-Barreto 2802 (BHCB!, F); Santana de Pirapama, Serra do Cipó - Serra Mineira, Fazenda Inhame, 1855"S 4354'W, 21.iii.1982, Pirani \& al. CFSC 8023 (SPF!); Santana do Riacho, Serra do Cipó, Trilha para as "Velozias gigantes", 23.v.2007, El Ottra \& Versieux 15 (SPF!); Santo Antônio do Itambé, Morro do Pico do Itambé, $18^{\circ} 25^{\prime \prime S} 43^{\circ} 21^{\prime} \mathrm{W}$, 4.iv.1982, Rossi \& al. CFCR 2995 (SPF!, U!); São Gonçalo do Abaeté, Rod. BR-365, km 261, 20.iii.1980, Hatschbach 42799 (MBM!, U!); São Gonçalo do Rio Preto, Parque Estadual do Rio Preto, da casa de hóspedes a cascata do Ribeirão das Éguas e então por fim ao camping, 187'34"S 43²1'24"W, 8.iv.2000, Lombardi \& al.

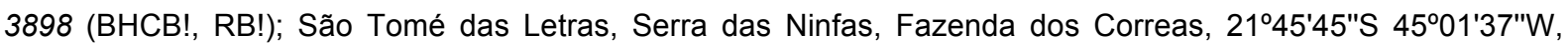
19.ii.2005, Mello-Silva \& Ferreira 2868 (CESJ, SPF!); Serro, Milho Verde, Estrada Diamantina - Milho Verde, afloramento rochoso ao lado esquerdo da estrada, ca. 3 km de Milho Verde, 4.iii.1999, Feres \& al. $99 / 42$ (UEC!). PARANÁ: Balsa Nova , Arredores do cemitério de Tamanduá, próximo à São Luiz do Purunã, 6.ii.1999, Bassani 11 (UPCB!); Bocaiúva do Sul, 9.iv.1999, Barbosa 251 (MBM!); Campina Grande do Sul, Araçatuba, i.1960, Stellfeld 501 (US!); Carambeí, Rio São João, Castro, 17.xii.1965, Reitz \& Klein 17907 (US!); Jaguariaíva, Fazenda Cajuru, 18.i.1965, Hatschbach \& al. 12271 (MBM!); Mandirituba, BR 116, sentido Rio Grande do SulMandirituba, 27.i.2004, Farinaccio \& al. 621 (SPF!, CHRB!); Ortigueira, Serra dos Mulatos, 17.i.1967, Hatschbach 15711 (MBM!, MO); Palmeira, Fazenda Sta. Rita, v.1980, Dombrowski 11916 (MBM!); Ponta Grossa, Vila Velha, 25.i.1910, Dusén 9112 (S!); São Jerônimo da Serra, 3 km ao N da cidade, 23.ii.1957, Hatschbach 3614 (MBM!); São José dos Pinhais, Rio Pequeno, 17.i.1969, Hatschbach \& Fontella 20800 (S!). SANTA CATARINA: Campo Alegre, Morro do lquererim, 9.i.1958, Reitz \& Klein 6083 (LP!, US!). SÃO PAULO: Campos do Jordão, Abernessia, 26.i.1935, Kuhlmann s.n. (SP!, SPF!); Itararé, Fazenda São Nicolau, 24016'02"S 4909'22.1"W, 
22.v.1993, Souza \& al. 3968 (ESA, SP!, SPSF!); São José do Barreiro, Parque Nacional da Serra da Bocaina, 20.ii.1998, Freitas \& al. 430 (UEC!); São Paulo, Jaraguá, 1.iii.1923, Gehrt 4133 (SP!, SPF!).

3. Calolisianthus pendulus (Mart.) Gilg in Engler \& Prantl Nat. Pflanzenfam. 4(2): 99. 1895

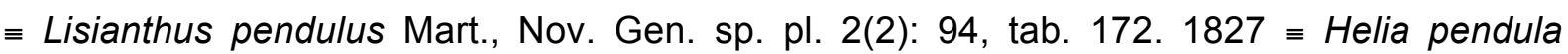
(Mart.) Kuntze, Revis. gen. pl. 2: 428. 1891 =Irlbachia pendula (Mart.) Maas, Proc. Kon. Ned. Akad. Wetensch. C. 88(4): 410. 1985 - Tipo: "Brasil, Minas Gerais et São Paulo septent., Camanducaja", Fevereiro, Martius 651 - Lectótipo (aqui designado): M [foto SPF!]; M [foto SPF!].

Ervas lenhosas na base, raramente subarbustos, 9-64 cm alt. Caule 1-3 mm diâm. na base da planta, 0.6-3.6 mm diâm. abaixo das flores, internós 1.3-20 mm compr. na base, 40-157 $\mathrm{mm}$ compr. abaixo das flores; costelas $0.1-0.2 \mathrm{~mm}$ larg. Folhas sésseis ou curto-pecioladas, pecíolo 0.5-3 $\mathrm{mm}$ compr., nectários extra-florais inconspícuos (raramente pouco conspícuos); lâmina estreitamente elíptica a largamente elíptica, lanceolada a ovada ou obovada, 8-62 × 4.8-28 mm, base atenuada, ápice agudo a acuminado ou arredondado; 12 pares de nervuras secundárias, nervuras terciárias inconspícuas. Flores 1-3(-7); brácteas foliáceas ou escamiformes, estreitamente elípticas a elípticas ou lanceoladas a ovadas, 0.9$30 \times 0.2-13 \mathrm{~mm}$, base truncada ou atenuada, margem inteira, ápice acuminado; bractéolas foliáceas ou escamiformes, elípticas ou lanceoladas a ovadas, $3.2-13 \times 0.9-4.8 \mathrm{~mm}$, base truncada ou atenuada, margem inteira ou levemente denticulada, ápice agudo a acuminado; pedicelo 4.5-80 × 0.6-1.6 mm. Cálice 8-12.3 × 4-7.5 mm; tubo 1-4 mm compr.; lobos (4-) 5(-6), estreitamente elípticos a elípticos, estreitamente oblongos a oblongos ou lanceolados a ovados, $5.2-10 \times 2.6-4.7 \mathrm{~mm}$, margem inteira, erosa ou levemente denticulada, ápice agudo a acuminado. Corola roxa a azulada, com ou sem guias de nectários alvescentes, ápice dos lobos alvescente a esverdeado, infundibuliforme ou hipocrateriforme, 23-59 mm compr., 2.5-4.3 vezes maior que o cálice; tubo 15.7-25(-36) mm compr., 2.3-4 mm larg. na base, $1.5-4.5 \mathrm{~mm}$ larg. abaixo da inserção dos estames, $4.5-18.5 \mathrm{~mm}$ larg. no ápice; lobos (4-)5(-6), estreitamente elípticos a largamente elípticos, oblongos ou lanceolados a ovados, 8-18 × 3.3-9 mm, margem plana, inteira a levemente sinuada, ápice agudo a acuminado, raramente apiculado, apículo 0.5-1.1 mm compr. Estames 4-6; filetes alvos a esverdeados, 4.3-12.5 mm compr.; anteras alvas a rosadas ou esverdeadas, estreitamente elípticas ou estreitamente oblongas, $1.4-4.3 \times 0.5-1.5 \mathrm{~mm}$, apêndice estéril 0.03-0.5 mm compr. Ovário verde, ovóide, 5.5-7.7 × 2.5-4.2 mm; estilete alvo-esverdeado, 7.5-18.2 × 0.5-0.9 mm; lobos do estigma alvo-esverdeados, estreitamente elípticos ou estreitamente oblongos, 4$7.8 \times 0.8-2 \mathrm{~mm}$. Fruto ovóide, 12.8-28 × 5.3-10 mm (Fig. 3, Fig. 5D-E). 
Etimologia e nomes populares. - Martius (1827) não explicitou, no protólogo, as razões para escolha do epíteto específico, mas presume-se que "pendulus" refira-se à estrutura caulinar que sustenta as flores, um pouco flexuosa em alguns espécimes. É denominada popularmente de genciana-brasileira, genciana-do-Brasil, raiz-amarga (PioCorrea, 1926) ou sininho (Cordeiro, 2005).

Taxonomia. - O material escolhido para lectotipificação apresenta flor em bom estado de preservação. Além disso, esse material havia sido selecionado como lectótipo por Groen e Maas, em 1985, durante estudo das Gentianaceae neotropicais - há uma etiqueta junto ao material indicando essa escolha, porém a lectotipificação nunca foi publicada.

Distribuição, habitat e conservação. - É encontrada em vegetações campestres, entre 1000 e $2100 \mathrm{~m}$ de altitude, principalmente na porção mineira da Cadeia do Espinhaço, e mais a oeste nas Serras da Canastra e da Ponte Alta. Também ocorre na Serra da Mantiqueira e Serra do Mar (nos estados de Minas Gerais, São Paulo e Rio de Janeiro), estendendo-se ao leste do Paraná (Fig. 9A). Segundo os critérios da IUCN (2001), essa espécie não se enquadra na categoria "ameaçada".

Morfologia e fenologia. - Essa espécie distingue-se das demais pelo porte freqüentemente diminuto e pelas pequenas flores de cor roxa a azulada. Encontrada com flores e frutos o ano todo.

Material selecionado. - Aproximadamente 160 coleções analisadas (relação completa no Apêndice A). BRASIL, MINAS GERAIS: Aiuruoca, Serra do Papagaio, Vertentes Oeste da

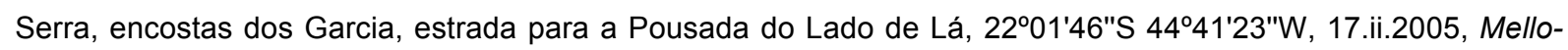
Silva \& Ferreira 2848 (CESJ!, CHRB!, SPF!); Andradas, estrada de Andradas/Caldas e Pocinhos, 22.i.1981, Shepherd \& al. 12184 (UEC! ); Antônio Carlos, Serra da Mantiqueira, 7.ii.1972, Krieger 11470 (CESJ!, SPF!); Barão de Cocais, Cocais, Serra do Sarimpo, 13.i.1921, Hoehne 4968 (SP!); Belo Horizonte, Serra do Curral, vii.1949, Vidal s.n. (R!); Bom Jardim de Minas, Torre da Embratel, 21.iii.1988, Krieger \& Brügger s.n. (CESJ,

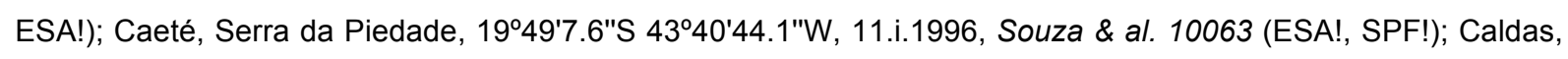
s.d., Regnell 122 (SP!); Catas Altas, Serra do Caraça, caminho para a cascatinha, ca. $100 \mathrm{~m}$ após o estacionamento, 2005'34"S 4328'47"W, 20.iv.2006, Pirani \& al. 5483 (SPF!); Itabirito, 10.vi.1971, Krieger 10614 (CESJ!); Lima Duarte, Parque Estadual do Ibitipoca, beira da trilha para Monjolinho - Lagoa Seca, perto do Monjolinho, 21042'13"S 43053'29"W, 18.i.2005, Calió \& al. 86 (SPF!); Mariana, Área da Samarco, 10.xii.2000, Brina s.n. (BHCB!); Moeda, Serra da Moeda, 1a estação de coleta, 19.xii.1989, Grandi \& Porto s.n. (BHCB!); Ouro Branco, Serra do Ouro Branco, atrás da torre da EMBRATEL, em frente à cidade de Ouro Branco, 19.i.2007, Delgado \& al. s.n. (SPF!, VIC); Ouro Preto, Parque Estadual do Itacolomi, subida do morro para a Lagoa Seca, 13.iii.2007, Araújo \& Coser s.n. (SPF!, VIC);Passa Quatro, Fazenda dos Martins, 25.iv.1948, Barb. \& Araujo 117 (RB!); Poços de Caldas, Morro do Ferro, 6.iii.1964, Becker 292 (R!); Santa Bárbara, Caraça, Caminho de asfalto indo até ao encontro dos rios, 15.iii.1990, Marcondes-Ferreira \& al. 286 (SPFR!); São Roque 
de Minas, Serra da Canastra PARNA, estrada para Sacramento, 3 km da sede administrativa, 12.xii.1996, Kinoshita \& Moreira 96-153 (UEC!). PARANÁ: Jaguariaíva, Fazenda Cajuru, 18.i.1965, Hatschbach \& al. 12267 (MBM, US!). RIO DE JANEIRO: Itatiaia, Serra Negra, 14.i.1936, Sem coletor 2853 (RB!). SÃO PAULO: Campos do Jordão, Reserva do Horto Florestal, 19.vii.1983, Giulietti \& al. 1038 (SPF!); Franco da Rocha, Parque Estadual do Juqueri, ao lado direito da estrada, antes da torre de energia, região central do parque, 10.ii.2003, Baitello \& Peres 1451 (SPSF!); Ibiúna, ca. 2 km da estrada que sai à esquerda (sentido São Paulo-lbiúna) da rodovia SP 250 km 63, 6.i.1999, Cordeiro \& al. 1850 (SP!); São Caetano do Sul , 21.i.1912, Brade 5553 (SP!); São José do Barreiro, Serra da Bocaina, Rodovia estadual da Serra da Bocaina (SP221), km 26,5, 2244'3.1"S 44³6'57.3"W, 7.ix.2007, Serafim 25 (SPF!); São Paulo, Jabaquara, 2.v.1952, Handro 300 (SP, SPF!).

4. Calolisianthus speciosus (Cham. \& Schltdl.) Gilg in Engler \& Prantl Nat. Pflanzenfam.

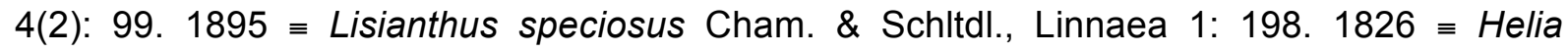
speciosa (Cham. \& Schltdl.) Kuntze, Revis. gen. pl. 2: 428. 1891 IIrlbachia speciosa (Cham. \& Schltdl.) Maas, Proc. Kon. Ned. Akad. Wetensch. C. 88(4): 410. 1985 - Tipo: "Brasil", 1814-31, Sellow s.n. - Holótipo: B [provavelmente destruído]; Lectótipo (aqui designado): HAL [imagem digitalizada da exsicata!]; $\mathrm{K}(\times 2)$ [imagens digitalizadas da exsicatas!], $\mathrm{P}$ [imagem digitalizada da exsicata!].

= Lisianthus alpestris Mart., Nov. Gen. sp. pl. 2(2): 93, tab. 171. 1827 = Helia alpestris (Mart.) Kuntze, Revis. gen. pl. 2: 428. 1891 - Citação do tipo: "Brasil, Minas Gerais, Serra Morro, V. R. [Vila Rica]", Março, Martius 690 - Holótipo: M [foto SPF!].

$=$ Lisianthus inflatus Mart., Nov. Gen. sp. pl. 2(2): 93, tab. 174. $1827-$ Tipo: "Brasil, Minas Gerais, Morro de V. R. [Vila Rica]", Março, Martius 1153 - Lectótipo (aqui designado): M [foto SPF!]; M [foto SPF!].

= Lisianthus ovatifolius Vell., Fl. flumin. [texto]: 74. 1829; [lcones] 2: tab. 79. 1831 -Tipo: tab. 79 de FI. flumin. - Lectótipo (aqui designado).

= Calolisianthus macranthus Gilg, Bot. Jahrb. Syst. 22: 346. 1896 - Tipo: "Brasil, Goyaz", 1842, Gardner 3896 - Holótipo: B [destruído, foto F!]; lectótipo (aqui designado): K [imagem digitalizada das exsicata!]; $\mathrm{E}(\times 2)$ [imagens digitalizadas das exsicatas!], $P$ [imagem digitalizada da exsicata!].

Ervas lenhosas na base a subarbustos (mais freqüente), $27-100 \mathrm{~cm}$ alt. Caule $1.7-6 \mathrm{~mm}$ diâm. na base da planta, 1.6-4.5 mm diâm. abaixo das flores, internós 6-47 mm compr. na base, 41-130 mm compr. abaixo das flores; costelas $0.3-0.4 \mathrm{~mm}$ larg. Folhas sésseis, 
nectários extra-florais conspícuos; lâmina elíptica a largamente elíptica ou obovada, 8-68 × 6-43.6 mm, base atenuada, ápice agudo ou geralmente arredondado, raramente mucronados, múcron 0.1-0.7 mm compr.; 2-3 pares de nervuras secundárias, nervuras terciárias conspícuas ou não, reticuladas. Flores 1-30; brácteas foliáceas ou escamiformes, estreitamente elípticas a largamente elípticas, $8-23 \times 6.5-18 \mathrm{~mm}$, base atenuada, margem inteira, ápice agudo ou arredondado; bractéolas escamiformes, largamente ovadas a muito largamente ovadas ou curto-deltóides, 1.5-3.5 × 1.5-3 mm, base truncada, margem inteira, esparsamente erosa ou denticulada, ápice agudo ou arredondado; pedicelo 6.7-30 × 1.3$2.0 \mathrm{~mm}$. Cálice 6-11 × 5-6.5 mm; tubo 2-5 mm compr.; lobos (4-)5, largamente ovados a depresso-ovados, 3-6.5 × 3.5-7 mm, margem inteira ou erosa, ápice arredondado. Corola lilás, raramente alva ou pálido-lilás, raramente com guias de nectários alvescentes, ápice dos lobos alvescente a esverdeado, campanulada, 31-100 mm compr., 3.7-6.6 vezes maior que o cálice; tubo $26-45 \mathrm{~mm}$ compr., 2-6 mm larg. na base, 6-9.5 mm larg. abaixo da inserção dos estames, 13-30 mm larg. no ápice; lobos (4-)5, largamente elípticos ou muito largamente ovados a depresso-ovados, 8.5-16 × 8-12 mm, margem ondulada, erosa, ápice arredondado, raramente apiculado, apículo 0.1-0.2 $\mathrm{mm}$ compr. Estames 5; filetes alvos a lilases, 11-30 mm compr.; anteras alvas, creme a amarelas, estreitamente elípticas, 6.3-8.7 × 1-1.5 mm, apêndice estéril 0.6-1.5 mm compr. Ovário verde, estreito-ovóide, 5.5-9 × 1.9$3.5 \mathrm{~mm}$; estilete alvo a lilás, 12-30.5 × 1-2 mm; lobos do estigma alvos a lilases, estreitamente elípticos a elípticos, 4.5-6.5 × 2-2.5 mm. Fruto ovóide, 11-18 × 6-8 mm (Fig. 4, Fig. 7).

Etimologia e nomes populares. - Apesar de Chamisso e Schlechtendal (1826) não terem explicitado as razões para escolha do epíteto específico, presume-se que "speciosus" refira-se às grandes e vistosas flores. É popularmente denominada de genciana-da-terra (referido para Lisianthus alpestris; Pio-Correa, 1926).

Taxonomia. - Segundo Stafleu \& Cowan (1976, 1985), os herbários que possuem coleções de Chamisso e Schlechtendal são, respectivamente, LE e HAL. Uma vez que não foram encontradas duplicatas do material-tipo em LE, optou-se por escolher o material de HAL para lectotipificação de Lisianthus speciosus. O espécime designado como lectótipo de L. inflatus foi escolhido por apresentar maior número de flores e por possuir uma porção do sistema subterrâneo. O outro espécime de L. inflatus encontrado apresenta, na etiqueta, informações diferentes daquela do material escolhido como lectótipo ("Brasil, Minas Gerais, Congonhas et Sabará"), mas coerentes com a descrição apresentada no protólogo. A exsicata selecionada como lectótipo de C. macranthus apresenta bom estado de 
preservação. Além disso, duplicatas dos materiais examinados por Gilg encontram-se sabidamente no K (Stafleu \& Cowan, 1976).

Distribuição, habitat e conservação. - Esse táxon encontra-se distribuído principalmente nas serras mineiras e goianas, com algumas ocorrências na porção baiana da Cadeia do Espinhaço e na Serra da Mantiqueira em São Paulo, além de dois registros do Tocantins (Fig. 9). Ocorre em campos rupestres e cerrados, em altitudes entre 700 e 1850 $\mathrm{m}$, mas freqüentemente acima de $800 \mathrm{~m}$. Não é categorizada como ameaçada pelos critérios da IUCN (2001).

Morfologia e fenologia. - Essa espécie apresenta grande variação morfológica, mas caracteriza-se pelos nectários extra-florais bastante evidentes e pelas flores freqüentemente numerosas, de forma campanulada e de coloração lilás. Pode ser encontrada com flores e frutos o ano todo.

Material selecionado. - Aproximadamente 400 coleções analisadas (relação completa no Apêndice A). BRASIL, BAHIA: Abaíra, Gerais do Pastinho, 4.vi.1992, Ganev 413 (HUEFS!, K,

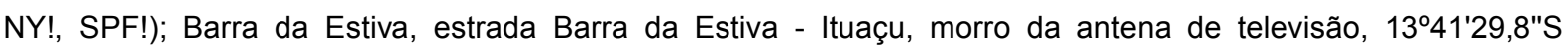
41019'5.1"W, 18.v.1999, Souza \& al. 22701 (ESA!); Érico Cardoso, Vereda, Estrada Capão - Vereda., 1316'7"S 4208'45"W, 5.vii.2001, Roque \& al. 581 (ALCB!, CEPEC!, HUEFS!); Rio de Contas, Morro ao lado direito logo

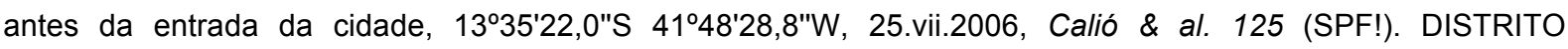
FEDERAL: Brasília, Área do Jardim Botânico, 5.vii.1990, Azevedo \& Brochado 770 (U!). GOIÁs: Água Fria de Goiás, Estação Repetidora da Telebrasília de Rocandor, 8.ii.1994, Hatschbach \& al. 60005 (MBM!); Alto Paraíso de Goiás, PARNA Chapada dos Veadeiros, estrada para a sede, 1409'41"S 47046'30"W, 15.viii.1995, Marquete \& al. 2291 (IBGE!); Anápolis, Rod. BR 153, 10 km de Anápolis, 22.v.1975, Hatschbach 36674 (MBM, U!); Caldas Novas, Morro do Vulcão, Pousada do Rio Quente, 8.x.1986, Kummrow 2824 (U!, US!); Campo Alegre de Goiás, Rod. BR-050, 25 km SE de Campo Alegre, 22.vi.1983, Hatschbach \& Kummrow 46587 (U!); Catalão, Rod. BR050, km 233, divisa Catalão-Campo Alegre, 7.v.2000, Hatschbach \& al. 70581 (MBM!); Cavalcante, Vila Veneno, Rio São Félix km 4, 27.vi.2001, Carvalho-Silva \& Silva 53 (CEN, SPF!); Cocalzinho de Goiás, Serra dos Pirineus, estrada de acesso a Serra dos Pirineus, a ca. de 8 km de Cocalzinho, 28.v.1998, Assis \& al. 559 (SPF!); Colinas

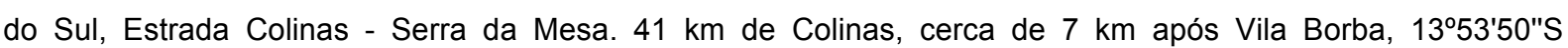
4807'20"W, 24.vi.1999, Walter \& al. 4350 (CEN!, U!); Corumbá de Goiás, 9.vii.1895, Macedo 3291 (US!); Cristalina, Rio Cristal, 44 km by road SE of Cristalina, 6.iv.1973, Anderson \& al. 8259 (NY!); Guarani de Goiás, Rodovia Brasília-Barreiras, $14 \mathrm{~km}$ norte do entroncamento de Posse (BR-020, km 243), $400 \mathrm{~m}$ cerrado adentro, perpendicularmente à rodovia, 1400'59"S 46013'56"W, 5.xii.2003, Mello-Silva \& al. 2309 (SPF!); Ipameri, Domiciano Ribeiro, 11.iv.1981, Hatschbach 43789 (S!, U!); Luziânia, Jardim Marajoara, 6.iv.1991, Melo \& França

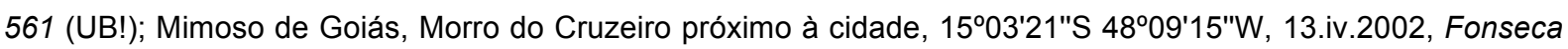
\& al. 3494 (IBGE!, RB, SP!); Minaçu, Reserva Serra da Cana Brava, 13²9'37"S 48¹6'11"W, 8.vi.1995, Afonso \&

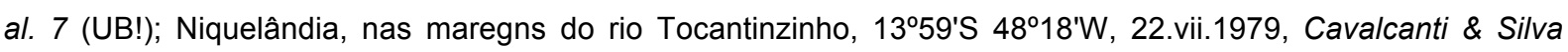
1606 (U!); Padre Bernardo, Estrada de Brazilândia/Padre Bernardo à esquerda, na estrada de chão, $15^{\circ} 33^{\prime} \mathrm{S}$ 48¹5'W, 7.v.1991, Vieira 723 (CEN, NY!); Pirenópolis, cerca de 10 km de Pirenópolis em direção a Corumbá de 
Goiás, 155'42"S 4851'03"W, 14.vii.2000, Souza \& al. 23855 (ESA!, SPF!); Planaltina, a 17,8 km de Planaltina de Goiás (Brasillinha) - a $12 \mathrm{~km}$ da Chácara Massangana, a 1,5 km do rio Maranhão, em direção à Brasília, 16.vii.2000, Fontella \& al. 3391 (R!); Portelândia, Serra da Urtiga, Rodovia BR-364 Mineiros-Santa Rita do Araguaia, próximo ao posto Urtigão, $17^{\circ} 22^{\prime} S$ 52³9'W, 6.vii.1996, Pietrobom-Silva \& al. 3345 (CTES!, MBM!, SJRP!); Posse , BR-020, Alvorada - Formosa, km 158, 17.viii.1990, Cavalcanti \& al. 817 (CEN, HUEFS!, SP!); São João d'Aliança, estrada pra Vãozinho, 9.ii.1994, Hatschbach \& al. 60253 (MBM!); Teresina de Goiás, a 15 km de Teresina de Goiás, do lado esquerdo na rodovia GO-118, 13²4'00,4"S 47²4'06,7"W, 16.vii.2006, Calió \& al. 103 (SPF!). MINAS GERAIS: Allfenas, estrada para ponte das amoras, 1.iii.1969, Carauta 811 (GUA!); Alpinópolis, próximo à barragem de Furnas, 18.ix.1977, Leitão Filho \& Martins 5956 (UEC!); Augusto de Lima, a $32,5 \mathrm{~km}$ da ponte do rio da Onça, na estrada para Francisco Dummont, 17045'S 4412'W, 25.iii.2000, Lima \& al. 121 (SPF!); Baependi, Toca dos Urubus, 3.v.2002, Ferreira \& al. 42 (SP!); Barbacena, Pinheiro Grosso, vii.1944, Vidal I-199 (R!); Belo Horizonte, Serra do Taquaril, 23.iii.1933, Mello-Barreto 2825 (BHCB!); Botumirim, trilha para o Cruzeiro, na entrada da cidade pelo acesso a partir de Cristália, 1651'26"S 430'46"W, 7.vii.2001, Fiaschi \& al. 846 (SP, SPF!); Brumadinho, Retiro das Pedras, 12.v.1990, Cabral \& Coelho s.n. (BHCB!); Caeté, Alto do Serrote, 1.xii.1933, Mello-Barreto 2858 (BHCB!); Carrancas, Cachoeira da Fumaça, 7.x.1998, Kinoshita \& al. 98435 (UEC!); Catas Altas, Serra do Caraça, trilha para o Pico do Inficionado, 5.vi.2000, Vasconcelos s.n. (BHCB!); Caxambu, vii.1954, Duarte 3836 (U!); Conceição do Mato Dentro, Serra do Cipó, 14.vi.1950, Alvim \& Oliveira s.n. (VIC!); Congonhas, Serra do Espinhaço, RPPN da Ferteco (Companhia Vale do Rio Doce), beira da estrada que corta que corta a RPPN, 31.viii.2003, Guarçoni \& al. 572 (VIC!); Congonhas do Norte, 15-20 km ao Norte, 20.v.1989, Hatschbach \& Nicolack 52999 (MBM!, U!, US!); Curvelo, 3.vi.1999, Tameirão Neto 3019 (BHCB!); Delfinópolis, Complexo do Claro, trilha para a Cachoeira do Claro, logo após a guarita, 10.vi.1999, Filliettaz \& al. 55 (SPF!, UEC!); Diamantina, estrada Diamantina-Biribiri, 5.vi.1985, Barros 1122 (SP, SPF!); Entre Rios de Minas, iii.1970, Krieger 8265 (CESJ, ESA!, SPF!); Formoso, Parque Nacional Grande Sertão Veredas., , 1519'07"S 460'21"W, 20.v.1998, Oliveira \& al. 1047 (IBGE!, RB, U!); Funilândia, Estrada Funilândia/Jequitiba, 12 km após Funilândia, lado direito da estrada, próx. à sede, 13.v.1987, Marquete \& al. 57 (HRB!, RB!); Gouveia, Km 604 da estrada Gouveia-Diamantina. ramo vicinal à esquerda, 18.vi.2000, Costa \& Fiaschi 196 (SPF!); GrãoMogol, estrada de terra para Grão-Mogol, 21.viii.2004, Pinna \& al. 20 (SPF!); Ibiraci, estrada entre Franca/SP e Ibiraci/MG, próximo à divisa dos estados, 6.ix.1998, Souza \& al. 21164 (ESA!); Itabirito, 10.vi.1971, Krieger 10659 (CESJ!); Itumirim, Serra da Bocaina, 29.vi.1987, Semir \& al. 19499 (UEC!); Jaboticatubas, Distrito de São José da Serra, estrada do rio Congo para a Lagoa Dourada, ca. de $15 \mathrm{~km}$ da rodovia Lagoa Santa - Conceição do Mato Dentro (MG 010), 19²5'6"S 4339'4"W, 23.iv.2006, Pirani \& al. 5538 (SPF!); João Pinheiro, estrada João Pinheiro - Brasilândia de Minas, MG 181, 57,6 Km do trevo da BR-040, 17017'21"S 465'12"W, 13.vii.2005, Forzza \& al. 4024 (RB, SPF!); Joaquim Felício, Serra do Cabral, estrada Joaquim Felício - Várzea da Palma, 3,4 km além da ponte sobre o Córrego da Onça, 17²43'36"S 4411'11"W, 26.i.2004, Calió \& al. 51 (SPF!); Lagoa Grande, 16.iii.1935, Cochran s.n. (US!); Lavras, Serra da Bocaina, Antena-Lavras, 27.iii.1987, DAC s.n. (ESAL, UEC!); Moeda, Serra da Moeda, 19.vi.1986, Grandi \& al. s.n. (BHCB!); Nova Lima, Morro do Chapéu, 23.ii.1980, Grandi 200 (BHCB!); Olaria, São Domingos da Bocaina, 11.vii.1987, Pires \& al. 21-499 (ESA!); Ouro Branco, estrada entre Ouro Branco e o Morro do Gabriel, ca. 9 km de Ouro Branco, 20²9'20.6"S 4339'49.1"W, 8.iii.1995, Souza \& al. 7914 (ESA!, HUFU!, SPF!); Ouro Preto, Pico do Itacolomi, 15.v.1983, Moura \& Vieira 423 (SPF!, VIC); Paraobeba, FLONA de Paraopeba, 15.iv.2003, Valente \& Meira Neto 1145 (VIC!); Passa Quatro, 29.iv.1929, Samp. 6222 (R!); Passos, Fazenda Paredão (Usina Açucareira Passos), estrada entre Furnas e Passos, ca. 16 km do rio Turvo (em direcão a Furnas), 1.vi.1996, Souza \& al. 11482 (BHCB, CESJ, CTES, ESA!, FUEL, HUEFS, M, MBM, RB, SPF!); Patos de Minas, 19.iv.1936, Mello-Barreto 4501 (BHCB!); Patrocínio, Fazendas da Terra: Boa Vista, 14.vii.1998, Farah \& Freitas 357 (ESA!); Perdizes, Unidade de Conservação do Galheiro, Divisa com João Alonso, 24.v.1994, Tameirão Neto \& Werneck 1070 (BHCB!); Poços de Caldas, Morro 
do Ferro, 2150'20"S 46³3'53"W, 2.xii.1982, Leitão Filho \& al. 1878 (UEC!); Presidente Olegário, Fazenda Vereda Grande, 1.v.1989, Grandi s.n. (BHCB!); Quartel Geral, CAF Santa Bárbara Ltda., 8.vii.2005, Raggi \& al. 36 (VIC!); Sabará, estrada de Caeté, km 29, 12.iv.1933, Mello-Barreto 2835 (BHCB!); Sacramento, 16 km da divisa SP/MG, 7 km do Ribeirão Canabrava em direção a Araxá, 6.vii.1996, Souza \& al. 12065 (ESA!); Santa Rita do Ibitipoca, 16.iv.1987, Krieger 21427 (CESJ, ESA!);Santana do Garambéu, trecho do Alto Rio Grande,

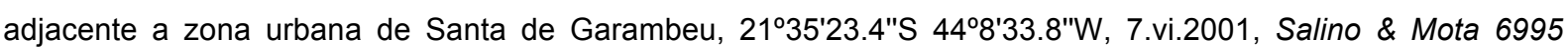
(BHCB!); Santana do Riacho, $16 \mathrm{~km}$ do início da estrada para Santana do Riacho, saindo da estrada Lagoa Santa - Conceição do Mato Dentro (MG010), 1907'9.7"S 4341'53"W, 23.ix.2006, Calió \& al. 125 (SPF!); São Gonçalo do Rio Preto, Parque Estadual do Rio Preto, trilha do alojamento até o córrego das Éguas, 18²'20"S 43²0'36"W, 19.ii.2002, Lombardi 4571 (BHCB!); São João del Rei, São Sebastião da Vitória, 18.iv.1988, Krieger \& Brügger 25600 (ESA!); São Roque de Minas, Serra da Canastra, próximo à cachoeira do centro de visitante do Parque Nacional da Serra da Canastra, 15.v.2007, Watanabe \& al. 111 (SPF!); São Sebastião do Paraíso, 8.ix.1982, Leitão Filho \& al. 1878 (UEC! ); São Tomé das Letras, 12.v.1989, Waligora s.n. (SPF!); Sete Lagoas, estrada Belo Horizonte-Brasília, Km 91- S. Lagoas, 15.vi.1967, Silva 52 (RB!, RBR!); Três Marias, estrada para Pedras, 20 km de Três Marias, 185'38"S 4510'38"W, 12.vii.2005, Forzza \& al. 4003 (RB, SPF!); Uberaba, 18 km north of Uberaba on highway BR-106, Stand 183, 6.vii.1967, Goodland 3120 (UB!); Unaí, cerca de $50 \mathrm{~m}$ a Oeste do portão central da UHE Queimado, 16²12'56"S 47019'32"W, 25.iii.2002, Pereira-Silva \& al. 6220 (CEN!). SÃO PAULO: Franca, 20³5'40"S 47²8'11'W, 28.iii.1997, Harley \& al. 28497 (SPF!); Pedregulho, Estreito, Usina de Estreito ("Acampamento de Estreito"), encosta à margem da represa, próxima ao antigo aeroporto, 209'52"S 47016'23"W, 18.iii.2003, Sasaki \& al. 222 (SPF!); Rifaina, 14.iv.1981, Leitão Filho \& al. 12504 (SPF!, UEC!); São José do Barreiro, Parque Nacional da Serra da Bocaina, estrada para o Bairro dos Macacos, localidade Alto do Caçador, 20.iii.1999, Freitas 651 (UEC!); São José dos Campos, ca. 8,5 km S of main plaza at São José dos Campos, 2.vi.1961, Eiten \& Eiten 2888 (SP!, US!) TOCANTINS: Ponte Alta do Tocantins, Córrego Fazendinha, 22.v.1984, Hakme 17 (SPF!).

\section{Espécies excluídas}

1. Calolisianthus amplissimus (Mart.) Gilg in Engler \& Prantl Nat. Pflanzenfam. 4(2): 99. 1895 = Lisianthus amplissimus Mart., Nov. Gen. sp. pl. 2(2): 96, tab. 175. $1827 \equiv$ Helia amplissima (Mart.) Kuntze, Revis. gen. pl. 2: 428. 1891 = Irlbachia amplissima (Mart.) Maas, Proc. Kon. Ned. Akad. Wetensch. C. 88(4): 410. 1985 - Tipo: "Brasilia, Prov. Minarum", s.d., Martius s.n. - Lectótipo (aqui designado): M [foto SPF!]; M [foto SPF!].

Nota: no herbário $M$ foram encontrados 2 síntipos. Optou-se por lectotipificar o exemplar com maior número de flores e melhor estado de preservação. Essa espécie foi tratada como pertencente a Calolisianthus desde a criação deste gênero. Somente com os resultados dos estudos filogenéticos baseados em dados morfológicos e moleculares (Calió \& al., em prep., Cap. 3), tornou-se evidente que essa espécie não era proximamente relacionada às demais espécies de Calolisianthus, mas sim a Chelonanthus purpurascens. Sendo assim, C. amplissimus será combinada em Chelonanthus (capítulo 6 da presente Tese). 
2. Calolisianthus acutangulus (Mart.) Gilg in Engler \& Prantl Nat. Pflanzenfam. 4(2): 99. 1895 = Lisianthus acutangulus Mart., Flora 21(2), Beibl. 4-5: 49. 1838, nom. illeg. (non $L$. acutangulus Ruiz \& Pav., FI. peruv. prodr. 1794) - Tipo: [Brasil, Mato Grosso], "Prope Cuiaba", s.d., Martius 216 - Lectótipo (aqui designado) BR [foto SPF!]; BR [foto SPF!], E [imagem digitalizada da exsicata!], G [foto U!], K [imagem digitalizada da exsicata!], P [imagem digitalizada da exsicata!].

=Lisianthus tetrago-alatus Steud., Nomencl. bot. 2: 55. 1841, nom. nud.

Nota: A escolha do material para lectotipificação baseou-se em seu melhor estado de preservação. O nome Lisianthus acutangulus Mart. é ilegítimo, pois se trata de um homônimo posterior ao nome Lisianthus acutangulus Ruiz \& Pavon, publicado anteriormente para designar uma espécie peruana, atualmente tratada como um sinônimo de Chelonanthus alatus (Aubl.) Pulle. O nome L. tetragono-alatus Steud. não foi validamente publicado, mas Steudel cita L. acutangulus Mart. como sinônimo de L. tetrago-alatus. Desde sua descrição, L. acutangulus Mart. foi tratada como pertencente ao gênero Calolisianthus. Somente com os resultados dos estudos filogenéticos baseados em dados morfológicos e moleculares (Calió \& al., em prep., Cap. 3), tornou-se evidente que essa espécie não era proximamente relacionada às demais espécies de Calolisianthus, mas sim a Chelonanthus purpurascens. A legitimação desse nome e a combinação em Chelonanthus serão apresentadas em outro trabalho (capítulo 6 da presente Tese).

3. Calolisianthus frigidus (Sw.) Gilg in Engler \& Prantl Nat. Pflanzenfam. 4(2): 101. $1895 \equiv$ Lisianthus frigidus Sw., Prodr. 40. 1788 = Helia frigida (Sw.) Kuntze, Revis. gen. pl. 2: 428. 1891 = Chelonanthus frigidus (Sw.) Urb., Symb. Antill. 3: 334. 1902 =Irlbachia frigida (Sw.) Maas, Proc. Kon. Ned. Akad. Wetensch. C. 88(4): 410. $1985 \equiv$ Wurdackanthus frigidus (Sw.) Maguire \& B.M.Boom, Mem. New York Bot. Gard. 51: 9. 1989 = Symbolanthus frigidus (Sw.) Struwe \& K. Gould, Novon 14(3): 356-358, f. 1. 2004 - Tipo: Dominica "Incolit regionem muscosam montis la Soufriere Insulae Dominicae", s.d., Ponthieu s.n. - Holótipo: BM (n.v.); isótipo: S (n.v.).

4. Calolisianthus imthumianus (Oliv.) Gleason, Bull. Torrey Bot. Club 56: 402. $1929 \equiv$ Lisianthus imthurnianus Oliv., Trans. Linn. Soc. London, Bot. 2(2): 279. $1887 \equiv$ Celiantha imthurmiana (Oliv.) Maguire, Mem. New York Bot. Gard. 32: 387. 1981 - Tipo: "Roraima", s.d., F. im Thurn 306 - Holótipo K [imagem digitalizada da exsicata!]. 
5. Calolisianthus tatei Gleason, Bull. Torrey Bot. Club 58: 449. $1931 \equiv$ Lisianthus tatei (Gleason) Steyerm., Fieldiana, Bot. 28(3): 498. 1953 = Irlbachia tatei (Gleason) Maguire, Mem. New York Bot. Gard. 32: 377. 1981 - Tipo: "Dry forest of savanna hills, flowers pink, summit of Mount Duida at $4400 \mathrm{ft}$ ", Agosto 1928 - Abril 1929, G.H.H. Tate 743 - Holótipo: NY [imagem digitalizada da exsicata!].

6. Calolisianthus tepuiensis Gleason, Brittonia 3: 188(-189). $1939 \equiv$ Macrocarpaea tepuiensis (Gleason) Steyerm., Fieldiana, Bot. 28(3): 498. $1953 \equiv$ Rogersonanthus tepuiensis (Gleason) Maguire \& B.M. Boom, Mem. New York Bot. Gard. 51: 4, f. 3.1989 - Tipo: Auyántepuí, 1800 m, Dezembro 1937, G.H.H. Tate 1361 - Holótipo: NY [imagem digitalizada da exsicata!].

\section{Referências Bibliográficas}

Angely, J. 1965. Flora analítica do Paraná, vol. 7 Coleção Saint-Hilaire. Phyton, São Paulo. Angely, J. 1971 [1970]. Flora analítica e fitogeográfica do Estado de São Paulo, vol. 4. Phyton, São Paulo.

Bell, A.D. 1991. Plant Form: an illustrated guide to flowering plant morphology. Oxford University Press, New York.

Bouman, F., Cobb, L., Devente, N., Goethals, V., Maas, P.J.M. \& Smets, E. 2002. The seeds of Gentianaceae. Pp. 498-572 in: Struwe, L. \& Albert, V.A. (eds.), Gentianaceae Systematics and Natural History. Cambridge University Press, Cambridge.

Cabrera, A.L. \& Willink, A. 1980. Biogeografia de America Latina. Secretaria General de la Organización de los Estados Americanos. Washington, D.C.

Calió, M.F. 2009. Gentianaceae. in: Neotropikey. Version 1, March 2009. Royal Botanic Gardens, Kew. http://www.kew.org/science/tropamerica/neotropikey/families/Gentianaceae.htm, acessado em 20/julho/2009.

Calió, M.F. \& Pirani, J.R., em prep. Nova lectotipificação de Calolisianthus Gilg (Helieae Gentianaceae). A ser submetido a Taxon.

Calió, M.F., Pirani, J.R. Struwe, L. \& Lepis, K.B., em prep. Estudo filogenético de Helieae (Gentianaceae) com ênfase nos limites genéricos de Calolisianthus Gilg, Chelonanthus Gilg e Helia Mart., baseado em dados moleculares e morfológicos. A ser submetido a Molecular Phylogenetics and Evolution.

Chamisso, L.K.A. von \& Schlechtendal, D.F.L. von. 1826. De plantis in expeditione speculatoria Romanoffiana observatis rationem dicunt Ad. de Chamisso et D. de Schlechtendal. Linnaea 1: 1-677. 
Cordeiro, I. 1983. Flora fanerogâmica da Reserva do Parque Estadual das Fontes do Ipiranga (São Paulo, Brasil) - 133 - Gentianaceae. Hoehnea 10: 49-52.

Cordeiro, I. 1987. Flora da Serra do Cipó, Minas Gerais. Gentianaceae. Bol. Bot. Univ. de São Paulo 9: 209-249.

Cordeiro, I. 2004. Flora de Grão-Mogol Minas Gerais: Gentianaceae. Bol. Bot. Univ. de São Paulo 22(2): 137-140.

Cordeiro, I. 2005. Gentianaceae. Pp. 211-222 in: Wanderley, M.G.L., Shepherd, G.J., Melhem, T.S., Giulietti, A.M. (eds.), Flora Fanerogâmica do Estado de São Paulo, vol. 4. FAPESP, São Paulo.

Costa, C.M.R., Herrmann, G., Martins, C.S., Lins, L.V. \& Lamas, I.R. 1998. Biodiversidade em Minas Gerais: um atlas para sua conservação. Fundação Biodiversitas, Belo Horizonte.

Delgado, M.N. 2008. Caracterização morfoanatômica de espécies de Gentianaceae em áreas de cerrado e campo rupestre em Minas Gerais. Dissertação, Universidade Federal de Viçosa, Viçosa.

ESRI, Environmental Systems Research Institute, INC. 2006. ArcGis - ArcView Desktop 9.2.

Fabris, H.A. \& Klein, R.M. 1971. Gentianaceae. Pp. 3-30 in: Reitz, P.R. (ed.), Flora llustrada Catarinense, parte 1, fascículo GENC. Herbário "Barbosa Rodrigues", Itajaí.

Fiaschi, P. \& Pirani, J.R. no prelo. Review of plant biogeographic studies in Brazil. J. Syst. Evol.

Freitas, L. \& Sazima, M. 2009. Floral biology and mechanisms of spontaneous selfpollination in five neotropical species of Gentianaceae. Bot. J. Linn. Soc. 160: 357-368.

Gilg, E. 1895. Gentianaceae. Pp. 50-108 in: Engler, H.G.A. \& Prantl, K.A.E. (eds.), Die natürlichen Pflanzenfamilien, vol. 4(2). Verlag von Wilhem Engelmann, Leipzig.

Giulietti, A.M. \& Pirani, J.R. 1988. Patterns of geographic distribution of some plant species from the Espinhaço Range, Minas Gerais and Bahia, Brazil. Pp. 39-69 in: Vanzolini, P.E. \& Heyer, W.R. (eds.), Proceedings of a workshop on neotropical distribution patterns. Academia Brasileira de Ciências, Rio de Janeiro.

Grisebach, A.H.R. 1839 [1838]. Genera et species plantarum. J.G. Cotta, Stuttgart and Tübingen.

Grisebach, A.H.R. 1845. Gentianaceae. Pp. 39-141 in: Candolle, A. de (ed.), Prodromus systematis naturalis regni vegetabilis, vol. 9. Fortin, Masson, et Sociorum, Paris.

Harley, R.M. 1988. Evolution and distribution of Eriope (Labiatae), and its relatives, in Brazil. Pp. 71-120 in: Vanzolini, P.E. \& Heyer, W.R. (eds.), Proceedings of a workshop on neotropical distribution patterns. Academia Brasileira de Ciências, Rio de Janeiro.

Harley, R.M. \& Simmons, N.A. 1986. Florula of Mucugê, Chapada Diamantina, Bahia, Brazil. A descriptive check-list of the campo rupestre area. Royal Botanic Gardens, Kew. 
Harvey, Y.B. 1995. Gentianaceae. Pp. 321-327 in: Stannard, B.L. (ed.), Flora of the Pico das Almas, Chapada Diamantina-Bahia, Brazil. Royal Botanic Gardens, Kew.

Hickey, L.J. 1979. A revised classification on the architecture of dicotyledonous leaves. Pp. 25-39 in: Metcalfe, C.R. \& Chalk, L. (eds.) Anatomy of the Dicotyledons. Vol. 1. Ed. 2. Clarendon Press, Oxford.

IUCN 2001. IUCN Red List categories and criteria. Version 3.1. IUCN, Gland, Switzerland \& Cambridge, U.K.

Klink, C.A. \& Machado, R.B. 2005. A conservação do Cerrado brasileiro. Megadiversidade 1(1): 147-155.

Kuntze, C.E.O. 1891. Revisio generum plantarum, vol. 2. Arthur Felix, Leipzig.

Maas, P.J.M. 1985. Nomenclatural notes on neotropical Lisyantheae (Gentianaceae). Proc. Kon. Ned. Akad. Wetensch., ser C, 88: 405-412.

Machado, R.B., Ramos Neto, M.B., Pereira, P.G.P., Caldas, E.F., Gonçalves, D.A., Santos, N.S., Tabor, K. \& Steininger, M. 2004. Estimativas de perda da área do Cerrado brasileiro. Relatório técnico não publicado. Conservação Internacional, Brasília, DF.

Maguire, B. 1981. Gentianacaea. Pp. 330-388 in: Maguire, B. \& collaborators (eds.), The Botany of the Guayana Highland - Part XI. Memoirs of the New York Botanical Garden 32, Bronx.

Maguire, B. 1985. Gentianaceae - part 2. Phytologia 57: 311-312.

Maguire, B. \& Boom, B.M. 1989. Gentianaceae - Part 3. Pp. 2-56 in: Maguire, B. \& collaborators (eds.), The Botany of the Guayana Highland - Part XIII. Memoirs of the New York Botanical Garden 51, Bronx.

Martius, C.F.P. von. 1827. Nova genera et species plantarum quas in itinere per Brasiliam, vol. 2, parte 2. V. Wolf, München.

Nilsson, S. 2002. Gentianaceae - a review of palynology. Pp. 377-497 in: Struwe, L. \& Albert, V.A. (eds.), Gentianaceae - systematics and natural history. Cambridge University Press, Cambridge.

Pio-Correa, M. 1926. Dicionário das plantas úteis do Brasil e das plantas cultivadas, vol. 3, F-G. Ministério da Agricultura, Rio de Janeiro.

Prance, G.T. 1994. A comparison of the efficacy of higher taxa and species number in the assessment of biodiversity in the neotropics. Phil. Trans. R. Soc. Lond. B 345: 89-99.

Pringle, J.S. 1995. Family 159A. Gentianaceae. Pp. 1-131 in: Harling, G.\& Andersson, L. (eds.), Flora of Ecuador, vol. 53. Department of Systematic Botany, Gothenburg University, Göteborg.

Progel, A. 1865. Gentianaceae. Pp. 198-248 in: Martius, C.F.P. von (ed.), Flora Brasiliensis, vol. 6, parte 1. Frid. Fleischer, Monachii.

Radford, A.E., Dickson, W.C., Massey, J.R. \& Bell, C.R. 1974. Vascular plant systematics. 
Harper \& Row Publishers, New York, Evanston, San Francisco, London.

Stafleu, F.A. \& Cowan, R.S. 1976. Taxonomic Literature: A selective guide to botanical publications and collections, with dates, commentaries and types. 2nd much enlarged ed. v. 1. Bohn, Scheltema \& Holkema, W. Junk b.v., Publishers, The Hague.

Stafleu, F.A. \& Cowan, R.S. 1985. Taxonomic Literature: A selective guide to botanical publications and collections, with dates, commentaries and types. 2nd much enlarged ed. v. 5. Bohn, Scheltema \& Holkema, Utrecht/Antwerpen; Boston, W. Junk b.v., Publishers, The Hague.

Struwe, L. \& Albert, V.A. 1998. Lisianthius P.Br., its probable homonym Lisyanthus Aubl. (Gentianaceae) and the priority of Helia Mart. over Irlbachia Mart. as its substitute. Harvard Pap. Bot. 3(1): 67-71.

Struwe, L., Albert, V.A., Calió, M.F., Frasier, C., Lepis, K.B., Mathews, K.G., Grant, J.R. 2009. Evolutionary patterns in neotropical Helieae (Gentianaceae): evidence from morphology, choroplast and nuclear DNA sequences. Taxon 58(2): 479-499.

Struwe, L., Kadereit, J., Klackenberg, J., Nilsson, S., Thiv, M., von Hagen, K.B. \& Albert, V.A. 2002. Systematics, character evolution and biogeography of Gentianaceae, including a new tribal and subtribal classification. Pp. 21-309 in: Struwe, L. \& Albert, V.A. (eds.), Gentianaceae - Systematics and Natural History. Cambridge University Press, Cambridge.

Struwe, L., Maas, P.J.M. \& Albert, V.A. 1997. Aripuana cullmaniorum, a new genus and species of Gentianaceae from white-sands of southeastern Amazonas, Brazil. Harvard Pap. Bot. 2(2): 235-253.

Weberling, F. 1989. Morphology of flowers and inflorescences. Cambridge University Press. New York.

Zijlstra, G., Maas, P.J.M., Gandhi, K. 1999. On the nonexistence of Lisyanthus Aublet. Harvard Pap. Bot. 4(1): 289-292. 


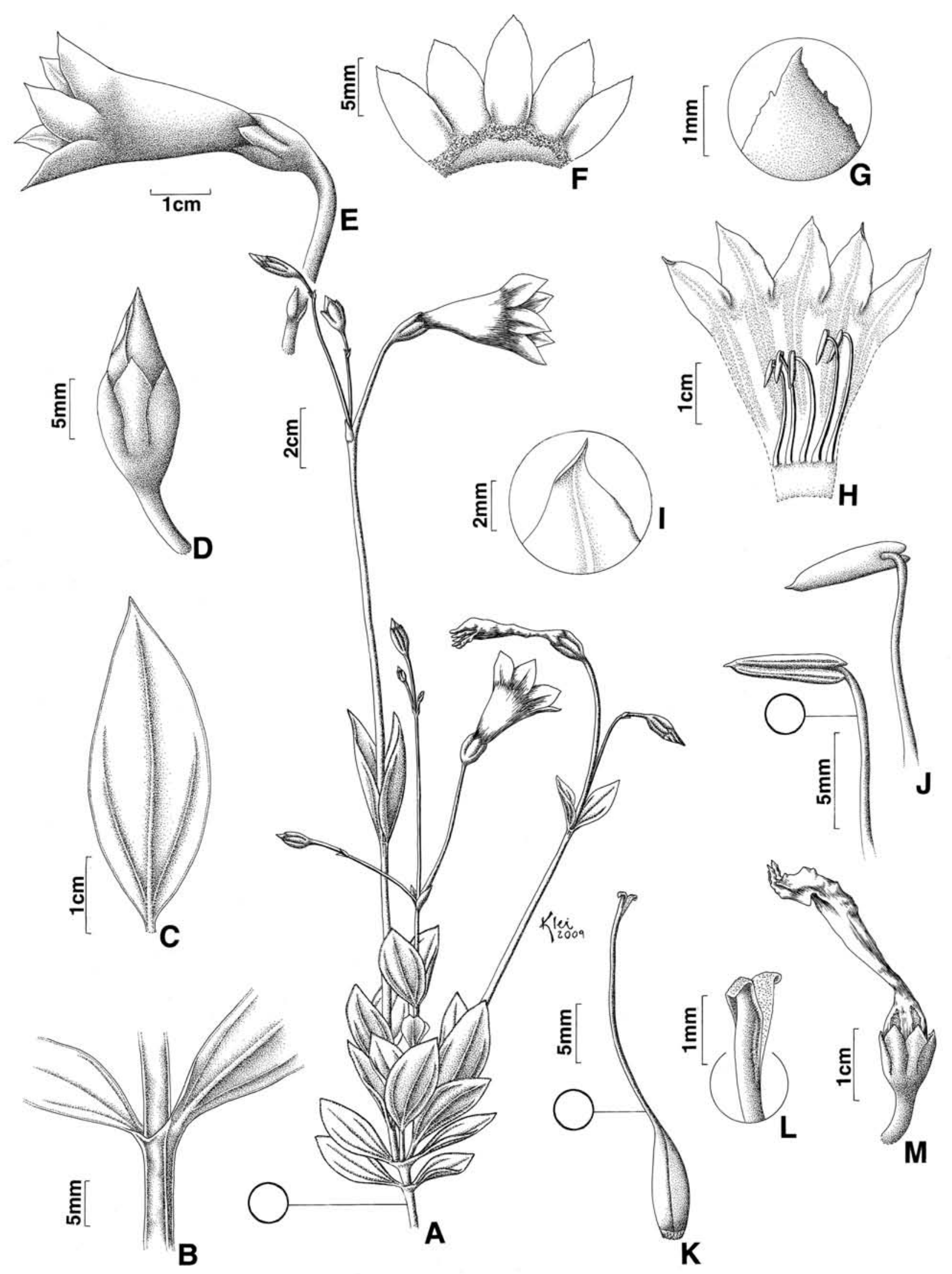

Fig. 1. Calolisianthus bellissimus. A, hábito, com representação esquemática da seção transversal do caule; $B$, detalhe do nó; $C$, face abaxial da folha; $D$, botão floral; $E$, flor isolada, visão lateral; F, cálice rebatido, evidenciando coléteres na região interior; $\mathbf{G}$, detalhe do ápice e margem do lobo do cálice; $\mathrm{H}$, corola rebatida, evidenciando inserção e tamanho desigual dos estames; I, detalhe do ápice e margem do lobo da corola; $\mathrm{J}$, estames (faces abaxial e adaxial), com representação esquemática da seção transversal do filete; $K$, gineceu, com representação esquemática da seção transversal do estilete; L, detalhe do estigma; M, fruto com cálice e corola persistentes. Todos desenhados a partir de Calió \& al. 87 (SPF). 


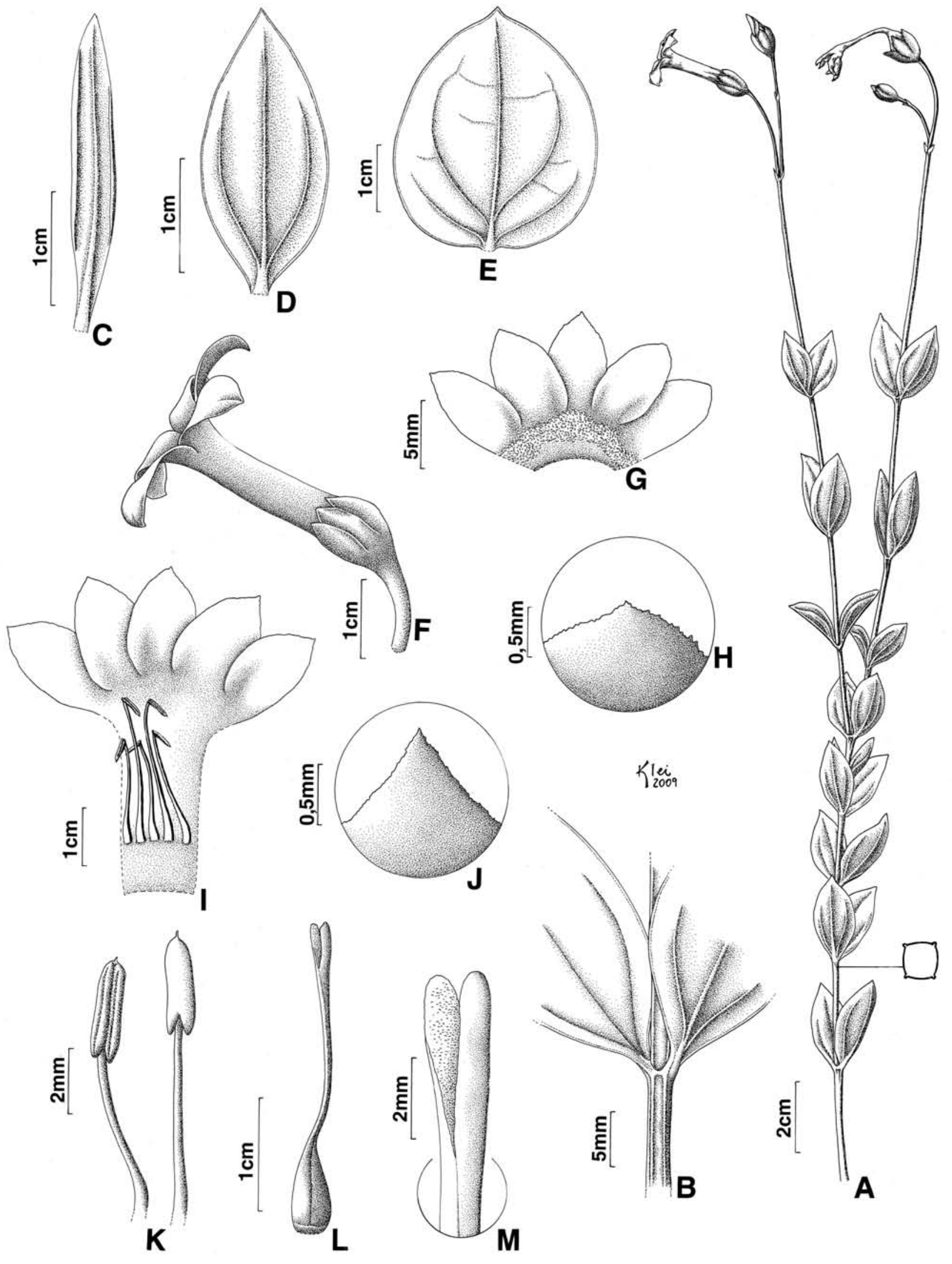

Fig. 2. Calolisianthus pedunculatus. A, hábito, com representação esquemática da seção transversal do caule; B, detalhe do nó; C-E, variação foliar, face abaxial; F, flor, visão lateral; G, cálice rebatido, evidenciando coléteres na região interior; $\mathrm{H}$, detalhe do ápice e margem do lobo do cálice; I, corola rebatida, evidenciando inserção e tamanho desigual dos estames; J, detalhe do ápice e margem do lobo da corola; K, estames (visão abaxial e adaxial); L, gineceu; M, detalhe do estigma. Todos desenhados a partir de Calió \& al. 173 (SPF), exceto (C) de Giulietti et al. CFCR 1319 (SPF) e (E) de Lovo \& al. 145 (SPF). 

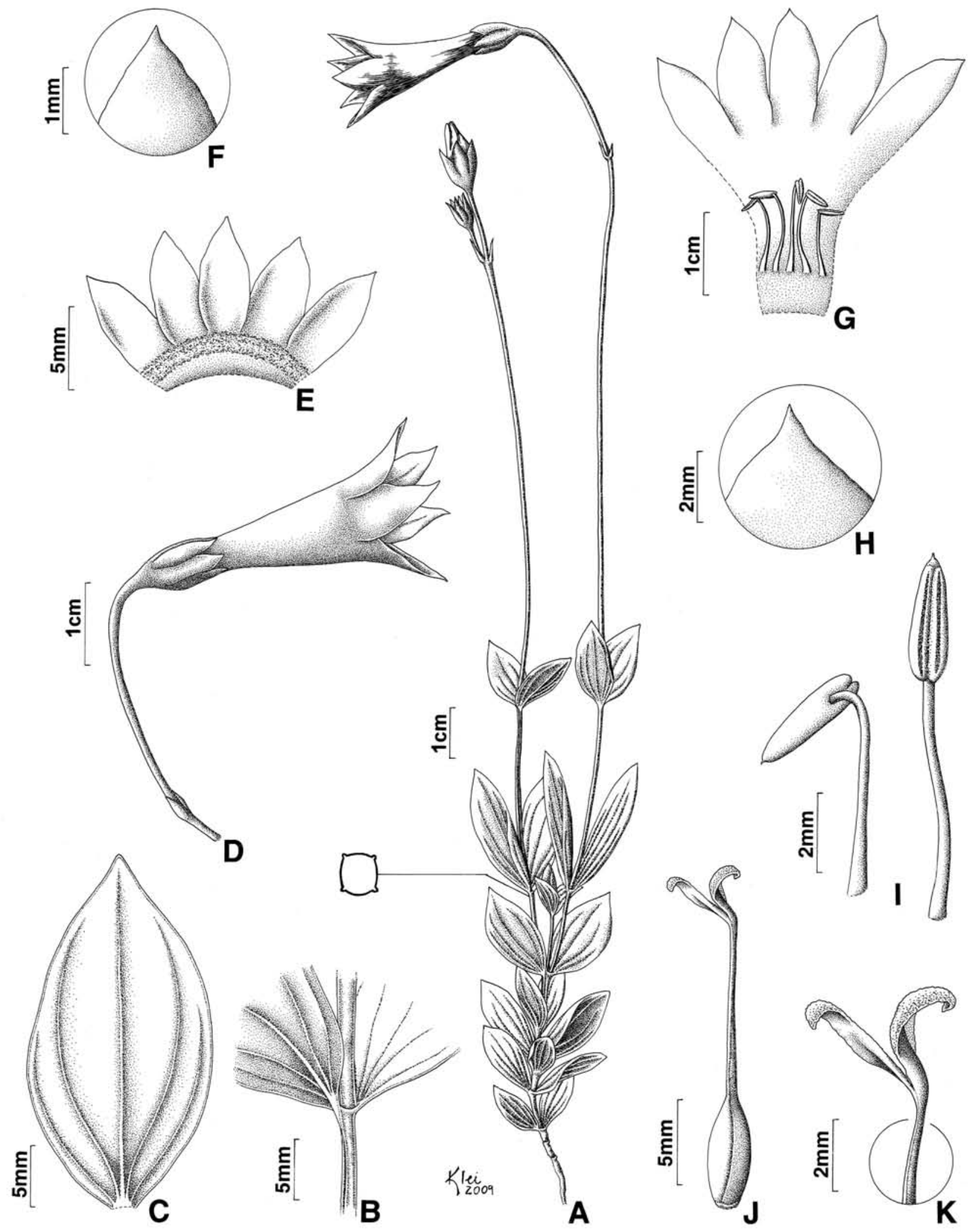

Fig. 3. Calolisianthus pendulus. A, hábito, com representação esquemática da seção transversal do caule; B, detalhe do nó; C, face abaxial da folha; D, flor, visão lateral; E, cálice rebatido, evidenciando coléteres na região interior; F, detalhe do ápice e margem do lobo do cálice; G, corola rebatida, evidenciando inserção e tamanho desigual dos estames; $\mathrm{H}$, detalhe do ápice e margem do lobo da corola; I, estames (visão abaxial e adaxial); J, gineceu; K, detalhe do estigma. Todos desenhados a partir de Calió \& al. 86 (SPF). 


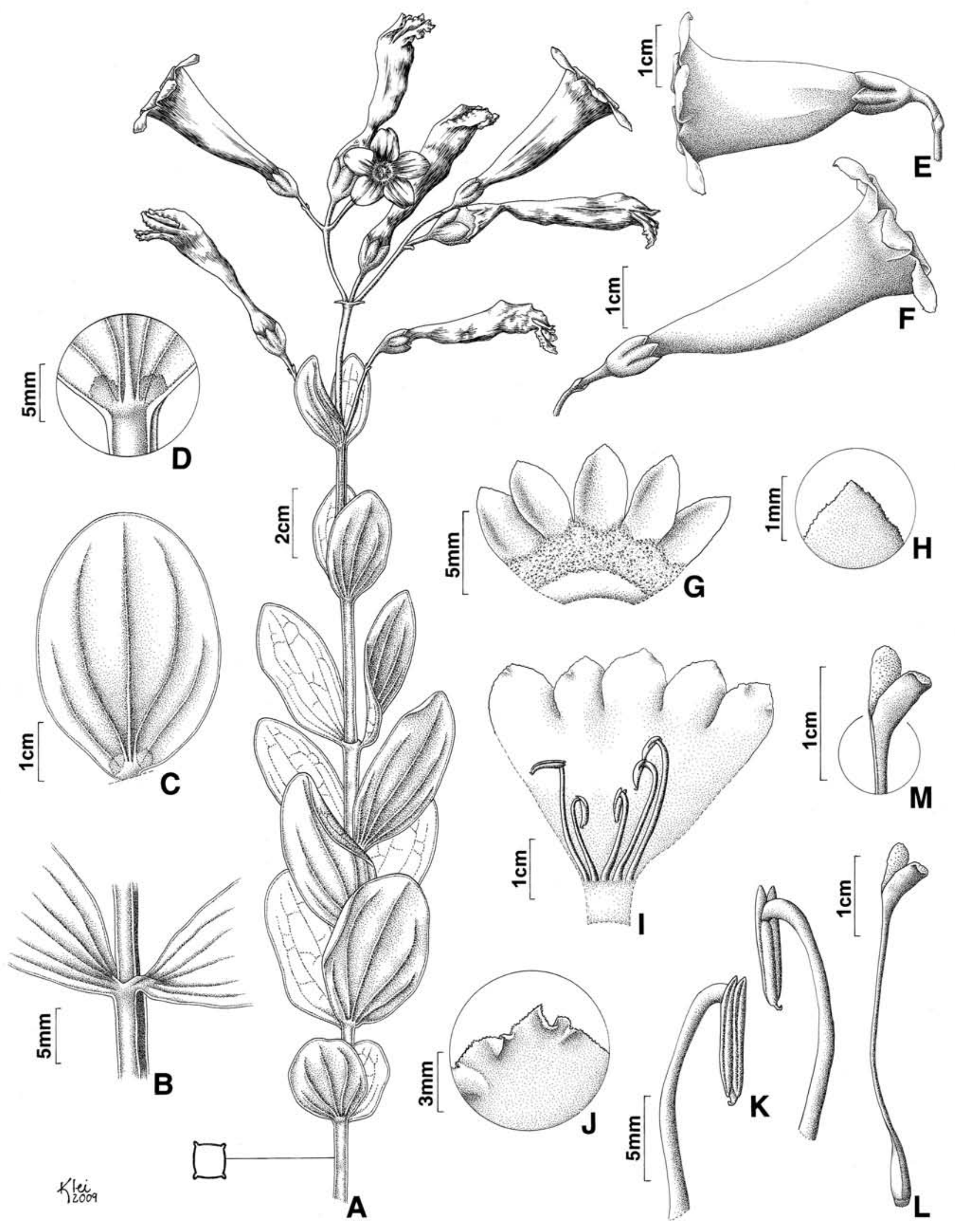

Fig. 4. Calolisianthus speciosus. A, hábito, com representação esquemática da seção transversal do caule; B, detalhe do nó; C, face abaxial da folha; D, detalhe dos nectários extra-florais na face abaxial da folha; E-F, variação floral, visão lateral; G, cálice rebatido, evidenciando coléteres na região interior; $\mathrm{H}$, detalhe do ápice e margem do lobo do cálice; I, corola rebatida, evidenciando inserção e tamanho desigual dos estames; J, detalhe do ápice e margem do lobo da corola; K, estames (visão abaxial e adaxial); L, gineceu; $M$, detalhe do estigma. Todos desenhados a partir de Watanabe \& al. 116 (SPF), exceto (A-D) de Calió \& al. 105 (SPF) e (F) de Calió \& al. 109 (SPF). 

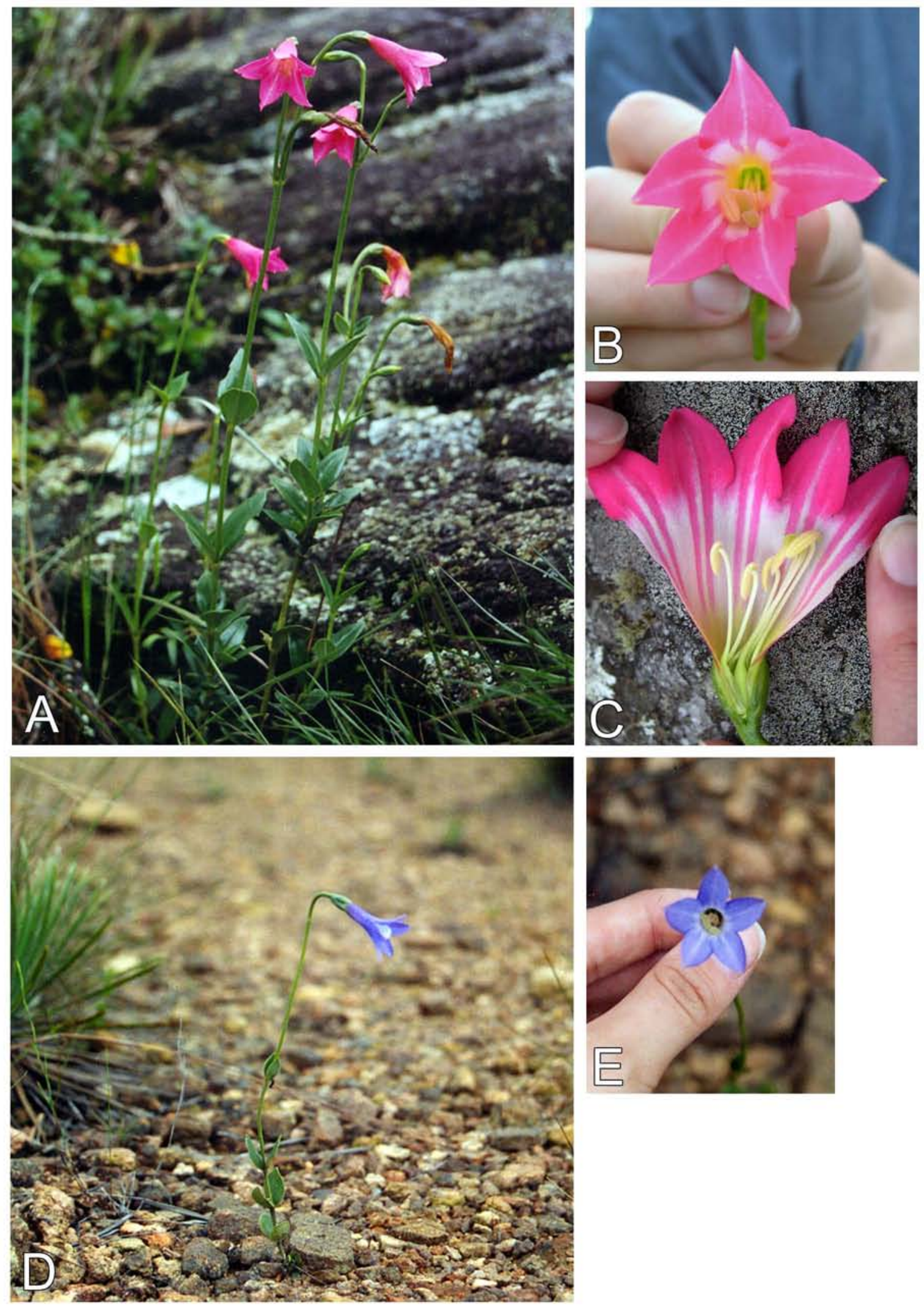

Fig. 5. Calolisianthus bellissimus. A, hábito; B, flor, visão frontal; C, flor com corola rebatida. Calolisianthus pendulus. D, hábito; E, flor, visão frontal. Fotos: B-C, Lívia Temponi; demais, Maria Fernanda Calió. 

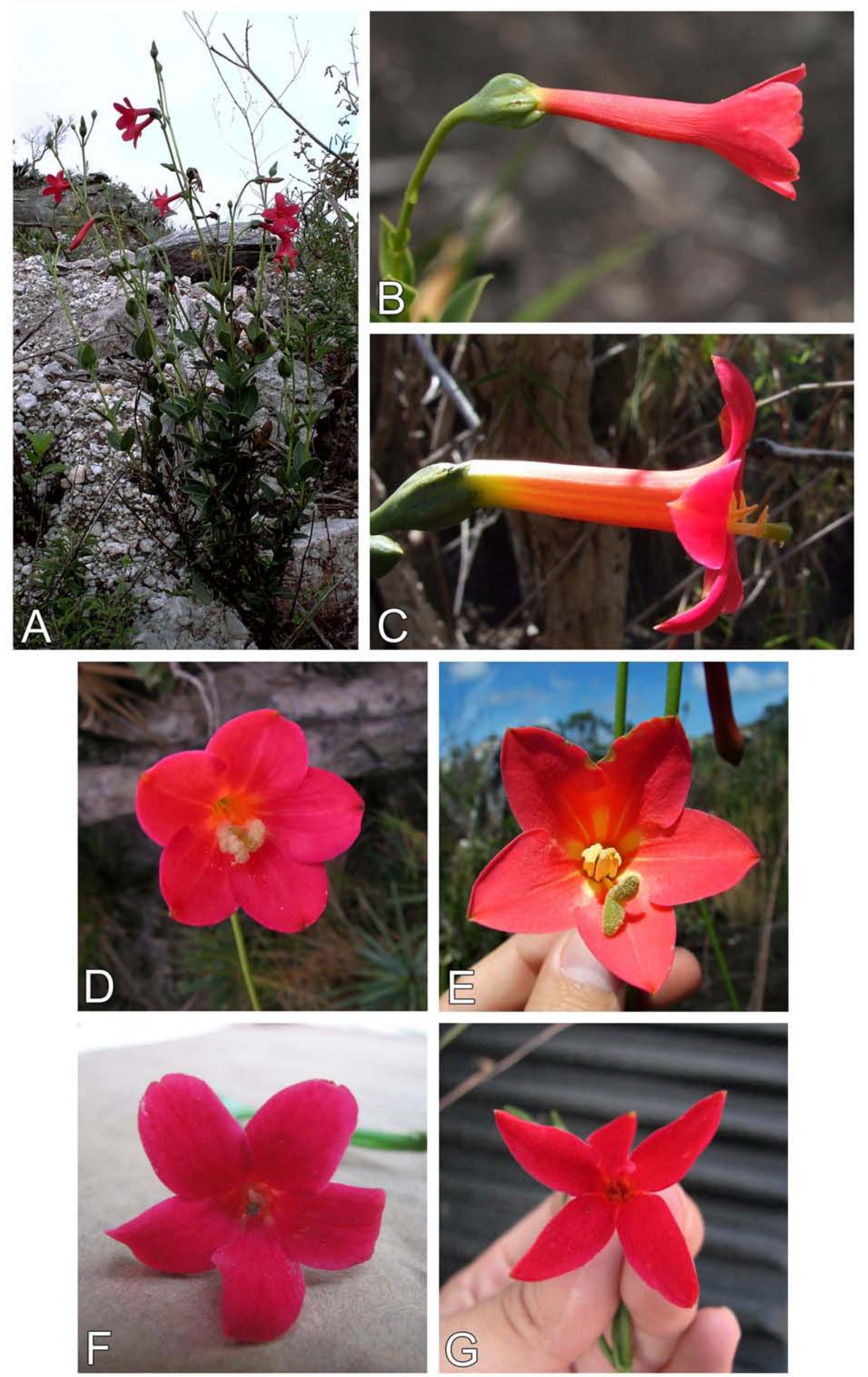

Fig. 6. Calolisianthus pedunculatus. A, hábito; B-C, variação floral, visão lateral; D-G, variação floral, visão frontal. Fotos: A, Katherine Lepis; B, Richard Winkworth; C, Lívia Echternacht; D, Juliana Lovo; E, Marcelo Trovó; F-G, Maria Fernanda Calió. 


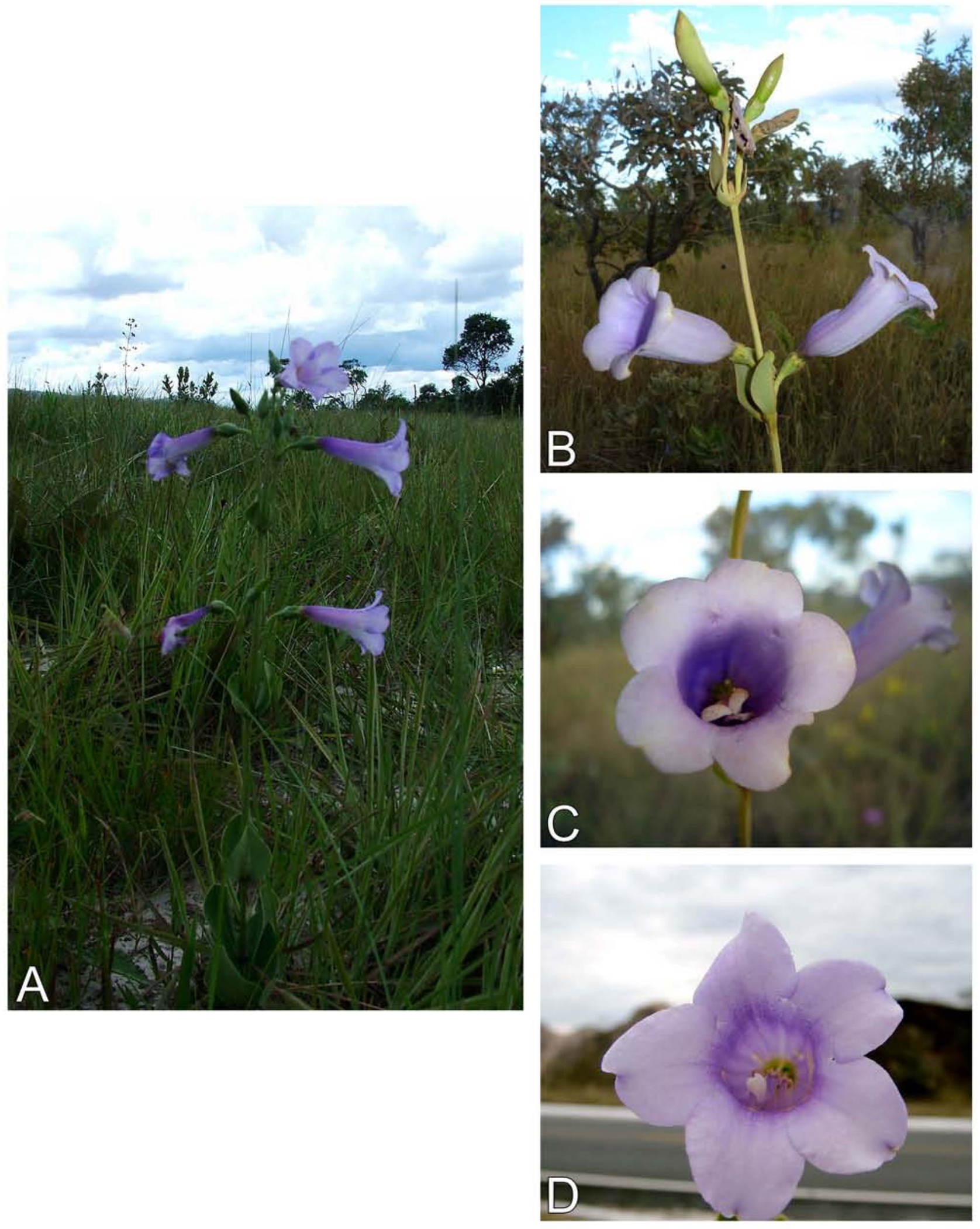

Fig. 7. Calolisianthus speciosus. A, hábito; B, inflorescência; C-D, variação floral, visão frontal. Fotos: A, Lia Bezerra; B-C, Benoît Loeuille; D, Marcelo Trovó. 

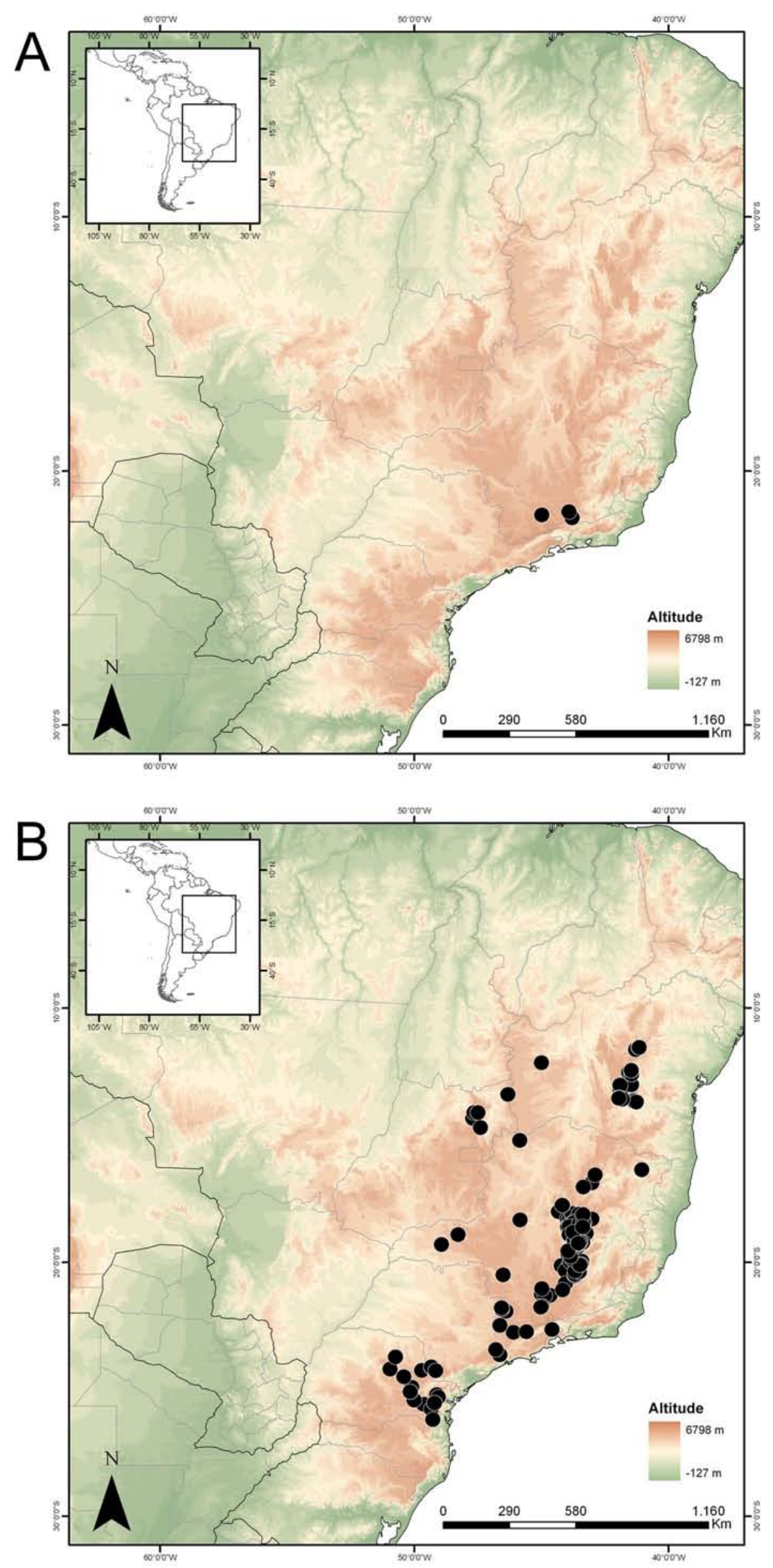

Fig. 8. Distribuição geográfica. A, Calolisianthus bellissimus; B, Calolisianthus pedunculatus. 

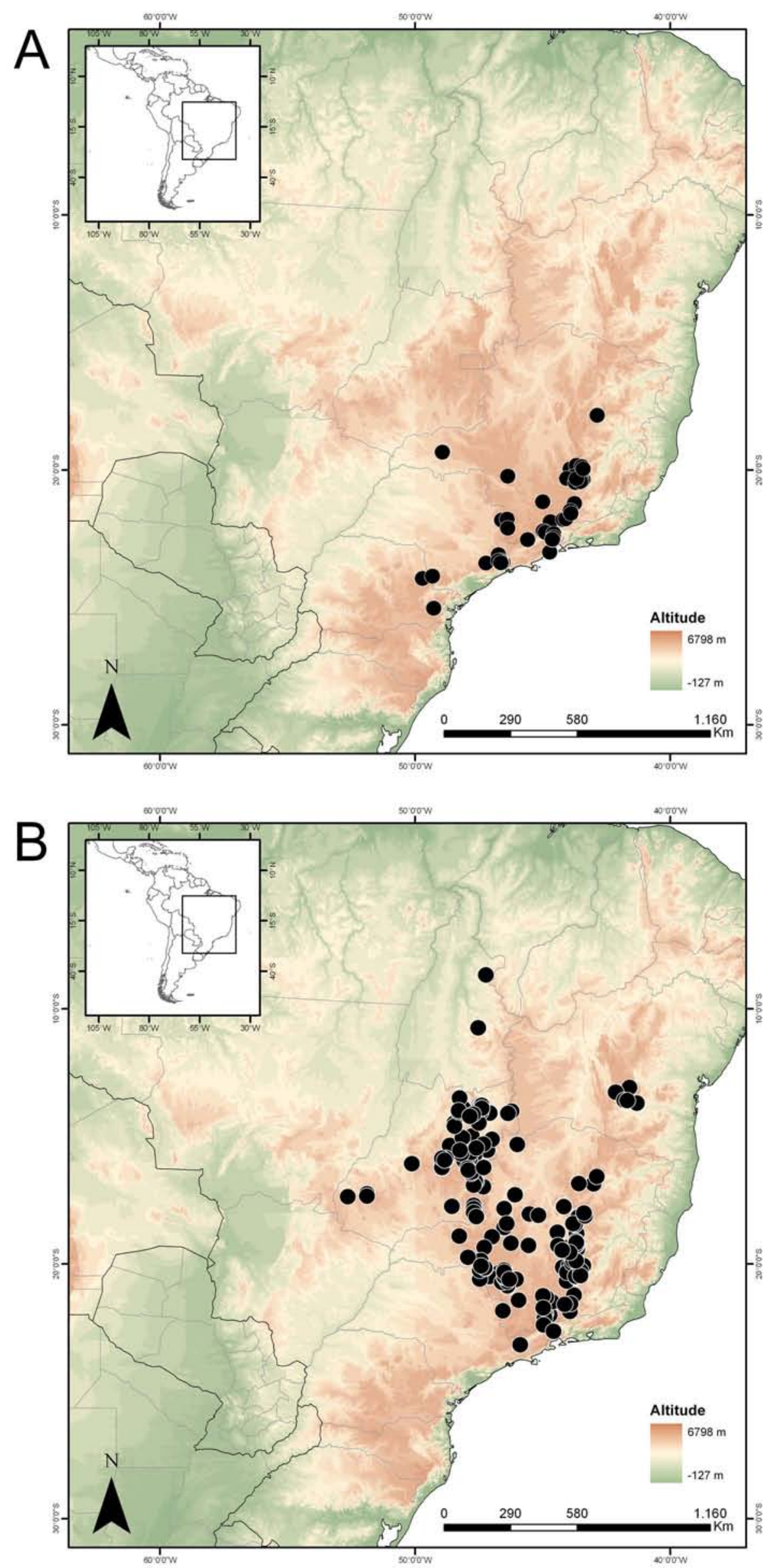

Fig. 9. Distribuição geográfica. A, Calolisianthus pendulus; B, Calolisianthus speciosus. 
Apêndice A. Lista de exsicatas, indicando coletor e número, número da espécie no tratamento taxonômico e herbários. Negrito = espécimes-tipo; scan = imagem digitalizada da exsicata. Calolisianthus bellissimus $=1$; Calolisianthus pedunculatus $=2 ;$ Calolisianthus pendulus $=3$; Calolisianthus speciosus $=4$.

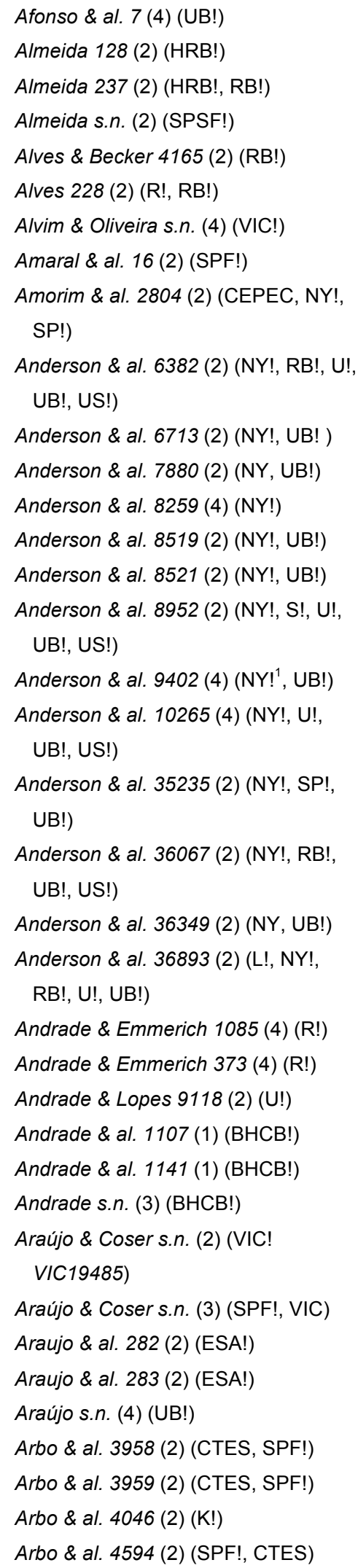

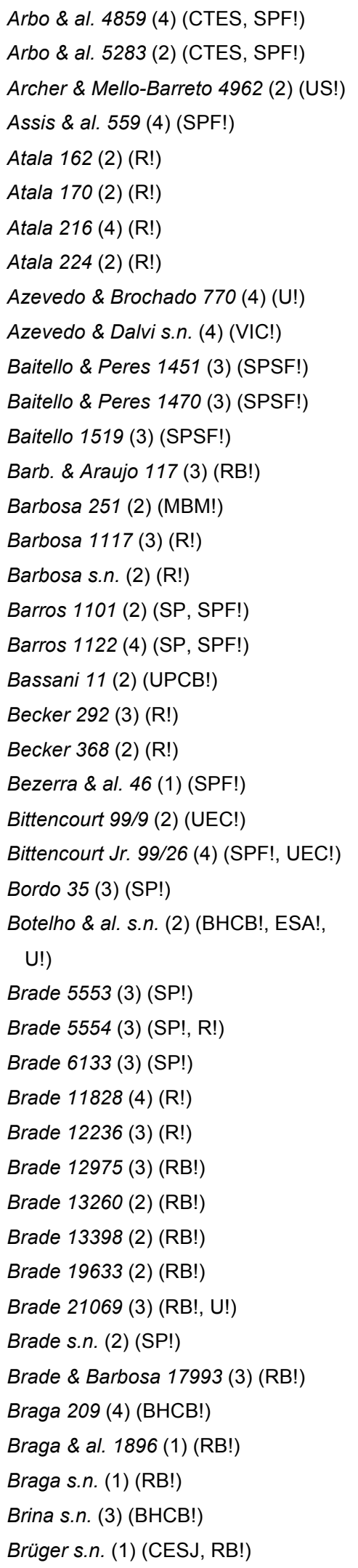

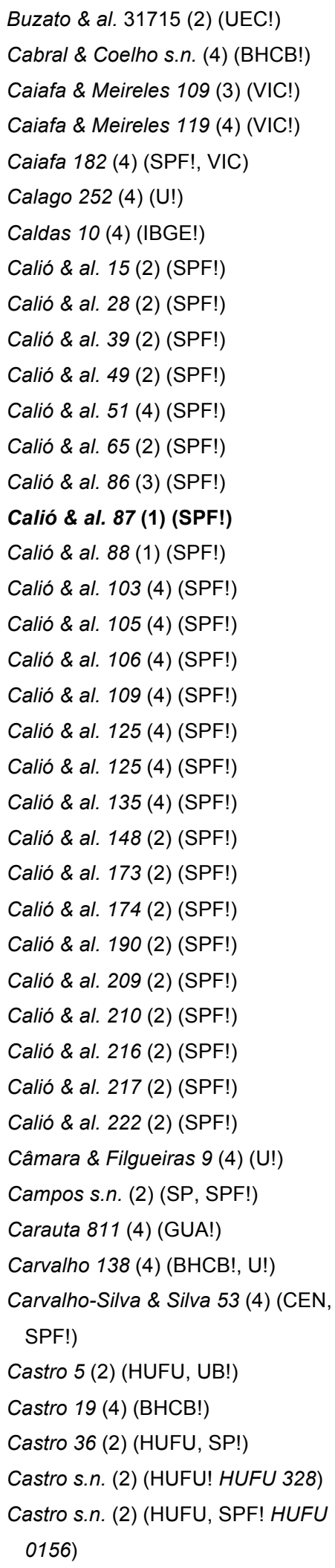


Castro s.n. (2) (HUFU, SPF! HUFU 5324)

Castro s.n. (2) (SP, SPF! SPF160453)

Cavalcanti \& Silva 1250 (4) (CEN, ESA!)

Cavalcanti \& Silva 1606 (4) (U!)

Cavalcanti \& al. 578 (4) (CEN, SP!)

Cavalcanti \& al. 817 (4) (CEN, HUEFS!, SP!)

Cavalcanti \& al. 2577 (2) (CEN!, U!)

Cavalcanti \& al. CFCR 8184 (4) (SPF!)

Cavalcanti \& al. CFCR 8274 (4) (SPF!)

Cavalcanti \& al. CFCR 9543 (2) (SPF!)

Cerati \& al. 229 (4) (SP, SPF!)

Cervi \& Hatschbach 2291 (2) (UPCB!)

Chaddad Jr. 18 (4) (ESA!)

Chaddad Jr. 91 (4) (ESA!)

Claussen 352 (2) (NY!)

Claussen s.n. (2) (NY!, P)

Cochran s.n. (4) (US!)

Conceição \& Grillo 192 (2) (SPF!)

Coons \& al. 77-319 (1) (VIC!)

Coons \& al. 77-332 (3) (VIC!)

Coradim \& al. 6403 (2) (CEN!, K!, U!)

Cordeiro \& al. 426 (2) (SPF!)

Cordeiro \& al. 439 (2) (SPF!)

Cordeiro \& al. 1850 (3) (SP!)

Cordeiro \& al. CFCR 9357 (2) (SPF!)

Cordeiro CFSC 7436 (4) (SPF!, U!)

Costa $72(4)(R !)$

Costa 312 (2) (RB!)

Costa \& Barroso s.n. (2) (ALCB!)

Costa \& Fiaschi 196 (4) (SPF!)

Costa \& al. 102 (4) (SPF!)

Costa \& al. 37 (2) (CHRB!, SPF!)

Crespo \& al. 58 (2) (UEC!)

Cutler 8007 (4) (US!)

DAC s.n. (4) (ESAL, UEC!)

Dalcin \& Farney 6 (2) (RB!)

Damazio 361 (2) (RB!, U!)

\section{Damazio 1480 (G [scan!])}

Damazio s.n. (3) (RB!)

Davis \& Shepherd 59611 (4) (UEC!)

Davis \& Shepherd 59674 (4) (UEC!)

Davis \& Shepherd 60018 (4) (UEC!)

Davis 60116 (4) (UEC!)

Davis \& al. 2389 (2) (UEC!)

Davis \& al. 2524 (2) (UEC!)

Delgado \& al. s.n. (3) (SPF!, VIC; VIC31361)
Delgado \& al. s.n. (4) (VIC! VIC31360)

Delgado \& al. s.n. (4) (SPF!, VIC; VIC31362)

Delgado \& al. s.n. (4) (SPF!, VIC; VIC31363)

Delgado \& al. s.n. (4) (SPF!, VIC; VIC31364)

Dias \& al. 128 (4) (CEN, RB!, SP!) Dombrowski 11916 (2) (MBM!)

Duarte 2156 (2) (U!)

Duarte 2435 (2) (RB!, U!)

Duarte 3836 (4) (U!)

Duarte 6457 (2) (RB!, U!)

Duarte 7574 (2) (NY!, RB!, U!)

Duarte 8107 (4) (RB!, U!)

Duarte 9917 (4) (RB, U!)

Duarte 10404 (2) (RB!, U!)

Duarte \& Matos 8213 (4) (U!)

Duarte \& Matos 8363 (4) (RB!, U!)

Ducke s.n. (2) (RB! RB19015)

Ducke s.n. (2) (RB! RB22399)

Dusén 2096 (3) (US!)

Dusén 2877 (2) (R!)

Dusen 3096 (2) (R!)

Dusén 9112 (2) (S!)

Dusen s.n. (2) (US!)

Dutilh \& Marcondes-Ferreira 33 (3) (CESJ!, SPF!)

Edwall s.n. (2) (SP, SPF!)

Eiten \& Eiten 2888 (4) (SP!, US!)

Eiten \& Eiten 10970 (2) (US!)

Eiten \& Eiten 10989 (2) (UB!, US!)

Eiten \& Eiten 10994 (2) (K!, NY!, $\mathrm{K} !, \mathrm{SP} !, \mathrm{UB} !, \mathrm{US}$ !)

Eiterer \& Freitas 63 (3) (ESA!)

Eiterer \& Freiras 87 (1) (CESJ, MBM!)

El Ottra \& Versieux 15 (2) (SPF!)

Elias \& Rolim 335 (3) (ESA!, HUFU)

Emygdio \& al. 2333 (4) (R!)

Esteves \& Kameyama 2480 (2) (RB!, $\mathrm{SP} !)$

Farah \& Freitas 357 (4) (ESA!)

Farah \& Freitas 374 (4) (ESA!)

Farah \& al. 956 (4) (ESA!)

Faria \& Mazucato 45 (2) (SPF!)

Farinaccio \& al. 302 (4) (SPF!)

Farinaccio \& al. 315 (4) (HRCB, HUFU, SPF!)

Farinaccio \& al. 334 (4) (HUFU, SPF!)

Farinaccio \& al. 621 (2) (SPF!, CHRB!)

Farinaccio \& al. 668 (2) (SPF!)

Farney 175 (3) (RB!)
Farney 665 (3) (RB!)

Felix 11 (4) (SPF!)

Feres \& al. 99/42 (2) (UEC!)

Fernandes (A.Macedo 5748) (2) (US!)

Fernandes (A.Macedo 5751) (4) (US!)

Ferreira \& Cunha 7881 (4) (CTES!)

Ferreira \& Ferreira 74 (2) (CESJ, SP!)

Ferreira 20 (2) (CESJ, SP!)

Ferreira 152 (2) (CESJ!, SPF!)

Ferreira 3773 (4) (GUA!)

Ferreira \& al. 42 (4) (SP!)

Ferreira s.n. (4) (UPCB, VIC!; VIC9343)

Ferreira s.n. (4) (SPF!, VIC; VIC9352)

Fiaschi \& Costa 309 (2) (SPF!)

Fiaschi \& al. 228 (3) (SPF!)

Fiaschi \& al. 846 (4) (SP, SPF!)

Figueiredo 1 (2) (SP!)

Figueiredo 3 (2) (SP!)

Figueiredo 4 (2) (SP, SPF!)

Filliettaz \& al. 55 (4) (SPF!, UEC!)

Fischer s.n. (3) (SP!)

Fonseca 52 (4) (RB!)

Fonseca \& al. 1487 (4) (IBGE!, RB)

Fonseca \& al. 1518 (4) (IBGE!)

Fonseca \& al. 3494 (4) (IBGE!, RB, $\mathrm{SP} !)$

Fontella \& al. 3391 (4) (R!)

Forzza s.n. (1) (SPF!)

Forero \& al. 7894 (2) (SP!)

Forzza \& al. 699 (2) (SPF!)

Forzza \& al. 757 (4) (SPF!)

Forzza \& al. 920 (4) (CEN, SPF!)

Forzza \& al. 1809 (1) (SP!)

Forzza \& al. 2140 (2) (CESJ, SP!)

Forzza \& al. 3084 (3) (RB, SPF!)

Forzza \& al. 4003 (4) (RB, SPF!)

Forzza \& al. 4024 (4) (RB, SPF!)

França \& al. 992 (2) (HUEFS!)

França \& Melo s.n. (4) (NY!, UPCB!)

Freire-Fierro \& al. 3005 (4) (SPF!)

Freitas 264 (3) (UEC!)

Freitas 651 (4) (UEC!)

Freitas \& Gajardo 520 (2) (SP!, UEC!)

Freitas \& Sazima 80 (3) (UEC!)

Freitas \& Sazima 81 (3) (SP!)

Freitas \& al. 430 (2) (UEC!)

Furlan \& Pirani CFSC 6219 (2) (SP!)

Furlan \& Sajo CFSC 5962 (2) (SPF!)

Furlan \& al. CFCR 2019 (2) (SPF!, U!)

Furlan \& al. CFCR 3220 (2) (SPF!, U!)

Furlan \& al. CFSC 8328 (2) (SP!) 
Ganev 413 (4) (HUEFS!, K, NY!, SPF!)

Ganev 436 (2) (HUEFS!, K, NY! SPF!)

Ganev 2795 (2) (HUEFS!, SPF!, NY!, UEC!)

Ganev 3311 (2) (HUEFS!, NY!, SPF!)

García \& Bridgewater A482 (4) (UB!)

Gardner 3896 (4) (B [foto F!], E [2, scans!], P [scan!])

Gardner 5017 (2) (BM, NY!, US!)

Gardner s.n. (4) (NY!)

Gehrt 150 (2) (SP, SPF!)

Gehrt 4133 (2) (SP!, SPF!)

Gehrt s.n. (2) (SP, SPF! SPF160450)

Ghert s.n. (4) (SP, SPF! SPF160445)

Gibbs 4117 (2) (MBM!, SP!, UEC!)

Gibbs \& al. 1772 (2) (UEC!)

Gibbs \& al. 5050 (2) (UEC!)

Gibbs \& al. 5073 (4) (MBM!, UEC!)

Gibbs \& al. 5135 (4) (SP!, UEC!)

Gibbs \& al. 5287 (2) (UEC!)

Giulietti \& Menezes 3985 (2) (SP!, UEC!)

Giulietti \& al. 1038 (3) (SPF!)

Giulietti \& al. CFCR 1309 (2) (SPF!, U!)

Giulietti \& al. CFCR 7708 (2) (SP!) Giulietti \& al. CFSC 12467 (4) (SPF!) Giulietti \& al. CFSC 12478 (2) (SPF!) Giulietti \& al. CFSC 7428 (4) (SPF!, U!)

Gondenberg \& al. 26419 (3) (UEC!)

Goodland 344 (4) (NY!, U(2)!)

Goodland 3120 (4) (UB!)

Goodland 3154 (4) (UB!)

Gouvea \& al. 720 (2) (UEC!)

Grandi \& Andrade 1016 (2) (BHCB!, U!)

Grandi \& Porto s.n. (3) (BHCB! BHCB16750)

Grandi \& Porto s.n. (3) (U!)

Grandi \& Tales 106 (3) (U(2)!)

Grandi \& Tales 490 (3) (BHCB, U!)

Grandi 200 (4) (BHCB!)

Grandi 931 (4) (BHCB!)

Grandi 1467 (4) (BHCB!)

Grandi \& al. 2250 (2) (BHCB!)

Grandi \& al. s.n. (2) (BHCB!

BHCB14259)

Grandi \& al. s.n. (4) (BHCB!, U! BHCB 12477)
Grandi \& al. s.n. (4) (BHCB! BHCB 12476)

Grandi s.n. (2) (BHCB! BHCB 8042)

Grandi s.n. (4) (BHCB! BHCB16696)

Grillo \& Conceição 198 (2) (SPF!)

Groppo Jr. \& al. 627 (2) (SPF!)

Groppo Jr. \& al. 628 (2) (SPF!)

Guarçoni \& al. 572 (4) (VIC!)

Guedes \& al. PCD 1941 (2) (ALCB!, $\mathrm{SP}$ !)

Guimarães 82 (2) (SPSF!)

Hakme 17 (4) (SPF!)

Handro 81 (2) (SP!, SPF!)

Handro 300 (3) (SP, SPF!)

Harley \& Sano 51294 (2) (CEPEC, HUEFS, K, SPF!)

Harley \& al. 15674 (2) (K, NY!, US!, $\mathrm{U} !)$

Harley \& al. 19665A (2) (CEPEC!, K!, $\mathrm{NY} !, \mathrm{U} !)$

Harley \& al. 20893 (2) (K, SPF!,U!)

Harley \& al. 22311 (2) (CEPEC!, U!)

Harley \& al. 22651 (2) (SPF!, U!)

Harley \& al. 22957 (2) (K, SPF!, U!)

Harley \& al. 24398 (2) (K, MBM, SPF!)

Harley \& al. 24502 (2) (CEPEC!,

HUEFS!, K!, MBM, SPF!, U!)

Harley \& al. 25263 (2) (F, MBM, SP, SPF!, U!)

Harley \& al. 28497 (4) (SPF!)

Harley \& al. 52763 (2) (SP, SPF!)

Harley \& al. 53327 (2) (HUEFS!, K, SP, SPF!)

Hashimoto 12782 (2) (MBM!)

Hatschbach 3614 (2) (MBM!)

Hatschbach 9799 (2) (MBM!)

Hatschbach 13519 (2) (F, MBM!)

Hatschbach 13991 (3) (BHCB!, MBM!, U!)

Hatschbach 15711 (2) (MBM!, MO)

Hatschbach 23466 (2) (NY!)

Hatschbach 27291 (2) (MBM!, U!)

Hatschbach 28762 (2) (U!)

Hatschbach 36674 (4) (MBM, U!)

Hatschbach 38714 (4) (MBM!, U!, US!)

Hatschbach 42782 (2) (MBM, SPF!)

Hatschbach 42799 (2) (MBM!, U!)

Hatschbach 43064 (4) (U!)

Hatschbach 43570 (2) (MBM!)

Hatschbach 43789 (4) (S!, U!)

Hatschbach 44659 (2) (MBM!, U!)

Hatschbach s.n. (2) (US!)
Hatschbach \& Ahumada 31294 (2) (MBM!)

Hatschbach \& Ahumada 31606 (2) (MBM!, NY!, U!)

Hatschbach \& Cordeiro 52827 (3) (MBM!)

Hatschbach \& Fontella 20800 (2) (S!) Hatschbach \& Guimarães 42415 (2) (MBM!, U!)

Hatschbach \& Haas 13992 (2) (MBM!) Hatschbach \& Hatschbach 50947 (2) (CESJ!, HRB!, HUCS!, HXBH!, MBM!, U!)

Hatschbach \& Kummrow 46587 (4)

(U!)

Hatschbach \& Nicolack 52999 (4) (MBM!, U!, US!)

Hatschbach \& Ribas 52058 (2) (U!) Hatschbach \& Silva 50305 (2) (MBM!) Hatschbach \& al. 11501 (4) (US!) Hatschbach \& al. 12267 (3) (MBM, US!)

Hatschbach \& al. 12271 (2) (MBM!)

Hatschbach \& al. 36422 (2) (NY!, U!) Hatschbach \& al. 51176 (4) (MBM!,

U!)

Hatschbach \& al. 51178 (2) (U!) Hatschbach \& al. 59263 (4) (MBM!) Hatschbach \& al. 60005 (4) (MBM!) Hatschbach \& al. 60253 (4) (MBM!) Hatschbach \& al. 64273 (2) (MBM!) Hatschbach \& al. 64697 (4) (BHCB!, CESJ, CTES!, MBM!, U!)

Hatschbach \& al. 64740 (2) (CTES!, MBM)

Hatschbach \& al. 66330 (2) (BHCB!, ESA!, R!)

Hatschbach \& al. 70581 (4) (MBM!) Hatschbach \& al. 70723 (4) (CTES!, MBM)

Hatschbach \& al. 71159 (2) (MBM!)

Hauff 36 (3) (SP!)

Hensold CFSC 8550 (2) (SPF!)

Hensold \& al. CFCR 2873 (2) (SPF!,

U!)

Hensold \& al. CFCR 2874 (3) (SPF!) Hensold \& al. CFCR 2920 (3) (SPF!) Heringer \& Castellanos 22165 (2) (R!) Heringer \& Castellanos 6202 (2) (R!, RB!, UB!)

Heringer 3517a (4) (UB!)

Heringer 3659 (4) (UB!)

Heringer 4852 (4) (U!) 


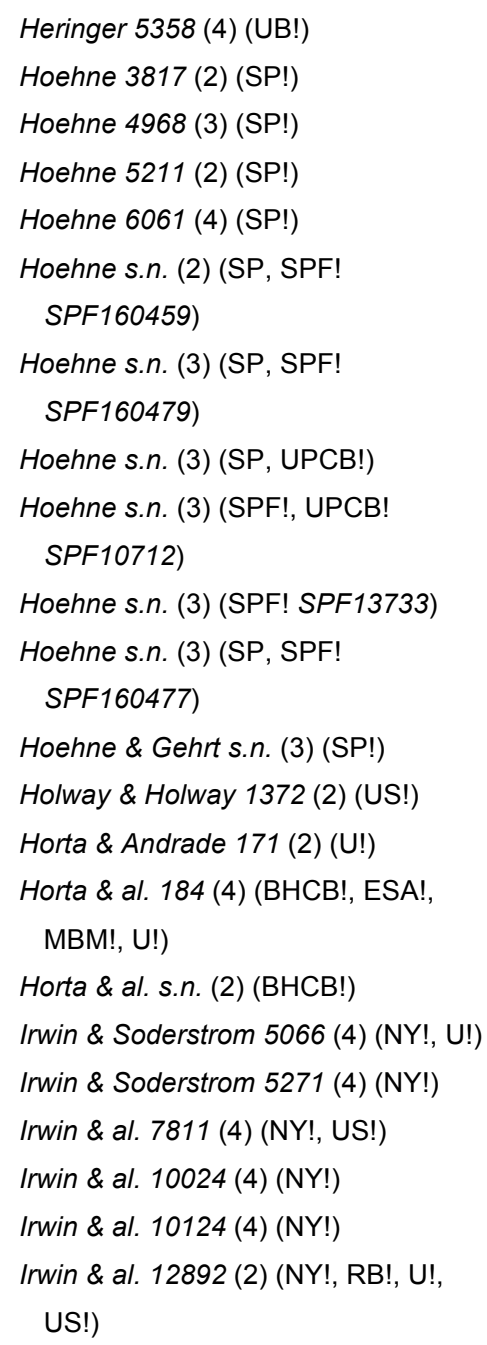

Irwin \& al. 29445 (3) (NY!, SP!, U!, UB!, US!)

Irwin \& al. 29447 (3) (NY!, U!, UB!) Irwin \& al. 30432 (2) (NY! SP!, U!, UB!, US!)

Irwin \& al. 32174 (2) (NY!, U!, UB!, US!)

Irwin \& al. 32414 (2) (C, NY!, UB!, US!, U!)

Irwin \& al. 33156 (4) (NY!, U!, UB!)

Joly \& Semir 2987 (2) (SP!)

Joly \& Semir 3186 (2) (SP!)

Joly \& Semir 3208 (2) (SP!, UEC!)

Joly \& al. 106 (2) (SP!)

Joly \& al. 238 (2) (SP!, UEC!)

Joly \& al. 945 (2) (SP!)

Joly \& al. 984 (2) (SP!)

Joly \& al. 1048 (2) (SP!, UEC!)

Joly \& al. 1107 (2) (SP!, UEC!)

Joly \& al. 1675 (4) (SP!, UEC!)

Joly \& al. 1842 (2) (SP!)

Joly \& al. 1875 (2) (SP!)

Joly \& al. 1893 (2) (SP!)

Joly \& al. 2116 (2) (SP!)

Joly \& al. 2473 (2) (SP!)

Kamei s.n. (4) (BHCB!, ESA!, U!)

Kameyama \& Esteves 26 (2) (SPF!)

Kinoshita \& Moreira 96-153 (3) (UEC!)

Kinoshita \& al. 98-435 (4) (UEC!)

Kinoshita \& al. 98-456 (4) (UEC!)

Kinoshita-Gouvêa \& al. 19157 (4) (UEC!)

Kirizawa \& Makino-Watanabe 2989

(2) (SP!)

Kirizawa \& Makino-Watanabe 3015

(2) (SP!)

Kirkbride Jr. \& Kirkbride 3475 (4) (UB!)

Koch 620 (2) (UEC!)

Kral \& al. 72904 (2) (SP!)

Krieger \& Brügger 25600 (4) (ESA!)

Krieger \& Brügger s.n. (3) (CESJ, ESA!)

Krieger 8265 (4) (CESJ, ESA!, SPF!)

Krieger 9670 (2) (CESJ, SPF!)

Krieger 10614 (3) (CESJ!)

Krieger 10659 (4) (CESJ!)

Krieger 11470 (3) (CESJ!, SPF!)

Krieger 11608 (4) (CESJ!, SPF!)

Krieger 20499 (2) (ESA!, SPF!)

Krieger 21427 (4) (CESJ, ESA!)

Krieger s.n. (1) (CESJ! CESJ16643)

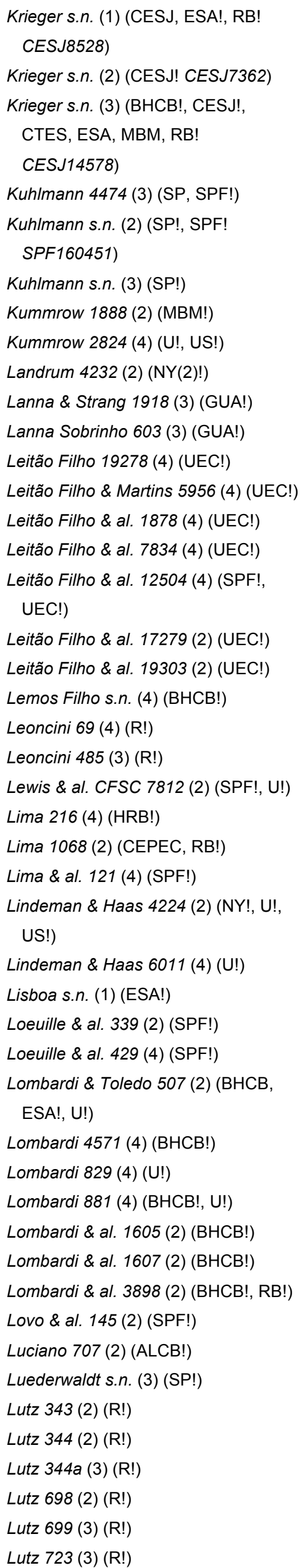

Krieger s.n. (2) (CESJ! CESJ7362)

Krieger s.n. (3) (BHCB!, CESJ!, CTES, ESA, MBM, RB!

CESJ14578)

Kuhlmann 4474 (3) (SP, SPF!)

Kuhlmann s.n. (2) (SP!, SPF!

SPF160451)

Kuhlmann s.n. (3) (SP!)

Kummrow 1888 (2) (MBM!)

Kummrow 2824 (4) (U!, US!)

andrum 4232 (2) (NY(2)!)

Leitão Filho 19278 (4) (UEC!)

Leitão Filho \& Martins 5956 (4) (UEC!)

Leitão Filho \& al. 1878 (4) (UEC!)

Leitão Filho \& al. 7834 (4) (UEC!)

Leitão Filho \& al. 12504 (4) (SPF!, UEC!)

Leitão Filho \& al. 17279 (2) (UEC!)

Lemos Filho s.n. (4) (BHCB!)

Leoncini 69 (4) (R!)

Leoncini 485 (3) (R!)

Lewis \& al. CFSC 7812 (2) (SPF!, U!)

Lima 216 (4) (HRB!)

Lima 1068 (2) (CEPEC, RB!)

Lima \& al. 121 (4) (SPF!)

Lindeman \& Haas 4224 (2) (NY!, U!, US!)

Lisboa s.n. (1) (ESA!)
Loeuille \& al. 339 (2) (SPF!)
Loeuille \& al. 429 (4) (SPF!)
Lombardi \& Toledo 507 (2) (BHCB,
ESA!, U!)
Lombardi 4571 (4) (BHCB!)
Lombardi 829 (4) (U!)
Lombardi 881 (4) (BHCB!, U!)
Lombardi \& al. 1605 (2) (BHCB!)
Lombardi \& al. 1607 (2) (BHCB!)
Lombardi \& al. 3898 (2) (BHCB!, RB!)
Lovo \& al. 145 (2) (SPF!)
Luciano 707 (2) (ALCB!)
Luederwaldt s.n. (3) (SP!)
Lutz 343 (2) (R!)
Lutz 344 (2) (R!)
Lutz $344 a(3)(\mathrm{R} !)$
Lutz 698 (2) (R!)
Lutz 699 (3) (R!)
Lutz 723 (3) (R!)


Lutz 1928 (3) (R!)

Macedo 16 (4) (UB!)

Macedo 117 (4) (SPSF!)

Macedo 3052 (3) (NY!, US!)

Macedo 3056 (2) (US!)

Macedo 3094 (3) (US!)

Macedo 3291 (4) (US!)

Macedo \& al. 31 (4) (SPSF!)

Macedo \& al. 106 (4) (SPSF!)

Magalhães 1045 (3) (BHCB!)

Magalhães 1046 (3) (BHCB!)

Magalhães 1091 (3) (BHCB!)

Magalhães 1771 (2) (BHCB!)

Magalhães 3203 (4) (US!)

Márcio s.n. (1) (BHCB!)

Marcondes-Ferreira \& Semir 285 (2) (SPF!, SPFR!)

Marcondes-Ferreira \& al. 228 (2)

(SPF!, SPFR!, UEC!)

Marcondes-Ferreira \& al. 286 (3)

(SPFR!)

Marcondes-Ferreira \& al. 379 (4)

(SPFR!)

Marcondes-Ferreira \& al. 383 (4)

(SPFR!)

Marcondes-Ferreira \& al. 1114 (4) (SPF!, SPFR!)

Marcondes-Ferreira \& al. 1229 (4)

(PMSP!, SPF!, SPFR!)

Marcondes-Ferreira \& al. 1479 (4) (SPF!)

Marinho s.n. (1) (CESJ, MBM!, RB!)

Marquete \& al. 31 (2) (HRB!, RB!)

Marquete \& al. 57 (4) (HRB!, RB!)

Marquete \& al. 2291 (4) (IBGE!)

Marquete \& al. 2736 (4) (IBGE!)

Martens 71 (2) (SPF!)

Martens 72 (4) (SPF!)

Martens 278 (2) (SPF!)

Martens 370 (2) (SPF!)

Martinelli 11283 (2) (RB!)

Martinelli \& Chautems 9283 (3) (RB!)

Martinelli \& Távora 2689 (3) (RB!)

Martinelli \& al. 21238 (2) (BHCB!)

Martinelli \& al. 7472 (4) (RB!)

Martins 131 (4) (UEC!)

Martins 155 (4) (UEC!)

Martins 274 (3) (GUA!)

Martins 888 (4) (SP!, SPF!)

Martins \& al. 59 (2) (SPF!)

Martins \& al. 100 (2) (SPF!)

Martins \& al. 102 (2) (SPF!)

Martins s.n. (2) (BHCB! BHCB8488)
Martins s.n. (4) (BHCB! BHCB8491)

Martius 651 (3) (M [fotos SPF!])

Martius 690 (4) (M [fotos SPF!])

Martius 1053 (2) (G!)

Martius 1054 (4) (G!, L(2)!, NY!)

Martius 1153 (4) (M [2, fotos SPF!])

Martius 1385 (2) (M [foto SPF!])

Martius s.n (2) (M [foto SPF!])

Mattos 13650 (4) (SP!)

Mattos s.n. (2) (MBM!, US!)

Mayo \& al. CFSC 7011 (2) (SPF!, U!)

Mazine \& al. 406 (3) (ESA!)

Meira \& al. 23 (2) (VIC!)

Meireles \& Nunes 2271 (3) (SPF!, UEC)

Meireles \& al. 2907 (3) (SPF!, UEC)

Mello-Barreto 657 (2) (BHCB!)

Mello-Barreto 2788 (2) (BHCB!, R!)

Mello-Barreto 2789 (2) (BHCB!)

Mello-Barreto 2791 (2) (BHCB!)

Mello-Barreto 2792 (2) (BHCB!)

Mello-Barreto 2794 (2) (R!)

Mello-Barreto 2795 (2) (BHCB!)

Mello-Barreto 2797 (2) (BHCB!, F, R!)

Mello-Barreto 2800 (2) (BHCB!, R!)

Mello-Barreto 2802 (2) (BHCB!, F)

Mello-Barreto 2825 (4) (BHCB!)

Mello-Barreto 2835 (4) (BHCB!)

Mello-Barreto 2854 (4) (R!)

Mello-Barreto 2858 (4) (BHCB!)

Mello-Barreto 4501 (4) (BHCB!)

Mello-Barreto s.n. (2) (BHCB!

BHCB658)

Mello-Barreto s.n. (4) (BHCB!

BHCB655)

Mello-Barreto \& Brade 1243 (2) (RB!, U!)

Mello-Silva \& Ferreira 2847 (4)

(CESJ!, SPF!)

Mello-Silva \& Ferreira 2848 (3)

(CESJ!, CHRB!, SPF!)

Mello-Silva \& Ferreira 2868 (2) (CESJ, SPF!)

Mello-Silva \& Forzza 2797 (2) (RB!, SPF!)

Mello-Silva \& al. 736 (4) (SPF!)

Mello-Silva \& al. 2309 (4) (SPF!)

Mello-Silva \& al. CRCR 9016 (2) (SP, SPF!)

Mello-Silva \& al. CFCR 9755 (2) (CHRB!, SPF!)

Melo \& França 561 (4) (UB!)

Mendonça \& al. 2786 (4) (IBGE!)
Mendonça \& al. 3503 (4) (IBGE!, RB) Mendonça \& al. 4793 (4) (IBGE!, RB ,SP!)

Menezes \& Meguro CFCR 9795 (2) (SPF!)

Menezes \& al. 426 (2) (SPF!, VIC) Menezes \& al. 439 (2) (SPF!, VIC) Menezes \& al. CFCR 7708 (2) (SPF!) Menezes \& al. CFSC 5809 (2) (SP!) Méxia 5842 (2) (NY!, US!)

Mimura 302 (4) (SP!)

Mimura 343 (4) (SP!)

Mimura 349 (4) (SP!)

Mimura 383 (4) (SP!, US!)

Mimura 395 (4) (SP!, UB!, US!)

Mimura 414 (4) (SP!, US!)

Mimura 416 (4) (NY!, SP!, UB!)

Mimura 432 (4) (SP!)

Monguilhot \& al. 102 (3) (SPF!)

Monguilhot \& al. 104 (4) (CHRB!, SPF!)

Monteiro \& Vianna 254 (2) (GUA!)

Monteiro 219 (2) (GUA!)

Monteiro 2989 (2) (RBR!, SPF!)

Monteiro s.n. (2) (GUA!)

Moreira 24 (4) (SPF!)

Moreira 53 (4) (U!)

Mori \& Benton 13587 (2) (CEPEC!,

NY!, RB!, U!)

Mori \& al. 16972 (4) (CEN!, CEPEC!, NY!)

Moura \& Vieira 423 (4) (SPF!, VIC)

Moura \& al. 405 (2) (VIC!)

Moura s.n. (3) (SP!)

Munhoz \& al. 108 (4) (UB!)

Munhoz \& al. 2729 (4) (SPF!)

Nakajima \& al. 1032 (4) (HUFU, SP!, SPF!)

Nakajima \& al. 1134 (4) (HUFU, SP!, SPF!)

Nakajima \& al. 500 (3) (HUFU, SP!, SPF!)

Nakajima \& al. 912 (3) (HUFU, SP!, SPF!)

Netto s.n. (3) (R, US! R14739)

Nogueira 143 (4) (SPF!)

Oldenburger \& Mecenas 1540 (4) (U!)

Oliveira s.n. (3) (UB!)

Oliveira s.n. (4) (R!)

Oliveira \& Forzza 44 (1) (SP!)

Oliveira \& Proença 120 (4) (UB!)

Oliveira \& al. 370 (4) (IBGE!)

Oliveira \& al. 1047 (4) (IBGE!, RB, U!) 
Oliveira \& al. 1081 (2) (IBGE, RB!, U!)

Passos \& Correia 7 (4) (SPF!)

Paula \& al. 3 (4) (VIC!)

Paula \& al. 26 (2) (VIC!)

Paula \& al. 27 (4) (VIC!)

Paula \& al. 122 (4) (VIC!)

Paula \& al. 493 (4) (VIC!)

Paula \& al. 587 (3) (VIC!)

Paula \& al. 602 (2) (VIC!)

Paula \& al. 689 (2) (VIC!)

Paula \& al. 691 (3) (VIC!)

Paula \& al. 715 (4) (VIC!)

Paula \& al. 726 (4) (VIC!)

Paula \& al. 747 (4) (VIC!)

Paula-Souza \& al. 4559 (4) (ESA!)

Paula-Souza \& al. 9389 (4) (CTES, SPF!)

Pavan s.n. (4) (SPF!)

Pereira 1486 (4) (RB!, U!)

Pereira 1540 (2) (RB!)

Pereira 630 (4) (RB!, U!)

Pereira 7498 (4) (HB, LP!)

Pereira \& Lucca 946 (2) (U!)

Pereira \& Pabst 2398 (2) (RB!, U!)

Pereira \& Pabst 2409 (2) (RB!)

Pereira \& Pabst 2904 (2) (HB, LP!, RB!, U!)

Pereira \& al. 841 (2) (UEC!)

Pereira-Silva \& al. 6220 (4) (CEN!)

Pickel 4595 (3) (IPA!, SP!)

Pickel 5196 (3) (SP!)

Pietrobom-Silva \& al. 3345 (4)

(CTES!, MBM!, SJRP!)

Piliackas \& al. CFSC 10875 (2) (CHRB!, SPF!)

Pinheiro Sobrinho s.n. (4) (BHCB!)

Pinna \& al. 20 (4) (SPF!)

Pinto s.n. (2) (ALCB!)

Pirani \& al. 1534 (4) (K, SPF!)

Pirani \& al. 1719 (2) (SP, SPF!)

Pirani \& al. 4229 (4) (SPF!)

Pirani \& al. 4355 (4) (SPF!)

Pirani \& al. 5393 (2) (SPF!)

Pirani \& al. 5483 (3) (SPF!)

Pirani \& al. 5538 (4) (SPF!)

Pirani \& al. CFCR 11208 (4) (CHRB!, SPF!)

Pirani \& al. CFCR 13089 (2) (SP, SPF!)

Pirani \& al. CFCR 2170 (4) (SPF!)

Pirani \& al. CFSC 12167 (2) (SPF!)

Pirani \& al. CFSC 8023 (2) (SPF!)

Pirani \& al. CFSC 8054 (2) (SPF!, U!)
Pires \& Mattos 9850 (4) (UB!)

Pires \& Nobre 424 (4) (CESJ!)

Pires 57016 (4) (NY!)

Pires 57978 (4) (NY!, U!, UB!, US!)

Pires 58070 (4) (NY!, U!)

Pires \& al. 21-499 (4) (ESA!)

Porto 3353 (3) (RB!, U!)

Proença \& al. 1962 (4) (UB!)

Queiroz 707 (2) (HUEFS!)

Queiroz \& al. 1892 (2) (HUEFS!)

Queiroz \& al. 1913 (2) (HUEFS!)

Queiroz \& al. 1934 (2) (HUEFS!)

Queiroz \& al. 4369 (2) (HUEFS!)

Queiroz \& al. 5009 (2) (HUEFS, SP! )

Raggi \& al. 36 (4) (VIC!)

Rapini \& al. 645 (4) (SPF!)

Ratter \& al. 3121 (4) (NY!,UEC!)

Ratter \& al. 7314 (4) (NY!, UB!)

Reeves \& al. 239 (4) (NY!, U!)

Regnell 122 (3) (SP!)

Regnell (I)299 (3) (US!)

Regnell (I)300 (3) (US(2)!)

Reis 10 (4) (SPF!)

Reitz \& Klein 6083 (2) (LP!, US!)

Reitz \& Klein 6166 (2) (US!)

Reitz \& Klein 17907 (2) (US!)

Renner 698 (2) (AAU!)

Ribas \& al. 2280 (2) (MBM!)

Riedel s.n. (4) (L!, US!)

Rizzo 8123 (4) (UFG!)

Rizzo \& Barbosa 6439 (4) (UFG!)

Rocha \& al. 17 (2) (SPF!)

Romaniuc Neto 338 (4) (SP!)

Romaniuc Neto \& Sajo 394 (4) (NY!, SP!)

Romaniuc Neto \& al. 634 (2) (NY!, SP!)

Rombouts s.n. (3) (IAG, SP!)

Romero \& Nakajima 1019 (3) (HUFU, SP!, SPF!)

Romero \& al. 921 (4) (HUFU, SP!, SPF!)

Romero \& al. 1934 (3) (HUFU, SP!, SPF!)

Romero \& al. 2134 (4) (HUFU, SP!, SPF!)

Romero \& al. 2366 (3) (HUFU, SP!, SPF!)

Romero \& al. 2486 (4) (HUFU, SP!, SPF!)

Romero \& al. 2661 (4) (HUFU, SP!, SPF!)

Romero \& al. 5528 (2) (UEC!)
Roppa 719 (4) (R!)

Roque \& al. 141 (2) (SPF!)

Roque \& al. 581 (4) (ALCB!, CEPEC!, HUEFS!)

Rossi \& al. CFCR 1045 (4) (CHRB!, SPF!, U!)

Rossi \& al. CFCR 1046 (4) (SPF!)

Rossi \& al. CFCR 1108 (2) (SPF!)

Rossi \& al. CFCR 1178 (2) (SPF!, U!)

Rossi \& al. CFCR 2995 (2) (SPF!, U!)

Rossi \& al. CFCR 3083 (2) (SPF!, U!)

Saint-Hilaire s.n. (2) (US!)

Saint-Hilaire s.n. (2) (NY!, P; 123)

Saint-Hilaire s.n. (2) (NY!, P; 125)

Saint-Hilaire s.n. (4) (NY!)

Sakane 59 (3) (SP!)

Sakuragui \& Souza 101 (2) (ESA!, HUEFS!)

Sakuragui \& Souza 161 (2) (ESA!)

Sakuragui \& al. CFCR 14008 (2) (SPF!)

Sakuragui \& al. CFCR 15169 (4)

(CHRB!, ESA!, SPF!)

Sakuragui \& al. CFCR 15269 (2)

(CHRB!, ESA!, SPF!)

Salimena s.n. (1) (CESJ!)

Salimena-Pires \& al. CFSC 11412 (2) (SPF!)

Salino \& Mota 6995 (4) (BHCB!)

Salino 4773 (4) (BHCB!, U!)

Salino \& al. 26414 (3) (UEC!)

Samp. $6222(4)(\mathrm{R} !)$

Sampaio 6837 (2) (R!)

Sanches \& al. 26566 (3) (UEC!)

Sano \& al. 929 (4) (SPF!)

Sano \& al. 940 (3) (SPF!)

Santiago 5 (4) (NY!)

Santos \& al. 1278 (4) (CEN, SPF!)

Sasaki \& Junqueira 473 (4) (SPF!, SPFR)

Sasaki \& Junqueira 521 (4) (SPF!)

Sasaki \& al. 222 (4) (SPF!)

Sasaki \& al. 347 (4) (SPF!)

Sazima \& Semir 3885 (2) (SP!, UEC!)

Sazima 4077 (2) (SP!)

Sazima 18948 (2) (UEC!)

Sazima \& al. 10 (4) (SP!)

Scatena \& al. CFCR 10649 (2) (SPF!)

Segadas-Vianna 2529 (3) (R!)

Segadas-Vianna 2543 (3) (R!)

Segadas-Vianna 3285 (3) (R!)

Segadas-Vianna 3286 (3) (R!)

Sellow 918 (2) (B (photo US!)) 
Sellow 1628 (2) (B, foto F!)

Sellow s.n. (2) (HAL [scan!], K

[scan!], L!, W!)

Sellow s.n. (3) (L!)

Sellow s.n. (4) (B [foto F!], HAL [scan!], K [2, scans!], P[scan!]) Sellow s.n. (4) (B, K [foto U!], L!) Sem coletor 1300 (3) (SP!) Sem coletor 1399 (2) (RB!) Sem coletor 1523 (3) (RB!) Sem coletor 2853 (3) (RB!) Sem coletor 98-565 (4) (UEC!) Sem coletor s.n. (2) (R! R94380) Sem coletor s.n. (2) (R! R94383) Sem coletor s.n. (2) (R! R94390) Sem coletor s.n. (2) (RB! RB10629) Sem coletor s.n. (2) (RUSU! RUSU481)

Sem coletor s.n. (2) (RUSU! RUSU686)

Sem coletor s.n. (2) (SPF! SPF83962)

Sem coletor s.n. (3) (RB! RB10369)

Sem coletor s.n. (3) (SP, SPF!

SPF160479)

Sem coletor s.n. (4) (R! R94391)

Semir \& Sazima 582 (2) (UEC!)

Semir \& Sazima 683 (2) (SP!)

Semir \& Sazima 713 (2) (SP!, UEC!)

Semir \& Sazima 729 (2) (SP!, UEC!)

Semir \& Sazima 752 (2) (SP!)

Semir \& Sazima 2009 (2) (SP!)

Semir \& Sazima 2094 (2) (SP!, UEC!)

Semir \& Sazima 2605 (2) (SP!)

Semir \& al. 01//59 (2) (UEC!)

Semir \& al. 634 (2) (SP!, UEC!)

Semir \& al. 2359 (2) (SP!)

Semir \& al. 2765 (2) (SP!)

Semir \& al. 19499 (4) (UEC!)

Semir \& al. 19585 (4) (UEC!)

Semir \& al. CFSC 9598 (2) (SP, SPF!)

Semir \& al. s.n. (3) (SPF!)

Serafim 25 (3) (SPF!)

Serafim 32 (3) (SPF!)

Serafim 33 (3) (SPF!)

Shepherd 10212 (2) (UEC!)

Shepherd \& al. 3938 (2) (UEC!)

Shepherd \& al. 12184 (3) (UEC!)

Shepherd \& al. 19008 (2) (UEC!)

Shepherd \& al. 19018 (4) (HUEFS!, UEC!, UPCB, VIC!)

Siegel s.n. (3) (RB!, U!)

Silva \& Abe 2897 (2) (MBM!)
Silva \& Santos 1219 (2) (HUEFS!, MBM)

Silva \& Santos 3288 (4) (IBGE!)

Silva 52 (4) (RB!, RBR!)

Silva 1011 (4) (SPF!, UB)

Silva 2703 (4) (U!)

Silva 5051 (4) (IBGE, SP!)

Silva \& al. 2014 (2) (IBGE!, U!)

Silveira 24 (4) (BHCB!, U!)

Silveira 531 (3) (R!)

Silveira $2180(3)(\mathrm{R} !)$

Simão \& al. CFSC 9655 (2) (SP, SPF!)

Simão-Bianchini 163 (4) (U!, SP, SPF!)

Simão-Bianchini \& Bianchini 1107 (3) (SP, SPF!)

Simonis \& Cordeiro CFCR 4009 (2)

(CHRB!, SPF!, U!)

Smith 4733 (4) (US!)

Smith 7033 (2) (NY!, R!, US!)

Smith \& al. 6760 (2) (US!)

Smith \& al. 14654 (2) (R!, US!)

Smith \& al. 14798 (3) (US!)

Soares s.n. (4) (BHCB!)

Souza 2 (4) (SPSF!)

Souza (A. Macedo 5765) (2) (US!)

Souza s.n. (3) (BHCB, SPF! SPF70605)

Souza s.n. (4) (BHCB!)

Souza \& Sakuragui 3314 (2) (ESA!)

Souza \& Sakuragui 3386 (4) (ESA!)

Souza \& Souza 22177 (2) (ESA!)

Souza \& Souza 22185 (2) (ESA!)

Souza \& al. 1482 (4) (SPF!)

Souza \& al. 2210 (4) (ESA!)

Souza \& al. 3968 (2) (ESA, SP!, SPSF!)

Souza \& al. 7804 (2) (ESA!, HUFU!, SPF!)

Souza \& al. 7866 (2) (ESA!, MBM!, SPF!)

Souza \& al. 7914 (4) (ESA!, HUFU!, SPF!)

Souza \& al. 7916 (4) (ESA!)

Souza \& al. 7917 (4) (ESA!)

Souza \& al. 10038 (2) (ESA!, SPF!)

Souza \& al. 10063 (3) (ESA!, SPF!)

Souza \& al. 11482 (4) (BHCB, CESJ, CTES, ESA!, FUEL, HUEFS, M, MBM, RB, SPF!)

Souza \& al. 11612 (2) (ESA!)

Souza \& al. 11725 (2) (ESA!)
Souza \& al. 12042 (4) (ESA!, SPF!)

Souza \& al. 12065 (4) (ESA!)

Souza \& al. 20893 (2) (ESA!)

Souza \& al. 20947 (2) (CESJ!, ESA!, HUEFS!, SPF!)

Souza \& al. 21164 (4) (ESA!)

Souza \& al. 22701 (4) (ESA!)

Souza \& al. 22711 (2) (ESA!)

Souza \& al. 22925 (2) (ESA!)

Souza \& al. 23855 (4) (ESA!, SPF!)

Souza \& al. 24752 (4) (ESA!, SPF!)

Souza \& al. 24819 (4) (ESA!, SPF!)

Souza \& al. 25111 (2) (BHCB, ESA!)

Souza \& al. 25170 (4) (ESA!)

Souza \& al. 25215 (2) (ESA!)

Souza \& al. 25360 (2) (ESA!)

Souza \& al. 26084 (2) (ESA!)

Souza \& al. 26852 (4) (ESA!)

Souza \& al. 26919 (4) (ESA!, SPF!)

Souza \& al. 28055 (3) (ESA!)

Souza \& al. 28068 (2) (ESA!, SPF!)

Souza \& al. 28165 (2) (ESA!, SPF!)

Souza \& al. 28380 (2) (ESA!)

Souza \& al. 28413 (2) (ESA!)

Souza \& al. 28655 (2) (ESA!, SPF!)

Souza \& al. 28721-A (2) (ESA!, SPF!)

Souza \& al. s.n. (1) (BHCB!, SPF! BHCB9076)

Souza \& al. s.n. (3) (BHCB!)

Stehmann \& Brandão 1106 (4) (BHCB!)

Stehmann \& al. 2894 (2) (BHCB, RB!)

Stellfeld 501 (2) (US!)

Studart s.n. (4) (UB!)

Sucre \& Krieger 6785 (1) (BR, CEN!, CEPEC, F, G, K, LIL, MBM!, MG, $\mathrm{MO}, \mathrm{RB}$ !, U!, UEC!)

Sucre \& Krieger 6859 (3) (RB!)

Sucre 760 (4) (NY!)

Tamashiro \& al. 17442 (4) (UEC!)

Tameirão Neto 3019 (4) (BHCB!)

Tameirão Neto \& Werneck 1070 (4) (BHCB!)

Taxonomy Class of Universidade de Brasilia 72 (4) (US!)

Taxonomy Class of Universidade de Brasília 73 (4) (US!)

Teixeira s.n. (2) (BHCB, U!

BHCB22047)

Teixeira s.n. (2) (BHCB, U! BHCB23938)

Teixeira s.n. (2) (BHCB!, U! BHCB23966) 


\begin{tabular}{|c|c|}
\hline Teixeira s.n. (4) (BHCB!, U! & Valente \& al. 1941 (4) (VIC!) \\
\hline BHCB26134) & Valente \& al. 1969 (4) (SPF!, VIC) \\
\hline Temponi \& al. 418 (2) (SPF!) & Valente \& al. 2039 (2) (SPF!, VIC) \\
\hline Toledo 527 (3) (RB!) & Valente \& al. 2065 (2) (SPF!, VIC) \\
\hline Toledo \& al. 111 (4) (NY!, SP!, SPF!) & Valente \& al. 2237 (4) (VIC!) \\
\hline Tombolato s.n. (1) (IAC! IAC31891) & Valente \& al. 2354 (3) (VIC!) \\
\hline Tombolato s.n. (3) (IAC! IAC31892) & Valle \& al. s.n. (1) (VIC!) \\
\hline Trindade 65 (2) (BHCB!) & Vasconcelos \& Lombardi s.n. (4) \\
\hline Trinta \& From 673 (4) (R!, RB!) & (BHCB!) \\
\hline Trovó \& Ribeiro 133 (2) (SPF!) & Vasconcelos s.n. (2) (BHCB!, \\
\hline Trovó \& Watanabe 361 (2) (SPF!) & ВНСВ31891) \\
\hline Trovó \& al. 140 (2) (SPF!) & Vasconcelos s.n. (2) (BHCB! \\
\hline Trovó \& al. 150 (2) (SPF!) & BHCB37882) \\
\hline Trovó \& al. 182 (1) (SPF!) & Vasconcelos s.n. (2) (BHCB, U! \\
\hline Trovó \& al. 183 (3) (SPF!) & BHCB41423) \\
\hline Trovó \& al. 415 (4) (SPF!) & Vasconcelos s.n. (2) (BHCB, U! \\
\hline Udulutsch \& al. 1286 (2) (ESA!) & BHCB41457) \\
\hline Uliana \& al. 630 (4) (ESA!, SPF!) & Vasconcelos s.n. (3) (BHCB! \\
\hline Uliana \& al. 634 (4) (ESA!) & BHCB47854) \\
\hline Uliana \& al. 692 (4) (ESA!, SPF!) & Vasconcelos s.n. (3) (BHCB! \\
\hline Usteri s.n. (3) (SP!) & ВНСB52716) \\
\hline Valente \& Araújo 171 (1) (CESJ, SP!) & Vasconcelos s.n. (4) (BHCB! \\
\hline Valente \& Azevedo 2248 (3) (SPF!, & BHCB37474) \\
\hline VIC) & Vasconcelos s.n. (4) (BHCB! \\
\hline Valente \& Azevedo 2249 (3) (SPF!, & BHCB41449) \\
\hline VIC) & Vauthier 167 (2) (G!, L!) \\
\hline Valente \& Meira Neto 1145 (4) (VIC!) & Viana 55 (3) (BHCB!) \\
\hline Valente \& al. 502 (4) (VIC!) & Viana 161 (4) (BHCB!) \\
\hline Valente \& al. 531 (2) (UPCB, VIC!) & Viana 226 (2) (BHCB!, U!) \\
\hline Valente \& al. 532 (2) (SPF!, VIC) & Viana 494 (4) (BHCB!) \\
\hline Valente \& al. 1222 (4) (SPF!, VIC) & Viana 502 (2) (BHCB!) \\
\hline Valente \& al. 1482 (3) (SPF!, VIC) & Viana \& Grandi 106 (2) (BHCB!) \\
\hline Valente \& al. 1717 (2) (SPF!, VIC) & Vidal 6388 (4) (R!) \\
\hline Valente \& al. 1718 (4) (SPF!, VIC) & Vidal l-199 (4) (R!) \\
\hline Valente \& al. 1936 (4) (SPF!, VIC) & Vidal II-5979 (2) (R!) \\
\hline
\end{tabular}

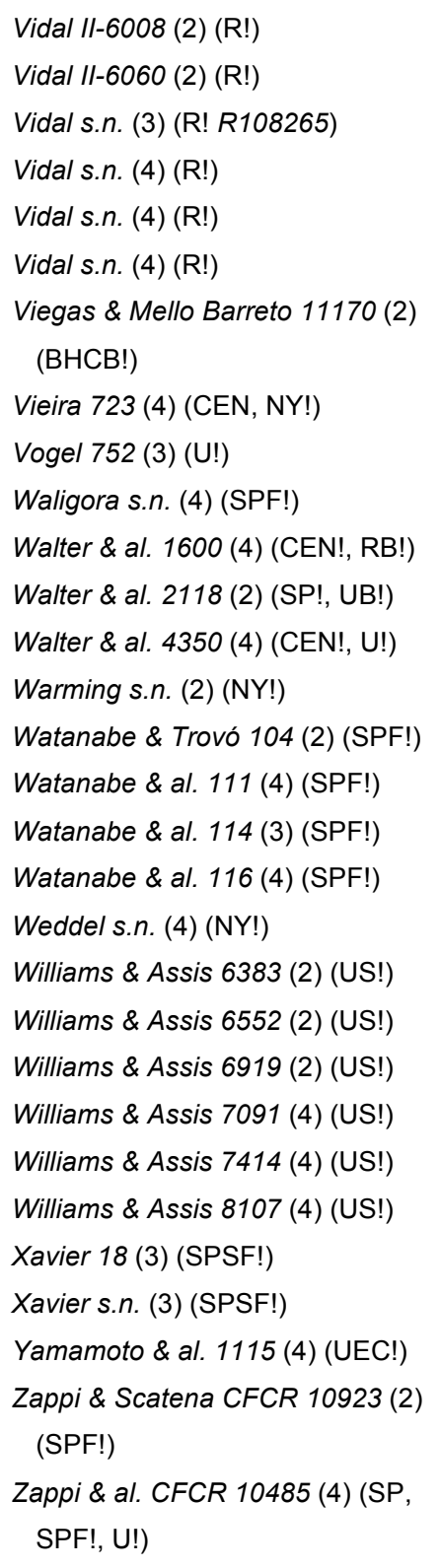

${ }^{1}$ Esse material possui também C. amplissimus (espécie excluída de Calolisianthus, ver tratamento taxonômico). 


\section{- Capítulo 6}

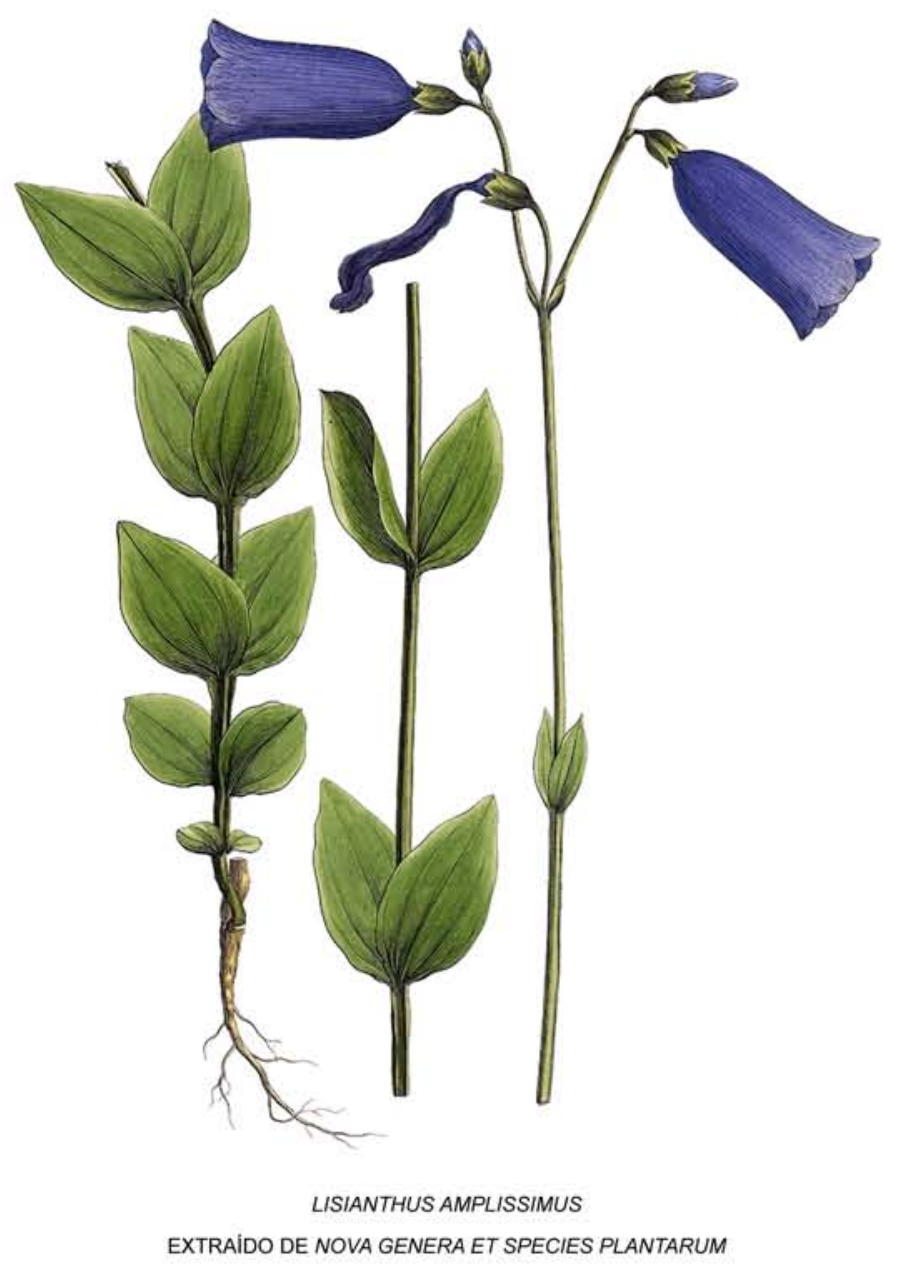

Novas combinações no gênero Chelonanthus Gilg

(Helieae, Gentianaceae) 


\title{
CAPÍTULO 6
}

\section{Novas combinações no gênero Chelonanthus Gilg (Helieae, Gentianaceae) ${ }^{1}$}

\begin{abstract}
Two South American species formerly placed in Calolisianthus Gilg are now transferred to Chelonanthus Gilg (Helieae, Gentianaceae). Morphological descriptions, illustrations and geographic distribution maps are presented.
\end{abstract}

Key words Calolisianthus, Chelonanthus, Morphology, Nomenclature, New combination

\section{Resumo}

Duas espécies sul-americanas que pertenciam ao gênero Calolisianthus Gilg são transferidas para Chelonanthus Gilg (Helieae, Gentianaceae). São apresentadas descrições morfológicas, ilustrações e mapas de distribuição geográfica.

Palavras-chave Calolisianthus, Chelonanthus, Morfologia, Nomenclatura, Novas combinações

\section{Introdução}

A partir dos resultados dos estudos filogenéticos realizados com base em dados morfológicos e moleculares (Calió \& al., em prep., Cap. 3) e do estudo de revisão do gênero Calolisianthus Gilg (Calió \& Pirani, em prep., Cap. 5), constatou-se a necessidade de excluir duas espécies de Calolisianthus e transferi-las para Chelonanthus Gilg. Neste capítulo, essas novas combinações são oficializadas, bem como são apresentadas as descrições morfológicas e mapas de distribuição geográfica de ambas as espécies.

\section{Materiais e Métodos}

Foram analisadas populações naturais durante expedições de coleta, bem como materiais provenientes dos seguintes herbários (exsicatas ou fotos): $\mathrm{BHCB}, \mathrm{BR}, \mathrm{CHRB}^{*}$, CEN, CEPEC, CESJ*, CTES, E, ESA*, G, HB*, HRB, HUEFS, HUFU, IAC, IBGE, K, L, LIL, $\mathrm{LP}, \mathrm{M}, \mathrm{MBM}^{*}, \mathrm{NY}^{*}, \mathrm{P}, \mathrm{PMSP}^{*}, \mathrm{R}^{*}, \mathrm{RB}^{*}, \mathrm{~S}, \mathrm{SP}^{*}, \mathrm{SPF}^{*}, \mathrm{SPFR}, \mathrm{SPSF}^{*}, \mathrm{U}, \mathrm{UB}, \mathrm{UEC}{ }^{*}, \mathrm{UPCB}^{*}$,

\footnotetext{
${ }^{1}$ As informações aqui apresentadas serão publicadas em conjunto com dados obtidos por K.B. Lepis em sua tese de doutorado sobre Chelonanthus. Maiores detalhes na Introdução Geral desta Tese.
} 
US*, VIC (* indica herbários visitados). Materiais-tipo dos herbários BR, E, G, K, M, P foram analisados apenas por meio de fotos. Uma listagem de todos os materiais examinados encontra-se no Apêndice A.

O estudo detalhado da morfologia foi feito sob microscópio estereoscópico SZ Olympus. Foram mensuradas apenas estruturas completamente desenvolvidas, com o auxílio de retículo milimétrico do microscópio para estruturas diminutas, e de paquímetro para estruturas maiores que $1 \mathrm{~cm}$. Flores foram re-hidratadas com gotas de glicerina por cerca de 40 segundos em forno de microondas, anteriormente às medições. As descrições de formas de estruturas, de padrões de venação e de tipologia das inflorescências basearam-se, respectivamente, em Radford \& al. (1974), Hickey (1979) e Weberling (1989). Dados sobre o status de conservação são fornecidos com base nos critérios da IUCN (2001).

Nesse estudo, são denominadas "bractéolas" as estruturas foliares mais próximas do cálice, "brácteas" as estruturas foliares subtendendo flores agrupadas (ou aquelas localizadas abaixo das bractéolas em flores solitárias), e "pedicelo" a estrutura caulinar compreendida entre a base do cálice e a bractéola.

Os mapas de distribuição geográfica foram elaborados com o programa ArcGIS 9.2 (ESRI, 2006), a partir de coordenadas informadas em etiquetas de material de herbário ou georreferenciadas posteriormente, tomando como base o município de ocorrência do espécime.

\section{Tratamento taxonômico}

Tradicionalmente, as duas espécies tratadas nesta trabalho eram descritas como pertencentes a Calolisianthus, tanto por compartilharem atributos morfológicos com as demais espécies do gênero (e.g. hábito herbáceo, corola campanulada de cor lilás), como por ocorrerem, de modo geral, na mesma região no leste do Brasil. Entretanto, o estudo filogenético de Calió \& al. (em prep., Cap. 3) demonstrou, com boa sustentação, o posicionamento de tais espécies juntamente com Chelonanthus purpurascens em um clado filogeneticamente distante das demais espécies de Calolisianthus. Dentro desse panorama, evidenciou-se que os atributos morfológicos compartilhados entre as espécies de Calolisianthus em sua circunscrição tradicional tratavam-se, de fato, de homoplasias. Além disso, o estudo detalhado sobre o tipo de habitat mostrou que essas duas espécies segregadas de Calolisianthus ocorrem em ambientes mais úmidos e sombreados, enquanto que as demais são encontradas preferencialmente em áreas mais secas e expostas (Calió \& Pirani, em prep., Cap. 5). 
1. Chelonanthus abditus Calió \& Pirani nom. nov. $\equiv$ Lisianthus acutangulus Mart., Flora 21(2), Beibl. 4-5: 49, 1838, nom. illeg. (non L. acutangulus Ruiz \& Pav., FI. peruv. prodr. 1794 ) = Calolisianthus acutangulus (Mart.) Gilg in Engler \& Prantl Nat. Pflanzenfam. 4(2): 99. 1895 - Citação do tipo: [Brasil, Mato Grosso], "Prope Cuiaba", s.d., Martius 216 - Lectótipo (designado por Calió \& Pirani, Cap. 5): BR [foto SPF!]; BR [foto SPF!], E [imagem da digitalizada da exsicata!], G [foto U!], K [imagem digitalizada da exsicata!], L(×2)!, P [imagem digitalizada da exsicata!].

Ervas, 15-70 cm alt. Caule 1.2-1.8 mm diâm. na base da planta, 1-4 mm diâm. abaixo das flores, internós 1.3-2.1 mm compr. na base, 25-74 mm compr. abaixo das flores; alas 0.5-3 $\mathrm{mm}$ larg. Folhas sésseis, nectários extra-florais na base das folhas ausentes; lâmina estreitamente elíptica, 9-58 × 2-16 mm, base decorrente, ápice acuminado; nervuras secundárias inconspícuas ou conspícuas (1 par), nervuras terciárias inconspícuas ou conspícuas, reticuladas. Flores 1-7; brácteas escamiformes, lineares a estreitamente elípticas, 8-21 × 1.8-2 mm, base truncada ou decorrente, margem inteira, ápice acuminado; bractéolas escamiformes, elípticas ou lanceoladas a ovadas, 3-4.5 × 1.6-3.5 mm, base truncada ou decorrente, margem inteira ou erosa, ápice agudo; pedicelo 4-11 × 0.8-1.7 mm. Cálice 9-11 × 6.5-8 mm; tubo 5-5.5 mm compr.; lobos 5, circulares ou largamente ovados a largamente depresso-ovados, 3-5.5 × 3-5.7 mm, margem erosa, ápice arredondado. Corola lilás, ápice dos lobos alvescente a amarelado, campanulada, 36-82 mm compr., 4.7-8.1 vezes maior que o cálice; tubo 34-60 mm compr., 2-2.5 mm larg. na base, 3-8 mm larg. abaixo da inserção dos estames, 23-32 mm larg. no ápice; lobos 5, largamente depressoovados a depresso-ovados, 10.6-21 × 15.8-24 mm, margem erosa, ápice obtuso a retuso. Estames 5; filetes alvos a esverdeados, 12.4-24.5 mm compr.; anteras alvas a amarelas, estreitamente elípticas, c. $4.5 \times 1.3 \mathrm{~mm}$, apêndice estéril c. $0.2 \mathrm{~mm}$ compr. Ovário verde, ovóide, 6-9.5 × 2.3-3 mm; estilete alvo ou creme a esverdeado, 26-39 ×0.5-0.9 mm; lobos do estigma alvos a esverdeados, ovados a largamente ovados, 5-11 × 5-7.5 mm. Fruto estreito-ovóide a ovóide, c. $11.5 \times 6$ mm (Fig. 1, Fig. 3A-C).

Etimologia. - O termo latino "abditus" significa oculto, escondido, secreto. A escolha desse epíteto baseia-se na "identidade secreta" dessa espécie, a qual, além de ter sido designada durante muito tempo por um nome ilegítimo, nunca fora reconhecida como espécie de Chelonanthus, fato evidenciado apenas recentemente com os resultados das análises filogenéticas (Calió \& al., em prep., Cap. 3). Sendo assim, a escolha do nome coaduna-se com sua qualidade de "espécie oculta de Chelonanthus". 
Taxonomia. - Ao escolher o epíteto "acutangulus" para designar essa espécie, Martius (1838) criou um homônimo posterior em relação ao nome Lisianthus acutangulus Ruiz \& Pavon, fato que torna L. acutangulus Mart um nome ilegítimo. Por essa razão e por não haver outro nome disponível, houve necessidade de atribuir um novo nome a essa espécie.

Distribuição, habitat e conservação. - A espécie ocorre principalmente em Goiás e Distrito Federal, mas a distribuição abrange Tocantins, Maranhão, Piauí e Pará, ao norte, Mato Grosso e Bolívia, a oeste, e Minas Gerais e Bahia, a leste (Fig. 4A). A altitude em que C. abditus é encontrada varia entre 100 e 1300 m, com maior freqüência entre 400 e 800 m. Essa espécie é encontrada em cerrados, campos úmidos e alagáveis, brejos e bordas de matas. Foi observada em locais expostos e ensolarados, mas ocorre freqüentemente em locais sombreados tanto pela presença de vegetação mais alta e densa, quanto pela presença de gramíneas. O solo das regiões de ocorrência de $C$. abditus é geralmente argiloso e raramente pedregoso. Segundo os critérios da IUCN (2001), essa espécie não é categorizada como ameaçada.

Morfologia e fenologia. $-C$. abditus apresenta morfologia muito semelhante a $C$. amplissimus, mas difere desta pela forma das folhas, que é sempre estreita (3.5 a 5 vezes mais longa do que larga), e pelas folhas basais e apicais com ápice agudo e com apenas um par de nervuras secundárias conspícuas. Encontrada com flores e frutos principalmente entre dezembro e julho.

Material selecionado. - Aproximadamente 100 coleções analisadas (relação completa no Apêndice A). BOLÍVIA, SANTA CRUZ: Santiago de Chiquitos, Cerro de San Micenato, II.1950, Cárdenas 4457 (US!). BRASIL, BAHIA: Abaíra, Catolés, encosta da Serra do Atalho em frente ao Mendonça, 131'' 4 4149'W, 3.iv.1992, Ganev 12 (HUEFS!, K, NY!, SP!, SPF!). DISTRITO FEDERAL: Brasília, bacia do Rio São Bartolomeu, 21.ii.1980, Heringer \& al. 3440 (IBGE, K!, NY!, UEC!). GOIÁS: Água Fria de Goiás, Estação Repetidora da Telebrasília de Rocandor, 8.ii.1994, Hatschbach \& al. 60003 (CTES!, MBM); Alto Paraíso de Goiás, Parque Nacional da Chapada dos Veadeiros, estrada para Vereda do Mulungu, 20.iii.2009, Trovó \& al. 470 (SPF!); Cavalcante, estrada Vila Veneno - Serra Branca, km 3,6, margem direita do rio Macacão, 13⒊' $25^{\prime \prime S}$ 4804'20"W, 20.ii.2002, Pereira-Silva \& al. 5901 (CEN, SPF!); Colinas do Sul, sobre el camino a Cavalcante, 5.ii.1990, Arbo \& al. 3712 (K!); Corumbá de Goiás, ca. 4 km da cidade, estrada para Aparecida, 1554'38"S 4845'44"W, 13.iii.2002, Fonseca \& al. 3171 (IBGE!, RB!, US); Formosa, Buraco das Araras que dá acesso ao

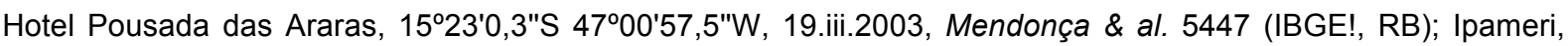
Fazenda Santo Antônio Fundão, córrego afluente na margem esquerda do rio Jacuba, $17^{\circ} 43^{\prime} \mathrm{S} 48^{\circ} 10^{\prime} \mathrm{W}$, 24.iii.1995, Cavalcanti \& al. 1396 (CEN!, CESJ!, SP!); Leopoldo de Bulhões, 16³5'27"S 4345'21"W, 20.iii.1989, Walter \& al. 148 (IBGE!, U!); Luziânia, 15 km ao sul da cidade, rio Vermelho, 1.iii.1984, Heringer 17212 (IBGE!,

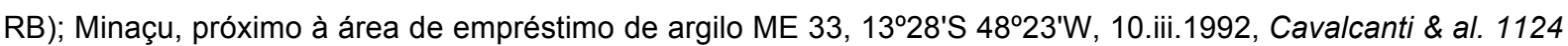


(U!); Morrinhos, Chapadão, 22.iii.1976, Hatschbach \& Kummrow 38225 (MBM!); Niquelândia, estrada de chão em direção à Reserva do IBAMA, 14²9'46"S 48²7'00"W, 1.iii.1996, Fonseca \& Barros 845 (U!); Pirenópolis, Morro do Frota, 26.i.1991, Barros 2219 (SP!); Santo Antônio do Descoberto, margem direita do rio descoberto, próximo a Barra com o Córrego Engenho das Lages, 1605'39"S 48¹6'27"W, 17.ii.2003, Pereira-Silva \& al. 7097 (CEN, SPF!); São João d'Aliança, Serra Geral do Paraná, $7 \mathrm{~km}$ by road of São João da Aliança, 22.iii.1973, Anderson \& al. 7642 (AAU!, NY!, S!, UB!); Vianópolis, 1645'S 48³2'W, 21.iii.1989, Alvarenga \& al. 198 (IBGE!). MARANHÃO: Balsas, Condomínio Kissy, Lote 23, 10.iii.1996, Silva \& al. 3491 (CEN!); Chapadinha, Vila

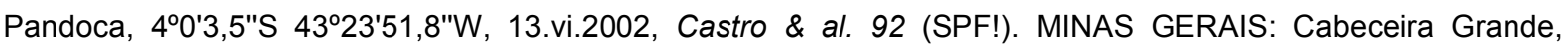
Fazenda São Bento, cerca de $400 \mathrm{~m}$ a montante da ponte nova sobre o rio Preto (divisa DF/MG), Área de influência da AHE Queimado, 1802'25"S 47018'26"W, 17.ii.2003, Santos \& Pereira 1818 (CEN, SPF!); Campina Verde, 12.iv.1989, Macedo 5492 (NY!, US!); Uberlândia, Reserva Ecológica do Panga, 26.ii.1998, Barbosa \& Araújo 231 (HUFU!, SP, SPF!). MATO GROSSO: Barra do Garças, Indianópolis, Fazenda Brasil (divisa com Fazenda Roncador), 1505'35"S 52²5'82"W, 20.iii.1997, Árbocz \& al. 3477 (ESA!); Canarana, estrada Água Boa-Nova Xavantina, ca. 40 km após a entrada de Canarana, 1354'29,3"S 5204'39.0"W, 23.iii.1997, Souza \& al. 14981 (ESA!); Chapada dos Guimarães, 26.iii.1997, Hashimoto s.n. (MBM!); Cuiabá, Chapada dos Guimarães, proximidades da Ponte da Salgadeira, 15¹7'25"S 5548'15"W, 16.xii.1978, Macedo \& al. 1002 (HCMT, UEC!); Poconé, rod. BR-070, km 584, 4.v.1995, Hatschbach \& al. 62238 (MBM!); Santo Antônio do Leverger, 6 km W de Palmeiras (Penitenciária), 30.i.1989, Krapovickas \& Cristóbal 43142 (U!); São Félix do Araguaia, Savana Parque, estrada entre a Vila de Pontinópolis e a Serra dos Magalhães, $11^{\circ} 33^{\prime} 39,4^{\prime \prime S}$ 51ํ1'0,7"W, 21.iii.1997, Souza \& al. 14726 (ESA!). PARÁ: Conceição do Araguaia, Redenção, about 4 km west of town center along highway PA-150, 802'S 5004'W, 21.ii.1980, Plowman \& al. 8962 (U!). PIAUÍ: Uruçuí, $7^{\circ} 15^{\prime} \mathrm{S} 44^{\circ} 32$ 'W, 27.iii.1984, Orlandi 598 (HRB!). TOCANTINS: Arraias, Estrada de terra, $17 \mathrm{~km}$ na rodovia entre Campos Belos (GO) e Arraias (TO), Beira da estrada, 1401'52,4"S 4654'21,1"W, 20.iii.2003, Mazine \& al. 883 (ESA!); Babaçulândia, Rod. Belém-Brasília, 29.iii.1976, Hatschbach \& Kummrow 38484 (MBM!, U!); Lagoa da Confusão, Parque Nacional do Araguaia, Sede do parque, llha do Bananal, próximo à estrada em direção a aldeia Carajá Macaúba, 10²7'48"S 50²8'52"W, 19.iii.1999, Silva \& al. 3987 (U!); Miracema do Tocantins, Região do Lajeadinho, 6.iv.2000, Soares \& al. 652 (IBGE!, HTINS).

2. Chelonanthus amplissimus (Mart.) Calió \& Pirani comb. nov. $\equiv$ Lisianthus amplissimus Mart., Nov. Gen. sp. pl. 2(2): 96, tab. 175. 1827 = Helia amplissima (Mart.) Kuntze, Revis. gen. pl. 2: 428. 1891 = Calolisianthus amplissimus (Mart.) Gilg in Engler \& Prantl Nat. Pflanzenfam. 4(2): 99. 1895 三 Irlbachia amplissima (Mart.) Maas, Proc. Kon. Ned. Akad. Wetensch. C. 88(4): 410. 1985 - Citação do tipo: "Brasilia, Prov. Minarum", s.d., Martius s.n. - Lectótipo (designado por Calió \& Pirani, cap. 5): M [foto SPF!]; isótipo: M [foto SPF!].

Ervas, 15-100 cm alt. Caule 1-3.1 mm diâm. na base da planta, 1.2-3.3 mm diâm. abaixo das flores, internós 0.9-3.5 mm compr. na base, 35-230 mm compr. abaixo das flores; alas 0.4-1.5 mm larg. Folhas sésseis, nectários extra-florais na base das folhas ausentes; lâmina estreitamente elíptica a orbicular, lanceolada a largamente ovada ou obovada a largamente obovada, 5-100 × 3.2-46 mm, base decorrente, ápice agudo (folhas apicais) ou 
arredondado (folhas basais); nervuras secundárias conspícuas (2-3 pares), nervuras terciárias conspícuas, reticuladas. Flores 1-6; brácteas foliáceas ou escamiformes, estreitamente elípticas ou lanceoladas a ovadas, 15-30 × 1-13.2 mm, base decorrente, margem inteira ou erosa, ápice agudo, obtuso, arredondado; bractéolas escamiformes, lanceoladas a largamente ovadas, $2.3-5 \times 1-4 \mathrm{~mm}$, base truncada ou decorrente, margem erosa, ápice agudo; pedicelo 4-15 × 0.9-2.8 mm. Cálice 7-11 × 4.5-8 mm; tubo 2.5-8 mm compr.; lobos 5, largamente ovados a largamente depresso-ovados, 2.8-6 × 3.5-6.5 mm, margem erosa, ápice agudo a arredondado. Corola lilás, ápice dos lobos alvescente a amarelado, campanulada, 28-84 mm compr., 4.7-8.1 vezes maior que o cálice; tubo 22-70 $\mathrm{mm}$ compr., 2.5-4 mm larg. na base, 3.5-9 mm larg. abaixo da inserção dos estames, 12$28 \mathrm{~mm}$ larg. no ápice; lobos 5, largamente depresso-ovados a depresso-ovados, 5-16.5 $\times$ 9-23 mm, margem inteira a levemente erosa ou levemente sinuada, ápice obtuso, arredondado ou emarginado. Estames 5; filetes alvos a lilases, 11-42 mm compr.; anteras alvas a amarelas, estreitamente elípticas, $4-7 \times 1.2-2.5 \mathrm{~mm}$, apêndice estéril $0.2-0.3 \mathrm{~mm}$ compr. Ovário verde, estreito-ovóide a ovóide, 5.5-9 × 2.5-3.5 mm; estilete alvo, 12-44 × $0.6-1.8 \mathrm{~mm}$; lobos do estigma alvos, ovados a depresso-ovados, 3.5-12 × 2.2-7 mm. Fruto estreito-ovóide a ovóide, 13-19 × 6-9 mm (Fig. 2, Fig. 3D-E).

Etimologia e nomes populares. - No protólogo dessa espécie, Martius (1827) descreve a corola como "muito grande" (amplissima); acredita-se que o epíteto específico baseie-se nesse atributo da planta. Conhecida popularmente como sininho (referência na etiqueta do material "Baitello \& Peres 1502").

Taxonomia. - Essa espécie havia sido escolhida como lectótipo do gênero Calolisianthus (Pringle, 1995). Entretanto, o estudo detalhado da morfologia do gênero (Calió \& Pirani, em prep., Cap. 5) e os resultados da filogenia morfológica e molecular da tribo (Calió \& al., em prep., Cap. 3) evidenciaram que C. amplissimus e as demais espécies de Calolisianthus não são proximamente relacionadas. Ainda, existe claro conflito desse táxon com o protólogo do gênero Calolisianthus. Sendo assim, a espécie foi excluída de Calolisianthus e um novo lectótipo foi designado para tal gênero (vide Calió \& Pirani, em prep., Cap. 4). Por fim, devido ao relacionamento próximo dessa espécie com Chelonanthus, foi feita a combinação do nome nesse último gênero.

Distribuição, habitat e conservação. $-C$. amplissimus ocorre no mesmo tipo de vegetação e solo em que ocorre $C$. abditus. Distribui-se principalmente nos estados de Minas Gerais e São Paulo, com menor número de ocorrências em Goiás e Distrito Federal e 
apenas uma referência para o Paraná e uma para o Rio de Janeiro (Fig. 4B). Apenas em Goiás e Distrito Federal há sobreposição da distribuição de C. amplissimus e C. abditus (Fig. 4). A altitude em que é encontrada varia entre 600 e $1500 \mathrm{~m}$, com maior freqüência entre 800 e 900 m. Essa espécie não se enquadra como ameaçada segundo os critérios da IUCN (2001).

Morfologia e fenologia. - Os atributos morfológicos que mais ressaltam nessa espécie são a grande corola campanulada, o caule alado e as folhas com base decorrente, sendo estas duas últimas características importantes na distinção entre $C$. amplissimus e as espécies do gênero Calolisianthus. A constante presença de folhas elípticas a circulares, largamente ovadas ou largamente obovadas (i.e., 0.9 a 2.5 vezes mais longas do que largas), com 2-3 pares de nervuras secundárias, além de ápice arredondado nas folhas basais, são as principais características que diferenciam essa espécie de C. abditus. Floresce e frutifica entre dezembro e julho.

Material selecionado. - Aproximadamente 160 coleções analisadas (relação completa no Apêndice A). BRASIL, DISTRITO FEDERAL: Brasília, Reserva Ecológica do IBGE, próximo ao Córrego Taquara, Cristo Redentor, 18.iii.1991, Brochado 161 (IBGE, RB!, SPF!). GOIÁs: Alto Paraíso de Goiás, Fazenda São Bento, margem direita da rodovia Alto Paraíso-Colinas, 23.ii.1991, Alvarenga \& al. 778 (IBGE!, SPF!, U!); Caldas Novas, ponte São Bento-Estrada Caldas Novas a Ipameri, $19 \mathrm{~km}$ Caldas Novas,

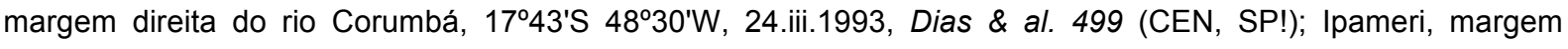
esquerda do rio Corumbá; em frente à estação de medição de vasão S.O.3, 23.iii.1993, Silva \& al. 1244 (CEN, SPF!); Pirenópolis, Morro da caixa d'água, 23.iv.1976, Heringer 15784 (UB!); Santa Rita do Araguaia, Rio Babilônia, 15.ii.1974, Hatschbach 34226 (MBM!, NY!); Silvânia, Fazenda Córrego Profundo, margem direita do rio Corumbá, 16¹9'13"S 48²0'44"W, 12.iii.2003, Pereira-Silva \& al. 7411 (CEN, SPF!). MINAS GERAIS: Aiuruoca, PCH Aiuruoca, Rio Aiuruoca, 16.ii.2000, Tameirão Neto 2917 (BHCB!, RB!); Alpinópolis, Furnas, Fazenda Salto, 23.iii.1975, Martins 38 (UEC!); Barbacena, estrada para Ibertioga, 12.iii.1982, Hensold CFCR 2943 (SPF!, U!); Barroso, Mata do Baú, 7.iii.2003, Assis \& al. 711 (CESJ!, RB); Belo Horizonte, Barreiro, 19.iv.1935, Mello-Barreto \& Brade 1322 (RB!); Betim, Capela Nova do Betim, iii.1916, Lutz 927 (R!); Caldas,

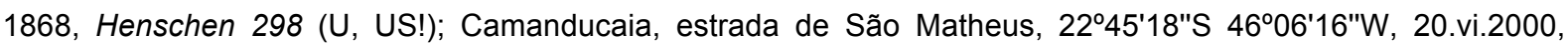
Kamino \& al. 48 (BHCB!); Corinto, Fazenda do Diamante, 2.iv.1931, Méxia 5529 (NY!, U!, US!); Couto de Magalhães de Minas, Fazenda das Abóboras, 16.vii.1984, Varanda \& al. CFCR 4543 (K!, SP!, SPF!); Datas, arredores da cidade, 23.ii.1983, Cordeiro \& Simonis CFCR 4014 (SPF!, U!); Entre Rios de Minas, 20.i.1970, Krieger 8335 (CESJ!); Frutal, 18.iv.1978, Shepherd \& al. 7397 (UEC!); Ibiá, ca. 8 km E of the Araxá junction highway 262 to Belo Horizonte, 29.ii.1976, Davidse \& D'Arcy 10864 (SP!); Jaboticatubas, $10 \mathrm{~km}$ ao norte de Lagoa Santa, km 56 da estrada Belo-Horizonte Conceição do Mato Dentro, 1940'S 4355'W, 23.iv.1952, Smith \& al. 6974 (US!); Lagoa Dourada, Fazenda do Bom Retiro, 8 km de Lagoa Dourada em direção a Entre Rios de Minas, 2051'40.6"S 4403'30.5"W, 8.iii.1995, Souza \& al. 7994 (ESA!, UEC!); Lagoa Santa, NW de Lagoa Santa, 19040'S 4355'W, 30.iv.1952, Smith 6721 (NY!, R!, US!); Lavras, ESAL, 2.ii.1939, Heringer 188 (SP, SPF!); Minas Novas, 24.iii.1993, Esteves \& Kameyama 2497 (SP!); Nova Lima, estrada de Itabirito km 43, rio acima, 29.iii.1933, Mello-Barreto 2820 (BHCB!); Ouro Branco, Serra do Ouro Branco, 1.iii.2001, Caiafa \& Meireles 125 
(VIC!); Ouro Preto, Rodrigo Silva, 6.iv.1901, Damazio 963 (RB!); Paraobeba, FLONA de Paraopeba, 8.iv.2004, Valente \& Meira Neto 1510 (SPF!, VIC); Passa Quatro, 11.iv.1929, Samp. 6157 (R!); Pimenta, estrada PimentaSanto Hilário, 13.ii.1998, Goldenberg \& al. 535 (UEC!); Piumhi, Serra do Andaime, Serra do Andaime, 14.ii.1998, Romero \& al. 5186 (UEC!); Poços de Caldas, Campo do Saco, 12.ii.1965, Emmerich 2376 (R!); Sabará, estrada de Caeté km 27, 23.iii.1934, Mello-Barreto 2824 (BHCB!); Sacramento, Represa de Furnas, fazenda próx. a barragem de Estreito, 1.iii.1992, Kawal 113 (SP, SPF!); São João del Rei, III.1970, Krieger 8263 (CESJ, SPF!); São Roque de Minas, Parque Nacional Serra da Canastra, estrada para sacramento, $11 \mathrm{~km}$ da sede administrativa, próximo ao Curral de Pedras, 18.iv.1994, Romero \& al. 926 (HUFU, SP!, SPF!); São Sebastião do Paraíso, arredores da cidade, 8.iv.1945, Brade \& Barbosa 17691 (RB!); Taquaraçu de Minas, Jangada, 21.iv.1980, Grandi 275 (BHCB!); Três Corações, rod. Três Corações-São Tomé das Letras, 4.ii.1973, Hatschbach \& Ahumada 31218 (MBM!, S!, U!). PARANÁ: Sengés, Morungava, 13.ii.1915, Dusén 16668 (NY!, US!). RIO DE JANEIRO: Rio de Janeiro, Ipanema, 1903, Sem coletor s.n. (SP, SPF!). SÃO PAULO: Alumínio, Chácara Sperancini, antiga área da Fazenda Vale Grande, 11.ii.2001, Amaral \& Bittrich 2001/12 (UEC!); Caieiras, 11.iv.1945, Hoehne s.n. (CHRB!, SPF!); Campos do Jordão, Fazenda da Guarda, 2248'0"S 4537'0"W, 18.iii.1964, Gomes 1642 (SP!); Franco da Rocha, Parque Estadual do Juqueri, 2321'29.4"S 46²41'45,5"W, 13.iv.2005, Calió \& al. 91 (CHRB!, SPF!); Itirapina, 28.iv.1923, Gehrt s.n. (SP, SPF!); Mogi-Guaçu, Fazenda Campininha, Campos das Sete Lagoas, just north of rio Mogi-Guaçu, about $10 \mathrm{~km} \mathrm{N-NE}$ of river \& village of

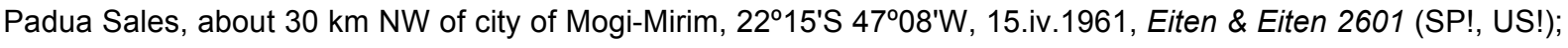
Mogi-Mirim, 23.v.1923, Hoehne s.n. (SP, SPF!); Pedregulho, Parque Estadual das Furnas do Bom Jesus, próximo ao encontra dos córregos Pedregulho e Bom Jesus, 20¹1'50"S 47²5'10"W, 21.iii.2004, Calió \& Sasaki 66 (CHRB!, SPF!); Pirassununga, 21.ii.1965, Vogel 640 (U!); Poços de Caldas, Campo do Saco, 21050'20"S 46³3'53"W, 16.ii.1981, Pereira 837 (UEC!); Santo Antônio de Posse, Fazenda Dona Amélia, 14.iii.1983, Sazima 14670 (UEC!); São Paulo, Butantã, 28.iii.1919, Hoehne s.n. (SP!).

\section{Referências Bibliográficas}

Calió, M. F., Pirani, J.R., em prep. Nova lectotipificação de Calolisianthus Gilg (Helieae, Gentianaceae). A ser submetido a Taxon.

Calió, M.F. \& Pirani, J.R., em prep. Revisão de Calolisianthus Gilg (Helieae, Gentianaceae), um gênero endêmico dos campos rupestres e cerrados no Brasil. A ser submetido a Taxon.

Calió, M.F., Pirani, J.R. Struwe, L. \& Lepis, K.B., em prep. Estudo filogenético de Helieae (Gentianaceae) com ênfase nos limites genéricos de Calolisianthus Gilg, Chelonanthus Gilg e Helia Mart., baseado em dados moleculares e morfológicos. A ser submetido a Molecular Phylogenetics and Evolution.

ESRI, Environmental Systems Research Institute, INC. 2006. ArcGis - ArcView Desktop 9.2. Hickey, L.J. 1979. A revised classification on the architecture of dicotyledonous leaves. Pp. 25-39 in: Metcalfe, C.R. \& Chalk, L. (eds.) Anatomy of the Dicotyledons. Vol. 1. Ed. 2. Clarendon Press, Oxford.

IUCN 2001. IUCN Red List categories and criteria. Version 3.1. IUCN, Gland, Switzerland \& 
Cambridge, U.K.

Martius, C.F.P. von. 1827. Nova genera et species plantarum quas in itinere per Brasiliam, vol. 2, pars2. V. Wolf, München.

Martius, C.F.P. von. 1838 [1837]. Gentianaceae. Flora 21(2), Beibl. 4-5. Monachii.

Radford, A.E., Dickson, W.C., Massey, J.R. \& Bell, C.R. 1974. Vascular plant systematics. Harper \& Row Publishers, New York, Evanston, San Francisco, London.

Pringle, J.S. 1995. Family 159A. Gentianaceae. Pp. 1-131 in: Harling, G. \& Andersson, L. (eds.), Flora of Ecuador, vol. 53. Department of Systematic Botany, Gothenburg University, Göteborg.

Weberling, F. 1989. Morphology of flowers and inflorescences. Cambridge University Press, New York. 


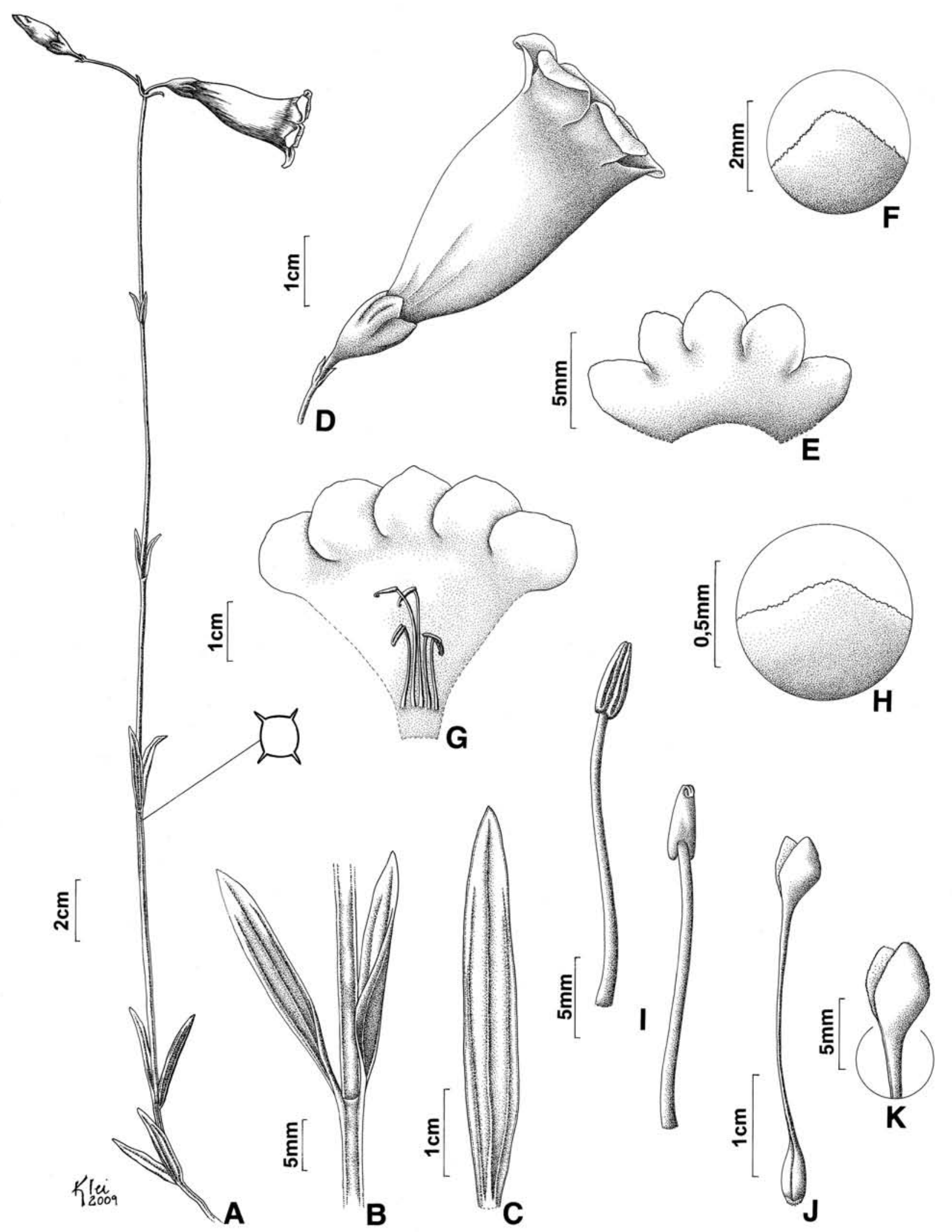

Fig. 1. Chelonanthus abditus. A, hábito, com representação esquemática da seção transversal do caule; B, detalhe do nó; C, face abaxial da folha; D, flor, visão lateral; E, cálice rebatido; F, detalhe do ápice e margem do lobo do cálice; G, corola rebatida, evidenciando inserção e tamanho desigual dos estames; $\mathbf{H}$, detalhe do ápice e margem do lobo da corola; I, estames (faces abaxial e adaxial); J, gineceu; K, detalhe do estigma. Todos desenhados a partir de Heringer \& al. 3340 (UEC). 


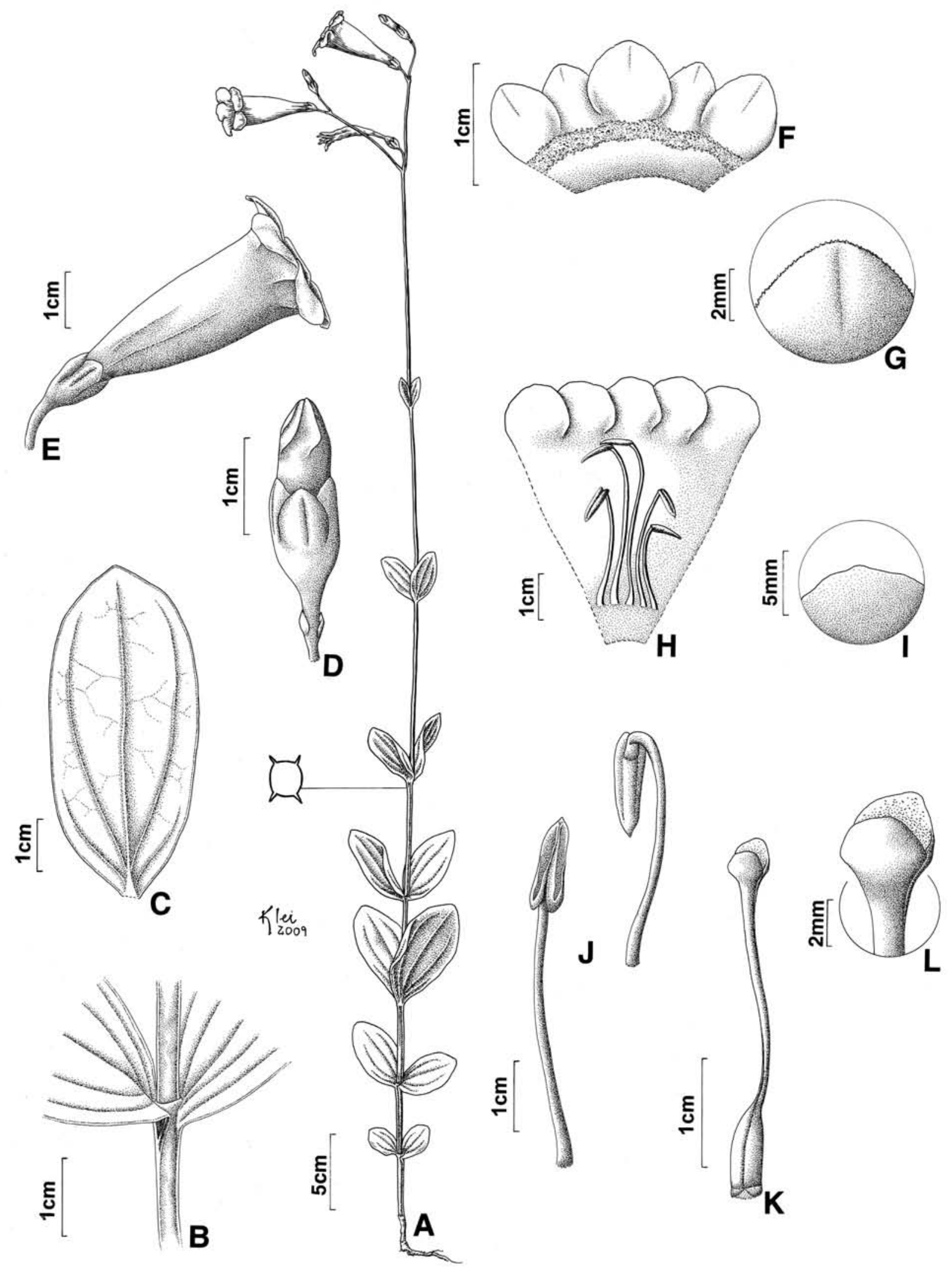

Fig. 2. Chelonanthus amplissimus. A, hábito, com representação esquemática da seção transversal do caule; B, detalhe do nó; C, face abaxial da folha; D, botão floral; E, flor, visão lateral; F, cálice rebatido; $\mathrm{G}$, detalhe do ápice e margem do lobo do cálice; $\mathrm{H}$, corola rebatida, evidenciando inserção e tamanho desigual dos estames; I, detalhe do ápice e margem do lobo da corola; J, estames (faces abaxial e adaxial); K, gineceu; L, detalhe do estigma. Todos desenhados a partir de Calió \& Sasaki 66 (SPF). 

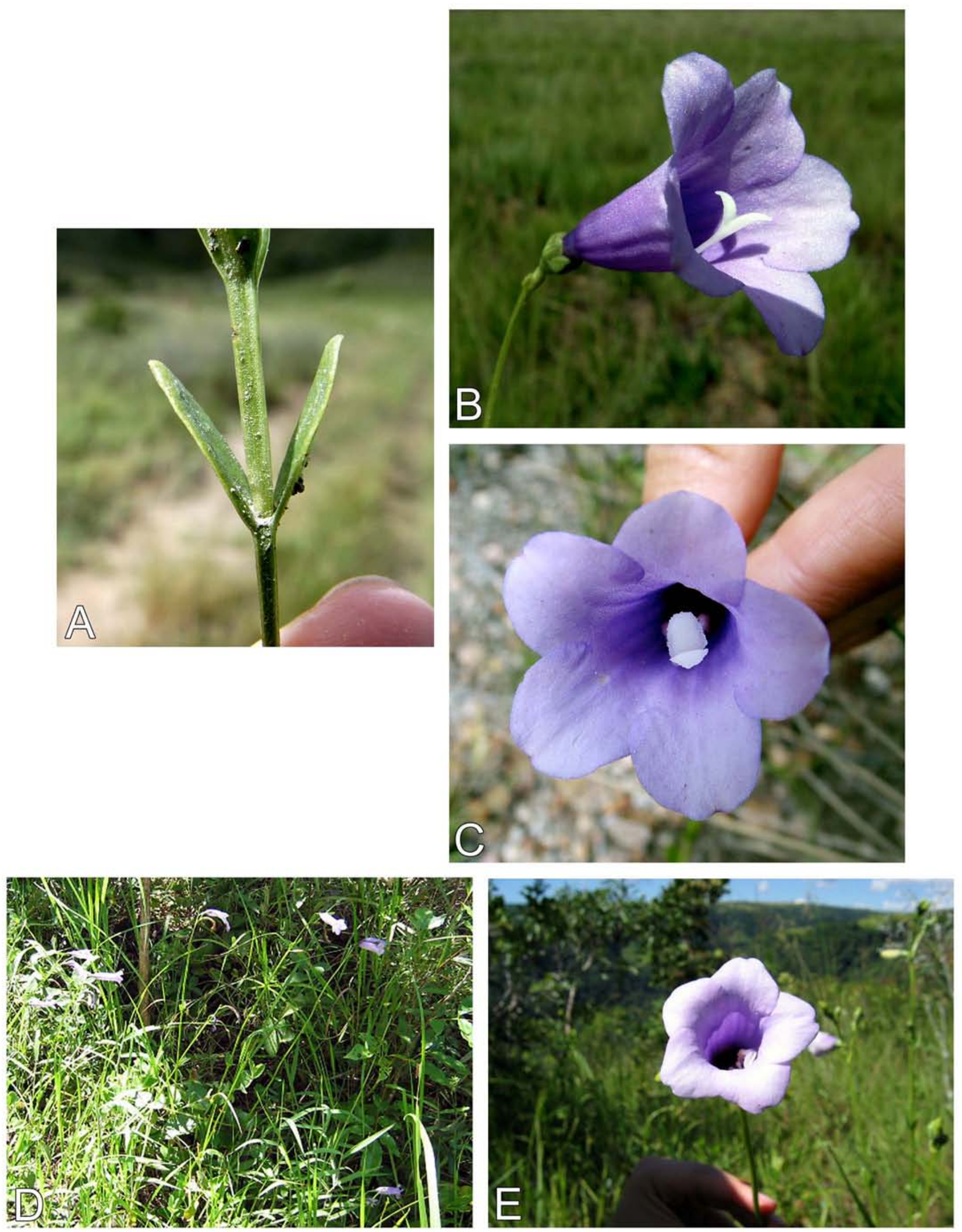

Fig. 3. Chelonanthus abditus. A, ramo com folhas; B, flor, visão lateral; C, flor, visão frontal. Chelonanthus amplissimus. D. hábito; E, flor, visão frontal. Fotos: A-C, Marcelo Trovó; D-E, Denise Sasaki. 

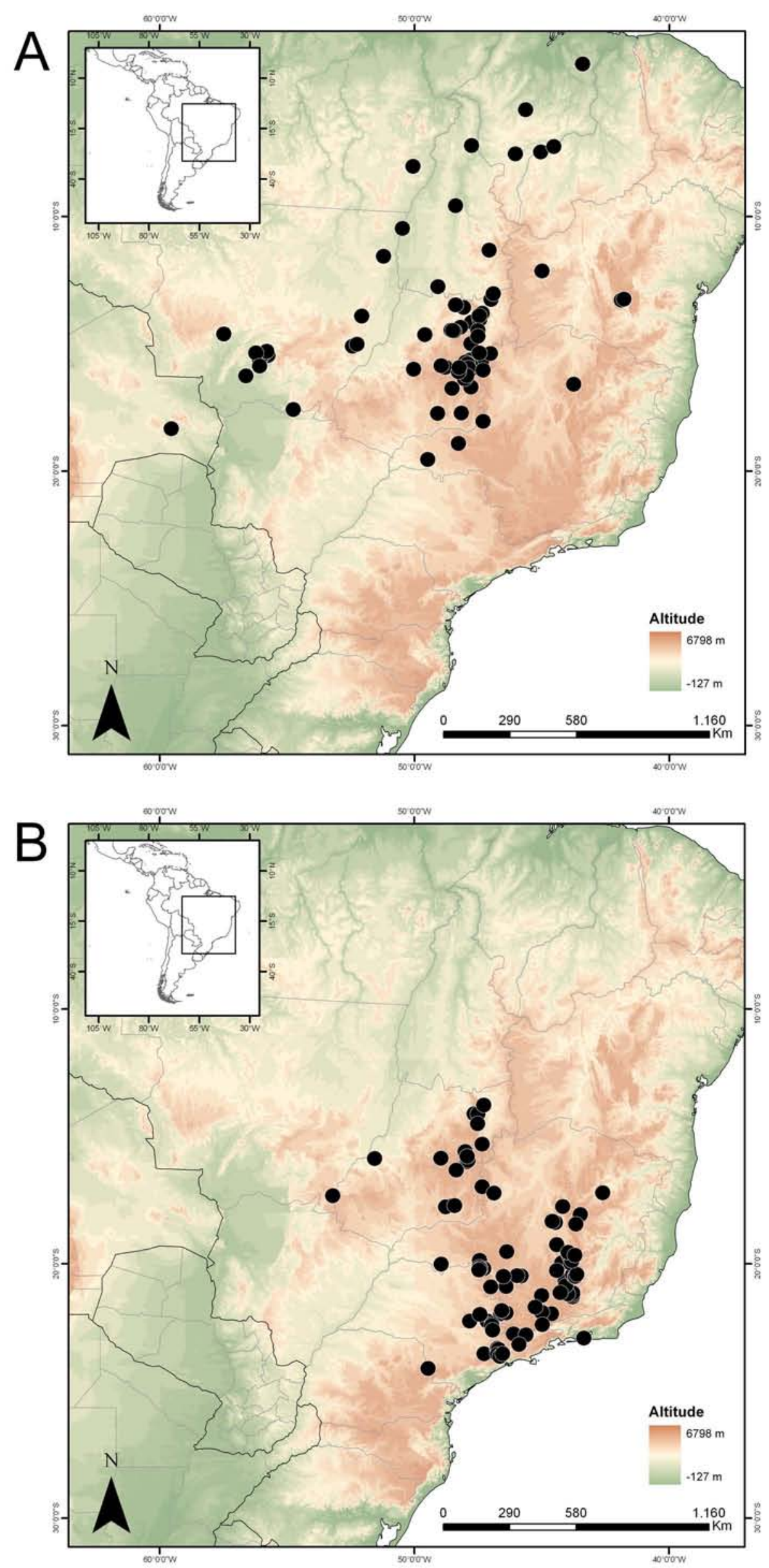

Fig. 4. Distribuição geográfica. A, Chelonanthus abditus; B, Chelonanthus amplissimus. 
Apêndice A. Lista de exsicatas, indicando coletor e número, número da espécie no tratamento taxonômico e herbários. Negrito = espécimes-tipo; scan = imagem digitalizada da exsicata. Chelonanthus abditus $=1 ;$ Chelonanthus amplissimus $=2$.

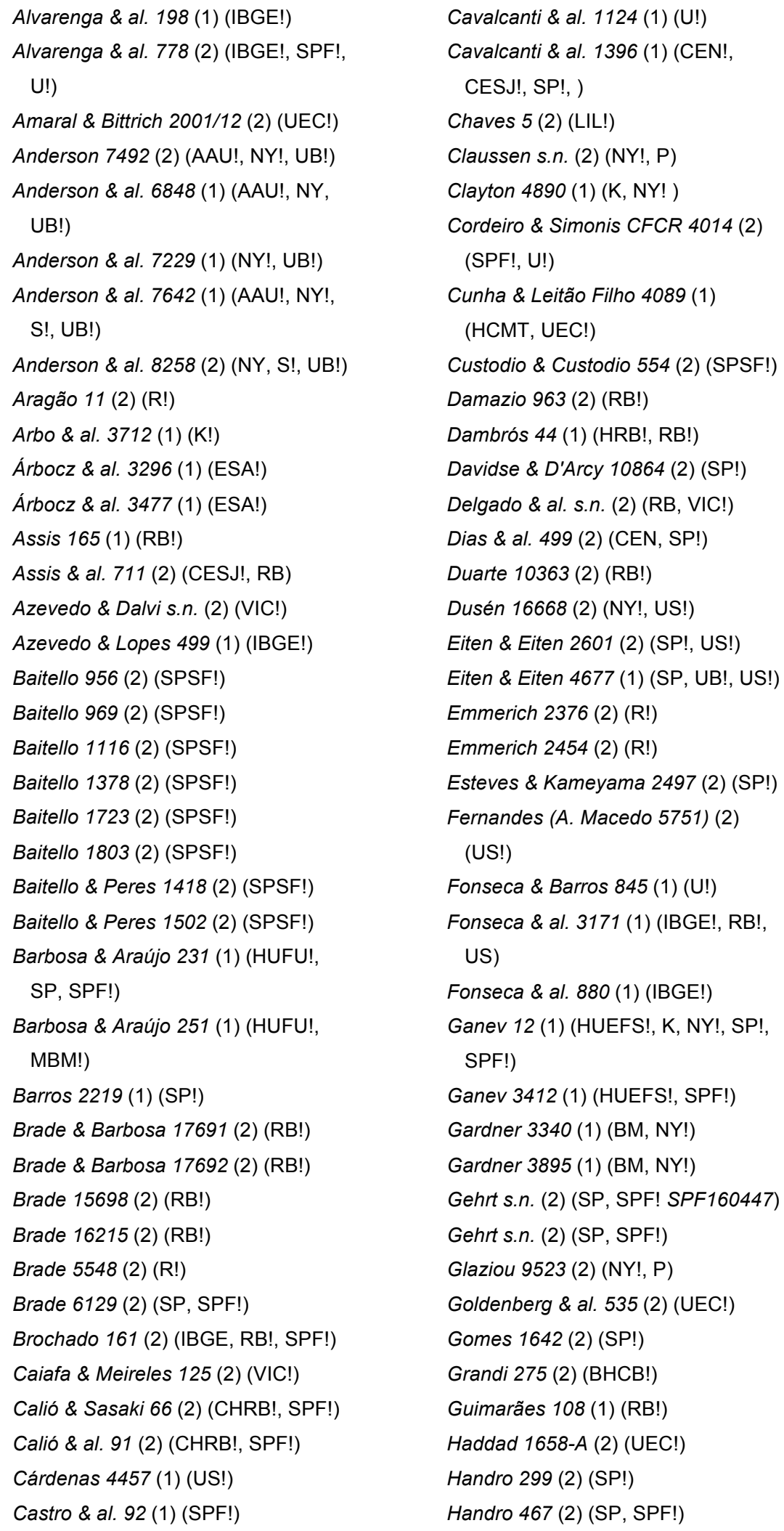

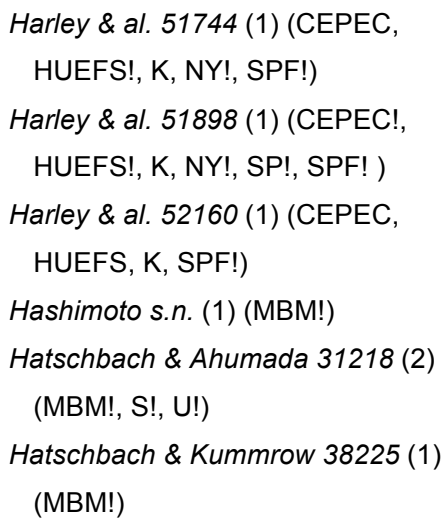


Hoehne s.n. (2) (CHRB!, SPF!
SPF11478)

Irwin \& al. 12095 (1) (NY!, SP!, U!)

Irwin \& al. 12243 (2) (NY!)

Irwin \& al. 13102 (2) (NY!, U!)

Irwin \& al. 13871 (1) (NY!, S!, SP!, US!, U!)

Irwin \& al. 14293 (2) (NY!, SP!, U!)

Irwin \& al. 15272 (2) (NY!, RB!)

Irwin \& al. 23790 (2) (NY!, UB!)

Irwin \& al. 24057 (1) (NY!, RB, S!,

UB!, US!)

Irwin \& al. 24376 (1) (NY!, S!, UB!, )

Irwin \& al. 24848 (2) (NY!, RB!, UB!, US!)

Irwin \& al. 26303 (2) (UB!, NY!)

Irwin \& al. 26760 (2) (NY!, S!, U!, UB!)

Irwin \& al. 27164 (2) (NY!, UB!)

Irwin \& al. 31426 (1) (NY, UB!)

Irwin \& al. 31948 (2) (NY, UB!)

Irwin \& al. 32012 (1) (NY!, SP!, U!,

UB!, US!)

Irwin \& al. 35016 (1) (LIL!, NY!, R!, S!, UB!, US!)

Jesus 56 (2) (NY!)

Joly s.n. (2) (SPF!)

Kamino \& al. 48 (2) (BHCB!)

Kawal 113 (2) (SP, SPF!)

Kirkbride Jr. 3788 (1) (US!)

Koehler \& al. 9915 (2) (UEC!)

Krapovickas \& Cristóbal 43142 (1)

(U!)

Krieger 8263 (2) (CESJ, SPF!)

Krieger 8335 (2) (CESJ!)

Krug 22 (1) (IAC!, SP!)

Kuhlmann 4188 (2) (SP!)

Lima 200 (1) (NY!)

Löfgren 38 (2) (RB!)

Löfgren 265 (2) (RB!)

Luederwaldt s.n. (2) (SP!)

Lund 1839_84 (2) (G!)

Lund 1839_92 (2) (G!)

Lutz 1647 (2) (R!)

Lutz 25 (2) (R!)

Lutz 927 (2) (R!)

Lutz 927a (2) (R!)

Macedo 1760 (1) (NY!)

Macedo 5492 (1) (NY!, US!)

Macedo \& al. 1002 (1) (HCMT, UEC!)

Magnago \& Silva 126 (1) (HRB!, U!)

Maia \& Eunice s.n. (1) (NY!, UB!)
Malme 133879 (1) (S!)

Marcondes-Ferreira \& al. 1129 (2)

(PMSP!, SPFR!)

Martins 38 (2) (UEC!)

Martius 216 (1) (BR [2, fotos SPF!], E [scan!], G [foto U!], L(2)!, K [scan!, P [scan!])

Martius s.n. (2) (M [2, fotos SPF!])

Mazine \& al. 883 (1) (ESA!)

Mello-Barreto 654 (2) (BHCB!)

Mello-Barreto 2820 (2) (BHCB!)

Mello-Barreto 2824 (2) (BHCB!)

Mello-Barreto 2826 (2) (BHCB!)

Mello-Barreto 2836 (2) (BHCB!)

Mello-Barreto 2850 (2) (R!)

Mello-Barreto \& Brade 1322 (2) (RB!)

Mendonça \& al. 2471 (1) (IBGE!, RB)

Mendonça \& al. 5447 (1) (IBGE!, RB)

Méxia 5529 (2) (NY!, U!, US!)

Mimura 318 (2) (SP!, US!)

Mimura 400 (2) (NY!, SP!)

Monteiro \& Leitão Filho 26 (1) (HCMT, UEC!)

Monteiro \& Leitão Filho 27 (1) (HCMT, UEC!)

Netto \& Joly 634 (2) (SPF!)

Orlandi 598 (1) (HRB!)

Paula \& al. 711 (2) (VIC!)

Paula-Souza \& al. 4558 (1) (ESA!)

Pereira \& Pabst 2352 (2) (HB, LP!)

Pereira \& Pabst 3018 (2) (HB, LP!, $\mathrm{RB}$ !)

Pereira 837 (2) (UEC!)

Pereira 839 (2) (HUFU!, UEC!)

Pereira-Silva \& al. 5901 (1) (CEN, SPF!)

Pereira-Silva \& al. 7097 (1) (CEN, SPF!)

Pereira-Silva \& al. 7298 (1) (CEN, SPF!)

Pereira-Silva \& al. 7411 (2) (CEN, SPF!)

Philcox \& Onishi 4779 (1) (K, NY!)

Plowman \& al. 8962 (1) (U!)

Ramos 230 (1) (UEC!)

Ratter \& Fonseca 2875 (2) (NY!, UEC!)

Ratter \& Fonseca 2934 (2) (NY!, UEC!)

Ratter 3030 (2) (MBM!, NY!, UEC!)

Regnell (I)298 (2) (LIL!, NY!, US!)
Riedel s.n. (2) (L! L0413286)

Riedel s.n. (2) (NY! NY644151)

Romero \& al. 926 (2) (HUFU, SP!, SPF!)

Romero \& al. 5186 (2) (SPF!, UEC!)

Salles 146 (1) (IBGE!)

Salles 146a (1) (IBGE!)

Samp. 6157 (2) (R!)

Santos \& Pereira 1818 (1) (CEN, SPF!)

Sasaki \& al. 391 (2) (SPF!, SPSF!)

Sasaki \& al. 91 (2) (SPF!)

Sazima 14670 (2) (UEC!)

Sellow s.n. (2) (L!)

Sem coletor? s.n. (2) (SP!)

Sem coletor s.n. (2) (SP!)

Sem coletor s.n. (2) (SP, SPF!)

Sem coletor s.n. (2) (SPF!)

Semir \& al. 976 (2) (UEC!)

Shepherd \& Gibbs 11250 (2) (UEC!)

Shepherd \& Shepherd 10952 (2)

(UEC!)

Shepherd \& al. 7397 (2) (UEC!)

Silva \& al. 1244 (2) (CEN, SPF!)

Silva \& al. 3491 (1) (CEN!)

Silva \& al. 3987 (1) (U!)

Smith 167 (1) (K (photo U!))

Smith 6721 (2) (NY!, R!, US!)

Smith \& al. 6974 (2) (US!)

Soares \& al. 652 (1) (IBGE!, HTINS)

Souza \& al. 14726 (1) (ESA!)

Souza \& al. 14981 (1) (ESA!)

Souza \& al. 7994 (2) (ESA!, UEC! )

Sugyiama \& Matovani 195 (2) (SP!)

Swallen 3698 (1) (US!)

Swallen 3750 (1) (US!)

Tameirão Neto 2917 (2) (BHCB!, RB!)

Taxonomy Class of Universidade de

Brasília 370 (1) (US!)

Teixeira s.n. (2) (SP!)

Trinta 573 (2) (R!)

Trovó \& al. 470 (1) (SPF!)

Usteri s.n. (2) (SP! SP15849)

Usteri s.n. (2) (SP! SP18639)

Valente \& Meira Neto 1510 (2) (SPF!, $\mathrm{VIC)}$

Valente \& Meira Neto 1668 (2) (VIC!) Valente \& Meira Neto 1669 (2) (VIC!) Valente \& Meira Neto 2084 (2) (SPF!, $\mathrm{VIC)}$ 
Varanda \& al. CFCR 4543 (2) (K!, SP!, SPF!)

Vauthier 168 (2) (G!)

Viegas s.n. (2) (IAG, SP!)

Vogel $640(2)(U !)$
Walter \& al. 148 (1) (IBGE!, U!)

Walter \& al. 1225 (1) (CEN!)

Walter \& al. 5075 (1) (CEN, SPF!)

Warming s.n. (2) (NY!)

Williams \& Assis 5923 (2) (US!)
Williams \& Assis 6120 (2) (US!)

Williams \& Assis 6549 (2) (US!)

Williams \& Assis 6617 (2) (US!)

Wood \& Goyder 16995 (1) (K!) 


\section{- Capítulo 7}

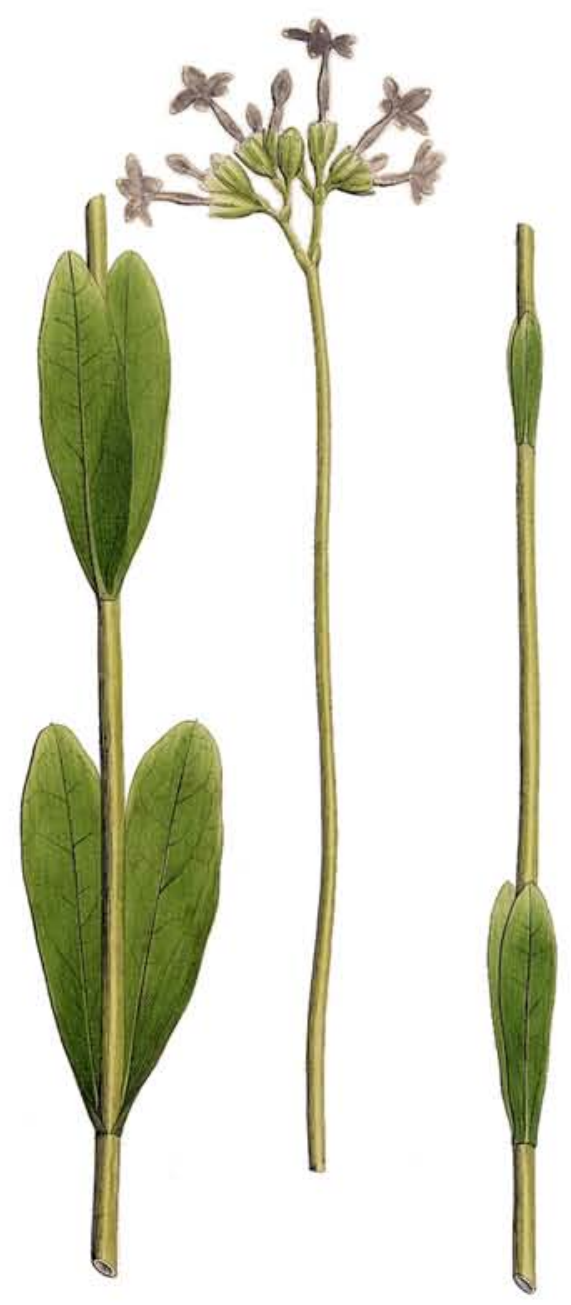

HELIA OBLONGIFOLIA

EXTRAIDO DE NOVA GENERA ET SPECIES PLANTARUM

Nova lectotipificação de Helia Mart. e revisão de Helia sensu stricto (Helieae, Gentianaceae) 


\title{
CAPÍTULO 7
}

\section{Nova lectotipificação de Helia Mart. e revisão de Helia sensu stricto (Helieae, Gentianaceae)}

\begin{abstract}
The existing lectotypification of Helia Mart. is questioned based on the difficulties in recognizing the material identity. It is proposed that this lectotype is rejected and superseded by the designation of a new lectotype. Helia sensu stricto comprises 2 species that occur in swamps and wet fields in Brazil and Paraguay. They are characterized by their herbaceous habit and greenish-yellow, cream or white, salverform corollas. Morphological descriptions, identification keys, illustrations, and distribution maps are provided.
\end{abstract}

Key words Helia, morphology, nomenclature, revision, typification

\section{Resumo}

A lectotipificação de Helia Mart. é questionada com base na dificuldade de reconhecimento da identidade do atual lectótipo. Propõe-se que esse lectótipo seja rejeitado e substituído pela designação de um novo. Helia sensu stricto compreende 2 espécies que ocorrem em brejos e campos úmidos do Brasil e Paraguai. Caracteriza-se pelo hábito herbáceo e pelas corolas salverformes de coloração amarelo-esverdeada, creme ou alva. São apresentadas descrições morfológicas, chave de identificação e mapas de distribuição.

Palavras-chave Helia, morfologia, nomenclatura, revisão, tipificação

\section{Introdução}

Helieae é uma tribo de Gentianaceae exclusivamente neotropical. Trata-se de um grupo de plantas morfológica e ecologicamente diverso e com histórico taxonômico bastante complicado. Helia Mart., o gênero que tipifica a tribo, variou consideravelmente quanto à sua circunscrição, tendo sido tratado tanto como um gênero amplo (Kuntze, 1891) quanto como um gênero mais restrito (e.g., Gilg, 1895). Além disso, teve suas espécies sinonimizadas em outro gênero, Irlbachia Mart. (Maas, 1985), porém tal sinonimização mostrou-se nomenclaturalmente incorreta, devido à prioridade do nome Helia sobre Irlbachia (Struwe \& Albert, 1998). Estudos filogenéticos moleculares auxiliaram na redelimitação de Helieae (Struwe \& al., 2002), mas o gênero Helia somente foi incluído nas análises mais 
recentemente (Struwe \& al., 2009). Os resultados dessas análises evidenciaram seu parentesco próximo com algumas espécies do gênero Chelonanthus Gilg, indicando a possibilidade de incluir tais espécies em um gênero Helia mais amplamente circunscrito. Com o aumento da amostragem das espécies e utilização de novas fontes de evidências (i.e. seqüências moleculares de 5S-NTS e novos dados morfológicos), o relacionamento entre Helia e Chelonanthus foi novamente sustentado (Calió \& al., em prep., Cap. 3). Com base nos resultados desse trabalho filogenético e de dois projetos de doutorado desenvolvidos em colaboração ${ }^{1}$, será proposta, futuramente, uma nova e mais ampla circunscrição de Helia. No presente capítulo serão descritos e discutidos apenas os resultados obtidos no âmbito do projeto desta Tese de Doutorado.

O presente estudo tem como objetivos: 1) apresentar os problemas quanto à lectotipificação de Helia e designar um novo lectótipo para o gênero; 2) apresentar a revisão taxonômica de Helia s.str., com descrições morfológicas, ilustrações e mapas de distribuição das espécies.

\section{Material e métodos}

A investigação da morfologia das espécies foi realizada a partir da análise de espécimes vivos durante trabalho de campo e de material proveniente dos seguintes herbários (exsicatas ou fotos): ALCB, BHCB, BR, CESJ*, CTES, ESA*, G, HB*, HUEFS,

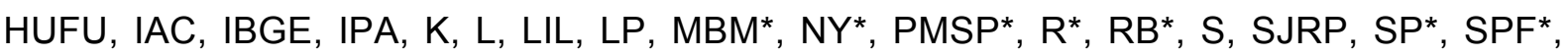
SPSF*, U, UB, UEC*, UPCB*, US*, VIC, $W^{*}$ (* indica herbários visitados). Materiais-tipo dos herbários $\mathrm{F}$ (B phototypes), G, K, M, P foram analisados apenas por meio de fotos. Uma listagem de todos os materiais examinados encontra-se no Apêndice $A$.

Utilizou-se um microscópio estereoscópico SZ Olympus para observação do material, a mensuração de estruturas diminutas sendo feita com auxílio do retículo micromilimetrado do microscópio, e a de estruturas maiores que $1 \mathrm{~cm}$ com auxílio do paquímetro. Apenas estruturas completamente desenvolvidas foram medidas. Previamente à mensuração, as flores foram re-hidratadas em água adicionada de gotas de glicerina e

${ }^{1} \mathrm{O}$ estudo da nomenclatura e morfologia do gênero Chelonanthus foi desenvolvido pela Dra. Katherine B. Lepis (Rutgers University, NJ, EUA) como parte de seu doutoramento, enquanto o estudo de Helia, em sua circunscrição mais estreita, fez parte do projeto da presente Tese de Doutorado e é apresentado neste capítulo. Os resultados obtidos por ambas as teses serão, futuramente, reunidos para produção de um artigo propondo uma nova e mais ampla circunscrição de Helia. Ver "Introdução Geral" desta Tese para maior detalhamento. 
aquecida em forno de microondas por aproximadamente 40 segundos. A descrição das formas das estruturas, dos padrões de venação e da tipologia das inflorescências seguiram, respectivamente, Radford \& al. (1974), Hickey (1979) e Weberling (1989). Dados sobre o status de conservação são fornecidos com base nos critérios da IUCN (2001).

A descrição de algumas estruturas morfológicas foi padronizada da seguinte forma: "bractéolas" são as estruturas foliares mais próximas da base do cálice; "pedicelo" é a estrutura caulinar compreendida entre a base do cálice e a bractéola; e "brácteas" são as estruturas foliares que subtendem várias flores, ou apenas uma flor (nesse caso, posicionando-se logo abaixo da bractéola).

Os mapas foram elaborados com o programa ArcGIS 9.2 (ESRI, 2006), utilizando coordenadas obtidas a partir de GPS, fornecidas nas etiquetas de material de herbário, ou a partir do georreferenciamento posterior, feito com base no município de coleta.

\section{Nova lectotipificação de Helia Mart.}

Em 1827, ao descrever o gênero Helia, Martius apresentou, além de dados sobre habitat e etimologia, uma longa descrição morfológica, indicando as características que faziam esse gênero diferenciar-se das espécies tratadas como Lisianthus. Seguindo a descrição genérica, Martius descreveu detalhadamente uma nova espécie, $H$. oblongifolia, encontrada na "Província de São Paulo", e ilustrou seu hábito, cálice e corola isolados, corola rebatida evidenciando inserção dos estames, anteras, ovário, fruto e sementes. Seguindo a legenda das características ilustradas, Martius (1827) escreveu a frase "além da espécie descrita, encontra-se em locais semelhantes a seguinte [espécie]" (Praeter species descriptam similibus locis invenimus sequetem) para introduzir a segunda espécie, $H$. spathulata, sendo Lisianthus spathulatus Kunth seu basiônimo. Ao lado do nome dessa espécie, Martius (1827) apresentou o símbolo "†", indicando que se tratava de uma espécie pouco conhecida. Possivelmente por essa razão, o autor descreveu-a apenas com uma frase e ilustrou, com poucos detalhes, somente sua flor, a qual é muito semelhante à ilustração da flor de $H$. oblongifolia. Martius (1827) concluiu a descrição de $H$. spathulata com a seguinte frase: "a mesma espécie trazida do Brasil austral pelo ilustre Sellow" (Eandem speciem e Brasília australi tulit cl. Sellow). Entretanto, é importante ressaltar que, no protólogo de L. spathulatus, Kunth (1819) reconheceu como localidade-tipo uma região próxima ao Rio Orinoco, na Venezuela ("Crescit locis calidissimus, humidis Insulae Pararumae, in flumine Orinoci").

Grisebach (1839) apresentou Lisyanthus seção Helia contendo 6 espécies. Tratou como pertencente a essa seção Lisyanthus spathulatus Kunth, indicando ter analisado o 
holótipo (Bonpland 866). Ao final da descrição dessa espécie, Grisebach escreveu a seguinte observação: "Helia spathulata Mart. afasta-se dessa espécie [L. spathulatus Kunth] pela forma da corola, anteras eretas, cálice foliáceo, flores agregadas, internós desiguais, habitat diferente [no sentido de localidade de ocorrência]" (Obs. Helia spathulata Mart.! ab hac specie recedit corollae figura, antheris erectis, calyce foliaceo, floribus aggregatis, internodiis inaequalibus, habito alieno). Em seguida, Grisebach (1839) apresentou $L$. oblongifolius (cujo basiônimo é Helia oblongifolia) e L. brevifolius [descrita alguns anos antes por Chamisso (1833) como H. brevifolia], e descreveu L. martii, indicando como basiônimo H. spathulata Mart., as três com ocorrência restrita ao Brasil. Além disso, Grisebach (1839) indicou ter analisado os materiais das espécies $L$. brevifolia e L. martii coletados por Sellow e depositados no "herb. reg.". Resumidamente, a opinião de Grisebach era de que o material que Martius analisou (provavelmente uma coleção de Sellow, a julgar pela última frase do protólogo de Helia) e descreveu como sendo semelhante a $L$. spathulatus Kunth tratava-se, de fato, de outra espécie. Sendo assim, Grisebach (1839) descreveu L. martii e indicou $H$. spathulata Mart como seu sinônimo. De fato, ao examinar o material citado no protólogo de L. spathulatus Kunth (Bonpland 866, B e foto F), deparamo-nos com um material com flor distinta da ilustrada por Martius como $H$. spathulata, o que corrobora a hipótese de Grisebach de que L. spathulatus Kunth não se tratava da mesma espécie que Martius nomeou de $H$. spathulata.

Nomenclator botanicus, escrito por Pfeiffer (1874), é considerado o primeiro livro de referência a indicar sistematicamente espécies-tipo de acordo com o CINB (Stafleu \& Cowan, 1983). Nessa obra, Pfeiffer escolheu Lisianthus spathulatus Kunth para tipificar Helia, apresentando a seguinte observação: " $\varepsilon \lambda \sigma \varsigma$, quia herba palustris" - que é exatamente a mesma frase utilizada por Martius (1827) para explicar a etimologia do nome Helia por ele criado. Apesar de Pfeiffer (1874) ter citado o trabalho de Grisebach (1839), que evidenciou os problemas com os conceitos da espécie "L. spathulatus", não é possível saber se Pfeiffer estava realmente se referindo a $L$. spathulatus sensu Kunth, ou se estava se referindo ao nome que Martius erroneamente utilizou. Portanto, um problema relacionado à lectotipificação proposta por Pfeiffer é a incerteza do material associado ao nome $L$. spathulatus, independentemente da citação do autor Kunth, pois esse nome pode estar associado a Bonpland 866 (L. spathulatus Kunth) ou a Sellow 1629 (L. spathulatus = L. martii Grisebach). Entretanto, se for considerado que Pfeiffer estava realmente se referindo a L. spathulatus Kunth, cujo tipo é Bonpland 866, outro problema emerge.

Durante a análise dos espécimes de Helia coletados no Brasil e no Paraguai, não foram encontrados, no presente estudo, exemplares que apresentassem as características morfológicas da coleção Bonpland 866. Por outro lado, o estudo de materiais de outros gêneros de Gentianaceae, especialmente os que ocorrem na Venezuela ao longo do Rio 
Orinoco (mesma localidade em que foi coletada a coleção Bonpland 866), evidenciou a existência de 13 espécimes que são semelhantes à referida coleção (KB Lepis, com. pess.). O que impede a confirmação da identidade desses exemplares é o péssimo estado de conservação do material remanescente da coleção Bonpland 866, que era composta por duas exsicatas, uma delas destruída durante a Segunda Guerra Mundial. Entretanto, mesmo se fosse possível identificar esses 13 materiais como conspecíficos de $L$. spathulatus Kunth (tipificada pela coleção Bonpland 866), nos depararíamos com mais um problema.

O estudo do gênero Chelonanthus Gilg reconheceu 10 espécies (Lepis, 2009). Os 13 exemplares supracitados, analisados na revisão de Lepis (2009), possuem características morfológicas intermediárias entre algumas das espécies de Chelonanthus, não sendo possível atribuir um nome específico a esse conjunto de materiais. Presume-se que os mesmos possuam natureza híbrida (Lepis, 2009). Se esse fato for confirmado, a coleção Bonpland 866 representaria um conjunto de espécimes híbridos, ao qual não é possível atribuir o status de espécie.

Dessa forma, com base em 1) incerteza quanto à identidade do nome utilizado para lectotipificação de Helia Mart. (L. spathulatus sensu Kunth $\times$ L. spathulatus sensu Martius), 2) impossibilidade de confirmação da identidade do atual lectótipo devido ao seu precário estado de preservação e 3) sua possível origem híbrida e conseqüente impossibilidade de atribuição de status específico, propomos que a lectotipificação feita por Pfeiffer (1874) seja rejeitada e substituída pela designação de um novo lectótipo para o gênero Helia.

Uma vez que Helia oblongifolia foi a espécie em que Martius (1827) fundamentalmente se baseou para descrever o gênero Helia, acreditamos que a lectotipificação desse gênero com essa espécie seja assaz adequada. Além disso, o holótipo de $H$. oblongifolia ainda existe e apresenta-se íntegro.

\section{Revisão de Helia sensu stricto}

Helia Mart., Nov. Gen. sp. pl. 2(2): 122 - Tipo: Helia oblongifolia Mart. (novo lectótipo, aqui designado).

O conceito de Helia s.l. ainda está sendo desenvolvido, pois o gênero passará a incluir mais nove espécies anteriormente tratadas como Chelonanthus. Nesta seção é apresentada somente uma breve descrição para caracterização geral das duas espécies tratadas como Helia s.str.

As espécies de Helia s.str. são ervas provavelmente anuais. O caule é cilíndrico e não apresenta costelas ou alas. As folhas são sésseis, verde-brilhantes e subcarnosas, 
tornando-se quebradiças quando secas. A base das folhas é conata, a margem é hialina e o ápice é arredondado. Entre a base das folhas, envolvendo o caule, encontra-se uma ócrea, mais evidente nos ramos de maior espessura. As inflorescências são freqüentemente congestas e os botões florais apresentam ápice arredondado. O cálice é verde e apresenta distinta região nectarífera na região dorsal dos cinco lobos, que apresentam margem hialina e ápice arredondado. A corola é salverforme e apresenta coloração freqüentemente amarelo-esverdeada. O tubo da corola é bastante estreito e usualmente possui uma região mais alargada, que corresponde, internamente, ao local em que se situam as anteras. São cinco os lobos da corola; apresentam ápice arredondado e uma mancha no porção mais distal do ápice, normalmente de coloração esverdeada. $O$ androceu é formado por cinco estames heterodínamos; as anteras podem ou não apresentar-se recurvadas e portam, em seu ápice, um apêndice estéril muitas vezes pouco conspícuo. O pólen é liberado em tétrades e possui exina grosseiramente reticulada na região equatorial e finamente reticulada a perfurada nos pólos distais (Nilsson, 2002). O gineceu é formado por um ovário verde, súpero, bicarpelar, bilocular, com placentação parietal. O estilete, cilíndrico, longo e delgado, é encimado por dois lobos estigmáticos. O estilete, a corola e o cálice são persistentes no fruto, que é uma cápsula amarronzada, com muitas sementes.

\section{Chave para as espécies de Helia sensu stricto}

1. Folhas da base agrupadas em roseta; inflorescência com 1-14 flores; bractéolas e lobos do cálice com margem inteira; comprimento da corola 3.2-4.5 vezes maior que o do cálice 1. H. brevifolia

1'. Folhas da base não agrupadas em roseta; inflorescência com 5-54 flores; bractéolas e lobos do cálice com margem serrilhada; comprimento da corola 1.9-2.8(-3.0) vezes maior que o do cálice

2. H. oblongifolia

1. Helia brevifolia Cham., Linnaea 8: 11. 1833 = Lisianthus brevifolius (Cham.) Griseb., Gen. sp. Gent., 187. 1839 - Citação do tipo: "Brasilia", s.d., Sellow s.n. - Holótipo: B [destruído, foto F!]; lectótipo (aqui designado): L (foto SPF!); W!

Ervas, 18-45 cm alt. Caule 0.9-4.5 mm diâm. na base da planta, 1-3.7 mm diâm. abaixo das flores, internós 1.5-15 mm compr. na base (com roseta basal), 37-200 mm compr. abaixo das flores. Folhas sésseis, ócrea 2-6 mm compr.; lâmina elíptica a largamente elíptica, lanceolada ou obovada, $15-70 \times 5.2-37 \mathrm{~mm}$, base conata, ápice arredondado; 2-3 
pares de nervuras secundárias, nervuras terciárias conspícuas, reticuladas. Flores 1-14; brácteas foliáceas ou escamiformes, ovadas a largamente ovadas, 5-6.2 ×2.2-5 mm, base truncada ou conata, margem inteira, ápice arredondado; bractéolas escamiformes, ovadas, 2.5-3 $\times 1.2-1.6 \mathrm{~mm}$, base truncada ou conata, margem inteira, ápice arredondado; pedicelo 1.5-3.5 × 1.4-1.5 mm. Cálice 6-8.5 × 3.8-6 mm; tubo 2.5-3 mm compr.; lobos 5, elípticos ou ovados a muito largamente ovados, 4-5.3 $\times 2.5-4.5 \mathrm{~mm}$, margem inteira, ápice arredondado. Corola alva, creme, amarela-sulfurina a esverdeada, sem guias de nectários, salverforme, 20-30 mm compr., 3.2-4.5 vezes maior que o cálice; tubo c. $22 \mathrm{~mm}$ compr., 2$2.5 \mathrm{~mm}$ larg. na base, $1.5-3.3 \mathrm{~mm}$ larg. abaixo da inserção dos estames, 6.5-13 mm larg. no ápice; lobos 5, elípticos a largamente elípticos ou muito largamente ovados, 4.5-8.5 × 3$7.7 \mathrm{~mm}$, margem inteira, ápice arredondado, com mancha esverdeada. Estames 5; filetes amarelados, 3.2-6.5 mm compr.; anteras alvas a amareladas, estreitamente elípticas, c. $2 \times$ $0.8 \mathrm{~mm}$, apêndice estéril c. $0.1 \mathrm{~mm}$ compr. Ovário verde, elipsóide ou ovóide, 4.5-6 × 2.4-4 $\mathrm{mm}$; estilete amarelo-esverdeado, 4.5-7 $\times$ 0.3-0.8 $\mathrm{mm}$; lobos do estigma amareloesverdeados, estreitamente elípticos, 2.5-3 × $0.5 \mathrm{~mm}$. Fruto ovóide, 8-12 × 4.7-8 mm (Fig. 1, Fig. 3).

Etimologia e nomes populares. - O epíteto específico escolhido por Chamisso (1833) para nomear essa espécie claramente se refere às folhas, que costumam ser proporcionalmente mais largas quando comparadas às folhas de $H$. oblongifolia. É denominada popularmente genciana-do-campo (Fabris \& Klein, 1971) ou genciana-da-terra (Pio-Correa, 1926).

Taxonomia. - Apesar da foto do holótipo destruído evidenciar o número do coletor, o protólogo não menciona nenhuma numeração. Por essa razão, optou-se por lectotipificar a espécie com um material do herbário L, que se encontra bem preservado.

Distribuição, habitat e conservação. - Ocorre do Rio Grande do Sul a Minas Gerais, mas principalmente no Paraná e em São Paulo. Foi coletada também em Goiás, Mato Grosso do Sul e Paraguai (Fig. 5A). É encontrada em áreas brejosas, campos com solos úmidos e freqüentemente arenosos, e mais raramente em pastos, entre 590 e $1800 \mathrm{~m}$ de altitude. Não é categorizada como ameaçada segundo os critérios da IUCN (2001).

Morfologia e fenologia. - As características que mais se destacam em $H$. brevifolia são as folhas organizadas em roseta na base da planta e as poucas flores na inflorescência. É encontrada com flores e frutos praticamente o ano todo. 
Material selecionado. - Aproximadamente 120 coleções analisadas (relação completa no Apêndice A). PARAGUAl: Cordillera de Altos, iii.1902, Fiebrig 577 (F!, L!). CAAGUAZÚ: iii.1905, Hassler 9372 (G, NY!, S!, W!); a 25 km al norte de Caaguazú el borde de un estero, s.d., Casas \& al. 7549 (NY!); Ihú, 24.i.1957, Sparre \& Vervoorst 2061 (LIL!). SAN PEDRO: Lima, Carumbé, 25.ii.1975, Pedersen 11090 (U!). YERBALES: Sierra de Maracayú, xii.1900, Hassler 5686 (G, K!, NY!, S!, W!). BRASIL, DISTRITO FEDERAL: Brasília, a $5 \mathrm{~km}$ W de Brasília, 19.iii.1966, Irwin \& al. 14120 (NY!). GOIÁS: Jataí, Rio Bom Sucesso, 17.xi.1973, Hatschbach \& Koczicki 33351 (MBM!, U!). MINAS GERAIS: Caldas, 20.i.1876, Mosén 4256 (S(2)!); Carandaí, 28.xi.1946, Duarte 680 (RB!); Carmo da Cachoeira, Rodovia Fernão Dias, km 677, 2.i.1996, Souza \& al. 297 (ESA!, SPF!); Itabirito, Pico do Itabirito, 29.iii.1994, Teixeira 23930 (U!). MATO GROSSO DO SUL: Campo Grande, APA Guariroba, 8.x.1997, Resende \& al. 1185 (CGMS!). MATO GROSSO: Rio Sapé, 9.x.1938, Rombouts 251 (IAC!, SP!). PARANÁ: Alto Paraná, Alto Paraná, $7 \mathrm{~km}$ al sur de Villa Fortuna, en un estero grande, 31.i.1982, Casas \& Molero 5770 (NY!); Campo Largo, Serra São Luís de Purunã, 23.ii.1960, Pereira 5445 (HB!, LP!); Castro, Campos de Castro, Estrada do Cerne, km 116-117, 9.i.1947, Hatschbach 582 (MBM!, RB!); Guaratuba, Serra do Araçatuba, 21.i.1994, Kummrow \& Cordeiro 3391 (ESA!, HUEFS!, MBM); Ipiranga, Faxinal do Tanque, 20.xii.1970, Hatschbach 25893 (S!); Jaguariaiva, Rio das Mortes, 29.xi.1993, Cervi \& al. 4187 (NY!, UPCB!); Monte-Alegre (Cidade Nova), 13.xii.1951, Mattos s.n. (MBM!); Palmeira, Capão da Índia, 12.xii.1998, Dunaiski Jr. \& Johanson 1000 (UPCB!); Pinhão, Rondinha, 24.ii.1996, Hatschbach \& Ziller 64500 (MBM!, SPF!); Piraí do Sul, Serra das Furnas, Rod. PR-090, 12.i.2000, Hatschbach \& al. 69886 (BHCB!, MBM!); Ponta Grossa, Fazenda Cabrijumos, 21.xii.2000, Cervi \& Tardio 8113 (UPCB!); São José dos Pinhais, BR-277, próximo ao Rio Pequeno, 15.ii.1995, Silva 1434 (MBM!); São Mateus do Sul, Rio Potinga, 16.xii.1956, Hatschbach 3617 (LIL!, MBM, US!); Tibagi, Guartelá, 23.xii.1992, Cervi 4000 (UPCB!); Tijucas do Sul, Campo Comprido, 13.iii.1991, Kummrow \& Cordeiro 3256 (HUEFS!, MBM). RIO GRANDE DO SUL: Cruz Alta, 16.i.1902, Malme 1118 (S(2)!). SANTA CATARINA: Campo Alegre, Morro do Iquererim, 10.i.1958, Reitz \& Klein 6124 (US!); Chapecó, Fazenda Campo São Vicente, 24 km west of Campo Erê, 26-29.xii.1956, Smith \& Sufridini 9431 (NY!, US!); Mafra, 11 km E of Mafra, on the road to Tinguí, 8.xii.1956, Smith \& Klein 8466 (K!, US!); Porto União, Fazenda Frei Rogério, 6.i.1962, Reitz \& Klein 11589 (US!); São Francisco do Sul, Monte Crista, Garuva, 21.xii.1960, Reitz \& Klein 10457 (L!, NY!, US!). SÃO PAULO: Angatuba, estrada para Itatinga, ca. 30 km de Angatuba, Bairro Santo Inácio, 27.iv.1996, Souza \& al. 534 (ESA, UEC!); Campos do Jordão, Umuarama, 29.i.1935, Kuhlmann s.n. (SP!, SPF!); Itararé, Alta da Ventania, Banhado, Colônia de resinagem, 9.ii.1991, Scaramuzza \& Souza 673 (ESA, MBM!, SP!); Itirapina, beira da estrada, próximo ao pedágio após a entrada da Estação Ecológica de Itirapina, 25.xi.2006, Trovó \& al. 316 (SPF!); São José do Barreiro, Serra da Bocaina, Pousada Recanto da Floresta, km

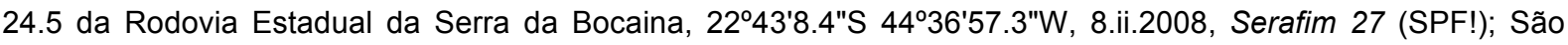
Paulo, Parque Estadual da Serra do Mar, Núcleo Curucutu, Beira da trilha da Cachoeira, 23⒌'42.2"S 46²4'11.4"W, 27.xi.2006, Calió \& al. 168 (SPF!); São Paulo, Butantã, 10.xii.1917, Hoehne s.n. (SP!).

2. Helia oblongifolia Mart., Nov. Gen. sp. pl. 2(2): 123, tab. $191.1827 \equiv$ Lisianthus oblongifolius (Mart.) Griseb., Gen. sp. Gent., 187. 1839 =Irlbachia oblongifolia (Mart.) Maas, Proc. Kon. Ned. Akad. Wetensch. C. 88(4): 410. 1985 - Citação do tipo: "Brasil, São Paulo", s.d., Martius 468 - Holótipo: M [foto SPF!]. 
= Helia martii (Griseb.) Gilg in Engler \& Prantl Nat. Pflanzenfam. 4(2): 101. $1895 \equiv$ Lisianthus martii Griseb., Gen. sp. Gent., 187. 1839 - Citação do tipo: "Brasilia", s.d., Sellow 1629 Holótipo: B [destruído, foto F!]; lectótipo (aqui designado): $\mathrm{K}$ excluído ramo com folhas de ápice agudo [foto SPF!].

= Helia loeseriana Gilg, Bot. Jahrb. Syst. 22: 346. 1896 - Citação do tipo: "Brésil, [Minas Gerais], Cachambú", 26 janeiro 1886, Glaziou 16264 - Holótipo: B [destruído, foto F!]; lectótipo (aqui designado): P [imagem digitalizada da exsicata!]; G [foto SPF!], R!.

= Helia micrantha Gilg, Bot. Jahrb. Syst. 22: 347. 1896 - Citação do tipo: "Paraguay, Caaguazu", 7 Março 1876, Balansa 2141 - Holótipo: B [destruído, foto F!]; lectótipo (aqui designado): G [foto SPF!]; G [foto SPF!], S [foto SPF!].

= Helia crispiflora Hassl., Addenda PI. Hassl. 1: 5. 1917, nom. nud.

Ervas, 40-120 cm alt. Caule 1.7-6.6 mm diâm. na base da planta, 1.6-4 mm diâm. abaixo das flores, internós $12-25 \mathrm{~mm}$ compr. na base (sem roseta basal), $70-330 \mathrm{~mm} \mathrm{compr}$. abaixo das flores. Folhas sésseis, ócrea 2-6 mm compr.; lâmina estreitamente elíptica a elíptica ou oblanceolada, 11-93 × 5.5-36 mm, base conata, ápice arredondado; 1-2 pares de nervuras secundárias, nervuras terciárias conspícuas, reticuladas. Flores 5-54; brácteas foliáceas ou escamiformes, estreitamente elípticas ou lanceoladas a ovadas, 2.4-6 × 1.8-6 $\mathrm{mm}$, base truncada ou conata, margem inteira, ápice arredondado; bractéolas escamiformes, lanceolares a ovadas ou triangulares, $2.5-5 \times 1.5-2.2 \mathrm{~mm}$, base truncada ou conata, margem serrilhada, ápice agudo; pedicelo 3-9 × 1-1.5 mm. Cálice 6-10.5 × 3.5-7 $\mathrm{mm}$; tubo 3-3.5 mm compr.; lobos 5, elípticos a largamente elípticos ou largamente ovados a muito largamente ovados, 3-6 × 2.2-4 mm, margem serrilhada, ápice arredondado. Corola creme, amarela-sulfurina a esverdeada, sem guias de nectários, hipocrateriforme, 13-26 $\mathrm{mm}$ compr., 1.9-2.8(-3.0) vezes maior que o cálice; tubo 14-16 mm compr., 1.7-2.5 mm larg. na base, 2-2.7 mm larg. abaixo da inserção dos estames, 4-4.5 mm larg. no ápice; lobos 5, largamente elípticos ou largamente ovados a muito largamente ovados, 3-4.5 × 2.5-4 mm, margem inteira, erosa ou levemente erosa, ápice arredondado, com mancha esverdeada. Estames 5; filetes amarelados, 3-5 $\mathrm{mm}$ compr.; anteras amareladas, estreitamente elípticas, $1.5-3.2 \times 0.8-1 \mathrm{~mm}$, apêndice estéril $0.14-1.3 \mathrm{~mm}$ compr. Ovário verde, ovóide, 3.5-6 × 1-3 mm; estilete esverdeado, $5.5-7 \times 0.4-0.9 \mathrm{~mm}$; lobos do estigma esverdeados, estreitamente elípticos, c. $2.5 \times 0.8 \mathrm{~mm}$. Fruto ovóide, 10-16 × 5-6 mm (Fig. 2, Fig. 4). 
Etimologia e nomes populares. - O epíteto específico refere-se às folhas em geral estreitamente elípticas a elípticas (oblongas a oblongo-lanceoladas, segundo Martius, 1827). Popularmente, é denominada genciana-do-campo (Cordeiro, 2005).

Taxonomia. - Apesar das descrições de H. martii (Grisebach, 1839), H. loeseriana e $H$. micrantha (Gilg, 1896) relatarem diferenças morfológicas entre essas espécies e $H$. oblongifolia, as coleções-tipo das referidas espécies não diferem significativamente das coleções de $H$. oblongifolia e, por essa razão, as três primeiras espécies foram sinonimizadas neste último nome. Apenas um isótipo de $H$. martii foi encontrado, sendo então utilizado na lectotipificação. Entretanto, trata-se de uma coleção misturada: há um ramo com folhas, no qual há uma etiqueta com o número 1629 (o mesmo do holótipo), e um ramo com inflorescência, ambos apresentando as mesmas características descritas no protólogo e idênticas às do holótipo destruído; há, entretanto, um ramo adicional com folhas de ápice agudo que claramente não pertence à mesma espécie. Helia loeseriana foi lectotipificada com a coleção de $\mathrm{P}$, pois esta última apresenta melhor estado de preservação. Foram encontradas algumas coleções disponíveis para lectotipificação de $H$. micrantha; a escolha por um dos materiais do $\mathrm{G}$ baseou-se na etiqueta em que se lê "Helia micrantha Gilg", com a grafia do próprio Gilg. O nome Helia crispiflora foi apresentado por Hassler (1917), que se referiu à coleção "Hassler 3734"; entretanto, a espécie não foi validamente publicada, pois o autor não apresentou diagnose.

Distribuição, habitat e conservação. - É encontrada principalmente nos estados de Minas Gerais e São Paulo, mas há referências mais esparsas para Goiás, Bahia, Mato Grosso do Sul, Rio Grande do Sul e Paraguai (Fig. 5B). Ocorre nos mesmos tipos de solo e habitat em que ocorre $H$. brevifolia, entre 800 e $1300 \mathrm{~m}$ de altitude. Segundo os critérios da IUCN (2001), essa espécie não se enquadra como ameaçada.

Morfologia e fenologia. - $H$. oblongifolia caracteriza-se pelas folhas longas, freqüentemente em grande quantidade, e pelo grande número de flores na inflorescência. É encontrada com flores e frutos de outubro a maio.

Material selecionado. - Aproximadamente 50 coleções analisadas (relação completa no Apêndice A). PARAGUAI, ALTO PARANÁ: Reserva Biológica Limony de Itaipu Binacional, 2551'S 5433"W, 18.iv.1968, Brunner \& Caballero 1905 (MO!). BRASIL, BAHIA: Cocos, Fazenda Trijunção, estrada para a Sede do Guará, próximo a um curral com caixa d'água/catavento, 144ㄴ $4.0^{\prime \prime S} 45^{\circ} 55^{\prime} 15^{\prime \prime} \mathrm{W}$, 11.xii.2001, Walter \& al. 4912 (CEN, IBGE!, US); Rio de Contas, Pico das Almas, Vertente leste, 9-11 km ao N-O da cidade, 1332'S 4153"W, 6.xi.1988, Harley \& al. 25924 (K, NY!). DISTRITO FEDERAL: Brasília, Parque do Gama, 12.vi.1976, Davis 60169 (UEC!). GOIÁs: Alto Paraíso de Goiás, 11 km N, 1.iii.1982, Oliveira \& Anderson 
485 (MBM!, U!); Goiania, xii.1936, Brade 15418 (RB!). MINAS GERAIS: Carmo do Rio Claro, Fazenda Renascência, 1.ix.1961, Andrade \& Emmerich 978 (HB!); Entre Rios de Minas, Bom Jardim dos Coelhos, 17.xii.1992, Carvalho 333-B (UPCB!,VIC!); Gouveia, Rodovia Diamantina -Gouveia (BR 259) a $27 \mathrm{~km}$ de Diamantina, $300 \mathrm{~m}$ sul do entroncamento para Datas, a oeste da rodovia, 18²5'3.0"S 4341'36.8"W, 21.i.2007, Calió \& al. 205 (SPF!); Joaquim Felício, Serra do Cabral, 21.x.1999, Hatschbach \& al. 69468 (MBM!); Patrocínio, Serra do Salitre, margem norte da Lagoa Campestre, 22.iii.1994, Ceccantini 180 (SPF!); Pouso Alegre, 2.v.1927, Hoehne s.n. (SP!); Santa Luzia, Serra do Cipó, 25.xi.1938, Mello-Barreto 8509 (F!); Santana do Riacho, campo próximo ao capão dos palmitos, 11.xii.2006, Santos \& al. 108 (SPF!); São Sebastião do Paraíso, Fazenda Fortaleza, 20.iv.1945, Brade \& Barbosa 17694 (RB!, U!); Uberaba, 18.i.1849, Regnell II-I901 (S(3)!, US!); Uberlândia, Reserva do Clube de Caça e Pesca Itororó, 14.xi.1997, Araújo \& Barbosa 1740 (HUFU!). RIO GRANDE DO SUL: Gravataí, Morungava, 28.i.1915, Dusén 16537 (S(2)!). SÃO PAULO: Jundiaí, Fazenda Traviú, 15.i.1941, Pickel s.n. (IPA!); Lageado, 2.iii.1913, Brade 6132 (S(2)!); Monte-Mór, estrada Monte-MórCampinas, 29.iii.1939, Viegas \& al. s.n. (IAG, SP!); São Paulo, Pinheiros, 8.iii.1914, Brade 6965 (SP!, SPF!).

\section{Referências bibliográficas}

Calió, M.F., Pirani, J.R. Struwe, L. \& Lepis, K.B., em prep. Estudo filogenético de Helieae (Gentianaceae) com ênfase nos limites genéricos de Calolisianthus Gilg, Chelonanthus Gilg e Helia Mart., baseado em dados moleculares e morfológicos. A ser submetido a Molecular Phylogenetics and Evolution.

Chamisso, L.K.A. 1833. Spicilegium plantarum e familiis jam prius recensitis, praesertim brasiliensium serius a Sellowio missarum. Linnaea 8(1): 7-17.

Cordeiro, I. 2005. Gentianaceae. Pp. 211-222 in: Wanderley, M.G.L., Shepherd, G.J., Melhem, T.S., Giulietti, A.M. (eds.), Flora Fanerogâmica do Estado de São Paulo, vol. 4. FAPESP, São Paulo.

ESRI, Environmental Systems Research Institute, INC. 2006. ArcGis - ArcView Desktop 9.2.

Fabris, H.A. \& Klein, R.M. 1971. Gentianaceae. Pp. 3-30 in: Reitz, P.R. (ed.), Flora llustrada Catarinense, parte 1, fascículo GENC. Herbário "Barbosa Rodrigues", Itajaí.

Gilg, E. 1895. Gentianaceae. Pp. 50-108 in: Engler, H.G.A. \& Prantl, K.A.E. (eds.), Die natürlichen Pflanzenfamilien, vol. 4(2). Verlag von Wilhem Engelmann, Leipzig.

Gilg, E. 1896. Beiträge zur Kenntnis der Gentianaceae I. Bot. Jahrb. Syst. 22: 301-347.

Grisebach, A.H.R. 1839 [1838]. Genera et species plantarum. J.G. Cotta, Stuttgart and Tübingen.

Hassler, E. 1917. Addenda ad Plantas Hasslerianas: familiae genera et species pro flora paraguariensi nova vel in Plantis Hasslerianis I et II haud enumerata. Parte 1. A. Kundig, Geneva.

Hickey, L.J. 1979. A revised classification on the architecture of dicotyledonous leaves. Pp. 25-39 in: Metcalfe, C.R. \& Chalk, L. (eds.) Anatomy of the Dicotyledons. Vol. 1. Ed. 2. Clarendon Press, Oxford.

IUCN 2001. IUCN Red List categories and criteria. Version 3.1. IUCN, Gland, Switzerland \& 
Cambridge, U.K.

Kunth, C.S. 1819 [1818]. Gentianaceae (Lisianthus). Pp. 180-185 in: Humboldt, A., Bonpland, A. \& Kunth, C.S. (eds.), Nova Genera et Species Plantarum, vol. 3. Paris, Lutetiae Parisiorum.

Kuntze, C.E.O. 1891. Revisio generum plantarum, vol. 2. Arthur Felix, Leipzig.

Lepis, K.B. 2009. Evolution and systematics of Chelonanthus (Gentianaceae). Dissertation. Rutgers The State University of New Jersey, New Brunswick.

Maas, P.J.M. 1985. Nomenclatural notes on neotropical Lisyantheae (Gentianaceae). Proc. Kon. Ned. Akad. Wetensch., ser C, 88: 405-412.

Martius, C.F.P. von. 1827. Nova genera et species plantarum quas in itinere per Brasiliam, vol. 2, parte 2. V. Wolf, München.

Nilsson, S. 2002. Gentianaceae - a review of palynology. Pp. 377-497 in: Struwe, L. \& Albert, V.A. (eds.), Gentianaceae - systematics and natural history. Cambridge University Press, Cambridge.

Pfeiffer, L.K.G. 1874. Nomenclator botanicus. vol. 1, parte altera. Cassellis, Sumptibus Theodori Fischeri.

Pio-Corrêa, M. 1926. Dicionário das plantas úteis do Brasil e das plantas cultivadas, vol. 3, F-G. Ministério da Agricultura, Rio de Janeiro.

Radford, A.E., Dickson, W.C., Massey, J.R. \& Bell, C.R. 1974. Vascular plant systematics. Harper \& Row Publishers, New York, Evanston, San Francisco, London.

Stafleu, F.A. \& Cowan, R.S. 1983. Taxonomic Literature: A selective guide to botanical publications and collections, with dates, commentaries and types. 2nd much enlarged ed. v. 4. Utrecht/Antwerpen, Bohn, Scheltema \& Holkema; Boston, W. Junk b.v., Publishers, The Hague.

Struwe, L. \& Albert, V.A. 1998. Lisianthius P.Br., its probable homonym Lisyanthus Aubl. (Gentianaceae) and the priority of Helia Mart. over Irlbachia Mart. as its substitute. Harvard Pap. Bot. 3(1): 67-71.

Struwe, L., Albert, V.A., Calió, M.F., Frasier, C., Lepis, K.B., Mathews, K.G., Grant, J.R. 2009. Evolutionary patterns in neotropical Helieae (Gentianaceae): evidence from morphology, choroplast and nuclear DNA sequences. Taxon 58(2): 479-499.

Struwe, L., Kadereit, J., Klackenberg, J., Nilsson, S., Thiv, M., von Hagen, K.B. \& Albert, V.A. 2002. Systematics, character evolution and biogeography of Gentianaceae, including a new tribal and subtribal classification. Pp. 21-309 in: Struwe, L. \& Albert, V.A. (eds.), Gentianaceae - Systematics and Natural History. Cambridge University Press, Cambridge.

Weberling, F. 1989. Morphology of flowers and inflorescences. Cambridge University Press. New York. 


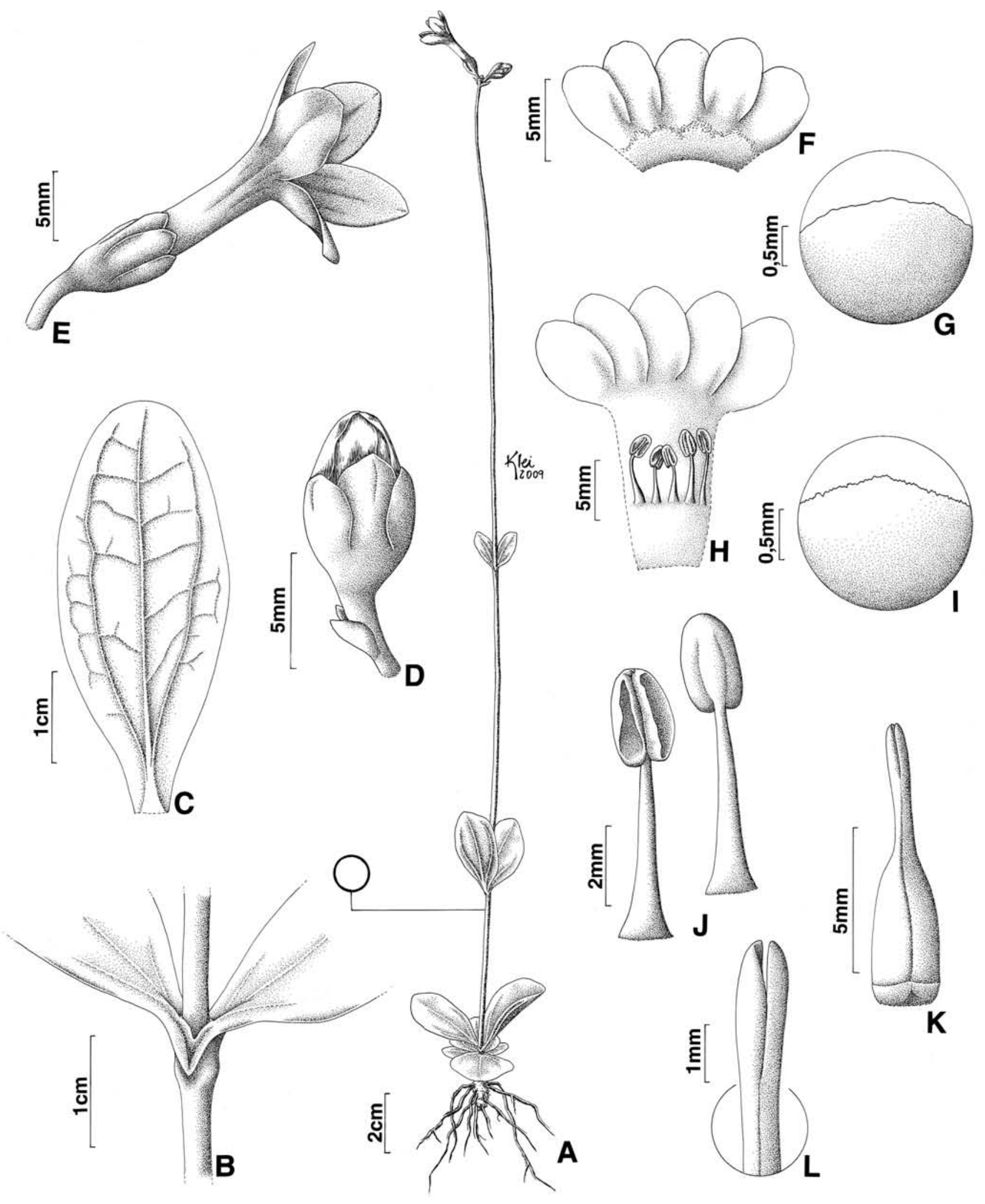

Fig. 1. Helia brevifolia. A, hábito, com representação esquemática da seção transversal do caule; B, detalhe do nó; C, face abaxial da folha; D, botão floral; E, flor, visão lateral; F, cálice rebatido; G, detalhe do ápice e margem do lobo do cálice; $\mathrm{H}$, corola rebatida, evidenciando inserção e tamanho desigual dos estames; I, detalhe do ápice e margem do lobo da corola; J, estames (faces abaxial e adaxial); K, gineceu; L, detalhe do estigma. Todos desenhados a partir de Trovó \& al. 316 (SPF), exceto (A) e (D) de Calió \& al. 169 (SPF). 

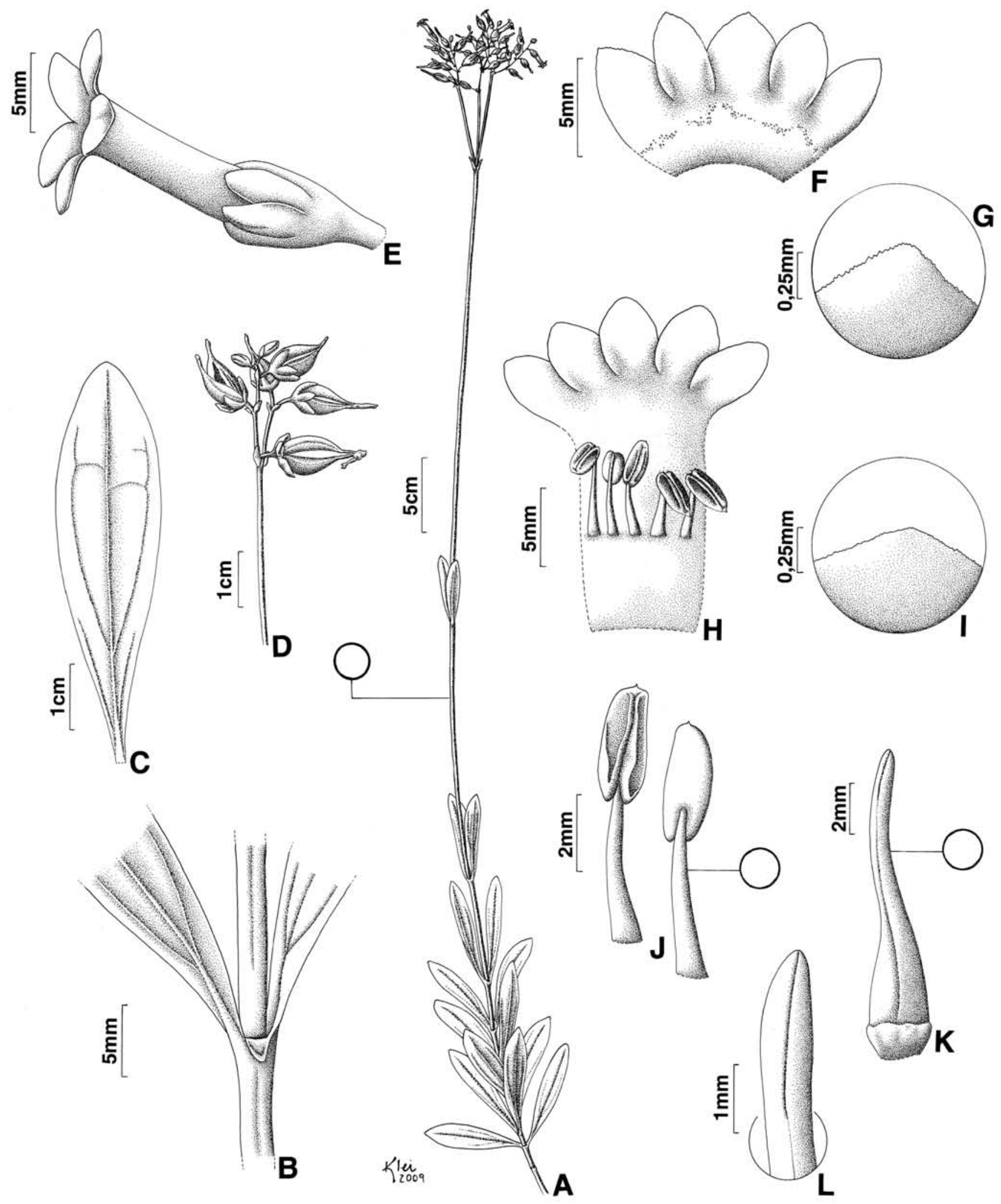

Fig. 2. Helia oblongifolia. A, hábito, com representação esquemática da seção transversal do caule; B, detalhe do nó; C, face abaxial da folha; D, inflorescência; E, flor, visão lateral; F, cálice rebatido; G, detalhe do ápice e margem do lobo do cálice; $\mathrm{H}$, corola rebatida, evidenciando inserção e tamanho desigual dos estames; I, detalhe do ápice e margem do lobo da corola; J, estames (faces abaxial e adaxial); K, gineceu; L, detalhe do estigma. Todos desenhados a partir de Calió \& al. 205 (SPF). 

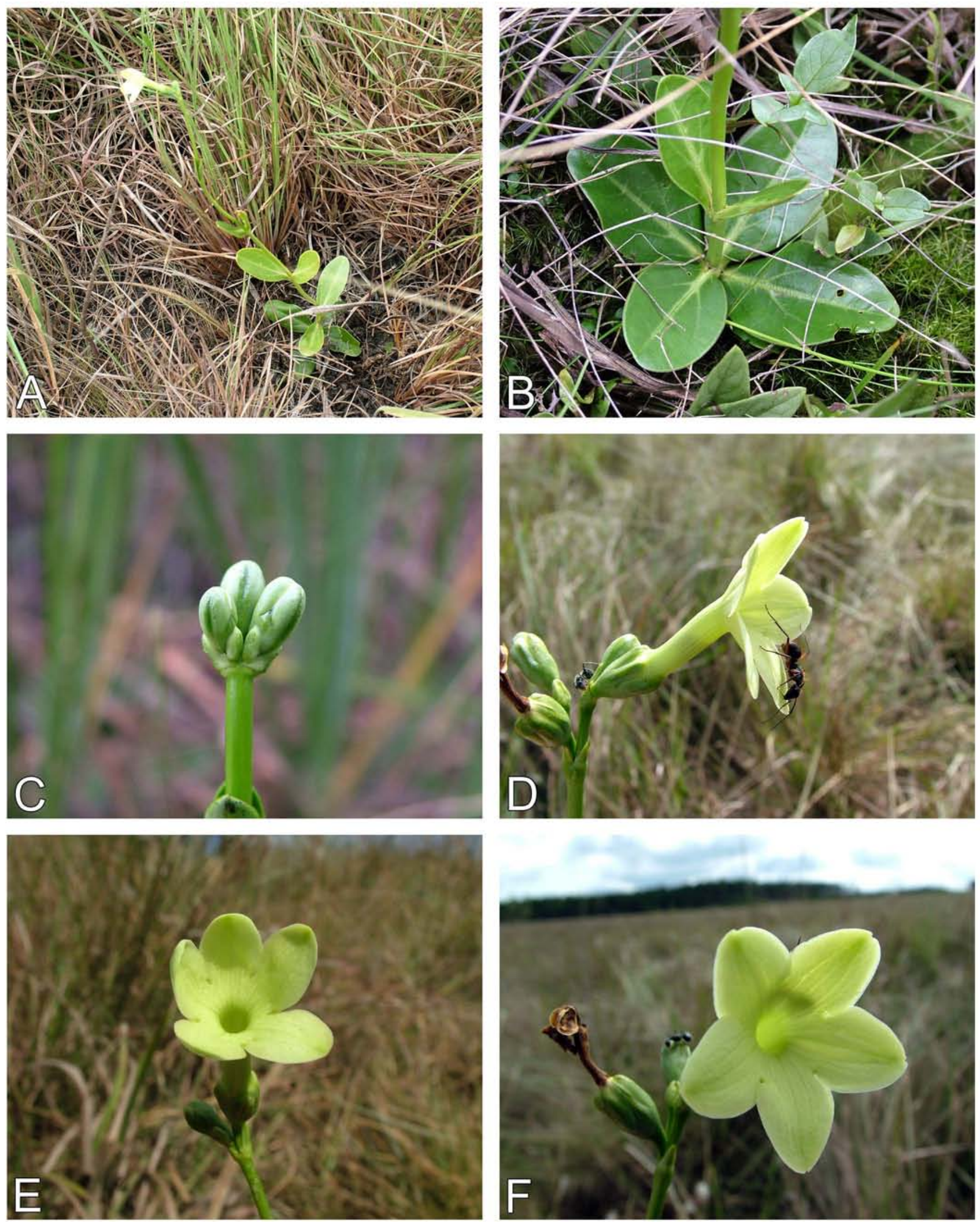

Fig. 3. Helia brevifolia. A, hábito; B, folhas dispostas em roseta; C, inflorescência jovem; D, flor, visão lateral; E-F, flor, visão frontal. Fotos: Marcelo Trovó. 

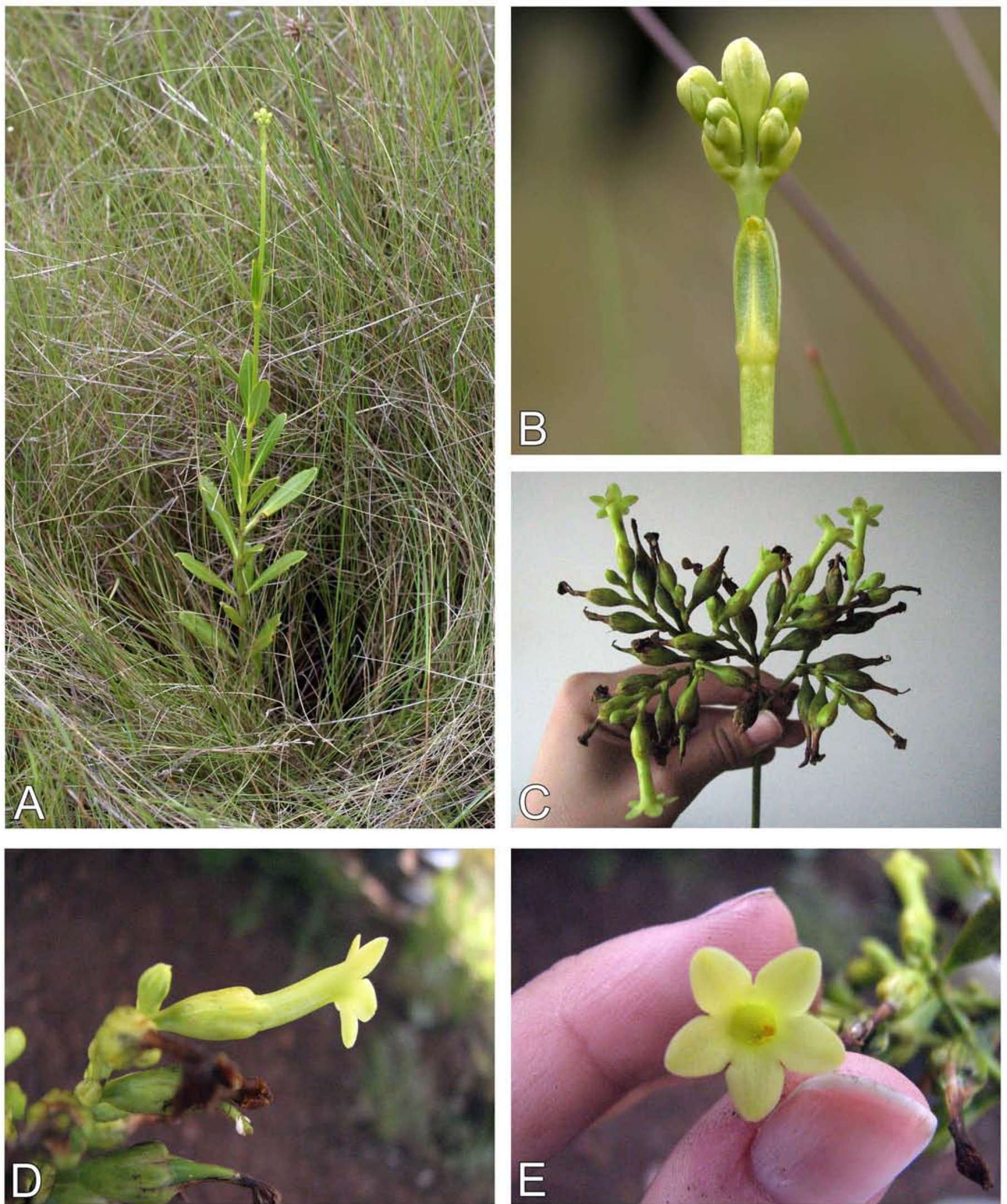

Fig. 4. Helia oblongifolia. A, hábito; B, inflorescência jovem; C, inflorescência madura; D, flor, visão lateral; E, flor, visão frontal. Fotos: A-B, Richard Winkworth; C-E, Maria Fernanda Calió. 

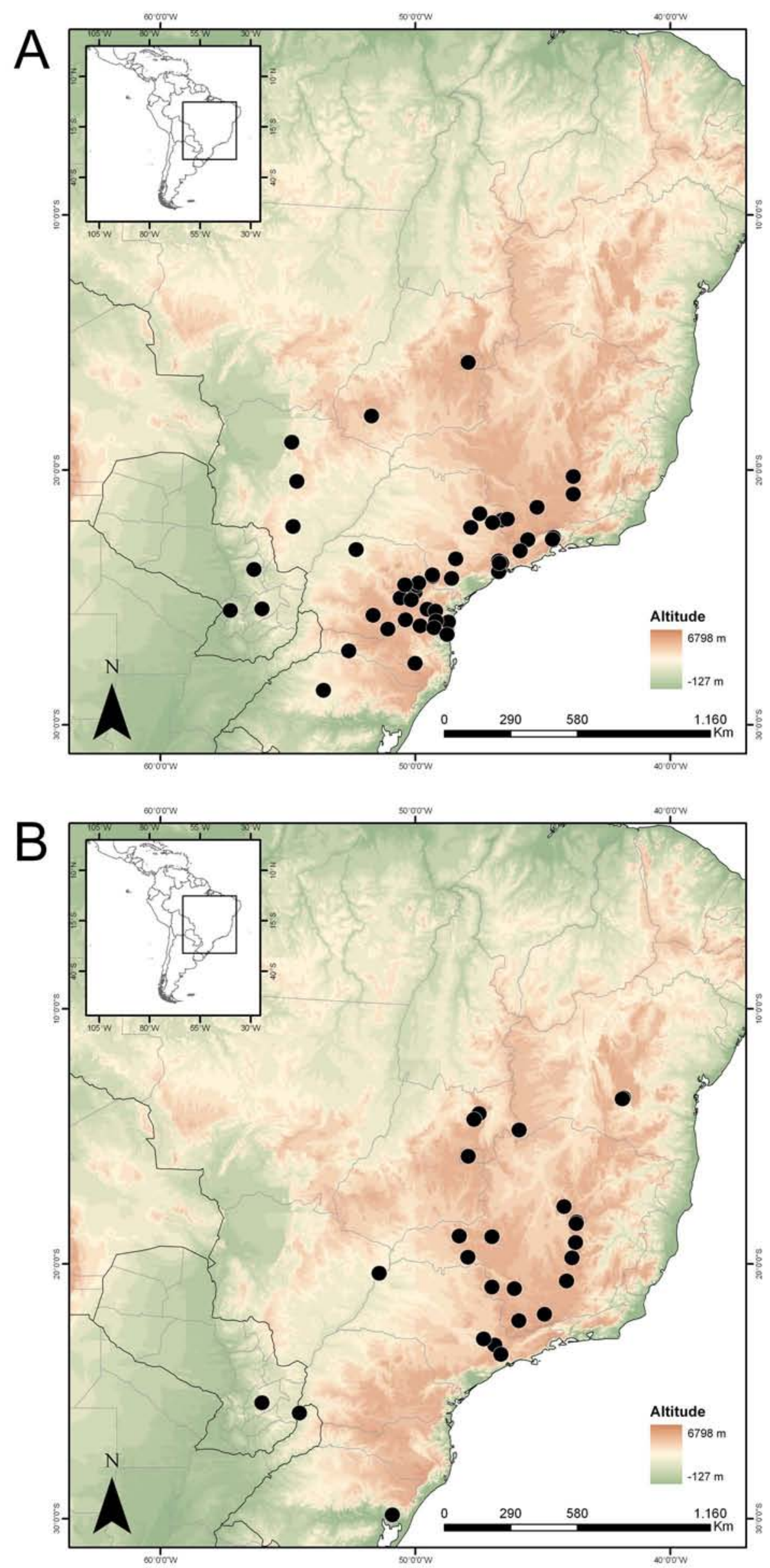

Fig. 5. Distribuição geográfica. A, Helia brevifolia; B, Helia oblongifolia. 
Apêndice A. Lista de exsicatas, indicando coletor e número, número da espécie no tratamento taxonômico e herbários. Negrito = espécimes-tipo; scan = imagem digitalizada da exsicata. Helia brevifolia $=1 ;$ Helia oblongifolia $=2$

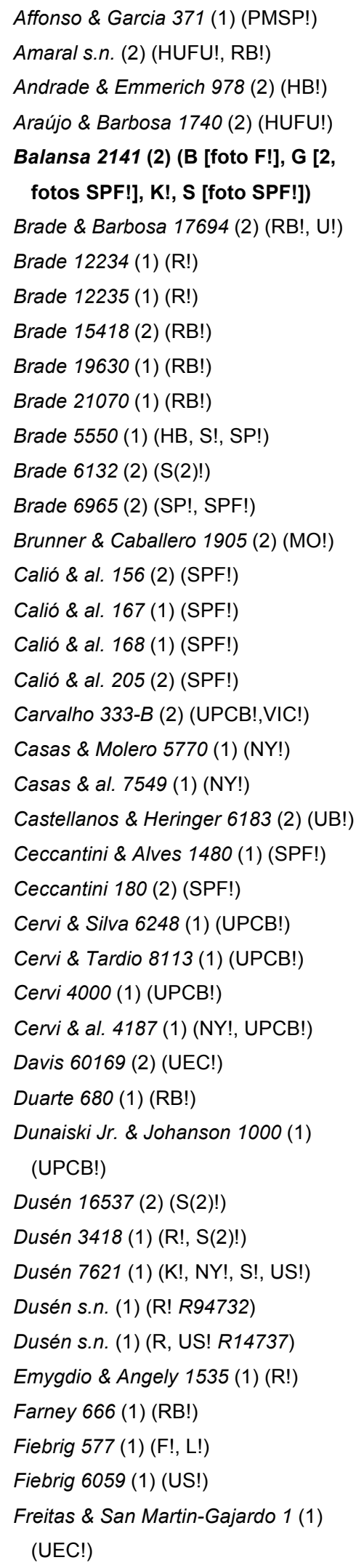

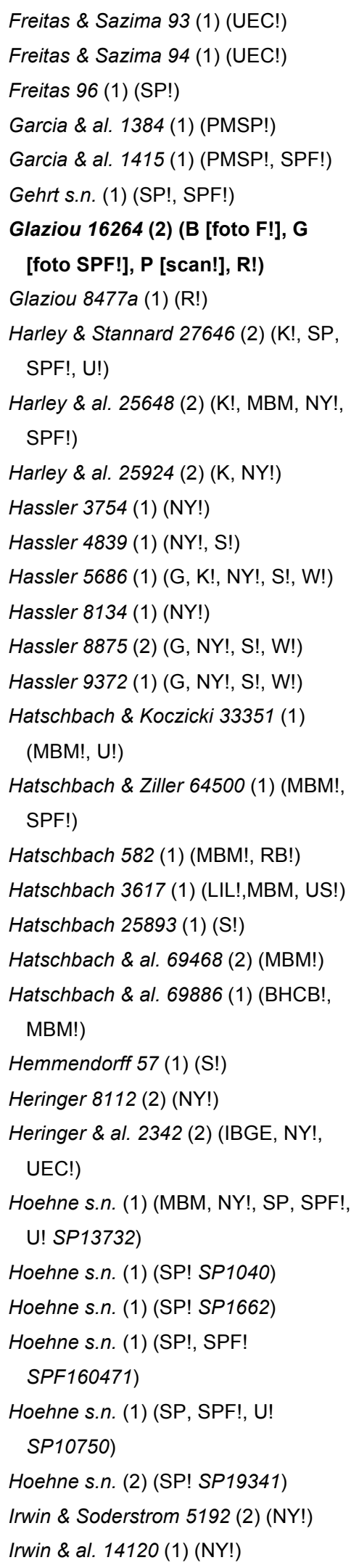

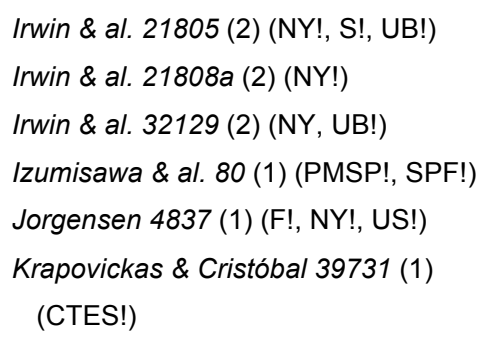


Reitz \& Klein 11589 (1) (US!)

Reitz \& Klein 16589 (1) (HB, LP!)

Resende \& al. 1185 (1) (CGMS!)

Ribas \& Guimarães 418 (1) (HUEFS!, MBM)

Ribas \& al. 2240 (1) (ALCB!, MBM!)

Rombouts 251 (1) (IAC!, SP!)

Roth 956 (1) (SP!)

Sano \& al. 584 (2) (SPF!)

Santos \& al. 108 (2) (SPF!)

Scaramuzza \& Souza 673 (1) (ESA,

MBM!, SP!)

Sello 1629 (2) (B [foto F!], $\mathrm{K}^{1}$

[fotoSPF!])

Sello 5363 (1) (B [foto F!])
Sellow s.n. (1) (B [foto F!], L!, W! L0004843)

Sellow s.n. (2) (L! L0004844)

Sem coletor s.n. (1) (CESJ!, SPF! CESJ20507)

Sem coletor s.n. (2) (SP!, SPF!)

Serafim 27 (1) (SPF!)

Shepherd \& Vieira 12258 (1) (UEC!)

Silva 1434 (1) (MBM!)

Silva \& al. 1873 (1) (MBM!, SJRP!)

Simão-Bianchini \& al. 889 (1) (PMSP!, SP, SPF!, SPSF!, UEC! )

Smith \& Klein 10746 (1) (US!)

Smith \& Klein 8466 (1) (K!, US!)

Smith \& Reitz 8720 (1) (US!)

Smith \& Sufridini 9431 (1) (NY!, US!)
Smith \& al. 14566 (1) (US!)

Smith \& al. 14802 (1) (US!)

Sordi \& al. 889 (1) (PMSP!, SPSF!)

Souza \& al. 297 (1) (ESA!, SPF!)

Souza \& al. 534 (1) (ESA, UEC!)

Sparre \& Vervoorst 2061 (1) (LIL!)

Sucre 10457 (1) (U!)

Tannus \& Daher 273 (1) (HRCB, SP!)

Teixeira 23930 (1) (U!)

Tombolato s.n. (1) (IAC!)

Trovó \& al. 316 (1) (SPF!)

Usteri s.n. (2) (SP!, SPF!)

Viegas \& al. s.n. (2) (IAG, SP!)

Walter \& al. 4912 (2) (CEN, IBGE!, US)

Widgren s.n. (1) (BR!, S(2)!)

\footnotetext{
${ }^{1}$ Excluído ramo com folhas de ápice agudo.
} 
- Considerações Finais 


\section{Considerações Finais}

Como resultado de um esforço conjunto de grupos de pesquisa internacionais, o conhecimento acerca de Helieae (Gentianaceae), uma tribo de plantas neotropicais taxonomicamente complexo, vem crescendo consideravelmente nos últimos anos. Por meio da integração de trabalhos de cunho filogenético e taxonômico, a real diversidade da tribo é aos poucos revelada, bem como se cria a base necessária para inferências acerca de padrões evolutivos e biogeográficos da tribo.

Nesse contexto, a presente Tese de Doutorado teve como principal objetivo estudar as espécies de Helieae cuja ocorrência é endêmica ou está centrada no leste do Brasil. Tais espécies agrupavam-se em quatro gêneros - Calolisianthus Gilg, Helia Mart., Prepusa Mart. e Senaea Taub. - e haviam sido muito pouco estudadas até então, já que grande parte das pesquisas envolvendo espécies de Helieae havia sido realizada com base em material proveniente das regiões amazônica e das Guianas.

Prepusa e Senaea são gêneros endêmicos a habitats montanos dos estados brasileiros da Bahia, Espírito Santo, Minas Gerais e Rio de Janeiro. Os dados coligidos durante o desenvolvimento desta Tese constataram o alto grau de endemismo e a restrita distribuição geográfica dessas espécies, o que levou à categorização das mesmas como "Vulneráveis" a "Criticamente em Perigo", segundo os critérios da IUCN. Além disso, empregando dados morfológicos, foi possível reconstruir as relações filogenéticas entre as espécies de Prepusa e Senaea, que compreendem, respectivamente, 5 e 2 espécies (Capítulo 1). Embora compartilhem atributos morfológicos com as demais Helieae, ambos os gêneros exibem morfologia bastante distinta dos demais, sendo que seu posicionamento na tribo era uma hipótese que carecia de embasamento filogenético.

Análises filogenéticas empregando dados moleculares (i.e, seqüências de matK, $\operatorname{trn} L$ intron, ITS) e morfológicos (127 caracteres estruturais, incluindo dados sobre pólen e semente) corroboraram o posicionamento de Prepusa e Senaea como grupos-irmãos dos demais gêneros de Helieae (Capítulo 2). Além disso, grande parte das espécies emergiu agrupada em dois clados principais: o subclado "Macrocarpaea" (incluindo os gêneros Chorisepalum Gleason \& Wodehouse, Macrocarpaea Gilg, Tachia Aubl. e Zonanthus Griseb.) e o subclado "Symbolanthus" (incluindo diversos gêneros, entre eles Calolisianthus e Helia). Tais análises também refutaram a monofilia de Chelonanthus Gilg e Irlbachia Mart. e diagnosticaram possíveis sinapomorfias morfológicas no nível genérico.

Com base em uma maior amostragem de táxons pertencentes ao subclado "Symbolanthus" e na inclusão de um novo conjunto de dados moleculares (seqüências de 5S-NTS), prosseguiu-se com a investigação das relações filogenéticas de Helieae (Capítulo 
3). As topologias resultantes dessas análises revelaram um quadro consistente das relações entre as espécies da tribo, embasando a proposição de novas circunscrições genéricas para Calolisianthus, Chelonanthus, Helia e Symbolanthus G. Don (Capítulo 3).

As espécies tradicionalmente tratadas como Calolisianthus emergiram em 2 clados filogeneticamente distantes: um contendo duas espécies (uma delas o lectótipo do gênero); e outro contendo quatro espécies. O estudo taxonômico das espécies de Calolisianthus evidenciou que as características morfológicas do lectótipo do gênero contradiziam o protólogo, fato que indicava a necessidade de uma nova lectotipificação. Portanto, com base nos resultados filogenéticos, designou-se um novo lectótipo para Calolisianthus, escolhido dentre as espécies que emergiram no clado com maior número de espécies, que condizem com o protólogo (Capítulo 4). A partir dessa nova lectotipificação, o gênero Calolisianthus, em sua nova circunscrição contendo apenas 4 espécies, foi revisado (Capítulo 5). Tais espécies são endêmicas dos campos rupestres e cerrados do Brasil e caracterizam-se pelo hábito herbáceo a subarbustivo, pelas flores de cor rosa, vermelha, roxo-azulada ou lilás, e pelas tétrades polínicas com exina reticulada, apresentando ilhas de retículo mais espessado.

As outras duas espécies tradicionalmente tratadas como Calolisianthus emergiram juntamente com Chelonanthus purpurascens, o tipo de Chelonanthus, formando um clado fortemente sustentado. Com base nesses resultados filogenéticos, ambas foram transferidas para esse gênero (Capítulo 6). As outras espécies de Chelonanthus, informalmente denominadas "Chelonanthus de flores verdes", emergiram em um grande clado filogeneticamente distante de Chelonanthus purpurascens, juntamente com Adenolisianthus arboreus, um gênero monoespecífico, e as duas espécies tradicionalmente tratadas como Helia (i.e. Helia s.str.). Os integrantes desse clado compartilham características morfológicas que, apesar de homoplásticas no nível da tribo, poderiam se configurar como sinapomorfias de um gênero amplamente circunscrito, que incluísse todas essas espécies. Com base nesses resultados, será realizado um estudo de revisão de Helia s.l. (o nome genérico mais antigo disponível para nomear esse clado), incluindo as duas espécies de Helia s.str., Adenolisianthus e as nove espécies de "Chelonanthus de flores verdes". Parte desse trabalho, i.e. dados parciais obtidos com a revisão das espécies de Helia s.str. e argumentação das questões relacionadas à tipificação do nome do gênero, é apresentada no capítulo 7 desta Tese.

Em suma, os resultados obtidos ao longo desse doutoramento trouxeram importantes contribuições para o conhecimento acerca da sistemática de Helieae. O estudo aprofundado de alguns clados esclareceu as relações entre diversas espécies, embasando circunscrições genéricas mais robustas, além de sugerir alguns padrões evolutivos e biogeográficos. Os resultados indicam ainda a necessidade do aumento da amostragem de 
táxons com dados moleculares, especificamente 5S-NTS, o que certamente trará maior resolução nas relações filogenéticas da tribo. Particularmente, há necessidade de concentrar esforços nas espécies de Macrocarpaea e Symbolanthus, os dois gêneros com maior número de representantes, mas pouco amostrados até o momento. Finalmente, há a necessidade da continuidade da investigação da morfologia comparada, com a busca por novas fontes de evidência que possam trazer contribuições ao entendimento da evolução do grupo.

Espera-se que haja prosseguimento das pesquisas envolvendo a sistemática de Helieae, bem como de toda a família Gentianaceae. As perspectivas de estudo nessa área são excelentes, visto que, nos últimos anos, houve rápido avanço no entendimento das relações filogenéticas das Gentianaceae neotropicais. Prevê-se que, com a continuidade desses estudos e com a obtenção de novos dados moleculares e morfológicos, será possível evidenciar um quadro mais consistente das relações entre os gêneros e espécies de Helieae e, dessa forma, elucidar padrões evolutivos e biogeográficos desse importante grupo de plantas neotropicais. 


\section{Resumo}

Helieae, uma das seis tribos de Gentianaceae, compreende 23 gêneros e mais de 200 espécies encontradas exclusivamente nos Neotrópicos. Trata-se de um grupo de plantas bastante diversificado e de complicada história taxonômica. Diversos gêneros de Helieae eram pouco conhecidos e as relações filogenéticas dentro da tribo careciam de resolução. Nesse contexto, a presente Tese, organizada em sete capítulos, teve como objetivo principal prover hipóteses sólidas quanto às relações filogenéticas da tribo, focando principalmente no estudo de quatro desses gêneros pouco conhecidos: Calolisianthus Gilg, Helia Mart., Prepusa Mart. e Senaea Taub., todos com distribuição centrada principalmente no Brasil. No primeiro capítulo são apresentadas a filogenia morfológica e as revisões taxonômicas de Prepusa e Senaea. Com base no estudo de coleções de herbários, cinco espécies de Prepusa e duas de Senaea foram reconhecidas. Todas são endêmicas a habitats montanos dos estados brasileiros da Bahia, Espírito Santo, Minas Gerais e Rio de Janeiro. São apresentadas descrições morfológicas, chaves de identificação, ilustrações e mapas da distribuição de cada espécie. Prepusa e Senaea são morfológica, geográfica e filogeneticamente isolados entre as Helieae e a presença de flores 6-meras sustenta sua proximidade filogenética. Análises filogenéticas de 33 caracteres morfológicos usando parcimônia e métodos Bayesianos apresentaram um quadro consistente das relações de Prepusa e Senaea; os gêneros são monofiléticos e irmãos entre si. No segundo capítulo desta Tese, são apresentadas análises filogenéticas de parcimônia incluindo 22 gêneros e 60 espécies de Helieae. Esse estudo baseou-se em dados de morfologia, palinologia e sementes (127 caracteres estruturais), bem como em seqüências de DNA (matK, trnL intron, ITS). As reconstruções filogenéticas baseadas em ITS e morfologia proveram maior resolução nas relações entre os gêneros da tribo. Celiantha, Prepusa e Senaea emergiram juntos como clado-irmão das demais Helieae, as quais se apresentaram subdivididas em dois grandes subclados: "Macrocarpaea" e "Symbolanthus". O primeiro subclado inclui Macrocarpaea, irmão de Chorisepalum, Tachia e Zonanthus. Irlbachia e Neblinantha emergiram como grupos-irmãos do subclado "Symbolanthus", o qual inclui Aripuana, Calolisianthus, Chelonanthus, Helia, Lagenanthus, Lehmanniella, Purdieanthus, Rogersonanthus, Roraimaea, Sipapoantha e Symbolanthus. No nível genérico foi evidenciado que Chelonanthus e Irlbachia são polifiléticos. Discute-se a evolução de alguns atributos morfológicos, sendo que novos caracteres polínicos e de sementes são avaliados pela primeira vez em uma análise filogenética combinada. No terceiro capítulo, as relações filogenéticas de Helieae foram investigadas com base em novos dados moleculares e maior amostragem de alguns clados. Seqüências de DNA de duas regiões nucleares (ITS e 5S- 
NTS) e dados morfológicos foram analisados separadamente e em conjunto por meio de inferências de parcimônia e Bayesiana. Foram incluídos 86 espécimes representantes de 17 gêneros e 51 espécies de Helieae. Desse total, 47 espécimes possuíam seqüências das duas regiões e oito possuíam apenas dados morfológicos. O conjunto de dados completo gerou topologias largamente congruentes com aquelas obtidas com a análise de dois subconjuntos, um sem "dados ausentes" e outro incluindo táxons sem dados para uma das partições moleculares. A inclusão de maior número de táxons e de um novo conjunto de dados gerou um resultado consistente quanto ao posicionamento relativo de alguns clados, permitindo a definição de novas circunscrições genéricas para Calolisianthus, Chelonanthus, Helia e, em menor grau, para Symbolanthus. O gênero Calolisianthus constituía-se de 6-10 espécies, mas como resultado desses estudos filogenéticos moleculares e morfológicos, no quarto capítulo desta Tese uma nova circunscrição é apresentada e a atual lectotipificação questionada com base em conflito com o protólogo. O gênero recircunscrito, revisado no quinto capítulo, contém 4 espécies (uma delas nova para a ciência) endêmicas dos campos rupestres e cerrados do Brasil. O gênero é caracterizado pelo hábito herbáceo a subarbustivo, pelas flores de cor rosa, vermelha, roxo-azulada ou lilás e por tétrades polínicas com exina reticulada, apresentando ilhas de retículo mais espessado. São fornecidas chave de identificação, descrições morfológicas, ilustrações, mapas de distribuição e comentários sobre o status de conservação de cada espécie. Também como resultado dos estudos filogenéticos desta Tese, duas espécies que pertenciam ao gênero Calolisianthus são transferidas para Chelonanthus. No sexto capítulo, são apresentadas descrições morfológicas, ilustrações e mapas de distribuição geográfica dessas espécies. Por fim, propõe-se que Adenolisianthus e os "Chelonanthus de flores verdes", os quais não são proximamente relacionados à espécie tipo do gênero, sejam incluídos em um gênero Helia mais amplamente circunscrito. No último capítulo, a lectotipificação de Helia é questionada com base na dificuldade de reconhecimento da identidade do atual lectótipo. Propõe-se que esse lectótipo seja rejeitado e substituído pela designação de um novo. Helia sensu stricto compreende 2 espécies que ocorrem em brejos e campos úmidos do Brasil e Paraguai. Caracteriza-se pelo hábito herbáceo e pelas corolas salverformes de coloração amarelo-esverdeada, creme ou alva. São apresentadas suas descrições morfológicas, chave de identificação e mapas de distribuição. 


\begin{abstract}
Helieae, one of the six Gentianaceae tribes, comprises about 23 genera and over 200 species found exclusively in the Neotropics. It is a highly diverse assemblage of plants, which have traditionally been problematic regarding generic circumscriptions. Several Helieae genera were understudied and phylogenetic relationships within the tribe were unclear. On these grounds, the present seven-chapter Thesis aimed to provide solid hypothesis on the phylogenetic relationships of the tribe, focusing primarily on the study of four of these poorly known genera, specifically, Calolisianthus Gilg, Helia Mart., Prepusa Mart. and Senaea Taub., which occur mainly in Brazil. In the first chapter, a morphologybased phylogeny and taxonomic revision of Prepusa and Senaea are presented. Based on studies of herbarium collections, five species of Prepusa and two species of Senaea are recognized. All are endemic to montane habitats in the Brazilian states of Bahia, Espírito Santo, Minas Gerais and Rio de Janeiro. Morphological descriptions, identification keys, illustrations and distribution maps for each species are provided. Prepusa and Senaea are morphologically, geographically, and phylogenetically isolated within Helieae, and their close relationship is supported by 6 -merous flowers. Phylogenetic analyses of 33 morphological characters using both parsimony and Bayesian methods provide a consistent picture of the relationships of Prepusa and Senaea. The two genera are monophyletic and sister to one another. Parsimony-based phylogenetic analyses including 22 genera and 60 species of the tribe Helieae are presented in the second chapter. This study is based on data from morphology, palynology, and seed micromorphology (127 structural characters), and DNA sequences (matK, trnL intron, ITS). Phylogenetic reconstructions based on ITS and morphology provided the greatest resolution. Celiantha, Prepusa and Senaea together appear as the sister clade to the rest of Helieae. The remainder of Helieae is largely divided into two large subclades, the "Macrocarpaea" subclade and the "Symbolanthus" subclade. The first subclade includes Macrocarpaea, sister to Chorisepalum, Tachia, and Zonanthus. Irlbachia and Neblinantha are placed as sisters to the "Symbolanthus" subclade, which includes Aripuana, Calolisianthus, Chelonanthus, Helia, Lagenanthus, Lehmanniella, Purdieanthus, Rogersonanthus, Roraimaea, Sipapoantha, and Symbolanthus. Generic-level polyphyly is detected in Chelonanthus and Irlbachia. Evolution of morphological characters is discussed, and new pollen and seed characters are evaluated for the first time in a combined morphological-molecular phylogenetic analysis. In the third chapter, phylogenetic relationships in Helieae were studied based on new data and larger sampling in particular clades. DNA sequences from two nuclear regions (ITS and 5S-NTS) and morphological data were analyzed separately and in combination using parsimony and Bayesian inference. A
\end{abstract}


total of 86 specimens representing 17 and 51 Helieae genera and species, respectively, were included in the phylogenetic analyses; 47 specimens are sequenced for both regions, and eight have only morphological data. The complete data set produced topologies largely congruent with the ones obtained from two subsets, one without missing data, and another including taxa without data for one molecular partition. The use of new information led to a consistent result in the relative position of some clades and allowed defining new generic circumscriptions for Calolisianthus, Chelonanthus, Helia, and, to a lesser extent, Symbolanthus. The genus Calolisianthus formerly encompassed 6-10 species. As a result of these molecular and morphological phylogenetic studies, in the fourth chapter a new circumscription is presented and the existing lectotypification of Calolisianthus is questioned. It is proposed that this lectotype is rejected and superseded by the designation of a new lectotype, based chiefly on the conflict with the protologue. The genus Calolisianthus in its new circumscription, revised in the fifth chapter, comprises 4 species (one new to science) endemic to campos rupestres and cerrados in Brazil. The genus is characterized by herbaceous to subshrubby habit, by pink, red, purple-blue or lilac flowers, and by shedding pollen in reticulate tetrads with islands of coarse reticulum. Taxonomic key, morphological descriptions, illustrations, distribution maps, and comments about conservation status are provided. Moreover, two former Calolisianthus species are transferred to Chelonanthus. Morphological descriptions, illustrations and geographic distribution maps of these species are presented in the sixth chapter. Finally, it is proposed that Adenolisianthus and the "green-flowered Chelonathus", which are not closely related to the type species, be included in a largely circumscribed Helia. In the final chapter, the existing lectotypification of Helia is questioned based on the difficulties in recognizing the material identity. It is proposed that this lectotype is rejected and superseded by the designation of a new lectotype. Helia sensu stricto comprises 2 species that occur in swamps and wet fields in Brazil and Paraguay. They are characterized by their herbaceous habit and greenish-yellow, cream or white, salverform corollas. Morphological descriptions, identification keys, illustrations, and distribution maps are provided for both of them. 
- Anexo 1

Morphology-based phylogeny and Revision of Prepusa and Senaea (Gentianaceae: Helieae) - rare endemics from eastern Brazil Calió MF, Pirani JR \& Struwe L 


\title{
Morphology-based phylogeny and revision of Prepusa and Senaea (Gentianaceae: Helieae) — rare endemics from eastern Brazil
}

\author{
Maria Fernanda Calió ${ }^{1}$, José Rubens Pirani ${ }^{1} \&$ Lena Struwe ${ }^{2}$
}

Summary. A morphology-based phylogeny and taxonomic revision of Prepusa Mart. and Senaea Taub. are presented. Based on studies of herbarium collections, five species of Prepusa and two species of Senaea are recognised. All are endemic to montane habitats in the Brazilian states of Bahia, Espírito Santo, Minas Gerais and Rio de Janeiro. Morphological descriptions, identification keys, illustrations and distribution maps for each species are provided. Prepusa and Senaea are morphologically, geographically, and phylogenetically isolated within Helieae, and their close relationship is supported by 6-merous flowers. Phylogenetic analyses of 33 morphological characters using both parsimony and Bayesian methods provide a consistent picture of the relationships of Prepusa and Senaea. The two genera are monophyletic and sister to one another. There is some support for the relationships within Prepusa.

Resumo. São apresentadas a filogenia morfológica e as revisões taxonômicas de Prepusa Mart. e Senaea Taub. Baseado no estudo de coleções de herbários, cinco espécies de Prepusa e duas de Senaea são reconhecidas. Todas são endêmicas a habitats montanos dos estados brasileiros da Bahia, Espírito Santo, Minas Gerais e Rio de Janeiro. São apresentados descrições morfológicas, chaves de identificação, ilustrações e mapas da distribuição de cada espécie. Prepusa e Senaea são morfológica, geográfica e filogeneticamente isolados entre as Helieae e a presença de flores 6-meras sustenta sua proximidade filogenética. Análises filogenéticas de 33 caracteres morfológicos usando parcimônia e métodos Bayesianos apresentam um quadro consistente das relações de Prepusa e Senaea. Os gêneros são monofiléticos e irmãos entre si. Há sustentação para as relações entre as espécies de Prepusa.

Key Words. distribution, Neotropics, Phylogeny, Prepusa, revision, Senaea, taxonomy.

\section{Introduction}

Prepusa Mart. and Senaea Taub. are members of Gentianaceae. They are rare herbs, shrubs or small trees restricted to montane habitats in the states of Bahia, Espírito Santo, Minas Gerais and Rio de Janeiro. Prepusa was described by Martius (1827). Although sometimes considered to be derived from the Latin word "praeputium" (for example, Barroso 1986), the protologue indicates that the name comes from the Greek " $\pi \rho \varepsilon \pi o v \sigma \alpha$ " meaning conspicuous, a reference to the remarkable overall appearance of the plants. The showiness of these plants is particularly striking when they are in flower; they are characterised by large, inflated calyces that are at least half the length of the corolla. Prepusa montana was the first species described (Martius 1827), and four species were added later by other researchers: $P$. connata Gardner (1839), P. hookeriana Gardner (1842), P. alata
Porto \& Brade (1935), and P. viridiflora Brade (1949). Senaea was established by Taubert (1893) and the protologue indicates the genus was named for a Brazilian botanist referred to only as "Sena". This genus has traditionally contained two species; $S$. coerulea, described by Taubert (1893) and S. janeirensis, described later by Brade (1932). Although Prepusa and Senaea share a few morphological features, these two genera are clearly distinguished by calyx size, Senaea having much smaller calyces. Apart from the original descriptions, these genera have only been treated in a few 19th century monographs (e.g., Grisebach 1839, 1845; Progel 1865; Gilg 1895) and in two recent local floras (Harley \& Simmons 1986; Cordeiro 1987).

A close relationship between Prepusa and Senaea has been suggested based on several shared morphological features; specifically, both have 6-merous flowers, membranaceous calyces, and a distinctive pollen type

\footnotetext{
Accepted for publication April 2008.

1 Departamento de Botânica, Instituto de Biociências, Universidade de São Paulo, Rua do matão, 277-CEP: 05508-090, São Paulo, São Paulo, Brazil, e-mail: mfernanda_calio@yahoo.com.br.

2 Department of Ecology, Evolution and Natural Resources, Rutgers University, 237 Foran Hall, 59 Dudley Road, New Brunswick, NJ 08901, USA.
} 
(Nilsson 2002; Struwe et al. 2002). They have also been tentatively placed in the tribe Helieae based on morphological characteristics, including a broadly bilamellate stigma and pollen shed as tetrads (Nilsson 2002; Struwe et al. 2002). However, their position has been considered uncertain because the characteristic floral features of these two genera are very different from those of most Helieae. The floral characteristics that link Prepusa and Senaea do not occur in Helieae, furthermore, the characteristic calycine dorsal glandular areas and thickened calyx keels found in many Helieae are absent from both Prepusa and Senaea. Recent phylogenetic analyses of molecular and morphological data have suggested a direct link between Prepusa and Senaea, and have also supported their relationship with Helieae (Struwe et al. submitted). However, these analyses have included either $P$. montana alone or this species along with both Senaea species. None of the herbaceous species of Prepusa were considered in these analyses and so the relationships of these to the woody taxa and to the remainder of the tribe are uncertain.

To improve our understanding of these two rare and endangered genera we performed a detailed morphological study of all seven species, as well as other members of Helieae. Based on these data, we performed phylogenetic analyses to test the monophyly of the genera and the relationships within and between them. We also produced a taxonomic revision of both genera providing field keys, illustrations, morphological descriptions, and geographic distribution maps. It is our hope that this new information will help efforts to conserve these rare plants and will serve as a basis for future studies on the tribe.

\section{Material and Methods}

Detailed morphological studies were based on herbarium material from AAU, ALCB, BHCB, BM*, BR*, C, CEN, CEPEC, CHRB*, CTES, ESA*, G*, HRB, HUEFS, IAN*, INPA*, K*, LIL, M, MBM*, MBML, MO, NY*, P, R*, RB*, S, SP*, SPF*, UB, UEC*, UPCB* and US* (* denotes herbaria visited by the authors). Only mature or fully developed structures were examined. Flowers and fruits were rehydrated in boiling water. All material was examined using a SZ Olympus dissecting microscope. Measurements were made using either a microscope interocular scale or calipers. Morphological descriptions follow Radford $e t$ al. (1974) and Stearn (1992) for two-dimensional shapes, and Weberling (1989) for inflorescences. Illustrations are based on both dried and rehydrated material. Preliminary conservation assessments follow IUCN (2001) guidelines.

For the phylogenetic analysis, we assembled a data set that included all species of Prepusa and Senaea. To ensure a proper rooting within the ingroup, 11 species from the tribe Helieae (i.e., Aripuana cullmaniorum,
Calolisianthus pedunculatus, Celiantha bella, Chelonanthus viridiflorus, Chorisepalum carnosum, Helia oblongifolia, Irlbachia nemorosa, Macrocarpaea rubra, Symbolanthus calygonus, Tachia grandiflora, and Tetrapollinia caerulescens) and Curtia verticillaris, from the most basally placed tribe Saccifolieae, were included as outgroups. Based on our detailed morphological investigations, we identified 33 characters, shown in Appendix A with character delimitation, character states and commentaries. With the exception of pollen aggregation (character 32), all characters were scored based on direct examination of herbarium sheets. Pollen data were taken from Nilsson (2002). Characters and character states were designed for resolving relationships among Prepusa and Senaea species.

Phylogenetic analyses were performed using both parsimony and Bayesian approaches. For the parsimony analysis, a branch and bound search was performed using PAUP* version 4.0b10 (Swofford 2003). All characters were treated as unordered and equally weighted; multistate characters were treated as uncertain. Tree lengths, consensus trees, consistency index (CI) and retention index (RI) were calculated using PAUP. Bootstrap values were calculated with 1000 replicates. Decay indices were calculated using PAUP* and MacClade version 4.08 (Maddison \& Maddison 2005).

The Bayesian analysis used the standard discrete model as implemented in MrBayes 3.1 (Huelsenbeck \& Ronquist 2001; Ronquist \& Huelsenbeck 2003). Searches used default settings for heating scheme (i.e., three "heated" chains and one "cold" chain), as well as for the priors on rate matrix $(0-100)$, branch lengths $(0-10)$, and gamma shape parameter $(0-10)$. Simultaneous, independent pairs of searches were initiated from random start trees and run for five million generations, sampling from the posterior distribution of trees every 100 generations (for a total of 50,000 samples). Burnin was determined by plotting likelihood scores versus generation number and inspection of PSRF values for all model parameters. Posterior probabilities were calculated using the postburnin sample of trees.

\section{Results \& Discussion}

\section{Phylogenetic Analyses}

It was not possible to score all characters for all taxa; in one case the character was inapplicable. Specifically, character 13 (i.e., bracteoles subtending terminal flower) could not be scored for Tachia grandiflora because in this species the flowers are axillary. In addition, $2.6 \%$ of the cells were coded as missing because it was not possible to determine the character states based on the available material.

Parsimony analysis resulted in 37 most parsimonious $(\mathrm{MP})$ trees, 91 steps long $(\mathrm{CI}=0.42, \mathrm{RI}=0.64)$. In 
all trees, the same set of relationships is recovered for Prepusa and Senaea, furthermore, the remaining representatives of Helieae form a clade in all trees. Differences between MP trees are restricted to relationships within this core Helieae clade (Fig. 1). In parsimony analyses, Prepusa and Senaea are sister to one another, although this relationship receives only limited bootstrap support. The two species of Senaea are also sister; this relationship is more strongly supported. Prepusa is recovered as monophyletic in all MP trees, but bootstrap support is less than $50 \%$. Within this clade, $P$. montana branches first, followed by $P$. viridiflora; P. alata is sister to the pairing of $P$. connata and
P. hookeriana. These relationships receive moderate to strong bootstrap support. Bremer support values are consistent with those from bootstrapping. Specifically, relationships that are poorly supported by bootstrapping also receive low decay indices.

Inspection of likelihood plots and PSRF values for all model parameters indicated that independent searches had reached stationarity and converged within 500 generations; the initial 500 generations were discarded as burnin. The $50 \%$ majority-rule tree for post-burnin topologies was highly similar to that recovered using parsimony. Specifically, Prepusa and Senaea are sister to one another, and the same

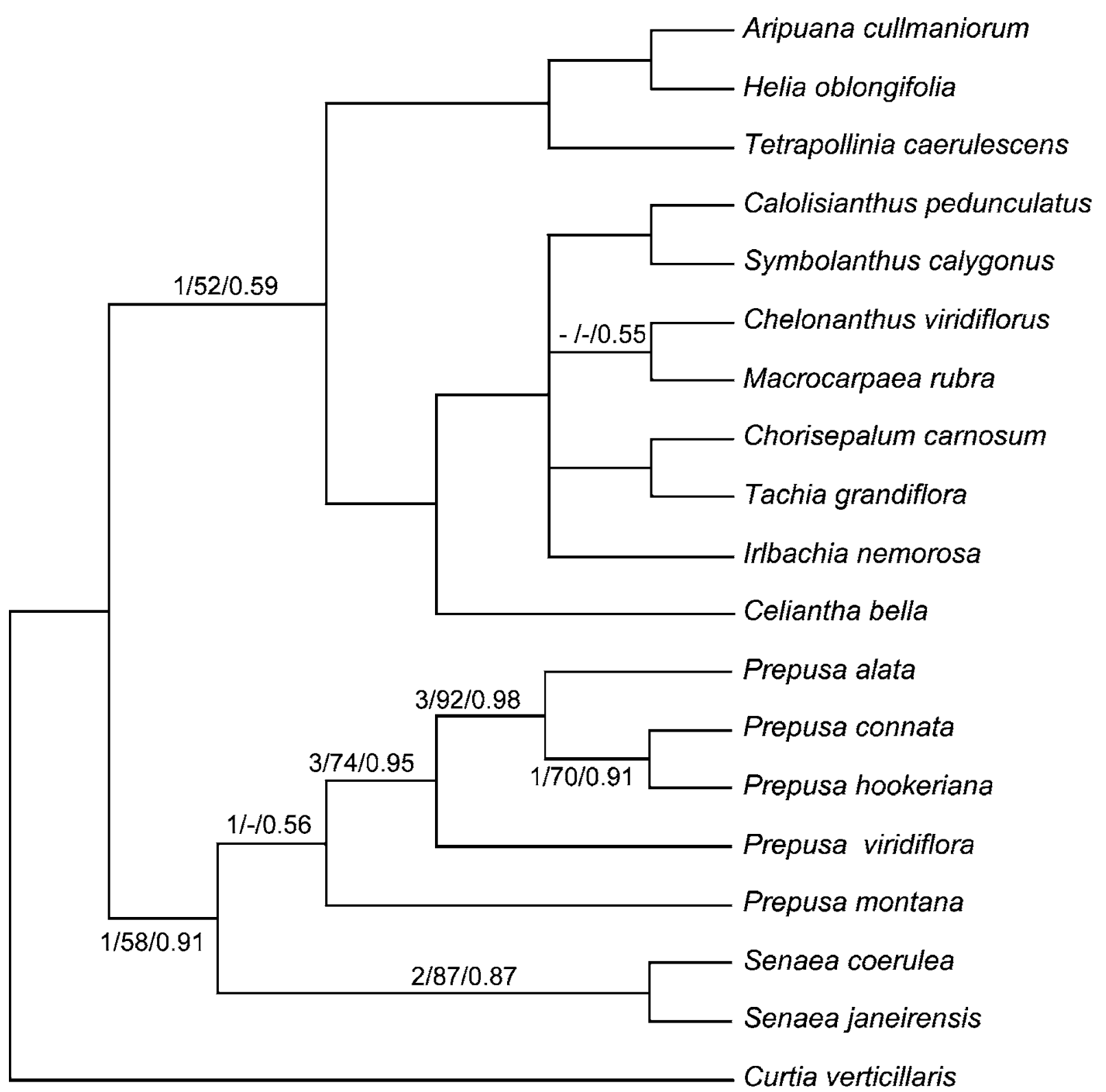

Fig. 1. Majority-rule consensus of 37 most parsimonious trees. Support for nodes is given by the decay index, parsimony bootstrap, and Bayesian posterior probabilities (in that order). A dash indicates that the corresponding node support value was either 0 for the decay index or was less than $50 \%$ for the parsimony bootstraping or posterior probability. 
relationships within Prepusa are recovered. Bayesian support values are generally consistent with those from the parsimony bootstrap analysis (see Fig. 1).

Additional analyses that included only a single representative of Helieae as an outgroup (Curtia verticillaris was not used) provide increased support for the monophyly of each of the genera, as well as for relationships within Prepusa. For example, when using Aripuana cullmaniorum and Symbolanthus calygonus as outgroups, bootstrap support for all nodes is above $80 \%$. A possible explanation is that in the broader context of the tribe, character conflict leads to reduced support values. For example, $P$. montana shares a woody habit with both Senaea species, as well as with Aripuana cullmaniorum, Chorisepalum carnosum, and Tachia grandiflora; prominent decurrent ridges on stem are present not only in Senaea but also in several other taxa sampled for this analysis. Indeed, it seems likely that homoplasy is a general problem for morphology-based phylogenetic analysis of Gentianaceae since the diversity of the group makes it difficult to identify features that are unique to specific taxa (e.g. Mészáros et al. 2002).

Our phylogenetic analyses are clearly consistent with the monophyly of Prepusa and Senaea, and with a direct link between them (Fig. 1). Inspection of the data matrix indicates that the sister group relationship between these taxa is based on the shared presence of membranaceous calyces (character 17), 6-merous corollas (ch. 23), and cylindric styles (ch. 33). The first two of these characters have commonly been used to distinguish these genera from other Gentianaceae. In contrast, Helieae generally have fleshy, sometimes leathery, calyces with dorsally thickened lobes that often have dorsal glandular areas; they also differ in that they have 5-merous corollas and flattened styles. Inspection of the matrix also indicates that monophyly of Prepusa is supported by only one character; specifically, winged calyces (ch. 21). Within Prepusa, the clade containing $P$. viridiflora, $P$. alata. $P$. connata and $P$. hookeriana is supported by several characters. These include leaves arranged in a basal rosette (ch. 3), connate leaf bases (ch. 8), non-prominent leaf midribs on abaxial surface (ch. 10), and connate bract bases (ch. 12). Within this subclade, the group formed by $P$. alata, $P$. connata, and P. hookeriana is supported by the red- to magenta-coloured leaf margins and apices (ch. 6), the presence of papillae on the inner side of calyces (ch. 19), and the reddish calyces (ch. 15). Finally, the link between $P$. connata and $P$. hookeriana is supported by urceolate calyces (ch. 16). The monophyly of Senaea receives moderate support. This link is supported by two characters; papillate corollas (ch. 26) and stamens exserted beyond the corolla (ch. 30).

It is important to note that while these characters appear to be useful for resolving phylogenetic rela- tionships within Prepusa and Senaea, at least some of them are homoplastic when considered across Helieae as a whole. Given the small scope of this analysis and the observation that Prepusa and Senaea share character states with other Helieae, it should be clear that detailed discussion of morphological evolution within the tribe is simply not possible. However, it should be said that given the morphological diversity of Helieae it seems likely that the shared characters represent independent evolutions.

\section{Biogeography and Conservation}

Prepusa and Senaea occur in the campo de altitude and campo rupestre areas of eastern Brazil. These vegetation types are characterised by a mosaic distribution, often forming vegetation islands associated with rocky outcrops and sandy soils (Giulietti \& Pirani 1988; Safford 1999). The individual islands are isolated from one another by areas of lower altitude that are both climatically and edaphically very different. Prepusa alata, $P$. connata, $P$. hookeriana, $P$. viridiflora and $S$. janeirensis occur in the campos de altitude, this vegetation type is associated with montane areas close to the Atlantic coast and the surrounding vegetation is Atlantic forest. In contrast, P. montana and S. coerulea occur in campo rupestre. This vegetation type occurs in more inland areas and the individual patches are isolated from one another by the distinctive cerrado vegetation. Similar patterns of disjunct distribution among campos rupestres and campos de altitude have been reported for other plant groups in eastern Brazil. For example, Bradea Standl. (Rubiaceae), Hindsia Benth. (Rubiaceae), Hockinia Gardner (Gentianaceae), Schlumbergera Lem. (Cactaceae), and Wunderlichia Riedel ex Benth \& Hook. f. (Asteraceae) have species that occur in both the campos rupestres and campos de altitude. Giulietti \& Pirani (1988), Safford (1999), and Safford \& Martinelli (2000) provide excellent discussions of plant distribution patterns in the campos rupestres and campos de altitude.

The patchwork distribution of campos de altitude and campos rupestres has been suggested as an explanation for their high levels of endemism and species richness (Giulietti \& Pirani 1988; Safford 1999). If this is the case, it seems reasonable to suggest that geographic isolation may have played a role in the diversification of Prepusa and Senaea. Paleobotanical evidence suggests that open floristic assemblages were more widely distributed in the Tertiary (Miocene) and have become more restricted and fragmented in response to climatic changes, chiefly during the glaciation cycles of the Quaternary (Safford 1999). This scenario implies that current species distribution may have arisen as the result of vicariance followed by allopatric speciation. That is, the distributions of formerly 
widespread taxa were fragmented, forming "vegetation refugia" (Veloso et al. 1991). Ancestral populations of Prepusa and Senaea in these refugia subsequently diverged in isolation, resulting in the contemporary species distributions. Additional analyses of biogeographic patterns using phylogeny, biogeographic methods, and GIS are planned for this group; we hope these will help us understand the historical context of diversification in these groups.

All Prepusa and Senaea species are local endemics and currently most are restricted to protected areas (Maps 1 and 2). The most widespread species, P. montana, occurs in Parque Nacional (P.N.) da Chapada Diamantina, Parque Estadual (P.E.) do Morro do Chapéu, and the Parque Municipal de Mucugê. This species is also known to occur outside these parks. Based on its relatively widespread distribution, $P$. montana is considered to be "vulnerable" based on the IUCN guidelines (IUCN 2001). Prepusa viridiflora and $P$. hookeriana each occur in two locations, and these species are considered "endangered." Specifically, $P$. viridiflora is found in P.E. da Pedra Azul and P.E. do Forno Grande, while P. hookeriana occurs in P.N. do Itatiaia and P.N. da Serra dos Órgãos. The remaining species are all placed in the "critically endangered" category. Three of these are known only from a single locality: P.E. do Desengano ( $S$. janeirensis and $P$. alata) and P.N. da Serra dos Órgãos ( $P$. connata). Although placed in the "critically endangered" category $S$. coerulea may well be extinct as it has not been found since 1982, despite researchers commonly visiting the localities where it was previously reported. Unfortunately, the localities for $S$. coerulea are unprotected.

Although these species' occurrence within parks provides some level of protection, they are highly dependent on the maintenance of these protected areas since their actual distribution is much more restricted, and they usually occur on just a single mountain peak. In all cases, loss of habitat, mainly due to fire, local habitat disturbance by cattle and humans, as well as increasing pressure from nearby human settlements, is of great concern. Not only do these activities greatly reduce the chance of finding additional populations outside of protected areas, but these also threaten the parks themselves. Careful management of these areas and the populations themselves is needed in order to assure longer-term survival.

\section{Taxonomic Treatment}

\section{Key to Genera}

1. Calyx large $(19-46 \times 14-33 \mathrm{~mm})$ and conspicuous, half as long or longer than the corolla; corolla lobes much shorter than corolla tube $\ldots \ldots \ldots \ldots \ldots \ldots \ldots \ldots \ldots \ldots \ldots \ldots$

1. Calyx small $(6.9-12 \times 5-8.5 \mathrm{~mm})$ and not conspicuous, much shorter than the corolla; corolla lobes almost as long as corolla tube $\ldots \ldots \ldots \ldots \ldots \ldots \ldots \ldots \ldots \ldots \ldots \ldots \ldots \ldots$

Prepusa Mart. (1827: 120). Type species: Prepusa montana Mart.

Herbs to shrubs or small trees, glabrous, unbranched or branched. Stems cylindrical from base to apex, with numerous, discontinuous, thin, vertical ridges (not extending from interstipular line to node directly below). Leaves clustered at base of stem, forming a basal rosette or clustered at branch apices, green to greenish-yellow, sessile, fleshy; margin entire, hyaline, reddish or green; venation acrodromous, primary and secondary veins conspicuous, tertiary veins inconspicuous. Inflorescence terminal, dichasium; bracts and bracteoles leaf-like, with entire, hyaline margins. Flowers actinomorphic, perfect, 6-merous, pedicellate. Calyx reddish, green or yellowish, campanulate or urceolate, inflated, marcescent; lobes equal; colleters present on inside of calyx. Corolla white, cream, yellow, yellowish-green or brown, funnel-shaped or campanulate with a constriction at the level of stamen insertion and widening above, membranaceous or marcescent, not papillate; lobes aestivation contort. Stamens 6, unequal or equal in length, included, inserted in the lower third of the corolla tube; filaments filiform, very rarely twisted when dry; anthers ovoid to ellipsoid, sagittate at base, dorsifixed, with sterile appendix at apex, introrse. Ovary ellipsoid; style slender, not twisted when dry; stigma bilamellate; placentation parietal; ovules numerous. Fruit a capsule, unilocular, 2-valvate, many-seeded, with persistent calyx, corolla, and style.

Prepusa comprises five species restricted to the campos rupestres and campos de altitude of the eastern Brazilian states of Bahia, Espírito Santo and Rio de Janeiro (Map 1). 


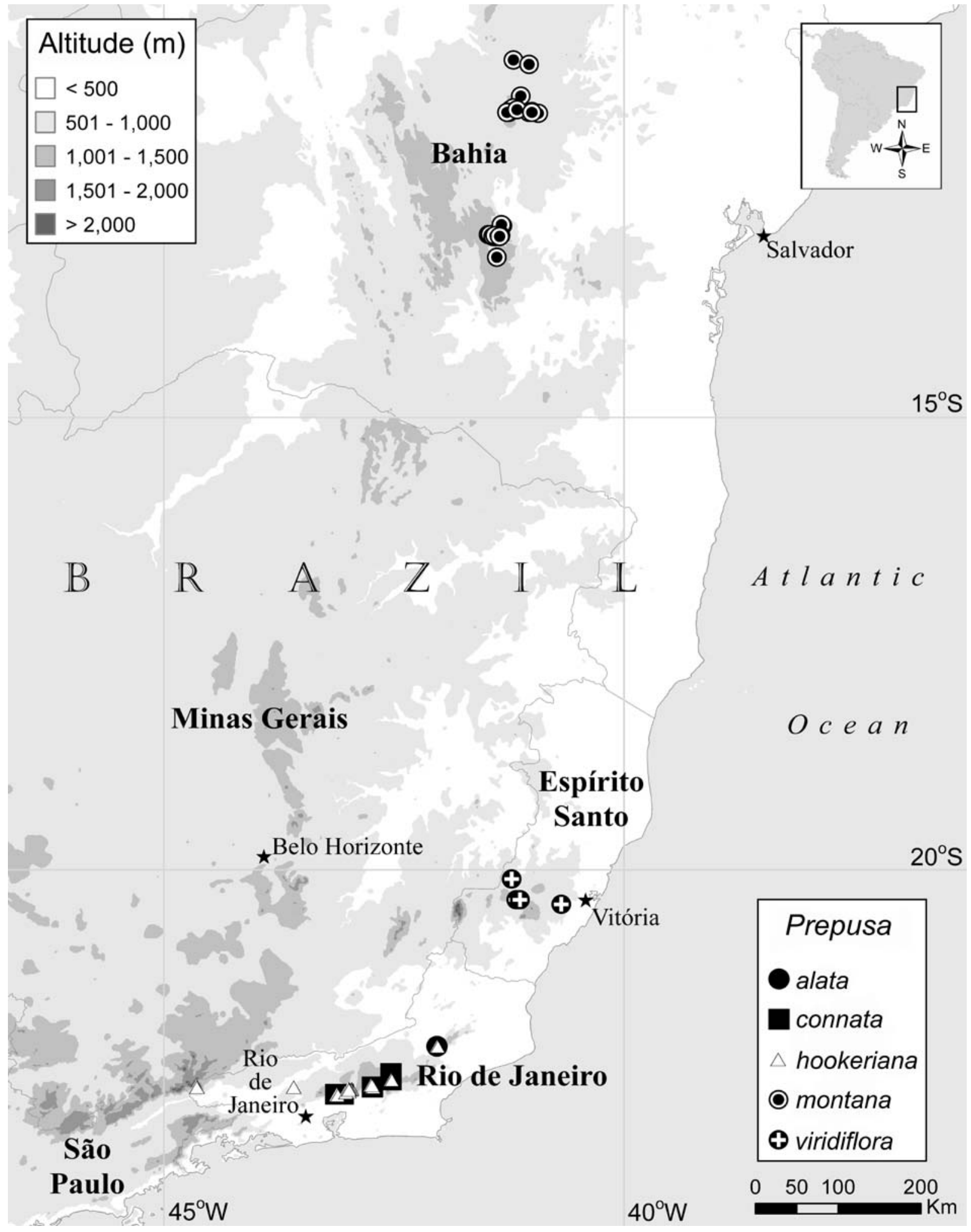

Map 1. Distribution of Prepusa species. 


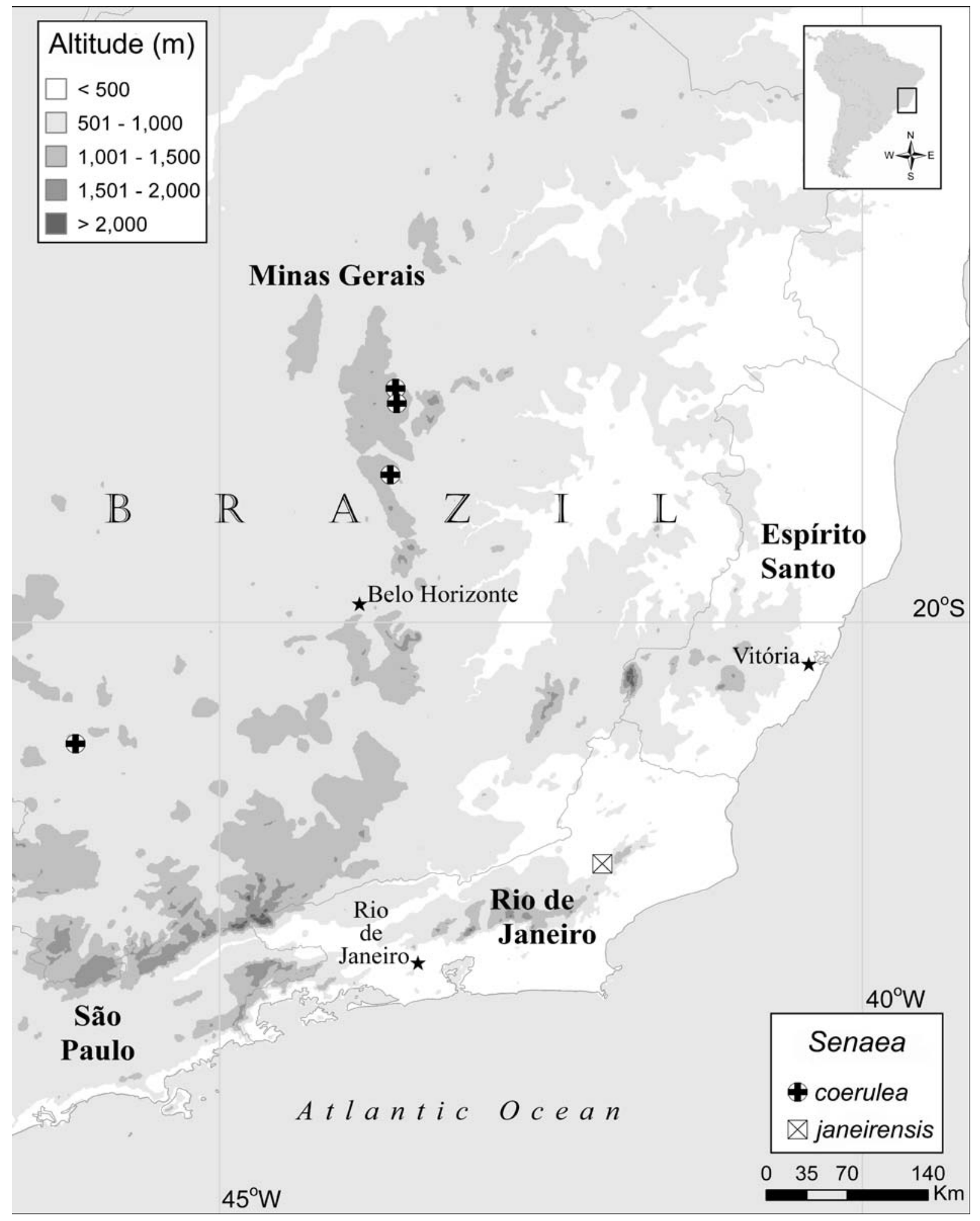

Map 2. Distribution of Senaea species. 


\section{Key to the species of Prepusa}

1. Stems woody, shrub or small tree; leaf apex obtuse and emarginate; corolla lobe margin entire, rarely slightly

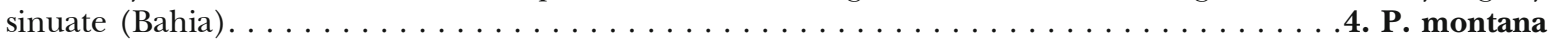

1. Stems not woody (herbaceous) or woody only at base (subshrub); leaf apex acuminate or acute; corolla lobe margin crenulate, very rarely entire (Rio de Janeiro and Espírito Santo):

2. Calyx winged:

3. Calyx reddish, winged from base to the apex of the calyx tube; calyx lobes transversely elliptic, widely elliptic or depressed ovate, with caudate to mucronate apex; corolla campanulate, longer than calyx (Rio de Janeiro $\ldots \ldots \ldots \ldots \ldots \ldots \ldots \ldots \ldots \ldots \ldots \ldots \ldots \ldots \ldots \ldots \ldots \ldots$ alata

3. Calyx greenish-brown, winged from base, but not reaching the apex of the calyx tube; calyx lobes triangular, with acute to acuminate apex; corolla funnel-shaped, shorter than to as long as calyx (Espírito Santo $\ldots \ldots \ldots \ldots \ldots \ldots \ldots \ldots \ldots \ldots \ldots \ldots \ldots \ldots \ldots \ldots$. viridiflora

2. Calyx not winged:

4. Bracts $34-61 \times 18-32 \mathrm{~mm}$, connate to $2 / 5-4 / 5$ of length, forming a bilabiate sheath; calyx lobe apex

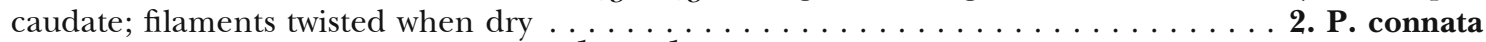

4. Bracts $19-27 \times 5-9 \mathrm{~mm}$, connate to only $1 / 10-1 / 5$ of length; calyx lobe apiculate to mucronate; filaments not twisted when dry $\ldots \ldots \ldots \ldots \ldots \ldots \ldots \ldots \ldots \ldots \ldots \ldots \ldots \ldots \ldots$. P. hookeriana

1. Prepusa alata Porto E Brade (1935: 222). Type: Brazil, Rio de Janeiro, Santa Magdalena (sic), Pedra das Flores, $1400 \mathrm{~m}$, Nov. 1933, J. Santos Lima 185 (holotype RB!; isotype RB!).

Herbs, woody at base, $20-80 \mathrm{~cm}$ tall, unbranched. Stems $2.5-4.0 \mathrm{~mm}$ in diam. below inflorescence, internodes 5 - $18 \mathrm{~mm}$ long at base of plant, 35 - 60 (-116) mm long below inflorescence. Leaves elliptic to narrowly elliptic, oblanceolate to obovate, $22-86 \times 11-26 \mathrm{~mm}$, base connate less than $1 / 10$ of length, margin reddish and straight, apex acute to acuminate; 1 - 3 pairs of secondary veins. Inflorescence $90-205 \mathrm{~mm}$ long, $1-4$ flowered; bracts elliptic to obovate, $29-33 \times 13-$ $20 \mathrm{~mm}$, base connate to c. $1 / 10$ of length, apex acute; bracteoles 1 pair per flower, inserted either at the base or at c. $1 / 5$ of pedicel length (from base), narrowly elliptic, oblanceolate or narrowly oblong, $10-40 \times 1.6-$ $13.5 \mathrm{~mm}$, base connate to $1 / 10-2 / 5$ of length, apex acute or acuminate; pedicel $50-156 \mathrm{~mm}$ long, $0.7-$ $3.0 \mathrm{~mm}$ in diam. Calyx reddish, campanulate, $20-30 \times$ $14-17 \mathrm{~mm}$ at anthesis, papillate on the inner side, minutely papillate on the outer side only close to the apex, dorsally winged from base to apex, wings $1.5-$ $4.5 \mathrm{~mm}$ wide; lobes elliptic to widely ovate, $2.7-4.5 \times$ $5.1-6.0 \mathrm{~mm}$, apex caudate or mucronate. Corolla white, cream, to pale yellow, campanulate, $36-43 \mathrm{~mm}$ long, 1.5 - 1.6 times longer than calyx; tube $25-31 \mathrm{~mm}$ long, 2.2 - $3.2 \mathrm{~mm}$ wide at base, $7.2-8.0 \mathrm{~mm}$ wide below filament insertion, $10-13 \mathrm{~mm}$ above filament insertion, $10-20 \mathrm{~mm}$ wide at mouth; lobes ovate, elliptic or obovate, $10-15 \times 6.5-8.1 \mathrm{~mm}$, margin crenulate (very rarely entire), apex apiculate. Filaments unequal in length, not twisted when dry, 21 - $30 \mathrm{~mm}$ long; anthers $4.1-5.0 \mathrm{~mm}$ long, attached to filament c. $2.1 \mathrm{~mm}$ from anther base. Ovary $11-14 \mathrm{~mm}$ long; style $13-21 \mathrm{~mm}$ long; stigma lobes broadly elliptic, $2.0-2.5 \mathrm{~mm}$ long. Fruit not seen. Fig. 2.

DISTRIBUtION. Brazil, Rio de Janeiro. Occurring only on Pedra do Desengano (Parque Estadual do Desengano). Map 1.

SPECIMENS EXAMINED. Rio de Janeiro: Santa Maria Madalena, Parque Estadual do Desengano, Pedra do Desengano, 17 Sept. 1986, Farney E Caruso 1195 (CEPEC, MG, RB!) \& 24 March 2002, Gomes et al. 153 (CHRB!, K, SPF!, SP!) \& 5 Oct. 1988, Martinelli et al. 13140 (RB!) \& March 1934, Santos Lima E Brade 14101 (RB!).

HABITAT. Campo de altitude, $1400-1800 \mathrm{~m}$. CONSERVATION STATUS. CR Blab(i,ii)+2ab(i,ii). This species is categorised as Critically Endangered due to its small extent of occurrence, confined to only one mountain peak.

PHENOLOGY. Flowering specimens have been found in March, Sept. and Oct.

ETYMOLOGY. The species epithet 'alata' was given because of the winged calyx.

2. Prepusa connata Gardner (1839: 225 - 226); Grisebach (1845: 81); Progel (1865: 243); Gilg (1895: 96). Type: Brazil, Rio de Janeiro, near the summits of Organ Mts, 1500 m, May 1837, Gardner 541 (holotype BM!; isotypes CGE!, G! (2 sheets), K!, NY! (2 sheets), P!, S!, US!).

Prepusa campanulata Grisebach (1845: 81) nom. nud.

Herbs, not woody at base, $28-69 \mathrm{~cm}$ tall, unbranched. Stems $2.5-6.8 \mathrm{~mm}$ in diam. below inflorescence, internodes $6-55(-105-110) \mathrm{mm}$ long at base of plant, $(8-) 35-75(-105) \mathrm{mm}$ long below 


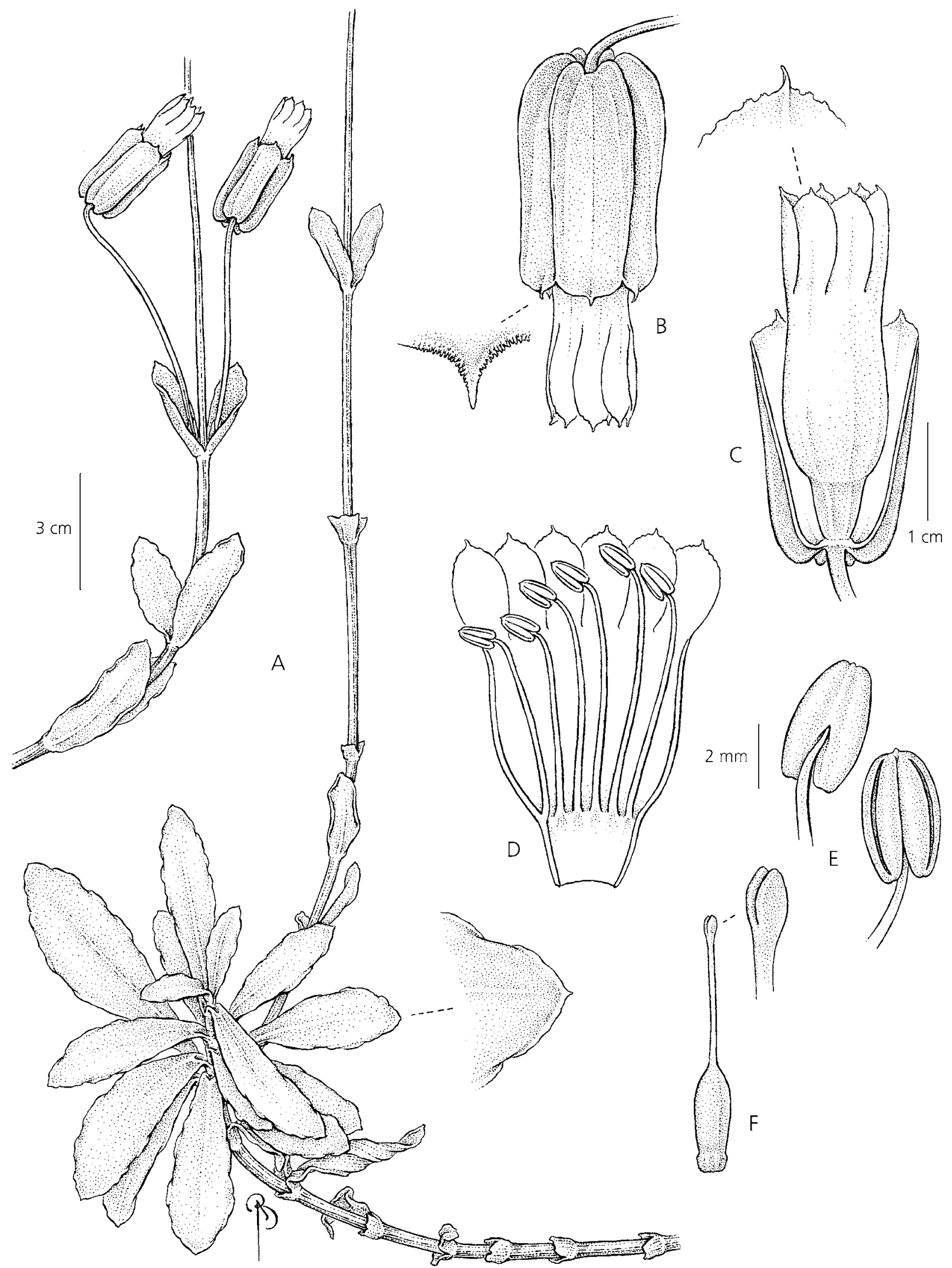

Fig. 2. Prepusa alata. A habit and leaf apex detail; B flower and calyx lobe apex detail; C corolla (calyx partly removed) and corolla lobe apex detail; D opened corolla; E anthers; F gynoecium and stigma detail. All from Gomes et al. 153. DRAWN BY BOBBI ANGELL. 
inflorescence. Leaves elliptic to narrowly elliptic, oblanceolate to obovate or oblong, $34-120 \times 16-$ $33 \mathrm{~mm}$, basal leaves base connate less than $1 / 10$ of length, apical leaves base connate $1 / 5-3 / 5$ of length, margin green and straight, apex acute to acuminate and mucronate to apiculate; $2(-5)$ pairs of secondary veins. Inflorescence 65 - $230 \mathrm{~mm}$ long, 3 - 7-flowered; bracts elliptic to obovate, $34-61 \times 18-32 \mathrm{~mm}$, base connate to $2 / 5-4 / 5$ of length, forming a bilabiate sheath, apex acute, acuminate or obtuse; bracteoles 1 pair per flower, inserted at the base of pedicel, lanceolate or oblanceolate, $9-24 \times 1-5 \mathrm{~mm}$, base connate to c. $1 / 10$ of length, apex acuminate; pedicel $51-150 \mathrm{~mm}$ long, $0.9-2.4 \mathrm{~mm}$ in diam. Calyx reddish, greenish-red, whitish-pink, or purple-red, urceolate, $20-29 \times 15-24 \mathrm{~mm}$ at anthesis, papillate on the inner side, not papillate on the outer side, not dorsally winged; lobes widely depressed ovate, $0.8-$ $1.8 \times 4.8-7.2 \mathrm{~mm}$, apex caudate. Corolla whitish-rose, white, cream or pale yellow tinged red, campanulate, $34-38 \mathrm{~mm}$ long, 1.3 - 1.9 times longer than calyx; tube $24-29 \mathrm{~mm}$ long, $2.8-3 \mathrm{~mm}$ wide at base, $5.8-$ $7.0 \mathrm{~mm}$ wide below filament insertion, $10-12 \mathrm{~mm}$ wide above filament insertion, $10-12 \mathrm{~mm}$ wide at mouth; lobes elliptic, $9-12 \times 5.1-6.9 \mathrm{~mm}$, margin crenulate, apex caudate or mucronate. Filaments unequal in length, twisted when dry, $19-23 \mathrm{~mm}$ long; anthers c. $4.6 \mathrm{~mm}$ long, attached to filament c. $2 \mathrm{~mm}$ from anther base. Ovary $13-16 \mathrm{~mm}$ long; style c. $17 \mathrm{~mm}$ long; stigma lobes obovate, c. $2.6 \mathrm{~mm}$ long. Fruit not seen. Fig. 3.

DISTRIBUTION. Brazil, Rio de Janeiro. Occurring only on Serra dos Órgãos (Parque Nacional da Serra dos Órgãos). Map 1.

SPECIMENS EXAMINED. Rio de Janeiro: Serra dos Órgãos, Frade, 7 Aug. 1869, Glaziou 3813 (BR!, C!, P!, R!); Nova Friburgo, 13 June 1999, Franzen 42 (MBM!) \& 13 May 1888, Glaziou 17238 (C!, IAN!, MO!, NY!) \& 18 May 1891, Glaziou 18372 (BM!, BR!, C!, G!, K!, NY! (2 sheets), P!); Petrópolis, Morro do Cuca, 27 Jan. 1983, Simonis \& Martinelli 20 (RB!) \& Vale das Videiras, 21 April 1974, Martinelli 240 (BR, CEN!, CEPEC!, F, GUA!, K, LIL, MBM!, MO, MG, RB!) \& 1 July 1975, Martinelli 602 (RB!) \& 12 June 1977, Martinelli 2561 (RB!) \& 10 Oct. 1979, Martinelli $\mathcal{E}$ Santos 6125 (RB!) \& 25 Aug. 1983, Martinelli et al. 9335 (RB!) \& 27 May 1995, Ribeiro et al. 2280 (GUA!) \& between Araras and Vale das Videiras, Pico Pindoba, s. d., Martinelli 9889 (RB!) \& 18 June 1985, Martinelli et al. 11148 (RB!); Teresópolis, Parque Nacional da Serra dos Órgãos, Pico da Pedra da Cruz, 6 June 2004, Pederneiras 16 (R!); Without locality, s.d., Gardner s.n. (R!).

HABITAT. Campo de altitude, $1500-1800 \mathrm{~m}$.

CONSERVATION STATUS. CR Blab(i,ii)+2ab(i,ii). This species is only found on the Organ Mountains, so its area of occupancy is very limited, leading to a classification as Critically Endangered.

PHENOLOGY. Flowering specimens have been collected in Jan., April to Aug. and Oct.

ETYMOLOGY. Prepusa connata is named after its connate bracts.

NOTE. Prepusa campanulata is not a validly published name. In 1845, when Grisebach cited this name as a synonym of $P$. connata, he created a nomem nudun.

3. Prepusa hookeriana Gardner (1842: 3909); Grisebach (1845: 81); Progel (1865: 244); Gilg (1895: 96). Type: Brazil, Rio de Janeiro, Summit of Organs Mts. Locis apertis humidis, 2050 m, 18 April 1841, Gardner 5823 (holotype BM!; isotypes CGE!, G! (3 sheets), K!, NY! (2 sheets), P!, RB!).

Herbs, not woody at base, $31-53 \mathrm{~cm}$ tall, unbranched. Stems $1.5-4.9 \mathrm{~mm}$ in diam. below inflorescence, internodes $2-5 \mathrm{~mm}$ long at base of plant, $(55-)$ $105-183 \mathrm{~mm}$ long below inflorescence. Leaves elliptic to narrowly elliptic, oblanceolate or linear, $16-82$ $(-150) \times 4-13 \mathrm{~mm}$, base attenuate, cuneate or connate less than $1 / 10$ of length, margin reddish and straight, apex acute to acuminate, some apiculate; $1-2$ pairs of secondary veins. Inflorescence $65-145 \mathrm{~mm}$ long, 1 - 5-flowered; bracts obovate to oblanceolate, $19-27 \times$ $5-9 \mathrm{~mm}$, base connate $1 / 10-2 / 5$ of length, apex acute to acuminate and mucronate to apiculate; bracteoles 1 pair per flower, inserted at the base or rarely at c. $3 / 10$ of the pedicel length (from base), oblanceolate or rarely lanceolate, $8-24 \times 2.0-7.7 \mathrm{~mm}$, base attenuate, apex acute and apiculate; pedicel $31-110 \mathrm{~mm}$ long, $0.4-$ $2.0 \mathrm{~mm}$ in diam. Calyx reddish, pink or rose, urceolate, $19-33 \times 14-25 \mathrm{~mm}$ at anthesis, papillate on the inner side, minutely papillate on the outer side close to the apex, not dorsally winged; lobes transversely elliptic to narrowly transversely elliptic, $0.7-3.0 \times 3.7-5.8 \mathrm{~mm}$, apex apiculate to mucronate. Corolla whitish-rose, white, cream, or pale yellow tinged red, campanulate, 26 $32 \mathrm{~mm}$ long, c. 1.4 times longer than calyx; tube $18-$ $23 \mathrm{~mm}$ long, $1.4-1.9 \mathrm{~mm}$ wide at base, $5.0-6.2 \mathrm{~mm}$ wide below filament insertion, $8-11 \mathrm{~mm}$ wide above filament insertion, $10-11 \mathrm{~mm}$ wide at mouth; lobes elliptic, obovate, widely obovate or widely ovate, $6-12 \times 3.3-$ $8.1 \mathrm{~mm}$, margin crenulate, apex apiculate. Filaments unequal in length, not twisted when dry, $9-13 \mathrm{~mm}$ long; anthers $3.6-4.3 \mathrm{~mm}$ long, attached to filament c. $2 \mathrm{~mm}$ from anther base. Ovary c. $10 \mathrm{~mm}$ long; style c. $7 \mathrm{~mm}$ long; stigma lobes elliptic, c. $2.4 \mathrm{~mm}$ long. Fruit not seen. Fig. 4.

DISTRIBUTION. Brazil, Rio de Janeiro. Occurring only on Serra dos Órgãos (Parque Nacional da Serra dos Órgãos) and on the Serra da Mantiqueira (Parque Nacional do Itatiaia) Map 1. 


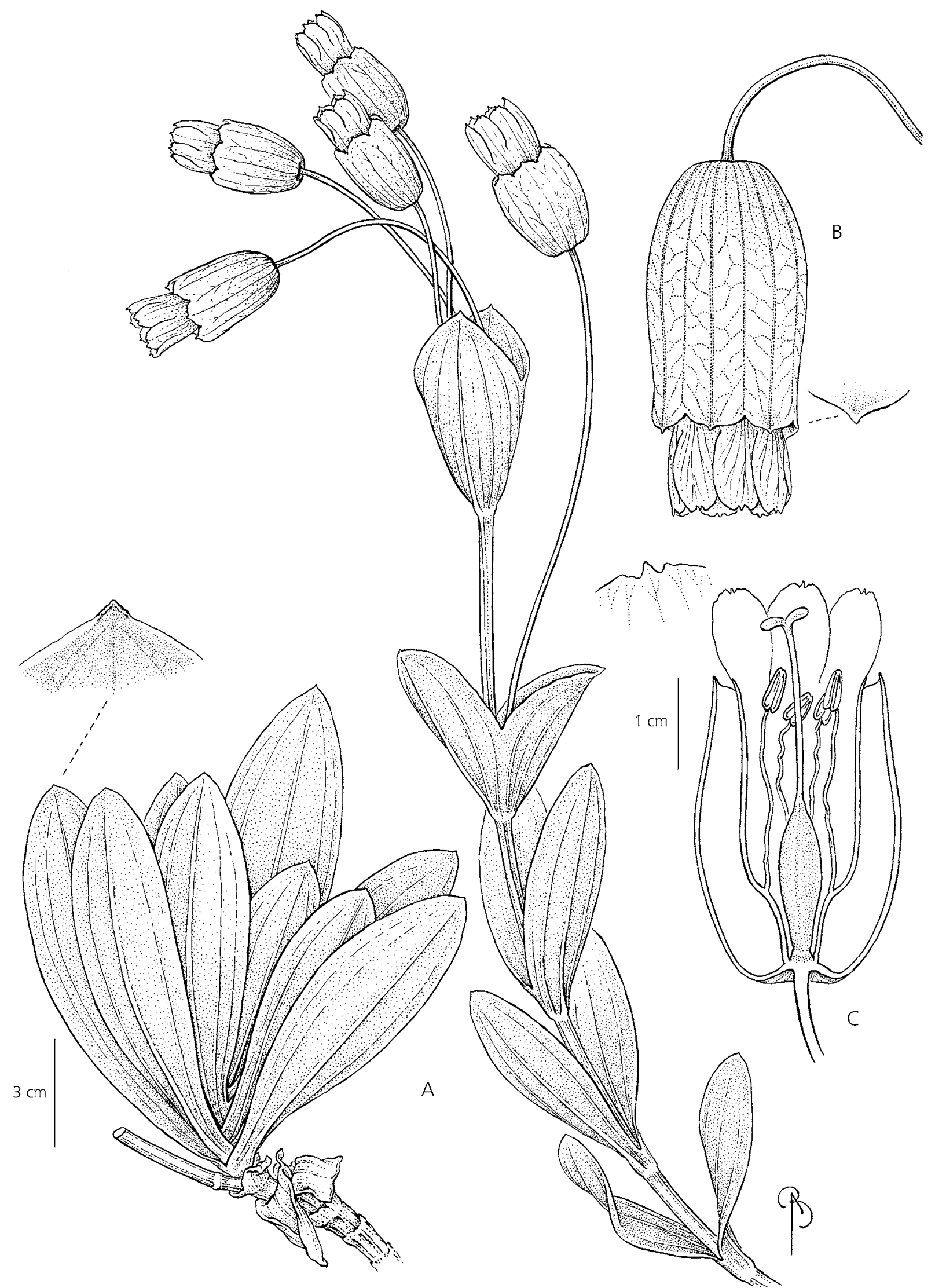

Fig. 3. Prepusa connata. A habit and leaf apex detail; B flower and adaxial surface of calyx lobe apex detail; C longitudinal section of flower and adaxial surface of corolla lobe detail. A from Gardner s.n.; B - C from Glaziou 18372. DRAWN BY BOBBI ANGELL. 
SPECIMENS EXAMINED. Rio de Janeiro: Itatiaia, Parque Nacional do Itatiaia, near Abrigo Rebouças, 13 April 1979, Shepherd E Kirszanzaft 9958 (UEC!); Serra dos Órgãos, 27 Feb. 1933, Brade 12464 (R!) \& July 1975, Camerilo B640 (K!) \& 1964, Duarte s.n. (RB!) \& 18 April 1841, Gardner s.n. (BM!) \& 3 April 1870, Glaziou 4099 (C!) \& 15 March 1888, Glaziou 16236 (R!) \& 1887, Moura s.n. (R!) \& s.d., Saldanha 7357 (RB!); Nova Friburgo, Caledônia, 15 May, Cappeli s.n. (RB!) \& Aug. 1951, Cappeli s.n. (RB!); Petrópolis, Parque Nacional da Serra dos Órgãos, Morro Açu, 4 April 1972, Bacia 534 (R!) \& 30 Sept. 1929, Brade 9502 (R!) \& 29 March 1937, Dionysio s.n. (RB!) \& 6 March 1910, Lützelburg s. n. (M!(2 sheets), NY!) \& 21 Feb. 1944, Vianna 116 (RB!) \& trail to Morro Açu, 31 Aug. 1985, Farney et al. 795 (K, NY!, RB!); Teresópolis, Feb. 1941, Ribeiro s.n. (R!) \& Jan. 1952, Vidal 182 (R!) \& Feb. 1952, Vidal 330 (R!) \& Parque Nacional da Serra dos Órgãos, 29 April 1962, Santos et al. 1221 (HB!, R!) \& Campo das Antas, 2 May 1930, Brade s.n. (RB!) \& 22 May 1948, Carris s.n. (GUA!, RB!) \& 13 July 1956, Castellanos 21660 (LIL!) \& 27 March 1883, Gabinete de Botânica da Escola Politécnica 7351 (R!) \& 16 April 1972, Kirkbride Jr. et al. 1723 (C!, NY!, UB!, US!, R!) \& 2 Feb. 1983, Martinelli E Simonis 9055 (RB!, US!) \& Feb. 1942, Santos E Frota Pessoa s.n. (R!) \& 1 Feb. 1983, Simonis E Martinelli 26 (NY!, RB!) \& Pedra da Baleia, Feb. 1953, Vidal 6431 (R!) \& Feb. 1953, Vidal 6447 (R!) \& 10 May 1981, Vilaça Ẽ Ribeiro 127 (GUA!) \& between Pedra da Baleia e Pedra do Dinossauro, 3 March 1981, Carauta et al. 3670 (GUA!) \& Pedra do Sino, 8 Oct. 1929, Brade 9620 (R!) \& 2 May 1931, Brade 10753 (BHCB!, R!) \& 12 Jan. 1960, Flaster 64 (R!) \& 17 March 2000, Gajardo E Sazima 3 (UEC!) \& 16 June 1946, Silva s.n. (RB!) \& 9 Dec. 1960, Strang 272 (GUA!) \& Feb. 1952, Vidal 597 (R!) \& July 1953, Vidal 6480 (R!) \& trail to Pedra do Sino, 22 27'6"S 430'4"W, 12 March 2001, Costa et al. 508 (SP!, SPF!); Without locality, s.d., Gardner s.n. (K!) \& s.d., Gardner s.n. (S!) \& s.d. Glaziou 3814 (BR!), \& March 1884, Glaziou 15242 (C!, G!, K!, P!, RB!) \& May 1887, Glaziou 16363 (C!, K!, P!, RB!).

HABITAT. Campos de altitude, found only once growing on swampy ground (Shepherd et al. 9958); $850-2700 \mathrm{~m}$. CONSERVATION STATUS. EN Blab(i,iii,iv)+2ab(i,iii,iv). There are only two known localities for this species, each from a different mountain chain. The localities are about $100 \mathrm{~km}$ apart and the species is here classified as Endangered.

PHENOLOGY. Flowering specimens have been found from Jan. to May and July to Oct.

ETYMOLOGY. Prepusa hookeriana was named in honour of W. J. Hooker (1785 - 1865), a famous British botanist. VERNACULAR NAME. Cravina-do-campo (Portuguese).

4. Prepusa montana Mart. (1827: 121); Grisebach (1839: 206); Grisebach (1845: 81); Progel (1865:
243); Gilg (1895: 96). Type: Brazil, Bahia, Serra do Sincorá, 660 m, 1817 - 1820, Martius 2108 (holotype M).

Shrubs to small trees, $1-3 \mathrm{~m}$ tall, branched. Stems $4.5-7.3 \mathrm{~mm}$ in diam. below inflorescence, internodes 32 - $150 \mathrm{~mm}$ long below inflorescence. Leaves elliptic, oblanceolate or obovate, $33-140 \times 13-$ $64 \mathrm{~mm}$, base attenuate, not connate, margin green and revolute, apex obtuse and emarginate; $1-2$ pairs of secondary veins. Inflorescence 102 - $330 \mathrm{~mm}$ long, 2 - 18-flowered; bracts elliptic or obovate, $21-58 \times$ $10-36 \mathrm{~mm}$, base attenuate, apex obtuse; bracteoles 1 pair per flower, inserted at $2 / 5-1 / 2$ of pedicel length (from base), oblanceolate, $8-17 \times 1.7-6.0 \mathrm{~mm}$, base attenuate, apex obtuse; pedicel $22-64 \mathrm{~mm}$ long, $1.3-2.0 \mathrm{~mm}$ in diam. Calyx greenish-yellow, yellowish-green, cream, to light green, campanulate, $22-33 \times 24-33 \mathrm{~mm}$ at anthesis, not papillate, dorsally winged from base to apex, wings 1.5 $4.5 \mathrm{~mm}$ wide; lobes transversely elliptic or depressed ovate, $6-9 \times 8.9-13 \mathrm{~mm}$, apex caudate. Corolla greenish-yellow, pale yellow, or cream, campanulate, $30-43 \mathrm{~mm}$ long, $1.3-1.6$ times longer than calyx; tube $20-31 \mathrm{~mm}$ long, $2-6 \mathrm{~mm}$ wide at base, $6.5-$ $11.0 \mathrm{~mm}$ wide below filament insertion, $13-22 \mathrm{~mm}$ above filament insertion, 13 - $24 \mathrm{~mm}$ wide at mouth; lobes widely elliptic or oblong, $8-19 \times 6.4-$ $11.0 \mathrm{~mm}$, margin entire or very rarely slightly sinuate, apex caudate, mucronate or cuspidate. Filaments slightly unequal or equal in length, not twisted when dry, 13 - $29 \mathrm{~mm}$ long; anthers 5.5 - $7.2 \mathrm{~mm}$ long, attached to filament $1.9-3 \mathrm{~mm}$ from anther base. Ovary 13 - $20 \mathrm{~mm}$ long; style 8 - $20 \mathrm{~mm}$ long; stigma lobes widely elliptic, obovate or depressed ovate, $1.2-3.0 \mathrm{~mm}$ long. Fruit not seen. Fig. 5.

DISTRIBUTION. Brazil, Bahia. Occurring in the Chapada Diamantina in the Parque Nacional da Chapada Diamantina, Parque Estadual do Morro do Chapéu, Parque Municipal de Mucugê, and outside the boundaries of these parks. Map 1.

SPECIMENS EXAMINED. Bahia: Andaraí, Serra AndaraíCapa Bode, road to Mucugê, 30 Oct. 1978, Martinelli et al. 5425 (RB!) \& 27 Oct. 1978, Martinelli et al. 5507 (RB!); Igatu, s.d., Gusmão 305 (ALCB!, HRB!, SP!); Morro do Chapéu, 17 May 1975, Barroso et al. s.n. (SPF!) \& 26 Sept. 1965, Duarte Eீ Pereira 9208 (GUA!, RB!) \& 11 Sept. 1956, Pereira 2020 (GUA!, RB!) \& 26 Sept. 1965, Pereira E Duarte 10118 (HB!, M!) \& 21 Sept. 1985, Pinto 116/85 (HRB!, UB!) \& 27 July 1975, Souza Eं Brito s.n. (ALCB!) \& $11^{\circ} 38^{\prime} 34^{\prime \prime} \mathrm{S} 40^{\circ} 55^{\prime} 45^{\prime \prime} \mathrm{W}, 26$ Aug. 1980, Orlandi 268 (HRB!, HUEFS!) \& $11^{\circ} 6^{\prime} 0^{\prime \prime} S 41^{\circ}$ 2'0"W, 3 Oct. 1991, Freire-Fierro et al. 1749 (SPF!) \& c. 7 km $\mathrm{S}$ of Morro do Chapéu, 16 Feb. 1971, Irwin et al. 32295A (MO!, NY!, US!) \& 16 Feb. 1971, Irwin et al. 32327 (MO!, NY!) \& Ferro Doido river, 14 Oct. 1981, Hatschbach 44263 (C!, MO!) \& 19.5 km SE of Morro do Chapéu 


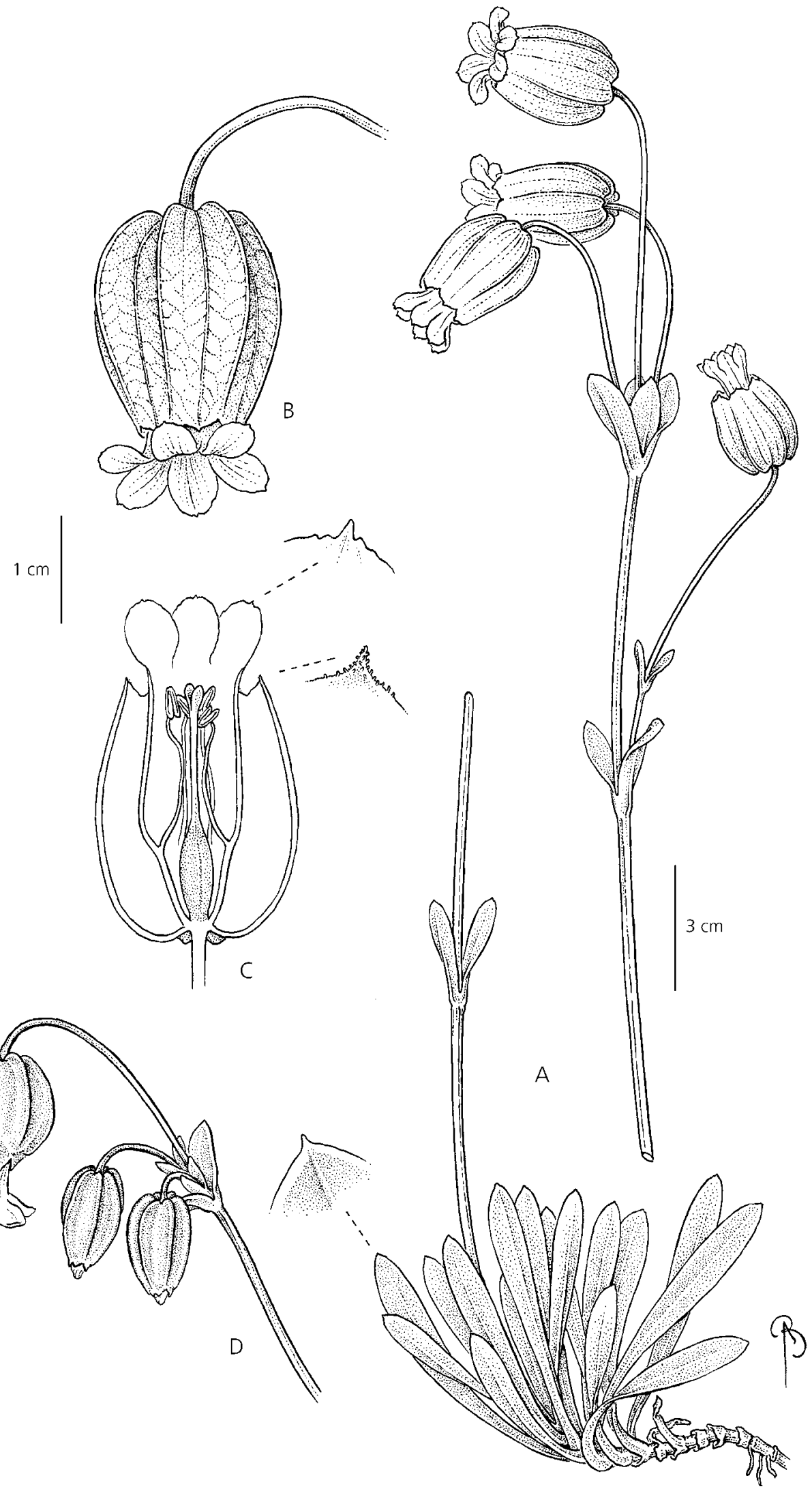

Fig. 4. Prepusa hookeriana. A habit and leaf apex detail; B flower; C longitudinal section of flower, adaxial surface of calyx, and corolla lobe detail; D inflorescence. All from Gardner 5823. DRAWN BY BOBBI ANGELL. 


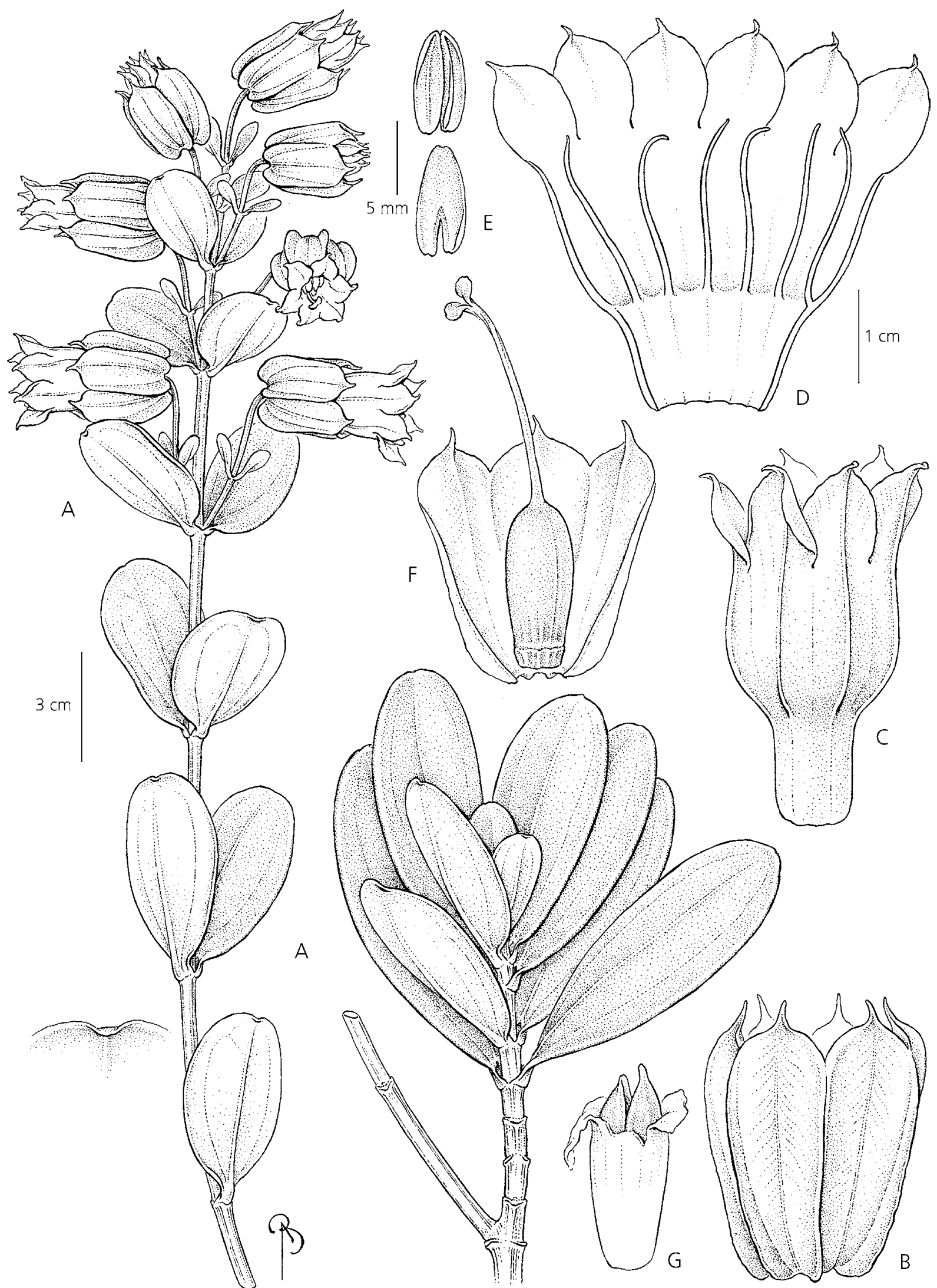

Fig. 5. Prepusa montana. A branch apex with inflorescence and leaf apex detail; B calyx; C corolla; D opened corolla (after anthesis); E abaxial and adaxial surface of anthers; F calyx and gynoecium; G fruit. A from Hatschbach \& Guimarães 42398 ; B - G from Mori \& Boom 14469. DRAWN BY BOBBI ANGELL. 
on the BA 052 highway to Mundo Novo, $11^{\circ} 38^{\prime} 0^{\prime \prime} \mathrm{S} 41^{\circ}$ 2'0"W, 31 May 1980, Harley et al. 22878 (AAU!, CEPEC!, K!, NY!, SPF!, US!) \& Ferro Doido waterfall, s.d., Martinelli et al. 5259 (RB!) \& 27 Oct. 1978, Martinelli et al. 5275 (GUA!, RB!) \& 14 June 1975,

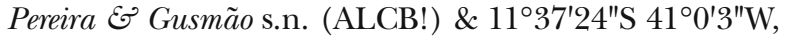
10 July 2000, Oliveira et al. 64 (HUEFS!, SPF!) \& $11^{\circ}$ 37'40"S 41 $0^{\prime} 5^{\prime \prime} \mathrm{W}, 28$ June 1996, Hind et al. 3165 (ALCB!, CEPEC!, HUEFS!, IBGE, SPF!) \& $20 \mathrm{~km}$

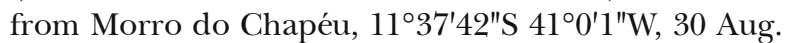
2003, Cavalcanti et al. 3214 (CEN, SPF!) \& 25 Sept. 1985, Wanderley et al. s.n. (SP!) \& road Lage do BatataMorro do Chapéu, km 66, 11 ${ }^{\circ} 27^{\prime} \mathrm{S} 41^{\circ} 7^{\prime} \mathrm{W}, 28$ June 1983, Coradin et al. 6230 (CEN!, RB!) \& road Morro do Chapéu-Jacobina, km 7, $11^{\circ} 6^{\prime} 0^{\prime \prime} \mathrm{S} 41^{\circ} 2^{\prime} 0^{\prime \prime} \mathrm{W}, 3$ Oct. 1990, Freire-Fierro et al. 1767 (CHRB!, SPF!) \& road to Bonito, 3 km SW, 10 July 1999, Peixinho E Vanilda s.n. (HUEFS!, SP!) \& road to Utinga, 8 Sept. 1990, Lima 3900 (CEPEC!, K!, SPF!) \& c. $5 \mathrm{~km}$ from Morro do

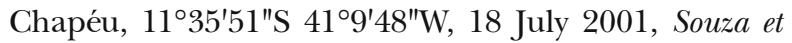
al. 26365 (ESA!, SP!) \& 28 Jan. 2005, Paula-Souza et al. 4866 (ESA!) \& summit of Morro do Chapéu, 16 July 1979, Hatschbach $\mathcal{E}$ Guimarães 42398 (AAU!, C!, CTES!, INPA!, MBM!, MO!, SPF!, UB!, US!) \& c. $8 \mathrm{~km} \mathrm{SW}$ of the town of Morro do Chapéu to W of the road to Utinga, $11^{\circ} 35^{\prime} 0^{\prime \prime} \mathrm{S} 41^{\circ} 12^{\prime} 0^{\prime \prime} \mathrm{W}, 30$ May 1980 , Harley et al. 22755 (CEPEC!, K!(2 sheets), SPF!) \& transmission tower, 26 April 1999, Amorim et al. 3009 (CEPEC!, NY!, SP!) \& 30 Aug. 1990, Hage et al. 2330 (CEPEC, HUEFS!, SP!, SPF!) \& 30 Oct. 1978, Martinelli 5243 (CEPEC, K, MG, RB!) \& c. 6 km S of Morro do Chapéu, 16 June 1981, Mori E⿱ Boom 14469 (NY!); Mucugê, 15 June 1984, Hatschbach Eॄ Kumrow 47930 (BR!, HUEFS!, MBM!, MO!, US!, UPCB!) \& 1 km N of Mucugê, $13^{\circ} 0^{\prime} 0^{\prime \prime} \mathrm{S} 41^{\circ} 23^{\prime \prime} 7^{\prime \prime} \mathrm{W}, 10$ Oct. 1987, Guedes et al. 1543 (ALCB!) \& 10 Oct. 1987, Queiroz et al. 1846 (HUEFS!, MBM!, NY!, UEC!) \& Projeto de SempreViva center, trail to Tiburtino, near Piabinha and Cumbuca rivers, $12^{\circ} 59^{\prime} 36^{\prime \prime} \mathrm{S} 41^{\circ} 20^{\prime} 29^{\prime \prime} \mathrm{W}, 25$ March 2000, Giulietti et al. 1926 (HUEFS!) \& road MucugêAbaíra, c. $3 \mathrm{~km}$ to Mucugê, near the bridge, $13^{\circ} 14^{\prime} 0 " \mathrm{~S}$ 4120'29"W, 11 Aug. 1992, Ganev 816 (HUEFS!, K!, SP!, SPF!, NY!) \& road Mucugê-Cascavel, km 3 - 6, near Paraguaçu river, 20 July 1981, Menezes et al. 1452 (CHRB!, HUEFS!, K!, SPF!) \& 20 July 1981, Menezes et al. 5823 (K!, SPF!) \& $13^{\circ} 00^{\prime} 18.9^{\prime \prime S} 41^{\circ} 23^{\prime \prime 29.9 " W, ~} 21$ July 2006, Calió et al. 116 (SPF!) \& road MucugêGuiné, $5 \mathrm{~km}$ from Mucugê, 7 Sept. 1981, Furlan et al. 1926 (CHRB!, K!, SPF!) \& road to Jussiape, $3 \mathrm{~km} \mathrm{~S}$ of Mucugê, $13^{\circ} 0^{\prime} \mathrm{S} 41^{\circ} 24^{\prime} \mathrm{W}$, s.d., Mori et al. 12552 (CEPEC!, RB!, US!) \& Trilha to Sibéria, 26 June 1993, Ferreira 555 (CTES!, HRB!, MBM!, RB!) \& Unidade de Manejo Sustentável, 1259'59"S 41²0' 46"W, 5 April 1997, Bautista E Silva 259 (HRB!); Without locality, 1914, Lützelburg 532 (M!, NY!).

HABITAT. Campo rupestre and cerrado, sometimes close to river margins and swamps; $700-1400 \mathrm{~m}$.
CONSERVATION STATUS. VU Blab(i,iii,iv)+2ab(i,iii,iv). The range of Prepusa montana is highly fragmented but estimated to be less than $20,000 \mathrm{~km}^{2}$ in total. Populations outside of protected areas are threatened by development and the expansion of settlements and agriculture. This species is classified as Vulnerable.

PHENOLOGY. Flowering specimens have been collected between Feb. and Oct., with a fruiting specimen found in March.

ETYMOLOGY. The epithet montana (mountain) reflects the high altitude areas where this species was first found.

5. Prepusa viridiflora Brade (1949: 18). Type: Brazil, Espírito Santo, Castelo, Forno Grande Pico, 12 Aug. 1948, Brade 19278 (holotype RB!; isotypes: RB! (7 sheets)).

Herbs, woody at base, $30-70 \mathrm{~cm}$ tall, unbranched. Stems $2-5 \mathrm{~mm}$ in diam. below inflorescence, internodes $2-11(-24) \mathrm{mm}$ long at base of plant, $(22-25-) 86-168$ (- 251) mm below inflorescence. Leaves elliptic to narrowly elliptic, oblanceolate, lanceolate, obovate or ovate, $25-106 \times 7-30 \mathrm{~mm}$, base connate less than $1 / 10$ of length, margin green and straight, apex acute or acuminate, some mucronate; $1-4$ pairs of secondary veins. Inflorescence $61-300 \mathrm{~mm}$ long, 2 - 7-flowered; bracts elliptic to narrowly elliptic, obovate, oblanceolate or lanceolate, 15 $23 \times 4-12 \mathrm{~mm}$, base connate less than $1 / 10$ of length, apex acute or acuminate; bracteoles $1-2$ pairs per flower, inserted at $2 / 5-1$ of pedicel length (from base), terminal flower commonly lacks subtending bracteoles, oblanceolate, narrowly elliptic or obovate, $8-16 \times 1.5-8.0 \mathrm{~mm}$, base attenuate to connate less than $1 / 10$ of length, apex acute, some apiculate; pedicel $(16-18-) 37-90(-135) \mathrm{mm}$ long at anthesis, $0.8-2.5 \mathrm{~mm}$ in diam. Calyx light green, brownishgreen, yellowish-green, campanulate, $33-46 \times 25-$ $33 \mathrm{~mm}$ at anthesis, papillate on the inner side, not papillate on the outer side, dorsally winged, wings $2.3-4.1 \mathrm{~mm}$ wide, not reaching the calyx tube apex; lobes triangular, $11-20 \times 7.5-11.2 \mathrm{~mm}$, apex acute or acuminate. Corolla greenish-yellow, yellow, green, funnel-shaped, 36 - 39 (- 45) $\mathrm{mm}$ long, $0.9-1.0$ times longer than calyx; tube $24-25 \mathrm{~mm}$ long, $2.5-$ $4.5 \mathrm{~mm}$ wide at base, $5.7-6.5 \mathrm{~mm}$ wide below filament insertion, $12-23 \mathrm{~mm}$ wide at mouth; lobes widely ovate, $12-15 \times 9.8-11.0 \mathrm{~mm}$, margin crenulate, apex caudate. Filaments slightly unequal or equal in length, not twisted when dry, $22-26 \mathrm{~mm}$ long; anthers 4.9 - $5.0 \mathrm{~mm}$ long, attached to filament $1.7-$ $2.1 \mathrm{~mm}$ from anther base. Ovary 10 - $15 \mathrm{~mm}$ long; style 16 - $20 \mathrm{~mm}$ long; stigma lobes very widely ovate or oblong, $3.0-3.3 \mathrm{~mm}$ long. Fruit ovoid, $16 \mathrm{~mm}$ long. Fig. 6. 
DISTRIBUTION. Brazil, Espírito Santo. Occurring on Atlantic mountains (Parque Estadual da Pedra Azul and Parque Estadual do Forno Grande). Map 1.

SPECIMENS EXAMINED. Espírito Santo: road ManhuaçuVitória, $\mathrm{km} \mathrm{89,} 7$ Sept. 1977, Shepherd et al. 5834 (UEC!); Castelo, Parque Estadual do Forno Grande, 12 May 1949, Brade 19782 (RB!) \& 13 Oct. 2000, Fraga E Kollmann 722 (MBML!, RB!) \& 13 Oct. 2000, Kollmann E Fraga 3188 (MBML!, SPF!); Domingos Martins, Pedra Azul, 15 June 1985, Hatschbach E Silva 49407 (C!, MBM!, MO!, US!) \& 19 Oct. 1994, Vieira $\mathcal{E}^{\circ}$ Gurken 650 (HB!) \& road Vitória-Belo Horizonte, km 89, 16 June 1984, Shepherd E ${ }^{\circ}$ Pereira s.n. (ALCB! UEC!); Without locality, 1969, Marx s.n. (RB!) \& 3 Sept. 1967, Duarte 10469 (HB!, RB!).

HABITAT. Campo de altitude; $1000-1200 \mathrm{~m}$.

CONSERVATION STATUS. EN Blab(i,iii,iv)+2ab(i,iii,iv). Prepusa viridiflora is restricted to two localities, c. $70 \mathrm{~km}$ apart, and classified as Endangered.

PHENOLOGY. Flowering specimens have been found in May, June, and Aug. to Oct.

ETYMOLOGY. Prepusa viridiflora was named for its green calyx and corolla.

Senaea Taub. (1893: 515). Type species: Senaea coerulea Taub.

Shrubs to small trees, glabrous, branched. Stems cylindrical at base, cylindrical to quadrangular below inflorescence, with numerous, discontinuous, thin vertical ridges plus two pairs of prominent, continuous vertical ridges that extend from each interstipular line to node directly below. Leaves not clustered at base or at branch apices, green, sessile, fleshy; margin entire, hyaline, green; venation acrodromous, primary and secondary veins conspicuous, tertiary veins inconspicuous. Inflorescence terminal, thyrsoid; bracts and bracteoles leaflike with entire, hyaline margins. Flowers actinomorphic, perfect, 6-merous, pedicellate. Calyx green to purplish-green, campanulate, inflated, membranaceous or marcescent; lobes equal or with deeper divisions between every second or third lobe; colleters present on inside of calyx. Corolla blue to purple, campanulate, with a constriction at the level of stamen insertion and widening above, membranaceous, papillate on inside and outside; lobes aestivation contort. Stamens 6, equal in length, exserted, inserted in the corolla tube, usually in the lower third; filaments filiform, twisted when dry; anthers yellow, narrowly ovoid, sagittate at base, dorsifixed, with sterile appendix on apex, introrse. Ovary ovoid; style slender, flattened and twisted when dry; stigma bilamellate; placentation parietal; ovules numerous. Fruit a capsule, unilocular, 2-valvate, many-seeded, with persistent calyx, corolla, and style.

Senaea comprises two species, which are reported from high altitude areas of the Brazilian states of Minas Gerais and Rio de Janeiro. Map 2.

\section{Key to the species of Senaea}

1. Leaves oblanceolate, obtuse and mucronate at apex; pedicels papillate; calyx papillate on outside, calyx lobe apices longer than $1.6 \mathrm{~mm}$; corolla 29 - $30 \mathrm{~mm}$ long, corolla lobes lanceolate; filaments 16.6 - $17.1 \mathrm{~mm}$ long; ovary c. 9 - $10 \mathrm{~mm}$ long; style c. $16 \mathrm{~mm}$ long. (Minas Gerais) . . . . . . . . . . . . . . 6. S. coerulea

1. Leaves elliptic, acute at apex; pedicels not papillate; calyx not papillate on outside, calyx lobe apices shorter than $0.8 \mathrm{~mm}$; corolla 20 - $23 \mathrm{~mm}$ long, corolla lobes ovate; filaments $9.2-12.0 \mathrm{~mm}$ long; ovary c. $6 \mathrm{~mm}$ long; style

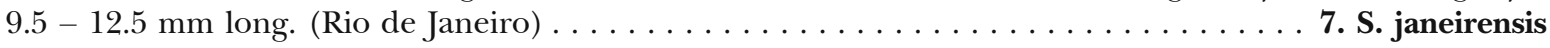

6. Senaea coerulea Taub. (1893: 516); Gilg (1895: 96). Type: Brazil, Minas Gerais, Biribiry (sic), 29 March 1892, Glaziou 19739, (holotype C; isotypes K!, P!).

Shrubs to small trees, up to $2 \mathrm{~m}$ tall, branched. Stems $3.1-$ $3.3 \mathrm{~mm}$ in diam. below inflorescence, internodes $19-$ $60 \mathrm{~mm}$ long below inflorescence. Leaves oblanceolate, $61-105 \times 13-31 \mathrm{~mm}$, base long attenuate, margin revolute, apex obtuse and mucronate or mucronulate; $1-2$ pairs of secondary veins. Inflorescence $90-180 \mathrm{~mm}$ long, 15 - 31-flowered; bracts oblanceolate, linear or rarely narrowly elliptic, $17-77 \times 1.2-20.0 \mathrm{~mm}$, base attenuate, apex obtuse and mucronate, acute or acuminate; bracteoles 1 pair per flower, inserted at $3 / 5-9 / 10$ of pedicel length (from base), terminal flower commonly lacks subtending bracteoles, linear, $7.4-16.0 \times 0.3-1.3 \mathrm{~mm}$, base attenuate to truncate, apex acute to acuminate; pedicel $1.9-12.0 \mathrm{~mm}$ long, $0.7-0.9 \mathrm{~mm}$ in diam., papillate. Calyx not winged, $6.9-$ $12 \times 5.0-5.8 \mathrm{~mm}$ at anthesis, not papillate on the inner side, papillate on the outer side; lobes transversely elliptic or narrowly transversely elliptic, $2.0-2.5 \times$ 1.7 - $4.3 \mathrm{~mm}$. Corolla 29 - $30 \mathrm{~mm}$ long, 2.5 - 3.3 times longer than calyx; tube 13.5 - $16.1 \mathrm{~mm}$ long, $2.0-$ $2.5 \mathrm{~mm}$ wide at base, $5.0-5.2 \mathrm{~mm}$ wide below filament insertion, $5.5-13 \mathrm{~mm}$ wide above filament insertion, 


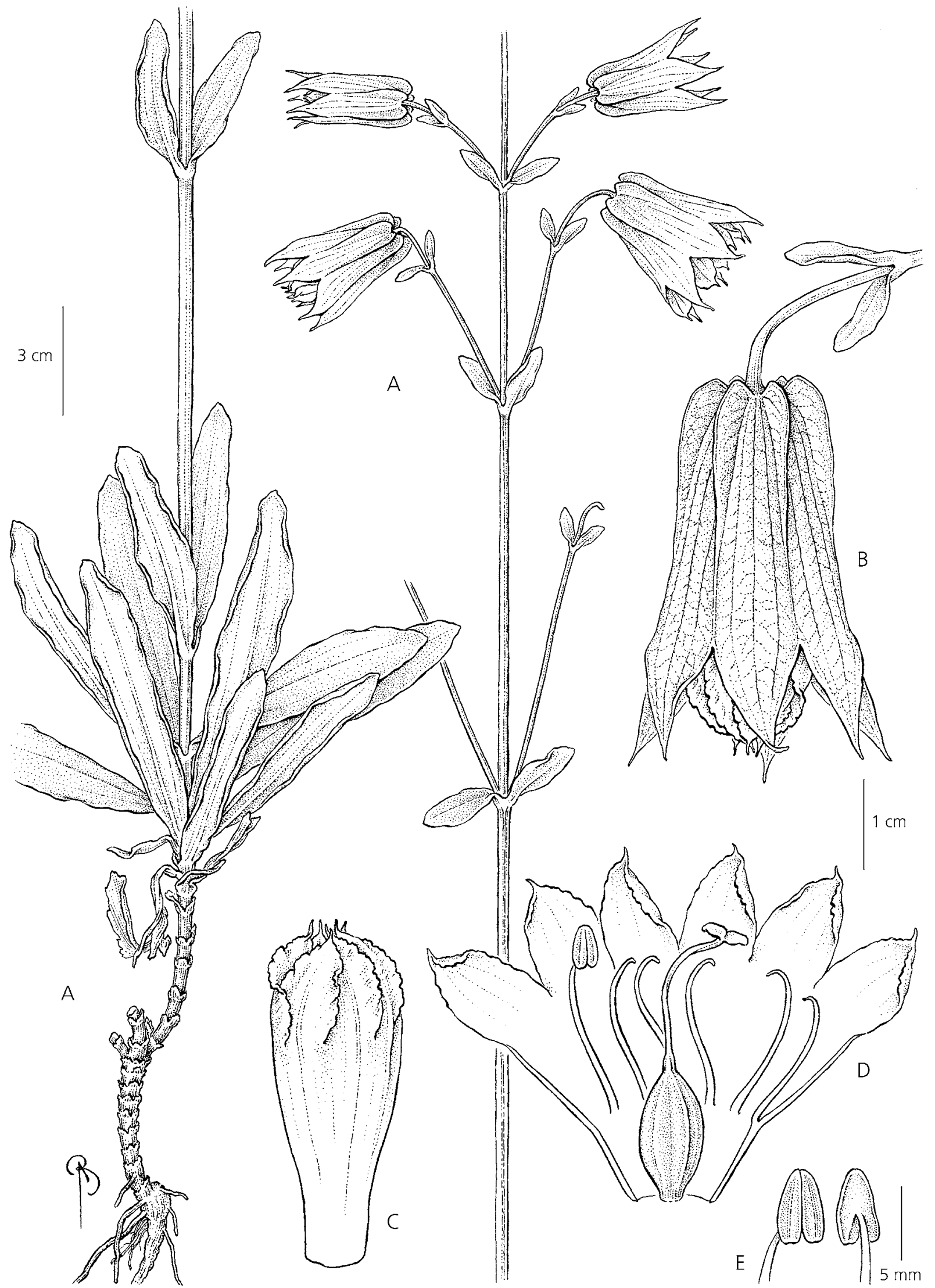

Fig. 6. Prepusa viridiflora. A habit; B flower; C isolated corolla; D opened corolla and gynoecium; E abaxial and adaxial surfaces of anthers. All from Hatschbach \& Silva 49707. DRAWN BY BOBBI ANGELL. 


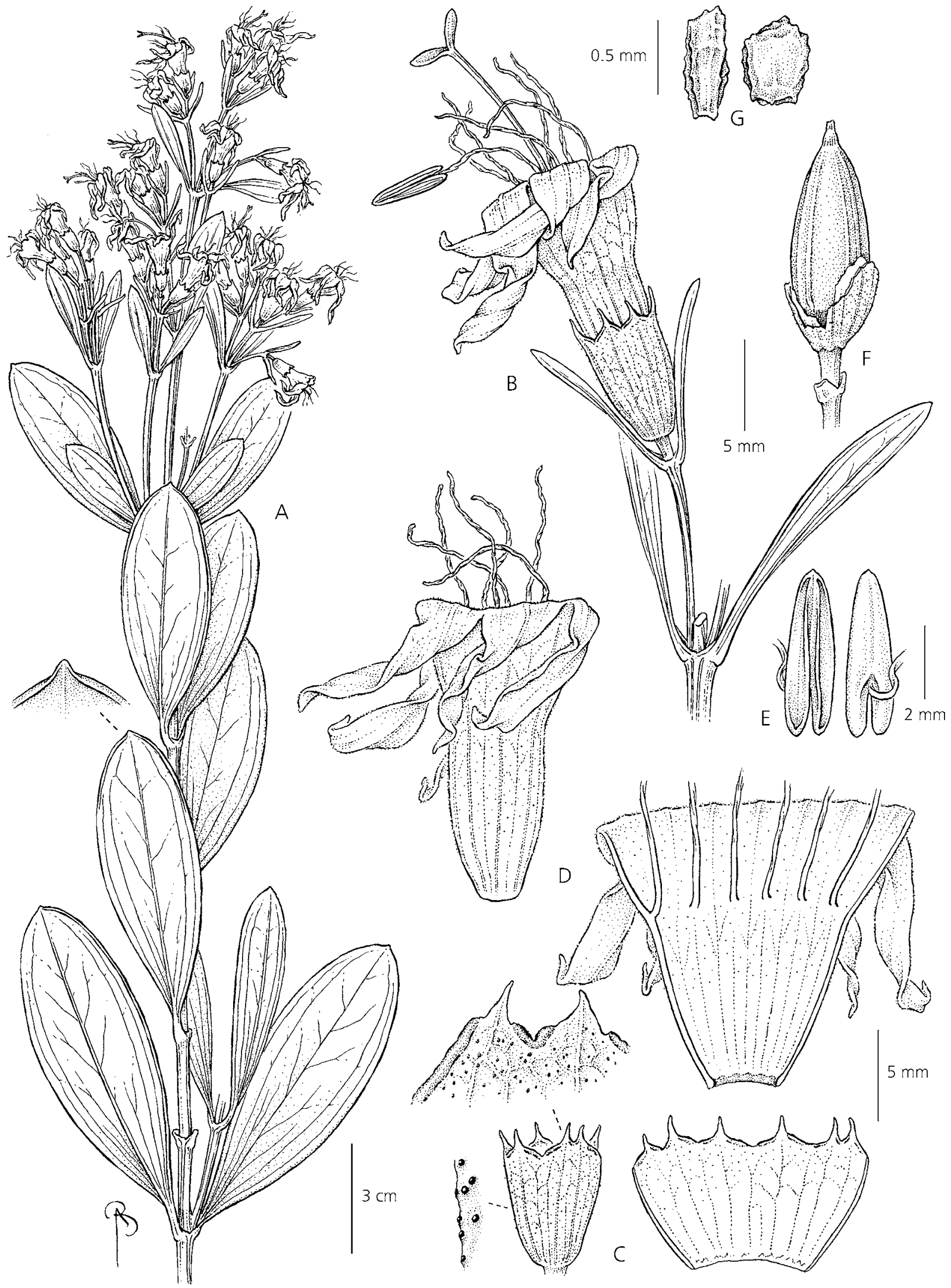

Fig. 7. Senaea coerulea. A branch apex with inflorescence and leaf apex detail; B flower; C calyx (from side and opened); D corolla (side view and opened); $\mathrm{E}$ abaxial and adaxial surfaces of anthers; F fruit; G seeds. All from Glaziou 19739. DRAWN BY BOBBI ANGELL. 
13.0 - $19.3 \mathrm{~mm}$ wide at mouth; lobes lanceolate, 13.8 $16.0 \times 4.1-6.2 \mathrm{~mm}$, margin entire, ondulate or crenulate, apex acute. Filaments 16.6 - $17.1 \mathrm{~mm}$ long; anthers $4.2-4.7 \mathrm{~mm}$ long, attached to filament at $1.4-$ $1.7 \mathrm{~mm}$ from anther base. Ovary $9-10 \mathrm{~mm}$ long; style c. $16 \mathrm{~mm}$ long; stigma lobes oblong, $1.8-2 \mathrm{~mm}$ long. Fruit ovoid, c. 13 mm long. Fig. 7.

DISTRIBUTION. Brazil. Minas Gerais. Occuring in Cadeia do Espinhaço in scattered locations. Map 2.

SPECIMENS EXAMINED. Minas Gerais: Carmo do Rio Claro, Fazenda Córrego Bonito, 7 Sept. 1961, Andrade Ẽ Emmerich 1110 (HB!); Congonhas do Norte, Serra da Mangabeira, close to Rio Preto, $18^{\circ} 5^{\prime} 0^{\prime \prime} \mathrm{S} 43^{\circ} 49^{\prime} 0^{\prime \prime} \mathrm{W}, 23$ April 1982, Amaral et al. CFSC 8476 (SP!, SPF!); Diamantina, 20 Jan. 1947, Romariz 127 (RB!) \& 1904, Schwacke s.n. (BHCB!).

HABITAT. Campo rupestre and cerrado, sometimes, on sandy soils close to river margins.

CONSERVATION STATUS. CR A4abc; B2ab(i,ii,iii,iv). Senaea coerulea is here classified as Critically Endangered, although it is not certain if this species still exists in the wild, since it has not been collected for over 20 years. The places where it was collected are now mainly occupied by towns or pasture areas, and its extent of occurrence must therefore be very fragmented if the species is still extant.

PHENOLOGY. Flowering specimens have been collected in Jan., April (also with fruits), and Sept.
ETYMOLOGY. Senaea coerulea was named for its blue corolla.

7. Senaea janeirensis Brade (1932: 118). Type: Brazil, Rio de Janeiro, Serra do Imbé, Alto da República, 1500 m, April 1932, Brade Ẽ Santos Lima 11784 (holotype R!).

Shrubs to small trees, $40-150 \mathrm{~cm}$ tall, branched. Stems $3.5-6.0 \mathrm{~mm}$ in diam. below inflorescence, internodes 23 - $40 \mathrm{~mm}$ long below inflorescence. Leaves narrowly elliptic, $50-80 \times 15-28 \mathrm{~mm}$, base long attenuate, margin revolute, apex acute; 2 pairs of secondary veins. Inflorescence 40 - $150 \mathrm{~mm}$ long, 11 - 35-flowered; bracts linear, narrowly elliptic or rarely elliptic, $12-53 \times$ 1 - $22 \mathrm{~mm}$, base attenuate, apex acute or acuminate; bracteoles 1 pair per flower, inserted at $3 / 5-9 / 10$ of pedicel length (from base), terminal flower commonly lacks subtending bracteoles, linear or rarely narrowly oblong, $7.2-15.0 \times 0.6-1.6 \mathrm{~mm}$, base attenuate to truncate, apex acuminate; pedicel $6-20 \mathrm{~mm}$ long, $0.8-1.4 \mathrm{~mm}$ in diam., not papillate. Calyx not winged, $6.9-8.0 \times 5.2-8.5 \mathrm{~mm}$ at anthesis, not papillate; lobes transversely elliptic or narrowly transversely elliptic, $0.7-2.8 \times 2.0-4.3 \mathrm{~mm}$, apex caudate to mucronate. Corolla 20 - $23 \mathrm{~mm}$ long, c. 2.9 times longer than calyx; tube $11-12 \mathrm{~mm}$ long, c. $3.5 \mathrm{~mm}$ wide at base, $5.2-6.5 \mathrm{~mm}$ wide below filament insertion, $5.4-10.0 \mathrm{~mm}$ wide above filament inser-

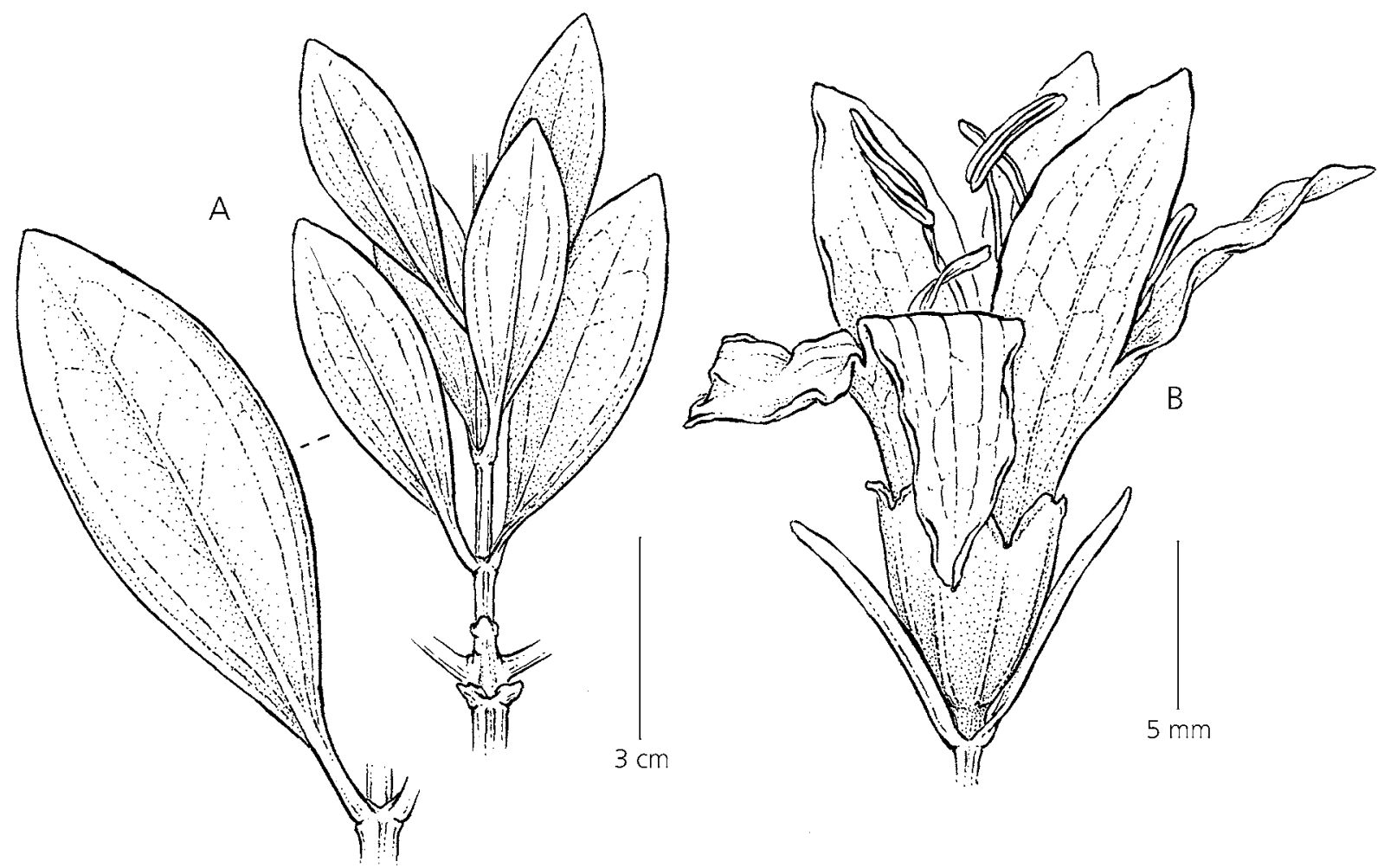

Fig. 8. Senaea janeirensis. A branch apex and leaf detail; B flower. All from Santos Lima \& Brade 14215. DRAWN BY BOBBI ANGELL. 
tion, $8-10 \mathrm{~mm}$ wide at mouth; lobes ovate, $9-11 \times$ $4.1-5.0 \mathrm{~mm}$, margin entire, ondulate or crenulate, apex acute to acuminate. Filaments 9.2 - $12.0 \mathrm{~mm}$ long; anthers $4.8-5.3 \mathrm{~mm}$ long, attached to filament at $2.0-2.5 \mathrm{~mm}$ from anther base. Ovary c. $6 \mathrm{~mm}$ long; style 9.5 - $12.5 \mathrm{~mm}$ long; stigma lobes elliptic, 1.8 $2.3 \mathrm{~mm}$ long. Fruit not seen. Fig. 8 .

DISTRIBUTION. Brazil, Rio de Janeiro. Occurring on Pedra da República and Pedra do Desengano (Parque Estadual do Desengano). Map 2.

SPECIMENS EXAMINED. Rio de Janeiro: Santa Maria Madalena, Nov. 1933, Santos Lima 217 (RB!, U!) \& Parque Estadual do Desengano, Pedra da República, 3 March 1935, Santos Lima \& Brade 14215 (RB!) \& March 1937, Santos Lima 62 (RB!) \& Pedra do Desengano, 17 Dec. 1986, Martinelli et al. 12003 (RB!). HABITAT. Campo de altitude, $1500-1600 \mathrm{~m}$.

CONSERVATION STATUS. CR A4b; B1ab(i,ii)+2ab(i,ii). Senaea janeirensis is classified as Critically Endangered due to its small extent of occurrence, restricted to only one mountain peak. It has not been collected for over 20 years.

PHENOLOGY. Flowering specimens have been found in March, and Nov. to Dec.

ETYMOLOGY. Senaea janeirensis was named after its geographic locality, Rio de Janeiro.

\section{Acknowledgements}

This research was supported by NSF (grant 317612 to LS), New Work Consortium (planning grant to LS and JRP), FAPESP (Ph.D. fellowship 03/10918 - 3 to MFC), and IAPT Research grant (2006, to MFC). We thank Jason R. Grant for help coding morphological features of Macrocarpaea, Daniela Zappi and Inês Cordeiro for suggesting groups of plants with similar patterns of distribution, Richard Winkworth for helping with analyses, Philip Miarmi for providing the maps, Bobbi Angell for specimen illustrations, and all herbaria and their staff mentioned under Material and Methods for loans. We also thank Thomas Waytt and the two anonymous reviewers for comments and suggestions.

\section{Appendix A}

Morphological characters with states coded.

1. Habit: herbaceous, not woody (0)/woody only at base (1)/woody from base to apex (2)

2. Prominent decurrent ridges on stems: absent $(0) /$ present (1)

3. Leaf arrangement at base: not in basal rosette (0)/ basal rosette (1).

Taxa presenting leaves evenly distributed along stem (and not grouped at base) were coded as "not in basal rosette". 4. Leaf general texture: membranaceous $(0) /$ fleshy, choriaceous (1)
5. Leaf margin texture: hyaline, membranaceous $(0) /$ not hyaline, chartaceus or choriaceous (1)

6. Leaf apex and margin color: green $(0) /$ red to magenta (1)

7. Leaf apex shape: acute or acuminate (0)/obtuse (1) 8. Leaf connation at base: not connate $(0)$ /connate (1). Leaf base is attenuate for most species, but some species have leaves connate at base.

9. Leaves venation: acrodromous (0)/brochidrodromous, pinnate (1)

10. Midrib prominence below: absent (0)/present (1)

11. Petiole: absent (0)/present (1)

12. Bracts base: not connate (0)/slightly connate (1)/ strongly connate (2).

Bracts were coded as "not connate" when they were attenuate at base, as "slightly connate" when the bracts were connate only $1 / 10$ of their total length, and as "strongly connate" when the connation was superior than $2 / 5$ of the bract total length.

13. Bracteoles subtending terminal flower: absent (0)/present (1)

14. Calyx merosity: $4(0) / 5(1) / 6$ (2)

15. Calyx main colour: green, yellow, cream $(0) / \mathrm{red}$, purple (1)

16. Calyx overall shape: urceolate (0)/campanulate (1). Calyx was coded as "urceolate" when it was constricted at mouth and as "campanulate" when the mouth was broader or as broad as the calyx tube.

17. Calyx texture: membranaceous (0)/coriaceous (1) Membranaceous calyces are those with thin texture, while coriaceous calyces are leathery and thick.

18. Calyx papillae on the outside: absent $(0) /$ present (1)

19. Calyx papillae on the inside: absent (0)/present (1)

20. Calyx dorsal thickening: absent (0)/present (1)

The calyx dorsal thickening is a glandular area that is more prominent than the rest of the calyx.

21. Calyx wings: absent (0)/present (1)

22. Corolla symmetry: actinomorphic (0)/zygomorphic (1)

23. Corolla merosity: $5(0) / 6$ (1)

24. Corolla basic colour: white, cream, yellow (0)/ blue, rose, purple (1)

25. Corolla tube below stamen insertion: not constrained (0)/constrained (1)

26. Corolla papillae on both sides of corolla: absent (0)/present (1)

27. Corolla fleshiness: not fleshy $(0) /$ fleshy (1)

28. Corolla bud apex: acute $(0) /$ round (1)

29. Stamen length: equal (0)/unequal (1)

30. Position of stamens: included in corolla (0)/ exserted from corolla (1)

31. Filaments in cross-section: filiform (0)/flattened (1)

32. Pollen aggregation: $\operatorname{monads}(0) /$ tetrads $(1) /$ polyads (2)

33. Style cross-section: cylindric (0)/flattened (1) 


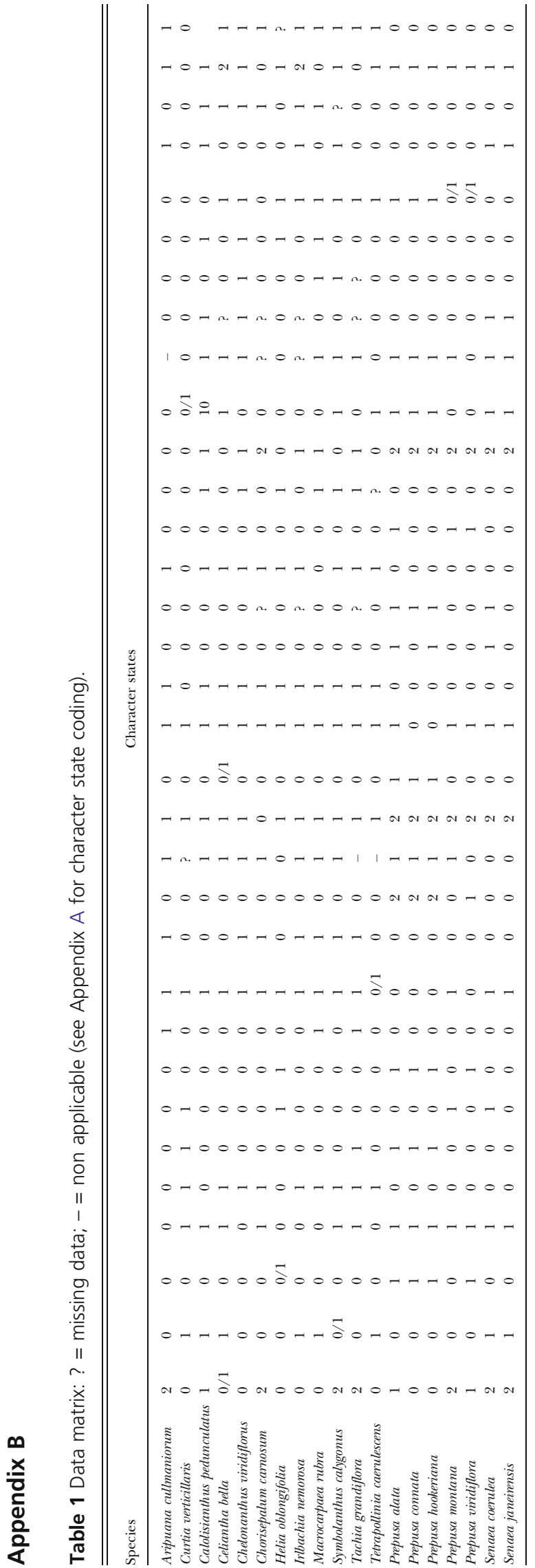

\section{Appendix C}

Index to collectors and material of all analysed specimens. Data are presented in the following sequence: collection, taxon number in the taxonomic treatment, herbarium. Prepusa alata $=1 ; P$. connata $=2 ; P$. hookeriana $=3 ; P$. montana $=4 ; P$. viridiflora $=5 ;$ Senaea coerulea $=6 ;$ S. janeirensis $=7$.

Amaral et al. CFSC 8476 (6) (SP!, SPF!); Amorim et al. 3009 (4) (CEPEC!, NY!, SP!); Andrade E Emmerich 1110 (6) (HB!)

Bacia 534 (3) (R!); Barroso et al. s.n. (4) (SPF!); Bautista E Silva 259 (4) (HRB!); Brade s.n. (3) (RB!), 9502 (3) (R!), 9620 (3) (R!), 10753 (3) (BHCB!, R!), 12464 (3) (R!), 19782 (5) (RB!)

Calió et al. 116 (4) (SPF!); Camerilo B640 (3) (K!); Cappel s.n. (3) (RB!); Cappeli s.n. (3) (RB!); Carauta et al. (3) (GUA!); Carris s.n. (3) (GUA!, RB!); Castellanos 21660 (3) (LIL!); Cavalcanti et al. 3214 (4) (CEN, SPF!); Coradin et al. 6230 (4) (CEN!, RB!); Costa et al. 508 (3) (SP!, SPF!)

Dionysio s.n. (3) (RB!); Duarte s.n. (3) (RB!), 10469 (5) (HB!, RB!); Duarte E Pereira 9208 (4) (GUA!, RB!)

Farney $\mathcal{E}$ Caruso 1195 (1) (CEPEC, MG, RB!); Farney et al. 795 (3) (K!, NY!, RB!); Ferreira 555 (4) (CTES!, HRB!, MBM!, RB!); Flaster 64 (3) (R!); Fraga E Kollmann 722 (5) (MBML!, RB!); Franzen 42 (2) (MBM!); Freire-Fierro et al. 1749 (4) (SPF!), 1767 (4) (CHRB!, SPF!); Furlan et al. 1926 (4) (CHRB!, K!, $\mathrm{SPF} !)$

Gabinete de Botânica da Escola Politécnica 7351 (3) (R!); Gajardo E⿱ Sazima 3 (3) (UEC!); Ganev 816 (4) (HUEFS!, K!, NY!, SP!, SPF!); Gardner s.n. (2) (R!), s.n. (3) (BM!), s.n. (3) (K!), s.n. (3) (S!); Giulietti et al. 1926 (4) (HUEFS!); Glaziou 3813 (2) (BR!, C!, P!, R!), 3814 (3) (BR!), 4099 (3) (C!), 15242 (3) (C!, G!, K!, P!, RB!), 16236 (3) (R!), 16363 (3) (C!, K!, P!, RB!), 17238 (2) (C!, IAN!, MO!, NY!), 18372 (2) (BM!, BR!, G!, C!, K!, NY! (2), P!); Gomes et al. 153 (1) (CHRB!, K, SPF!, SP!); Guedes et al. 1543 (4) (ALCB!); Gusmão 305 (4) (ALCB!, HRB!, SP!)

Hage et al. 2330 (4) (CEPEC, HUEFS!, SP!, SPF!); Harley et al. 22755 (4) (CEPEC!, K!(2), SPF!), 22878 (4) (AAU!, CEPEC!, K!, NY!, SPF!, US!); Hatschbach 44263 (4) (C!, MO!)

Hatschbach $\mathcal{E}$ Guimarães 42398 (4) (AAU!, C!, CTES!, INPA!, MBM!, MO!, SPF!, UB!, US!); Hatschbach $\mathcal{E}$ Kumrow 47930 (4) (BR!, HUEFS!, MBM!, MO!, UPCB!, US!); Hatschbach E Silva 49407 (5) (C!, MBM!, MO!, US!); Hind et al. 3165 (4) (ALCB!, CEPEC!, IBGE, $\mathrm{SPF}$ !)

Irwin et al. 32295A (4) (MO!, NY!, US!), 32327 (4) (MO!, NY!)

Kirkbride Jr. et al. 1723 (3) (C!, NY!, R!, UB!, US!); Kollmann E Fraga 3188 (5) (MBML!, SPF!)

Lima 3900 (4) (CEPEC!, K!, SPF!); Lützelburg s.n. (3) (M!(2), NY!), 532 (4) (M!, NY!) 
Martinelli 240 (2) (BR, CEN!, CEPEC, F, GUA!, K, LIL, MG, MO, MBM!, RB!), 602 (2) (RB!), 2561 (2) (RB!), 5243 (4) (CEPEC, K, MG, RB!), 9889 (2) (RB!); Martinelli $\mathcal{E} \sim$ Santos 6125 (2) (RB!); Martinelli $\mathcal{E} \sim$ Simonis 9055 (3) (RB!, US!); Martinelli et al. 5259 (4) (RB!), 5275

(4) (GUA!, RB!), 5425 (4) (RB!), 5507 (4) (RB!), 9335

(2) (RB!), 11148 (2) (RB!), 12003 (7) (RB!), 13140 (1) (RB!); Marx s.n. (5) (RB!); Menezes et al. 1452 (4) (CHRB!, HUEFS! K!, SPF!), 5823 (4) (K!, SPF!); Mori $\mathcal{E}$ Boom 14469 (4) (NY!); Mori et al. 12552 (4) (CEPEC!, RB! US!); Moura s.n. (3) (R!)

Newton Santos E Frota Pessoa s.n. (3) (R!)

Oliveira et al. 64 (4) (HUEFS!, SPF!); Orlandi 268 (4) (HRB!, HUEFS!)

Paula-Souza et al. 4866 (4) (ESA!); Peixinho Ẽ Vanilda s.n. (4) (HUEFS!, SP!); Pederneiras 16 (2) (R!); Pereira 2020 (4) (GUA!, RB!); Pereira E Duarte 10118 (4) (F, HB!, K, M!); Pereira Ẽ Gusmão s.n. (4) (ALCB!); Pinto 116/85 (4) (HRB!, UB!)

Queiroz et al. 1846 (4) (HUEFS!, MBM!, NY!, UEC!)

Ribeiro s.n. (3) (R!); Ribeiro et al. 2280 (2) (GUA!); Romariz 127 (6) (RB!)

Saldanha 7357 (3) (RB!); Santos et al. 1221 (3) (HB!, R!); Santos Lima 62 (7) (RB!), 217 (7) (RB!, U!); Santos Lima EF Brade 14101 (1) (RB!), 14215 (7) (RB!); Schwacke s.n. (6) (BHCB!); Shepherd Eं Kirszanzaft 9958 (3) (UEC!); Shepherd Eै Pereira s.n. (5) (ALCB!, UEC!); Shepherd et al. 5834 (5) (UEC!); Silva s.n. (3) (RB!); Simonis E Martinelli 20 (2) (RB!), 26 (3) (NY!, RB!); Souza E Brito s.n. (4) (ALCB!); Souza et al. 26365 (4) (ESA!, SP!); Strang 272 (3) (GUA!)

Vianna 116 (3) (RB!); Vidal 182 (3) (R!), 330 (3) (R!), 597 (3) (R!), 6431 (3) (R!), 6447 (3) (R!), 6480 (3) (R!); Vieira Ẽ Gurken 650 (5) (HB!); Vilaça Ẽ Ribeiro 127 (3) (GUA!)

Wanderley et al. s.n. (4) (SP!)

\section{References}

Barroso, G. M. (1986). Sistemática de angiospermas do Brasil, V. 3, p. 57. Imprensa Universitária, Universidade Federal de Viçosa, Viçosa, Brasil.

Brade, A. C. (1932). Espécies novas de plantas do estado do Rio de Janeiro. Arq. Mus. Nac. Rio de Janeiro 34: 118.

- (1949). Contribuição para o conhecimento da flora do estado do Espírito Santo - II. espécies novas das famílias Orchidaceae, Rubiaceae e Gentianaceae. Arch. Jard. Bot. Rio de Janeiro 9: 18.

Cordeiro, I. (1987). Flora da Serra do Cipó: Gentianaceae. Bol. Bot. Univ. São Paulo 9: 227 - 242.

Gardner, G. (1839). Icon. Pl. 31: 225. Longman, Rees, Orme, Brown, Green \& Longman, London. (1842). Bot. Mag. 15: 3909. Stephen Couchman, London.
Gilg, E. F. (1895). Gentianaceae. In: H. G. A. Engler \& K. A. E. Prantl (eds.), Nat. Pflanzenfam. 4 (2): 50 108. Verlag von Wilhelm Engelmann, Leipzig.

Giulietti, A. M. \& Pirani, J. R. (1988). Patterns of geographic distribution of some plant species from the Espinhaço range, Minas Gerais and Bahia, Brazil. In: P. E. Vanzolini \& H. R. Heyer (eds.), Proceedings of a workshop on neotropical distribution patterns: $39-$ 69. Academia Brasileira de Ciências, Rio de Janeiro.

Grisebach, A. H. R. (1839). Gen. sp. Gent. J. G. Cotta, Stuttgart, Tübingen.

. (1845). Gentianaceae. In A. L. P. P. de Candolle (ed.) Prodr.: Gentianaceae. 9. Fortin, Masson et Sociorum, Paris.

Harley, R. M. \& Simmons, N. A. (1986). Florula of Mucugê, Chapada Diamantina, Bahia, Brazil. A descriptive check-list of the campo rupestre area. Royal Botanic Gardens, Kew.

Huelsenbeck, J. P. \& Ronquist, F. (2001). MRBAYES: Bayesian inference of phylogenetic trees. Bioinformatics 17: $754-755$.

IUCN (2001). IUCN Red List categories and criteria. Version 3.1. IUCN, Gland, Switzerland \& Cambridge, U.K.

Maddison, D. R. \& Maddison, W. P. (2005). MacClade 4: Analysis of phylogeny and character evolution, vers. 4.08. Sinauer Associates, Sunderland, Massachusetts, U.S.A.

Martius, G. F. P. Von. (1827). Nov. Gen. sp. pl. 2 (2): 121. Wolf, München.

Mészáros, S., De Laet, J., Goethals, V., Smets, E. \& Nilsson, S. (2002). Cladistics of Gentianaceae. a morphological approach. In: L. Struwe \& V. A. Albert (eds.), Gentianaceae. systematics and natural history, pp. $310-$ 376. Cambridge University Press, Cambridge, U.K.

Nilsson, S. (2002). A review of palynology. In: L. Struwe \& V. A. Albert (eds.), Gentianaceae. systematics and natural history, pp. 377 - 497. Cambridge University Press, Cambridge, U.K.

Porto, P. C. \& Brade, A. C. (1935). Contribuição para a Flora Fluminense. Arq. Inst. Biol. Veg. 13: 222.

Progel, A. (1865). Gentianaceae. In: C. F. P. Von Martius, Fl. Bras. 6 (1): 198 - 247. München.

Radford, A. E., Dickison, W. C., Massey, J. R., \& Bell, C. R. (1974). Vascular Plant Systematics. Harper \& Row Publishers Inc., New York.

Ronquist, F. \& Huelsenbeck, J. P. (2003). MrBayes 3: Bayesian phylogenetic inference under mixed model. Bioinformatics 19: 1572 - 1574.

Safford, H. D. (1999). Brazilian Páramos I: an introduction to the physical environment and vegetation of campos de altitude. J. Biogeogr. 26: 693 - 712.

- \& Martinelli, G. (2000). Southeast Brazil. In: S. Porembski, \& W. Barthlott (eds.), InselbergsBiotic diversity of isolated rock outcrops in tropical 
and temperate regions, pp. 339 - 389. SpringerVerlag, Berlin, Heidelberg.

Stearn, W. T. (1992). Botanical Latin - History, Grammar, Syntax, Terminology and Vocabulary. 4th edition. Timber Press, Portland, Oregon.

Struwe, L., Albert, V. A., Calió, M. F., Frasier, C., Lepis, K. B., Mathews, K. G. \& Grant, J. R. (submitted). Evolutionary patterns in neotropical Helieae (Gentianaceae): evidence from morphology, chloroplast and nuclear DNA sequences. Taxon.

, Kadereit, J. W., Klackenberg, J., Nilsson, S., Thiv, M., von Hagen, K. B. \& Albert, V. A. (2002). Systematics, character evolution, and biogeography of Gentianaceae, including a new tribal and subtribal classification. In: L. Struwe, \& V. A. Albert (eds.), Gentianaceae: systematics and natural history, pp. 21309. Cambridge University Press, Cambridge, U.K.

Swofford, D. L. (2003). PAUP*: phylogenetic analysis using parsimony (*and other methods), vers. 4.0. Sinauer Associates Inc., Sunderland, Massachusetts, U.S.A.

Taubert, P. (1893). Plantae glaziovianae novae vel minus cognitae IV. Bot. Jahrb. Syst. 17: 516.

Veloso, H. P., Rangel Filho, A. L. R. \& Lima, J. C. A. (1991). Classificação da vegetação brasileira, adaptada a um sistema universal. IBGE, Departamento de Recursos Naturais e Estudos Ambientais, Rio de Janeiro.

Weberling, F. (1989). Morphology of flowers and inflorescences. Cambridge University Press, New York. 
- Anexo 2

Evolutionary patterns in neotropical Helieae (Gentianaceae): EVIDENCE FROM MORPHOLOGY, CHLOROPLAST AND NUCLEAR DNA SEQUENCES Struwe L, Albert VA, Calió MF, Frasier C, Lepis KB, Mathews KG \& Grant JR 


\title{
Evolutionary patterns in neotropical Helieae (Gentianaceae): evidence from morphology, chloroplast and nuclear DNA sequences
}

\author{
Lena Struwe, ${ }^{1,2}$, Victor A. Albert ${ }^{3}$, M. Fernanda Calió ${ }^{4}$, Cynthia Frasier ${ }^{2}$, Katherine B. Lepis ${ }^{2}$, \\ Katherine G. Mathews ${ }^{5}$ \& Jason R. Grant ${ }^{6}$
}

${ }^{1}$ Department of Ecology, Evolution, and Natural Resources, Rutgers University, 237 Foran Hall, 59 Dudley Road, New Brunswick, New Jersey 08901, U.S.A. struwe@aesop.rutgers.edu (author for correspondence)

2 Department of Plant Biology and Pathology, Rutgers University, 59 Dudley Road, New Brunswick, New Jersey 08901, U.S.A.

${ }^{3}$ Department of Biological Sciences, 109 Cooke Hall, University at Buffalo (SUNY), Buffalo, New York 14260, U.S.A.

${ }^{4}$ Departamento de Botânica, Instituto de Biociências, Universidade de São Paulo, Rua do Matão, travessa 14, $n^{\circ}$ 321, CEP: 05508-090, São Paulo, SP, Brazil

${ }^{5}$ Department of Biology, Western Carolina University, 132 Natural Science Building, Cullowhee, North Carolina 28723, U.S.A.

${ }^{6}$ Laboratoire de botanique évolutive, Institut de botanique, Faculté des Sciences, Université de Neuchâtel, rue Émile-Argand 11, Case Postale 158, 2009 Neuchâtel, Switzerland

\begin{abstract}
Parsimony-based phylogenetic analyses of the neotropical tribe Helieae (Gentianaceae) are presented, including 22 of the 23 genera and 60 species. This study is based on data from morphology, palynology, and seed micromorphology (127 structural characters), and DNA sequences (matK, trnL intron, ITS). Phylogenetic reconstructions based on ITS and morphology provided the greatest resolution, morphological data further helping to tentatively place several taxa for which DNA was not available (Celiantha, Lagenanthus, Rogersonanthus, Roraimaea, Senaea, Sipapoantha, Zonanthus). Celiantha, Prepusa and Senaea together appear as the sister clade to the rest of Helieae. The remainder of Helieae is largely divided into two large subclades, the Macrocarpaea subclade and the Symbolanthus subclade. The first subclade includes Macrocarpaea, sister to Chorisepalum, Tachia, and Zonanthus. Irlbachia and Neblinantha are placed as sisters to the Symbolanthus subclade, which includes Aripuana, Calolisianthus, Chelonanthus, Helia, Lagenanthus, Lehmanniella, Purdieanthus, Rogersonanthus, Roraimaea, Sipapoantha, and Symbolanthus. Generic-level polyphyly is detected in Chelonanthus and Irlbachia. Evolution of morphological characters is discussed, and new pollen and seed characters are evaluated for the first time in a combined morphological-molecular phylogenetic analysis.
\end{abstract}

KEYWORDS: evolution, Gentianaceae, Gentianales, Helieae, molecular systematics, morphology

\section{INTRODUCTION}

The gentian tribe Helieae is a highly diverse assemblage of neotropical plants. This group of 23 genera and over 200 species includes species ranging from Andean cloud forest trees to diminutive annual herbs from seasonally flooded lowland savannas (Table 1). The Helieae have received attention for showing high generic diversity on the tepuis of the Guayana Highlands, as well as high species diversity in the Andes (Struwe \& al., 1999, 2002). On the Guayana Shield, several endemic genera were described by the tepui explorers of the 20th Century, with many species found on only one or a few of these isolated mountain tops (Maguire, 1981; Maguire \& Boom, 1989). Similarly, the largest genus, Macrocarpaea, has around 105 primarily Andean species distributed from Costa Rica to Bolivia, but often with narrowly restricted distributions (Grant, 2004, 2005, 2007). Helieae taxa are also found in all tropical areas of Brazil, the Guianas, and on a few islands in the Caribbean. One genus, Chelonanthus, reaches southern Mexico. Some of the better known genera of Helieae are Chelonanthus, Irlbachia, Macrocarpaea, Symbolanthus, and Tachia. From a pharmacological point of view, Chelonanthus alatus and Tachia grandiflora are used in traditional medicine to treat malaria, fungal diseases, and other ailments (Jensen \& Schripsema, 2002).

In addition to distributional diversity, this group contains a diverse array of variations on the gentian floral bauplan, from hanging red and tubular hummingbird-flowers, funnel-shaped flowers visited by bats, moths, and hummingbirds, as well as smaller presumably bee-pollinated flowers. Habit ranges from small annuals to large trees, but flower morphology shows larger variation than vegetative morphology within the tribe. A suite of morphological characteristics distinguishes Helieae from other tribes, such as broadly bilamellate stigmas, long styles that become 


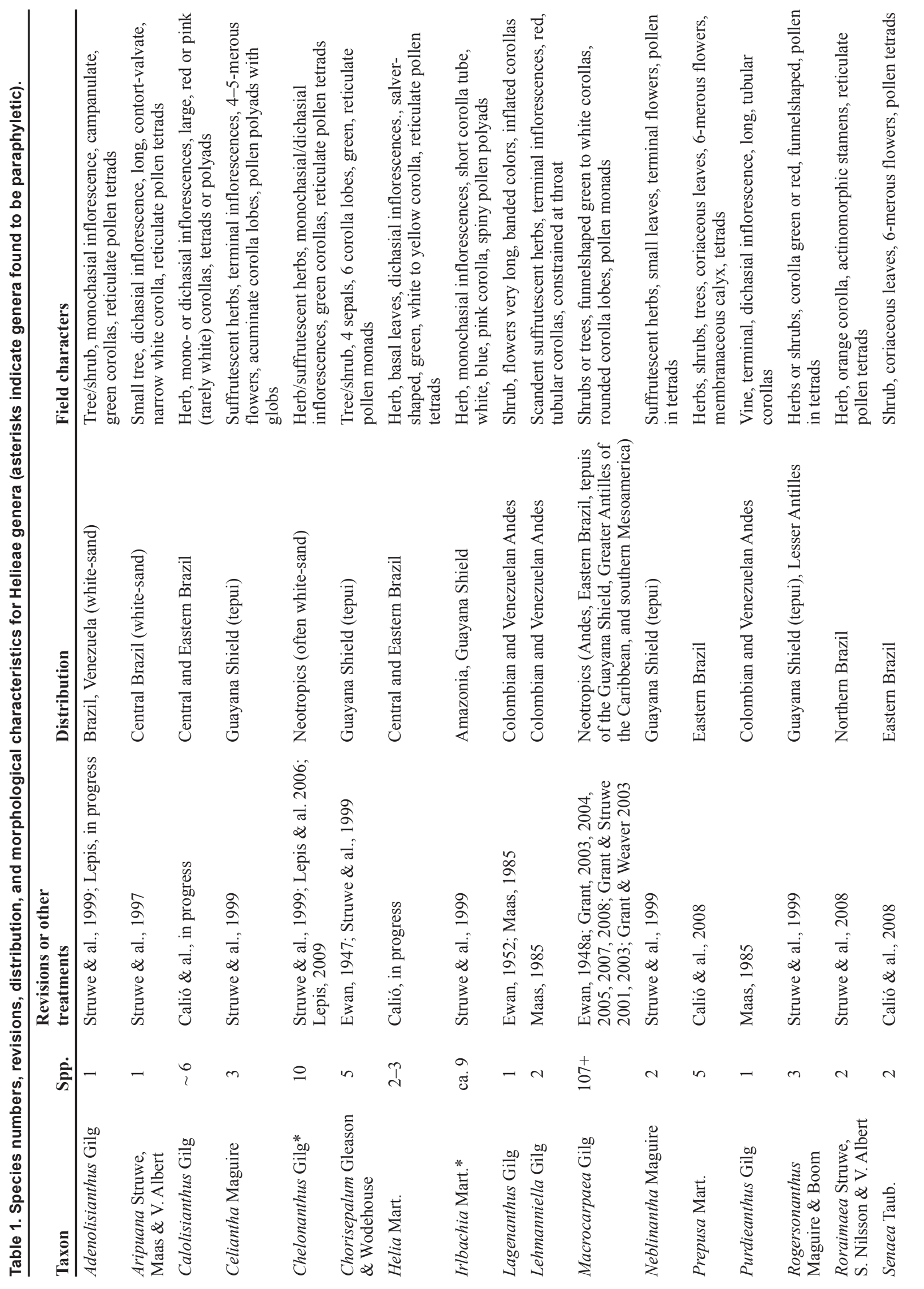


flattened and twisted when drying and aging, a glandular disk or glandular area at the base of a sessile ovary, and pollen often released as tetrads or polyads and with elaborate exine sculpturing (Struwe \& al., 2002; see also Gentian Research Network's website for illustrations and information on Helieae taxonomy and morphology, http:/gentian.rutgers.edu/).

Generic circumscriptions and relationships within Helieae are poorly known in comparison to Gentianaceae tribes Gentianeae, Potalieae, and Chironieae. The Helieae has existed in something of a taxonomic "chaos" since its description two centuries ago. Species from the Helieae described as "Lisyanthus"/“Lisianthus" by Grisebach $(1839,1845)$, have been confused with the Caribbean genus Lisianthius in tribe Potalieae (Struwe \& Albert, 1998a). To deal with this potential problem of homonymous generic names, botanists in the late 1800 s and 1900 s either transferred these species to other genera or segregated them as new genera (Kuntze, 1891; Gilg, 1895; Maas, 1985). These conflicting views led to unstable generic circumscriptions that are still present today. Some authors favored broadly circumscribed genera such as Helia (Kuntze, 1891) or Irlbachia (Maas, 1985). Narrow circumscriptions were proposed by Gilg (1895), who segregated many of the species into palynologically distinct genera, a view that was followed by Maguire (1981, 1985), Maguire \& Boom (1989), and from a phylogenetic standpoint, by Struwe and collaborators (Struwe \& al. 1997, 1999, 2002; Struwe \& Gould, 2004).

Phylogenetic studies of plastid trnL intron and matK DNA sequences have provided a good understanding of the phylogenetic relationships within the Gentianaceae and have formed the basis for a new tribal classification (Struwe \& al., 2002). In total, there are six major clades (now recognized as tribes) in the family, including the formerly monotypic family Saccifoliaceae (Thiv \& al., 1999a) and the former tribe Potalieae of the Loganiaceae. The Helieae is deeply nested inside Gentianaceae and forms a polytomy with tribes Gentianeae and Potalieae. In the current tribal classification Helieae is monophyletic; however, this has not always been the case. Genera that are now in Helieae were previously placed in tribes Helieae, Rusbyantheae, and Gentianeae-Tachiinae in Gilg's (1895) classification, and Helieae sensu Gilg included parts of current Chironieae.

Global studies of Gentianaceae using the plastid trnL intron and mat $K$ have shown that more rapidly changing sequences will be necessary for understanding infra-group relationships in Helieae, which show very little resolution in trees derived from these data (Struwe \& al., 2002). The utility of the internal transcribed spacer regions (ITS1, ITS2) of nuclear ribosomal DNA (rDNA) at relatively low levels in taxonomic hierarchies has been demonstrated for a number of plant groups, including Gentianaceae (e.g., Chassot \& al., 2001; Mansion \& Struwe, 2004; Thiv \& al., 1999b; Yuan \& al., 2003).

Here, we present a larger analysis including all genera of Helieae (except Yanomamua J.R. Grant, Maas \& Struwe; Grant \& al., 2006) based on additional sequencing of the nuclear ITS region, as well as a comprehensive morphological dataset. The goals of this study were: (1) to evaluate phylogenetic hypotheses and generic circumscriptions within Helieae using several types of genetic and phenotypic data; and (2) to evaluate the utility and agreement of morphological data as compared to molecular data; (3) to evaluate support for current generic circumscriptions; and (4) to identify valuable field characters for monophyletic genera and clades. 


\section{MATERIALS AND METHODS}

Sampling. - All genera in Helieae were included in this study, except for Yanomamua (Table 1; Appendix 1). For each genus, generally all species were included if the number of species in the genus were fewer than five, and if more, a selection of species was included. Exceptions from this were Lehmanniella, Prepusa, and Senaea, where fewer species were included. For morphologically heterogeneous genera, a range of species was sampled to cover a variety of phenotypes. Care was taken to include species that in previous studies have been placed on basally positioned branches in smaller studies. For example, 6 of Tachia's 13 species, 6 of Macrocarpaea's 105+ species, and 4 of Symbolanthus's ca. 30 species were included. The phylogenies of these genera have been analyzed in more restricted studies and the monophyly of each has been supported based on morphological synapomorphies as well as molecular studies (Gould \& Struwe, 2004; Struwe \& Gould, 2004; Grant, 2004; Struwe \& Kinkade, in prep.). The recently described Brazilian genus Yanomamua was not included in this analysis due to lack of material (no flowers are known), but recent phylogenetic analyses suggested a position of Yanomamua in the Symbolanthus subclade (Grant \& al., 2006).

A large selection of outgroup taxa was included since the sister group to Helieae is not known with certainty. Tribes Gentianeae and Potalieae form a trichotomy with Helieae in recent analyses (Struwe \& al., 2002), so taxa selected from both of these tribes were sampled, as well as from the more remotely placed tribe Chironieae. Nine taxa from Gentianeae (both subtribes represented; Gentianinae, Swertiinae) and seven taxa from Potalieae (all three subtribes represented; Faroinae, Lisianthiinae, Potaliinae) were included, as well as seven taxa from Chironieae (two subtribes out of three included; Coutoubeinae, Chironiinae). It was hoped that such a wide selection of outgroup taxa should ensure an accurate estimate of the internal rooting of Helieae.

Morphological data. - Morphological characters and character states were obtained through observations of pressed and liquid-preserved plant materials during comprehensive revisions and floristic treatments over the last fifteen years, including approximately 4,000 herbarium collections from the following herbaria: AAU, AFP, ALA, ALCB, B, BHCB, BM, BP, BR, BRIT, BSB, C, CAS, CAUP, CEN, CESJ, CGMS, CHOCO, CHRB, CM, COAH, COL, CONN, COR, CR, CTES, CUVC, CUZ, CVRD, DAV, DUKE, E, EHH, ESAL, F, FAUC, FI, FLAS, FMB, FR, G, GB, GH, GOET, HAC, HAL, HAM, HAO, HB, HRB, HUA, HUCP, HUCS, HUEFS, HUFU, HUQ, HUT, HXBH, IAN, IBGE, ICN, INB, INPA, JAUM, JBSD, JE, K, L, LD, LIL, LINN, LOJA, LP, LPB, LS, M, MA, MANCH, MARY, MBM, MBML,
MEDEL, MER, MG, MICH, MIN, MO, MOL, MSB, MU, MY, NA, NEU, NO, NSW, NY, OXF, P, PH, PORT, PR, PRC, Q, QAP, QCA, QCNE, QPLS, QUSF, R, RB, RNG, S, SBBG, SEL, SJRP, SP, SPF, TEX, U, UB, UC, UCWI, UDBC, UEC, UPCB, UPS, UPTC, US, USM, VALLE, VEN, VIC, W, WAG, WIS, WU, YU, and Z. Morphological data obtained from literature were confirmed with new observations as far as possible. The following works were consulted with regard to morphological characters for Helieae (see also Table 1): Lindley, 1849; Ewan, 1947, 1948a, b, 1952; Leon \& Alain, 1957; Maguire \& Weaver, 1975; Maas, 1981, 1985; Maguire, 1981, 1985; Maguire \& Boom, 1989; Struwe \& al., 1997, 1999, 2002, 2008; Cobb \& Maas, 1998; Struwe \& Albert, 1998b, 2004; Grant \& Struwe, 2001, 2003; Thiv, 2002; Grant, 2003, 2004, 2005, 2007; Grant \& Weaver, 2003; Struwe, 2003; Gould \& Struwe, 2004; Struwe \& Gould, 2004; and Molina \& Struwe, 2008. Unpublished theses and documents written by P.J.M. Maas, E. Groen, E.C.H. van Heusden, and J.E. Simonis were also consulted. Outgroup data were based on our own observations from the field and herbarium material as well as species descriptions from a variety of floristic works and revisions. The majority of seed and pollen data was derived from investigations presented in Bouman \& al. (2002), Struwe \& al. (2002), and Nilsson (1968, 1970, 2002). Seed data for Macrocarpaea were from Grant (2005) or unpublished by J.R. Grant, and unpublished pollen photographs from B. Maguire's investigations at The New York Botanical Garden's SEM photo collection were also consulted.

Characters (Appendix 2) were selected and states delineated based on their low polymorphism rate within taxa, apparent indifference to environmental variables (i.e., genetically based), phylogenetic utility (i.e., sufficient variation within the study group), applicability to all or most taxa, and our ability to discern distinct character states (following Hoot \& al., 1994). No quantitative characters were included. Detailed investigations of herbarium sheets (gross morphology, vegetative and floral characters) as well as rehydrated or liquid-preserved flowers (flower morphology) were made for all included taxa. Characters were coded as binary or multi-state, and were treated as non-additive. If applicable, polymorphic species were coded as polymorphic regardless of the quantitative distribution of different states within each species. In total, 127 structural characters (Appendix 2) were recorded for 59 Helieae species and 23 outgroups. The data matrix is available at TREEBASE (www.treebase.com; study accession number S2329).

Evaluation of morphological characters was based on retention indices obtained for each morphological character as mapped onto single most parsimonious trees from the large and small combined analyses (see Appendix 2 for character retention indices). 
Morphological characters were also mapped using Winclada with "Fast optimization" for: habit (ch. 1) and merosity of flowers (chs. 32, 44) for the small combined analysis, and pollen aggregation (ch. 89) for the large combined analysis.

Molecular methods and selection of markers. Sequence data were obtained from herbarium specimens or field collected material (see Appendix 1 for vouchers and GenBank numbers). Sequences for chloroplast $m a t K$ and $t r n L$ intron were previously published in Struwe \& al. (2002), and due to their already known limited resolving power within Helieae, no further sequencing of Helieae taxa for these regions was attempted. Available sequences of $t r n L$ intron and $m a t K$ were included, nonetheless, due to their resolving power between subtribes and tribes of Gentianaceae, and to provide support for the proper rooting of Helieae.

New sequences were obtained for the nuclear internal transcribed spacer (ITS1, ITS2) for Coutoubea spicata and for Helieae species. Other ITS sequences were downloaded from GenBank (Appendix 1). Previously extracted DNA was used or DNA was extracted from fresh leaf material dried in silica gel or from herbarium specimens from as many Helieae genera as possible. DNA extraction from several Helieae taxa was limited or made impossible by the rarity of plant material. DNA extraction, amplification, and DNA sequencing for ITS followed the protocol of Struwe \& al. (1998) with the modifications outlined in Frasier \& al. (2008).

For some taxa, amplification of ITS2 was not successful despite several attempts, so only ITS1 was included in the analysis (Adenolisianthus arboreus, Aripuana cullmaniorum, Calolisianthus pulcherrimus, Chelonanthus albus, Irlbachia nemorosa, Prepusa montana; only last part of ITS2 missing for Tachia parviflora; internal part of ITS missing for Tetrapollinia caerulea). For some ITS sequences downloaded from GenBank, 5.8S was missing between ITS1 and ITS2 (Bartonia virginica, Centaurium maritimum, Chironia linoides, Crawfurdia thibetica, Gentiana lutea, Gentianopsis crinita, Halenia palmeri, Ixanthus viscosus, Macrocarpaea angelliae, Obolaria virginica, Orphium frutescens, Sabatia angularis). Since the 5.8S rRNA is nearly identical for gentians as a whole, this was not expected to affect the analyses in a negative way.

Alignments. - Obtained ITS sequences were edited using Sequencher 4.0 (GeneCodes). The DNA sequences from the $m a t K, \operatorname{trnL}$ intron, and ITS regions were aligned by eye in separate alignments using Sequencher 4.0. Alignments were exported as NEXUS-files and imported into Winclada, where insertion/deletions were coded for ITS and $t r n L$ intron based on the 'simple gap coding' method (Simmons \& Ochoterena, 2000; see Appendices 3 and 4 in the online version of this article) as binary absent/present characters added to the end of each data matrix. Following this method, potentially informative insertions and deletions in the trnL intron and ITS matrices were coded in separate matrices using binary characters for absence or presence of gaps. Characters were optimized such that as few characters as possible were used to explain gaps, but not allowing for differences in gap length within a character. For example, the three sequences NNNNN, N--NN, and $\mathrm{N}---\mathrm{N}$, would lead to the coding of two characters, one for the nucleotide position 2-3, and one for position 4. See Table 2 for the numbers of informative characters, indel characters, and aligned sequence length. All matrices had less than $1 \%$ polymorphisms. All data matrices,

Table 2. Data matrix characteristics for the six datasets used in phylogenetic analyses.

\begin{tabular}{|c|c|c|c|c|c|c|c|c|c|c|c|c|}
\hline \multirow[b]{2}{*}{ 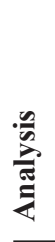 } & \multirow[b]{2}{*}{ Dataset } & \multicolumn{6}{|c|}{ Matrix characteristics } & \multicolumn{5}{|c|}{ Result } \\
\hline & & 节 & 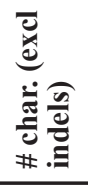 & 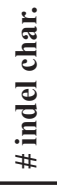 & 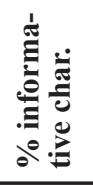 & 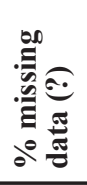 & 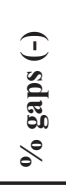 & 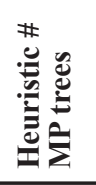 & 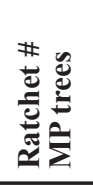 & Steps & CI & RI \\
\hline 1 & Chloroplast data (matK $+\operatorname{trn} L$ intron) & 41 & 1,180 & 15 & $15 \%$ & $23 \%$ & $7 \%$ & 3,352 & 1,295 & 639 & 0.74 & 0.77 \\
\hline 2 & Nuclear data (ITS) & 53 & 676 & 46 & $48 \%$ & $11 \%$ & $7 \%$ & 48 & 48 & 1,546 & 0.47 & 0.69 \\
\hline 3 & All DNA data (ITS, matK, trnL intron) & 59 & 1,841 & 61 & $28 \%$ & $37 \%$ & $5 \%$ & 2,035 & 86 & 2,198 & 0.54 & 0.70 \\
\hline 4 & Morphology & 82 & 127 & 0 & $100 \%$ & $12 \%$ & $0 \%$ & 24 & 965 & 717 & 0.23 & 0.69 \\
\hline 5 & Small combined & 59 & 2,029 & 61 & $32 \%$ & $35 \%$ & $5 \%$ & 4 & 4 & 2,837 & 0.48 & 0.68 \\
\hline 6 & Large combined & 82 & 2,029 & 61 & $32 \%$ & $52 \%$ & $4 \%$ & 30 & 30 & 2,979 & 0.46 & 0.69 \\
\hline
\end{tabular}

Abbreviated column headers: number of terminals/taxa; number of characters; number of added indel characters (coded gaps); $\%$ phylogenetically informative characters. The table also includes results from the phylogenetic analyses for the simple heuristic approach and the ratchet method (number of most parsimonious trees and number of steps), and consistency (CI) and retention indices $(\mathrm{RI})$. 
alignments, and trees are available at TREEBASE (www .treebase.com; study accession number S2329).

Phylogenetic analysis. - Parsimony analyses were performed using NONA (Goloboff, 2002) launched through Winclada ver. 1.00.08 (Nixon, 2002). Two types of searches were employed for each data matrix. Preliminary searches showed that different but complementary sets of most-parsimonious trees were found using both the heuristics and ratchet methods with these datasets. First, a heuristics search was performed with the following settings: hold 10,000 (maximum trees), mult*200 (200 random addition replicates), hold/10 (10 starting trees per replicate), random seed $=0$, search strategy multiple TBR + TBR (mult*max*) and unconstrained. Second, a parsimony ratchet analysis was performed to search for potential tree islands (Nixon, 1999) using the following settings: 10 replicates (repeating search, as multi-ratchet), 200 iterations per replicate, hold 10 trees per iteration, ambiguous collapsing option ('amb- poly=', default), $10 \%$ of the characters resampled, and random constraint level $=10$. Consistency index, retention index (Farris, 1989), number of steps, and strict consensus trees were calculated using Winclada. In the trees all unsupported nodes were "hard collapsed".

Branch support was evaluated using a jackknife analysis (Farris \& al., 1996) performed through Winclada with the following settings: 1,000 replicates, 10 random search replications each, one starting tree per replicate, "don't do max (TBR)", save consensus, and maxtrees $=1,000$. All analyses were performed on a desktop or laptop PC computer with a Pentium 4 processor.

In total, four different data matrices $(\operatorname{trn} L+\operatorname{trn} L$ indels, $m a t K$, ITS + ITS indels, and morphology) were run in the following six combinations: (1) $\operatorname{trnL}$ intron plus $\mathrm{matK}$ (chloroplast DNA data), (2) ITS and ITS indels (nuclear data), (3) all DNA sequence data, (4) morphological data, (5) DNA and morphological data combined for all taxa with sequence data ("small combined"), (6) all available morphology and sequence data (including several taxa without DNA data, "large combined"). Characteristics for each matrix/combination are outlined in Table 2.

Concerns about data combination because of possible heterogeneity of hierarchical information among different datasets (e.g., Bull \& al., 1993; Huelsenbeck \& al., 1996; Yoder \& al., 2001; Ramírez, 2006) may not be alleviated using available tests since it will not necessarily be known, e.g., whether hierarchical pattern is globally incongruent or only locally so. However, following reviewers suggestions, we did employ the partition-homogeneity test (ILD test; Farris \& al. 1994) as implemented in PAUP* on the following data partitions: cpDNA vs. ITS and all-DNA vs. morphology. For each ILD test, heuristic searches were employed with 1,000 random repartitions of the data and "maxtrees" set at 1,000 .

\section{RESULTS}

The partition-homogeneity test for the cpDNA vs. ITS partition returned a $P$ value of 0.003 , and that for the all-DNA vs. morphology partition returned a $P$ value of 0.001 , indicating that there was significant heterogeneity between the different datasets. However, we decided to run combined analysis since it has been shown that the ILD test is problematic and only can detect incongruence to a limited degree, especially when the number of characters are low (as in the cpDNA dataset) or the substitution rate is heterogeneous (which at least can be assumed for the morphological data; Darlu \& Lecointre, 2002).

The individual topological results from different datasets were largely congruent with each other and with the two combined analyses (one including all taxa and one including only the taxa with DNA data). Details regarding the different results are outlined below and in Table 2. Differences appeared in the positions of only a few taxa, and in the lack of resolution particularly in separate analyses based on only chloroplast or morphology data. Chloroplast data largely failed to provide much resolution within Helieae, but provided support for relationships for and among outgroups (tree not shown). Morphology provided substantial support for many smaller groupings, but failed to group larger clades (Fig. 1B). The strict consensus tree based on the small combined analysis was the most resolved (Fig. 2), and where most branches received substantial jackknife support (JF).

When taxa with only morphology data were added to the small combined data matrix to create a large combined matrix and to place unsequenced species and genera, the combination of data still provided a nearly completely resolved consensus tree, albeit with some internal branches not receiving jackknife support above 50\% (Fig. 3).

Heuristic and ratchet analyses provided trees of the same lengths in all cases, and with identical strict consensus trees from partially different sets of trees. This indicated that topological differences between sets of tree were isolated to ambiguously or non-supported branches that collapsed in the strict consensus trees.

cpDNA (trnL intron plus matK). - Forty-one taxa were analyzed in the cpDNA matrix, including 1,165 aligned nucleotides and 15 coded indels (Table 2). Heuristic parsimony yielded 3,352 most-parsimonious (MP) trees, and subsequent use of the parsimony ratchet resulted in 1,295 trees. Little resolution was found within Helieae, which was supported as monophyletic (JF 56\%; consensus tree not shown). Tribe Potalieae and Chironieae (JF 74\% and $100 \%$. respectively) were also monophyletic. Within Helieae, there was no resolution at all in the strict consensus tree.

ITS. - The ITS plus indels matrix, which had 676 aligned nucleotides and 46 coded indels, included 53 taxa 


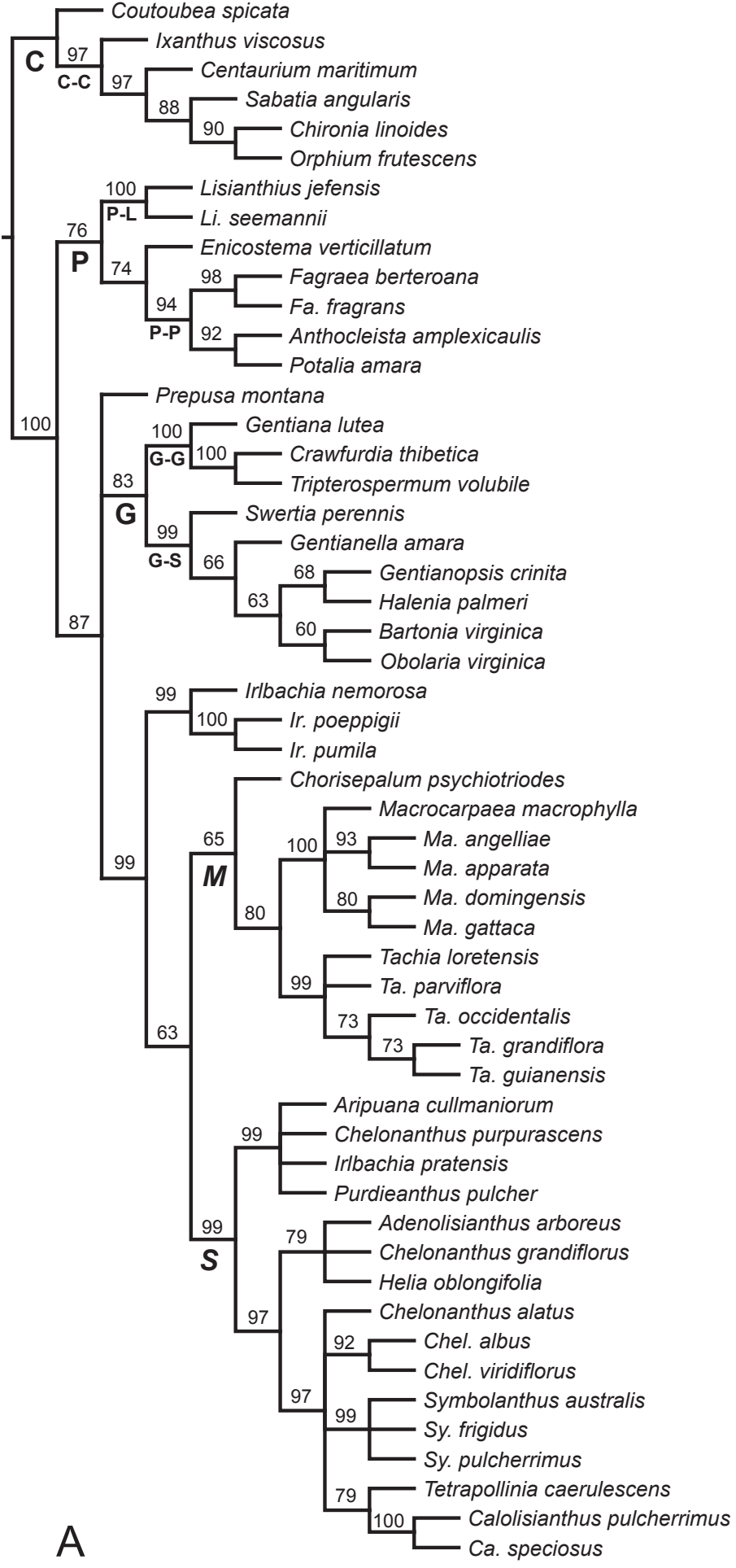

Fig. 1. Strict consensus trees obtained from separate parsimony analysis of nuclear sequence data from the internal transcribed spacer (ITS) and morphological characters; jackknife support is indicated above branches. Tribes and subtribes that are monophyletic are indicated with letters: $C$ (Chironieae), C-C (Chironieae-Chironiinae), G (Gentianeae), G-G (Gentianinae), G-S (Swertiinae), P (Potalieae), P-L (Lisianthiinae), P-P (Potaliinae); as well as the Macrocarpaea subclade $(M)$ and the Symbolanthus subclade $(S)$. A, result from data matrix of ITS and coded ITS indels (Table 2). B, result from morphological data matrix (Table 2).

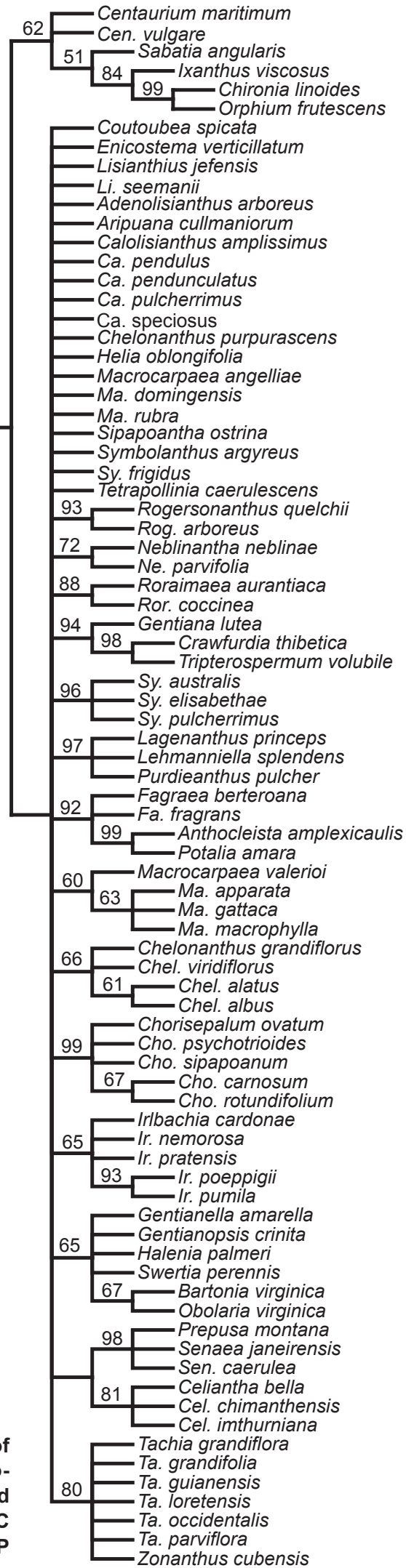

B 


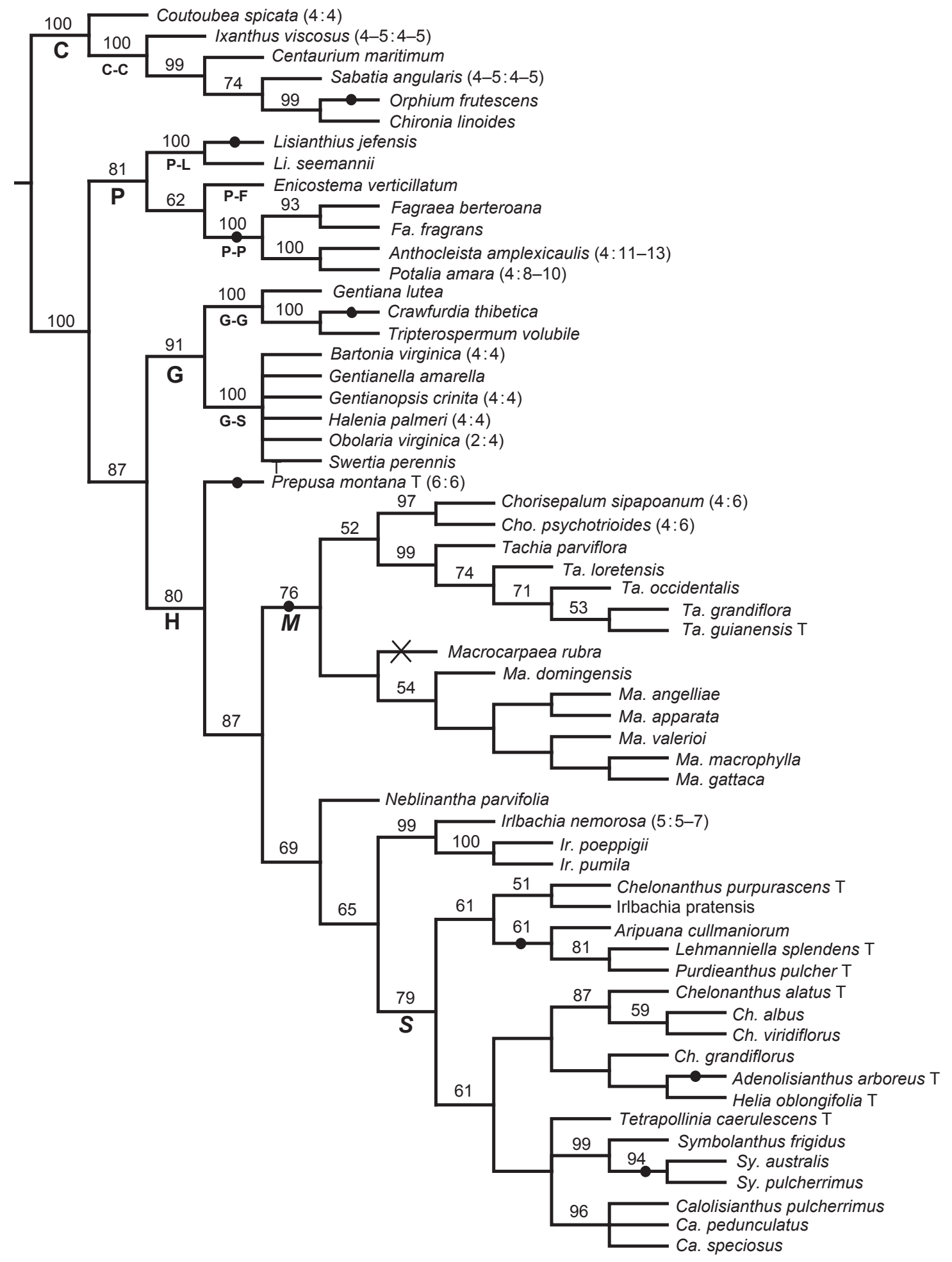

Fig. 2. Strict consensus tree obtained from analysis of combined morphological and molecular data including all taxa that have at least some molecular data; jackknife support is indicated above branches (Table 2). Tribes and subtribes that are monophyletic are indicated with letters: C (Chironieae), C-C (Chironieae-Chironiinae), H (Helieae), G (Gentianeae), G-G (Gentianinae), G-S (Swertiinae), P (Potalieae), P-F (Faroinae), P-L (Lisianthiinae), P-P (Potaliinae); as well as the Macrocarpaea subclade $(M)$ and the Symbolanthus subclade $(S)$. Character 1 (habit) is mapped with black circles, showing nine derivations of a woody habit with $X$ marking the single reversal. Type species for Helieae genera are indicated with a " $T$ ". The flower merosity of non-pentamerous flowers are indicated with number (calyx: corolla) after each taxon name. 
(Table 2). Forty-eight MP trees were found using heuristic parsimony, and the parsimony ratchet also resulted in $48 \mathrm{MP}$ trees. The consensus trees from the heuristic and ratchet analyses were identical, and nearly all branches present in the consensus trees received jackknife support above $70 \%$ (Fig. 1A). The monophyly of the Helieae was supported (JF 99\%), with the exception of the placement of Prepusa in a trichotomy with Gentianeae and the rest of Helieae (JF 87\%).

Within the core Helieae, Irlbachia (excl. I. pratensis; JF 99\% for monophyly) was sister to the rest of the tribe, which was divided into two large subclades. Chorisepalum, Macrocarpaea, and Tachia formed one clade (hereafter called the Macrocarpaea subclade), with Chorisepalum sister to the other two genera. The sister group relationship of Macrocarpaea to Tachia had some branch support (JF 80\%), and each of these genera were strongly supported (JF 100\% and JF 99\%, respectively).

The other large subclade (hereafter called the Symbolanthus subclade; JF 99\%) contained species from the following genera: Adenolisianthus, Aripuana, Calolisianthus, Chelonanthus, Helia, Irlbachia (pratensis), Purdieanthus, Symbolanthus, and Tetrapollinia. One inner clade was composed of Aripuana, Ch. purpurascens, I. pratensis, and Purdieanthus (JF 99\%). Polyphyly was evident for Chelonanthus, since its species were present in two inner clades. Generic monophyly was supported for Calolisianthus (JF 100\%) and Symbolanthus (99\%). Tetrapollinia was placed as the sister group to Calolisianthus (JF 79\%).

All DNA data. - The analysis of the data matrix (including all DNA data, 1,841 characters and 59 taxa) resulted in 2,035 MP trees from the heuristic analysis, and 86 trees from the ratchet analysis. In the strict consensus tree (not shown), these clades had substantial jackknife support: tribe Chironieae (JF 100\%), tribe Potalieae (JF 87\%), tribe Gentianeae (JF 71\%), subtribe Potalieae (JF 99\%), subtribe Chironieae (100\%), subtribe Gentianinae (JF 99\%), and subtribe Swertiinae (JF 97\%). Additional support was found for some smaller clades and genera, but most of Helieae was unresolved, but monophyletic without jackknife support over 50\%.

Morphology. - The morphology matrix included the greatest number of terminals (82), with the aim of placing several taxa that could not be sequenced. In total, 127 characters were included (Appendix 2), with some missing data cells primarily due to partial lack of seed and pollen information. Characters that had data available only for some taxa were included for a preliminary evaluation of their usefulness for phylogenetic studies in Helieae.

The parsimony analyses resulted in 24 (heuristic) and 965 (ratchet) trees of 717 steps (Table 2). The consistency index was the lowest among all analyses (0.23), however, the retention index was comparable to that of the ITS plus ITS indel analysis (0.69), showing that these morphological characters, while homoplastic, retained a similar amount of an initial similarity as synapomorphies as the ITS nucleotide data. The large number of trees was due to conflicting arrangements of smaller subclades, as seen in the largely unresolved strict consensus tree (Fig. 1B). No tribe of Gentianaceae appeared as monophyletic. However, monophyletic subtribes that were recovered included Chironiinae (JF 62\%), Gentianinae (JF 94\%), Potaliinae (JF 92\%), and Swertiinae (JF 65\%). Helieae genera recovered as monophyletic were Celiantha (JF 81\%), Chorisepalum (JF 99\%), Irlbachia (JF 65\%), Neblinantha (JF 72\%), Rogersonanthus (in the circumscription by Struwe \& al., 2008; JF 93\%), and Roraimaea (JF 88\%). The monophyly of Lagenanthus + Lehmanniella + Purdieanthus was also supported (JF 96\%), as well as Prepusa + Senaea (JF 98\%).

Small combined analysis including only taxa with DNA data. - A smaller combined data matrix was analyzed that included only taxa represented by DNA sequences ("small combined"; Table 2). It should be noted that several taxa still had missing data for some of the DNA regions in this analysis. The resulting strict consensus tree (from $4+4$ MP trees) was nearly completely resolved and had jackknife values above $50 \%$ for nearly all nodes (Fig. 2). This result was also in concordance with the ITS analysis, with a few exceptions, and resolved several unresolved branches in that analysis (cf. Fig. 1A). Both the Macrocarpaea subclade (JF 76\%) and Symbolanthus subclade were monophyletic (JF 79\%). In Helieae, monophyly was found for Calolisianthus (JF 96\%), white/ green-flowered Chelonanthus + Helia + Adenolisianthus (JF $>50 \%$ ), Chorisepalum (JF 97\%), Macrocarpaea (JF $>50 \%$ ), Tachia (JF 99\%) and Symbolanthus (JF 99\%). Irlbachia was supported as monophyletic (JF 99\%) with the exception of I. pratensis, which was placed sister to Chelonanthus purpurascens in the Symbolanthus subclade (JF 51\%). Chorisepalum was placed as sister to Tachia (JF $52 \%$ ), and these two were in turn sister to Macrocarpaea (JF 76\%). Neblinantha was positioned basal to Irlbachia s.str. at the base of the Symbolanthus clade (see Fig. 2 for further details).

Mapping of the habit character (ch. 1) for this analysis showed herbaceousness as a plesiomorphic trait within the family as well as within Helieae, and nine derivations of a woody habit (Fig. 2). Mapping of flower merosity provided evidence for an ancestral 5-merous flower in Gentianeae, Helieae, and Potalieae, with subsequent reversals to a complete 4-merous flower in some Swertiinae (with a 2-merous calyx in Obolaria) and Celiantha chimantensis (Fig. 2). Four-merous flowers are also present in the outgroup, Chironieae. Furthermore, supermerous flowers (over 5) are present in three lineages, with two of these having 4-merous calyces (Chorisepalum [Helieae: 6-merous corolla] and Anthocleista + Potalia [Potalieae: 


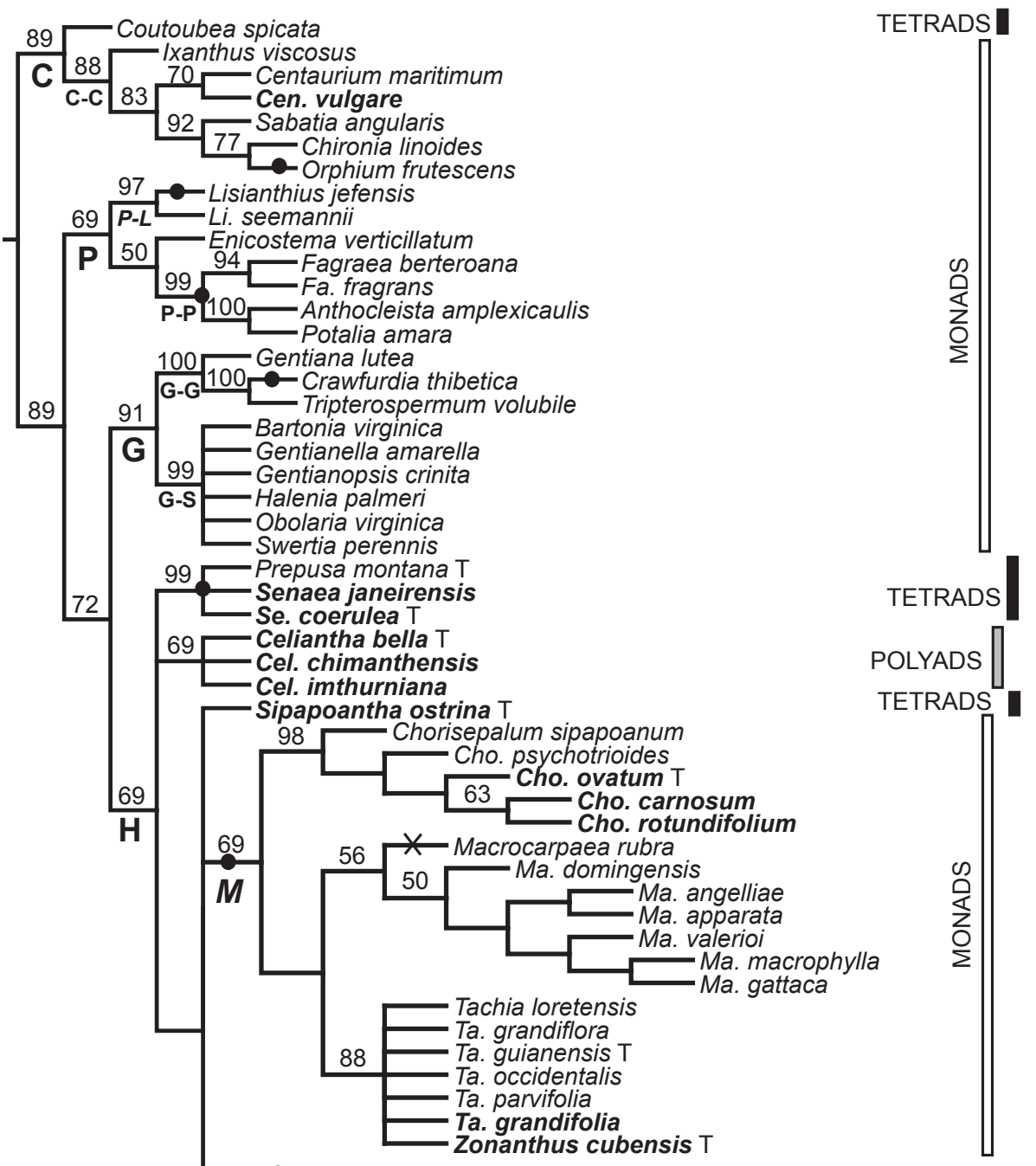

Fig. 3. Strict consensus tree obtained from analysis of large combined matrix, i.e., including all data and also species that only have morphological data; jackknife support is indicated above branches (Table 2). Species in bold only had morphological data. Tribes and subtribes that are monophyletic are indicated with letters: C (Chironieae), C-C (ChironieaeChironiinae), H (Helieae), G (Gentianeae), G-G (Gentianinae), G-S (Swertiinae), P (Potalieae), P.P (Potaliinae); as well as the Macrocarpaea subclade (M) and the Symbolanthus subclade (S). Type species for Helieae genera are indicated with a " $T$ ". Character 1 (habit) is mapped with black circles, showing nine derivations and one reversal $(X)$ of a woody habit. Character 89 (pollen aggregation) is indicated to the right for each taxon.

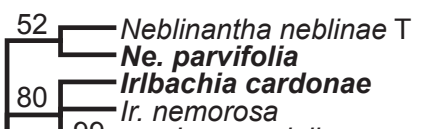




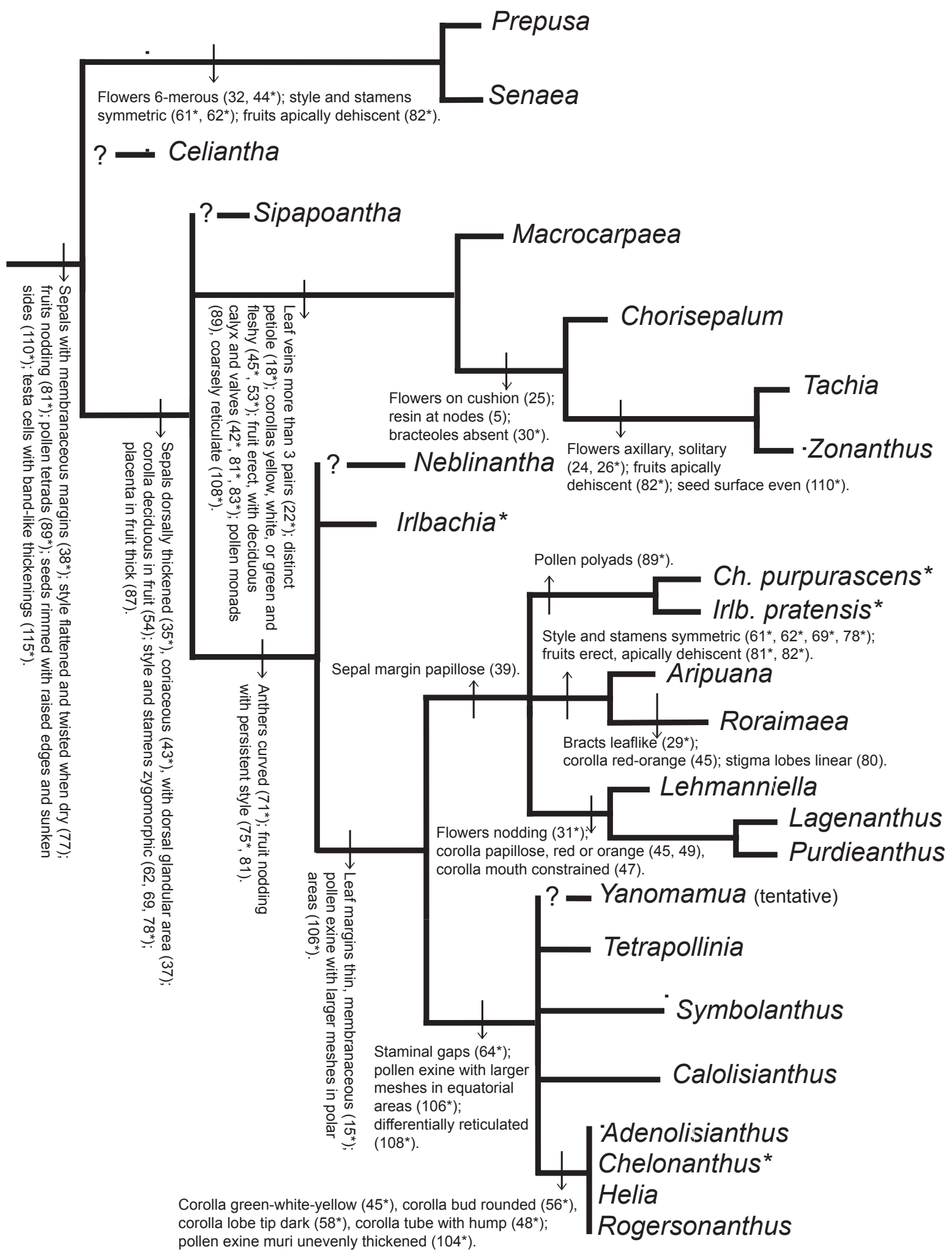

Fig. 4. Simplified tree of all Helieae genera showing inferred phylogenetic relationships based on the overall results in this paper. Possible synapomorphies are listed for each node and their character number in the morphology matrix (* indicates either later reversal or parallel evolution of that character, not all changes for all characters are indicated). Taxa placed without DNA data are indicated with a "?" on their branch. The position of Yanomamua is based on Grant \& al. (2006). Asterisks indicate genera found to be para- or polyphyletic. 
8-16-merous corolla]). Supermerous calyces are only known from the third lineage, the completely 6-merous Prepusa and Senaea, of the taxa included in this analysis (additional supermerous taxa excluded from this analysis includes Blackstonia and some Sabatia species).

\section{Large combined analysis including all taxa. -} The number of terminals increased from 59 to 82 when species with only morphological data were included in the combined analysis ("large combined"; Table 2). The analysis resulted in 30 (heuristic) and 30 (ratchet) MP trees (Table 2). The strict consensus tree (Fig. 3) was highly resolved for internal branches and most genera, less so within a few genera (Calolisianthus, Celiantha, Symbolanthus, Tachia). A majority of branches received substantial jackknife support, except for several internal branches within Helieae. The Macrocarpaea subclade was recovered (JF 69\%), as was the Symbolanthus subclade ( $\mathrm{JF}<50 \%$ ). Rare genera without DNA data (Celiantha, Lagenanthus, Neblinantha, Rogersonanthus, Roraimaea, Senaea, Sipapoantha, Zonanthus) showed distinct placements in the strict consensus tree, but their inferred relationships received none or only low branch support, most likely due to the missing DNA data for these taxa. Senaea was placed with Prepusa (JF 99\%), Zonanthus with Tachia (JF 88\%), Roraimaea with Aripuana (JF < 50\%), Lagenanthus with Purdieanthus (JF 75\%), Rogersonanthus with Adenolisianthus $+\mathrm{He}$ lia + green/white-flowered Chelonanthus (JF $<50 \%)$, and Sipapoantha and Celiantha were placed on basal branches within Helieae. All species with only morphology data placed themselves within congeneric clades (e.g., species of Calolisianthus, Chorisepalum, Irlbachia, Neblinantha, and Symbolanthus). The found relationships were highly congruent with all previous analyses.

When habit (ch. 1) is mapped for this analysis, the number of derivations of woody habit increases to nine, with one reversal within Macrocarpaea (Fig. 3). Mapping of the pollen aggregation character (ch. 89) for this analysis showed monads as a plesiomorphic trait within the family, with ambiguous character state optimization at the base of the Helieae (either tetrads with a reversal to monads in the Macrocarpaea subclade, or 2-4 derivations of tetrads in the tribe). Within Gentianaceae as a whole, there are at least two, maybe up to five, derivations of pollen tetrads and at least two derivations of pollen polyads. A summary of generic relationships found in these analyses are shown in Fig. 4, with field characters and some synapomorphies marked on branches.

\section{DISCUSSION}

Sister group to Helieae. - In previous published analyses the relationships between tribes Gentianeae, Helieae, and Potalieae have been unresolved (e.g., Struwe \& al. 2002). In our two combined analyses Gentianeae is the sister group to Helieae (JF $87 \%$ and $72 \%$, respectively; Figs. 2, 3). A better sampling of non-Helieae taxa for the ITS data is needed to confirm this result, as is inclusion of additional DNA sequence regions.

Monophyly of Helieae. - The Helieae is among the most morphologically diverse tribes of gentians (Struwe $\&$ al., 2002). Despite the variation in flower morphology, habit, seed and pollen anatomy, the tribe is supported by several synapomorphies that are nearly uniformly present within the species of the tribe (Fig. 4): sepals with membranaceous margins (ch. 38); a flat, twisted style persistent in fruits and old flowers (character 77); nodding fruits (ch. 81), pollen in tetrads (ch. 89); and rimmed seeds (ch. 110) with testa cells with band-like thickenings (ch. 115). In addition, several plesiomorphic traits such as a nectary desk at the base of the ovary (ch. 73) and inrolled placentas (ch. 88) are important field characters for Helieae. In Gilg's (1895) classification, mostly based on a few pollen characters, the Helieae genera were classified in three different groups (Gentianeae-Tachiinae [monads], Helieae [polyads and tetrads], and Rusbyantheae [tetrads]), none of which are supported as monophyletic by the present results. Helieae are clearly monophyletic in our analyses, with two distinct subclades and a few genera with less certain placement (Celiantha, Irlbachia, Neblinantha, Sipapoantha; cf. Fig. 4).

Phylogenetic history of Helieae. - Three genera are consistently placed as the sister taxa to the rest of the tribe: Prepusa, Senaea, and Celiantha (Fig. 4). In the rest of the Helieae, two major evolutionary lineages appear to be present: the Macrocarpaea subclade and the Symbolanthus subclade, as well as a few smaller clades with more uncertain positions.

Celiantha, Prepusa, and Senaea are rare and endangered genera from the eastern Brazilian Highlands and the Venezuelan tepuis, which have not been previously included in any phylogenetic analyses, but they were tentatively included in Helieae in the Struwe \& al.'s (2002) Gentianaceae classification. Neither Celiantha nor Senaea has yet been successfully sequenced, so their position in this analysis is based on optimization of morphological characters onto a backbone of combined data (Fig. 3). Their more basal position in the tribe is supported by plesiomorphic character states such as the presence of membranaceous calyces (ch. 43), persistent corollas (ch. 54), and an actinomorphic androecium (ch. 62).

Prepusa and Senaea lack some of the typical characters of the Helieae (such as glandular, thickened calyx lobes, chs. 37 and 43), and have unique 6-merous flowers (ch. 44), the Prepusa pollen type (Nilsson, 2002), and inflated calyces (Calió \& al., 2008). Celiantha has the typical Helieae flower bauplan (except for non-glandular calyx lobes) and medially dehiscing fruits, but shares the 
synapomorphies of porate pollen (ch. 90) and nodding fruits (ch. 81) with Prepusa and Senaea (both character states are homoplasious and also occur in the Symbolanthus subclade). It is clear that the best classification of these three genera is in Helieae (Figs. 2, 3), particularly since the monophyly of the other three tribes (Chironieae, Gentianeae, Potalieae) are strongly supported and therefore not in question. However, since this result is based only on ITS for Prepusa, matK for Neblinantha, and morphology for all three genera, further confirmation with additional molecular data is needed. We see no need to segregate this subclade as its own tribe, especially since it shares some, if not all, Helieae synapomorphies, and since the exact position of Celiantha is not known. If Helieae is eventually divided into subtribes, then the Prepusa subclade might form a new subtribe.

Sipapoantha, a monotypic genus of blue-flowered herbs from the tepuis, was placed one step up towards Helieae from the Prepusa subclade (Fig. 3), and positioned without DNA sequence data. We consider this position tentative, pending sequencing of this rare taxon. Sipapoantha shares some pollen character states with the Prepusa group, for example scabrate/verrucose pollen exine (ch. 107), muri as small pila (ch. 103), and pores with a thin margin (ch. 96).

The Macrocarpaea subclade, which is characterized by being woody plants with pollen shed as single, usually reticulate pollen grains (chs. 89, 107), contains, by far, the largest genus in the tribe, Macrocarpaea (ca. 105 species), together with Chorisepalum, Tachia, and Zonanthus (Fig. 4). Chorisepalum is endemic to tepuis of the Guayana Shield, and is sister to Tachia + Zonanthus. Both Chorisepalum and Tachia have strong generic morphological synapomorphies, such as 6-merous corollas (ch. 44) and 4-merous calyces (ch. 32) for Chorisepalum, and sessile, axillary flowers for Tachia (ch. 25), and a joint synapomorphy of resin present at the nodes (ch. 5; also present in Potalia, Potalieae; Struwe \& Albert, 2004). This is the first time the monotypic and poorly known Cuban genus Zonanthus has been included in a phylogenetic analysis, and its position as the sister group to South and Central American Tachia (Fig. 3) is supported by the strong synapomorphy of having axillary, single flowers (chs. 24, 26). Zonanthus was tentatively placed in the Helieae in the classification of Struwe \& al. (2002). If this subclade was to be classified as a subtribe, it would receive the already available name Tachiinae but in a more narrow circumscription than Gilg's (1895), which included nine genera now placed in four different tribes.

The monophyly of Macrocarpaea was not strongly supported in the combined analysis, most likely due to a weak placement of the floral morphologically aberrant species $M$. rubra (sometimes segregated into its own subgenus Paranagenes; Ewan 1948a; Figs. 1B, 2, 3). In particular, $M$. rubra is the only species sampled from southeastern Brazil, and the other species in this area are morphologically more similar to the Andean and tepui species in the genus, and could possibly provide phylogenetic 'links' that would strengthen the monophyly of the genus for the morphological data. The weak placement of M. rubra might also be the result of the absence of ITS data for this species, and that some of its morphological traits are dissimilar to the rest of Macrocarpaea (such as flattened and winged filaments, straight anthers, and anticlinal testa cell walls with anticlinal band-like thickenings). Macrocarpaea is monophyletic in other more comprehensive analyses of the genus (Grant, 2007).

Irlbachia, the sole member of the Irlbachia subclade sensu Struwe \& al. (2002), is an herbaceous genus of many white-sand and tepui species with unique pollen in spiny polyads (Struwe \& al., 1997). Irlbachia pratensis, with a different pollen type (Chelonanthus-type) than the rest of Irlbachia, is placed outside of Irlbachia in the Symbolanthus subclade, rendering Irlbachia polyphyletic.

Neblinantha, a poorly known and unsequenced tepui genus of two herbaceous species, appears to be closely related to Irlbachia s.str. and/or the Symbolanthus subclades. Additional sequence data are needed to fully understand the relationships among these deeply nested lineages. Indeed, the positions of Celiantha, Neblinantha, and Sipapoantha should all be viewed with caution.

The Symbolanthus subclade contains an assortment of herbaceous or woody genera, all with pollen in tetrads or polyads, and often with large, colorful corollas and zygomorphic stamens with curved anthers. The only primarily woody genera in this subclade are Aripuana, Rogersonanthus, and Symbolanthus, and three small genera that are straggling shrubs or vines (Lagenanthus, Lehmanniella, Purdieanthus). The Symbolanthus subclade divides into two groups, but without strong branch support (Figs. 2, 3).

The grouping of the morphologically diverse genera in the clade consisting of Aripuana, Lagenanthus, Lehmanniella, Purdieanthus, and Roraimaea, together with Chelonanthus purpurascens and Irlbachia pratensis, has consistently been found as a monophyletic group, but is not supported by any unambiguous, nonhomoplastic morphological characters (Fig. 4). Roraimaea coccineus, was placed in Rogersonanthus when described (Struwe \& Albert, 1998b), but groups with Roraimaea aurantiaca, a recently described taxon and it was recently included in this genus (Struwe \& al., 2008). Roraimaea coccineus shares linear stigma lobes, a herbaceous habit, leaf-like bracteoles, pollen type, and a red-orange corolla with $R$. aurantiaca. The sister relationship between Roraimaea and Aripuana has not been proposed previously, and is supported by several strong morphological synapomorphies such as actinomorphic stamens of equal length and straight anthers (chs. 61, 62, 
69), actinomorphic styles (ch. 78), erect fruits with apical dehiscence (chs. 81, 82), and leaves with many pairs of straight secondary veins (chs. 20, 22, in Aripuana and $R$. aurantiaca only; Fig. 4).

The strongly supported relationship found between Lagenanthus, Lehmanniella, and Purdieanthus was suggested already by Simonis in Maas (1985) based on floral morphology, who included all species in a larger Lehmanniella (Fig. 4). In the circumscription followed here, Lagenanthus and Purdieanthus are monotypic, whereas Lehmanniella has two species, of which only one was included. Therefore, it remains to be seen if Lehmanniella is monophyletic, or if the generic concepts need to be changed in this group. Common characters for all three genera are nodding, red, and tubular to narrowly salvershaped corollas constrained at the mouth and with a papillose surface (and most likely hummingbird-pollinated; chs. $31,45,47,49)$.

Irlbachia pratensis and Chelonanthus purpurascens are two species that are untypical in their respective genera in morphological terms, and their phylogenetic placement here renders both genera polyphyletic. Perhaps unfortunately, $C$. purpurascens is the type species (as the synonym C. uliginosus) for Chelonanthus, so this generic name must follow this species. A close relationship between Irlbachia pratensis and Chelonanthus purpurascens has been suggested in the past based on their unique pollen polyads with loop-like exine extensions (chs. 89, 92; Fig. 4), sometimes as spines in I. pratensis (Nilsson, 2002). Also, both taxa have blue or purple corollas (ch. 45), in contrast to all other currently recognized Chelonanthus species. Their distribution is overlapping, with $C$. purpurascens being widespread in Amazonia and outlying areas, and I. pratensis being endemic to whitesand areas in the Upper Rio Negro region (Struwe \& al., 1999). Future reclassifications should probably include Irlbachia pratensis inside a smaller, recircumscribed Chelonanthus.

The majority of species in the Symbolanthus subclade are placed in a clade dominated by the genera Calolisianthus, Chelonanthus, and Symbolanthus. Also included are species from Adenolisianthus, Helia, Rogersonanthus, and Tetrapollinia. This is a diverse group, and the combined analysis (Figs. 2, 3) shows it divided into two clades that follow corolla color and bud apex shape: one green/ white-colored clade with round apices (Adenolisianthus, Chelonanthus p.p., Helia, Rogersonanthus p.p.), and another blue-purple-pink-red-colored clade with tapering, sharp corolla apices (Calolisianthus, Symbolanthus, and Tetrapollinia, the only exception being $S$. frigidus; chs. 45, 56).

Basally placed in the green/white Chelonanthus and Rogersonanthus clade are Helia and Adenolisianthus, all with strongly similar pollen and green-white corollas.
Since the type species of Chelonanthus is placed outside of this clade, the green-white Chelonanthus species need to be renamed and the generic circumscriptions changed. Several options are possible, depending on the suitability of either recognizing one or several genera in this group. In Kuntze's (1891) classification, most of these species were included in Helia together with species of many other Helieae genera. Helia, providing the oldest generic name (Martius, 1826-27), is a southeastern Brazilian genus of 2, 3 species and primarily differs from the others in having leaves in basal rosettes, and narrow corolla tubes. Adenolisianthus is a suffrutescent genus from lowland Amazonian white sand areas (Struwe \& al., 1999), differing only from Chelonanthus in its obovate leaves, a leaf shape that also is present in Rogersonanthus. The nesting of Rogersonanthus inside white- to green-flowered Chelonanthus is also not surprising, since the two original Rogersonanthus species ( $R$. arborescens, $R$. quelchii) are primarily only differentiated from Chelonanthus based on their woody habit, and have green-yellow corollas as well. The pollen tetrads of Rogersonanthus are nearly indistinguishable from Chelonanthus (Nilsson, 2002), and both groups have horizontal corollas with a 'hump' on their adaxial side (ch. 48).

The flower morphology and pollen anatomy of $A d-$ enolisianthus, Chelonanthus p.p., Helia, and Rogersonanthus are very similar, and we suggest that these species should eventually be included in a broadly recircumscribed Helia, similar to the circumscription proposed by Kuntze (1891). The number of species in such a Helia s.l. is uncertain, since the widespread, polymorphic, and weedy taxon Chelonanthus alatus has functioned as a 'lumping taxon' for over a handful poorly known and morphologically similar species. The green/white Chelonanthus alatus group is currently being revised and is estimated to contain at least eleven species (Lepis \& al., 2006).

Morphological character analysis. - Generic classifications in the Helieae have historically been difficult and a variety of key characters have been used. In the classifications of Gilg (1895), Maguire (1981), and Maguire \& Boom (1989), pollen characters such as aggregation and exine sculpturing were used for generic circumscription and identification, together with floral morphology. This study evaluated these traditional characters in a phylogenetic context, as well as many other additional characters that previously had not been considered at all or had been considered as too homoplastic to identify and circumscribe genera. Some of these performed extremely well in our analyses, whereas others did not (see Appendix 2; Fig. 4). When morphological characters are compared overall to molecular data, they only perform slightly worse than molecular data as measured by the retention index. 
Field characters. In recent classifications, several key morphological characters have been used at the generic level, and these were also evaluated. Many of these characters show homoplasy in our results, but still function as good synapomorphies inside particular clades/groups, and when used in combination with other characters, also perform as good genus-level key characters. Some examples are leaf-like bracts (ch. 29), found separately in Macrocarpaea, Zonanthus, Irlbachia, and Roraimaea. These are four groups that are not placed closely together, and that can be further separated based on other key field characteristics. Other characters that show great promise and show no or low homoplasy (but high retention indices) within Helieae are resin at nodes (ch. 5), vagination of petioles (ch. 19; inside Macrocarpaea), thickened leaf margins and decussate sepals (chs. 16 and 34; Chorisepalum), inflorescence type (ch. 25), and coronas (ch. 65; inside Symbolanthus). Of the characters used as key field characters for Helieae, calyx lobes dorsally thickened and with a glandular area (chs. 35 and 37) and a style in fruit or old flowers that is thin, long and twisted (ch. 76) had high retention indices.

There are also morphological characters that show a high degree of homoplasy inside Helieae, and that are not recommended for use in further classification and phylogenetic reconstructions, such as leaves in basal rosette (ch. 7), recurved leaf margins (ch. 17), calyx color (ch. 33), and keeled sepals (ch. 36).

The behavior of all characters is dependent on the sampling of taxa and the influence of other datasets on the combined analysis, and some caveats to these conclusions are in order. When retention indices for individual morphological characters from the large and small combined results are compared, some characters shift from high to low retention indices and vice versa, based on the sampling (Appendix 2). Therefore, the behavior of a morphological character in an analysis that does not include all species should not be predictive of the behavior of the same character in a more taxon-complete analysis. Inclusion of as many species as possible is always advisable when evaluating patterns of morphological evolution. In our discussion below we therefore base our conclusions on the large combined analysis, even if jackknife support is lower for individual branches due to the lack of molecular data for several terminals.

Pollen. It is remarkable that despite the confusing nomenclature that this tribe has suffered from, the current generic classification of Struwe \& al. (2002) has identified genera that are monophyletic here, with a few exceptions. Chelonanthus and Irlbachia's possible polyphyletic status was already noted in the works by Nilsson (1968, 1970, 2002) based on the divergent pollen morphology in these genera. When the pollen types identified by Nilsson are broken down into individual characters for specific exine features (chs. 89-108), they provide significant and supporting information for evolutionary divergences. Of the pollen characters that performed best within Helieae are pollen in tetrads or polyads (ch. 89; supporting the Symbolanthus subclade + Irlbachia + Neblinantha), polar areas with thicker exine (ch. 94; supporting three different subgroups inside the Symbolanthus clade and Irlbachia s.str.), smooth or granular lumina (ch. 98; dividing the Macrocarpaea and Symbolanthus subclades), and larger meshes in equatorial vs. polar areas (ch. 106; the Symbolanthus clade; Appendix 2).

Seed anatomy. Fewer taxa have been investigated for seed anatomy than for pollen, so the inclusion of seed data in this study was largely an exploratory effort considering the substantial amount of missing data for some taxa. Furthermore, some characters can only be evaluated in SEMs of seeds where the outer testa wall has been removed. Also, characters were not based on types (e.g., Symbolanthus type of pollen), but were broken down into as many detailed, independent characters as possible (chs. 109-127). The seed characters that show promise include rimmed seeds with band-like thickenings (possible synapomorphies for Helieae, chs. 110 and 115) and a single wing around the seeds (ch. 111, state 1, a synapomorphy for Chorisepalum). On the other hand, testa cell shape (ch. 113), presence of sunken anti-clinal boundaries (ch. 118), and band-like thickenings on anticlinal walls (ch. 119) showed great of homoplasy (Appendix 2).

In summary, it appears that pollen and seed anatomy data behave like most gross morphological data - there are some that are very homoplastic, and some with very little homoplasy that provide good synapomorphies and/ or key characters in combination with other data-which ones these are largely depends on the taxonomic group under investigation. The preferred means to uncover which characters are of the most value for a phylogenetic taxonomy is through a combined analysis including as much character data as possible.

Evolution of a woody habit. - Woodiness is a character that is infrequently present in the Gentianaceae, with the subtribe Potalieae and some genera in Helieae being the most well-known examples. It is also present in Saccifolium (Saccifolieae), Lisianthius (Potalieae), and Orphium (Chironieae), and it is generally thought that most woody species have evolved from herbaceous or suffrutescent herbs based on their wood anatomy (Thiv \& al., 1999b; Carlquist \& Grant, 2005). This view is also supported in the present analysis, where woodiness appears to have evolved at least nine times among four tribes (ch. 1; Figs. $2,3)$. It appears that every time woodiness has evolved in Gentianaceae, the lineage stays woody with no subsequent evolutionary reversals back to an herbaceous habit. Perennial versus annual habits were not analyzed in this paper, but it would be interesting to analyze the connection 
between these two traits. A perennial herbaceous habit presumably should be a precursor for woodiness, and anecdotal evidence is that most herbaceous species are perennial, and sometimes woody at the base, if only short-lived. Species numbers might also increase with the evolution of a shrub- or tree-habit due to longer generations and more stationarity, as seen in Fagraea, Macrocarpaea, and Symbolanthus - all of which also grow in areas that might have undergone large allopatric speciation. Macrocarpaea and Symbolanthus are particularly species-rich in the Andes, whereas Australasian Fagraea species are often restricted to particular islands or mountain areas in Asia (Leenhouts, 1963; Wong \& Sugau, 1996).

Evolution of supermerous flowers. - The evolution of supermerous flowers in Potalieae, the tribe that has the largest variation in flower merosity ( 3 to 24 corolla lobes), was discussed by Struwe \& al. (2002: 211). In all gentians that have supermerous flowers, the gynoecium is still bicarpellate in contrast to many super-merous $\mathrm{Ru}$ biaceae, e.g., Gardenia (Smith, 1974). In the Helieae, most flowers are either 4- or 5-merous, with three exceptions; Prepusa and Senaea both have 6-merous calyces, corollas, and androecium, in contrast to Chorisepalum which is also 6-merous in its corolla and stamens, but with a 4-merous calyx (Fig. 2). Chorisepalum calyx lobes are furthermore free and decussate, a condition otherwise only found in supermerous Anthocleista and Potalia (Potalieae; Struwe \& Albert, 2004). As this is also the case with Anthocleista and Potalia, the sister group is completely 5-merous, so an evolutionary shift in both calyx and corolla merosity has occurred at least three times independently (Fig. 2). In all these species, the number of stamens is the same as the corolla lobes, so it could be possible that a single gene mutation is affecting merosity. Such a change between tetra- and pentamerous flowers of Arabidopsis has been shown to be caused by a mutation in the PERIANTHIA gene (Chuang \& al., 1999). A further mutation causing supernumerary floral organs has been shown to occur in the ULTRAPETALA locus (Fletcher, 2001).

Comparison of different datasets. - In contrast to the $\operatorname{trnL}$ intron and $m a t K$ data, ITS is highly divergent and informative for the Helieae, similar to findings in the gentian tribes Chironieae (Thiv \& al. 1999b; Mansion \& Struwe, 2004) and Gentianeae (Chassot \& al., 2001). Chloroplast DNA sequences provide some, but insufficient, resolution of relationships within Helieae, and rarely these relationships are contradicted by ITS and morphological data, e.g., the position of Aripuana and Tetrapollinia with Tachia in the $\operatorname{trn} L$ intron analysis, which is supported by a $\operatorname{trn} L$ indel character (results not shown). However, such cases are likely due to the limited number of character changes in the chloroplast datasets, as shown by the few branches that are resolved and have strong branch support in the chloroplast consensus tree.

\section{SUMMARY}

This paper presents the first large-scale phylogenetic analysis of the neotropical tribe Helieae of the Gentianaceae. Based on combined molecular, morphological, and anatomical data, strong support has been found for both the monophyly of the tribe as well as subdivisions within Helieae, such as the monophyly of several genera and the two major subclades. A few genera (Chelonanthus, Irlbachia) were found to be paraphyletic, and reclassification of some taxa in these groups is needed. A woody habit and supermerous flowers have evolved several times independently in the family, and the combination of detailed morphological data and DNA sequences proved significant in resolving the evolutionary history of tribe Helieae.

\section{ACKNOWLEDGEMENTS}

This research was supported by grants from the National Science Foundation (\#317612 to LS), Rutgers Research Council (to LS), Hatch-USDA grant (to LS), and Rutgers Research Council (to LS). Initial parts of this research were performed at The Cullman Program for Molecular Systematics Studies at The New York Botanical Garden, which also provided some seed funding. MFC was funded by FAPESP (Ph.D. fellowship 03/10918-3) and by IAPT Research Grant Program (2006). We thank all herbaria and their staff mentioned under Materials and Methods for access to material and information. We also wish to thank colleagues that have provided research material for this study (Paul Berry, James Luteyn, Paul J.M. Maas, Scott Mori), as well as Paul J.M. Maas, E. Groen, E.C.H. van Heusden, and J.E. Simonis, who provided access to unpublished manuscripts.

\section{LITERATURE CITED}

Bouman, F., Cobb, L., Devente, N., Goethals, V., Maas, P.J.M. \& Smets, E. 2002. The seeds of Gentianaceae. Pp. 498-572 in: Struwe, L. \& Albert, V.A. (eds.), Gentianaceae - Systematics and Natural History. Cambridge University Press, Cambridge.

Bull, J.J., Huelsenbeck, J.P., Cunningham, C.W., Swofford, D.L. \& Waddell, P.J. 1993. Partitioning and combining data in phylogenetic analysis. Syst. Biol. 42: 384-397.

Calió, M.F., Pirani, J.R. \& Struwe, L. 2008. Morphologybased phylogeny and revision of Prepusa and Senaea (Gentianaceae - Helieae) — rare endemics from eastern Brazil. Kew Bull. 63: 169-191.

Carlquist, S. \& Grant, J.R. 2005. Wood anatomy of Gentianaceae, tribe Helieae: diversification in relation to ecology, habit, and systematics; the effect of sample diameter. Brittonia 57: 276-291.

Chassot, P., Nemomissa, S., Yuan, Y.-M. \& Küpfer, P. 2001. High paraphyly of Swertia L. (Gentianaceae) in the 
Gentianella-lineage as revealed by nuclear and chloroplast DNA sequence variation. Pl. Syst. Evol. 229: 1-21.

Chuang, C.-F., Running, M.P., Williams, R.W. \& Meyerowitz, E.M. 1999. The PERIANTHIA gene encodes a bZIP protein involved in the determination of floral organ number in Arabidopsis thaliana. Genes Developm. 13: 334-344.

Cobb, L. \& Maas, P.J.M. 1998. A new species of Tachia (Gentianaceae) from Suriname. Brittonia 50: 11-18.

Darlu, P. \& Lecointre, G. 2002. When does the Incongruence Length Difference test fail? Molec. Biol. Evol. 19: 432-437.

Ewan, J. 1947. A revision of Chorisepalum, an endemic genus of Venezuelan Gentianaceae. J. Wash. Acad. Sci. 37: 392-396.

Ewan, J. 1948a. A revision of Macrocarpaea, a neotropical genus of shrubby gentians. Contr. U.S. Natl. Herb. 29: 209-250.

Ewan, J. 1948b. A review of Purdieanthus and Lehmanniella, two endemic Colombian genera of Gentianaceae, and biographical notes on Purdie and Lehmann. Caldasia 5: 85-98.

Ewan, J. 1952. A review of the neotropical lisianthoid genus Lagenanthus (Gentianaceae). Mutisia 4: 1-5.

Farris, J.S. 1989. The retention index and the rescaled consistency index. Cladistics 5: 417-419.

Farris, J.S., Albert, V.A., Källersjö, M., Lipscomb, D. \& Kluge, A.G. 1996. Parsimony jackknifing out-performs neighbor-joining. Cladistics 12: 99-124.

Farris, J.S., Källersjö, M., Kluge, A.G. \& Bult, C. 1994. Testing significance of incongruences. Cladistics 10: 315-319.

Fletcher, J. 2001. The ULTRAPETALA gene controls shoot and floral meristem size in Arabidopsis. Development 128: 1323-1333.

Frasier, C., Albert, V.A. \& Struwe, L. 2008. Amazonian lowland, white sand areas as ancestral regions for South American biodiversity: biogeographic and phylogenetic patterns in Potalia (Gentianaceae). Org. Div. Evol. 8: 44-57.

Gilg, E. 1895. Gentianaceae. Pp. 50-108 in: Engler, A. \& Prantl, K. (eds.), Die natürlichen Pflanzenfamilien, vol. 4. Engelmann, Leipzig.

Goloboff, P. 2002. NONA, vers. 2.0. http://www.cladistics .com/aboutNona.thm.

Gould, K.R. \& Struwe, L. 2004. Phylogeny and evolution of Symbolanthus and Wurdackanthus (GentianaceaeHelieae) in the Guayana Highlands and Andes, based on ribosomal 5S-NTS sequences. Ann. Missouri Bot. Gard. 91: 438-446.

Grant, J.R. 2003. De Macrocarpaeae Grisebach (ex Gentianaceis) speciebus novis II: typification of the Ruiz \& Pavon names. Harvard Pap. Bot. 7: 423-436.

Grant, J.R. 2004. De Macrocarpaeae Grisebach (ex Gentianaceis) speciebus novis V: twenty-three new species largely from Peru, and typification of all species in the genus. Harvard Pap. Bot. 9: 11-49.

Grant, J.R. 2005. De Macrocarpaeae Grisebach (ex Gentianaceis) speciebus novis VI: seed morphology, palynology, an infrageneric classification, and another twenty-three new species, largely from Colombia. Harvard Pap. Bot. 9: 305-342.

Grant, J.R. 2007. De Macrocarpaeae Grisebach (ex Gentianaceis) speciebus novis VII: four new species and two natural hybrids. Harvard Pap. Bot. 11: 129-139.
Grant, J.R. 2008. De Macrocarpaeae Grisebach (ex Gentianaceis) speciebus novis VIII: two new species from Ecuador. Harvard Pap. Bot. 13: 253-259.

Grant, J.R., Maas, P.J.M. \& Struwe, L. 2006. Yanomamua araca (Gentianaceae: Helieae), a new genus and species from outliers of the Guayana Shield on Serra Aracá in Amazonian Brazil. Harvard Pap. Bot. 11: 33-41.

Grant, J.R. \& Struwe, L. 2001. De Macrocarpaeae Grisebach (ex Gentianaceis) speciebus novis I: an introduction to the genus Macrocarpaea and three new species from Colombia, Ecuador, and Guyana. Harvard Pap. Bot. 5: 489-498.

Grant, J.R. \& Struwe, L. 2003. De Macrocarpaeae Grisebach (ex Gentianaceis) speciebus novis III: six new species of moon-gentians (Macrocarpaea, Gentianaceae: Helieae) from Parque Nacional Podocarpus, Ecuador. Harvard Pap. Bot. 8: 61-81.

Grant, J.R. \& Weaver, R.E. 2003. De Macrocarpaeae Grisebach (ex Gentianaceis) speciebus novis IV: twelve new species of Macrocarpaea (Gentianaceae: Helieae) from Central and South America, and the first report of the presence of a stipule in the family. Harvard Pap. Bot. 8: 83-109.

Grisebach, A.H.R. 1839 [1838]. Genera et Species Gentianearum. J.G. Cotta, Stuttgart \& Tübingen.

Grisebach, A.H.R. 1845. Gentianaceae. Pp. 39-141 in: Candolle, A. de (ed.), Prodromus Systematis Naturalis Regni Vegetabilis, vol. 9. Fortin, Masson, et Sociorum, Paris.

Hoot, S.B., Reznicek, A.A. \& Palmer, J.D. 1994. Phylogenetic relationships in Anemone (Ranunculaceae) based on morphology and chloroplast DNA. Syst. Bot. 19: 169-200.

Huelsenbeck, J.P., Bull, J.J. \& Cunningham, C.W. 1996. Combining data in phylogenetic analysis. Trends Ecol. Evol. 11: 152-158.

Jensen, S.R. \& Schripsema, J. 2002. Chemotaxonomy and pharmacology of Gentianaceae. Pp. 573-632 in: Struwe, L. \& Albert, V.A. (eds.), Gentianaceae - Systematics and Natural History. Cambridge University Press, Cambridge.

Kuntze, C.E.O. 1891. Revisio Generum Plantarum, vol. 2. Arthur Felix, Leipzig.

Leenhouts, P.W. 1963. Loganiaceae. Pp. 293-387 in: Van Steenis, C.G.G.J. (ed.), Flora Malesiana, vol. 1 (6). WoltersNoordhoff, Groningen.

Leon, H. \& Alain, H. 1957. Gentianaceae. Pp. 158-168 in: Leon, H. \& Alain, H. (eds.), Flora de Cuba, vol. 4. Contribuciones Ocasionales del Museo de Historia Natural del Colegio "De la Salle", no. 16. P. Fernandez, Habana.

Lepis, K.B. 2009. Evolution and Systematics of Chelonanthus (Gentianaceae). Ph.D. dissertation, Rutgers University, New Brunswick.

Lepis, K.B., Kulakowski, D. \& Struwe, L. 2006. A new taxonomic classification for Chelonanthus (Gentianaceae) as supported by ribosomal nuclear, chloroplast and morphological data. Botany 2006 conference, Chico, CA, 28 July-3 Aug, 2006. http://www.2006.botanyconference.org/ engine/search/index.php? func $=$ detail\&aid $=523$.

Lindley, J. 1849. Memoranda concerning some new plants recently introduced into gardens otherwise than through the Horticultural Society, no 1. J. Hort. Soc. London 4: 261-269.

Maas, P.J.M. 1981. On the true identity of Lagenanthus parviflorus Ewan (Gentianaceae). Ann. Missouri Bot. Gard. 68: 685-686.

Maas, P.J.M. 1985. Nomenclatural notes on neotropical 
Lisyantheae (Gentianaceae). Proc. Kon. Ned. Akad. Wetensch., Ser. C, Biol. Med. Sci. 88: 405-412.

Maguire, B. 1981. Gentianaceae. Pp. 330-388 in: Maguire, B. \& collaborators (eds.), The Botany of the Guayana Highland - Part XI. Memoirs of the New York Botanical Garden 32. The New York Botanical Garden, Bronx.

Maguire, B. 1985. Gentianaceae - part 2. Phytologia 57: 311-312.

Maguire, B. \& Boom, B.M. 1989. Gentianaceae-Part 3. Pp. 2-56 in: Maguire, B. \& collaborators (eds.), The Botany of the Guyanan Highlands-Part XIII. Memoirs of the New York Botanical Garden 51. The New York Botanical Garden, Bronx.

Maguire, B. \& Weaver, R.E. 1975. The neotropical genus Tachia (Gentianaceae). J. Arnold Arbor. 56: 103-125.

Mansion, G. \& Struwe, L. 2004. Molecular phylogeny of the subtribe Chironiinae: evidences for a polyphyletic genus Centaurium Hill (Gentianaceae). Molec. Phylog. Evol. 32: 951-957.

Martius. C.F.P. von. 1826-27. Nova Genera et Species Plantarum quas in Itinere per Brasiliam, vol. 2. V. Wolf, München.

Molina, J. \& Struwe, L. 2008. Revision of ring-gentians (Symbolanthus, Gentianaceae) from Bolivia, Ecuador and Peru, with a first assessment of conservation status. Syst. Biodiv. 6: 477-501.

Nilsson, S. 1968. Pollen morphology in the genus Macrocarpaea (Gentianaceae) and its taxonomical significance. Svensk Bot. Tidskr. 62: 338-364.

Nilsson, S. 1970. Pollen morphological contributions to the taxonomy of Lisianthus L. s. lat. (Gentianaceae). Svensk Bot. Tidskr. 64: 1-43.

Nilsson, S. 2002. Gentianaceae - a review of palynology. Pp. 377-497 in: Struwe, L. \& Albert, V.A. (eds.), Gentianaceae - systematics and natural history. Cambridge University Press, Cambridge.

Nixon, K. 1999. The parsimony ratchet, a new method for rapid parsimony analysis. Cladistics 15: 407-414.

Nixon, K. 2002. Winclada, vers. 1.00.08. http://www.cladistics .com/about winc.htm.

Ramírez, M.J. 2006. Further problems with the incongruence length difference test: "hypercongruence" effect and multiple comparisons. Cladistics 22: 289-295.

Simmons, M.P. \& Ochoterena, H. 2000. Gaps as characters in sequence-based phylogenetic analyses. Syst. Biol. 49: 369-381.

Smith, A.C. 1974. Studies of Pacific Island Plants. XXVII. The genus Gardenia (Rubiaceae) in the Fijian Region. Amer. J. Bot. 61: 109-128.

Stearn, W.T. 1995. Botanical Latin, 4th ed. Timber Press, Portland.

Struwe, L. 2003. Revision of Bolivian Symbolanthus (Gentianaceae-Helieae). Harvard Pap. Bot. 8: 19-24.

Struwe, L. \& Albert, V.A. 1998a. Lisianthius (Gentianaceae), its probable homonym Lisyanthus, and the priority of Helia over Irlbachia as its substitute. Harvard Pap. Bot. 3: 63-71.
Struwe, L. \& Albert, V.A. 1998b. Six new species of Gentianaceae from the Guayana Shield. Harvard Pap. Bot. 3: 181-197.

Struwe, L. \& Albert, V.A. 2004. Monograph of neotropical Potalia (Gentianaceae: Potalieae). Syst. Bot. 29: 670-701.

Struwe, L. \& Gould, K. 2004. Redefinition of Symbolanthus to include Wurdackanthus (Gentianaceae-Helieae). Novon 14: 354-359.

Struwe, L., Kadereit, J., Klackenberg, J., Nilsson, S., Thiv, M., Hagen, K.B. von \& Albert, V.A. 2002. Systematics, character evolution, and biogeography of Gentianaceae, including a new tribal and subtribal classification. Pp. 21-309 in: Struwe, L. \& Albert, V.A. (eds.), Gentianaceae-Systematics and Natural History. Cambridge University Press, Cambridge.

Struwe, L., Maas, P.J.M. \& Albert, V.A. 1997. Aripuana cullmaniorum, a new genus and species of Gentianaceae from white sands of southeastern Amazonas, Brazil. Harvard Pap. Bot. 2: 235-253.

Struwe, L., Maas, P.J.M., Pihlar, O. \& Albert, V.A. 1999. Gentianaceae. Pp. 474-542 in: Berry, P.E., Yatskievych, K. \& Holst, B.K. (eds.), Flora of the Venezuelan Guayana, vol. 5. Missouri Botanical Garden, St. Louis.

Struwe, L., Nilsson, S. \& Albert, V.A. 2008. Roraimaea (Gentianaceae: Helieae) — a new gentian genus from white sands and tepuis of Brazil and Venezuela. Harvard Pap. Bot. 13: 35-45.

Struwe, L., Thiv, M., Kadereit, J., Motley, T., Pepper, A. S.-R., Rova, J., Potgieter, K., White, P. \& Albert, V.A. 1998. Saccifolium (Saccifoliaceae), an endemic of Sierra de la Neblina on the Brazilian-Venezuelan frontier, is related to a temperate-alpine lineage of Gentianaceae. Harvard Pap. Bot. 3: 199-214.

Thiv, M. 2002. Flora de la república de Cuba, vol. 6 (1). Koeltz Scientific Books, Königstein.

Thiv, M., Struwe, L., Albert, V.A. \& Kadereit, J.W. 1999a. The phylogenetic relationships of Saccifolium bandeirae Maguire \& Pires (Gentianaceae) reconsidered. Harvard Pap. Bot. 4: 519-526.

Thiv, M., Struwe, L. \& Kadereit, J.W. 1999b [2000]. The phylogenetic relationships and evolution of the Canarian laurel forest endemic Ixanthus viscosus (Alt.) Griseb. (Gentianaceae): evidence from $m a t K$ and ITS sequence variation, and floral morphology and anatomy. Pl. Syst. Evol. 218: 299-317.

Wong, K.M. \& Sugau, J.B. 1996. A revision of Fagraea (Loganiaceae) in Borneo, with notes on related Malesian species and 21 new species. Sandakania 8: 1-93.

Yuan, Y.-M., Wohlhauser, S., Möller, M., Chassot, P., Mansion, G., Grant, J., Küpfer, P. \& Klackenberg, J. 2003. Monophyly and relationships of the tribe Exaceae (Gentianaceae) inferred from nuclear ribosomal and chloroplast DNA sequences. Molec. Phylog. Evol. 28: 500-517.

Yoder, A.D., Irwin, J.A. \& Payseur, B.A. 2001. Failure of the ILD to determine data combinability for slow loris phylogeny. Syst. Biol. 50: 408-424. 
Appendix 1. List of investigated species (with tribal affiliation) with GenBank accession numbers for the trnL intron (marked with superscript T), matK part 1 (position in tobacco 469-849, superscript M1) and matK part 2 (tobacco 963-1244, superscript M2), and ITS (superscript I), as well as vouchers and herbarium (for new sequences only).

Adenolisianthus arboreus Gilg, Helieae, EU709784 ${ }^{\mathrm{I}}$, B. Maguire 55601 (NY); Anthocleista amplexicaulis Baker, Potalieae, AF102375 ${ }^{\mathrm{T}}$, AJ388137 ${ }^{\mathrm{Ml} 1}$, AJ388206 ${ }^{\mathrm{M} 2}$, DQ449914 $4^{\mathrm{I}}$ A Aripuana cullmaniorum Struwe, Maas \& V.A. Albert, Helieae, AJ242603 ${ }^{\mathrm{T}}$, AJ388140 ${ }^{\mathrm{M} 1}$, AJ388209 ${ }^{\mathrm{M} 2}$, EU709785 ${ }^{\mathrm{I}}$, C. Ferreira 5906 (NY); Bartonia virginica (L.) Britton, Sterns \& Poggenb., Gentianeae, AJ315185 ${ }^{\mathrm{T}}, \mathrm{AJ} 388141^{\mathrm{M1}}$, AJ388210 ${ }^{\mathrm{M} 2}, \mathrm{AJ} 318533^{\mathrm{I}}$, AJ410312 ${ }^{\mathrm{I}}$; Calolisianthus pendulus (Mart.) Gilg, Helieae, AF102387 ; Calolisianthus pulcherrimus (Mart.) Gilg, Helieae, AF102388 $8^{\mathrm{T}}$, AJ388142 ${ }^{\mathrm{Ml}}$, AJ388211 ${ }^{\mathrm{M} 2}$, EU709786 ${ }^{\mathrm{I}}$, R.M. Harley \& al. 15674 (NY); Calolisianthus speciosus Gilg, Helieae, EU709787'ㄹ. R.F. Vieira 723 (NY); Centaurium maritimum (L.) Fritsch, Chironeae, AY251733 ${ }^{\mathrm{T}}$, AJ010508 ${ }^{\mathrm{M} 1}, \mathrm{AJ} 011437^{\mathrm{M} 2}$, AJ011466 ${ }^{1}$, AJ011476 ${ }^{1}$ Chelonanthus alatus (Aubl.) Pulle, Helieae, EU709790 ${ }^{\mathrm{I}}$, P. Berry 5541 (NY); Chelonanthus albus (Spruce ex Progel) Badillo, Helieae, AF102397', EU709789', J.M. Poole 2049 (NY); Chelonanthus grandiflorus (Aubl.) Chodat \& E. Hassl., Helieae, EU709788 ${ }^{1}$, S. Mori \& al. 24801 (NY); Chelonanthus purpurascens (Aubl.) Struwe, S. Nilsson \& V.A. Albert, Helieae, AF102398 ${ }^{\mathrm{T}}, \mathrm{AJ} 388146^{\mathrm{M} 1}, \mathrm{AJ} 388215^{\mathrm{M} 2}$, EU709791 ${ }^{\mathrm{I}}$, P. Berry 5533 (NY); Chelonanthus viridiflorus (Mart.) Gilg, Helieae, AF102399 ${ }^{\mathrm{T}}$, EU709792 ${ }^{\mathrm{I}}$, W. Anderson 9743 (NY); Chironia linoides L., Chironeae, AY $251747^{\mathrm{T}}$, AY251692 ${ }^{\mathrm{I}}$, AY251722 ${ }^{\mathrm{I}}$; Chorisepalum psychotrioides Ewan, Helieae, EU709793' , T.W. Hankel 4267 (NY); Chorisepalum sipapoanum (Maguire) Struwe \& V.A. Albert, Helieae, AJ388147 ${ }^{\mathrm{M} 1}$, AJ388216 ${ }^{\mathrm{M} 2}$ (originally as C. ovatum); Coutoubea spicata Aubl., Chironeae, $\mathrm{AY} 251745^{\mathrm{T}}, \mathrm{AJ}_{388150}{ }^{\mathrm{M} 1}$,

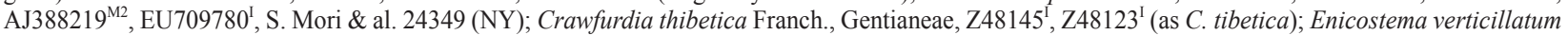
(L.) Engl. ex Gilg, Potalieae, AF102414 ${ }^{\mathrm{T}}$, AJ388155 ${ }^{\mathrm{M1}}$, AJ388224 ${ }^{\mathrm{M} 2}$, EU709781 ${ }^{\mathrm{I}}$, S.R. Hill 22020 (NY); Fagraea berteroana A. Gray, Potalieae, AF102419 ${ }^{\mathrm{T}}$, AJ388157 $7^{\mathrm{M} 1}$, AJ388226 ${ }^{\mathrm{M} 2}$, DQ449918'; Fagraea fragrans Roxb., Potalieae, AF102421 $1^{\mathrm{T}}$, AY251689 ${ }^{\mathrm{I}}$, AY251719 ${ }^{\mathrm{I}}$; Gentiana lutea L., Gentianeae, X75702 ${ }^{\mathrm{T}}$, Z481221 Z48119'; Gentianella amarella (L.) Börner, Gentianeae, AJ406326 ${ }^{\mathrm{M} 1}$, AJ406355 ${ }^{\mathrm{M} 2}$, AJ580573 ${ }^{\mathrm{I}}$; Gentianopsis crinita (Froel.) Ma, Gentianeae,

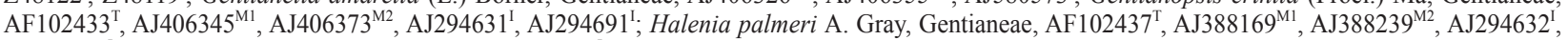

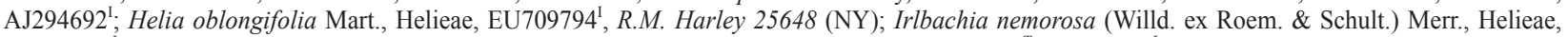
EU709795 ${ }^{1}$, H. Klinge s.n. (NY); Irlbachia poeppigii (Griseb.) L. Cobb \& Maas, Helieae, AF102441 ${ }^{\mathrm{T}}$, EU709796 ${ }^{\mathrm{I}}$, C. Toedzia \& al. 2278 (NY); Irlbachia pratensis (H.B.K.) Griseb., Helieae, AF102442 ${ }^{\mathrm{T}}$, EU709797 ${ }^{\mathrm{I}}$, P. Berry 7579 (NY); Irlbachia pumila (Benth.) Maguire, Helieae, EU709798 ${ }^{\mathrm{I}}$, P.J.M. Maas 6907 (U); Ixanthus viscosus (H.B.K.) Griseb., Chironeae, AY251741 ${ }^{\mathrm{T}}$, AJ010521 ${ }^{\mathrm{M} 1}$, AJ011450 ${ }^{\mathrm{M} 2}$, AJ011481 ${ }^{1}$, AJ011471 ${ }^{\mathrm{I}}$; Lehmanniella splendens (Hook.) Ewan, Helieae, AJ388172 ${ }^{\mathrm{M} 1}$, AJ388242 ${ }^{\mathrm{M} 2}$; Lisianthius jefensis A. Robyns \& T.S. Elias, Potalieae, AF102448, AJ010522 ${ }^{\mathrm{M} 1}, \mathrm{AJ} 011451^{\mathrm{M} 2}$, EU709782 ${ }^{\mathrm{I}}, J$. Luteyn 14796 (NY); Lisianthius seemannii (Griseb.) Kuntze, Potalieae, EU709783 ${ }^{1}$, R.L. Weaver 24310 (NY); Macrocarpaea angelliae J.R. Grant \& Struwe, Helieae, AY397760' ${ }^{1}$ AY397761 ${ }^{1}$; Macrocarpaea apparata J.R. Grant \& Struwe, Helieae, DQ401413 ${ }^{1}$; Macrocarpaea domingensis Urb. \& Ekman, Helieae, AF102454 $4^{\mathrm{T}}$, AJ010523 ${ }^{\mathrm{Ml}}$, AJ011452 ${ }^{\mathrm{M} 2}$, EU709799 ${ }^{1}$, P.J.M. Maas 8395 (U); Macrocarpaea gattaca J.R. Grant, Helieae,DQ401414 ; Macrocarpaea macrophylla Gilg, Helieae, AF $102455^{\mathrm{T}}$ (originally as M. glabra), AJ489915 $5^{\mathrm{I}}$; Macrocarpaea rubra Malme, Helieae, AF102457 $7^{\mathrm{T}}$, AJ388175 ${ }^{\mathrm{M} 1}$, AJ388245 ${ }^{\mathrm{M} 2}$; Macrocarpaea valerii Standley, Helieae, AF102456 ${ }^{\mathrm{T}}$, AJ388176 ${ }^{\mathrm{M} 1}$, AJ388246 ${ }^{\mathrm{M} 2}$; Neblinantha parvifolia Maguire, Helieae, AF102461 ${ }^{\mathrm{T}}$, AJ388179 ${ }^{\mathrm{M} 1}$, AJ388249 ${ }^{\mathrm{M} 2}$; Obolaria virginica L., Gentianeae, AF102464 $4^{\mathrm{T}}, \mathrm{AJ} 388180^{\mathrm{M} 1}$, AJ388250 ${ }^{\mathrm{M} 2}$, AJ318549, $\mathrm{AJ} 410328^{\mathrm{I}}$; Orphium frutescens (L.) E. Mey., Chironeae, AY251748 ${ }^{\mathrm{T}}$, $\mathrm{AJ} 010525^{\mathrm{M} 1}, \mathrm{AJ} 011454^{\mathrm{M} 2}$, AJ011465', AJ011475' ; Potalia amara Aubl., Potalieae, AF102470 ${ }^{\mathrm{T}}$, AJ388183 ${ }^{\mathrm{M} 1}, \mathrm{AJ} 388253^{\mathrm{M} 2}$, DQ449919'; Prepusa montana Mart., Helieae, EU709805' $5^{1}$ L. Queiroz 1846 (NY); Purdieanthus pulcher (Hook.) Gilg, Helieae, EU709800', H. St. John 20673 (US); Sabatia angularis (L.)

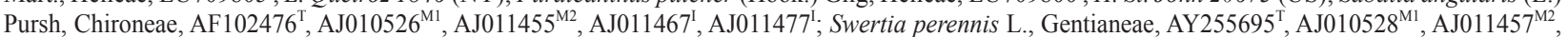
AJ580550; Symbolanthus australis Struwe, Helieae, AF102489 ${ }^{\mathrm{T}}$ (as. S. calygonus), EU709801 ${ }^{\mathrm{I}}$, L.J. Dorr \& al. 6691 (NY); Symbolanthus frigidus (Sw.) Struwe \& K. Gould, Helieae, AF102498, AJ388198 ${ }^{\mathrm{M} 1}$, AJ388268 ${ }^{\mathrm{M} 2}$, EU709802', G.R. Cooley 8211 (NY); Symbolanthus pulcherrimus Gilg, Helieae, AF102488 ${ }^{\mathrm{T}}$, EU709803 ${ }^{\mathrm{I}}$, J.F. Morales \& al. 1600 (NY); Tachia grandiflora Maguire \& Weaver, Helieae, AJ388193 ${ }^{\mathrm{M} 1}$, AJ388263 ${ }^{\mathrm{M} 2}$ (originally listed as T. grandifolia), DQ401415'; Tachia guianensis Aubl., Helieae, AJ011433 ${ }^{\mathrm{M} 1}, \mathrm{AJ} 011461^{\mathrm{M} 2}$, DQ401419'; Tachia loretensis Maguire \& Weaver, Helieae, AF102492 ${ }^{\mathrm{T}}$, DQ401421 ${ }^{1}$; Tachia occidentalis Maguire \& Weaver, Helieae, DQ401423'; Tachia parviflora Maguire \& Weaver, Helieae, DQ401424'; Tetrapollinia caerulescens (Aubl.) Maguire \& B.M. Boom, Helieae, AF102494 ${ }^{\mathrm{T}}$, AJ388194 ${ }^{\mathrm{M} 1}, \mathrm{AJ} 388264^{\mathrm{M} 2}$, EU709804 ${ }^{1}$, M.N. Silva \& al. 145 (NY); Tripterospermum volubile (D. Don) Hara, Gentianeae, AY858667'.

Appendix 2. Morphological characters and their states. All characters were treated as unordered. Coding of data was based on own observations as far as possible, which also served as confirmation of literature data (see Materials and Methods for references). Retention indices from the most-parsimonious solution from the large combined (first) and small combined (second) analyses are presented in parenthesis after each character. If a character was an uninformative, the retention index was not applicable (n/a). Morphological terminology follows Stearn (1995).

1. Habit: woody $=0$; herbaceous ( sometimes woody at very base $)=1 .(0.73$; $0.70)$. Suffrutescent herbs were coded as herbaceous, and the woody state was restricted to plants with branches and stems with secondary growth.

2. Saprophytes: no $=0$; yes $=1 .(1.00 ; 1.00)$. No saprophytes are known from Helieae, but are present in two taxa included from the Gentianaceae, Bartonia and Obolaria.

3. Stems: not twining $=0$; twining $=1 .(1.00 ; 1.00)$. Twining stems are only found in Crawfurdia and Tripterospermum (Gentianeae-Gentianinae), and not in the Helieae.

4. Stem color: green-brown $=0$; white, yellow, or orange $=1$; red or purple $=2$. $(0.42 ; 0.50)$.

5. Resin at nodes: absent $=0$; present $=1 .(0.84 ; 0.88)$. This resin is presumably produced by colleters, small fingershaped glands in the leaf axils and insides of sepals. Colleters are also present in many taxa that do not produce copious amounts of this sticky and usually clear resin (Struwe \& Albert, 2004).

6. Position of leaves, branch apex: evenly distributed along stem $=0$; crowded at branch apices $=1 .(0.42 ; 0.50)$. Some woody plants have leaves that are more tightly crowded at branch apices than along the stem, and sometimes the stems only have the leaf scars from leaves that have fallen off (e.g., Adenolisianthus, Prepusa montana, Potalia).
7. Position of leaves, base: not in basal rosette $=0$; in basal rosette $=1 .(0.20$; $0.00)$. Rosette leaves are restricted to herbaceous species.

8. Young branches: glabrous $=0$; hairy $=1 ;$ spiculate $=2$; papillose $=3$. $(0.44$; 0.50 ). Hairy branches are only found in some Macrocarpaea and Chorisepalum species, spiculate in Enicostema, and papillose only in $\mathrm{Ce}$ liantha bella, Chorisepalum ovatum, Lagenanthus, and Purdieanthus.

9. Indumentum on vegetative parts as very short, papill-like: absent $=0$; present $=1 .(0.00 ; 0.00)$. This type is only present in Enicostema and Purdieanthus.

10. Indumentum on vegetative parts as short straight hairs: absent $=0$; present $=1 .(0.33 ; 0.33)$. Chironia and some Macrocarpaea have this type of hairs.

11. Indumentum on vegetative parts as short, white bristles: absent $=0$; present $=1 .(1.00 ; \mathrm{n} / \mathrm{a})$.

12. Leaf margin: entire $=0 ;$ crenulate $=1 ;$ dentate $=2 .(0.50 ; 1.00)$. Most gentians have entire margins, the excepts are Crawfurdia thibetica, Lagenanthus and Tripterospermum volubile (with crenulate margins), and Irlbachia poeppigii (dentate).

13. Underside of leaves with indumentum: absent $=0$; present $=1$. $(0.42$; $0.42)$.

14. Leaf margin with small hairs: glabrous $=0$; ciliate or hairy $=1$. $(0.50$; $0.50)$. 
15. Leaf margin: herbaceous $=0$; thin, colorless, and membranaceous $=1$. $(0.60 ; 0.58)$.

16. Leaf margin: not thickened $=0$; thickened $=1$. $(1.00 ; 1.00)$. Thickened leaf margins only occur in Chorisepalum, and are not correlated with coriaceous leaves.

17. Leaf margin: flat $=0$; recurved $=1$. $(0.25 ; 0.12)$.

18. Petiole: present, distinct $=0$; absent or indistinct (leaves sessile $)=1$. $(0.69 ; 0.70)$. In leaves with attenuate leaf bases this character can be hard to code, but we coded it strictly based on if the lamina reaches the base of the leaf or not (i.e. "winged petioles" would be coded as not having a petiole if the wing, the lamina, reached the base of the leaf).

19. Petiole vagination: absent $=0$; present $=1$. $(0.75 ; 0.75)$. In several species of Macrocarpaea the petiole's upper side is vaginated into a shorter or longer furrow.

20. Interstipular structures: line $=0$; sheath $=1 .(0.53 ; 0.55)$. The difference between a line and sheath is that the line is merely a scar-like area whereas the sheath is a interpetiolar ridge (low ochrea) that partly encloses the stem. Sheaths are only found in tree-like or shrubby species.

21. Lower secondary veins: straight $=0$; bent towards apex (arcuate $)=1$. $(0.61 ; 0.66)$. Leaf venation in the Gentianaceae is not very complex with all taxa having pinnate venation, but differs in the curvature of secondary veins. Leaves often have only a few secondary veins that diverge at the base of the leaf or below middle, and curve outwards, upwards towards the tip of the leaf (arcuate, like arches). In contrast, other species have secondary veins that are straight towards the leaf edge.

22. Pairs of secondary veins (number): $0=0 ; 1-2=1 ; 3$ or more $=2$. $(0.60$; $0.57)$. It seems like that larger leaves and woody habit are somewhat correlated with an increased number of secondary veins.

23. Secondary veins underneath leaf: not prominent $=0$; prominent and raised $=1$. $(0.50 ; 0.33)$. The midvein is generally raised in all gentians, but the secondary veins can either be raised or not from the lower leaf surface.

24. Inflorescence position: terminal $=0$; axillary $=1 .(0.61 ; 0.54)$.

25 . Inflorescence type: cymose (with top flower) $=0$; racemose (no top flower, incl. thyrse) $=1$; on cushion, not cymose or racemose $=2$. $(0.90 ; 1.00)$. Chorisepalum and Tachia are the only genera with flowers positioned on small cushions (short shoots?) in the leaf axils.

26. Flower number: 2 or more per inflorescence $=0$; solitary $=1$. $(0.41 ; 0.20)$. Rarely plants with solitary flowers have two flowers together, but they were still coded as single flowers. Similarly, very small individuals of the annual Tetrapollinia might only have one flower, but this is likely due to limited resources and the production of dwarf-like specimens, not genetic traits, since the whole plant is reduced in size.

27. Inflorescence branches hairs: glabrous $=0$; hairy $=1$; spiculate or papillate $=2 ;$ tuberculate $=3 .(0.28 ; 0.25)$. This character was not coded for Tachia, since their flowers are sessile.

28. Main inflorescence branches fusion: not fused $=0$; fused at base only $=$ 1. $(1.00 ; 1.00)$. Fused branches in the basal part of the inflorescence is a character state only known from Macrocarpaea.

29. Bracteoles, shape and structure: triangular, scale-like $=0$; leaf-like $=1$. $(0.65 ; 0.65)$. In some species with leaf-like bracteoles, the more apical bracteoles become more scale-like. Bracteoles refer to the paired bracts below each flower.

30. Bracteoles: present $=0$; absent $=1$. $(0.57 ; 0.80)$. Bracteoles are absent from Tachia and some Chorisepalum.

31. Flower orientation at anthesis: erect or horizontal $=0$; nodding or nu$\tan t=1 .(0.60 ; 0.60)$. The pedicel position is an important taxonomic character.

32. Calyx merosity: $5(6-7)$-merous $=0 ; 4$-merous $=1 ; 2$-merous $=2 .(0.63$; $0.57)$.

33. Calyx color: green $=0$; white, yellow, orange $=1$; red, purple, blue $=$ 2. $(0.11 ; 0.12)$.

34. Sepals position: one whorl $=0$; decussate $=1 .(0.83 ; 0.66)$.

35. Sepals dorsally thickened: not thickened $=0$; thickened $=1 .(0.86 ; 0.85)$. Helieae and most species in subtribe Potaliinae are characterized by sepals that are dorsally thickened.

36. Dorsal keel on sepals: not keeled $=0$; dorsal keel $=1$; one dorsal wing (distinct thin wing $)=2$; two dorsal wings (distinct thin wing $)=3 .(0.15$; $0.11)$. A dorsal wing and keel is different from the general thickening of the sepals (ch. 35) in that in cross-section a keel and wing do not show a gradual increase in thickness from the edge to the center, instead it is more abrupt. A keel has a broader base than a wing, which is thin and narrow.

37. Dorsal glandular area on sepals: absent $=0$; present $=1 .(1.00 ; 1.00)$. The glandular areas are often only seen as darker areas in dried specimens, but are seen as more shiny areas in the field and in photos. These glands are often visited by ants in Calolisianthus, Chelonanthus and Helia.

38. Sepal margin: chartaceous $=0$; membranaceous $=1 .(0.63 ; 0.68)$.

39. Sepal margin, indumentum: glabrous, entire or erose $=0$; ciliate or papillose $=1 .(0.44 ; 0.36)$.

40. Sepals outside, indumentum: glabrous $=0$; simple hairs $=1$. $(0.33 ; 0.33)$.

41. Sepals outside, indumentum: glabrous $=0$; short, white bristles $=1$. $(1.00 ; \mathrm{n} / \mathrm{a})$.

42. Calyx persistence in fruit: persistent $=0$; deciduous $=1$. $(0.84 ; 0.78)$. The persistence of the calyx in fruit appears to be a good character for phylogenetic purposes, and in Helieae, deciduous calyces is a synapomorphy for the Macrocarpaea subclade. However, in some species the calyx only falls off in old fruits, after the fruits have opened.

43. Calyx texture: membranaceous and/or papyraceous $=0$; woody/coriaceous $=1 .(0.87 ; 0.83)$

44. Corolla merosity: $5=0 ; 4=1 ; 6(-7)=2 ; 8$ or more $=3$. $(0.76 ; 0.57)$.

45. Corolla basic color: green, white, or yellow $=0$; blue, pink, or purple $=$ 1 ; red or orange $=2 .(0.47 ; 0.40)$. Blue species can very rarely have white corollas (like Campanula), but were coded as blue here. The blue and red coloring is likely due to anthocyanins, but color chemistry has not been investigated within the tribe yet.

46. Corolla tube inflation right above stamen insertion point: not inflated $=0$; inflated $=1 .(0.79 ; 0.71)$. This is a distinct character both in living and dried specimens. In species with inflated corolla tubes, the corolline-staminal tube is thinner and narrower, and above the stamens, the corolla tube becomes thicker and is immediately widened, sometimes up to 10 times the width of the corolline-staminal tube. Often the lower part of the corolla is hidden inside the calyx, and this character could only be coded for species where we had abundant herbarium or pickled material.

47. Corolla constrained at mouth (inflated): not constrained at mouth $=0$; constrained at mouth (more balloon-shaped) $=1 .(0.50 ; 0.33)$. The corolla tube is constricted right below the corolla lobes in Lagenanthus, Lehmanniella, and Purdieanthus, creating an inflated corolla tube.

48. Corolla tube, abaxial part: symmetric, not hump-like $=0$; asymmetric, with hump (Chelone-like $)=1$. $(1.00 ; 0.66)$. A hump is a zygomorphic inflation of the corolla tube, toward the upper part of a horizontal flower. This character is only present in green-white flowered Chelonanthus and Rogersonanthus species, and hard to see in pressed material, but is more obvious in the field, in photos, and in liquidpreserved collections.

49. Corolla outside papillose: glabrous $=0$; papillose $=1$. $(1.00 ; 1.00)$.

50 . Corolla plicae: absent $=0$; present $=1$. $(1.00 ; 1.00)$. Plicae are extra folds of coralline tissue in the sinuses of the corolla lobes.

51. Corolla inside, indumentum: absent $=0$; present $=1 .(0.00 ; \mathrm{n} / \mathrm{a})$.

52. Corolla inside, glands: absent $=0$; glands present $=1$. $(0.75 ; 0.75)$. Corolline glands are known from subtribe Swertiinae.

53. Corolla texture: not fleshy, thin $=0$; fleshy or coriaceous, thick $=1$. $(0.75 ; 0.74)$. This character is possible to code from dried herbarium collections, since thin corollas dry to paper-like texture, and the fleshy corollas are thicker and not transparent when dried.

54. Corolla persistence in fruit: persistent $=0$; deciduous at base $=1$. $(0.62$; $0.54)$.

55. Corolla lobes, apical appendages: absent $=0$; appendage present $=1$. $(0.25 ; 0.00)$. Corolla lobes with apical appendages are strongly acuminate, but when they are absent the lobe apices are obtuse to acute.

56. Corolla bud apex: round $=0$; tapering to sharp point $=1$. $(0.62 ; 0.59)$. This character is neither influenced by the type of aestivation, nor the shape of the corolla lobes.

57. Corolla aestivation: contort $=0$; valvate-contort $=1 ;$ imbricate $=2 .(0.50$; 0.00). Valvate-contort corolla lobes are only found in Aripuana, where the corolla lobes are valvate in their lower parts, and contort only at the corolla lobe apices

58. Corolla lobe apex with darkened tip: not darkened $=0$; darkened $=1$. 
(0.66; 0.60). Adenolisianthus, Calolisianthus, Chelonanthus (not $C$. purpurascens), and Helia have corolla lobes with darker, often green apices.

59. Corolla lobe margin: entire or erose $=0$; fringed $=1$; ciliate or papillose $=2$. $(0.41 ; 0.38)$. Papillose and ciliate margins can usually only be seen under at least $10 \times$ magnification, not with the naked eye.

60. Stamina-corolla insertion: stamen inserted in corolla tube, not close to corolla lobe sinuses $=0$; inserted in corolla lobe sinuses $=1$; inserted in corolla tube, but very close to sinuses $=2$. $(0.63 ; 0.55)$.

61. Filaments, length: of equal length $=0$; of unequal lengths $=1 .(0.88$; 0.84)

62. Androecium, symmetry: actinomorphic $=0 ;$ zygomorphic with stamens bent and anthers clustered in lower part of corolla mouth $=1$. $(0.80$; 0.72 ).

63. Filament-corolla fusion: filaments free $=0$; filaments on a fleshy base, no annulus $=1$; inserted on fleshy ring (annulus) or with basal staminal appendages $=2 .(0.25 ; 0.25)$.

64. Staminal gaps: absent $=0$; present $=1 .(0.70 ; 0.60)$. Staminal gaps are pockets between the corolla and the filament traces in the corolla tube, and these are only known from the Helieae.

65. Staminal corona: absent $=0$; present $=1 .(1.00 ; 1.00)$. A staminal corona is a structure unique to Symbolanthus, and consists of a ring or flaps of tissue in the inside of the corolla tube at the insertion point of the stamens.

66. Filament base: not winged $=0$; winged $=1 .(0.68 ; 0.61)$.

67. Corolla tube inside: not winged $=0$; winged below insertions of stamens (or ridges) $=1$. $(0.33 ; 0.33)$. When wings are present, these are usually extensions from winged filaments that extend down into the corolla tube.

68. Filament at insertion into corolla: not knee-bent $=0$; knee-bent $=1$. $(0.64$ $0.61)$. Filaments that are kneebent are bent about 90 degrees, while most stamens are inserted straight into and parallel to the corolla tube.

69. Filaments close to anther: not curved $=0$; curved 180-360 degrees $=$ 1. $(0.71 ; 0.55)$.

70. Filaments shape in cross-section: filiform $=0$; flattened to winged $=1$. $(0.57 ; 0.65)$

71. Anther shape at anthesis: straight $=0$; curved, recurved $=1$; spirally twisted lengthwise $=2$; backwards bent, versatile $=3 .(0.70 ; 0.68)$.

72. Anther apex: not sterile $=0$; sterile tip $=1 .(0.58 ; 0.72)$

73. Disk around base of ovary: no disk $=0$; with disk or nectariferous tissue $=1$. $(0.52 ; 0.56)$.

74. Ovary position: sessile $=0$; stipitate $=1 .(0.60 ; 0.40)$.

75. Style persistence in fruit: persistent $=0$; deciduous (sometimes the base is left $)=1 .(0.61 ; 0.60)$.

76. Style shape: thin, long $=0$; stout, short $=1 .(0.88 ; 0.88)$.

77. Style, when dry: filiform $=0$; flattened, twisted lengthwise $=1$. $(0.94$; $0.93)$. The flattened and twisted dry styles are an excellent field identification character for Helieae.

78. Style, symmetry: actinomorphic $=0$; zygomorphic (bent upwards at apex $)=1 .(0.72 ; 0.61)$.

79. Stigma shape: bilamellate $=0$; obconical-simple $=1$; capitate-peltate $=2 .(0.33 ; 0.33)$.

80. Stigma lobe shape: round to elliptic $=0$; linear $=1 .(0.50 ; 0.50)$. Linear lobes are at least three times as long as wide.

81. Fruit position: erect $=0$; pendulous, nodding $=1$. $(0.78 ; 0.70)$.

82. Dehiscence type: indehiscent $=0$; bivalved, apical $=1 ; 4$-valved $($ Chorisepalum type $)=2$; bivalved, medial $=3 .(0.81 ; 0.75)$. In medially dehiscent fruits, the persistent style forces the apex of the fruit shut, so it opens medially out of necessity from the development of the fruit.

83. Fruit valves, persistence: persistent $=0$; deciduous, without dried vascular traces $=1$; deciduous, with persistent vascular traces $=2 .(0.88 ; 1.00)$.

84 . Fruit skin, texture when fresh: dry $=0$; fleshy $=1$; leathery $=2$. $(1.00$; $1.00)$

85. Fruit, mesocarp: no separation $=0$; mesocarp splits into a thinner outer part, and an inner more fibrous part $=1 .(0.83 ; 0.87)$.

86. Fruit color, when mature and fresh: brown, beige $=0$; green, yellow $=$ $1 ;$ red, purple $=2 .(0.66 ; 0.66)$.
87. Placenta on mature fruits: not prominent $=0$; thin, erose bands $=1$; woody, thick $=2$; fleshy $=3 .(0.57 ; 0.58)$.

88. Placenta, shape: simple $=0$; peltate $=1 ;$ inrolled $=2 .(0.87 ; 0.87)$.

89. Pollen when released: monads $=0$; tetrads $=1$; polyads $=2$. $(0.86 ; 0.85)$.

90. Pollen, aperture: colporate $=0$; porate $=1 .(0.55 ; 0.44)$.

91. Columellae/muri as spines: absent $=0$; spines present $=1$. $(0.60 ; 0.50)$.

92. Columellae/muri as loops: absent $=0$; loops present $=1$. $(0.50 ; 0.50)$.

93. Exine thickness, equator: not thicker at equator $=0$; thickest at equator $=1$. $(0.78 ; 0.75)$.

94. Exine thickness, polar: polar areas not thicker $=0$; polar areas with thicker exine $=1 .(0.75 ; 0.61)$

95. Special polar end processes: none $=0$; one glob $=1$; one spine $=2$; many spines $=3 .(0.83 ; 0.66)$.

96. Pores: without thick lamellar margin $=0$; with thick lamellar margin $=1$; protruding margins $=2$; intruding margins $=3 .(0.87 ; 1.00)$.

97. Internal wall perforated (in tetrads and polyads only): not perforated $=$ 0 ; perforated $=1 .(0.66 ; 0.00)$.

98. Lumina: smooth $=0$; granular $=1$. $(0.75 ; 0.50)$.

99. Tectum: absent $=0$; present, solid $=1$; present, perforate $=2 .(0.27 ; 0.33)$.

100. Columellae/muri as globules (macro): absent $=0$; present $=1$. $(0.75$; $\mathrm{n} / \mathrm{a})$.

101. Columellae/muri as microglobules: absent $=0$; present $=1$. $(0.57 ; 0.00)$.

102. Columellae/muri as large pila: absent $=0$; reticulum as elongated processes (large pila) $=1 .(0.20 ; 0.00)$.

103. Muri/columellae as small pila: absent $=0$; as small pila $=1 .(0.61 ; 0.33)$.

104. Muri: evenly thickened $=0$; unevenly thickened $=1$. $(0.80 ; 0.83)$.

105. Muri: smooth $=0 ;$ granular $=1 ;$ keeled $=2 ;$ not fused $=3$. $(0.50 ; 0.50)$.

106. Mesh-size in reticulum: even mesh-size $=0 ;$ larger meshes in polar areas $=1 ;$ larger meshes in equatorial areas $=2 .(0.75 ; 0.70)$.

107. Columellae/tectum pattern: reticulate $=0$; scabrate, verrucose $=1$; striate $=2 .(0.62 ; 0.60)$.

108. Reticulum: finely reticulate, striate $=0$; coarsely reticulate $=1$; differentially reticulated $=2 .(0.70 ; 0.57)$.

109. Seed shape: angular/polyhedral $=0$; globose $/$ subglobose $/$ elliptic $=1$; flattened $=2 .(0.65 ; 0.65)$.

110. Seeds, shape with ridges: surface even $=0$; rimmed with raised ridges and sunken sides $=1 .(0.82 ; 0.86)$.

111. Seed wing: absent $=0$; present all around (single wing, sometimes on 3 sides) $=1$; present on one to many side, partial wing, sometimes many $=2 .(0.75 ; 0.60)$.

112. Seed, hilum: indistinct $=0$; distinct, sunken $=1$. $(1.00 ; 1.00)$.

113. Testa, testa cells shape: polygonal $=0$; elongated $=1$. $(0.33 ; 0.33)$.

114. Testa, outer wall: collapsed, thin, pressed against inner wall or absent, concave $=0$; not collapsed, dome-like, cells convex (rarely collapsed on sides $)=1 .(0.80 ; 0.80)$.

115. Testa, outer wall, band-like thickenings: without $=0$; with band-like thickenings $=1 .(0.80 ; 0.86)$

116. Testa, anticlinal walls: straight (to slightly bent $)=0$; curved, S-shaped at most $=1$; waved, zig-zag-shaped $=2 .(0.46 ; 0.36)$.

117. Testa, anticlinal walls: thin $=0$; thick $=1 .(0.50 ; 0.33)$.

118. Testa, anticlinal boundaries: smooth $=0 ;$ raised $=1$; sunken $=2$. $(0.46$; $0.44)$.

119. Testa, anticlinal wall, thickenings: absent $=0$; band-like thickenings present $=1$. $(0.00 ; 0.00)$.

120. Testa, anticlinal wall structure: smooth $=0$; papillate, granular $=1$. $(0.50 ; 1.00)$.

121. Testa, anticlinal walls structure: not pitted $=0 ;$ pitted $=1 .(0.60 ; 0.50)$.

122. Testa, anticlinal walls: not reticulate $=0$; reticulate $=1$. $(0.50 ; 0.33)$.

123. Testa, inner wall, thickenings: without band-like thickenings $=0$; with band-like thickenings $=1 .(0.75 ; 0.00)$

124. Testa, inner wall, structure: smooth $=0$; pitted (many pits $)=1$. $(0.64$; $0.55)$.

125. Testa, inner wall, papillae: absent $=0$; papillate, granular $=1$. $(0.46$; 0.40 ).

126. Testa, inner wall, reticulum: not reticulate $=0$; reticulate $=1 .(0.70$; $0.44)$.

127. Testa, cuticle: smooth $=0$; granular with exudates $=1 .(0.50 ; 0.50)$ 
Appendix 3. Coded insertions/deletions (indels) for ITS using the simple gap coding method. Leftmost numbers refer to character number (within parenthesis in the combined data matrix), positions refer to nucleotide position in the ITS alignment. For each indel, state 0 is the absence of a nucleotide, and 1 is the presence of one.
1 (802) position 25
$2(803)$ position 39
3 (804) position $40-41$
4 (805) position 55
5 (806) position 60
$6(807)$ position 62
7 (808) position 64
8 (809) position 89
9 (810) position 90
10 (811) position 107
11 (812) position 108-109
12 (813) position 111
13 (814) position 112
14 (815) position 134
15 (816) position 135
16 (817) position 136
17 (818) position 144
18 (819) position 146
19 (820) position 157
20 (821) position $169-171$
21 (822) position 174
22 (823) position 183
23 (824) position 197
24 (825) position 209
25 (826) position 237
26 (827) position 252
27 (828) position 253
28 (829) position 432
29 (830) position 433
$30(831)$ position 434
31 (832) position 439
32 (833) position $440-446$
33 (834) position 452
34 (835) position 453
35 (836) position 462
36 (837) position 468
37 (838) position 469-470
38 (839) position 475
39 (840) position 485
40 (841) position 486
41 (842) position 514
42 (843) position 603
43 (844) position 610
44 (845) position 629
45 (846) position 640
$46(847)$ position 649

Appendix 4. Coded insertions/deletions (indels) for the trnL intron using the simple gap coding method. Leftmost numbers refer to character number (within parenthesis in the combined data matrix), positions refer to nucleotide position in the $\operatorname{trnL}$ intron alignment. For each indel, state $\mathbf{0}$ is the absence of a nucleotide, and 1 is the presence of one.
1 (2013) position 73-76
2 (2014) position 88-89
3 (2015) position 92
4 (2016) position $124-126$
5 (2017) position 127
6 (2018) position $128-132$
7 (2019) position 133
8 (2020) position 134-137
9 (2021) position 146
10 (2022) position 147
11 (2023) position 164-174
12 (2024) position 175
13 (2025) position 237
14 (2026) position 324-334
15 (2027) position 468 